\title{
Modeling Growing Economies in Equilibrium and Disequilibrium
}

\author{
Edited by \\ Allen C. Kelley \\ Warren C. Sanderson \\ and \\ Jeffrey G. Williamson
}

Duke Press Pollcy Studies 
Modeling Growing Economies 


\title{
Modeling Growing Economies in Equilibrium and Disequilibrium
}

\author{
Edited by \\ Allen C. Kelley \\ Warren C. Sanderson \\ and \\ Jeffrey G. Williamson \\ Published in cooperation with the \\ International Institute for Applied \\ Systems Analysis
}

Duke Press Policy Studies Durham, N.C. 1983 
(c) 1983, International Institute for Applied Systems Analysis, all rights reserved

Printed in the United States of America

Library of Congress Cataloging in Publication Data Main entry under title:

Modeling growing economies in equilibrium and disequilibrium.

(Duke Press policy studies)

Papers presented at a meeting held at the International Institute for Applied Systems Analysis in Nov. 1980.

Includes bibliographies and indexes.

I. Economic development-Mathematical modelsCongresses. 2. Economics-Mathematical modelsCongresses. 3. Equilibrium (Economics)-Congresses. I. Kelley, Allen C. II. Sanderson, Warren C.

III. Williamson, Jeffrey G., 1935- . IV. International Institute for Applied Systems Analysis.

V. Series.

HD75.5.M62 1983

$338.9^{\prime} 00724$

$83-1480$

ISBN 0-8223-0567-4 


\section{PREFACE}

During the 1960 s and early 1970 s multisectoral models developed along two distinct paths.

In the first tradition, "systems" models of global growth (e.g., Meadows et al., 1972) dealt with cumulative interactions among sectors, and showed that resource-intensive rapid growth would result in economic collapse, and, worse yet, that the world would not recognize the catastrophe before it occurred. These models possessed no prices to encourage resource saving, nor did they induce technological change to augment supply, both of which would attenuate or eliminate the predicted catastrophe. At the same time, there appeared a set of increasingly complex planning models, characterized by highly disaggregated input-output structures, and focusing on "internal-consistency" compromises to reconcile various demand and supply imbalances implied by the process of economic growth (for a review, see Blitzer et al., 1975). Here too, little attention was paid to how these inconsistencies could be reconciled without invoking ad hoc government policies to ameliorate their consequences.

A second and quite diffe rent tradition began with the pioneering study by Johanson (1959); in his general equilibrium model, price adjustments reconcile demand and supply and optimal resource allocation is generated endogenously without the intervention of ad hoc policy.

The 1970s saw an explosion of complex multisectoral growth models in the first tradition. They incorporated fairly rigid technological relations, utilized large and expanding data bases, and relied extensively on computers for their solution and analysis. These complex models stressed sectoral detail and did not dwell on the actions of the economic agents that in the real world tie these sectors together into a viable political economy. Rather, governments largely represented the agents responsible for setting goals and "reconciling" perceived shortages or gluts of commodities and factors. These models were expanding black boxes with thousands of equations and an even larger number of parameters designed to guide the policy makers in aggregate economic management.

The first tradition had its detractors and many scholars were beginning to recognize the possibility that complex government planning models were yielding diminishing returns: their data requirements were excessive; they highlighted limited choices rather than flexible tradeoffs; they demanded sophisticated control systems to implement their objectives; and they were unreliable in predicting the future course of economic events (see Sanderson, 1980, for a review of some of these models). At the same time, macroeconomic theory was being treated with increasing skepticism, and scholars showed an increasing interest in the microeconomic foundations of the aggregate economy (for a review, see Weintraub, 1977).

The stage was set to move back toward the second tradition, to simpler general equilibrium models, which highlight specifications of microeconomic behavior. For modeling market economies this meant increased attention to the role of prices in overcoming 
scarcity. The time was ripe to return to the classic problem of understanding how resources reallocated themselves in response to economic growth. What was required was a return to fundamentals: understanding the microfoundations of macroeconomic performance; appreciating the mechanisms of communication between producers, consumers, and other economic agents; specifying alternative ways in which economic compromises are made in the real world in contrast to the first tradition, which 'imposed" internal consistency through arbitrary computer algorithms or equally ad hoc government responses. A new class of models began to emerge that urged a return to some of the oldest traditions in economics: in the tradition of Adam Smith's "invisible hand", and Alfred Marshall's integrated market structures, the new breed of modelers offered a general equilibrium approach to macroeconomic problems.

The emphasis turned to the means by which economic agents reconciled their competing differences. In market-oriented economies, where most of this modeling has taken place, the mandate was to characterize market solutions for wages, interest rates, and commodity prices. Yet, this market-oriented approach need not be the only way in which conflicting self-interests between economic agents are reconciled. In planned economies, other resource-allocation techniques can be and are used, but even in these situations there are often incursions of market approximations or realities. The central thrust of this general equilibrium modeling, however, is an increasing emphasis on explicit mechanisms (markets, government regulations, planning boards, lotteries) for reconciling problems of scarcity.

This new general equilibrium tradition has proceeded along numerous fronts, many of which were represented at a November 1980 workshop held at the International Institute for Applied Systems Analysis (IIASA), Laxenburg, Austria. The first is a theoretical literature stressing the microeconomics of macroeconomic behavior, represented by studies ranging from that of Kornai (1971) on antiequilibrium to that of Leijonhufvud (1974) on general equilibrium. The second has focused on neoclassical specifications of long-run development, represented by the early work of Jorgenson (1961) and Kelley et al.(1972). A third, represented by World Bank analysts(Blitzer et al., 1975), has focused on short- and medium-run Third World trade and distribution problems. The early models were simple, but by the late 1970 s expanded data bases, the increasing power of computers, and the development of sophisticated solution algorithms, all led to experimentation with more elaborate general equilibrium formulations of national economies.

Somewhat by design, and somewhat by coincidence, much of this emerging work has concentrated at IIASA, where the general equilibrium framework has been used to study the consequences of national energy policies in small, open economies (see Bergman, 1978); to examine the structural transformations experienced by nations evolving from agrarian to industrial societies; and to develop a system of national agricultural models. Parallel methodological expertise and solution techniques have also been developed to accommodate the increasing demands for general equilibrium modeling at IIASA. Since these beginnings in the late 1970s, several country studies have emerged: IIASA models have been developed for Hungary, Japan, Mexico, Poland, and Sweden; similar work was going on independently in Australia, the United States, and Europe.

A November 1980 meeting held at IIASA brought together most of the active workers in this area; the papers in this volume were presented and discussed there. The meeting's goals were to stimulate interaction and collaboration, and to encourage setting research priorities for the future. 
Indeed, it is in this latter area where the meeting appeared to yield some of its greatest benefits. It became clear from the deliberations that much needs to be done to better specify the microfoundations of general equilibrium models. More realistic specifications of "conflict resolution" in resource allocation, in both market and nonmarket economies, need to be developed. Equally importantly, much work is required to explore the role of economic disequilibrium in economic growth and development. "Equilibrium" and "disequilibrium" are positive, not normative concepts; neither view is right or wrong; neither will necessarily yield desired social outcomes at all stages of development, or across all regions. Rather, they yield quite different outcomes, which themselves should be the subjects of scientific inquiry. The meeting pointed out the potential for expanding the conceptions of general equilibrium modeling to incorporate elements of disequilibrium analy sis, so that this framework may not only be increasingly relevant to Eastern countries, but so that the possibilities of East-West interaction on critical aspects of resource allocation and economic growth can be enhanced.

While the discussion and debate was active, reproduction of the sessions' complete transcript in this volume was infeasible. However, the last chapter contains an edited version of a panel discussion that provided a systematic treatment of several issues fundamental to general equilibrium modeling. This panel discussion, held on the last day, mentions only a selection of the topics considered. Nevertheless, the reader may find it instructive to review it before proceeding to the workshop papers.

We are indebted to many persons at IIASA who contributed to holding this meeting. Andrei Rogers, the Chairman of the Human Settlements and Services Area, and Andrzej Wierzbicki, the Chairman of the System and Decision Sciences Area, provided not only financial support, but also strong intellectual encouragement at every stage. Susie Riley played the crucial roles of administrative assistant, typist, and conscience from the early days when the meeting was first being organized to the final days when we were preparing to send the final manuscript to press. To these people and to the many others at IIASA who made this volume possible, we are truly grateful.

\author{
ALLEN C. KELLEY \\ WARREN C. SANDERSON \\ JEFFREY G. WILLIAMSON
}

\title{
REFERENCES
}

Bergman, L. (1978). Energy Policy in a Small Open Economy: The Case of Sweden. RR-78-16. International Institute for Applied Systems Analy sis, Laxenburg, Austria.

Blitzer, C.R., Clark, P.B., and Taylor, L. (1975). Economy-Wide Models and Development Planning. Oxford University Press, Oxford, for the World Bank.

Johanson, L. (1959). A Multisectoral Study of Economic Growth. North-Holland, Amsterdam.

Jorgenson, D.W. (1961). The development of a dual economy. Economic Journal, 71:309-334.

Kelley, A.C., Williamson, J.G., and Cheetham, R.J. (1972). Dualistic Economic Development: Theory and History. The University of Chicago Press, Chicago, Illinois.

Kornai, J. (1971). Anti-Equilibrium. North-Holland, Amsterdam.

Leijonhufvud, A. (1974). Varieties of Price Theory: What Microfoundations for Macrotheory. Discussion Paper. University of California at Los Angeles, California. 
Meadows, D.H., Meadows, D.L., Randers, J., and Behrens, William H., III (1972). Limits to Growth. Universe Books, New York.

Weintraub, E.R. (1977). The microfoundations of macroeconomics: a critical survey. Journal of Economic Literature, 15:1-24.

Sanderson, W.C. (1980). Economic-Demographic Simulation Models: A Review of Their Usefulness for Policy Analy sis. RR-80-14. International Institute for Applied Systems Analysis, Laxenburg, Austria. 


\section{CONTENTS}

\section{PART ONE: THE APPLICATION OF GENERAL EQUILIBRIUM MODELS TO THE PROBLEMS OF ECONOMIC DEVELOPMENT}

A computable general equilibrium model of Third-World urbanization and

city growth: preliminary comparative statics. . . . . . . . . . . .

A.C. Kelley and J.G. Williamson

Foreign protectionism and resource allocation in a developing economy: a general equilibrium analysis. . . . . . . . . . . . . . . 43

K. Dervis

Policy adjustment rules in an open exchange model with money and endogenous balance of trade deficit . . . . . . . . . . . 57 M.A. Keyzer

General equilibrium model for Egypt $\ldots \ldots \ldots \ldots \ldots \ldots \ldots \ldots \ldots$ F.D. McCarthy

Modeling dualism in Japan . . . . . . . . . . . . . . . . . . 103 H. Shishido

PART TWO: THE USEFULNESS OF GENERAL EQUILIBRIUM AND DISEQUILIBRIUM MODELING TO THE GOALS OF CENTRALLY PLANNED ECONOMIES

Modeling different socioeconomic mechanisms . . . . . . . . . . . 141 B. Mihailov

Estimates of disequilibria in Poland's consumer markets (1965-1978) . . . . . . 167 L. Podkaminer

A nonlinear multisectoral model for Hungary: general equilibrium versus optimal planning approaches E. Zalai

PART THREE: THE APPLICATION OF GENERAL EQUILIBRIUM MODELS TO THE PROBLEMS OF DEVELOPMENT OF MARKET ECONOMIES

A model of multisectoral economic growth in a small open economy . . . . . . . 225 L. Bergman

The agricultural sector of ORANI 78: theory, data, and application . . . . . . 237 P.B. Dixon, B.R. Parmenter, A.A. Powell, and D.P. Vincent 
PART FOUR: DEMOGRAPHIC ASPECTS OF GENERAL EQUILIBRIUM MODELING

Aspects of the design of BACHUROO, an economic-demographic model of labor supply . . . . . . . . . . . . . . . . . . . . 277 A.A. Powell

A two-sex general equilibrium marriage model $\ldots \ldots \ldots \ldots \ldots \ldots$. . . . . 301 W.C. Sanderson

Incorporating demography into general equilibrium modeling 317 R.M. Schmidt

PART FIVE: PANEL DISCUSSION

Comments by K. Dervis, A.P. Wierzbicki, J. Kornai, F. Bourguignon, and L. Taylor. . . 341

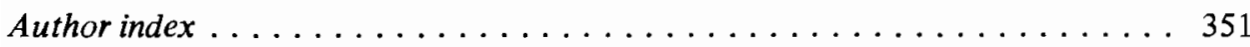

Subject index ............................ 353

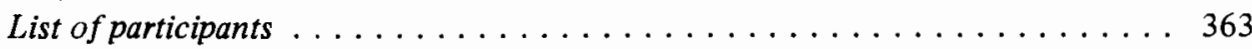




\section{Part One}

The Application of General Equilibrium Models to the Problems of Economic Development 



\title{
A COMPUTABLE GENERAL EQUILIBRIUM MODEL OF THIRD-WORLD URBANIZATION AND CITY GROWTH: PRELIMINARY COMPARATIVE STATICS
}

\author{
Allen C. Kelley \\ Duke University, Durham, North Carolina (USA) \\ Jeffrey G. Williamson \\ The University of Wisconsin, Madison, Wisconsin (USA)
}

\section{SOURCES OF URBANIZATION AND CITY GROWTH*}

While observers recognize that Third-World urbanization is nothing short of spectacular, there is little agreement as to its "sources" and consequences. Nor is there agreement on the validity and relevance of the projections to the year 2000 , or even whether urban growth is good or bad. Pessimists stress the Third World's inability to cope with the social overhead requirements of rapid urban growth. High urban capital intensity is a critical issue here. There can be little doubt that urban growth requires high rates of accumulation. But are the requirements so severe that urbanization might slow down because of a saving constraint? Pessimists also stress that the choice of technique is biased toward higher capital intensities for another reason: the larger and most capital-intensive cities are growing most rapidly.

Pessimists also believe that the Third World is suffering from "over-urbanization" emanating from at least three sources. First, migrants are induced to move to the cities in the hope that they (or their children) will be selected for employment in the "favored" highwage sectors. Apparently, new immigrants are willing to accept underemployment in the (allegedly) low-wage traditional service sectors while waiting. They will wait, say the pessimists, only for a limited period of time before social discontent erupts. Second, migrants are attracted to the cities by the presence of public facilities and infrastructure. The social costs of in-migration thus exceed the private costs, creating too many cities containing too many people. When the economy can no longer finance such excesses, the rate of urbanization may slow down. Third, the pessimists believe that Third-World urbanization has in the past been closely related to the availability of cheap energy, the diffusion of technologies which favor "modern" sectors, and unusually rapid population growth.

*This and the following section draw heavily on Kelley and Williamson (1982), parts 1 and 3. 
These conditions seem likely to change in the future, suggesting that Third-World countries may have "over-urbanized" in the past. Thus, the pessimist may well expect that the currently projected high rates of urban growth cannot be achieved over the next two decades, given the OPEC-induced fuel scarcity (cities being fuel-intensive), the likelihood that technological regression may soon hit the Third World (especially in the "modern" sectors which have borrowed heavily from the more advanced countries), and the probability that population growth will slow down.

Since nobody has offered a quantitative assessment of the effect of these forces over the past two decades, there is really no evidence to call upon in the debate over the accuracy of projections. In general, city-growth projections are either not based on an economic-demographic model at all, or else employ models based on the relationship between urban costs and the decision to migrate to a more urban environment. In addition, de tailed analyses of Third-World cities by urban economists and planners conventionally assume that the number of in-migrants is an exogenous variable. It is our view that more useful information can be obtained by the use of a general equilibrium model of Third-World development that includes some of the costs of urbanization so that "natural limits" to urban growth can be evaluated.

This paper reports a first attempt to apply such a model to Third-World urbanization and development. Section 2 discusses modeling strategy and some of the key forces that might serve to retard the rate of urbanization. Section 3 offers a brief overview of the Kelley-Williamson (KW) model. Section 4 examines quantitative problems. How is the model implemented empirically? How is it to be validated? Rather than examining a particular country in detail, the present study draws upon the empirical record of a synthetic "representative developing country" (RDC). Analysis of the KW model is still in the preliminary stages, so Section 5 contains some initial comparative static experiments only: refinements of the model, validation, projection, and dynamic analysis will be reported in future papers. Section 6 discusses future research plans and also considers some possible extensions to the model.

\section{LIMITS TO CITY GROWTH}

Rapid city growth is explained in part by rapid population growth, but, despite popular opinion, the same is unlikely to be true of urbanization. We make much of this point in Section 5 , but even if we are wrong, any attempt to identify the sources of and limits to urban growth should certainly begin by examining the unusual population pressures that have beset the Third World in the mid-20th century; we should then try to identify the other factors contributing to the rapid rate of urbanization in the Third World.

Simon Kuznets has shown that when urbanization is plotted against time we obtain the familiar S-shaped diffusion curve. Why do some economies exhibit high rates at the point of inflexion, indicating that the transformation of the economy from an agrarian to a modern urban structure is very rapid? If there are endogenous forces that tend to inhibit the rate of urbanization (disregarding any overt anti-urban policy), what are they? One could appeal to the mechanics of the demographic transition to provide a potential limit to urban growth: fertility rates are known to be lower in cities than in rural areas, thus implying an eventual reduction in population growth as urbanization proceeds. This factor 
alone would cause city growth to slow down. However, it seems unlikely that these longrun forces would be of sufficient magnitude to offer limits to urban growth in the next quarter century (Kelley et al., 1972).

Additional insights into the limits of urban growth might be gained by examining the various urban costs that influence the decision to migrate and the rising urban investment requirements that compete with "productive" capital accumulation. For example, restrictions on the land available for urban development can provide an important limit to urban expansion. Land constraints serve to raise (market or shadow) rents, increase the cost of living in the city relative to that of living in rural areas, and inhibit in-migration. The importance of these land constraints on city rents must be evaluated in a general equilibrium model that considers the use of land for a variety of functions: low-cost residential settlements, factory sites, public social facilities, and luxury housing. The housing-cumsocial investment requirements of city growth must also be examined. "Unproductive" urban investments of this type (see Coale and Hoover, 1958) may well take priority over those forms of accumulation that create capacity for future urban employment. In any case, "unproductive" urban-investment requirements compete directly with "productive" capital accumulation. If the housing-cum-social investment is foregone, then housing costs will rise and the quality of urban services will fall, further discouraging in-migration. In short, the rise in the relative cost of living in the city may impose a limit to city growth. On the other hand, any rise in urban "unproductive" investment requirements will diminish the rate of "productive" urban capital accumulation and new urban job vacancies, and this would also limit urban growth.

There are other possible urbanization constraints worth considering. "Modern" sectors tend to be relatively intensive in both skills and intermediate material requirements, imported materials in particular. The most visible manifestation of the latter is fuel. The role of skill "bottlenecks" is more uncertain. If capital and skills are complementary, and the skills learnt in one field may not be transferred to another, then rapid rates of urban capital formation imply increasing demands for skilled labor. Models of Third-World urbanization must be designed to take these potential skill bottlenecks into account, for they may constrain capacity expansion in the modern urban sectors and retard the rate of growth in urban employment, thus placing further limits on urban development. Furthermore, any attempts to relax this constraint by accumulation of skills are likely to compete with "productive" urban capital accumulation and therefore offer an alternative limit to city growth.

These and other limits to urban growth can be effectively evaluated in a general equilibrium model of Third-World urbanization.

\section{A BRIEF REVIEW OF THE KELLEY-WILLIAMSON MODEL*}

Our model of Third-World urbanization and economic growth has been presented in detail elsewhere (Kelley and Williamson, 1980) so this section will offer only a brief overview.

\footnotetext{
*This section draws heavily on Kelley and Williamson (1980), pp. 3-7.
} 
The model possesses a high degree of closure: most input and output prices are determined endogenously. Nested CES (constant elasticity of substitution) production functions are assumed to hold in manufacturing and "modern" urban services, while Cobb--Douglas functions describe the production activities in agriculture, "traditional" services, and all housing sectors. Price-responsive demand relationships are embedded in an Extended Linear Expenditure System (ELES) of household demand and saving. Comparative static equilibrium is achieved by constrained factor mobility which tends to equalize expected factor rents and rates of return. Optimization is imposed on firms and households, both of which are assumed to maximize returns and utility subject to constraints. Furthermore, government income and expenditures are determined endogenously.

The model distinguishes between tradeables and nontradeables, the latter including various location-specific services. The presence of nontradeables results in urban-rural cost-of-living differentials. Since migrants are assumed to move in response to expected real earnings differentials, these cost-of-living differentials may exert an important influence on city growth. One nontradeable stressed in the model is housing (and associated support services). In-migration may increase the rents charged for buildings and land, making further in-migration less appealing. Furthermore, the building of new houses (and the associated social overhead investment) serves to diminish the rate of accumulation in plant and equipment, resulting in fewer new jobs and slower city growth.

The model deals with a portfolio of heterogeneous capital stocks consisting of "productive" conventional capital (plant and equipment), "unproductive" capital in residential structures (housing), and human capital (training and skills). There are four capital-goodsproducing sectors satisfying these investment demands: the manufacturing sector (which produces equipment), the "modern" service sector (which provides education and training as well as producing high-rent buildings), and the "traditional" urban and rural service sectors (which produce low-rent buildings). Investment is financed out of a common saving pool and, subject to the constraints of capital market fragmentation (including the absence of a mortgage market), is allocated to produce the greatest expected return. Thus, the economy's allocation of resources between different sectors obeys neoclassical rules, though the institutional realities of the Third-World capital market partially constrain this allocation.

The model also considers optimal land-use problems, albeit in a simple way. An expression for the rate of urban encroachment on farmland as the city grows is provided, though we do not employ the urban economist's land-gradient function. Endogenously determined land use and rents can influence cost-of-living differentials and thus in-migration. The model considers two residential uses of urban land - for "luxury" high-rent housing and for low-rent "squatter settlements" -- each produced by different technologies and geared to the demands of different socioeconomic classes.

The model was not developed to examine income distribution problens in detail, but it does offer some insights into inequality. There are five basic socioeconomic classes in our system: landlords, capitalists, urban skilled, urban unskilled, and rural landless. The model endogenously determines the average income according to socioeconomic class, the factor shares, and the wages structure.

There are also many variables that are exogenous to the model; among these are demographic variables, sectoral rates of total factor productivity growth, flows of capital from abroad, world market prices for exports and imports, land stocks, and various policy parameters. 


\section{THE REPRESENTATIVE DEVELOPING COUNTRY (RDC) APPROACH: ESTIMATION, DYNAMICS, AND VALIDATION}

\subsection{Concept of the Representative Developing Country}

Both time-series and cross-sectional studies show that there exists a "typical pattern" of development. This pattern is characterized by systematic shifts in industrial structure, urbanization, population and labor-force growth, the structure of private demand (Engel's Law), the size and structure of government (Wagner's Law), the distribution of income (Kuznets' Curve), accumulation rates (trend acceleration), and so forth. City growth has added other characteristics to this list: rising urban cost of living, rising "populationsensitive" investment in the cities, increasing urban land scarcity, rising land values, and the like. While many countries deviate from this pattern, the statistical regularity is too great to be ignored. Given this evidence, we have elected to use the concept of a Representative Developing Country (RDC) to calibrate the model. The RDC is a statistical artifact, a fictional economy based on apparently diverse experience from three continents. Nonetheless, we have found that the RDC concept is a useful first step in introducing empirical content into our general equilibrium model of Third-World urbanization and economic development.

Three critical decisions must be made in constructing the fictional RDC. First, a sample of developing countries must be chosen to serve as the data base. Second, a procedure for summarizing the relevant national experiences must be selected. Third, a benchmark date must be selected; this defines the period which the RDC's parameters and initial conditions will represent. The criteria employed in selecting the developing countries to be included in the sample are discussed in Section 4.2. The benchmark year 1960 was taken as the initial date for the simulations. This is the earliest year for which a reasonably complete data set is available and which nevertheless provides a period of quantitative experience long enough to check the model's long-run predictions.

We require a statistical procedure bringing together the results obtained from the sample of developing countries to produce one set of data corresponding to the RDC. For a number of reasons, we have elected to compute the (unweighted) average value of each economic and demographic variable, evaluated over all the countries in the sample. It is, after all, the record of individual countries that constitutes the unit of analysis. Furthermore, these variables form the basis of the empirical generalizations on the uniformity of development patterns, cited above. To weight some countries more than others in constructing the RDC would imply that some countries are in some sense more "representative" than others. The development process is still not clear enough to make it possible to assign such weights.

\subsection{The RDC Sample}

Two main criteria are used to select the developing countries to be included in the sample: data availability and the extent to which the country conforms to the model's key assumptions.

Beginning with the list of 101 developing countries provided in World Tables 1976, 24 countries were eliminated because they failed to supply industrial production data for 
1960. The countries excluded by this criterion were Afghanistan, Burma, Burundi, Fiji, Guinea, Iceland, Kuwait, Laos, Lesotho, Liberia, Libyan Arab Republic, Madagascar, Nepal, Oman, Papua New Guinea, Qatar, Republic of Ireland, Saudi Arabia, Sierra Leone, Somalia, Tanzania, Tunisia, Upper Volta, and Venezuela.

The World Tables does not clearly define what is meant by a "developing country". While any single statistic is arbitrary, an average income of 500 US dollars per capita in 1960 appears to represent a reasonable threshold. This criterion eliminates Argentina, Finland, Greece, lsrael, and Spain, and reduces the sample to 72.

Three additional criteria were imposed. Countries were excluded if they had: mineral exports exceeding $20 \%$ of the gross domestic product; a net deficit in the foreign trade account exceeding $10 \%$ of the gross domestic product during the period 1960-1965; and a growth rate of per capita income falling short of $1 \%$ per annum during the $1960 \mathrm{~s}$. Our model does not have a fine classification of tradeable goods. It is designed to examine those nations whose exports in 1960 were mainly agricultural goods, and whose imports were composed largely of industrial products and raw materials. There is, however, a group of developing countries, including the oil-producing nations, that is heavily committed to mineral exports. In the 1970 s these countries were also "price setters", behavior at variance with our model's small-country price-taker assumptions. Thus, those nations dependent on mineral exports have been excluded. Furthermore, we have ignored any countries heavily dependent on foreign capital.

Finally, our model is designed to analyze a country undergoing successful development. It does not examine the conditions of stagnation, retardation, or politically and inilitarily induced instability. Thus, we have excluded from the sample those countries that experienced either negative or only minimal growth in per capita income during the 1960s.

Table 1 lists the 32 developing count ries with sufficient documentation to be included in the sample but eliminated for the reasons given above. The most common failing was extremely poor growth ( 14 countries). This was followed by high dependence on foreign capital ( 8 countries), and heavy reliance on mineral exports ( 7 countries). A total of 40 countries remain to form the sample, and these are listed in Table 2.

TABLE 1 Developing countries with sufficient documentation to be included in the sample, but excluded for the reasons given.

\begin{tabular}{ll}
\hline Reason for exclusion & Countries \\
\hline Mineral export dependence & Bolivia, Gabon, Iran, Iraq, Jamaica, Mauritania, Zaire \\
Foreign capital dependence & $\begin{array}{l}\text { Barbados, Botswana, Malta, Congo, Cyprus, Jordan, Lebanon, } \\
\text { Malawi }\end{array}$ \\
Poor growth & $\begin{array}{l}\text { Central African Republic, Chad, Niger, Rwanda, Senegal, Sudan, } \\
\text { Trinidad, Benin, Cambodia, Ghana, Mali, Mauritius, Uruguay, } \\
\text { Zimbabwe }\end{array}$ \\
& Guyana, South Vietnam, Zambia \\
\hline
\end{tabular}


TABLE 2 The 40-country sample used to specify the RDC.

\begin{tabular}{llll}
\hline Algeria & Egypt & Korea (South) & Philippines \\
Bangladesh & El Salvador & Malaysia & Portugal \\
Brazil & Ethiopia & Mexico & Sri Lanka \\
Cameroon & Gambia & Morocco & Swaziland \\
Chile & Guatemala & Nicaragua & Syria \\
Taiwan & Honduras & Nigeria & Thailand \\
Colombia & India & Pakistan & Togo \\
Costa Rica & Indonesia & Panama & Turkey \\
Dominican Republic & Ivory Coast & Paraguay & Uganda \\
Ecuador & Kenya & Peru & Yugoslavia \\
\hline
\end{tabular}

\subsection{Initial Conditions, Historical Change, and Model Validation}

The comparative static model has now been constructed. The model adopts initial conditions typical of the 40-country RDC sample in 1960; these are summarized in Table 3.

TABLE 3 Some of the initial conditions in the RDC model (based on data from the 40-country sample for 1960).

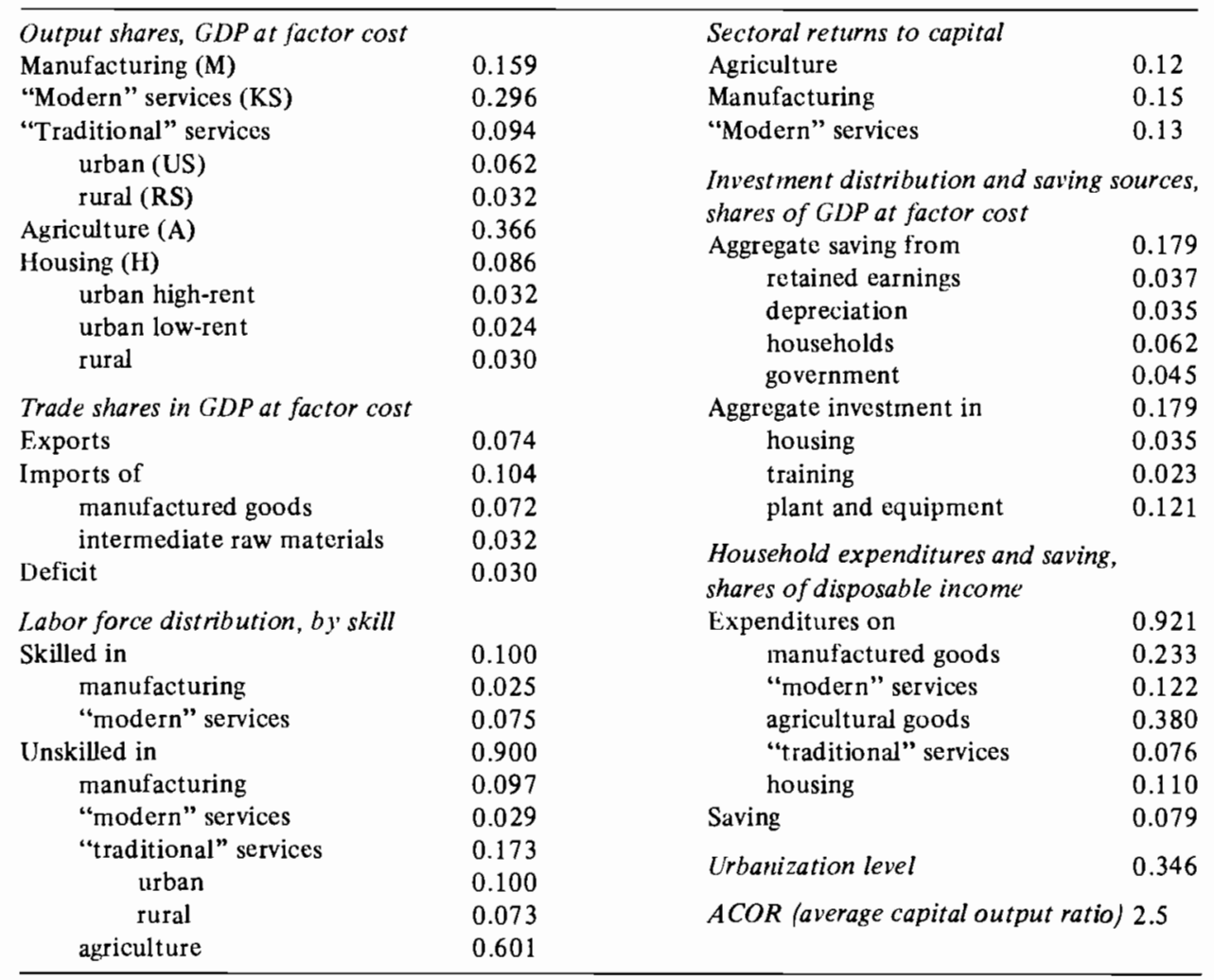


The underlying parameters are also estimated from this group of 40 countries wherever possible; however, in some cases the parameters are estimated from other Third-World economies, a few are simply plausible guesses, and several are derived from the comparative static solution itself.

The next step in the research design is to simulate the historical development of an RDC. Can the RDC model reproduce the major characteristics of growth and structural change from the early 1960s to the mid-to-late 1970s? We have not yet been able to perform these "validation" tests, and they are critical to the research design. Accordingly, the comparative statics reported in Section 5 must be viewed as tentative since the RDC parameters about which we are most uncertain may be revised as we search for "maximum likelihood" estimates. Only after the model has been tested successfully with the ThirdWorld RDC evidence drawn from the 1960s and 1970s can we be reasonably confident in its results.

\section{COMPARATIVE STATIC EXPERIMENTS}

\subsection{Sources of Urbanization: A First Look at Some Comparative Statics}

The causes of past and future Third-World urbanization fall into three main categories: changes in the exogenous variable thought to influence endogenous rates of urbanization, the comparative static impact of that exogenous variable on urbanization, and the long-run dynamic forces set in motion by the short-run comparative static influences. Our future research will examine all three of these influences. This section will focus on the second -- comparative static elasticities - although the analysis will at points be extended and/or qualified by speculations regarding the first -- the change in the exogenous variable. These distinctions are often crucial. A small elasticity may correspond with an unusually important influence if the exogenous variable itself undergoes dramatic change. In addition, small comparative static elasticities may conceal very large dynamic elasticities. For example, while changes in the inflow of foreign capital may have a trivial comparative static impact on urbanization, the dynamic influences may be large since capital accumulation is likely to be augmented.

Which exogenous variables have the greatest comparative static impact on urbanization and city growth? Which are least likely to offer a partial explanation of rapid urbanization in the Third World? This section supplies some tentative answers to these questions. We first discuss the elasticities $(\epsilon)$ of urbanization and city growth to key exogenous variables as reported in Table 4 . Tables 5-8 examine additional influences. In each case, these tables report only a limited set of elasticities, restricted to the endogenous variables of special interest. Readers interested in the elasticities of other endogenous variables

should refer to the Appendix. It should be noted that our model has adopted the initial conditions and parameter values characteristic of our sample of developing countries circa 1960 , and one might well expect different comparative static elasticities for different initial conditions. This issue is discussed in Section 6.

\subsubsection{Unbalanced Productivity Growth}

One potentially important influence on the rate of urbanization is the relative growth in productivity in different sectors. If output demand is relatively price-elastic, 
TABLE 4 Comparative static sources of urbanization: elasticities of urbanization and city growth to some key exogenous variables. ${ }^{a}$

\begin{tabular}{|c|c|c|}
\hline \multirow[t]{2}{*}{ Exogenous variable } & \multicolumn{2}{|c|}{ Endogenous variable } \\
\hline & Urbanization, $u$ & City growth, CPOP \\
\hline \multicolumn{3}{|l|}{ Exogenous prices } \\
\hline$P_{Z}$ & -0.39 & -0.39 \\
\hline$P_{\mathrm{W}}^{\mathrm{M}}$ & +2.00 & +2.00 \\
\hline$P_{\mathrm{W}}^{\mathrm{A}}$ & -1.70 & --1.70 \\
\hline Unskilled labor force, $L$ & -0.60 & +0.25 \\
\hline Land stock, $R$ & -0.36 & -0.36 \\
\hline Wage gap, $\kappa$ & -0.48 & -0.48 \\
\hline \multicolumn{3}{|l|}{ Property taxes, $\tau_{\mathbf{H}, j}$} \\
\hline on low-rent real estate & -0.14 & -0.14 \\
\hline on high-rent real estate & 0 & 0 \\
\hline Import ad valorem tariff rate, $\tau_{\mathrm{T}, \mathrm{M}}$ & +0.05 & +0.05 \\
\hline Foreign aid inflow share in GDP, $F$ & -0.01 & -0.01 \\
\hline \multicolumn{3}{|c|}{ Disembodied sectoral total factor productivity } \\
\hline$A_{\mathrm{M}}$ & +2.05 & +2.05 \\
\hline$A_{\mathrm{KS}}$ & +0.19 & +0.19 \\
\hline$A_{\mathrm{A}}$ & -1.39 & -1.39 \\
\hline$A_{\mathrm{US}}$ & -0.13 & -0.13 \\
\hline$A_{\mathrm{RS}}$ & +0.01 & +0.01 \\
\hline \multicolumn{3}{|l|}{ "Productive" capital stocks } \\
\hline$K_{\mathrm{M}}$ & +0.35 & +0.35 \\
\hline$K_{\mathrm{KS}}$ & -0.13 & -0.13 \\
\hline$K_{\mathrm{A}}$ & -0.30 & -0.30 \\
\hline \multicolumn{3}{|l|}{ Housing stocks } \\
\hline$H_{\mathrm{KS}}$ & +0.02 & +0.02 \\
\hline$H_{\mathrm{US}}$ & -0.59 & -0.59 \\
\hline$H_{\mathrm{RS}}$ & +0.19 & +0.19 \\
\hline
\end{tabular}

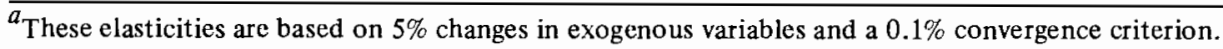

then increased productivity in one sector tends to increase output rather than reducing prices. This distinction is important since the effect of cost-reducing innovations will be passed on to the consumer by falling prices in the inelastic demand case. Thus, in an inelastic situation, the rise in the marginal physical productivity of factors used in the technologically dynamic sector will be partially offset by the decline in price, so that marginal value products rise less sharply, and resource shifts to the technologically dynamic sector are minimized. If, however, urban sectors tend, on average, to have relatively high rates of total factor productivity growth, and if demand for urban output is price-elastic, final demand will shift toward the dynamic urban sectors, urban employment will expand, and city growth will take place. The higher the price elasticities of demand for urban output, the greater the rate of urbanization.

The importance of demand elasticities may be deduced from Table 4. Disembodied improvements in total factor productivity $\left(A_{j}\right)$ in agriculture $(\mathrm{A})$ and the manufacturing industries (M) exert a much greater impact on urbanization (negative for agriculture and 
positive for the manufacturing industries) than do improvements in productivity in any of the three service sectors. The explanation is straightforward: the prices of agricultural and manufactured goods, $P_{\mathrm{A}}$ and $P_{\mathrm{M}}$, are fixed by invoking the "small country" assumption of infinite price elasticity; services are nontradeables with lower price elasticities of demand, and in some cases price-inelastic demand. Thus, increased productivity in the manufacturing sector represents a potentially important factor in Third-World urbanization. In contrast, improved productivity in the agricultural sector tends to discourage migration to the city. (This is in sharp contrast with the closed dual economy where increased agricultural productivity releases resources, thus avoiding the "too many farmers" syndrome associated with inelastic demand and declining terms of trade.) It follows that the unbalanced rate of total factor productivity growth (TFPG) between manufacturing industries and agriculture has probably exerted a strong influence on Third-World urbanization since World War II. Not only are the comparative static elasticities in Table 4 consistent with this assertion, but limited evidence suggests that the annual rates of TFPG in manufacturing have been especially high in the most successful Third-World economies. These have also tended to be the countries experiencing the most rapid rates of urbanization.

Technological progress tends to be slower in the service sectors, but Table 4 suggests that rapid TFPG in these sectors - including the modern capital-cum-skill-intensive urban KS sector -- would have little impact on urbanization, for the demand elasticity reasons already discussed.

\subsubsection{Exogenous Prices and World Market Conditions for Tradeables}

Equally important potential determinants of Third-World urbanization are the world prices of agricultural exports $\left(P_{\mathrm{W}}^{\mathrm{A}}\right)$, the world prices of imported manufactured goods $\left(P_{\mathrm{W}}^{\mathrm{M}}\right)$, and the price of imported raw materials $\left(P_{\mathrm{Z}}\right)$. The signs of the elasticities reported in Table 4 are quite predictable, but the absolute values are more surprising. The larger elasticities associated with $P_{\mathrm{W}}^{\mathrm{A}}$ and $P_{\mathrm{W}}^{\mathrm{M}}$ appear to suggest that these prices have more effect on urbanization than $P_{Z}$. Given what has happened since 1960, however, one must be cautious in drawing the conclusion that $P_{\mathrm{W}}^{\mathrm{A}}$ and $P_{\mathrm{W}}^{\mathrm{M}}$ represent the dominant international price influence on urbanization and city growth. For example, $P_{Z}$ soared in the 1970s. If $P_{\mathrm{M}} / P_{\mathrm{A}}$ changes were relatively small, then it could well be that changes in $P_{\mathrm{Z}}$ exerted the dominant influence on urbanization over the past two decades, even though the measured elasticity is relatively small. All of this underscores the caution with which comparative static results must be treated when used to infer the sources of past or future urban growth.

\subsubsection{Accumulation, Capacity, and Job Creation}

The comparative static impact on urbanization of exogenous changes in manufacturing capital stocks relative to agricultural capital stocks is predictable. Somewhat surprisingly, however, the elasticities are much lower than those associated with relative price changes $\left(P_{\mathrm{M}} / P_{\mathrm{A}}\right)$ and with unbalanced TFPG $\left(A_{\mathrm{M}}\right.$ versus $\left.A_{\mathrm{A}}\right)$. On the other hand, the annual rate of capital accumulation is likely to be far higher than the rate of TFPG, in either absolute or relative terms. There are additional surprises in Table 4. One would have thought that increased availability of low-rent housing (a rise in $H_{\text {US }}$ ) would have encouraged in-migration. It does not. One would also have thought that capital formation in the modern service sector $\left(K_{\mathrm{KS}}\right)$ would have had some effect on employment and thus on urbanization, even given its high capital intensity. It does not. The answer in both cases 
lies in the short-run impact of these changes (especially that of low-rent housing construction) on employment in the urban service sectors. We shall return to this point in Section 5.2 below.

\subsubsection{Land and Labor}

Popular accounts of rapid Third-World urbanization emphasize that high population growth rates lie at the core of the "problem". Table 4 shows that this is simply not the case, and we shall use the Rybczynski Theorem in Section 5.3 to justify our empirical result. City growth is fostered by national population growth, but the positive elasticity is only small. The availability of more land tends to reduce the rate of urbanization and city growth. While an abundance of land inhibits urbanization, this comparative static result is unlikely to produce any major effects on Third-World urbanization simply because land availability has not been growing sufficiently rapidly to have played an important role since 1960.

\subsubsection{Policy and Institutional Change}

The model includes many policy and institutional parameters, five of which are included in Table 4. Each of these parameters has been discussed in the qualitative literature. First, consider the "wage gap" $K$ between the favored modern sectors (M and KS) and the "informal" urban service sector (US). This "wage gap" is determined exogenously in our model by unions and/or public wage policy. Corden and Findlay (1975) have shown that under conditions of capital immobility and with wage-inelastic employment demands in the modern sectors, "wage gaps" imply higher levels of urbanization and faster city growth. The explanation is that people migrate to cities because the expected earnings are higher. Thus, the fact that our model shows that a rise in $k$ tends to inhibit urbanization may come as a surprise. The apparent conflict is resolved in Section 5.5.

Property taxes on urban real estate have a predictable negative impact on urbanization, and are far more important to unskilled people in low-rent housing than to any other group. The effect is not trivial, and is discussed at length in Section 5.2.

\subsection{Some Details: Government Squatter-Settlement Policy and Investment Allocation Response}

Current investment patterns have an important comparative static impact on the RDC. As Section 3 points out, there are three modes of accumulation in the model: "unproductive" investment in housing -- urban "squatter" housing, urban high-rent housing (and social amenities), and rural housing; "productive" investment in producer durables capital formation in manufacturing industries (M), in capital-intensive urban services (KS), and in agriculture (A); and investment in education and training programs. These investment activities are important potential influences on urban in-migration and city growth, even though comparative statics ignore the future capacity-creating effects of the investments. ("Productive" investment in A, M, and KS does not augment capacity and employment until the new capital goods are operational. Thus, investment in new projects does not have capacity-creating effects in the comparative statics.) Nevertheless, current investment decisions do have an important impact on urbanization. 
The important point to remember is that there are several capital goods sectors in the model, and each is associated with a characteristic location and factor intensity. The construction of low-rent housing in urban and rural areas is highly labor-intensive; that of urban luxury housing (and social amenities) is more capital- and skill-intensive, as is the production of producer durables. Thus, any economic event that serves to change the pattern of investment among these activities will also affect the structure of demand and thus employment (see Table 5).

Consider a misanthropic government policy of eviction and demolition of urban squatter settlements (represented by a decline in $H_{\mathrm{US}}$ ), a policy that may be motivated by the misguided belief that city growth will be reduced as a result. The first effect is to create a housing shortage and increase rents $\left(\epsilon P_{\mathrm{H}, \mathrm{US}}=+3.68\right)$ for poor urban households. This generates a rise in the cost of living in cities relative to rural areas $\left(\epsilon \mathrm{COL}_{\mathrm{R} / \mathrm{US}}=\right.$ -0.58 ), which serves to reduce the advantages of city life, in terms of expected real earnings, and thus reduces urban in-migration. Viewed on these grounds alone, the misanthropic demolition policy is successful.

However, the cost-of-living effect is more than offset by the effects on employment caused by changes in the pattern of investment. First, the rent and profitability of urban low-rent housing both rise sharply in response to government-induced scarcity $\left(\epsilon r_{\mathrm{H}, \mathrm{US}}=\right.$ +4.04 and $\hat{\epsilon}_{\mathrm{H}, \mathrm{US}}=+5.35$ ). Second, investment from the current saving pool is biased in favor of low-rent housing $\left(\epsilon I_{\mathrm{H}, \mathrm{US}} / \mathrm{GDP}=+8.92\right)$. Third, the sector producing low-cost urban dwellings increases both its output $\left(\epsilon Q_{\mathrm{US}}=+2.07\right)$ and its price $\left(\epsilon P_{\mathrm{US}}=+0.17\right)$. But this production takes place in the informal urban service sector where labor intensities are high, so that employment rises sharply in this sector $\left(\epsilon L_{\mathrm{US}}=+2.18\right)$. What is the net comparative static impact of the misanthropic policy on city growth? City growth is increased $(\epsilon \mathrm{CPOP}=+0.59)$ and urbanization is encouraged $(\epsilon u=+0.59)$ ! Only experience and observation will show whether the long-run effects reverse these short-run influences.

Consider a very different policy. Suppose that the "tax" on urban low-rent housing $\left(\tau_{\mathrm{H}, \mathrm{US}}\right)$ is in fact a net transfer of benefits to the urban poor in squatter settlements. The benefits may include water supply, paved roads, police protection, and health clinics, while the property taxes may in fact be nonexistent. This would amount to a negative tax on urban property. Now consider a government policy that raises this tax by lowering the benefits received by each household. First, there is a compensating fall in rents $\left(\epsilon P_{\mathrm{H}, \mathrm{US}}=\right.$ -0.47 ), and second, a fall in the profitability of investment in urban low-rent housing $\left(\epsilon \hat{r}_{\mathrm{H}, \mathrm{US}}=-0.92\right)$. This induces a reduction in low-rent housing investment $\left(\epsilon I_{\mathrm{H}, \mathrm{US}} / \mathrm{GDP}\right.$ $=-2.04)$ and a contraction in the sector supplying the necessary investment goods ( $\epsilon Q_{\mathrm{US}}$ $=-0.48$ ). Since the construction of low-rent housing is a very labor-intensive activity, any contraction in the industry will be reflected in a reduced demand for urban labor. What happens to urbanization and city growth? On the one hand, the cost of living in the city relative to rural areas declines $\left(\epsilon \mathrm{COL}_{\mathrm{R} / \mathrm{US}}=+0.09\right)$, but on the other hand, there are fewer jobs in the informal urban services $\left(\epsilon L_{\mathrm{US}}=-0.51\right)$. It appears that the effect on employment dominates and urbanization slows down $(\epsilon u=-0.14)$.

In contrast, consider a government policy taxing high-rent "luxury" buildings $\left(\tau_{\mathrm{H}, \mathrm{KS}}\right)$ in the cities. Once again, the first-order impact is to lower the rents of the buildings and reduce the profitability of high-rent housing investment $\left(\epsilon r_{\mathrm{H}, \mathrm{KS}}=-0.26\right.$ and $\left.\epsilon \hat{r}_{\mathrm{H}, \mathrm{KS}}=-0.14\right)$. Investment in high-rent housing is reduced $\left(\epsilon I_{\mathrm{H}, \mathrm{KS}} / \mathrm{GDP}=-5.61\right)$ and investment in training programs $\left(\epsilon I_{\mathrm{S}, \mathrm{KS}} / \mathrm{GDP}=+1.18\right)$ and producer durables $\left(\epsilon I_{\mathrm{M}}=\right.$ 
$\left.+0.21, \epsilon I_{\mathrm{M}, \mathrm{M}} / \mathrm{GDP}=+1.83, \epsilon I_{\mathrm{KS}, \mathrm{M}} / \mathrm{GDP}=-0.62, \epsilon I_{\mathrm{A}, \mathrm{M}} / \mathrm{GDP}=+2.18\right)$ is increased. In contrast with the two cases discussed above, the net impact on sectoral output is trivial. In particular, note that the impact of the fall in $I_{\mathrm{H}, \mathrm{KS}}$ is offset by the rise in $I_{\mathrm{S}, \mathrm{KS}}$. Thus, the demand for factors employed intensively in KS (i.e., capital and skills) is only slightly affected since output and prices remain almost unchanged $\left(\epsilon Q_{\mathrm{KS}}=-0.04\right.$ and $\epsilon P_{\mathrm{KS}}=$ -0.07 ). The demand for investment in new skills is maintained under the property tax policy, and thus the increased supply of "productive" saving serves to encourage the accumulation of skills $(\epsilon S=+1.16)$. However, the net effect on city growth is negligible $(\epsilon u \simeq 0)$.

It is evident that any comparative static analysis which ignores policy-induced changes in the pattern of investment may be misleading. The model suggests that government housing-cum-social-overhead policy may have a significant effect on employment, as the investors respond to the implications of the new policy. Thus, a policy introduced to curb or encourage urbanization may produce precisely the opposite effect over the short term. This makes predictions of long-run dynamic effects even more difficult.

\subsection{Some Details: Population Pressure and Land Scarcity}

The factors producing rapid city growth and the factors causing urbanization are not necessarily the same. The Rybczynski Theorem states that increased availability of any given factor involved in production should favor the expansion of the sectors using the factor most intensively. It has been shown (Lewis, 1977) that urban activities are very capital-intensive. Our model agrees with this; urban activities are, on average, far less laborintensive than rural activities, even given the presence of the labor-intensive informal service sector. Whatever its source, population-induced labor-force growth should therefore encourage rural activities and suppress urbanization. This analysis suggests that population growth is not a cause of urbanization. However, population growth may still produce city growth. Having made this simple but important distinction, we can assess the quantitative influence of population growth and land scarcity in our comparative static model.

Consider a $1 \%$ rise in the economy-wide unskilled labor force, produced by some previous demographic event. In our model, the economic theory underlying the decision to migrate applies to "movers" and "stayers" alike. Furthermore, both rural and urban unskilled workers are assumed to have the same expected real earnings, subject to the differences in cost of living and job availability in rural and urban areas. Thus, the spatial source of the economy-wide labor-force growth does not matter: it may well be centered in rural areas where fertility rates are high. The point here is that the demographers' concern with the relative contributions of migration and natural increase (excess of births over deaths) to urbanization (Davis, 1965; Ledent, 1982; Rogers, 1982) is irrelevant in a model such as ours.

Table 6 shows that labor-force growth and population pressure have Malthusian consequences. First, per capita income falls $(\epsilon \mathrm{GDP} / N=-0.25)$, a victim of diminishing returns. The most dramatic decline in productivity takes place in agriculture $\left(\epsilon Q_{\mathrm{A}} / L_{\mathrm{A}}=\right.$ -0.36 ), where labor is used most intensively and complementary inputs are least mobile. The prices of tradeables $\left(P_{\mathrm{A}}\right.$ and $\left.P_{\mathrm{M}}\right)$ are assumed to be fixed by world market and commercial policy conditions, so only the prices of nontradeables change in response to the 


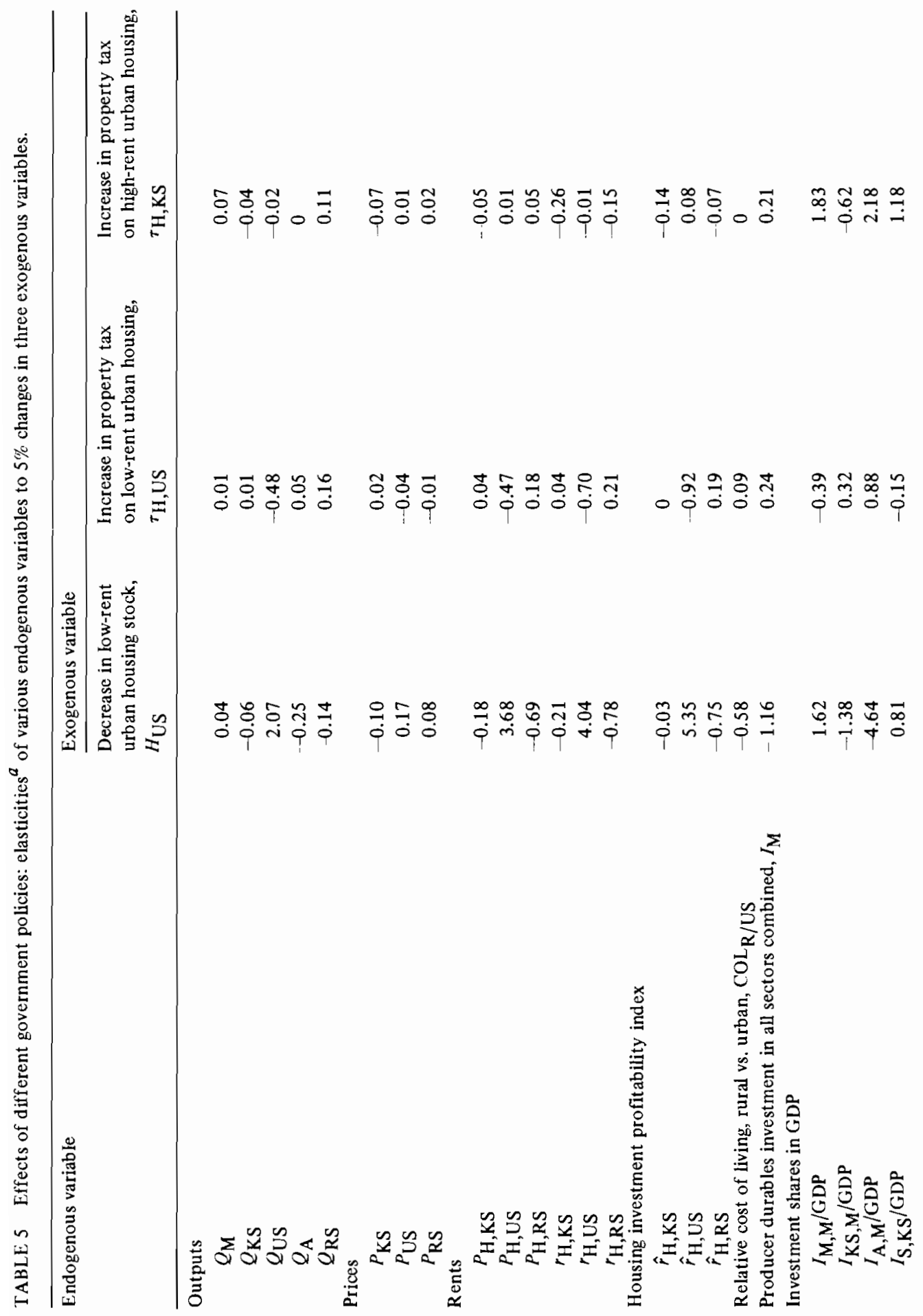




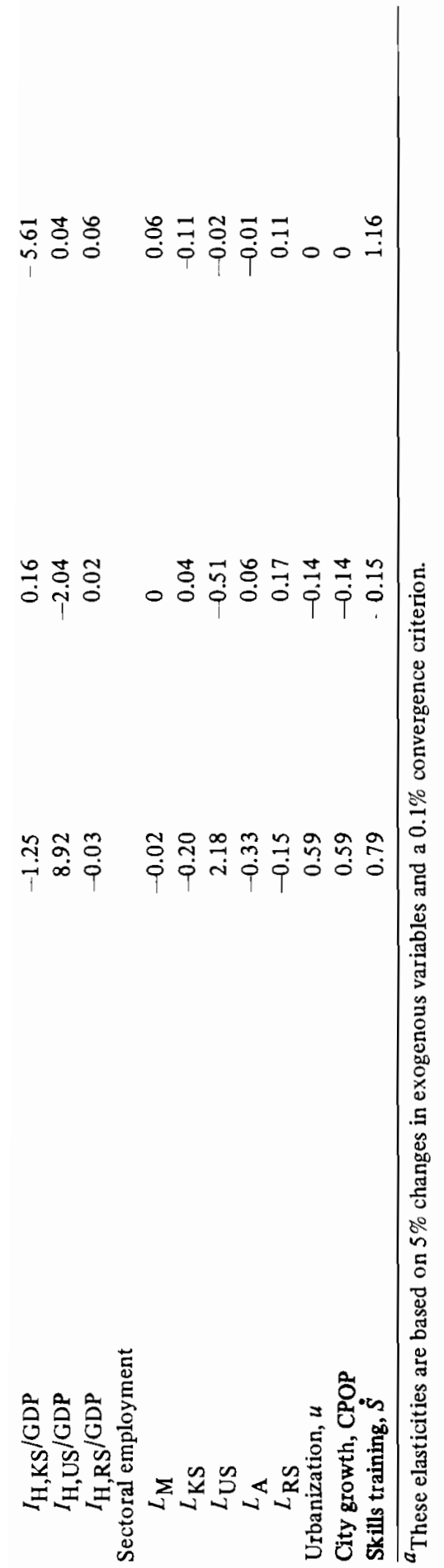


TABLE 6 Effects of population pressure and land scarcity: elasticitics ${ }^{a}$ of various endogenous variables to $5 \%$ changes in two exogenous variables.

\begin{tabular}{|c|c|c|}
\hline \multirow[t]{2}{*}{ Endogenous variable } & \multicolumn{2}{|l|}{ Exogenous variable } \\
\hline & $\begin{array}{l}\text { Increase in unskilled } \\
\text { labor force, } \\
L\end{array}$ & $\begin{array}{l}\text { lncrease in } \\
\text { land stock, } \\
R\end{array}$ \\
\hline Per capita income, GDP $/ N$ & 0.25 & 0.15 \\
\hline \multicolumn{3}{|c|}{ Sectoral labor productivity (constant price) } \\
\hline$Q_{\mathrm{M}} / L_{\mathrm{M}}$ & -0.26 & 0.07 \\
\hline$Q_{\mathrm{KS}} / L_{\mathrm{KS}}$ & -0.20 & 0.06 \\
\hline$Q_{\mathbf{U S}} / L_{\mathrm{US}}$ & -0.24 & 0.06 \\
\hline$Q_{\mathrm{A}} / L_{\mathrm{A}}$ & -0.36 & 0.10 \\
\hline$Q_{\mathrm{RS}} / L_{\mathrm{RS}}$ & -0.36 & 0.10 \\
\hline \multicolumn{3}{|l|}{ Prices } \\
\hline$P_{\mathrm{KS}}$ & 0.18 & 0.09 \\
\hline$P_{\mathrm{US}}$ & 0.22 & 0.01 \\
\hline$P_{\mathrm{RS}}$ & -0.32 & 0.11 \\
\hline \multicolumn{3}{|c|}{ Saving ra te and housing investment } \\
\hline SAVING/GDP & --0.17 & 0.10 \\
\hline$I_{\mathrm{H}}$ & 1.80 & -1.46 \\
\hline \multicolumn{3}{|l|}{ Outputs } \\
\hline$Q_{\mathrm{M}}$ & 0.12 & -0.20 \\
\hline$Q_{\mathrm{KS}}$ & 0.10 & 0.06 \\
\hline$Q_{\mathrm{US}}$ & 0.36 & -0.98 \\
\hline$Q_{\mathrm{A}}$ & 0.86 & 0.29 \\
\hline$Q_{\mathrm{RS}}$ & 0.80 & 0.19 \\
\hline \multicolumn{3}{|c|}{ Land use and residential density } \\
\hline$R_{\mathrm{A}}$ & 0.01 & 1.08 \\
\hline$R_{\mathrm{KS}}$ & -0.23 & 0.94 \\
\hline$R_{\mathrm{US}}$ & 0.09 & -0.61 \\
\hline$R_{\mathrm{KS}} / \mathrm{OCC}^{b}$ & -0.23 & 0.94 \\
\hline$R_{\mathrm{US}} / \mathrm{OCC}^{b}$ & -0.30 & -0.05 \\
\hline \multicolumn{3}{|l|}{ Sectoral employment } \\
\hline$L_{\mathbf{M}}$ & 0.38 & -0.27 \\
\hline$L_{\mathrm{KS}}$ & 0.48 & 0.09 \\
\hline$L_{\mathrm{US}}$ & 0.38 & -1.03 \\
\hline$L_{\mathrm{A}}$ & 1.25 & 0.19 \\
\hline$L_{\mathrm{RS}}$ & 0.85 & 0.20 \\
\hline Urbanization, $u$ & -0.60 & -0.36 \\
\hline City growth, CPOP & 0.25 & -0.36 \\
\hline
\end{tabular}

${ }_{b}$ These elasticities are based on $5 \%$ changes in exogenous variables and a $0.1 \%$ convergence criterion.

${ }^{b}$ Residential land per occupant.

increase in population. The effects of supply appear to dominate as prices decline in the labor-intensive sectors $\left(\epsilon P_{\mathrm{US}}=-0.22\right.$ and $\epsilon P_{\mathrm{RS}}=-0.32$, in contrast with $\left.\epsilon P_{\mathrm{KS}}=+0.18\right)$. Also note some Coale-Hoover (1958) signs of worse things to come. Not only does the aggregate saving rate decline $(\epsilon \mathrm{SAVING} / \mathrm{GDP}=-0.17)$, but population-sensitive housing investment rises $\left(\epsilon I_{\mathrm{H}}=+1.80\right)$, leaving even less for "productive" capital accumulation in 
the future. (This result should be compared with that suggested by the simpler KWC model, where the rate of accumulation is augmented by population growth. See Kelley et al., 1972.)

At the sectoral and spatial level, the economy becomes more bucolic. The output of the agricultural and rural services increases $\left(\epsilon Q_{\mathrm{A}} / \mathrm{GDP}=+0.44, \epsilon Q_{\mathrm{RS}} / \mathrm{GDP}=+0.39\right)$ at the expense of all urban activities, "modern" sectors in particular $\left(\epsilon Q_{\mathrm{M}} / \mathrm{GDP}=-0.29\right.$, $\left.\epsilon Q_{\mathrm{KS}} / \mathrm{GDP}=-0.31, \epsilon Q_{\mathrm{US}} / \mathrm{GDP}=-0.05\right)$. In other words, the labor-intensive sectors expand. The sector with the greatest demand elasticity is agriculture, and its increased output is either "vented" on to world markets or serves to displace imports. Since employment is linked to sectoral growth, urbanization is arrested $(\epsilon u=-0.60)$ with a relatively high elasticity. Thus, as predicted by the Rybczynski Theorem, urbanization in the RDC is suppressed by rapid population growth.

What about city growth? Here, more conventionally, economy-wide population pressure causes city growth $(\epsilon \mathrm{CPOP}=+0.25)$, but the impact appears to be smaller than some economic demographers have suggested. We shall discuss other sources of city growth and urbanization in more detail below, but for the moment it is sufficient to note that the rather modest comparative static impact of population growth bodes ill for the "population expansion breeds city growth" school of thought when dynamics are considered. Population growth tends to lower the rate of saving and to shift investment into "unproductive" housing, thus suppressing future "productive" accumulation. Dynamic changes of this type imply that the long-run quantitative impact of population growth on urbanization and city growth would be even weaker than the short-run effects.

How do land markets respond to population pressure in our model? More land is used for agricultural activities $\left(\epsilon R_{\mathrm{A}} / R=+0.01\right)$, but the largest changes are first the decline in the amount of residential space available to each city dweller $\left(\epsilon R_{\mathrm{KS}} / \mathrm{OCC}=\right.$ -0.23 and $\epsilon R_{\mathrm{US}} / \mathrm{OCC}=-0.30$ ), as households save on the increasingly scarce urban land, and second the shift in the use of urban land from high-rent "luxury" housing to low-rent "squatter" settlements $\left(\epsilon R_{\mathrm{KS}} / R=-0.23, \epsilon R_{\mathrm{US}} / R=+0.09\right)$.

Some of these effects can be seen more clearly by reference to changes in the total amount of land available. The comparative static elasticities of various endogenous variables with respect to the availability of land are displayed in Table 6. Urbanization is inhibited by greater availability of land $(\epsilon u=-0.36)$, as it was by population growth, but in this case city growth is also suppressed $(\epsilon \mathrm{CPOP}=-0.36)$. These responses may be explained in much the same way as the reactions to population growth: one can appeal to the formal properties of the Rybczynski Theorem and the land-intensive nature of agriculture, or one can simply argue that employment opportunities in agriculture are proportional to the amount of land under cultivation, an area that Simon recently suggested has expanded at a rate of $0.7 \%$ per annum since the early 1960s (Simon, 1980, p. 1432). However, the model implies that land use does not increase at the same rate in each sector. Agricultural land use increases slightly $\left(\epsilon R_{\mathrm{A}}=+1.08\right)$, but once again the largest shift is between high-rent and low-rent urban residential sectors $\left(\epsilon R_{\mathrm{KS}}=+0.94, \epsilon R_{\mathrm{US}}=-0.61\right)$. The explanation is not difficult to find. The large decline in city growth $(\epsilon \mathrm{CPOP}=-0.36)$ is induced by a decline in the urban employment of unskilled labor $\left(\epsilon L_{\mathrm{M}}=-0.27, \epsilon L_{\mathrm{KS}}\right.$ $=+0.09, \epsilon L_{\mathrm{US}}=-1.03$ ). In contrast, skilled workers and property owners find that their combined incomes increase; all of these high-income households consume urban high-rent housing with income-elastic demand. 


\subsection{Some Details: Fuel and Nonfuel Intermediate Input}

Our model does not distinguish between imported fuels and other intermediate materials. But both commodities are natural-resource intensive, and most Third-World economies are heavily dependent on other countries for their supply. Indeed, rapid industrialization and urbanization have increased these import requirements to the extent that Third-World development was often described as "import dependent" in the 1960s. Similarly, the popular view in the 1970s was that urbanization breeds balance-of-payments problems and foreign indebtedness (Lewis, 1977). Our model is able to explore the general magnitude of these forces, but it cannot separate the effects of importing fuel from those of importing other intermediate inputs. Rather, $Z$ includes both fuel and nonfuel intermediate inputs, and $P_{\mathrm{Z}}$ is a composite of the prices of all imported raw materials, fuels included. In what follows we shall refer to $Z$ as "fuels" and $P_{Z}$ as "fuel prices", but it is important to remember the qualification.

An exogenous increase in the price of fuels has a powerful impact on the RDC economy, even though the model assumes that long-run fuel-saving measures are introduced. There are two ways of saving fuel: first, all firms, farms, and households reduce their consumption; second, those sectors using fuel-intensive techniques decline in relative importance as the rise in their relative cost reduces the final demand for their products. The total effect of these fuel-saving measures (documented in Table 7) is impressive ( $\epsilon Z=$ $-1.17)$, although the greatest decline in consumption takes place in the manufacturing industries $\left(\epsilon Z_{\mathrm{M}}=-1.33\right)$. This is consistent with the fact that manufacturing is the most fuel-intensive sector; thus, manufacturing output declines $\left(\epsilon Q_{M}=-0.40\right)$, as does its current-price value-added share in the GDP $\left(\epsilon Q_{\mathrm{M}} P_{\mathrm{M}} / \mathrm{GDP}=-0.31\right)$. There is less employment in the manufacturing industries $\left(\epsilon L_{\mathrm{M}}=-0.37\right)$, and this has important "multiplier effects" on employment in the urban informal service sector. One of these "multiplier effects" acts through low-rent housing. Since the demand for low-rent dwellings falls with the decline in manufacturing, the rents of urban low-cost housing are reduced $\left(\epsilon P_{\mathrm{H}, \mathrm{US}}=\right.$ $-1.33)$ and investment in this type of housing diminishes $\left(\epsilon I_{\mathrm{H}, \mathrm{US}} / \mathrm{GDP}=-3.92\right)$. This causes output and employment in informal urban services to decline $\left(\epsilon Q_{\mathrm{US}}=-1.00\right.$ and $\epsilon L_{\mathrm{US}}=-1.06$ ). In short, urbanization is checked by increases in the cost of fuels and other raw materials $(\epsilon u=-0.39)$.

This experiment demonstrates yet another important point. While the structure of the economy responds dramatically to the increase in fuel prices - the decline in urbanization being one manifestation of this response - aggregate income per capita is hardly affected $(\epsilon \mathrm{GDP} / N=-0.02)$. Indeed, if the structure of the economy had not been affected so greatly, the impact on aggregate income per capita would have been far larger. Our model allows for structural adjustments since it incorporates high elasticities in both demand and supply. In contrast, a "structuralist" model - in which commodities and inputs have low substitution elasticities, and where there is little movement of the labor force between sectors - would have predicted a far smaller comparative static impact on urbanization than that reported here.

Finally, note that there are some signs of future recovery: the saving rate increases slightly $(\epsilon$ SAVING/GDP $=+0.08)$ and "unproductive" housing investment declines $\left(\epsilon I_{\mathrm{H}}\right.$ $=-1.16$ ), leaving a larger residual for future accumulation. 
TABLE 7 Effects of a shortage of fuels and other natural resources: elasticities ${ }^{a}$ of various endogenous variables to a $5 \%$ change in the price of raw materials, $P_{Z}$.

\begin{tabular}{ll}
\hline Endogenous variable & Exogenous variable \\
\cline { 2 - 2 } & $\begin{array}{l}\text { Increase in price of } \\
\text { imported raw materials, } P_{Z}\end{array}$ \\
\hline Intermediate input use & -1.17 \\
$Z$ & -1.33 \\
$Z_{\mathrm{M}}$ & -0.92 \\
$Z_{\mathrm{KS}}$ & -0.82 \\
$Z_{\mathrm{A}}$ & \\
Outputs & -0.40 \\
$Q_{\mathrm{M}}$ & 0.03 \\
$Q_{\mathrm{KS}}$ & -1.00 \\
$Q_{\mathrm{US}}$ & 0.14 \\
$Q_{\mathrm{A}}$ & 0.13 \\
$Q_{\mathrm{RS}}$ & -0.31 \\
Manufacturing output share (current price), $Q_{\mathrm{M}} P_{\mathrm{M}} / \mathrm{GDP}$ & \\
Sectoral employment & -0.37 \\
$L_{\mathrm{M}}$ & 0.08 \\
$L_{\mathrm{KS}}$ & -1.06 \\
$L_{\mathrm{US}}$ & 0.21 \\
$L_{\mathrm{A}}$ & 0.14 \\
$L_{\mathrm{RS}}$ & \\
Low-rent housing: rents and investment & -1.33 \\
$P_{\mathrm{H}, \mathrm{US}}$ & -3.92 \\
$I_{\mathrm{H}, \mathrm{US}} / \mathrm{SAVING}$ & -0.39 \\
Urbanization, $u$ & \\
Dynamic indicators and per capita GDP & 0.08 \\
SAVING/GDP & -1.16 \\
$I_{\mathrm{H}}$ & -0.02 \\
$\mathrm{GDP} / N$ & $0.1 \% c 0 \mathrm{n}$ \\
\hline
\end{tabular}

$\overline{a_{\text {These elasticities are based on }} \% \% \text { changes in the exogenous variable and a } 0.1 \% \text { convergence criterion. }}$

\subsection{Some Details: Urban Wage Policy and the Todaro-Corden-Findlay Analysis}

The "Todaro model" has enjoyed considerable popularity since it was introduced in 1969. Todaro's thesis is simple and elegant, but the most effective illustration of this model can be found in Corden and Findlay (1975). Their version, reproduced in Figure 1, assumes capital immobility, constant output prices, and only two (explicit) sectors - agriculture (A) and manufacturing (M). By ignoring cost-of-living differentials, assuming that wages are equalized through migration, and ignoring overt unemployment, equilibrium is achieved at $\mathrm{E}$, where the two labor demand curves $\left(\mathrm{AA}^{\prime}\right.$ and $\left.\mathrm{MM}^{\prime}\right)$ intersect. Corden and Findlay then incorporate the widely-held belief that the wage rate in Third-World manufacturing sectors is set at an artificially high level, $\bar{w}_{\mathrm{M}}$. Alternatively, one can view this wage rate as the result of a policy that attempts to increase the "wage gap" between 


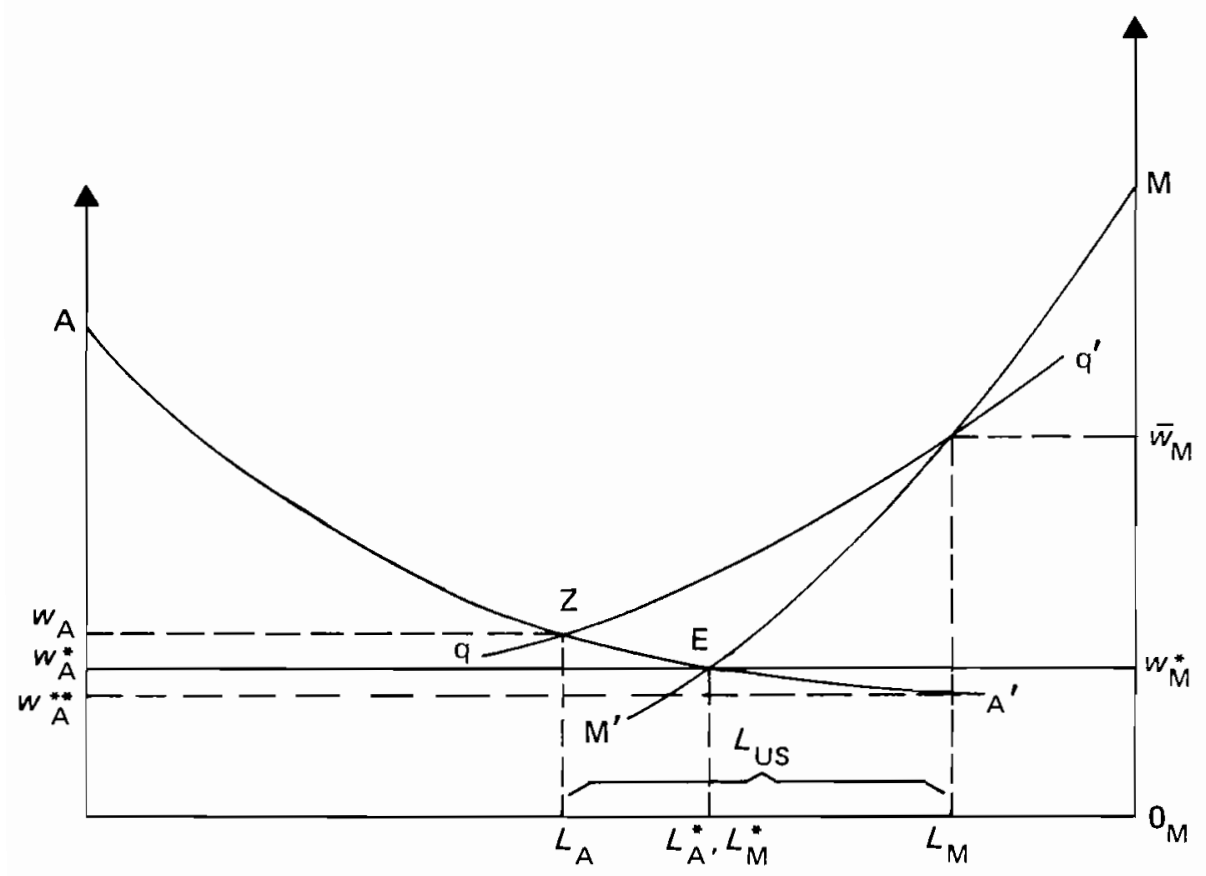

FIGURE 1 Urban wage policy and the Todaro-Corden-Findlay model.

agricultural and manufacturing sectors to $\kappa=\bar{w}_{M} / w_{A}$, as we do in our model. If overt unemployment is ignored, then all who fail to secure the favored jobs in $M$ will accept the lower-paying jobs in $\mathrm{A}$ at a wage rate $w_{\mathrm{A}}^{* *}$. In this situation, urban employment is reduced by the urban wage policy and urbanization is inhibited.

As Todaro (1969) initially pointed out, however, the rates of urban growth in the Third World have increased dramatically. Furthermore, there has been an increase in underemployment in the traditional urban service sector. Todaro explains this apparent conflict - movement to the cities in the face of urban underemployment of the work force - by developing a simple search model of rural--urban migration in which expectations of employment in the favored sector are important. Given the "pegged" wage in $M$, at what rural wage would the potential migrant be indifferent between "underemployment" in the traditional urban service sector and employment in the agricultural sector? This is the essence of the qq' curve in Figure 1. Equilibrium in this case is given by $\mathrm{Z}$, where the $\mathrm{qq}^{\prime}$ curve intersects the $\mathrm{AA}^{\prime}$ curve.

What does the Todaro-Corden-Findlay model reveal about the sources of urbanization? Any urban policy that raises the wage in the favored sector (M), or raises the "wage gap" between the favored sector and alternative employment, will serve to increase urbanization. This counterintuitive result is based on another assumption which appears innocuous: since $\mathrm{qq}^{\prime}$ can be shown to have an elasticity of unity, then the labor dcmand function 
$\left(\mathrm{MM}^{\prime}\right)$ in the favored sector exhibits an own-wage elasticity of less than one. We have no objection to this assumption; in fact, it is also present in our model.

TABLE 8 Effects of wage differentials between sectors: elasticities ${ }^{a}$ of various endogenous variables to a $5 \%$ increase in the wage gap $\kappa$.

\begin{tabular}{lc}
\hline Endogenous variable & Exogenous variable \\
\cline { 2 - 2 } & Increase in the "wage gap", $\kappa$ \\
\hline Unskilled wages & -0.07 \\
$w_{\mathrm{AL}}$ & -0.63 \\
$w_{\mathrm{US}}$ & 0.34 \\
$w_{\mathrm{ML}}$ & -0.04 \\
$w_{\mathrm{U}}$ & \\
Outputs & -0.56 \\
$Q_{\mathrm{M}}$ & 0.05 \\
$Q_{\mathrm{KS}}$ & -0.73 \\
$Q_{\mathrm{US}}$ & 0.19 \\
$Q_{\mathrm{A}}$ & 0.18 \\
$Q_{\mathrm{RS}}$ & \\
Low-cost housing rents and investment & -1.60 \\
$P_{\mathrm{H}, \mathrm{US}}$ & -3.87 \\
$I_{\mathrm{H}, \mathrm{US}} /$ GDP & \\
Sectoral employment of unskilled labor & -0.92 \\
$L_{\mathrm{M}}$ & 0.20 \\
$L_{\mathrm{KS}}$ & -0.77 \\
$L_{\mathrm{US}}$ & 0.26 \\
$L_{\mathrm{A}}$ & 0.19 \\
$L_{\mathrm{RS}}$ & -0.48 \\
Urbanization, $u$ &
\end{tabular}

${ }^{a}$ These elasticities are based on $5 \%$ changes in exogenous variables and a $0.1 \%$ convergence criterion.

In contrast to the Todaro-Corden-Findlay predictions, however, our model (Table 8) shows that a rise in the exogenous "wage gap" tends to lower the level of urbanization $(\epsilon u=-0.48)$. What accounts for the difference in the results of the Todaro-CordenFindlay and Kelley -Williamson models? Both models assume capital immobility in their comparative static analysis, take the prices of commodity outputs to be constant, and assume that the expected wage dictates migration behavior (though our model allows for cost-of-living differentials while the Todaro-Corden-Findlay model does not).

The source of the difference in predictions between the two models lies in the treatment of the urban service sector(s). In the Todaro-Corden-Findlay model, the urban service sector passively accepts all workers who wish to work there while waiting for employment in the manufacturing sector. Wages do not fall in response to this labor surplus, since the wage in the sector is implicitly zero. Nor are labor-demand conditions in the "traditional" urban service sector of any importance since any urban worker failing to secure employment in the manufacturing sector can be sure of (under)employment in the service sector: informal service sector demand is immaterial! 
Our model rejects this view. Instead, we adopt the position that employment in the "traditional" urban service sector is determined by supply and demand, just as in any other market. What makes the sector different, however, is its very great dependence on unskilled labor. In addition, much of its output is purchased (directly or indirectly) by the urban poor themselves. Furthermore, the price of urban "traditional" services is not assumed to be constant but, like all nontradeables in our model, is determined endogenously.

Given these differences between the two approaches, the findings in Table 8 should now be less surprising to those familiar with the Todaro model.

An increase in $\kappa$ produces a greater differential between wages in the favored urban sectors (in both $\mathrm{KS}$ and $\mathrm{M}, \epsilon w_{\mathrm{ML}}=+0.34$ ) and wages in the informal urban service sector $\left(\epsilon w_{U S}=-0.63\right)$. However, the equilibrium urban wage expected by potential city in migrants is basically the weighted average of these wages, and this figure declines $\left(\epsilon w_{\mathbf{U}}=\right.$ $-0.04)$. This is not the case in the Todaro-Corden-Findlay model: indeed, Figure 1 shows that $w_{\mathrm{U}} \equiv w_{\mathrm{A}}$ rises when $\bar{w}_{\mathrm{M}}$ is greater than the equilibrium wage, $w_{\mathrm{M}}^{*}$. However, in our model $w_{\mathrm{U}}$ falls and, as a result, in-migration slows down and urbanization is inhibited.

This result may be explained by the ability of the informal service sector to absorb the unskilled labor displaced from the formal sector. In our model, the demand for urban informal services is very sensitive to the urban wage policy, so that output in this sector declines $\left(\epsilon Q_{\mathrm{US}}=-0.73\right)$. One source of the reduced demand for urban informal services is the collapse in low-rent housing investment $\left(\epsilon I_{\mathrm{H}, \mathrm{US}} / \mathrm{GDP}=-3.87\right)$, a response triggered by the sharp decline in rents $\left(\epsilon P_{\mathrm{H}, \mathrm{US}}=-1.60\right)$, which was itself induced by the fall in the total wages earned by the urban unskilled. Thus, employment drops not only in the formal sectors paying higher wages $\left(\epsilon L_{\mathrm{M}}=-0.92, \epsilon L_{\mathrm{KS}}=-0.20\right)$, but also in the informal urban service sector $\left(\epsilon L_{\mathrm{US}}=-0.77\right)$ through what might be called "urban multiplier" effects.

In summary, our model reveals that a policy that sets wages in the formal sector above market levels will tend to inhibit urbanization; the opposite is shown by the Todaro-Corden-Findlay model. The difference in results is not explained by the greater complexity of our general equilibrium model, but rather, by different interpretations of the urban informal service sector.

\section{FUTURE EXTENSIONS}

\subsection{Projections to the Year 2000}

Although the previous section considered only comparative statics, the model is also equipped to handle dynamic situations. Indeed, the optimal distribution of investment among sectors in a given period has already been determined in the comparative static solution, and it is only necessary to add net investments to the existing sectoral capital and housing stocks to describe accumulation over time. Similarly, the investment in training has already been determined for the current period so that these newly-trained skilled workers can enter the active labor force in the nex.t. The accumulation of "human capital" has therefore already been set in motion by the comparative static solution. The dynamic behavior of the economy can be generated, given additional information on the past trends in exogenous commodity prices, land growth, technological progress in each 
sector, external capital inflows, and the demographic forces driving population and the labor force. Each of these exogenous variables has been documented from 1960 to the late 1970s, using the data base from which the World Tables was derived, among other sources.

We are now able to project our Third-World urbanization model from 1960 to the year 2000. The first part of the projection, from 1960 to the late-1970s, may be used to "validate" the model.

While a projection to the year 2000 may be helpful in guiding long-run policy, it seems more useful to dwell on the causes of urbanization and city growth in the RDC. Is there any evidence of "limits" to future urban growth? If so, what produces these limits? The increased investment requirements of city-building? Increases in the cost of living in cities relative to rural areas, associated with increased land scarcity and higher rents? Reductions in the quality of life in urban areas? These and other issues will be examined in our future research.

\subsection{Speculations on Comparative Statics for the Years 1980 and 2000}

The shortage of fuel may well affect national economies in different ways. Similarly, the effects of urban wage policies and agricultural policies may differ from country to country. Thus, the comparative static results presented in Section 5 might well have been different if we had chosen different initial conditions, e.g., those of 1980 or 2000 rather than 1960.

Future research will involve the examination of comparative static elasticities in 1960,1980 , and 2000 . Which elasticities are most stable over time? Which vary systematically over time? What changes in economic structure exert the greatest impact on the comparative static responses of urbanization and city growth to the exogenous variables of interest? Among other things, we hope that this work will aid in the selection of country studies to enrich our comparative Third-World "histories".

\subsection{Speculations on Comparative Dynamics}

What is the likely long-run effect of changes in each of the exogenous variables explored in Section 5? We will consider the problem in two stages. First, we shall calculate the elasticity of, say, city growth to all exogenous variables of interest. Second, we shall also estimate the likely size of the changes in certain exogenous variables in future decades. What would be the impact on city growth if OPEC doubled the relative price of oil every decade? How would Third-World urbanization be affected if some misanthropic policy halted public aid to developing countries? Questions of this type might be of greater interest than simply exploring the elasticity of $u$ or CPOP to a $1 \%$ change in $P_{Z}$ or $F$. We have more to say about this issue in the Appendix.

\subsection{Model Revisions: The Land Market}

The comparative static model has gone through a number of alterations over the past two years. In the process, the economics has been improved and the structure made 
more "relevant". However, further revision is still possible. For example, the land market currently has an active "extra-marginal" urban fringe which implies that land may be used for urban or rural purposes so that the rent paid in urban residential and rural farming areas is equal. While this is certainly "unrealistic", any assumption that urban land should be excluded from farm use (and vice versa) might be viewed with similar skepticism. We hope to identify the empirical relevance of these two alternative and extreme assumptions in future extensions of the model.

\subsection{Model Extensions: Introducing Demography}

In an overview of economic-demographic simulation models, Sanderson (1980) points out that our present model has little demographic content. This shortcoming will be remedied in the near future. The procedure we intend to adopt is outlined below.

Given an initial regional distribution of the labor force consistent with short-run equilibrium in the comparative static model, the age--sex-region distribution of the total population in the initial period, and the age-sex-region-specific probabilities of being a member of the labor force, we can determine the population distribution (by age, sex, and region) consistent with the equilibrium distribution of the labor force. With additional information on mortality and fertility rates in each region, we can calculate the changes in the population in the next period. Applying the constant age--sex-regionspecific probabilities of being a member of the labor force to the new population, the demographic submodel can predict the labor force available to the economy in this second period.

Whether the inclusion of demographic factors will affect the urbanization and city growth predicted by the model is an issue of some interest. If it does, the influence will be felt by the location-specific attributes of the demographic parameters themselves.

\section{ACKNOWLEDGMENTS}

We are grateful to Robert Schmidt for his important contribution to computer programming on this project. In addition, many have helped with the algorithm: special mention should be made of András Pór and Sherman Robinson.

\section{REFERENCES}

Coale, A.J. and Hoover, E.M. (1958). Population Growth and Economic Development in Low-Income Countries. Princeton University Press, Princeton, New Jersey.

Corden, W. and Findlay, R. (1975). Urban unemployment, in tersectoral capital mobility and development policy. Economica, 42:59-78.

Davis, K. (1965). The urbanization of the human population. Scientific American, 213(3):41-53.

International Bank for Reconstruction and Development (1976). World Tables, 1976. Johns Hopkins Press, Baltimore, Maryland.

Kelley, A.C. and Williamson, J.G. (1980). Modeling Urbanization and Economic Growth. RR-80-22. International Institute for Applied Systems Analysis, Laxenburg, Austria. 
Kelley, A.C. and Williamson, J.G. (1982). The limits to urban growth: suggestions for macromodeling third world economies. Economic Development and Cultural Change, 30:595-623.

Kelley, A.C., Williamson, J.G., and Cheetham, R.J. (1972). Dualistic Economic Development: Theory and History. The University of Chicago Press, Chicago, Illinois.

Ledent, J. (1982). Rural-urban migration, urbanization, and economic development. Economic Development and Cultural Change, 30:507-538.

Lewis, W.A. (1977). The Evolution of the International Economic Order. Discussion Paper No. 74. Research Program in Development Studies, Woodrow Wilson School, Princeton University, Princeton, New Jersey.

Rogers, A. (1982). Sources of urban population growth and urbanization, 1950-2000: a demographic accounting. Economic Development and Cultural Change, 30:483-506.

Sanderson, W.C. (1980). Economic-Demographic Simulation Models: A Review of Their Usefulness for Policy Analysis. RR-80-14. International Institute for Applied Systems Analysis, Laxenburg, Austria, p. 102.

Simon, J.L. (1980). Resources, population, environment: an oversupply of false bad news. Science, 208:1431-1437.

Todaro, M. (1969). A model of labor, migration, and urban unemployment in less developed countries. American Economic Review, 59:138-148.

\section{APPENDIX: Comparative Static Elasticities in Detail}

The computer printout in the following pages reports elasticities on 51 endogenous variables. This list does not deal with all the endogenous variables in the model, but the most important ones are included. The printout reports these elasticities with respect to changes in 26 exogenous variables and parameters. This list of exogenous variables is not exhaustive, but it is sufficient for present purposes. The printout also contains a "Baseline" column which refers to the initial (circa 1960) conditions for the RDC model. Similarly, the row "Original" refers to the initial value of the parameter or exogenous variable being varied. Definitions of the notation used in the printout are given in Table A1 at the end of the Appendix.

This Appendix not only supplies more detail than is available in Tables 4-8 but may also prompt an examination of two issues: the nature of the convergence criteria and the size of the shock imposed on some parameter of interest in computing elasticities.

The comparative static model never supplies an exact solution following any shock to the system. However, this does not hold for the initial conditions themselves, since the "initial conditions model" yields exact solutions that replicate where possible the initial (circa 1960) conditions prevailing in the 40-country sample. In contrast, the comparative static model supplies only approximate solutions. The convergence criterion applied in all the elasticity experiments is $0.1 \%$; in other words, excess demand for or supply of the commodity, service, or factor considered cannot exceed $0.1 \%$ of total supply in any market. This is true, for example, of the capital, unskilled labor, land, and savings/investment markets. However, the skilled labor and commodity markets have even tighter clearing conditions. Furthermore, it is quite possible that when the convergence criterion is met, many markets may in fact be much closer to equilibrium.

This rather strict convergence criterion was satisfied in all but four experiments: the exceptions were $A_{\mathrm{M}}$ at $10 \% ; A_{\mathrm{US}}$ at $1 \% ; P_{\mathrm{W}, \mathrm{M}}$ at $10 \%$; and $K_{\mathrm{KS}}$ at $10 \%$. In each of these cases, the economy did not reach (approximate) equilibrium at any time and thus the elasticities are not to be trusted. 
The model is a highly nonlinear general equilibrium system. We feel that the nonlinearities are essential for describing economies passing through long historical periods of, say, two decades or more. For example, the hypotheses embedded in the nested CES production functions with respect to factor input complementarity and substitutability among primary inputs are felt to be sufficiently important that their nonlinear complexities are worth studying. Similarly, fixed input coefficients for intermediate inputs seem inappropriate for long-run analyses where raw material and/or fuel savings are real options available in response to increased scarcity. Furthermore, investment allocation must allow for considerable scope for agents' response to rates of return, including government investment allocation. We believe that any model that allows investment allocation to be ridden with lags, rules of thumb, and persistent government irrationality is a bad model for longrun analysis. In addition, the "minimum subsistence bundle" in the extended linear expenditure system - a feature that makes this demand system quite nonlinear - is sufficiently relevant to low-income households to make its introduction essential in a model of ThirdWorld urbanization. The same kind of argument could be made in defense of price flexibility, labor migration, and land use. In short, ours is not a "structuralist" paradigm, but rather a flexible neoclassical model.

However, nonlinear models have their own disadvantages. Not only are they difficult to solve, but they often make interpretation ambiguous. Consider, for example, the impact on measured elasticities from the size of a shock to the comparative static model. The computer printout supplies elasticity estimates for three "shocks": namely, $1 \%, 5 \%$, and $10 \%$ changes in the parameter or exogenous variable of interest. While Tables $5-8$ report only the $5 \%$ elasticities, it should be noted that the elasticities do vary over the three levels of "shock". For some parameters and exogenous variables, the discrepancies are quite large (e.g., those in $P_{\mathrm{A}}^{\mathrm{W}}, P_{\mathrm{Z}}, H_{i}$, and $S$ ). How does one choose between the various elasticities? It is necessary to be sensitive to the size of the "shocks" that have in fact taken place in recent Third-World history and the likely size of any "shocks" that will take place in the next two decades. These seem to us the most relevant criteria for choosing between the three experiments, although the present paper has focused, rather arbitrarily, on $5 \%$ elasticities throughout. 
ะ ¿ |

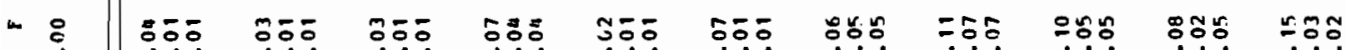

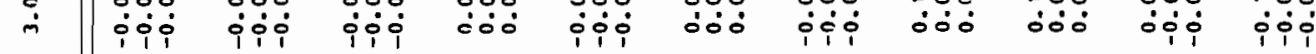
F ت

ป $\underset{1}{2}$

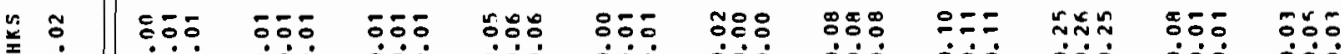
․

ธ

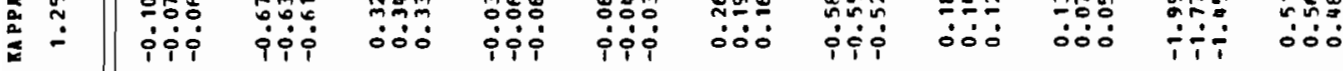

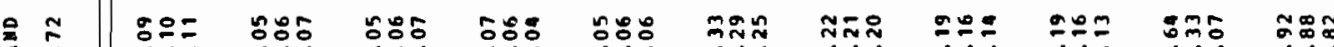
$\exists$ \$

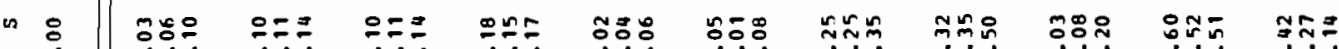

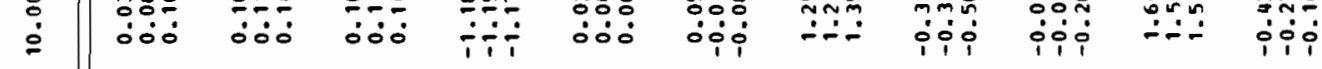

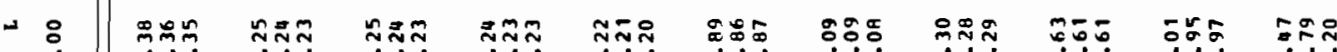

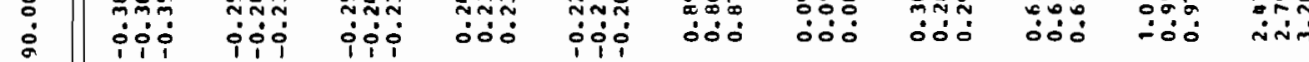

n

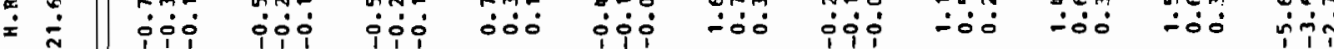

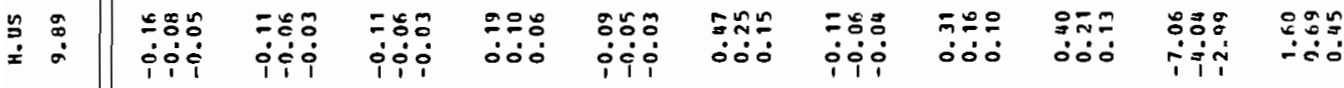

ะ

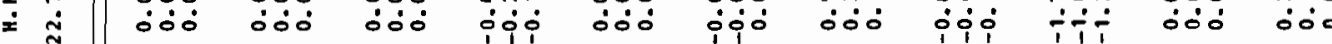

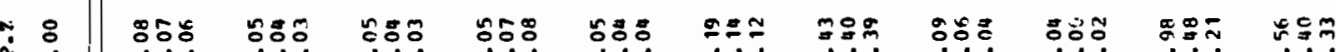

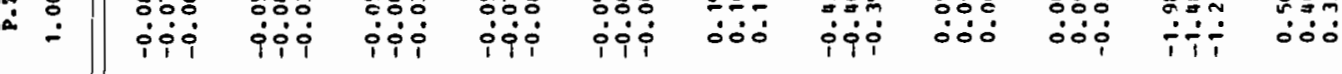

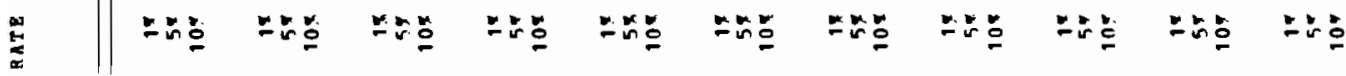

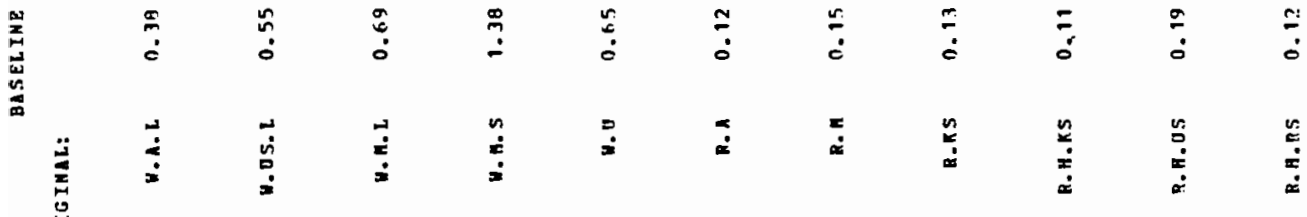


i|

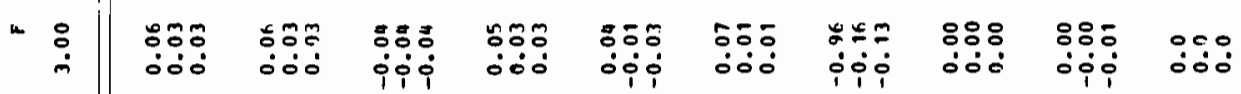

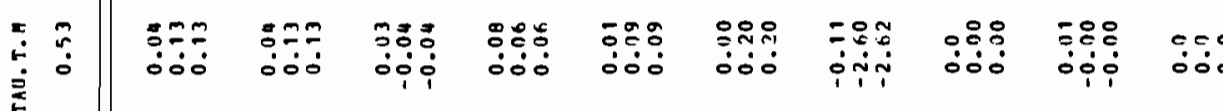

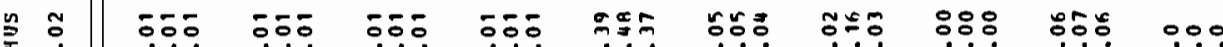

¿

\&

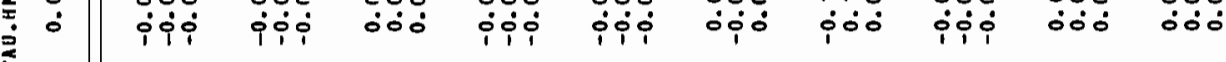

¿

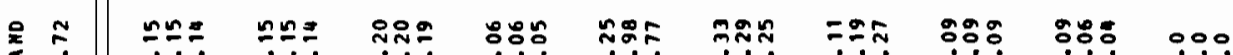

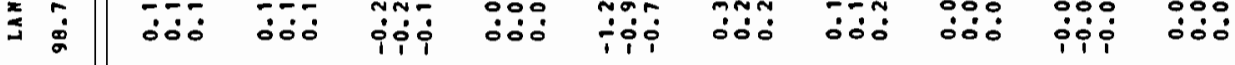

is 8

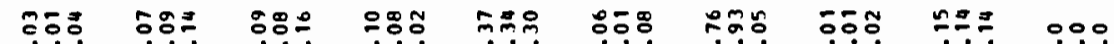

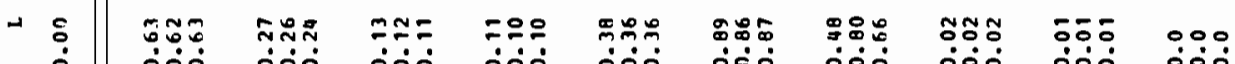

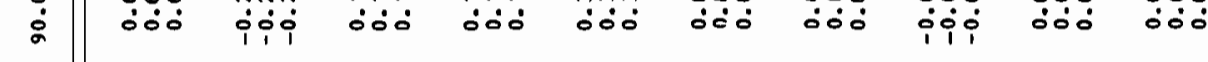

« ¿

س.

Uี

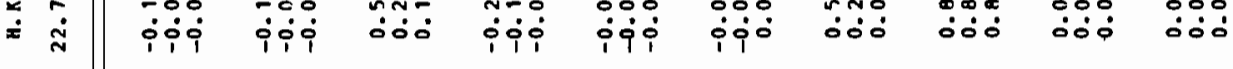

¿ :

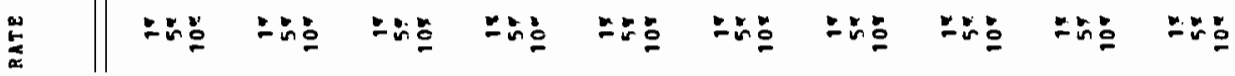

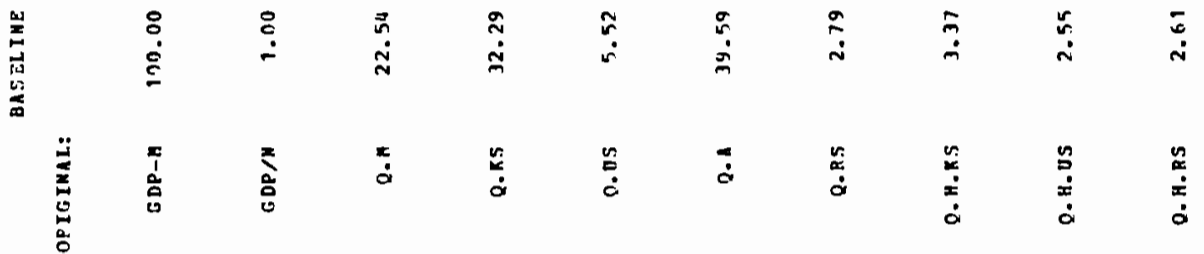




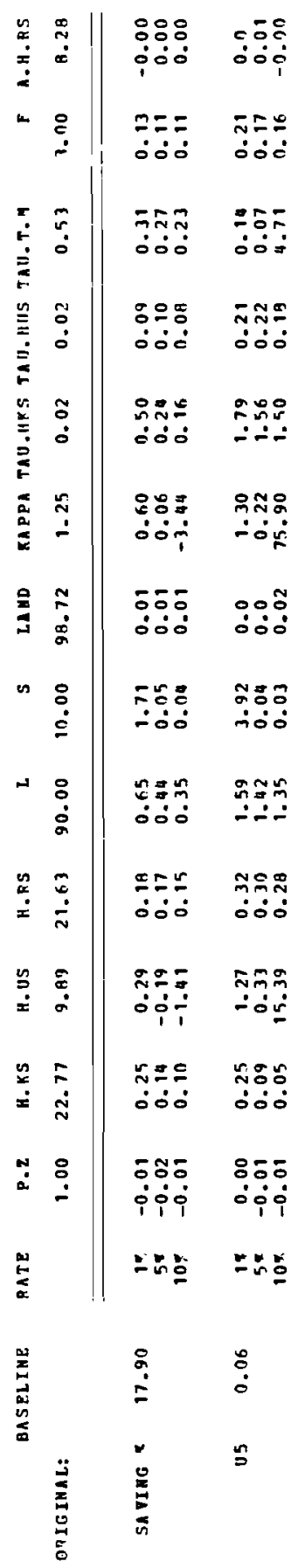




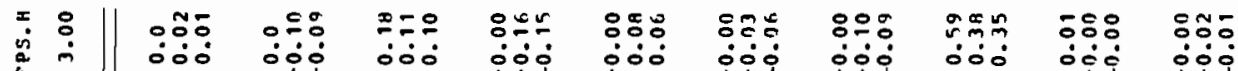

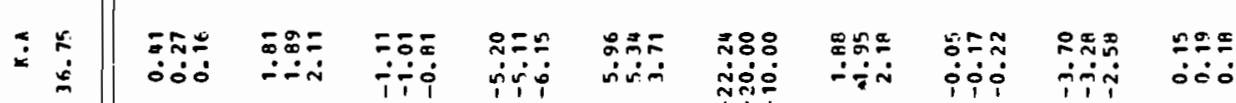

m

₹

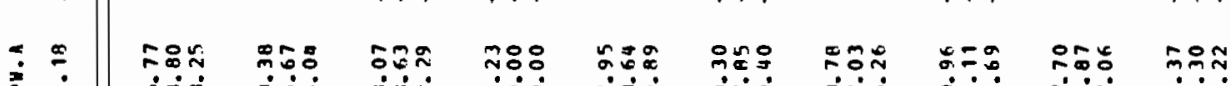

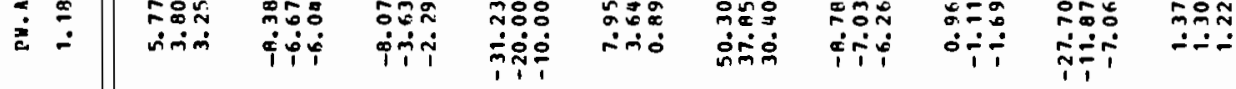

×

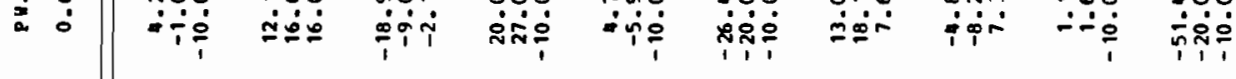

\#

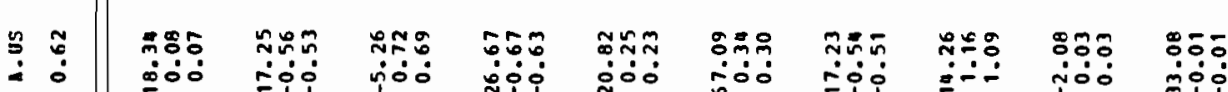

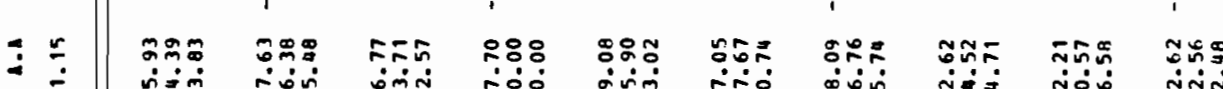

- जंड फि

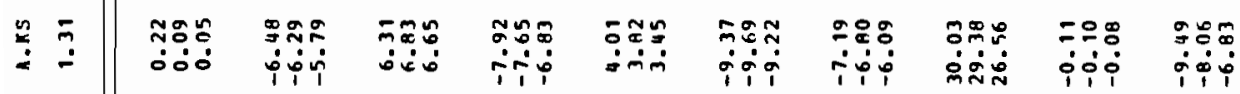

×

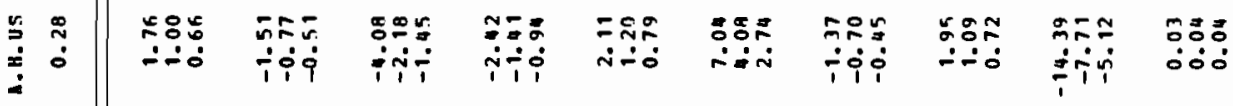

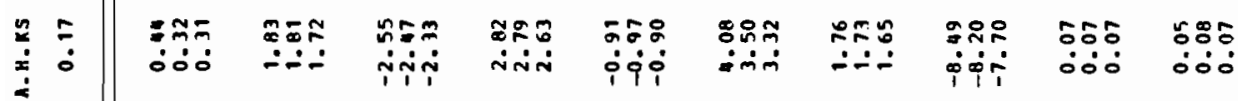

点

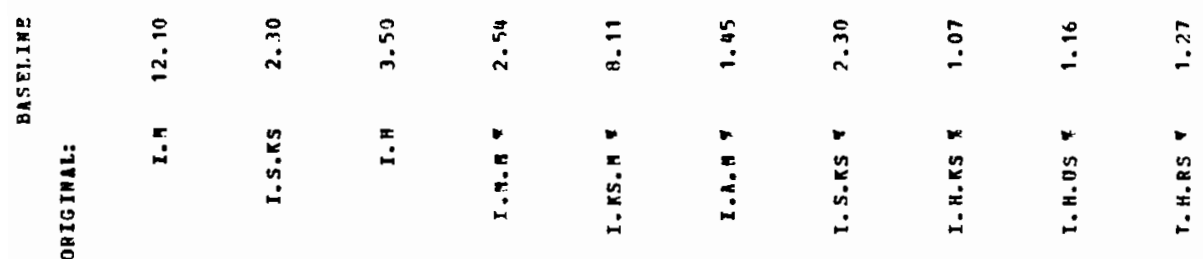




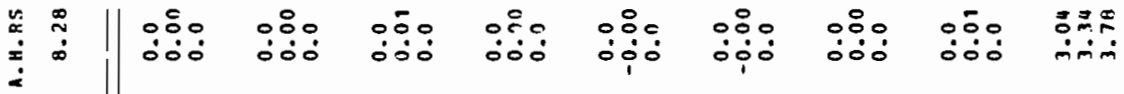

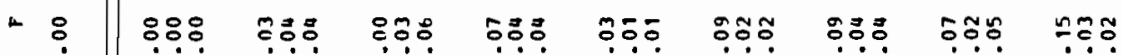

F 5 :

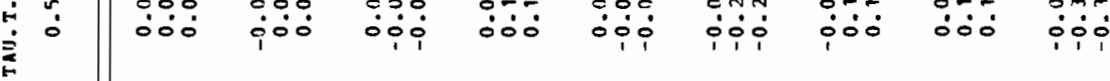

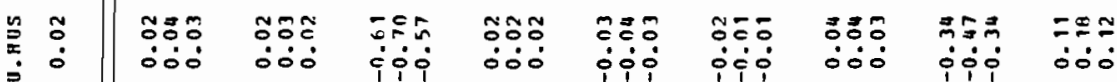

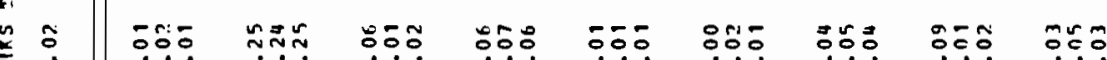

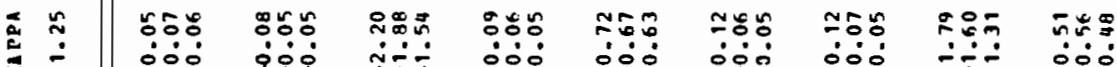

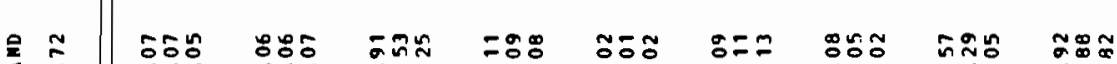

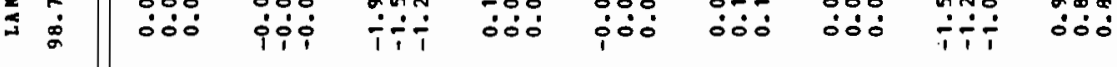

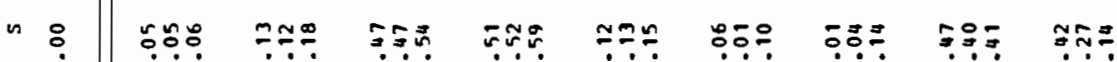

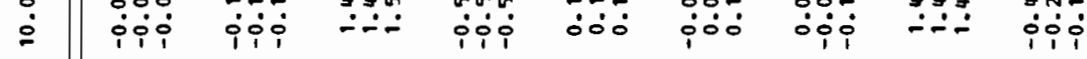

-

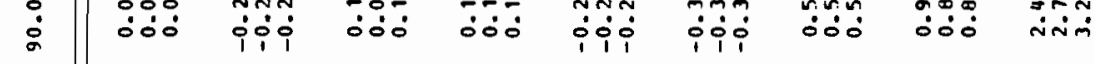

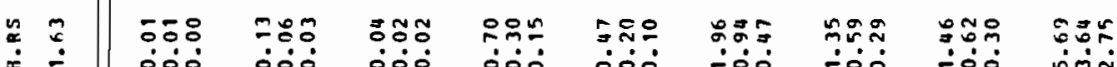

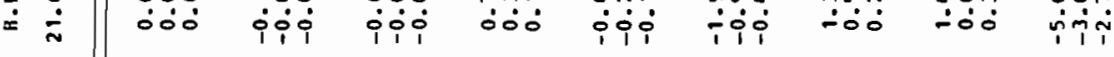

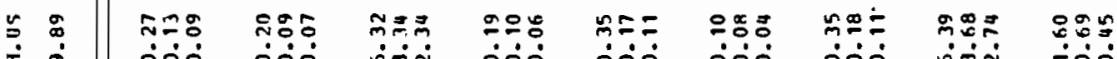

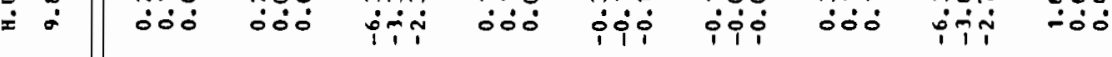

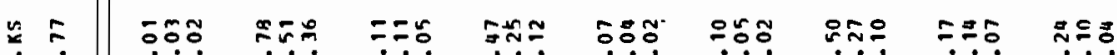

$\dot{N}$ ல்

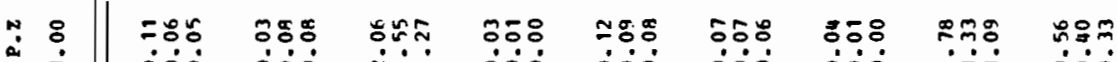

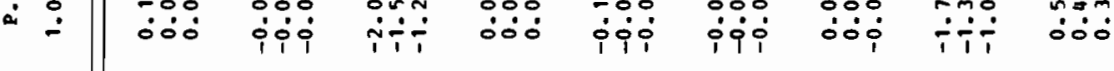

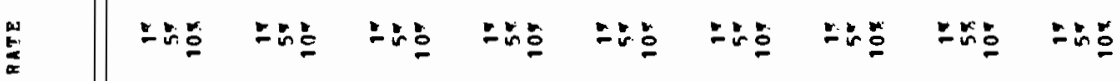

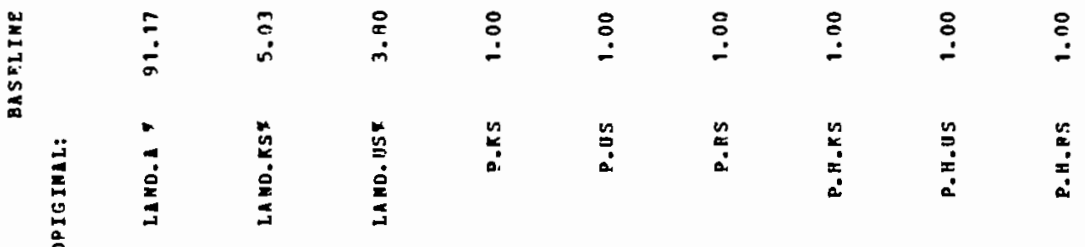




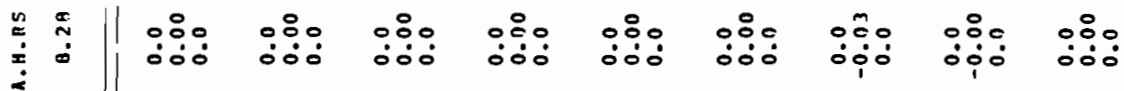

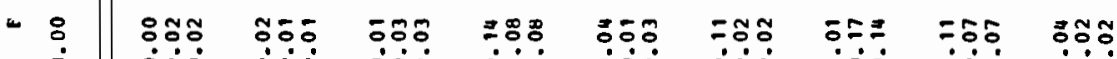

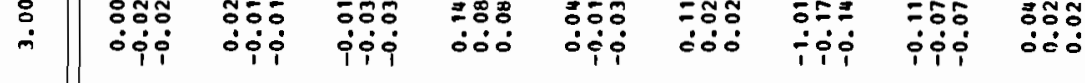

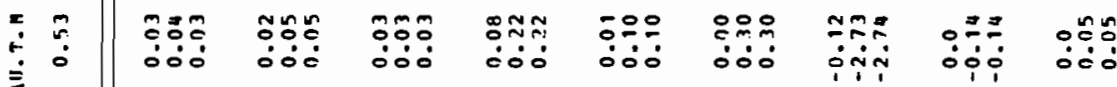

ย

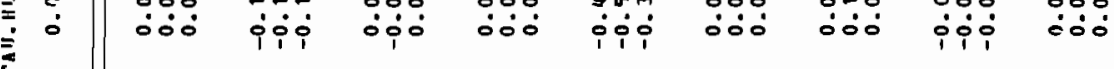

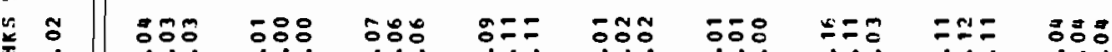

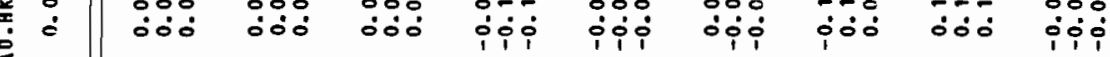

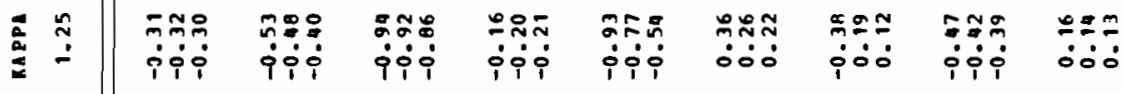
ล

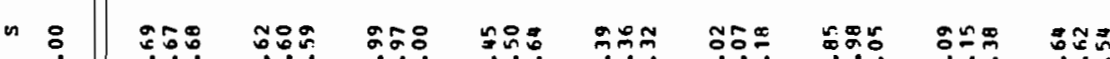

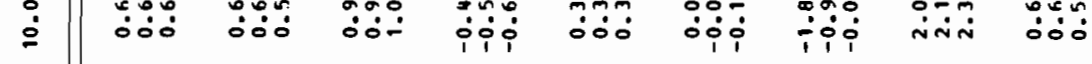

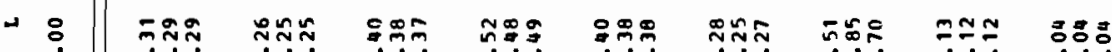

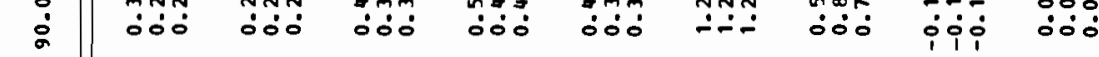

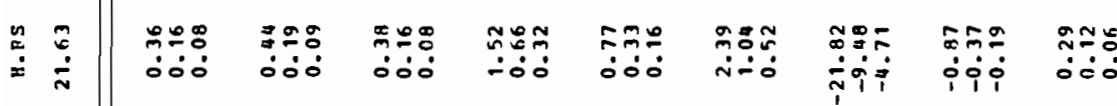

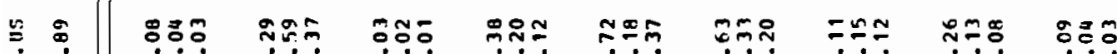

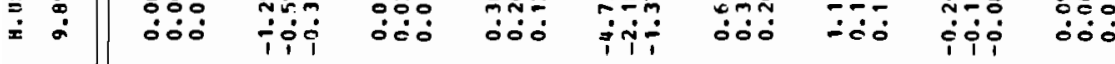

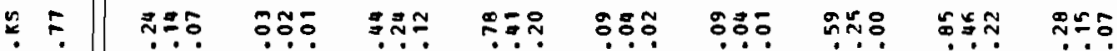

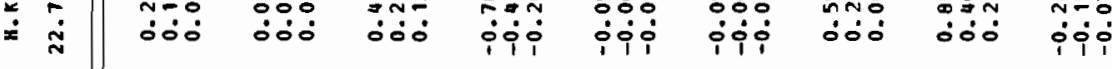

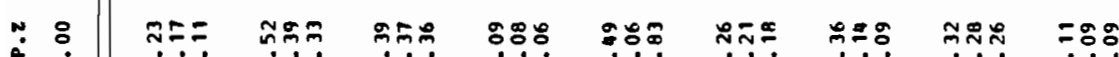

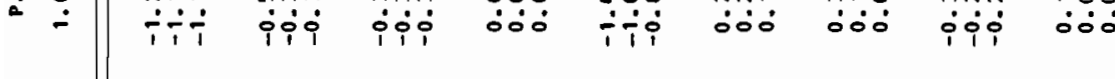

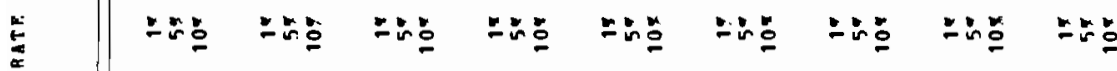

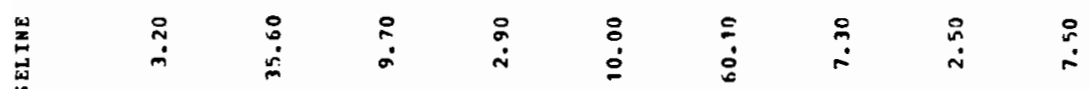

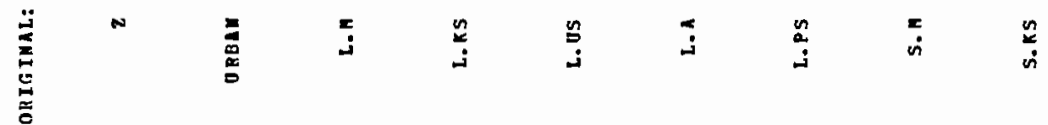




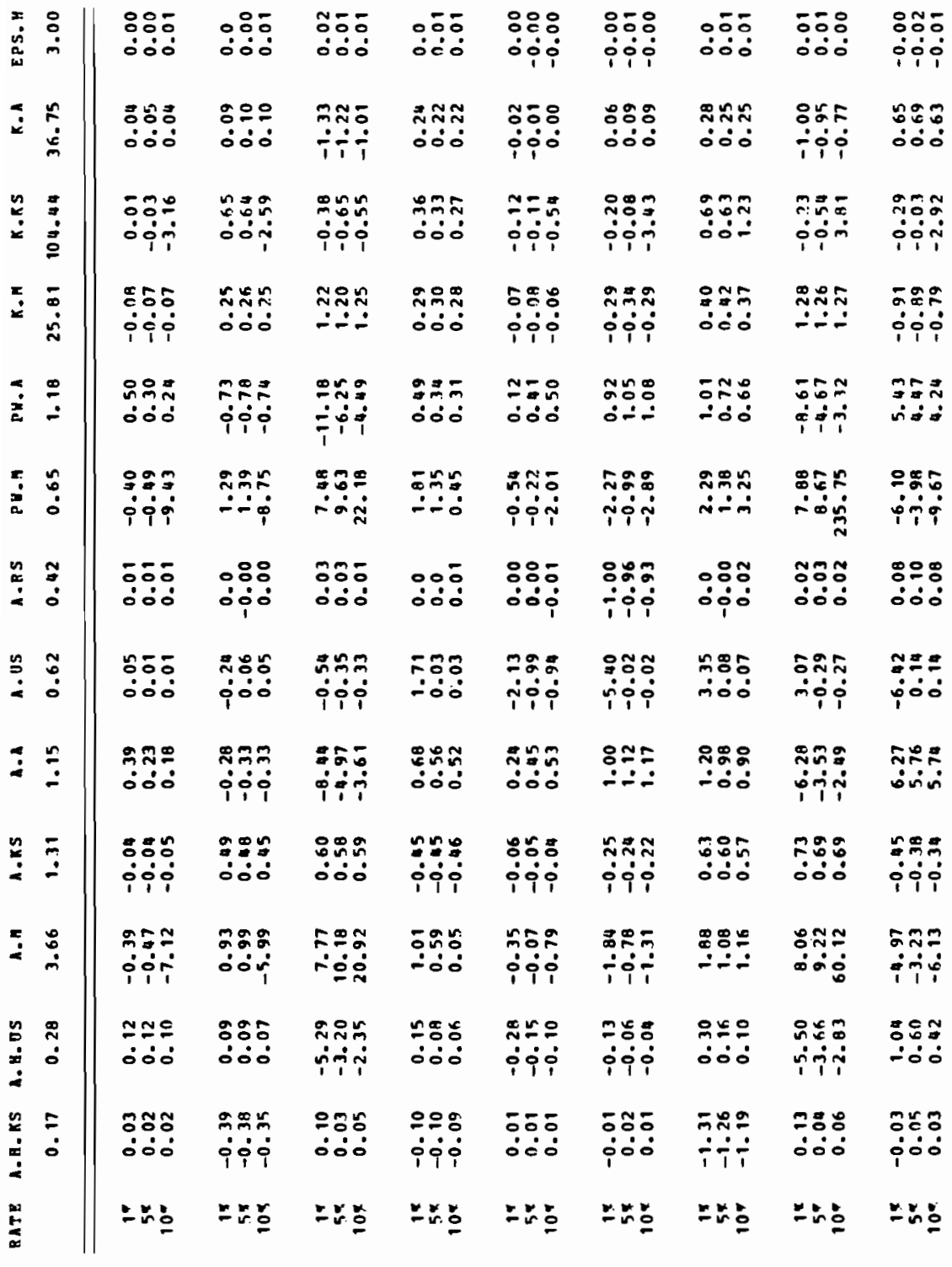

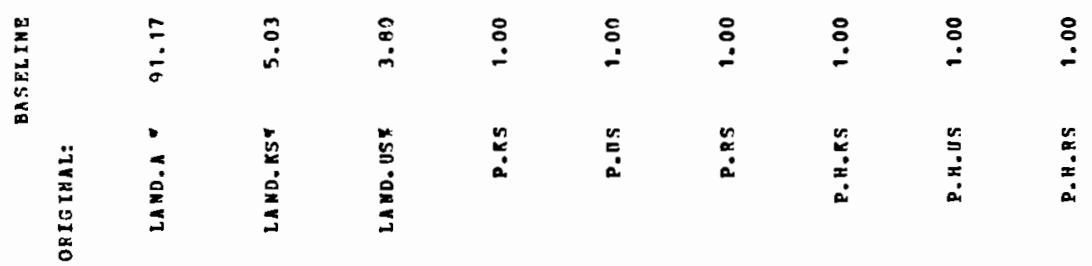




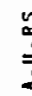

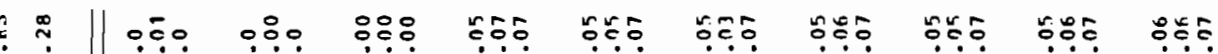

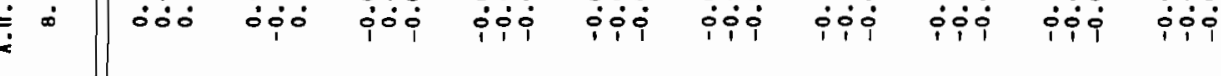

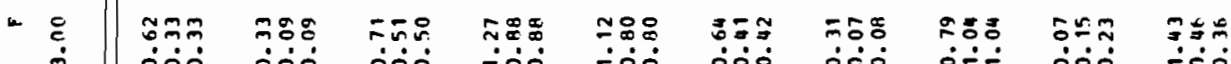

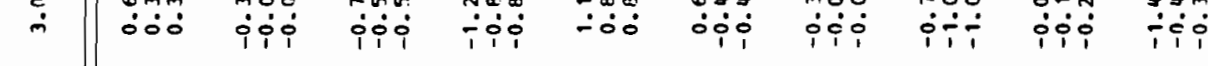

F.

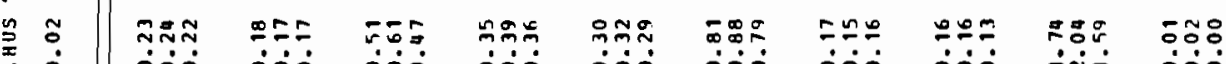

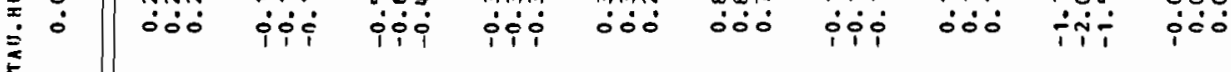

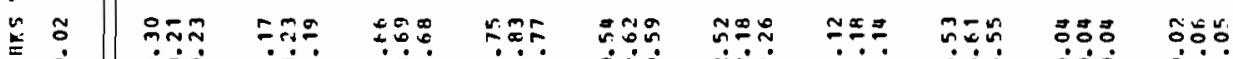

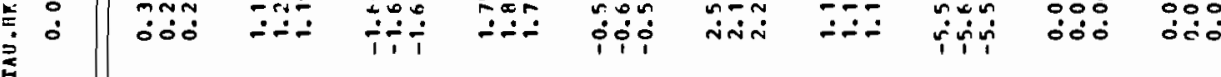

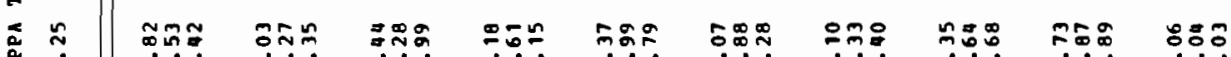

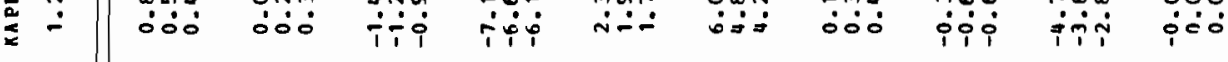

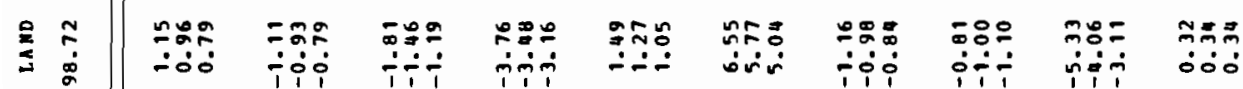

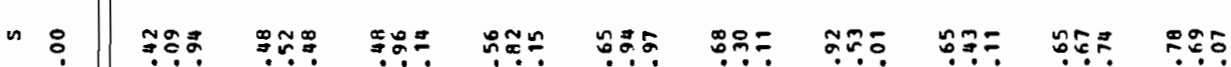

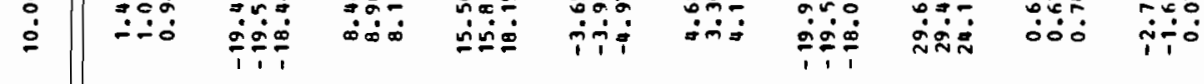

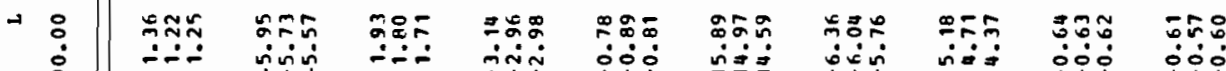

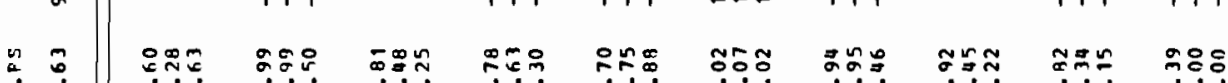
×

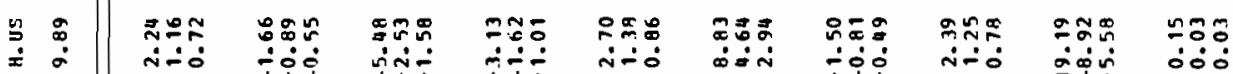

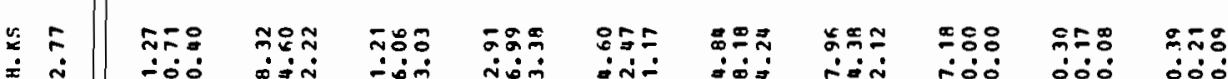

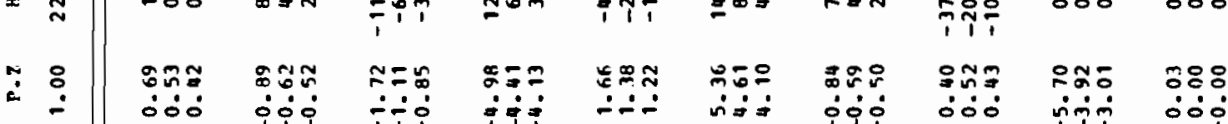

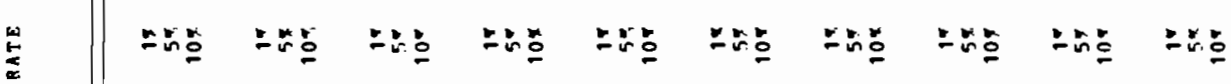

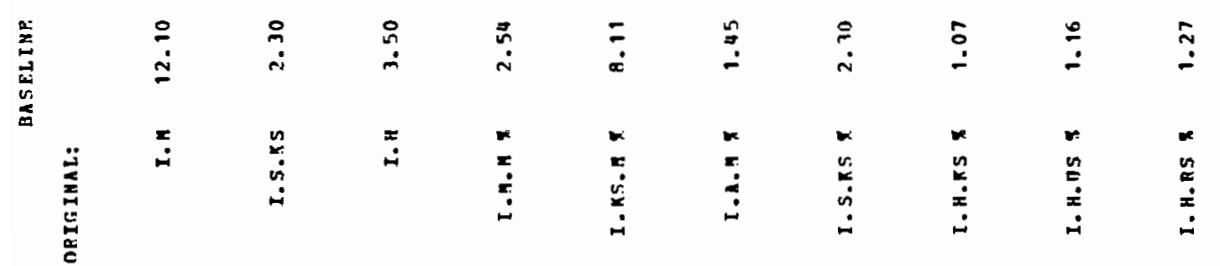




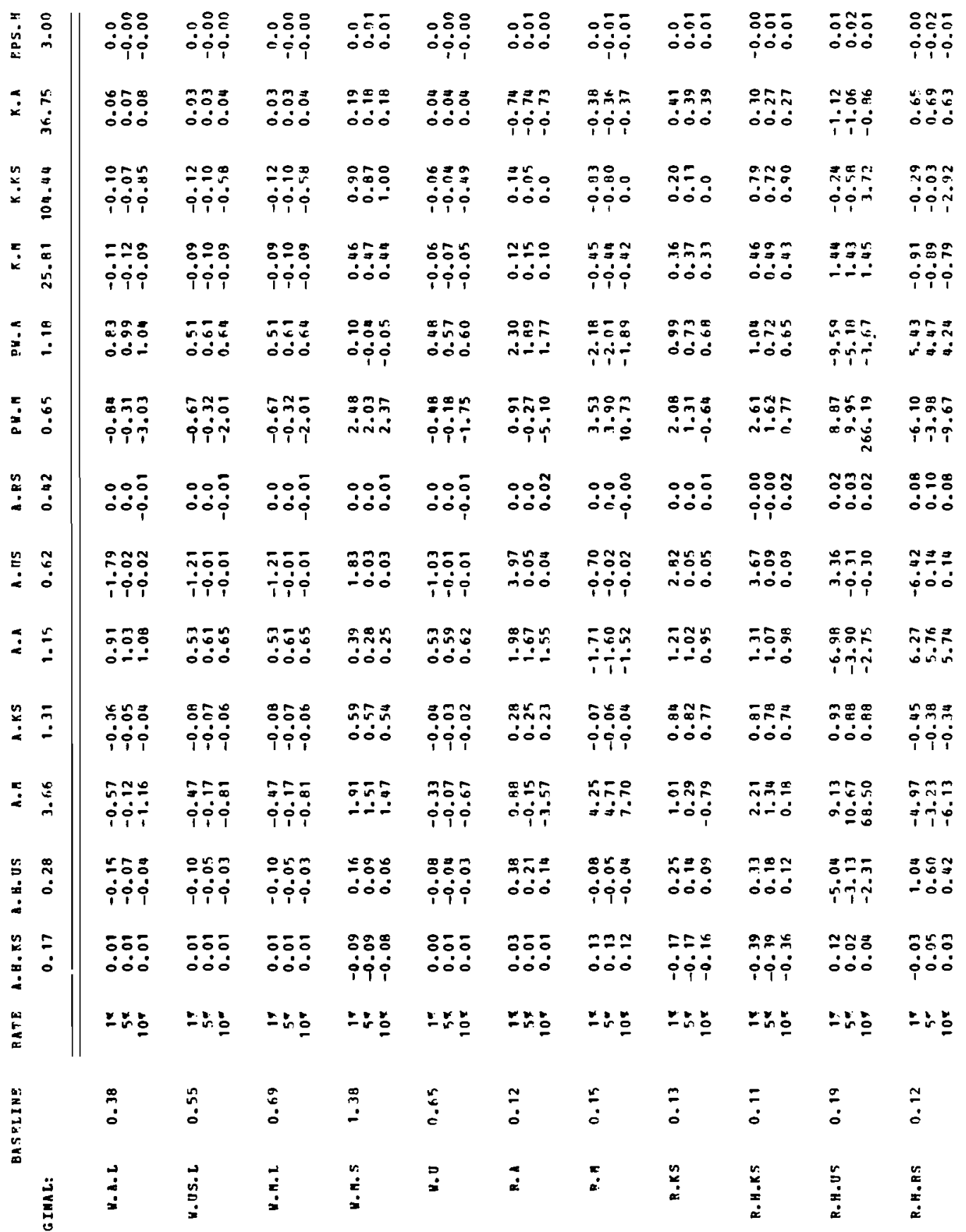




\begin{tabular}{|c|c|c|c|c|c|c|c|c|c|c|}
\hline 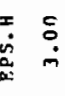 & $\begin{array}{l}5: 0 \\
\vdots 00 \\
000\end{array}$ & $\begin{array}{l}800 \\
\vdots 00 \\
00\end{array}$ & 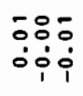 & $\begin{array}{l}100 \\
\vdots 0 \\
\vdots 0\end{array}$ & $\begin{array}{l}: 0: \\
\vdots 00 \\
0\end{array}$ & $\begin{array}{l}850 \\
\vdots 00 \\
\vdots 0\end{array}$ & $\begin{array}{l}\text { ao } \\
00 \\
\text { ojo }\end{array}$ & \begin{tabular}{l}
$0: 0$ \\
\hdashline \\
0 \\
0
\end{tabular} & $\begin{array}{l}00: \\
\vdots \\
0 \\
0\end{array}$ & :00 \\
\hline 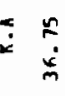 & 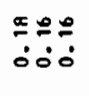 & 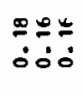 & 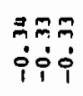 & 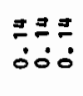 & $\begin{array}{l}\text { Do: } \\
\text { ios }\end{array}$ & 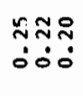 & $\begin{array}{l}000 \\
000 \\
00\end{array}$ & $\begin{array}{l}\bar{c}-\overline{0} \\
\vdots 0 \\
0\end{array}$ & $\begin{array}{l}m= \\
\text { iojo }\end{array}$ & $\dot{\circ}^{\circ}$ \\
\hline 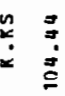 & 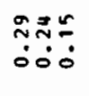 & 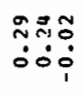 & 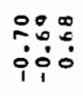 & 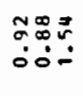 & $\begin{array}{l}\overrightarrow{0} \approx \pi \\
\dot{0} \\
00^{\circ}\end{array}$ & 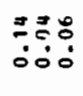 & 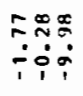 & $\begin{array}{l}0.00 \\
\vdots 00 \\
00 \\
00\end{array}$ & 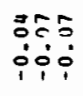 & ó \\
\hline $\begin{array}{l}x-\bar{x} \\
\dot{x} \\
\dot{\sim}\end{array}$ & $\begin{array}{l}=\frac{x}{x} \\
\therefore 0^{\circ}\end{array}$ & $\begin{array}{l}= \pm 0 \\
\therefore 0^{\circ}\end{array}$ & 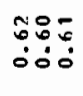 & $\begin{array}{l}8000 \\
000 \\
00 \\
00\end{array}$ & 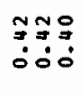 & 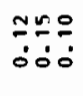 & 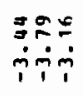 & $\begin{array}{l}\text { âcõ } \\
\dot{0}: 0\end{array}$ & \begin{tabular}{l}
$\simeq \approx \simeq$ \\
\hdashline 00 \\
\hdashline 0
\end{tabular} & $\ddot{\circ 0}$ \\
\hline$\dot{\square}$ & 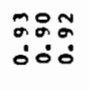 & $\begin{array}{l}\text { Fूa } \\
\text { SO }\end{array}$ & $\begin{array}{l}=50 \\
\dot{\uparrow} \\
\dot{1}\end{array}$ & $\begin{array}{l}\text { mon } \\
\text { Mndo }\end{array}$ & 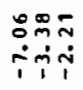 & 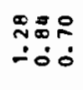 & $\begin{array}{l}5=0 \\
5=0 \\
\therefore-20\end{array}$ & $\begin{array}{l}500 \\
000 \\
\text { iों }\end{array}$ & 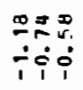 & $\ddot{\circ}$ \\
\hline$\stackrel{n}{0}$ & 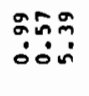 & 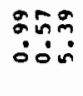 & 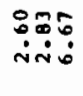 & 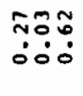 & 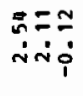 & 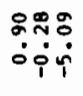 & 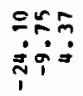 & 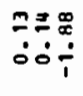 & 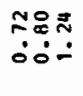 & $\because 0$ \\
\hline 品 & $\begin{array}{l}: 50 \\
\vdots 00 \\
000\end{array}$ & $\begin{array}{l}850 \\
050 \\
000\end{array}$ & $\begin{array}{l}\text { No: } \\
\vdots 00 \\
\text { O०ं }\end{array}$ & $\begin{array}{l}\overline{0} \overline{0} \overline{0} \\
\dot{0} 0 \dot{0}\end{array}$ & $\begin{array}{l}\overline{5} \overline{0} \overline{0} \\
\vdots 00 \\
000 \\
0\end{array}$ & $\begin{array}{l}\overline{0-00} \\
000 \\
000\end{array}$ & 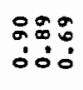 & $\begin{array}{l}008 \\
000 \\
00\end{array}$ & $\begin{array}{l}8: 8 \\
000\end{array}$ & $\therefore 0$ \\
\hline 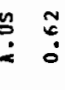 & $\begin{array}{l}50 \overline{0} \\
\vdots \\
\vdots 0\end{array}$ & \begin{tabular}{l}
$50 \overline{0}$ \\
\hdashline 00 \\
00 \\
0
\end{tabular} & $\begin{array}{l}\text { 30\% } \\
\text { iōo }\end{array}$ & 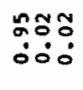 & 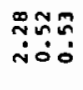 & 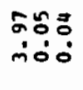 & 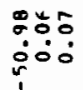 & 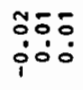 & 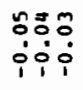 & $\dot{0}$ \\
\hline 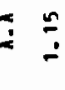 & $\nsubseteq \simeq$ & 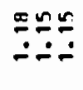 & 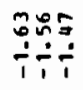 & 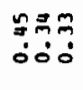 & 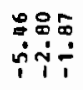 & 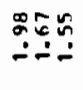 & 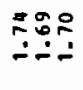 & 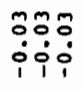 & 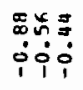 & $\ddot{\circ}$ \\
\hline$\stackrel{5}{5}$ & 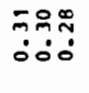 & 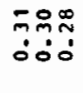 & 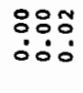 & నొని & 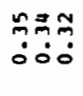 & 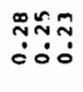 & 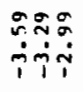 & 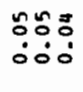 & 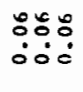 & $\begin{array}{ll}0 \\
0\end{array}$ \\
\hline ¿ & 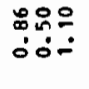 & 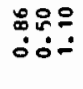 & 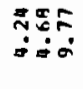 & 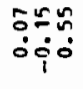 & $\begin{array}{l}\text { इ50 } \\
\text { iño }\end{array}$ & 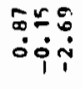 & 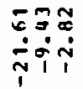 & $\begin{array}{l}\text { :o } \\
\text { So }\end{array}$ & 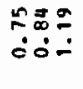 & $\dot{0}$ \\
\hline 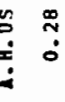 & 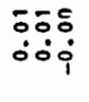 & $\begin{array}{l}550 \\
000 \\
00\end{array}$ & $\begin{array}{l}\text { ö o } \\
\text { ióo }\end{array}$ & 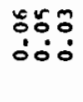 & $\begin{array}{l}25= \\
\dot{1} \div \div\end{array}$ & $\begin{array}{l}\bar{a}= \\
00 \\
00\end{array}$ & $\begin{array}{l}n=5 \\
000\end{array}$ & $\begin{array}{l}\overline{0} \overline{0} \\
\vdots 00 \\
000\end{array}$ & 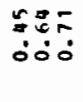 & :0 \\
\hline 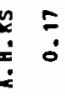 & $\begin{array}{l}\text { mon } \\
\text { ơojo }\end{array}$ & $\begin{array}{l}\text { on } \\
\text { ióo }\end{array}$ & $\begin{array}{l}\because=\bar{F} \\
\therefore 00\end{array}$ & 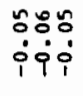 & 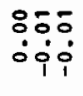 & $\begin{array}{l}\overline{0} \overline{0} \\
\vdots 00 \\
00\end{array}$ & $\begin{array}{l}00 \\
000 \\
0\end{array}$ & $\begin{array}{l}5 \% 0 \\
\therefore 00 \\
\therefore 0\end{array}$ & $\begin{array}{l}58: \\
\vdots 00 \\
000\end{array}$ & $\dot{0}_{0}^{\circ}$ \\
\hline 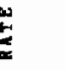 & 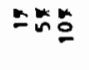 & $=0$ & 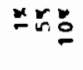 & $\underline{0}$ & $=\underline{m}$ & 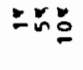 & 兹。” & שx & $=00$ & $=8$ \\
\hline 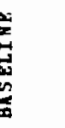 & $\begin{array}{l}\stackrel{0}{0} \\
\dot{0}\end{array}$ & $\stackrel{\square}{\square}$ & $\begin{array}{l}\vec{z} \\
\dot{\sim} \\
\dot{N}\end{array}$ & 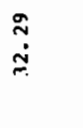 & مَ & $\begin{array}{l}\stackrel{x}{n} \\
\text { s. }\end{array}$ & $\stackrel{\tilde{i}}{\dot{i}}$ & $\dot{m}$ & r. & $\stackrel{\bar{i}}{i}$ \\
\hline$\ddot{ت}$ & $\begin{array}{l}5 \\
1 \\
\vdots \\
\vdots\end{array}$ & 产 & $\dot{d}$ & $\stackrel{n}{a}$ & $\stackrel{n}{a}$ & $\dot{\alpha}$ & 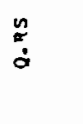 & $\begin{array}{l}\stackrel{y}{x} \\
\dot{x} \\
\dot{0}\end{array}$ & $\begin{array}{l}\stackrel{n}{\square} \\
\dot{\square} \\
\dot{a}\end{array}$ & $\begin{array}{l}\stackrel{n}{x} \\
\dot{x} \\
\dot{0}\end{array}$ \\
\hline
\end{tabular}




\begin{tabular}{|c|c|c|c|c|c|c|c|c|c|}
\hline 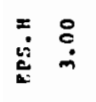 & 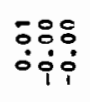 & 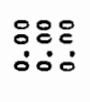 & $\begin{array}{l}5: 8 \\
\vdots 00 \\
i 0 \\
1\end{array}$ & 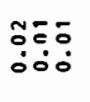 & $\begin{array}{l}8: 0 \\
\vdots 00 \\
00\end{array}$ & $\begin{array}{l}850 \overline{0} \\
\dot{0} 00\end{array}$ & $\begin{array}{l}\text { co: } \\
\text { ioj } \\
\text { iojo }\end{array}$ & آن & 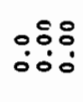 \\
\hline$\dot{\dot{x}}$ & $\begin{array}{l}m=5 \\
\text { isio } \\
\text { iì }\end{array}$ & $\begin{array}{l}\text { nos } \\
\text { jois }\end{array}$ & $\begin{array}{l}\text { mon } \\
\text { iojo } \\
\text { io }\end{array}$ & 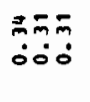 & $\begin{array}{l}\text { a: } \\
\text { iojo } \\
\text { ioi }\end{array}$ & 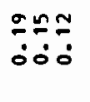 & 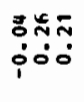 & 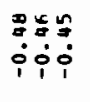 & 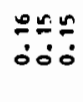 \\
\hline 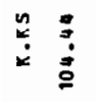 & 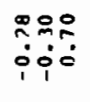 & 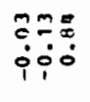 & 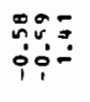 & ‡ॅ̄ & 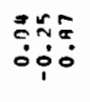 & $\begin{array}{l}n=8 \\
\vdots 0\end{array}$ & 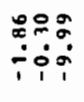 & 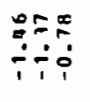 & 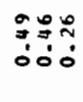 \\
\hline 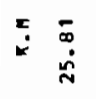 & 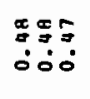 & 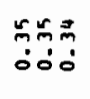 & $\begin{array}{l}F=0 \\
\therefore 00 \\
\therefore 00\end{array}$ & 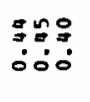 & 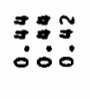 & 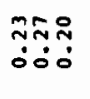 & 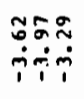 & 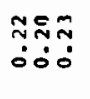 & $\begin{array}{l}\text { oj } \\
\text { os } \\
\end{array}$ \\
\hline$\stackrel{0}{ \pm}$ & 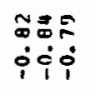 & 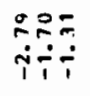 & 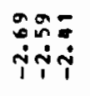 & 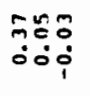 & 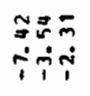 & 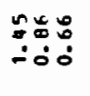 & 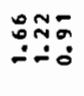 & 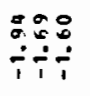 & 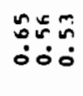 \\
\hline 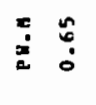 & 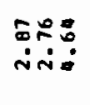 & 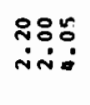 & 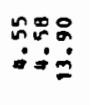 & 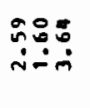 & 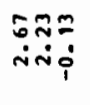 & 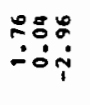 & 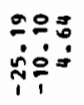 & $\begin{array}{l}\tilde{\Phi}: \bar{n} \\
\dot{0}=\dot{n}\end{array}$ & 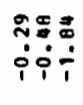 \\
\hline \begin{tabular}{ll}
0 \\
0 \\
\hdashline
\end{tabular} & 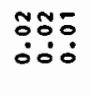 & 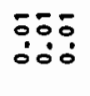 & 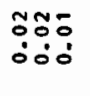 & $\begin{array}{l}0 \tilde{0} \\
\dot{0} 00 \\
00\end{array}$ & $\begin{array}{l}5 \overline{0} \\
\dot{0} 0 \dot{0}\end{array}$ & $\begin{array}{l}\overline{0}=\overline{0} \\
\dot{0} 0 \dot{0}\end{array}$ & $\begin{array}{l}=0 \\
\text { iojo } \\
\text { ioj }\end{array}$ & $\begin{array}{l}00 \\
0 \\
0\end{array}$ & :0: \\
\hline \begin{tabular}{ll}
$n$ \\
\hdashline \\
$\dot{Z}$ & 0 \\
\end{tabular} & $\begin{array}{l}000 \\
\vdots 00 \\
\vdots 0\end{array}$ & 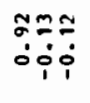 & 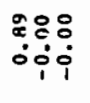 & 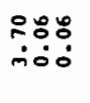 & 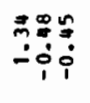 & 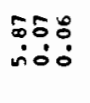 & 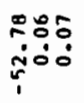 & $\begin{array}{l}\text { Nazo } \\
\text { rojo }\end{array}$ & :0 \\
\hline 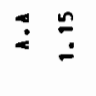 & 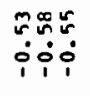 & 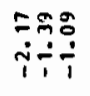 & 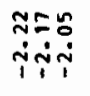 & 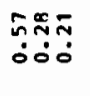 & 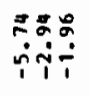 & 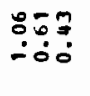 & 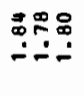 & 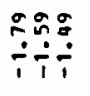 & 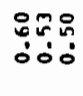 \\
\hline$\stackrel{m}{\stackrel{m}{x}}$ & $\frac{6}{\dot{0}} \stackrel{\frac{n}{0}}{\circ}$ & $\begin{array}{l}\stackrel{i}{9}=\frac{\infty}{0} \\
\dot{0} 0\end{array}$ & 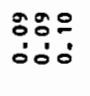 & 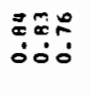 & 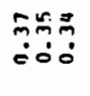 & $\begin{array}{l}\vec{m} \bar{N} \\
\dot{0} \dot{0}\end{array}$ & 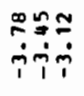 & 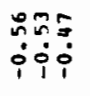 & $\frac{9}{0}$ \\
\hline ¿ & 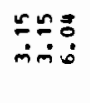 & 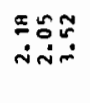 & 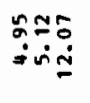 & 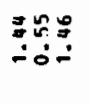 & 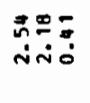 & 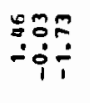 & 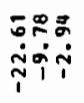 & 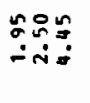 & $\begin{array}{l}0 \\
0 \\
0\end{array}$ \\
\hline 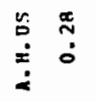 & 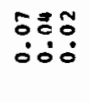 & $\begin{array}{l}\bar{z} \bar{n} \\
\text { iojo }\end{array}$ & 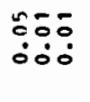 & $\begin{array}{l}E=\overline{0} \\
\dot{0} \dot{0}\end{array}$ & 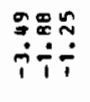 & 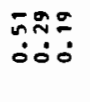 & $\begin{array}{l}\hat{m}=\frac{1}{0} \\
\dot{0} 0\end{array}$ & 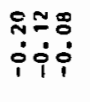 & $\begin{array}{l}5: 0 \\
00\end{array}$ \\
\hline 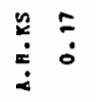 & $\begin{array}{l}\hat{0}: 0 \% \\
000 \\
00\end{array}$ & $\begin{array}{l}0 \overline{0} \\
\vdots 00 \\
00\end{array}$ & $\begin{array}{l}=50 \\
\dot{0} 0\end{array}$ & $\begin{array}{l}n=0 \\
\text { iosi }\end{array}$ & $\begin{array}{l}\text { so: } \\
\text { ợ }\end{array}$ & 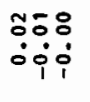 & 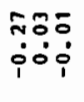 & $\begin{array}{l}\text { פx= } \\
\therefore 00\end{array}$ & 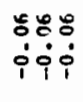 \\
\hline 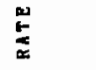 & $\because \underbrace{\circ}$ & $=$ & 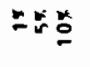 & E5 & 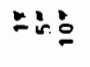 & Ing & $\Rightarrow 50$ & $\because 8$ & $=5$ \\
\hline 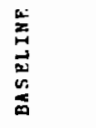 & 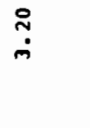 & ب. & $\stackrel{9}{\circ}$ & : & $\begin{array}{l}\delta \\
\dot{\vdots}\end{array}$ & $\frac{5}{\dot{\delta}}$ & $\stackrel{\circ}{\check{r}}$ & $\stackrel{s}{i}$ & $\stackrel{8}{i}$ \\
\hline 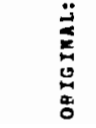 & $N$ & 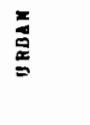 & E & $\stackrel{n}{i}$ & $\stackrel{n}{=}$ & 5 & $\stackrel{\infty}{\infty}$ & $\dot{r}$ & ñ \\
\hline
\end{tabular}




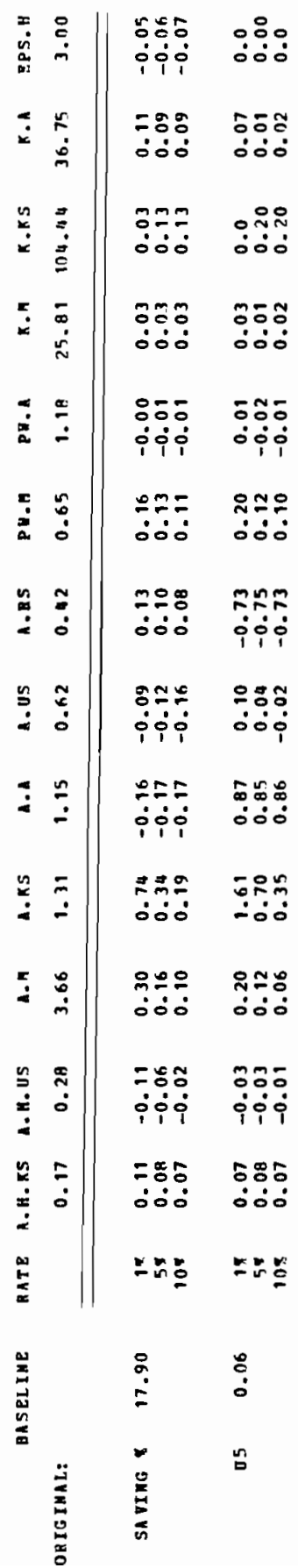


TABLE A1 Definitions of variables in the computer printout.

Endogenous variables

GDP-M = GDP at current market price

GDP $/ \mathrm{N}=$ GDP per capita at current market price

$\mathrm{Q} . i=$ Output in sector $i$, where $i=\mathrm{M}$ (manufacturing), KS ("modern" urban services), US (urban "traditional" services), A (agriculture), RS (rural "traditional" services)

Q.H. $j=$ Housing services from type $j$ dwellings, where $j=$ KS ("luxury" or high-rent urban), US ("squatter settlement" or low-rent urban), RS (rural)

$\mathrm{Z}=$ Imported intermediate inputs (quantities)

URBAN $=$ Number living in urban areas

$\mathbf{L} . i=$ Employment of unskilled labor in sector $i$

$\mathrm{S} . i=$ Employment of skilled labor in sector $i$

LAND $i \%=$ Land used in activity $i$, where $i=$ A (farmland), KS (high-rent urban residential) (\% of total land stock)

P. $i=$ Final demand price for output of sector $i$

P.H. $j=$ House rent in type $j$ dwelling, buyer's price

W. $i . \mathrm{L}=$ Unskilled wage in sector $i$

W.i.S $=$ Skilled wage in sector $i$

$\mathrm{W} . \mathrm{U}=$ Expected urban wage used in the migration decision

R. $i=$ Rental rate on capital in sector $i$

R.H. $j=$ Structure rent on dwellings of type $j$

U5 $=$ Urban land rent per unit

I.M = Total productive investment (plant and equipment) in constant prices

I.S.KS = Investment in skills training in constant prices

$\mathrm{I} . \mathrm{H}=$ Total housing investment in constant prices

I.M.M $\%=$ Investment in sector $M$ capital (\% of GDP)

I.KS.M \% = Investment in sector KS capital (\% of GDP)

I.A.M $\%=$ Investment in sector A capital (\% of GDP)

I.S.KS $\%=$ Total investment in skills training (\% of GDP)

I.H. $j \%=$ Investment in housing of type $j$ (\% of GDP)

SAVING $\%=$ Aggregate domestic saving (\% of GDP)

\section{Exogenous variables}

$P . Z=$ Price of intermediate inputs

H. $j=$ Housing stock of type $j$

$\mathrm{L}=$ Total unskilled labor force

$\mathrm{S}=$ Total skilled labor force

LAND $=$ Total land stock

KAPPA = Fixed wage ratio of unskilled labor between "favored" sectors and US

TAU.H $j=$ Property tax imposed on current value, housing type $j$

$\mathrm{F}=$ Level of foreign aid and private capital inflow

A.H. $j=$ Intercept in housing service production function, type $j$ housing

A. $i=$ Intercept in the production function of sector $i$

PW.M = World market price of $M$ goods, c.i.f.

PW.A = Export price of A goods, f.o.b.

$\mathrm{K} . i=$ Capital stock in sector $i$

EPS.H $=$ Elasticity parameter in the net housing investment functions 



\title{
FOREIGN PROTECTIONISM AND RESOURCE ALLOCATION IN A DEVELOPING ECONOMY: A GENERAL EQUILIBRIUM ANALYSIS
}

\author{
Kemal Dervis \\ International Bank for Reconstruction and Development, Washington, D.C. \\ (USA)
}

\section{INTRODUCTION}

In many of the newly industrializing nations a strong tendency towards less reliance on import substitution and more emphasis on export expansion has been apparent since the late 1960s. As noted in several studies (e.g., Bhagwati, 1978) rather than actually introducing a pro-export bias, countries have chosen to promote exports by incentives that do not positively discriminate against exports. Starting from initial conditions tending to favor import substitution and inward-looking development, a transformation took place in many countries towards a structure of incentives more nearly balanced between import-substituting and export-oriented production. This was achieved by a reduction of trade restrictions, a movement towards more flexible exchange rates, and the use of export subsidies as counterweights to import duties. Korea and Taiwan have had spectacular success with such "outward-looking" strategies and other countries in Latin America and the Far East have started to follow their example. Even countries such as India and Turkey, though hesitant, have moved towards more export-oriented policies.

However, just as the transition towards more outward-looking trade and development strategies gathered momentum, a new wave of protectionist pressure emerged in the advanced industrial nations, triggered by the oil crisis and the ensuing slowdown in OECD growth. This called into question both the feasibility and the desirability of export expansion and outward-looking development strategies in the newly industrializing countries. The threat of increased OECD protectionism has given new impetus to the debate on optimal trade and incentive policy in developing economies and may strengthen the position of those who oppose further movement towards liberal trade regimes and outwardlooking development strategies. (The "new protectionism" is discussed, e.g., in Balassa, 1978.)

It has been stated that increased OECD protectionism may necessitate across-theboard tariffs to allow the required import substitution to proceed, while it has also been argued that foreign protectionism will induce an across-the-board increase in production 
for the home market. On the other hand, there are those who maintain that when exporting is "more difficult" the exports themselves are "all the more valuable" and that increased attention should therefore be given to export promotion. Moreover, it is not always clear in this debate whether a particular statement simply predicts what will happen or whether it is normative and tries to tell us what should happen as a consequence of foreign protectionism. Will exports fall, and if so, is it optimal for then to fall? Will import substitution increase and, if so, is this optimal? What will and/or should happen in sectors producing nontradable commodities? These are the questions discussed here. We assume a unilateral across-the-board increase in OECD protectionism leading to a contraction of export demand as an exogenous event and analyze its impact on a single semi-industrial developing economy. The analysis is microeconomic and aggregate-demand effects are not considered. Section 2 describes the general equilibrium model used for the analysis, Sections 3 and 4 report and discuss the results, and Section 5 summarizes and concludes.

\section{THE MODEL}

The analysis is based on a small, seven-sector general equilibrium model of a "typical" semi-industrial economy. This section describes the essential features of the model. The coefficients and parameter values are based on Turkish data but have been somewhat modified to free the data base from some peculiarities of the Turkish situation. The model should be viewed as a stylized one that attempts to capture the various mechanisms and interactions that are important when analyzing the effect of changes in foreign demand on resource allocation in the domestic economy.*

\subsection{Production and Supply}

The model distinguishes seven sectors: agriculture, consumer goods, intermediate goods, capital goods, construction, infrastructure, and services. This represents the minimum amount of disaggregation that still provides an interesting variety in sectoral behavior and characteristics. Each sector $i$ produces domestic output, $X_{i}$, using capital, labor, and intermediate inputs. Intermediate input technology is given by an input-output matrix of fixed Leontief coefficients, but capital and labor substitute according to a two-level constant elasticity of substitution (CES) production function. Labor of different skills or occupational categories is first combined into a CES labor aggregate. The latter is then combined, again via a CES function, with capital to produce sectoral output. Capital stock in each sector is considered fixed during the period studied. Each sector maximizes profits, hiring labor until wages equal marginal revenue products. The demand for labor so generated must match the supply of labor, which is given exogenously. For a given set of product prices there are, therefore, as many excess-demand functions for labor as there are labor categories. Given product prices, these excess-demand functions can be solved to yield wages by labor category such that the demand for labor matches the supply.

\footnotetext{
*An appendix containing the complete set of model equations and variables is available from the author upon request.
} 
Employment and output are then determined in each sector. Thus we can visualize supply functions, one for each sector, that associate a vector of domestic outputs with any vector of prices. These supply functions will be of the form:

$$
X_{i}^{\mathrm{S}}=X_{i}^{\mathrm{S}}\left(P D_{1}, P D_{2}, \ldots, P D_{n} ; E R\right) \quad(i=1,2, \ldots, n)
$$

where the $P D_{i}$ denote domestic commodity prices and $E R$ denotes the exchange rate. Equilibrium wages, the determination of which underlies the derivation of the supply curves, are dependent only on $P D_{i}$ and $E R$ and can, therefore, be removed from the supply functions by substitution. Note that the exchange rate appears in the supply functions because it determines import prices and therefore affects intermediate input prices and through these the marginal revenue product equations.

\subsection{Imports and Exports}

The specification of foreign trade and its interaction with the domestic economy constitutes the most important part of the model. First, let us consider imports. The specification adopted here follows that of Armington (1969) and more recent work on general equilibrium models of open economies (e.g., Dixon et al., 1977; Dervis and Robinson, 1978; Dervis, 1980; and de Melo and Robinson, 1980). For each commodity category an "aggregate" or composite commodity $Q_{i}$ is defined, which is a CES function of imports, $M_{i}$, and domestic goods, $D_{i}$ :

$$
Q_{i}=\gamma_{i}\left[\delta_{i} M_{i}^{-\rho_{i}}+\left(1-\delta_{i}\right) D_{i}^{-\rho_{i}}\right]^{-1 / \rho_{i}} \quad(i=1,2, \ldots, n)
$$

where $\gamma_{i}, \delta_{i}$, and $\rho_{i}$ are paraneters, with $\sigma_{i}=1 /\left(1+\rho_{i}\right)$ denoting the "trade substitution elasticity" between foreign and domestic goods. Consumers (producers) demand (supply) this composite commodity such that the demands for imports and domestic goods become derived demands in the same way that factor-input demands are treated as derived demands in traditional production models. With $P D_{i}$ denoting the domestic price of the good and $P M_{i}$ denoting the user price of imports (in domestic currency), first-order conditions for cost minimization yield:

$$
m_{i}=M_{i} / D_{i}=\left(P D_{i} / P M_{i}\right)^{\sigma_{i}}\left(\delta_{i} /\left[1-\delta_{i}\right]\right)^{\sigma_{i}} \quad(i=1,2, \ldots, n)
$$

and

$$
d_{i}=D_{i} / Q_{i}=\left(1-\delta_{i}\right)^{\sigma_{i}}\left(P_{i} / P D_{i}\right)^{\sigma_{i}} \gamma_{i}^{-\rho_{i} \sigma_{i}} \quad(i=1,2, \ldots, n)
$$

where $m_{i}$ is the ratio of imports to domestic goods, $d_{i}$ is the ratio of domestic goods to total composite-commodity demand, and the $P_{i}$ denote composite-commodity prices. These prices are simply given by the cost function corresponding to the CES aggregation function:

$$
P_{i}=\left(1 / \gamma_{i}\right)\left[\delta_{i}^{\sigma_{i}} P M_{i}^{1-\sigma_{i}}+\left(1-\delta_{i}\right)^{\sigma_{i}} P D_{i}^{1-\sigma_{i}}\right]^{1 /\left(1-\sigma_{i}\right)} \quad(i=1,2, \ldots, n)
$$


Note that import prices to the domestic user are given by:

$$
P M_{i}=\overline{P W}_{i}\left(1+t m_{i}\right) E R \quad(i=1,2, \ldots, n)
$$

where the $\overline{P W}_{i}$ denote world prices (in "dollars"), $E R$ is the exchange rate, and $t m_{i}$ are ad valorem tariff rates.

This specification allows a flexible and realistic treatment of imports. They are not perfect substitutes for domestic goods and the model allows two-way trade. The domestic price system has a certain autonomy and, while influenced by world prices and tariffs, it is not entirely determined by them. On the other hand, contrary to the rigid two-gap type models that used to be popular in the development literature, relative prices do matter and domestic goods can substitute for imports. Note, finally, that we assume infinitely elastic foreign-supply curves for imports: the $\overline{P W}_{i}$ are fixed and the country is "small" on the import side.

Turning now to exports, we assume downward-sloping foreign-demand curves of the form:

$$
E_{i}=E_{i}\left(P W E_{i}\right)^{-\eta_{i}}
$$

where the $E_{i}$ denote exports, $\eta_{i}$ are the price elasticities of foreign demand, and the $P W E_{i}$ are the dollar prices of our country's exports:

$$
P W E_{i}=P D_{i} /\left(1+t e_{i}\right) E R
$$

where the $t e_{i}$ are rates of export subsidy. We do not assume that the country is necessarily "small" on the export side though a large value of $\eta_{i}$ will approximate the small-country assumption. It is, however, unrealistic to specify infinitely elastic export-demand functions in an applied general equilibrium model. The magnitude of the export-demand elasticities will depend not only on a country's market share but also on the degree of product differentiation characterizing products from different countries. The more significant a country's share in the world market and/or the more differentiated the product in question, the lower one would expect export-demand elasticities to be. Finally, note that export supply is derived residually by subtracting domestic demand from total domestic production.

\subsection{Supply, Demand, and the General Equilibrium Solution}

As discussed above, domestic prices and the exchange rate yield $n$ sectoral supply functions (eqn. (1)). Using the domestic use ratios $d_{i}$ defined in eqn. (4) above, we can build up corresponding sectoral demand functions. Let $V_{i}, C_{i}$, and $Z_{i}$ denote, respectively, intermediate demand, consumption demand, and investment demand in the domestic economy. Each one of these demands depends on the relative price system, including the exchange rate. The domestic demand functions for domestically-produced commodities will be of the form

$$
D_{i}=d_{i}\left(P D_{i} ; E R\right) \cdot\left(V_{i}+C_{i}+Z_{i}\right) \quad(i=1,2, \ldots, n)
$$


where the $d_{i}$ are given by eqn. (4) and

$$
\left.\begin{array}{ll}
V_{i}=V_{i}\left(P D_{1}, P D_{2}, \ldots, P D_{n} ; E R\right) & (i=1,2, \ldots, n) \\
C_{i}=C_{i}\left(P D_{1}, P D_{2}, \ldots, P D_{n} ; E R\right) & (i=1,2, \ldots, n) \\
Z_{i}=Z_{i}\left(P D_{1}, P D_{2}, \ldots, P D_{n} ; E R\right) & (i=1,2, . ., n)
\end{array}\right\}
$$

since each component of demand for the composite commodity depends on incomes and relative prices. To obtain total demand for domestically-produced commodities, we must, of course, add export demand to domestic demand. Substituting eqn. (10) into eqn. (9), and adding eqn. (7), yields sectoral aggregate demand functions of the form

$$
X_{i}^{\mathrm{D}}=X_{i}^{\mathrm{D}}\left(P D_{1}, P D_{2}, \ldots, P D_{n} ; E R\right)
$$

Subtracting the sectoral aggregate supply functions of eqn. (1) from eqn. (11) gives us $n$ excess-demand functions. For general equilibrium we must set all excess demands to zero:

$$
\begin{gathered}
E X_{i}=X_{i}^{\mathrm{D}}\left(P D_{1}, P D_{2}, \ldots, P D_{n} ; E R\right)-X_{i}^{\mathrm{S}}\left(P D_{1}, P D_{2}, \ldots, P D_{n} ; E R\right)=0 \\
(i=1,2, \ldots, n)
\end{gathered}
$$

This gives us $n$ equations in $n+1$ variables: the $n$ domestic commodity prices and the exchange rate. We also have the balance-of-payment constraint:

$$
\begin{gathered}
E F_{i}=\sum_{i=1}^{n} \overline{P W}_{i} M_{i}\left(P D_{1}, P D_{2}, \ldots, P D_{n} ; E R\right)-\sum_{i=1}^{n} P W E_{i} E_{i}\left(P D_{1}, P D_{2}, \ldots, P D_{n} ; E R\right)-\bar{F}=0 \\
(i=1,2, \ldots, n)
\end{gathered}
$$

where $\bar{F}$ stands for the exogenous value of the net foreign-resource inflow $(\bar{F}=0$ if there is trade balance). This gives us $n+1$ equations in $n+1$ variables. The excess-demand equations are, however, not independent (from Walras' Law) and we require a price normalization or numeraire to close the system. The normalization equation will take the form

$$
\sum_{i=1}^{n} \Omega_{i \mathrm{~d}} P D_{i}+\sum_{i=1}^{n} \Omega_{i \mathrm{~m}} P M_{i}=\bar{P} \quad(i=1,2, \ldots, n)
$$

where $\Omega_{i \mathrm{~d}}$ and $\Omega_{i \mathrm{~m}}$ are fixed weights so that an overall price index of all commodities (domestic and imported) remains constant at $\bar{P}$. Given that $P M_{i}=\overline{P W}_{i}\left(1+t m_{i}\right) E R$, the normalization equation is again one with $P D_{i}=1,2, \ldots, n$ and $E R$ as the only endogenous variables. The price level equation (14) closes the system and in principle allows us to solve for domestic commodity prices and the exchange rate as a function of the exogenous parameters and government policy variables. We cannot solve the model analytically, but we can solve it numerically and use it as a systematic device to explore the general equilibrium effects of changes in exogenous variables and parameters. (The solution technique is based on a modification of the principle of Walrasian tâtonnement: an initial guess at 
prices and the exchange rate is progressively revised taking account of indirect linkages until excess demands disappear.)

\section{THE EFFECTS OF AN EXOGENOUS SHIFT IN EXPORT DEMAND}

Let us consider an exogenous rise in foreign protectionism such that, at initial export prices, foreign demand for our country's exports is $20 \%$ lower than it used to be (see Figure 1). All other parameters in the model remain constant and the government keeps the overall price level constant by appropriate macroeconomic policies. What will be the price and resource-allocation effects of the inward shift in export demand?

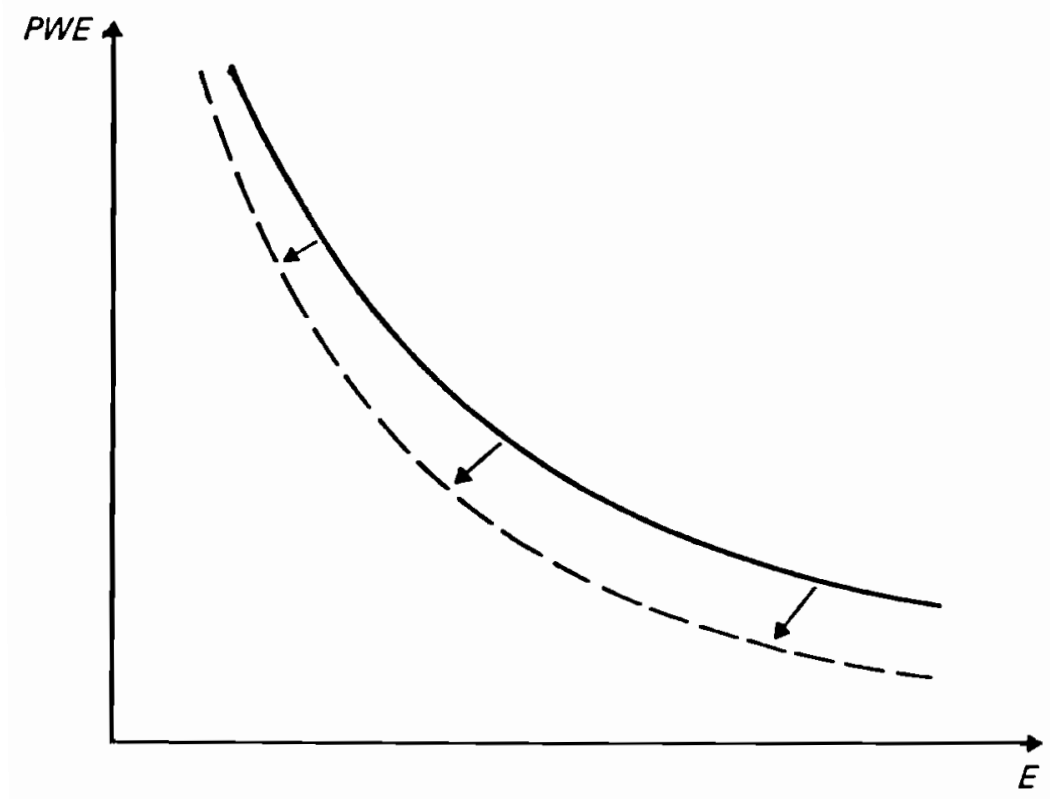

FIGURE 1 A shift in export demand caused by foreign protectionism.

Consider a sector that exports a considerable fraction of its total output. The initial effect of the contraction in export demand will be to create excess supply in this sector. Producers will no longer be able to export the same amount as before and total supply in these sectors will exceed total demand, i.e., the sum of domestic and foreign demand. Summing over all sectors, there will also be excess demand for foreign exchange as export revenues are no longer sufficient to pay for imports. These disequilibria, brought about by the inward shift of the export demand functions, will lead to price adjustments that restore general equilibrium in the economy. In response to excess supply, the domestic price of exportables will tend to fall. In response to excess demand for foreign exchange, however, the exchange rate will tend to increase, putting upward pressure on the price of all tradables and depressing the price of nontradables. Note, furthermore, that the world prices of exports, $P W E_{i}$, are obtained by dividing the domestic prices by the exchange 
rate adjusted for export subsidies, so that an upward adjustment in the exchange rate (i.e., a devaluation) will lead to an expansion in exports along the demand curves depicted in Figure 1. In any particular sector, exports may be higher or lower than before the disturbance, depending on whether or not the devaluation-induced expansion in exports along the demand curve more than compensates for the decline in exports due to the inward shift of the demand curve. The extent to which exports expand after devaluation depends crucially on the export demand elasticities. With other factors equal, an across-the-board increase in foreign protectionism will lead to an increase in exports characterized by high price sensitivity, and a decrease in exports with low price sensitivity of demand. In the former case the outward movement along the demand curves due to devaluation will outweigh the inward shift in the same curves whereas in the latter case the reverse will be true. Figure 2 illustrates the difference. In Sector $X$ export demand is elastic enough for the devaluation-induced fall in $P W E$ from $P W E^{0}$ to $P W E^{1}$ to lead to exports $O C$ higher than the initial 0A. In contrast, in Sector $\mathrm{Y} \mathrm{OM}<0 \mathrm{~K}$ because the movement from $\mathrm{L}$ to $\mathrm{M}$ on $E^{1}$ is not enough to compensate for the shift from $E^{0}$ to $E^{1}$.
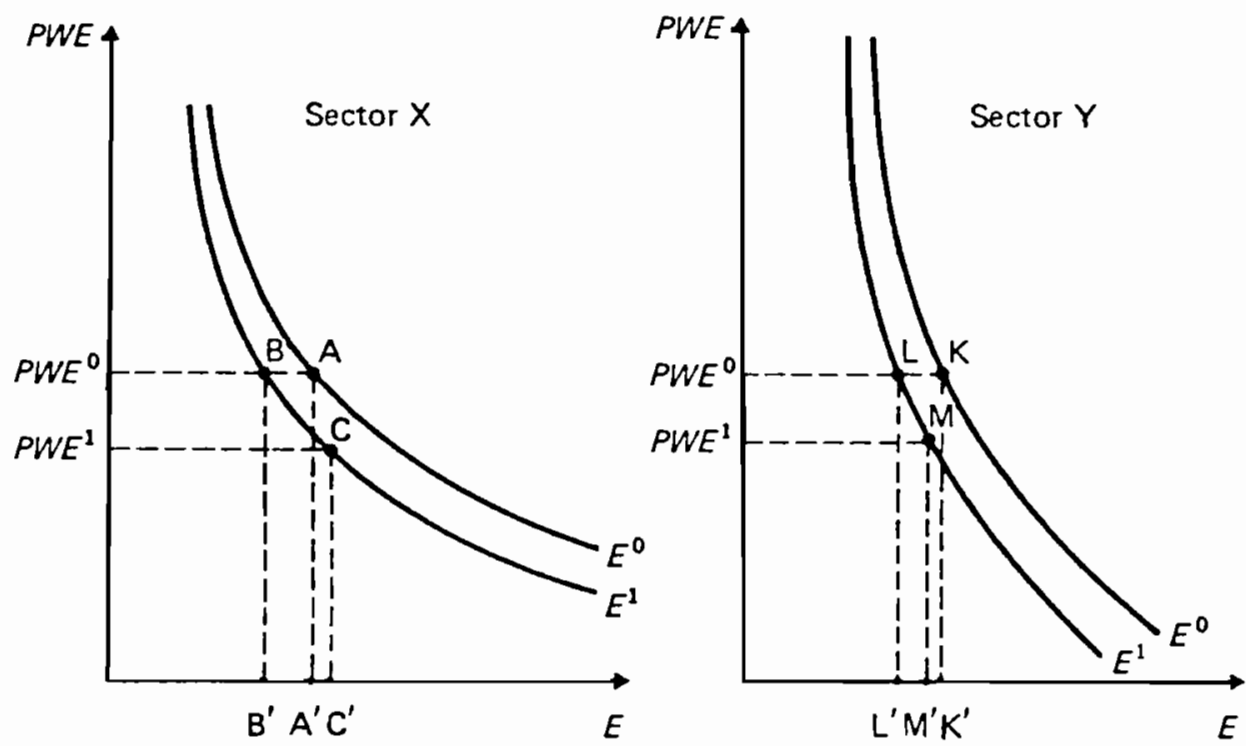

FIGURE 2 Compensating devaluation and the behavior of export volume in high-and low-elasticity sectors.

The discussion above is based on the assumption of constant domestic prices, $P D_{i}$, so that the $P W E_{i}$ change only because of the exchange-rate adjustment. In fact, however, domestic relative prices do not remain unchanged. As noted before, domestic prices will tend to fall in sectors where exports constitute a large proportion of output. In contrast, 
they will tend to rise in sectors producing import substitutes because the exchange-rate adjustment will lead to substitution favoring an increased demand for domestic goods. If these primarily import-substituting sectors also export some fraction of their output, exports will be adversely affected by the domestic price rises. Thus, exports from a sector may decline even though the elasticity of export demand is very high, if the domestic currency price goes up significantly in that sector.

All these factors interact in determining the impact of a rise in foreign protectionism on resource allocation in the domestic economy. Table 1 summarizes the effect of a $20 \%$ inward shift of all export demand curves on domestic currency prices, export prices, and export volumes in the model.

Note first that there is a $5.1 \%$ exchange-rate adjustment after the decline in foreign demand. This devaluation in itself causes all export prices $P W E_{i}$ to decline. Some, however, decline more than others reflecting variation in the behavior of domestic prices. We have

$$
P W E_{i}=P D_{i} /(1+t e) E R
$$

so that

$$
P \hat{W} E_{i}=\hat{P D}-\hat{E R}
$$

where ( $($ ) stands for percentage change. Compare, for example, Sectors 2 and 3. Both are characterized by the same high, export demand elasticities, but consumer-goods exports expand by $8.7 \%$ whereas intermediate-goods exports contract by $5.8 \%$. The reason for this is the substantial increase in the domestic price of intermediates which offsets part of the devaluation. The remaining $2.8 \%$ decline in the export price is not enough to compensate for the inward shift of the demand curve for exports. The opposite is the case for consumer goods. Here the domestic price remains almost constant so that the devaluation translates into a $5.3 \%$ decline in the export price. This more than offsets the effect of the inward shift of the demand curve and exports expand by $8.7 \%$.

Why do domestic prices behave so differently? The explanation is largely to be found in the shares of exports and imports, $e_{i}$ and $m_{i}$, in total domestic output, and the trade substitution elasticities $\sigma_{i}$. The prices of intermediate goods and capital goods rise because these sectors have high import shares and devaluation causes substitution towards domestic goods, thus causing upward pressure on prices. This pressure is strongest in the intermediategoods sector because of the higher substitution elasticity, 1.5 , compared with only 0.5 for capital goods. There is no import-substitution effect in other sectors because the share of imports is insignificant to start with.

Consider now agriculture and services. Despite the fact that export prices fall in both sectors by even more than do the prices for consumer goods, export volumes also fall. This reflects the low export demand elasticities in those sectors: the movement along the demand curves is not enough to compensate for their inward shift.

Note, finally, that total export volume in base domestic prices falls almost imperceptibly by $0.03 \%$, but dollar earnings fall by a much more significant $5.6 \%$ from 1,762 to 1,663 million dollars.

Let us next consider what happens to value-added or net prices as an indicator of the sectoral resource-pulls generated by the shift in foreign demand. 


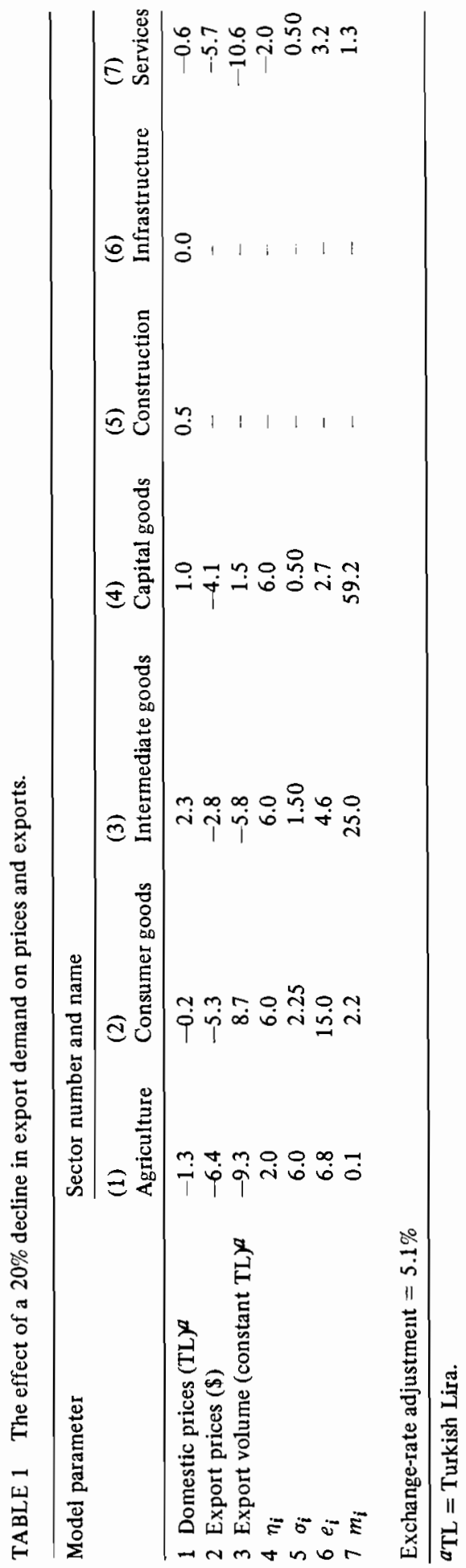


TABLE 2 The effect of a $20 \%$ decline in export demand on per-unit value-added.

\begin{tabular}{llllllll}
\hline & \multicolumn{3}{c}{ Sector $^{a}$} & & & & \\
\cline { 2 - 7 } & $(1)$ & $(2)$ & (3) & (4) & (5) & (6) & (7) \\
\hline Change in net prices & -1.7 & 0.5 & 2.5 & -0.6 & -0.5 & -0.9 & -0.7 \\
\hline
\end{tabular}

${ }^{a}$ The sectors are numbered as in Table 1 .

Table 2 shows that only consumer goods and intermediate goods are positively affected. Several factors determine the behavior of net prices. First, the net price in a sector is of course affected by the particular gross output price in that sector. Thus with a $1.3 \%$ decline in output price, one expects a decline in per-unit value added in agriculture. The net price in any sector, however, is also affected by changes in intermediate input prices of sectors supplying intermediate inputs, including imported intermediates. The decline in agriculture prices, for example, will have a positive effect on consumer goods because that sector purchases a significant amount of agricultural inputs. Table 2 describes the net results. Nontradable commodities, sectors heavily dependent on imported intermediate inputs (such as the capital goods sector), and sectors producing exports with low foreign-demand elasticities (such as agriculture) suffer a decline in net price. Sectors that produce price-elastic exportables such as the consumer goods sector, and sectors that can provide import substitutes without being too heavily dependent on inputs, such as intermediate goods, benefit from a rise in net price.

This essentially sums up the story. The experiment illustrates some of the most important general equilibrium effects that can be expected from a decline in foreign demand in an economy that adjusts to it by letting the exchange rate find its new equilibrium value. Export volumes may decline or rise depending on the magnitude of the shift in foreign demand, the sensitivity of export demand to prices, and the changes in the domestic price system. Total export earnings will decline. Imports will, therefore, also decline in value and in volume since we assume fixed world prices for imports. In the domestic economy, net prices will increase in import-substituting sectors provided they are not too heavily dependent on imported intermediate inputs. Price-elastic exportables will also benefit. Producers of nontradable commodities and producers of exports with low price elasticities will experience a decline in net prices.

\section{THE EFFECT ON OPTIMAL POLICY}

In this section we consider in what sense and direction optimal policy advice should change, if at all, after a decline in export demand induced by foreign protectionism. For this purpose consider four experiments. The first two are those that we have already described above. Experiment E-1 has the initial export demands, whereas Experiment E-2 assumes an across-the-board $20 \%$ decline in foreign demand. Both situations are characterized by trade taxes and subsidies that distort resource allocation and bias incentives against exports. Experiment E-3 assumes the initial, higher export demands of E-1, but it also assumes free trade and, therefore, no anti-export bias in trade policy. Finally, Experiment E-4 has the same 20\% decline in foreign demand as Experiment E-2, but continues to assume a "neutral" (free trade) incentive policy. Let us define this neutral structure of 
incentives as optimal but note that free trade may not in actual fact be optimal. With export demand less than infinitely elastic, there is a "first-best" argument for export taxes. There may also be other second-best arguments for protection, but for simplicity let us consider free trade as the most desirable policy and illustrate how policy advice, as such, is affected by a shift in foreign demand.

Consider situation E-1. With anti-export bias in incentives, good policy advice should try to move the economy closer to what it would be under free trade, or to what it is under E-3. How will the nature of this advice be affected by the exogenous decline in export demand? Clearly E 4 represents the free-trade equilibrium, and instead of moving from E-1 to E-3, the economy should move from E-1 to E-4. Note that without policy changes it will, in fact, move to E-2 as described above. Table 3 summarizes the most important results in terms of percentage changes from the E-1 base.

Consider first net prices. A movement to free trade before the rise of foreign protectionism (Experiment E-3) would have increased per-unit value added in all sectors, except in the strongly-protected intermediate-goods sector. The same is true if there is a movement to free trade simultaneously with a decline in foreign demand (Experiment E-4). While the general direction of resource-pulls does not change, the ranking of sectors does change because of the differential impact of the exogenous decline in foreign demand on the different sectors. The difference in ranking between the net price results of E-3 and E4 reflects what is already summarized in the results for E-2: an across-the-board decline in export demand positively affects the consumer-goods and intermediate-goods sectors. All other sectors suffer a loss in net price and this result is independent of the initial level of trade taxes and subsidies.

The percentage changes in export and import volumes also presented in Table 3 illustrate more vividly the effect of moving to free trade and the impact of a shift in export demand on the consequences of free trade. The predicted consequences of trade liberalization on trade volumes and patterns definitely change when one combines trade liberalization with a decline in foreign demand. The differences are again to be explained largely in terms of differing export demand elasticities, trade-substitution elasticities and trade shares, and their general equilibrium interaction.

Let us attempt to summarize the results. An across-the-board decline in foreign demand will lead to a change in relative prices and an exchange-rate adjustment. Sectors producing very price-elastic exports and sectors producing import substitutes will benefit from the change in the structure of prices. Sectors producing nontradable commodities and sectors producing exports with a low price elasticity of demand will suffer a decline in their net prices. As regards the question of optimal policy advice, one must distinguish between advice on optimal policy, as such, and advice on specific sectors and projects. If free trade is believed to be an optimal policy, a decline in foreign export demand should not affect either that belief or the advice to implement free-trade policies. If, on the contrary, a certain pattem of protection is considered optimal on the basis of, for example, terms-of-trade and/or infant-industry arguments, the nature of optimal policy again should not be affected by a change in foreign demand conditions. If, however, by policy advice we mean advice on specific projects or sectoral expansion programs, the situation is, of course, quite different. This kind of policy advice can and should be affected by a decline in world demand for a country's exports. Consider, for example, the following situation. Two large export-oriented projects are under consideration, one in agriculture, the other in the consumer-goods sector. How should the decline in export demand affect appraisal 


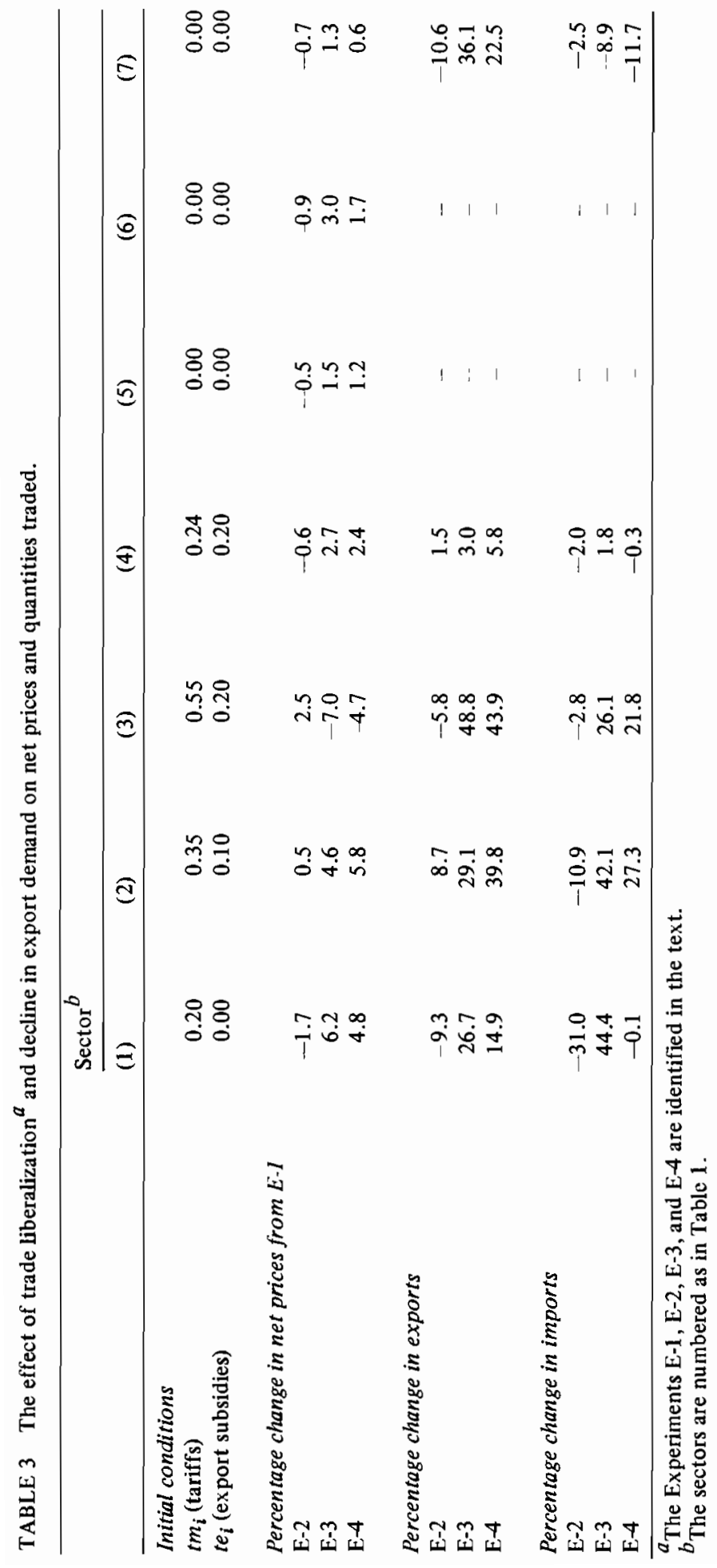


of these two projects? To discuss this question, let us refer back to the percentage change in export volumes under E-2, E-3, and E-4 presented in Table 3. In the project-appraisal literature projects are of ten viewed as a means for moving the economy towards the situation it would move to if optimal policies could be pursued, even though these optimal policies are not actually in effect. If we view these projects as instrumental in moving the economy towards free trade, they would probably both be justified since exports from both sectors expand substantially after trade liberalization, by 26.7 and $27.1 \%$, respectively, with constant foreign demand, and by 14.9 and $39.8 \%$, respectively, with declining foreign demand. If the projects are large and mutually exclusive, however, the decline in foreign demand makes the second project (in the consumer-goods sector) look more important since required export expansion in agriculture declines from 26.7 to $14.9 \%$ while required export expansion in consumer goods increases from 29.1 to $39.8 \%$.

Suppose, on the other hand, that we do not believe that trade taxes should, in fact, be abolished and that we view the existing set of taxes as optimal or at least as permanent. In that case what would happen with hypothetical free-trade policies is not important and E-2 becomes the relevant experiment. A decline in foreign demand with constant trade taxes leads to a $9.3 \%$ decline in agricultural exports. The first project should, therefore, be rejected. The second project can be accepted provided it is not too large, since the across-the-board decline in foreign demand will, in fact, require an $8.7 \%$ increase in exports of consumer goods.

\section{CONCLUSION}

The experiments described above illustrate how a general equilibrium model can lielp clarify the effects of a possible rise in OECD protectionism on resource allocation and project selection in developing economies. General statements concerning resource allocation effects can be made but they are more subtle and qualified than those sometimes heard in current discussions. Finally, it must be stressed that we have analyzed the effects of a once-and-for-all decline in export demand on a single economy. Questions of retaliation and North--South bargaining have not been discussed. Furthermore, if OECD protectionism takes the form of a continuous chain of reactions tending to limit export expansion from LDCs whenever and in whatever markets expansion occurs, the situation would be quite different from that examined here.

\section{ACKNOWLEDGMENTS}

I would like to thank J. de Melo and S. Robinson for fruitful collaboration. The essential structure of the computable general equilibrium model used in the analysis is based on our joint work (Dervis et al., 1982).

\section{REFERENCES}

Armington, P. (1969). A theory of demand for products distinguished by place of production. IMF Staff Papers, 16:159-178. 
Balassa, B. (1978). The new protectionism and the international economy. Journal of World Trade Law, 12(5):409-436.

Bhagwati, J. (1978). Anatomy and Consequences of Exchange Control Regimes. Ballinger, Cambridge, Massachusetts.

de Melo, J. and Robinson, S. (1980). Trade Adjustment Policies and Income Distribution in Three Archetype Developing Economies. Working Paper 442. World Bank, Washington, D.C.

Dervis, K. (1980). Analyzing the resource pull effects of devaluation under exchange control. Journal of Development Economics, 7:23-47.

Dervis, K. and Robinson, S. (1978). The foreign exchange gap, growth and industrial strategy in Turkey: 1973-1983. World Bank Staff Working Paper, No. 306. World Bank, Washington, D.C.

Dervis, K., de Melo, J., and Robinson, S. (1982). General Equilibrium Models for Development Policy. Cambridge University Press.

Dixon, P.B., Ryland, G.J., Parmenter, B.R., and Sutton, J. (1977). Orani: A General Equilibrium Model of the Australian Economy, Vol. 2. 


\title{
POLICY ADJUSTMENT RULES IN AN OPEN EXCHANGE MODEL WITH MONEY AND ENDOGENOUS BALANCE OF TRADE DEFICIT
}

\author{
Michiel A. Keyzer \\ Centre for World Food Studies, Free University of Amsterdam, Amsterdam \\ (The Netherlands)
}

\section{POLICIES AND POLICY ADJUSTMENT RULES}

\subsection{Problems in Distinguishing between Target and Instrument}

We shall consider the role of policy variables in a model of general economic equilibrium. In this context a policy variable is one whose level is decided by a "ruling" actor in the model, such as a national government or an international agency. We do not follow the traditional practice of subdividing policy variables into targets and instruments. We first explain the problems related to this distinction, both as a descriptive and as a modeling concept, and then outline the approach taken in this paper.

We consider a national government which has taken an official decision to run a specified trade deficit. The mere taking of this decision does not, of course, enforce its realization. In order to realize the targeted trade deficit, international trade and foreign credit have to adjust, and these adjustments, in turn, must be enforced. For this purpose the government has at its disposal price instruments such as tariffs on trade, premiums on foreign credit, and variations in exchange rate, quantity instruments such as quotas on international trade, rationing of domestically available foreign currency, and regulation of money supply, and financial instruments such as government expenditure and income tax. Government policy usually has more than one target and several of the instruments listed above may have target values of their own. Thus any classification of policy variables into targets and instruments would require revision as soon as any of the targets appeared to be mutually incompatible or insufficient as determinants of unique instrument values.

\subsection{Distinction between Target and Instrument in an Economic Model}

In terms of mathematical models this problem can be summarized as follows. Let $\left(u_{1}, u_{2}, \ldots, u_{m}\right)$ be policy instruments and $\left(x_{1}, x_{2}, \ldots, x_{m}\right)$ be policy targets. Further, let policy instruments be related to targets according to the function 


$$
x_{i}=f_{i}\left(u_{1}, u_{2}, \ldots, u_{m}\right) \quad(i=1,2, \ldots, n)
$$

The question is now whether, for a given target value $\hat{x}_{i}$ of $x_{i}$, we can uniquely solve

$$
\hat{x}_{i}=f_{i}\left(u_{1}, u_{2}, \ldots, u_{m}\right) \quad(i=1,2, \ldots, n)
$$

In a linear model this is generally not too difficult to achieve although it is of course dependent on $f_{i}$ and on $\hat{x}_{i}$ (see Tinbergen, 1956). But even in a linear model a negative answer can occur, requiring a respecification of the model. In order to avoid this type of trial-and-error procedure it is better to formulate the model in terms of "goal programming" (see Charnes et al., 1975):

$$
\min _{u_{1}, u_{2}, \ldots, u_{m}} \sum_{i}\left|x_{i}-\hat{x}_{i}\right|
$$

subject to

$$
x_{i}=f_{i}\left(u_{1}, u_{2}, \ldots, u_{m}\right)
$$

However, this model still has two disadvantages. First, there may be an infinity of optimal numerical values of $\left(u_{1}, u_{2}, \ldots, u_{m}\right)$. Second, all deviations from target have to be combined into one single objective function. As long as a unique solution $\left(u_{1}^{*}, u_{2}^{*}, \ldots\right.$, $u_{m}^{*}$ ) exists such that $x_{i}=\hat{x}_{i}$ for all $i$ this is not a problem. In a nonlinear model such an outcome would be rather fortuitous and a solution with nonzero deviations from target is likely to occur: then the specification of the objective becomes a critical determinant of the outcome since it reflects the decision-maker's preferences among various deviations from target of the variables $x_{i}$.

From a mathematical point of view one can easily generalize this into a utilitymaximizing formulation:

$$
\max g\left(x_{1}, x_{2}, \ldots, x_{n} ; \hat{x}_{1}, \hat{x}_{2}, \ldots, \hat{x}_{n}, u_{1}, u_{2}, \ldots, u_{n}\right)
$$

subject to

$$
x_{i}=f_{i}\left(u_{1}, u_{2}, \ldots, u_{n}\right) \quad(i=1,2, \ldots, n)
$$

This general formulation merely shifts the problem to one of finding an adequate specification of the objective. Moreover, numerical solution may be very cumbersome since even in simple applications $f_{i}$ may be nonlinear, nonconvex, and not differentiable at every point, as we shall see below.

We therefore follow a different approach here: we do not distinguish between policy targets and policy instruments but merely use the concepts of policy variables and policy adjustment rules. 


\subsection{Policy Variables}

We define an $x$-policy as a string of variables $\left\{x^{l}\right\}_{l=0}^{L}, x^{l} \in R^{n}$, which describes $L$ adjustment phases between an original, exogenously specified policy target $x^{0}$ and a final policy realization $x^{L}$ (notation: $x \equiv x^{L}, \hat{x} \equiv x^{0}$ ). Each variable $x^{l}$ is constrained within an adjustment set $X^{l}$ :

$$
x^{l}:=\left\{x \in R^{n} \mid \underline{x}^{l} \leqslant x \leqslant \bar{x}^{l}\right\}
$$

for given $\underline{x}^{l}$ and $\bar{x}^{l}$ such that

$$
X^{l} \subset X^{l+1}
$$

In the same way we can define a $y$-policy, a $z$-policy, etc.: these could be, for example, a price policy, a buffer-stock policy, an income-tax policy, etc.

\subsection{Policy Adjustment Rules}

Policy targets within the same economic model may be conflicting. We define adjustment rules between policies in order to resolve possible conflicts, and state that in the $l$ th adjustment phase $y$-policy has a weak adjustment rule with respect to $x$-policy if, for $i=1,2, \ldots, n$ :

$$
\underline{y}_{i}^{l}<y_{i}^{l}<\bar{y}_{i}^{l} \quad \text { implies } \quad x_{i}^{l}=x_{i}^{l-1}
$$

We denote this type of rule by $x^{l} \Theta y^{l}$.

Similarly, in the $l$ th adjustment phase $y$-policy has a positive adjustment rule with respect to $x$-policy if, for $i=1,2, \ldots, n$ :

$$
\begin{array}{lll}
y_{i}^{l}=\bar{y}_{i}^{l} & \text { implies } & x_{i}^{l} \geqslant x_{i}^{l-1} \\
\underline{y}_{i}^{l}<y_{i}^{l}<\bar{y}_{i}^{l} & \text { implies } & x_{i}^{l}=x_{i}^{l-1} \\
y_{i}^{l}=\underline{y}_{i}^{l} & \text { implies } & x_{i}^{l} \leqslant x_{i}^{l-1}
\end{array}
$$

We denote this type of rule by $x^{l}+\Theta y^{l}$.

Finally, we speak of a negative adjustment rule of a $y$-policy with respect to an $x$-policy in the $l$ th adjustment phase if, for $i=1,2, \ldots, n$ :

$$
\begin{array}{lll}
y_{i}^{l}=\bar{y}_{i}^{l} & \text { implies } & x_{i}^{l} \leqslant x_{i}^{l-1} \\
y_{i}^{l}<y_{i}^{l}<\bar{y}_{i}^{l} & \text { implies } & x_{i}^{l}=x_{i}^{l-1} \\
y_{i}^{l}=\underline{y}_{i}^{l} & \text { implies } & x_{i}^{l} \geqslant x_{i}^{l-1}
\end{array}
$$

We denote this type of rule by $x^{l}-\Theta y^{l}$. 
These policy adjustment rules can also be formulated in the language of mathematical complementarity problems:

$$
\begin{aligned}
& \left\{x^{l} \Theta y^{l}\right\}=\left\{(x, y) \in\left(X^{l} \times Y^{l}\right) \mid\left(x_{i}-x_{i}^{l-1}\right)\left(\bar{y}_{i}^{l}-y_{i}\right)\left(y_{i}-y_{i}^{l}\right)=0\right. \\
& \text { for } \left.i=1,2, \ldots, n \text { and given } x^{l-1} \in X^{l-1}\right\} \\
& \left\{x^{l}+\Theta y^{l}\right\}=\left\{(x, y) \in\left(X^{l} \times Y^{l}\right) \mid x=x^{l-1}+\Delta^{+} x-\Delta^{-} x, \Delta^{+} x \cdot\left(\bar{y}^{l}-y\right)=0,\right. \\
& \left.\Delta^{-} x \cdot\left(y-\underline{y}^{l}\right)=0, \Delta^{+} x \geqslant 0, \Delta^{-} x \geqslant 0, \text { for given } x^{l-1} \in X^{l-1}\right\} \\
& \left\{x^{l}-\Theta y^{l}\right\}=\left\{(x, y) \in\left(X^{l} \times Y^{l}\right) \mid x=x^{l-1}+\Delta^{+} x-\Delta^{-} x, \Delta^{+} x .\left(y-y^{l}\right)=0,\right. \\
& \left.\Delta^{-} x .\left(\bar{y}^{l}-y\right)=0, \Delta^{+} x \geqslant 0, \Delta^{-} x \geqslant 0, \text { for given } x^{l-1} \in X^{l-1}\right\}
\end{aligned}
$$

Figure 1 shows the adjustment rules for $x^{l}, y^{l} \in R^{l}$.

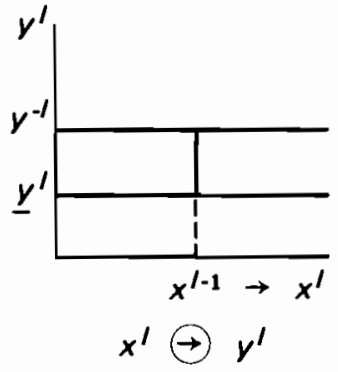

(a)

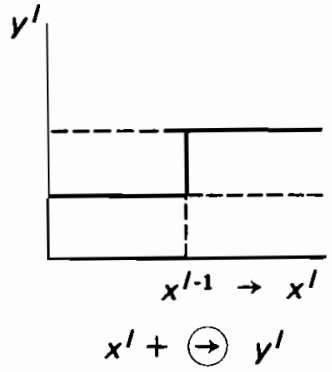

(b)

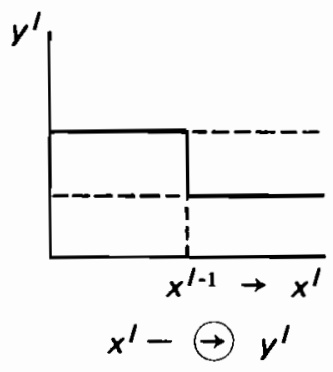

(c)

FIGURE 1 Weak (a), positive (b), and negative (c) policy adjustment rules.

Once the policy adjustment rules have been specified we can formulate a minimization of the deviation from target:

$$
\min \|x-\hat{x}\|+\|y-\hat{y}\|
$$

This norm minimization ensures that, in the case of multiple solutions, the solution with the largest number of variables on target for each element of the vectors $x, y$ is selected.

\section{AN OPEN EXCHANGE MODEL WITH ENDOGENOUS TRADE DEFICIT}

We apply the foregoing definitions of policy adjustment rules in the formulation of a one-period general equilibrium model of an open economy with lagged production (given endowments), and we consider a private demand sector and a government as actors. There are $n$ commodities indexed $i$ or $h$. 


\subsection{Private Demand}

The private demand sector follows a generalized linear expenditure system:

$$
p_{i} x_{i}=\nu \sum_{h} p_{h}\left(\lambda_{1} \overline{\bar{a}}_{h i}+\bar{b}_{h i}\right)
$$

where

$p_{i}=$ domestic price (policy variable),

$x_{i}=$ private demand,

$\lambda_{i}=$ tax variable (policy variable),

$\overline{\bar{a}}_{h i}, \bar{b}_{h i}=$ fixed coefficients, ${ }^{*}$

$\nu=$ overall demand adjustment variable (policy variable).

\subsection{Government Demand}

Government has a demand $w$ for buffer stock and a public demand $g$. Public demand consists of $(K-1)$ categories indexed $k$.

$$
g_{i}=\nu \sum_{k=2}^{K} \lambda_{k} \overline{\bar{c}}_{k i}
$$

where

$g_{i}=$ public demand,

$\lambda_{k}=$ level of $k$ th public demand activity (policy variable),

$\left(\overline{\bar{c}}_{k 1}, \overline{\bar{c}}_{k 2}, \ldots, \overline{\bar{c}}_{k n}\right)=$ commodity bundle in $k$ th demand category $\left(\bar{c}_{k i} \geqslant 0\right)$.

\subsection{Balance Equations}

\subsubsection{Commodity Balance}

Net import equals net domestic demand:

$$
z_{i}^{+}-z_{i}^{-}=x_{i}+w_{i}+g_{i}-\bar{y}_{i}
$$

where

$$
\begin{aligned}
& z_{i}^{+}=\text {import } \\
& z_{i}^{-}=\text {export }
\end{aligned}
$$

\footnotetext{
* It will be shown below in Section 3 that this demand model is consistent with a Stone-Geary linear expenditure system with income equal to the value of endowments and taxation proportional to income. The double bar ${ }^{\circ}$ over a variable indicates a fixed coefficient.
} 
$z_{i}=$ net import

$x_{i}=$ private demand,

$w_{i}=$ buffer-stock demand (policy variable),

$g_{i}=$ public demand,

$\overline{\bar{y}}_{i}=$ total supply,

and

$z_{i}^{+}, z_{i}^{-}, x_{i}, w_{i}, g_{i} \geqslant 0$

\subsubsection{Financial Balance}

For a given import price $p_{i}^{\omega+}$ and export price $p_{i}^{\omega-}\left(p_{i}^{\omega+}, p_{i}^{\omega-}>0\right)$ the following balance of payments must hold:

$$
\sum_{i}\left(p_{i}^{\omega+} z_{i}^{+}-p_{i}^{\omega-} z_{i}^{-}\right)=\lambda_{0}
$$

where

$p_{i}^{\omega^{+}}, p_{i}^{\omega-}=$ import and export prices,

$z_{i}^{+}, z_{i}^{-}=$import and export quantities,

$\lambda_{0}=$ trade deficit (policy variable).

\subsection{Policy Adjustment Rules}

\subsubsection{Market Policies}

Market policies are here taken to mean those policies referring to international trade, buffer stocks, and prices. International trade is subject to quotas expressed as upper and lower bounds on net trade in each commodity. Price policy is characterized by a central price target and combined with the following buffer-stock arrangement. As long as net trade in a given commodity stays within its preset bounds, prices remain on target if a tariff is imposed on international trade. A buffer-stock agency therefore buys at a floor price and sells at a ceiling price. As long as total trade has not reached a bound, the price remains on target and the buffer-stock agency buys the target quantity. When a lower bound on net import is in operation, the price drops below target. As long as the price remains above the floor price the buffer-stock agency will remain passive and just buy the target quantity. As soon as the price reaches the floor price the stock agency buys until the maximum stock capacity is met. Then it cannot buy any more and the price can drop further. The reverse type of mechanism holds when an upper bound on net import is in operation. In terms of the definitions given earlier, these policy adjustment rules can be written compactly as

$$
p^{2}-\Theta w-\Theta p^{1}+\Theta z
$$

All these policies imply budgetary costs (or benefits) for the government and affect financial policies. 


\subsubsection{Financial Policies}

Financial policies are here taken to mean those policies concerning tax, public demand, and balance of trade. The overall demand adjustment is only introduced to guarantee the existence of a solution in case the bounds on other financial policies have been set too tight (see Keyzer, 1981). The adjustment rules for financial policies are specified as

$$
\lambda_{k(L)}^{L} \Theta \ldots \ldots \Theta \lambda_{k(1)}^{1}
$$

where $k(1), k(2), \ldots, k(L)$ is a specified priority ranking with $k(1)$ for the lowest priority (first adjustment) and $k(L)$ for the highest priority.

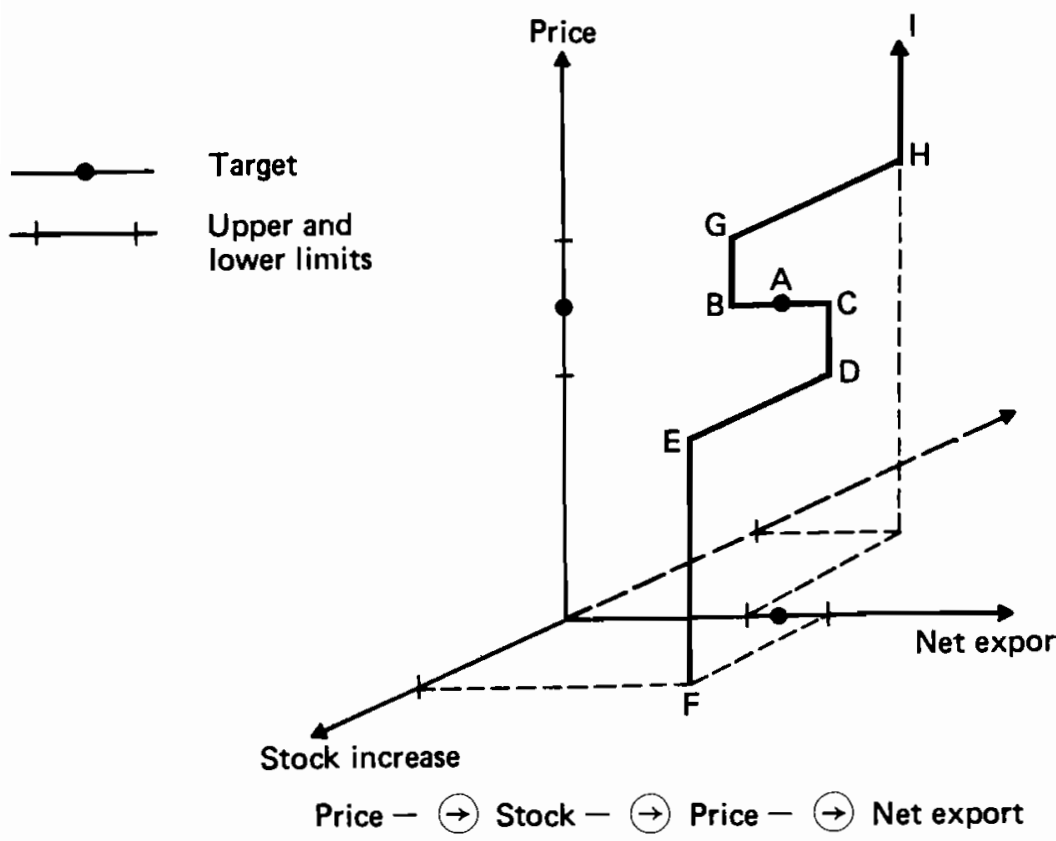

FIGURE 2 Interaction of price, stock, and trade policy.

Figure 2 illustrates the following adjustment phases of market policies:

A price, stock, and trade are at target level;

$\mathrm{BC}$ price and stock are at target level, and trade adjusts;

$\mathrm{GB}, \mathrm{CD}$ price adjusts, stock is on target, and trade is at a bound;

$\mathrm{ED}, \mathrm{GH}$ price is at a bound, stock adjusts, and trade is at a bound;

EF, HI price adjusts, and stock and trade are at bounds.

Conditions have been stated elsewhere (Keyzer, 1981) which guarantee the existence and uniqueness of a solution to this model and an algorithm to compute this 
solution will be given. Now, in order to illustrate the applicability of the open exchange model we formulate a more specific model.

\section{AN APPLICATION: MONEY AND INCOME FORMATION IN THE OPEN EXCHANGE MODEL}

The private demand sector is now disaggregated into $J$ income groups, indexed $j$. We explicitly describe demand for money and income formation without departing from the mathematical framework of the open exchange model of Section 2. Commodities, indexed $i$, can be goods as well as factor services: their total supply is given.

\subsection{Private Demand}

\subsubsection{Consumption*}

$$
p_{i} x_{i j}=\overline{\bar{\gamma}}_{i j}\left(m_{j}^{\prime}-\sum_{h} p_{h} \overline{\bar{x}}_{h j}\right)+p_{i} \overline{\bar{x}}_{i j}
$$

\subsubsection{Expenditure}

$$
m_{j}^{\prime}=m_{j}-s_{j}
$$

\subsubsection{Saving}

$$
s_{j}=\overline{\bar{\sigma}}_{j} m_{j}+v_{j}(\overline{\bar{r}})
$$

3.1.4 After-Tax Income**

$$
m_{j}=(1-t)\left(\sum_{i}\left(p_{i} \overline{\bar{y}}_{i j}\right)+\overline{\bar{f}}_{j}+q_{-1 j}\right)
$$

\subsubsection{Investment in Commodity $\mathrm{i}$}

$$
p_{i} i_{i j}=\overline{\bar{\psi}}_{i j} m_{j}+p_{i} \overline{\bar{i}}_{i j}+\kappa_{i j}(\overline{\bar{r}})
$$

3.1.6 Money Demand

$$
\begin{aligned}
d_{j}= & \bar{\delta}_{1 j} \sum_{i} p_{i}\left(x_{i j}-\overline{\bar{x}}_{i j}^{\prime}+i_{i j}\right) & & \text { (active cash) } \\
& +[t /(1-t)] m_{j} & & \text { (income tax) } \\
& +\delta_{1 j}(\bar{r}) & & \text { (inactive cash) }
\end{aligned}
$$

\footnotetext{
* Following a Stone-Geary linear expenditure system.

** A minus-one subscript denotes a one-period lag.
} 


\subsubsection{Money Supply}

$$
v_{j}=v_{-1 j}+s_{j}-\sum_{i} p_{i} i_{i j}
$$

\subsubsection{Interest Income (Next Period)}

$$
q_{j}=\rho_{-1} \bar{F}\left(v_{j}-d_{j}\right)
$$

The variables used above have the following meanings:

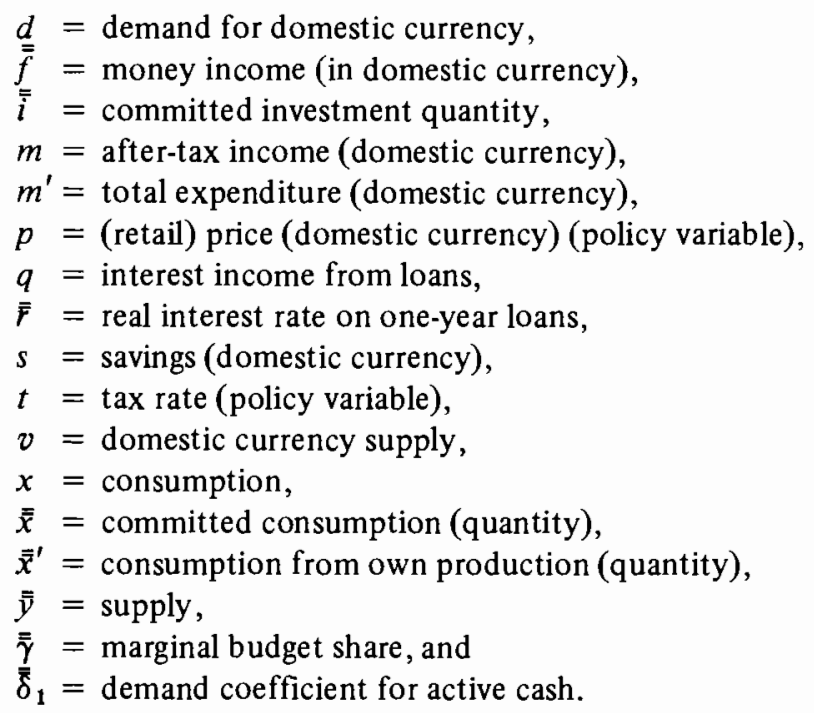

All variables refer to the private sector.

\subsection{Government Demand}

Public demand, $g$, for commodities is specified as in eqn. (2):*

$$
g_{i}=\sum_{k} \lambda_{k} \bar{c}_{i k}
$$

Apart from public demand, government has a buffer-stock demand, $w$, for commodities, and a net buffer-stock demand, $l$, for money $(l=$ liquidity absorption by the central bank).

\footnotetext{
* We disregard overall demand adjust ment here since this is purely a computational device.
} 


\subsection{Balance Equations}

\subsubsection{Commodity Balance}

$$
z_{i}^{+}-z_{i}^{-}=\sum_{j}\left(x_{i j}+i_{i j}\right)+w_{i}+g_{i}-\bar{y}_{i}
$$

\subsubsection{Money Balance}

$$
z_{n+1}^{+}-z_{n+1}^{-}=\sum_{j} d_{j}+1-\sum_{j} v_{j}
$$

\subsubsection{Balance of Payments}

$$
\sum_{i}\left(p_{i}^{w+} z_{i}^{+}-p_{i}^{w-} z_{i}^{-}\right)=\lambda_{0}
$$

\subsubsection{Convertibility of Currency}

Case 1: Full Convertibility

$$
z_{n+1}^{+}-z_{n+1}^{-}+\lambda_{0}=0
$$

Case 2: Non-Convertibility

$$
z_{n+1}^{+}-z_{n+1}^{-}=0
$$

where

$p_{i}^{\omega-}, p_{i}^{w+}=$ export and import prices, ${ }^{*}$

$z_{i}^{-}, z_{i}^{+}=$export and import quantities,

$z_{n+1}^{-}, z_{n+1}^{+}=$export and import of domestic currency,

$\lambda_{0}=$ balance of trade deficit ${ }^{*}$ (policy variable),

and

$$
z_{\bar{i}}^{-}, p_{i}^{w-}, z_{i}^{+}, p_{i}^{w+} \geqslant 0
$$

\subsection{Policy Targets and Policy Adjustment Rules}

\subsubsection{Policies on Commodity Markets}

The same price, stock, and trade policy as was specified in Section 2.4 is assumed to hold:

\footnotetext{
* Expressed in international convertible currency.
} 


$$
p^{2}-\Theta w-\Theta p^{1}+\Theta z
$$

The price target $p^{0}$ is taken to be the result of a fixed-tariff policy with respect to import price:

$$
p_{i}^{0}=\pi p_{i}^{\omega+}\left(1+\bar{\theta}_{i}\right)
$$

where

$$
\begin{aligned}
p^{0} & =\text { price target (domestic currency) } \\
p^{w+} & =\text { import price } \\
\bar{\theta}_{i} & =\text { tariff rate }, \text { and } \\
\pi & =\text { exchange rate. }
\end{aligned}
$$

\subsubsection{Monetary Policy}

\section{Inflation Policy}

The target rate of domestic inflation $\hat{\rho}$ is assumed to be a linear function of the rate of inflation of international currency $\rho^{w}$ :

$$
\hat{\rho}=\overline{\bar{\tau}} \rho^{w}
$$

Inflation control is realized through liquidity adjustment:

$$
(1 / \rho)-\Theta l
$$

\section{Exchange-Rate Determination}

The inflation policy codetermines the exchange rate

$$
\pi=\left(\rho / \rho^{w}\right) \pi_{-1}
$$

where

$$
\begin{aligned}
\rho & =\text { one plus domestic inflation rate } \\
\rho^{w} & =\text { one plus international inflation rate } \\
l & =\text { liquidity absorption by the central bank (domestic currency), and } \\
\pi & =\text { exchange rate (domestic currency per unit of international currency). }
\end{aligned}
$$

\subsubsection{Financial Policy}

Trade deficit adjustment forms the first line of defense of national financial policy: once this adjustment is at its bound, public demand adjusts, and finally, if all components of public demand are at their respective bounds, the rate of income tax adjusts:

$$
t \odot \lambda_{2} \odot \ldots \odot \lambda_{\kappa} \odot \lambda_{0}
$$




\subsection{Reduction to the Open Exchange Model}

We now show how the model can be reformulated into a special case of the open exchange model specified in Section 2.

We define deflated commodity prices as

$$
\widetilde{p}_{i}=p_{i} / \rho
$$

and money price as

$$
\tilde{p}_{n+1}=1 / \rho
$$

In addition, the tax variable $\lambda_{1}$ is given by

$$
\lambda_{1}=1-t
$$

We further define the following coefficients of the private demand system:

$$
\begin{array}{ll}
\overline{\bar{a}}_{h i}^{j}=\overline{\bar{y}}_{h j}\left(\overline{\bar{\psi}}_{i j}+\overline{\bar{\gamma}}_{i j}\left(1-\overline{\bar{\sigma}}_{j}\right)\right) & (h, i=1,2, \ldots, n) \\
\overline{\bar{b}}_{h i}^{j}=\left(\overline{\bar{x}}_{h j}+\overline{\bar{i}}_{h j}\right)\left(\delta_{h i}-\overline{\bar{x}}_{h j} \overline{\bar{\gamma}}_{i j}\right) & (h, i=1,2, \ldots, n)
\end{array}
$$

where $\delta_{h i}=1$ if $i=h$ and 0 otherwise.

$$
\begin{array}{ll}
\overline{\bar{a}}_{n+1, i}^{j}=\left(\overline{\overline{f_{j}}}+q_{-1 j}\right)\left[\overline{\bar{\psi}}_{i j}+\overline{\bar{\gamma}}_{i j}\left(1-\overline{\bar{\sigma}}_{j}\right)\right] & (i=1,2, \ldots, n) \\
\overline{\bar{b}}_{n+1, i}^{j}=\kappa_{j}(\overline{\bar{r}})-v_{j}(\overline{\bar{r}}) \overline{\bar{\gamma}}_{i j} & (i=1,2, \ldots, n)
\end{array}
$$

The coefficients for net money demand can be derived as follows:

$$
\begin{aligned}
d_{j}-v_{j}= & \bar{\delta}_{1 j}\left[\left(m_{j}-s_{j}\right)-\sum_{i} p_{i}\left(\bar{x}_{i j}^{\prime}-i_{i j}\right)\right]+[t /(1-t)] m_{j}+\delta_{2 j}(\overline{\bar{r}}) \\
& -s_{j}-v_{-1 j}+\sum_{i} p_{i} i_{i j}
\end{aligned}
$$

Thus, for $i=1,2, \ldots, n$, we can define

$$
\begin{aligned}
& \overline{\bar{a}}_{n+1, i}^{j}=\left\{-\left(1+\overline{\bar{\sigma}}_{j}\right)+\overline{\bar{\delta}}_{1 j}\left[\left(1-\sigma_{j}\right)+\sum_{h} \psi_{h j}\right]+\sum_{h} \overline{\bar{\psi}}_{h j}\right\} \overline{\bar{y}}_{i j} \\
& \overline{\bar{a}}_{n+1, n+1}^{j}=\left(-\left(1+\overline{\bar{\sigma}}_{j}\right)+\bar{\delta}_{1 j}\left[\left(1-\sigma_{j}\right)+\sum_{h} \psi_{h j}\right]+\sum_{h} \overline{\bar{\psi}}_{h j}\right)\left(\overline{\bar{f}}_{j}+q_{-1 j}\right) \\
& \overline{\bar{b}}_{n+1, i}^{i}=\left(1+\bar{\delta}_{1 j}\right) \overline{\bar{i}}_{i j}-\delta_{1 j} \overline{\bar{x}}_{i j}^{\prime}+\delta_{1 j} y_{i j}
\end{aligned}
$$




$$
\overline{\bar{b}}_{n+1, n+1}^{j}=\delta_{2 j}(\overline{\bar{r}})-v_{j}(\overline{\bar{r}})-v_{-1 j}+\overline{\bar{\delta}}_{1 j}\left(\overline{\bar{f}}_{j}+q_{-j}\right)+\left(1+\overline{\bar{\delta}}_{1 j}\right)\left[\sum_{i} \kappa_{i j}(\overline{\bar{r}})-v_{j}(\overline{\bar{r}})\right]
$$

Summation over $j$, for $i, h=1,2, \ldots, n+1$, yields the coefficients of the demand system.

Monetary policy can be looked at as a buffer-stock and price policy for money (money "price" is $1 / \rho$ ). In Case 1 (full convertibility) the balance of trade including money inflow has to be zero and cannot adjust further since all financial adjustment takes place in the $(n+1)$ th commodity. In Case 2 (non-convertibility) the balance of trade can adjust.

We have thus shown that the open exchange model with money can be considered as a special case of the model described in Section 2.

\subsection{Operation of the Model}

In order to explain the functioning of this model let us consider what might happen as a consequence of a downward shift in supply of the first commodity, say oil, on the international market:

(a) $p_{1}^{w+}, p_{1}^{w-\uparrow}$

First, we would expect an increase in international oil prices (expressed in international currency).

(b) $\lambda_{0} \uparrow$

Assuming net imports to be inelastic in the short run, we expect that the trade deficits of all importing countries would increase.

(c) $\rho^{w \uparrow}$

The oil exporters would in the short run absorb these deficits. However, after a while they would start spending so that the international currency market would get oversupplied, forcing the money price to drop, i.e., international inflation might possibly start to offset the hike in the oil price.

(d) $\rho=\rho^{w}, \pi$ constant

If the central bank of a country with nonconvertible currency tried to keep its exchange rate fixed it would have to adjust its money supply and thus import inflation, as would be the case under free trade.

(e) $m_{j} / \rho \downarrow$

For an oil-importing country, the increase in inflation would reduce the real income of the consumer to an extent dependent on the inflation compensation the country would obtain.

(f) $x_{i} \downarrow, w_{i} \uparrow, \overline{\bar{y}}_{t+1} \downarrow$

This increase in real income would decrease demand and possibly increase the level of stocks in the country and this might tend to depress the next period's supply. 
(g) $\lambda_{0} \downarrow, \lambda_{1} \uparrow,\left(\lambda_{2}, \lambda_{3}, \ldots, \lambda_{k}\right) \downarrow, \bar{y}_{t+1} \downarrow$

Even worse depressing effects could occur if a country's government tried to keep inflation below the level of international inflation and to fight the rise in trade deficit by increasing tax $\left(\lambda_{1}\right)$ and decreasing public demand. In such a situation stocks would increase heavily and supply would have to adjust accordingly, forcing a true depression to occur. This effect would be even stronger if all countries pursued such a deflationary policy.

Obviously this verbal analysis makes implicit and very debatable assumptions about the numerical values of the model coefficients and a sequential discussion of effects will always be in conflict with the simultaneous nature of the model. Nevertheless such a discussion may help the reader to understand the model. The discussion above also mentioned international price adjustment and this presupposes the existence of an international model. It has been shown elsewhere (Keyzer, 1981) how this national model can be linked into an international one.

\section{REFERENCES}

Charnes, A., Cooper, W.W., Klingman, D., and Niehaus, R.J. (1975). Explicit solutions in convex goal programming. Management Science, $22: 438-448$.

Keyzer, M.A. (1981). The International Linkage of Open Exchange Economies. Ph.D.Thesis. Free University, Amsterdam.

Tinbergen, J. (1956). Economic Policy, Principles and Design. North-Holland, Amsterdam. 


\title{
GENERAL EQUILIBRIUM MODEL FOR EGYPT*
}

\author{
F. Desmond McCarthy** \\ Center for International Studies, Massachusetts Institute of Technology, \\ Cambridge, Massachusetts 02139 (USA)
}

\section{INTRODUCTION}

Any logical framework for economic policy analysis is a compromise between the ambitions of comprehensiveness and precision and the limitations of theoretical understanding, computational feasibility, and data availability. The models presented here reflect a particular set of ambitions and a set of limitations. Both must be appreciated in order to benefit from the insights that the model makes possible and to be aware of the necessary qualifications to those insights. A critical discussion of the models, emphasizing both the capabilities and inadequacies, will be given first and then the structure of the models will be described in detail. The models developed here have a number of intellectual sources. These General Equilibrium Models (GEMs) are variations of the model developed by McCarthy and Taylor (1978), which in turn is distantly related to the models of Adelman and Robinson (1977) and of Lysey and Taylor (1978), and still more distantly to a number of other planning models.

The model presented here in various versions is a simplified multisector, static GEM with flexible prices. In the different versions it achieves macroeconomic consistency, identifies discrepancies in resource demands and availabilities as well, and also adjusts resource prices and uses to resource availabilities. However, as is the case with other types of policy models, it would be a mistake to judge the effectiveness of the GEMs in terms of the product of only a single solution of any one of them. The models become powerful tools of analysis by being used to explore alternative policies that may be applied at any one time or at successive times.

The devising of the alternative policies to be tested and the comparison, analysis, and significance of the resulting solutions are as essential a part of the use of the models as the calculations called for by the formal structure of the model which take place in the computer. It is, in fact, useful to regard the formal structure of the model and the

\footnotetext{
* This paper reports on work carried out by a joint team from Cairo University and MIT during 1978; improvements made in Cairo during the summer of 1980 in conjunction with staff of the Cairo University Development Research Center are also included. For further details see Eckaus et al. (1979).

** Present address: Economic Analysis and Projections Department, The World Bank, 1818 H Street, Washington, D.C. 20433, USA.
} 
calculations it requires as a means of relieving the economic analyst and policy maker of the burden of a set of complex and rather tedious calculations that demonstrate the implications of a particular policy or set of policies. Yet the easing of that burden is itself a major achievement as it permits the examination in greater depth of many more alternatives than would otherwise be possible and frees time and attention for the exercise of economic judgment.

Since the structure of the economic models presented here is explicit, it will be seen readily that they are "unrealistic", and this is a valid criticism of the GEMs. But that, of course, is also a valid criticism of any model or theory or any other approach to understanding an economy. Theories and models in every field of science are abstractions of reality and are necessary because of the complexity of reality in terms of both the intricacy and the quantitative magnitude of the interrelations. Yet, it is a mistake to think that the "commonsense" approach of the practical man to economic issues, though it can sometimes be quite successful, avoids the simplifications characteristic of economic theory. Indeed, when a pragmatic and commonsense approach is successful, this stems from the ability to isolate and reduce to their most relevant essence the relationships that are the key to the circumstances. However, when this is done at the level of intuition, it is neither reproducible by others nor verifiable, and acceptance of the insights becomes a matter of faith in the individual.

Because of the complexity of economic reality, it is not possible within the structure of a single formal model to analyze all the issues and policies that are important for development. The GEMs are, therefore, intended to be the first of a set of models that will be constructed for policy analysis for the Egyptian economy; they are useful for simple macroeconomic effective demand analysis and for the study of the macroeconomic and some limited microeconomic effects of expenditure, export and import and tax and subsidy policies affecting prices and factor returns, and distributional issues. The GEMs are also more useful for the investigation of price and factor return issues than most other types of planning models. In contrast, they are not well suited for the exploration of the growth implications of alternative resource allocations and investment policies, for which additional models will be developed.

The decision to begin with the GEMs is a matter partly of research strategy and partly of tactics. The Egyptian economy is widely regarded as characterized by a variety of goods and factor price distortions created by market imperfections and government interventions through taxes, subsidies, and direct regulation. These distortions, in turn, are often thought to be major barriers to the efficient use of intermediate and final products and primary resources although, at the same time, interventions may, to some extent, offset market distortions and help achieve distributive goals. In addition, the subsidies are widely considered to be a major drain on the government budget and, thus, an important, direct cause of government deficits, which are monetized and contribute to inflationary pressures. Again this may be an unwarranted attribution of responsibility which may be more properly placed on inadequate provisions for government revenues. In any case, there is a high priority for analyses, such as the GEMs provide, that can deal with this set of issues as compared to the more conventional models framed in terms of indices or measures of amounts of "physical" goods and resources without explicit consideration of price formation influences.

There are also tactical reasons for using the GEMs initially. They are relatively easy 
to compute as compared to, say, dynamic simulation or programming models, and much of the data necessary to implement them is more readily available.

Yet, the GEMs and, as importantly, the data that they embody, represent a major potential advance for economic policy-making in Egypt. Some of the data have never before been estimated and none of them have been organized into a consistent Social Accounting Matrix (SAM). Nor has an explicit model structure of this type ever been constructed for Egypt and the solutions computed. However, it is important to be modest in claims for the significance of the results, though insistent about the insights obtained. To assist in this, the model will be presented in detail, each relationship being described and then the whole structure and its operation reviewed.

The model relies heavily on the accounting relationships of the SAM. This is given in Table 1 and is discussed in more detail in Eckaus et al. (1979). The tabulation is a statement of the economic relations in the economy and to a large degree is value-free. Depending on how one perceives the economy, a suitable model may be developed. Inevitably such models imply value judgment and may be legitimately questioned. The general equilibrium structure proposed here should be viewed simply as one such perception of the economy.

\section{STRUCTURE OF THE GEM MODELS}

\subsection{GEM-1: Determination of a Consistent Set of Prices, Outputs, and Incomes}

The GEM-1 model can, perhaps, be thought of most readily as a multisector macroeconomic model that determines sectoral output levels and relative output prices, valueadded and factor incomes, and the distribution of total income among rural and urban groups and among income class sizes within each group. In addition, consumption and imports, as well as government revenues by major type are endogenously determined. This is done by exogenous specification of all the major components of final demand except consumption and imports, and a large number of other parameters as well. The latter fix the input-output ratios for intermediate uses of goods and services, the shares of labor, capital, and land in value-added in the various sectors as generated by a CobbDouglas production function, and a host of marginal consumption ratios, tax-income ratios, import ratios, and so on. A glance at Tables 2 and 3, which list the endogenously determined and the exogenously specified variables and parameters, respectively, will help to show the limits within which the formal model works. Again, however, by changing the exogenous specifications it is possible to explore a wide range of alternatives. One of the distinguishing features of the models is a relatively detailed accounting of government taxes and subsidies, tariffs, and government trading activity so that the various "wedges" between production costs and prices are taken into account.

The structure of the model is presented in Table 4 . The variables are defined in Tables 2 and 3 . To a considerable extent the model structure follows from the accounting presented in the Social Accounting Matrix (SAM) and consists largely of the identities in that matrix. The equations which create a descriptive theoretical model will be emphasized later.

There are eight blocks of equations and identities in GEM-1. Another block is 
TABLE 1 Social accounting matrix for Egypt, 1976 (millions of Egyptian pounds). ${ }^{a}$

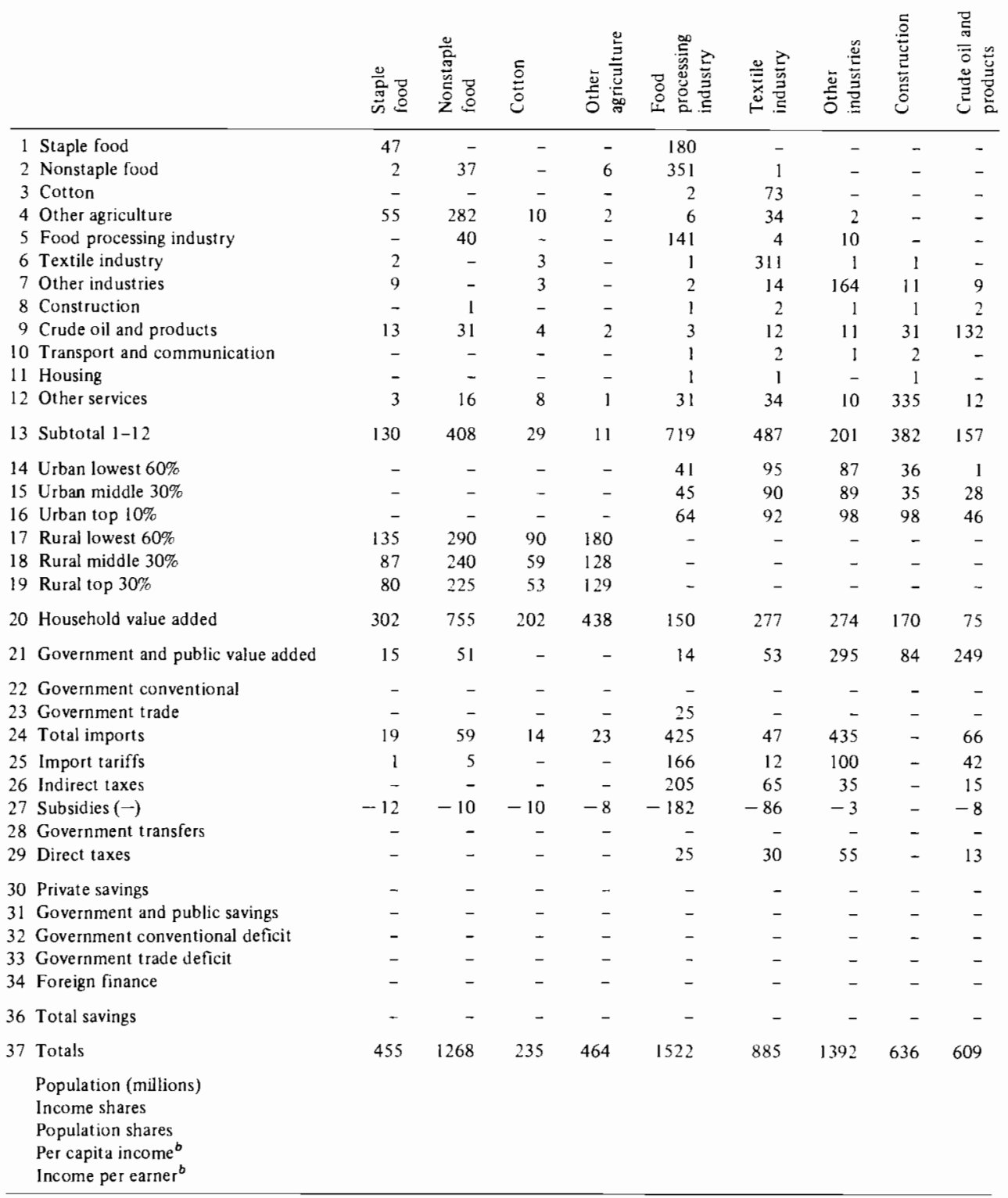

a Some totals do not add precisely due to rounding errors.

${ }^{b}$ Egyptian pounds per year. 
TABLE 1 (continued)

$\begin{array}{llllllllll}10 & 11 & 12 & 13 & 14 & 15 & 16 & 17 & 18 & 19\end{array}$

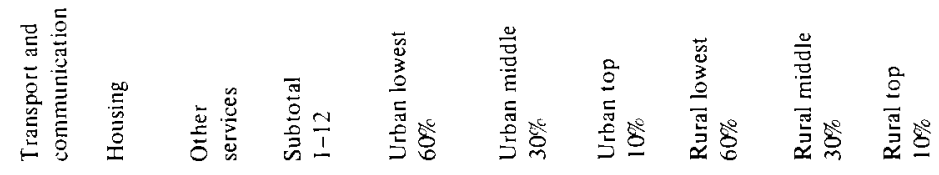

\begin{tabular}{|c|c|c|c|c|c|c|c|c|c|c|c|}
\hline 1 & Staple lood & 1 & - & 10 & 238 & 22 & 14 & 5 & 23 & 7 & 5 \\
\hline 2 & Nonstaple food & 1 & - & 18 & 416 & 180 & 187 & 111 & 114 & 66 & 53 \\
\hline 3 & Cotton & - & - & - & 75 & 2 & - & - & 2 & 1 & 1 \\
\hline 4 & Other agriculture & 1 & - & - & 392 & 14 & 16 & 12 & 7 & 4 & 2 \\
\hline 5 & Food processing industry & 2 & - & 93 & 290 & 325 & 275 & 140 & 235 & 101 & 71 \\
\hline 6 & Textile industry & - & - & 53 & 373 & 80 & 97 & 55 & 38 & 31 & 26 \\
\hline 7 & Other industries & 9 & - & 71 & 292 & 96 & 99 & 60 & 45 & 23 & 20 \\
\hline 8 & Construction & 9 & 6 & 14 & 37 & - & - & - & - & - & - \\
\hline 9 & Crude oil and products & 35 & - & 81 & 355 & 22 & 18 & 9 & 12 & 5 & 3 \\
\hline 10 & Transport and communication & 2 & - & 31 & 40 & 30 & 45 & 171 & 8 & 6 & 5 \\
\hline 11 & Housing & - & - & 6 & 10 & 17 & 39 & 55 & 4 & 4 & 8 \\
\hline 12 & Other services & 26 & 2 & 489 & 968 & 208 & 223 & 153 & 78 & 63 & 76 \\
\hline 13 & Subtotal $1-12$ & 87 & 8 & 867 & 3486 & 994 & 1015 & 772 & 565 & 311 & 268 \\
\hline 14 & Urban lowest $60 \%$ & 52 & 34 & 631 & 977 & - & - & - & - & - & - \\
\hline 15 & Urban middle $30 \%$ & 61 & 40 & 647 & 1035 & - & - & - & - & - & - \\
\hline 16 & Urban top $10 \%$ & 79 & 51 & 684 & 1212 & - & - & - & - & - & - \\
\hline 17 & Rural lowest $60 \%$ & - & - & - & 695 & - & - & - & - & - & - \\
\hline 18 & Rural middle $30 \%$ & - & - & - & 514 & - & - & - & - & - & - \\
\hline 19 & Rural top 30\% & - & - & - & 487 & - & - & - & - & - & - \\
\hline 20 & Household value added & 193 & 125 & 1962 & 4923 & - & - & 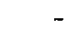 & - & - & - \\
\hline 21 & $\begin{array}{l}\text { Government and public value } \\
\text { added }\end{array}$ & 261 & 9 & 87 & 1118 & - & - & - & - & - & - \\
\hline 22 & Government conventional & - & - & - & - & - & - & - & - & - & - \\
\hline 23 & Government trade & - & - & - & 25 & 20 & 15 & 8 & 20 & 11 & 5 \\
\hline 24. & Total imports & 51 & - & 94 & 1208 & 57 & 64 & 103 & 48 & 42 & 28 \\
\hline 25 & Import tariffs & - & - & - & 326 & 10 & 11 & 18 & 8 & 7 & 5 \\
\hline 26 & Indirect laxes & - & - & 20 & 340 & 38 & 39 & 31 & 19 & 15 & 8 \\
\hline 27 & Subsidies $(-)$ & -15 & - & -12 & -346 & -64 & -48 & -24 & -13 & -10 & -10 \\
\hline 28 & Government transfers & - & - & - & - & 79 & 94 & 123 & - & - & - \\
\hline 29 & Direct taxes & - & - & 100 & 223 & 6 & 34 & 71 & 4 & 15 & 26 \\
\hline 30 & Private savings & - & - & - & - & -97 & -98 & 203 & 70 & 144 & 173 \\
\hline 31 & Government and public savings & - & - & - & - & - & - & - & - & - & - \\
\hline 32 & Gov. conventional deficit & - & - & - & - & - & - & - & - & - & - \\
\hline 33 & Governnent trade deficil & - & - & - & - & - & - & - & - & - & - \\
\hline 34 & Foreign linance & - & - & - & - & - & - & - & - & - & - \\
\hline 36 & Total savings & - & - & - & - & -97 & -98 & 203 & 70 & 144 & 173 \\
\hline 37 & Totals & 577 & 142 & 3118 & 11303 & 1043 & 1126 & 1305 & 721 & 535 & 503 \\
\hline & Population (nillions) & & & & & 12.798 & 6.399 & 2.133 & 10.139 & 5.069 & 1.690 \\
\hline & Income shares & & & & & 0.300 & 0.324 & 0.376 & 0.410 & 0.304 & 0.286 \\
\hline & Population shares & & & & & & 0.558 & & & 0.442 & \\
\hline & Per capita income ${ }^{b}$ & & & & & 81 & 176 & 612 & 71 & 106 & 298 \\
\hline & Income per earner ${ }^{b}$ & & & & & 261 & 563 & 1957 & 228 & 338 & 952 \\
\hline
\end{tabular}


TABLE 1 (continued)

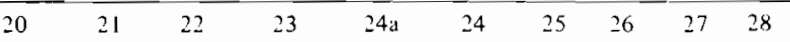

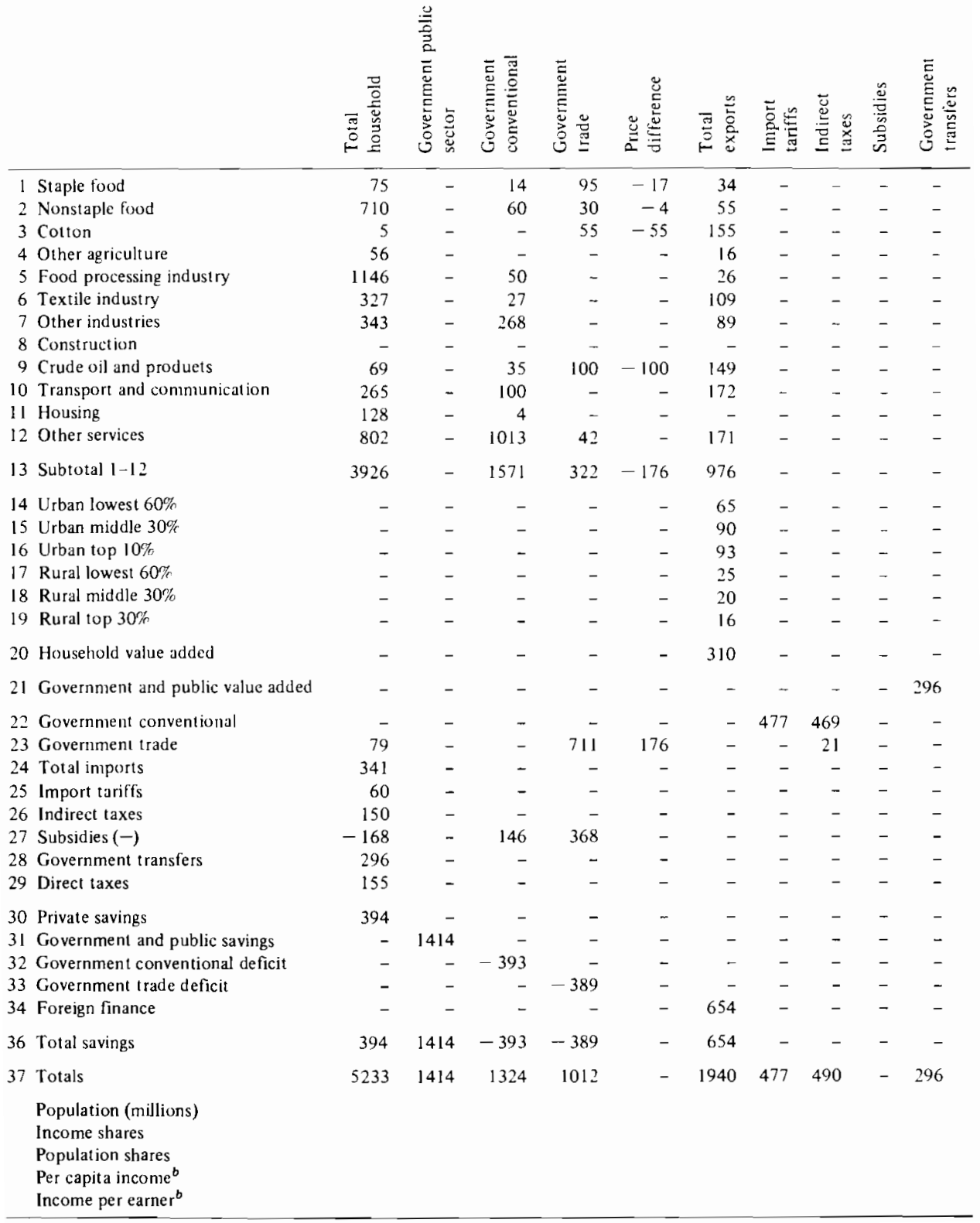


TABLE 1 (continued)

\begin{tabular}{|c|c|c|c|c|c|c|c|c|}
\hline & 志总芯 & 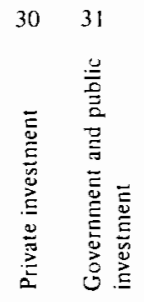 & 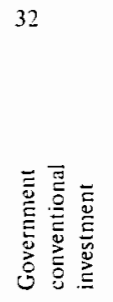 & 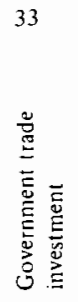 & 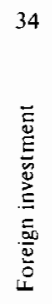 & 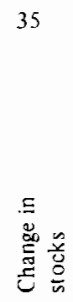 & 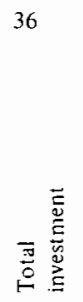 & $\frac{\frac{n}{\pi}}{\frac{\pi}{6}}$ \\
\hline 1 Staple food & - & & $=$ & & & 16 & 16 & 455 \\
\hline 2 Nonstaple food & - & & 1 & & & - & 1 & 1268 \\
\hline 3 Cotton & - & & - & & & - & - & 235 \\
\hline 4 Other agriculture & - & & - & & & - & - & 464 \\
\hline 5 Food processing industry & - & & - & & & 10 & 10 & 1522 \\
\hline 6 Textile Industry & - & & 3 & & & 46 & 49 & 885 \\
\hline 7 Other industries & - & & 360 & & & 40 & 400 & 1392 \\
\hline 8 Construction & - & & 599 & & & - & 599 & 636 \\
\hline 9 Crude oil and products & - & & - & & & 1 & 1 & 609 \\
\hline 10 Transporl and communication & - & & - & & & - & - & 577 \\
\hline 11 Housing & - & & - & & & - & - & 142 \\
\hline 12 Other services & - & & 122 & & & - & 122 & 3118 \\
\hline 13 Subtotal $1-12$ & - & & 1085 & & & 113 & 1198 & 11303 \\
\hline 14 Urban lowest $60 \%$ & - & & - & & & - & - & 1043 \\
\hline 15 Urban middle $30 \%$ & - & & - & & & - & - & 1126 \\
\hline 16 Urban top $10 \%$ & - & & - & & & - & - & 1305 \\
\hline 17 Rural lowest $60 \%$ & - & & - & & & - & - & 721 \\
\hline 18 Rural middle $30 \%$ & - & & - & & & - & - & 535 \\
\hline 19 Rural top $30 \%$ & - & & - & & & - & - & 503 \\
\hline 20 Household value added & - & & - & & & - & - & 5233 \\
\hline 21 Government and public value added & - & & - & & & - & - & 1414 \\
\hline 22 Government conventional & 378 & & - & & & - & - & 1324 \\
\hline 23 Government trade & - & & - & & & - & - & 1012 \\
\hline 24 Total imporis & - & & 391 & & & - & 391 & 1940 \\
\hline 25 Import tariffs & - & & 91 & & & - & 91 & 477 \\
\hline 26 Indirect taxes & - & & - & & & - & - & 490 \\
\hline 27 Subsidies $(-)$ & - & & - & & & - & - & - \\
\hline 28 Government transfers & - & & - & & & - & - & 296 \\
\hline 29 Direct taxes & - & & - & & & - & - & 378 \\
\hline 30 Private savings & - & & - & & & - & - & 394 \\
\hline 31 Government and public savings & - & & - & & & - & - & 1414 \\
\hline 32 Government conventional deficit & - & & - & & & - & - & -393 \\
\hline 33 Government trade deficil & - & & - & & & - & - & -389 \\
\hline 34 Foreign finance & - & & - & & & - & - & 654 \\
\hline 36 Total savings & - & & - & & & - & - & 1680 \\
\hline 37 Totals & 378 & & 1567 & & & 113 & 1680 & - \\
\hline $\begin{array}{l}\text { Population (millions) } \\
\text { Income shares } \\
\text { Population shares } \\
\text { Per capit a inconere } \\
{\text { Income per earne }{ }^{b}}^{b}\end{array}$ & & & & & & & & \\
\hline
\end{tabular}


TABLE 2 Endogenous variables.

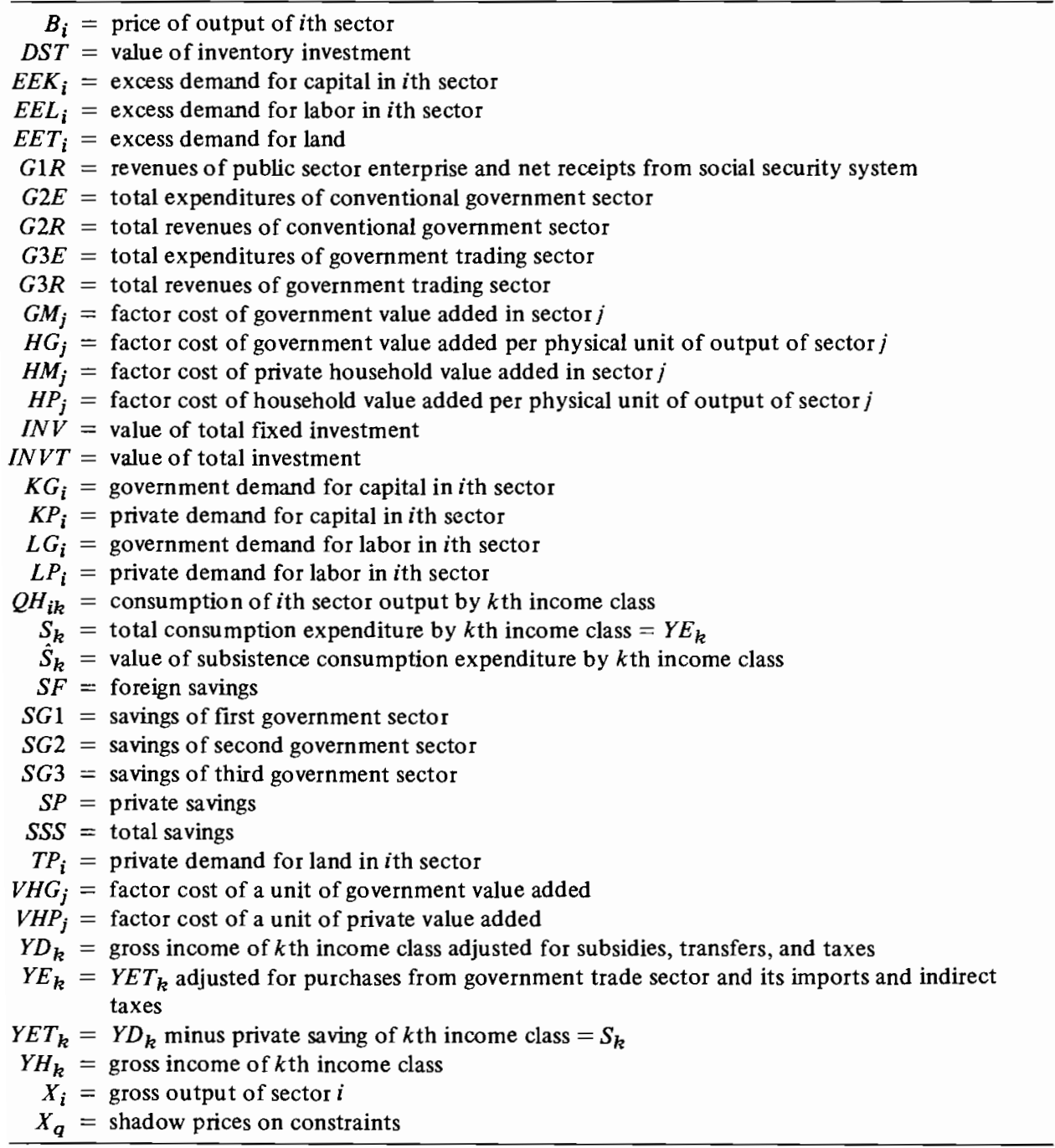

added for GEM-2 and still another to form GEM-3. Each block will be described separately. The equations are presented in Table 4.

\subsubsection{Input-Output Relations}

The twelve production accounting relations in eqn. (1.1) of Table 4 are identities that stand at the heart of the SAM. Essentially they read across each row of the twelve productive sectors and stipulate that the sum of the various uses of domestic output of that sector must be equal to the total domestic production of that output. The intermediate uses are $\sum_{j=1}^{12} a_{i j} X_{j}$, where the input-output coefficients $a_{i j}$ in this system are 
TABLE 3 Exogenous variables and parameters.

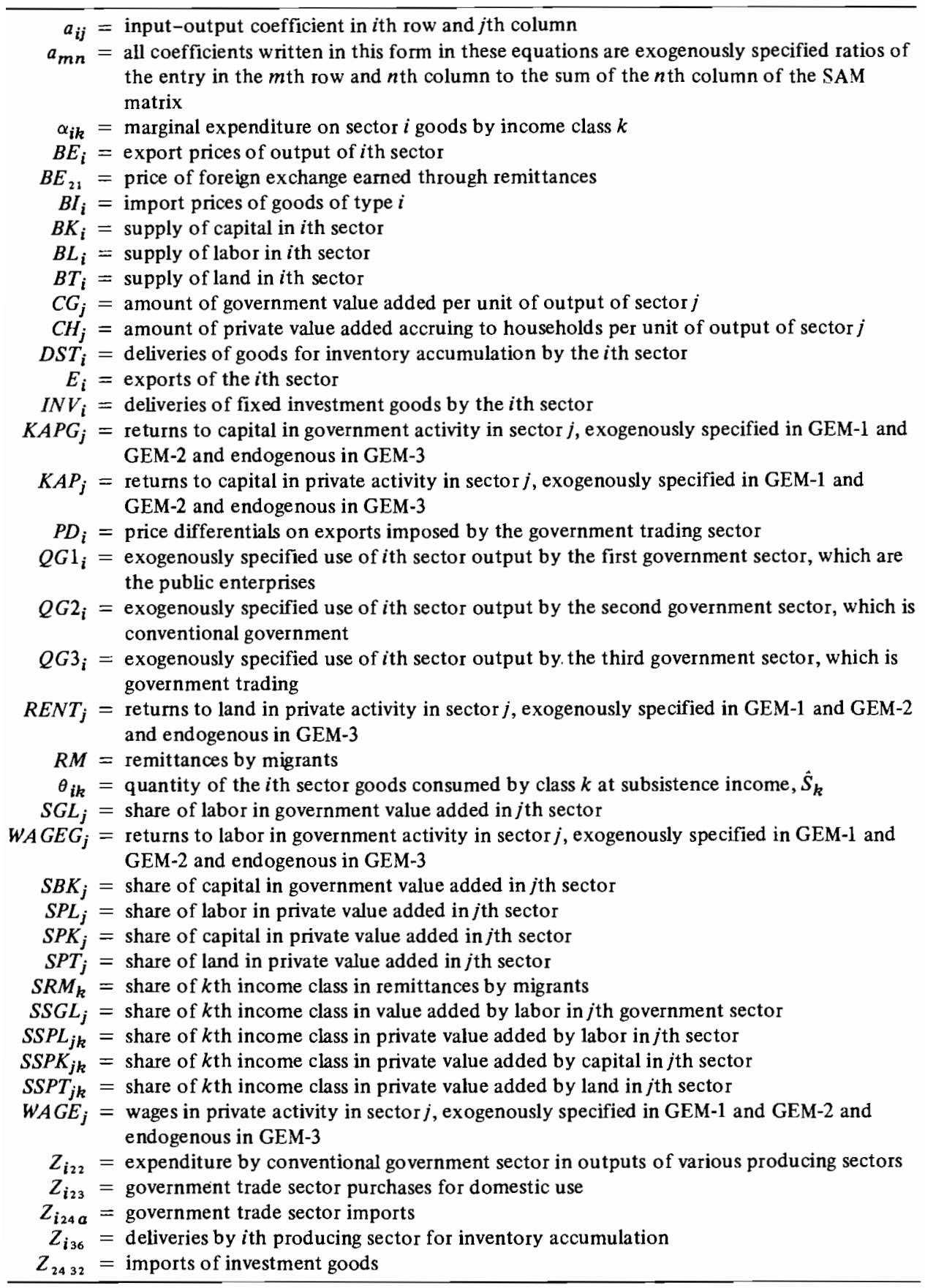


TABLE 4 Equations for the Egyptian general equilibrium models.

1. Input-output relations

$X_{i} \equiv \sum_{i=1}^{12} a_{i j} X_{j}+\sum_{k=1}^{6} Q H_{i k}+Q G 1_{i}+Q G 2_{i}+Q G 3_{i}+E_{i}+I N V_{i}+D S T_{i} \quad(i=1,2, \ldots, 12)$

2. Household consumption

$$
\begin{aligned}
\hat{S}_{k} & =\sum_{i=1}^{12} \theta_{i k} B_{i} & (i=1,2, \ldots, 12 ; k=1,2, \ldots, 6) \\
Q H_{i k} & =\theta_{i k}+\left(\alpha_{i k} / B_{i}\right)\left[S_{k}-\hat{S}_{k}\right] & (i=1,2, \ldots, 12 ; k=1,2, \ldots, 6)
\end{aligned}
$$

3. Price determination

$$
\begin{gathered}
B_{j}=\sum_{i=1}^{12} a_{i j} B_{i}+H P_{j}+H G_{j}+a_{23 j} B_{j}+a_{24 a j} B I_{j}+a_{24} B_{j}+a_{25 j} B I_{j}+a_{26 j} B_{j}+a_{27 j} B_{j}+a_{29 j} B_{j} \\
(j=1,2, \ldots, 12)
\end{gathered}
$$

4. Determination of value added by sector

$$
\begin{aligned}
& V H P_{j}=W A G E_{j}^{S P L_{j}} K A P_{j}^{S P K_{j}} R E N T_{j}^{S P T_{j}} \quad(j=1,2, \ldots, 12) \\
& S P L_{j}+S P K_{j}+S P T_{j}=1 \quad(j=1,2, \ldots, 12) \\
& H P_{j}=C H_{j} \cdot V H P_{j} \quad(j=1,2, \ldots, 12) \\
& H M_{j}=H P_{j} \cdot X_{j} \quad(j=1,2, \ldots, 12) \\
& V H G_{j}=W A G E G_{j}^{S G L_{j}} K A P G_{j}^{S B K_{j}} \quad(j=1,2, \ldots, 12) \\
& S G L_{j}+S B K_{j}=1 \quad(j=1,2, \ldots, 12) \\
& H G_{j}=C G_{j} \cdot V H G_{j} \quad(j=1,2, \ldots, 12) \\
& G M_{j}=H G_{j} \cdot X_{j} \quad(j=1,2, \ldots, 12)
\end{aligned}
$$

5. Income generation

$$
\begin{aligned}
Y H_{k}= & \sum_{i=1}^{12} H M_{j}\left[S P L_{j} \cdot S S P L_{j k}+S P K_{j} \cdot S S P K_{j k}+S P T_{j} \cdot S S P T_{j k}\right] \\
& \times \sum_{j=1}^{12} G M_{j}\left[S G L_{j} \cdot S S G L_{k}\right]+R M \cdot S R M_{k} \quad(k=1,2, \ldots, 6) \\
Y D_{k}= & {\left[1-a_{27 k}-a_{28 k}-a_{29 k}\right] Y H_{k} \quad(k=1,2, \ldots, 6) } \\
Y E T_{k}= & {\left[1-a_{30 k} Y H_{k} / Y D_{k}\right] Y D_{k} \quad(k=1,2, \ldots, 6) } \\
Y E_{k}= & {\left[1-\left(a_{23 k} B I+a_{24 a k} B I+a_{26 k}\right) Y H_{k / Y E T_{k}}\right] Y E T_{k} \quad(k=1,2, \ldots, 6) }
\end{aligned}
$$


TABLE 4 (continued)

6. Government expenditure and revenue

$$
\begin{aligned}
& G 1 R=\sum_{j=1}^{12} G M_{j} \cdot S G K_{j}+\sum_{k=1}^{6} a_{28 k} Y H_{k} \\
& G 2 E=\sum_{i=1}^{12} Z_{i 22} B_{i}-0.284\left[\sum_{j=1}^{12} a_{27 j} B_{j} X_{j}+\sum_{k=1}^{6} a_{27 k} Y H_{k}\right] \\
& G 2 R=\sum_{j=1}^{12} a_{25 j} B I_{j} X_{j}+0.324 \sum_{k=1}^{6} Q H_{24 b k} B I_{24 b}+0.2327 Z_{24 b, 36} B I_{24} \\
& +0.957\left[\sum_{j=1}^{12} a_{26 j} B_{j} X_{j}+\sum_{k=1}^{6} a_{26 k} Y H_{k}\right]+\sum_{j=1}^{12} a_{29 j} B_{j} X_{j}+\sum_{k=1}^{6} a_{29 k} Y H_{k} \\
& G 3 E=\sum_{i=1}^{12} Z_{i 23} B_{i}+\sum_{j=1}^{12} a_{24 a j} B I_{j} X_{j}+\sum_{k=1}^{6}\left(a_{23 k}+a_{24 a k}\right) Y H_{k} \\
& -0.716\left[\sum_{j=1}^{12} a_{27 j} B_{j} X_{j}+\sum_{k=1}^{6} a_{27 k} Y H_{k}\right]+\sum_{i=1}^{12} Z_{i 23 a} \cdot B_{i} \\
& G 3 R=\sum_{j=1}^{12} a_{24 a j} B I_{j} X_{j}+\sum_{k=1}^{6} a_{24 a k} Y H_{k}+\sum_{k=1}^{6} a_{23 k} Y H_{k}+a_{23,5} B I_{5} X_{5}+\sum_{i=1}^{12} Z_{i 23} B E_{i} \\
& +0.043\left[\sum_{j=1}^{12} a_{26} B_{j} X_{j}+\sum_{k=1}^{6} a_{26 k} Y H_{k}\right] \sum_{i=1}^{12} Z_{i 23 a} \cdot B I \\
& P D=\sum_{i=1}^{12} Z_{i 23 a}\left(B E_{i}-B_{i}\right)
\end{aligned}
$$

7. Exports and imports

$$
\begin{aligned}
E X P & =\sum_{i=1}^{12} Z_{i 24} B E_{i}+R M B E_{20} \\
I M P & =\sum_{j=1}^{12} a_{24 a j} B I_{j} X_{j}+\sum_{k=1}^{6} a_{24 a k} Y H_{k}+\sum_{j=1}^{12} a_{24 b j} B I_{j} X_{j}+0.676 \sum_{k=1}^{6} Q H_{24 b k} B I_{26}+Z_{24,32} B I_{32}
\end{aligned}
$$

8. Savings and investment

$$
\begin{aligned}
S P & =\sum_{k=1}^{6} a_{30 k} Y H_{k} \\
S G 1 & \equiv G 1 R-G 1 E
\end{aligned}
$$


TABLE 4 (continued)

\begin{tabular}{|c|c|c|}
\hline \multicolumn{2}{|l|}{$S G 2 \equiv G 2 R-G 2 E$} & $(8.3)$ \\
\hline \multicolumn{2}{|l|}{$S G E \equiv G 3 R-G 3 E$} & (8.4) \\
\hline \multicolumn{2}{|l|}{$S F \equiv I M P-E X P$} & (8.5) \\
\hline \multicolumn{2}{|c|}{$S S S \equiv S P+S G 1+S G 2+S G 3+S F$} & (8.6) \\
\hline \multicolumn{2}{|c|}{$I N V=\sum_{i=1}^{12} I N V_{i} B_{i}+1.232 Z_{24,32} B I_{32}$} & (8.7) \\
\hline \multicolumn{2}{|l|}{$D S T=\sum_{i=1}^{12} Z_{i, 35} B_{i}$} & (8.8) \\
\hline \multicolumn{2}{|l|}{$I N V T \equiv I N V+D S T$} & (8.9) \\
\hline \multicolumn{2}{|l|}{$S S S=I N V T$} & $(8.10)$ \\
\hline \multicolumn{3}{|l|}{ 9. Resource demands } \\
\hline$L P_{i}=S P L_{i} H M_{i} / W A G E_{i}$ & $(i=1,2, \ldots, 12)$ & $(9.1)$ \\
\hline$K P_{i}=S P K_{i} H M_{i} / K A P_{i}$ & $(i=1,2, \ldots, 12)$ & $(9.2)$ \\
\hline$T P_{i}=S P T_{i} H M_{i} / R E N T_{i}$ & $(i=1,2, \ldots, 12)$ & (9.3) \\
\hline$L G_{i}=S G L_{i} G M_{i} / W A G E G_{i}$ & $(i=1,2, \ldots, 12)$ & (9.4) \\
\hline$K G_{i}=S G K_{i} G M_{i} / K A P G_{i}$ & $(i=1,2, \ldots, 12)$ & $(9.5)$ \\
\hline \multicolumn{3}{|l|}{ 10. Resource constraints } \\
\hline$E E L_{i}=L P_{i}-B L_{i}$ & $(i=1,2, \ldots, 12)$ & $(10.1)$ \\
\hline \multicolumn{2}{|l|}{$E E K_{i}=L K_{i}-B K_{i}$} & $(10.2)$ \\
\hline \multicolumn{2}{|l|}{$E E T=\sum_{i=1}^{4} L T_{i}-\sum_{i=1}^{4} B T_{i}$} & (10.3) \\
\hline
\end{tabular}

specified exogenously but can be varied parametrically to reflect technical changes. The use of output of each sector for consumption is $\Sigma_{k=1}^{6} Q H_{i k}$, where $k$ refers to the six personal income classes that are distinguished in the model, as noted in the SAM, Table 1. $Q G 1_{i}, Q G 2_{i}$, and $Q G 3_{i}$ are the deliveries to the three types of government sectors that are distinguished. However, since all productive public enterprises in $G 1$ are absorbed in the producing sectors, there are no final deliveries to this sector. $E_{i}$ are the exports of each sector. In some sectors all or part of the exports are traded by government, which realizes a price differential $P D_{i}$ on the exports. There is scope in the SAM for distinguishing deliveries of fixed investment to different types of purchase rs, but this distinction has not 
yet been successfully implemented so all the investment goods delivered by each sector are aggregated into $I N V_{i}$. The change in stocks contributed by each sector is similarly aggregated in to $D S T_{i}$. Of the uses of output of each sector, only the intermediate and private consumption demands are endogenous and require explanation. All other uses are specified exogenously.

This is a conventional specification of the uses of final demand, except that, in this accounting scheme, all imports are treated as if they were noncompetitive imports. Thus, the intermediate flows in the input-output table do not include the allocation of imports defined by sector to each sector that uses them. As a result, it is not necessary to subtract imports from final demands in order to obtain only the gross domestic production of each sector.

\subsubsection{Private Consumption}

The determination of private consumption is endogenous to the model and follows the linear expenditure system suggested by Stone (1954); see also Lluch et al. (1977). For each income class, $k$, a base level of total consumption expenditure, $\hat{S}_{k}$, is estimated in eqn. (2.1) of Table 4, which can be interpreted as a subsistence level that is independent of both price and income effects. The $\hat{S}_{k}$ term is a price-weighted sum of amounts of commodities $\theta_{i k}$ consumed independently of price and income effects. Then the actual expenditure on consumption of the output of each sector by each income class is computed from eqn. (2.2) of Table 4 as the sum of the commodities $\theta_{i k}$ and the product of a marginal expenditure share, normalized by price, $\alpha_{i k} / B_{i}$, times the difference between total expenditure $S_{k}\left(=Y E T_{k}\right)$ by class $k$ and $\hat{S}_{k}$.

\subsubsection{Price Determination}

Output prices are determined in this model essentially on a markup based on valueadded in each sector in eqn. (3.1) of Table 4. For each sector, $j$, all the costs of intermediate inputs are first added up. These are $\sum_{i=1}^{12} a_{i j} B_{i}$, where the $B_{i}$, again, are sectoral prices. These costs are added to private value-added per unit of output, $H P_{i}$, and government value-added per unit of output, $H G_{i}$. Then each of the contributions to unit costs deriving from domestic government trade $a_{23 j} B_{j}$, government trade imports, $a_{24 a j} B I_{j}$, where $B I_{j}$ are exogenously specified import prices, other imports, $a_{24 b j} B I_{j}$, and import tariffs, $a_{25 j} B I_{j}$, are added. The costs of indirect taxes, $a_{26 j} B_{j}$, are also added and government subsidies per unit, $a_{27 j} B_{j}$, are subtracted. Any direct taxes on sectoral output, $a_{29 j} B_{j}$, are included. The $a_{m j}$ terms are parameters specified as ratios of the values of the various concepts in the $m j$ box in the SAM matrix to total output of the $j$ th sector, but can be changed exogenously.

\subsubsection{Determination of Value-Added by Sector}

The cost of a unit of value-added in each producing sector is computed separately for the private and government sectors. The computation is based on the assumption of the use of primary factors in Cobb-Douglas production functions so that costs can be computed from the corresponding cost functions, eqns. (4.1) and (4.4) of Table 4. The shares of households in value-added in private and government production, $\mathrm{CH}_{j}$ and $C G_{j}$, in each sector are used in eqns. (4.2) and (4.5) of Table 4 to determine the household value-added per unit of output in each sector. This in turn is multiplied by the total 
output in each sector, $X_{j}$, to obtain the total household value-added in private production and government activity in each sector $j$.

The use of the Cobb-Douglas production function with its accompanying assumption of constant returns to scale and constant factor shares is, of course, open to skeptical questioning as a general procedure for developing or even advanced countries. Moreover, the use of that production function to derive a cost function as shown assumes competitive markets for primary resources. This is also clearly an assumption that is not generally warranted, but especially not in developing countries. However, in a static model intended only to investigate the significance of alternative policies within a limited range of alternatives, the Cobb-Douglas production function device is not only plausible but realistic. Also the assumption of competitive resource markets is not particularly critical for small policy changes as the initial distributions of value-added among resources can be specified exogenously.

\subsubsection{Income Generation and Definition}

The gross income earned by each class, $Y H_{k}$, is computed from eqn. (5.1) in Table 4 by calculating the shares of each income class in value-added in each sector. Private value-added in each sector, $H M_{j}$, is decomposed into returns to labor, capital, and land, using the share ratios for each sector $S P L_{j}, S P K_{j}$, and $S R T_{j}$. The shares of each income class in those returns are calculated using the income class share ratios $S S P L_{k}, S S P K_{k}$, $S S P T_{k}$. Only the labor share in government value-added in each sector, $G M_{j}$, is calculated as part of household income using the labor-share ratio $S G L_{i}$. Then that labor share is distributed among income classes using the share of each class in government labor income, $S S G L_{k}$. In addition, total remittances $R M$ are distributed among income classes using a class share ratio $S R M_{k}$.

A gross disposable income concept for each income class is calculated in eqn. (5.2) of Table 4 by using ratios that add subsidies $a_{\mathbf{2 7 , 2 0}}$, subtract transfers $a_{\mathbf{2 8}, 20}$, which are net payments to the social security system, and subtract direct taxes $a_{29,20}$.

In eqn. (5.3) of Table 4 the amount left for expenditure after deduction of savings, determined by the ratio $a_{30,20}$, is calculated. And finally, in eqn. (5.4) of Table 4, the net total private expenditure by each income class is calculated after subtracting the expenditure on government-traded goods, the value of expenditure on government-traded imports, and the indirect taxes paid by each class as determined by the appropriate ratios.

\subsubsection{Government Expenditure and Revenue}

The government sector as reported in the SAM is divided into three categories: $G-1$, mainly publicly owned productive enterprise; $G \cdot 2$, the conventional government sector; and $G-3$, the government trading or supply sector involving purchase and sale of commodities.

$G-1$, the public enterprise sector, has no expenditures, as these are all incorporated in the sector in which the enterprises are located. The revenues of the public enterprise sector $G 1 R$, calculated in eqn. (6.1) of Table 4, are, first of all, the eamed surpluses, which are computed by multiplying the value-added in that sector, $G M_{j}$, by the share retained by the enterprise, $S B K_{j}$, and summing over all productive sectors. For convenience, the net payments to the social security system are also included in the revenues of this sector. These payments are the product of the payments per unit of gross income by 
each income class, $a_{28, k}$, times the gross income of each income class, $Y H_{k}$, summed over all income classes.

$G 2 E$, the expenditures by the conventional government sector, in eqn. (6.2) of Table 4, include the value of the expenditures on the output of the various producing sectors $\sum_{i=1}^{12} Z_{i 22} B_{i}$ plus that part of the net subsidies paid by this conventional government sector. These subsidies are listed as negative items in the SAM so are preceded by a minus sign to convert them into positive expenditures. The total subsidies paid are the sum of the subsidies paid to each producing sector $\Sigma_{j=1}^{12} a_{27 j} B_{j} X_{j}$, where the coefficients $a_{27 j}$ are the subsidy rates, plus the subsidies paid to the household sector $\Sigma_{k=1}^{6} a_{27, k} Y H_{k}$, where the coefficients $a_{27, k}$ are the subsidy rates. Of this total, $28.4 \%$ is paid by the conventional government sector and included in its expenditures.

The revenues of the conventional government sector in eqn. (6.3) of Table 4 are the returns from the various taxes. The first are the tariffs on imports of intermediate goods by the various producing sectors $\sum_{j=1}^{12} a_{26 j} B I_{j} K_{j}$, where the coefficients $a_{25 j}$ are the tariff rates and the $B I_{j}$ terms are the import prices. To this are added tariffs paid on imports by the household sector which are $\Sigma_{k=1}^{6} Q H_{24 b k} B I_{24 b}$ for which the average tariff rate is 0.324 . Then the tariffs raised on imports of investment goods, $A_{24 b, 36}$, is added at the average rate of 0.2327 .

The second type of revenue source is indirect taxes. The indirect tax rates, $a_{29, j}$, in each sector are multiplied by the value of each sector's output and summed for all sectors. Similarly the average indirect tax rates applied on consumer expenditure of each income class, $a_{26 k}$, are applied to the gross income of that class. However, only $95.7 \%$ of these are received by this sector; the remainder, as will be seen, are recorded as revenue to the government trade sector.

Finally, direct taxes are paid by the producing sectors at the rates $a_{29 j}$ and by the various income classes at the rates $a_{29 k}$. So these rates are applied to the corresponding output or income concepts.

The expenditures of the government trading sector $G 3 E$ in eqn. (6.4) of Table 4 again have a number of components. The first is the sum of purchases by this component of government of the output of the various producing sectors $\left\{\sum_{i=1}^{12} z_{i 23} B_{i}\right\}$. The next component is the sum of imports by this sector, $\left\{\Sigma_{j=1}^{12} a_{24 a j} B I_{j} X_{j}\right\}$, where these are valued at import prices, $B I_{j}$. As will be seen, this is offset by a corresponding revenue to the sector, reflecting sales to the private sectors. Next must be added the sum of imports by this sector on behalf of consumers, $\sum_{k=1}^{6} a_{24 a k} Y E T_{k}$, which will again be recorded as revenues when sold to consumers. The total subsidies are computed again, as for the conventional government sector, and $76.1 \%$ of these are paid by this government trading sector. Finally, expenditures on domestic goods supplied to consumers are $\Sigma_{k=1}^{6} a_{23 k} Y E T_{k}$.

The revenues of the government trading sector are first of all the imports by this sector sold to the producing sectors and consumers $\sum_{j=1}^{12} a_{24 a j} B I_{j} X_{j}+\sum_{k=1}^{6} a_{24 a k} Y H_{k}+$ $\sum_{k=1}^{6} a_{23 k} Y H_{k}$. There is also a revenue from direct sales to the food-processing sector, $a_{23,5} B I_{5} X_{5}$. The revenue from direct exports by government are the sum of the exports of the first, second, and third sectors, 17,2, and 100, respectively, valued at their domestic prices. With the latter initialized at unity, the total is 119 , as in the SAM, row 23 column 24a. The $4.3 \%$ of indirect taxes collected by this sector are entered next.

Finally, the price differentials collected by this government sector on certain exports are added; as these are calculated as negative numbers, they are preceded by a minus 
sign. These price differentials, calculated in eqn. (6.6) of Table 4 , arise because of the difference between the domestic price $B_{j}$, at which the government trading sector buys some part of the output of sectors $1,2,3$, and 9 , and the export price, $B E_{j}$, at which it sells. The particular items are, by sector, rice, onions, cotton, and oil products, respectively. The particular quantities of each export are multiplied by the price differential. The export prices of the items in the various sectors are set at 2,3,1.55, and 3.041 times the initialized price of unity in the respective domestic sectors.

\subsubsection{Exports and Imports}

The first term in the export eqn. (7.1) of Table 4 is the sum of the exports of the various producing sectors valued at their export prices, $\Sigma_{j=1}^{12} A_{i 24} B E_{i}$. The remittances of Egyptian workers abroad is entered here, $R M B E_{20}$, as a foreign exchange earning by a domestic factor.

It should be noted again that all imports are treated as if they were noncompetitive. The first term in the import equation is $\sum_{j=1}^{12} a_{24 a j} B I_{j} X_{j}$, the sum of the imports of each sectoral type by the government trading sector, which was entered as an expenditure by that sector. The second term is the sum of consumption goods imports by the government trading sector for the various income classes $\Sigma_{k=1}^{6} a_{24 a k} Y H_{k}$, which was also an expenditure by that sector. The direct imports for the various producing sectors is the sum $\sum_{j=1}^{12} a_{24 b j} B I_{j} X_{j}$. The imports by the household sector itself are $\sum_{k=1}^{6} Q H_{24 b k} B I_{24 b}$. But only $125 / 185$ of that is the c.i.f. value of the imports, the remainder $(60 / 185)$ being tariff duties. The final term, $Z_{24,32} B I_{32}$, is the value of imports of investment goods.

\subsubsection{Savings and Investment Relations}

Total saving $S S S$ (in eqn. 8.6 of Table 4 ) is the sum of saving by households, $S P$, saving by the various government sectors, $S G 1, S G 2$ and $S G 3$, and foreign saving, $S F$. Household saving (eqn. 8.1 of Table 4) is computed by applying savings coefficients to gross household income, $\Sigma_{k=1}^{6} a_{30 k} Y H_{k}$. Saving by each type of government is defined in eqns. (8.2), (8.3), and (8.4) of Table 4 as the difference between its revenues and expenditures. Foreign saving in eqn. (8.5) of Table 4 is the difference between imports and exports.

Total fixed investment in eqn. (8.7) of Table 4 is the sum of the deliveries of investment by the various sectors $\sum_{i=1}^{12} Z_{i 32} B_{i}$ plus the imported investment good valued at import prices, the latter being "inflated" by the proportion of import tariffs in the tota] value of imported investment goods, $Z_{24,32} B I_{32}(1.232)$. All of the physical values are specified exogenously.

The change in inventories in each sector is also specified exogenously as $Z_{i, 35}$ but the value is computed by multiplying by the price in eqn. (8.8) of Table 4 .

Total investment, $I N V T$, is the sum in eqn. (8.9) of Table 4 of fixed investment and inventory investment.

Finally, the equilibrium and balance condition for GEM-1 is that total saving must be equal to total investment, as given by eqn. (8.10) of Table 4 .

\subsubsection{Overview of GEM-I}

As is now apparent after this review of the identities and equations that make up the structure of GEM-1, this is a static consistency model. It contains exogenous demand 
and factor share specifications, the assumption of Cobb-Douglas production and cost functions, price markup assumptions, and assumed constancy for a number of inputoutput, consumption, tax, import, and other ratios. If there were only two goods and one class of income recipients, GEM-1 would appear to be a rather simple model of consistent price and output determination with a detailed accounting of government sector activities. With a number of sectors and a number of classes of income recipients, the model gains considerably in richness as the assumptions implicit in more aggregated models, of constancy in the relative proportions of the outputs of the sectors and of income distribution and consumption proportions, can be dropped. Nonetheless, GEM-1 remains solely a model of consistent price and output determination.

It may be useful to note the differences between the conventional input-output models and GEM-1 : the latter is closed on the output side by the endogenous determination of consumption and import requirements, instead of these being exogenously specified. Also, the assumption of Cobb-Douglas production functions for the use of primary resources, with the additional assumption of competition in the factor markets, makes it possible to determine the cost of value-added per unit of output in the various sectors. Then, with factor shares and income class shares in value-added assumed to be constant, this in tum not only permits the determination of prices, assuming that they are equal to the costs of intermediate inputs and value-added, but also the distribution of incomes. The detailed accounting of government taxes and expenditures is extended by the assumption of constancy of tax/income or tax/output ratios to permit the calculation of the effects of various policies on government revenues or the calculation of the effects of changes in government tax and expenditure policies, as embodied in tax ratios and sectoral expenditure levels. Import, export, and sectoral investment policies can be analyzed similarly to determine their effects on output levels, consumption and import levels, prices, and other endogenous variables.

\subsection{Overview of GEM-2}

This model, as indicated previously, is a small extension of GEM-1 in that the demands for the various resources are calculated from the solutions of GEM-1. The results of this calculation can then be compared with the available resources as a basis for judgment about the feasibility of a solution. It should be emphasized that the model itself does not force a feasible solution but remains a consistency model only. However, it does provide additional information with which to judge feasibility.

The demands for the various resources in the various producing sectors are calculated by dividing the total retums of each resource by their rate of retum. This is done by specifying parametrically the shares in value-added for each type of factor, labor, capital, and land, in each of the private sectors and the public sector, separately. These parameters are $S P L_{i}, S P K_{i}$, and $S P T_{i}$ for the private sector and $S G L_{i}$ and $S G K_{i}$ for the public sector. Multiplying these parameters by total value-added in each sector, $H M_{i}$ and $G M_{i}$, and dividing by the nominal wage rate, capital services return, and land rental, $W A G E_{i}$, $K A P_{i}, R E N T_{i}$, for the private sector and the corresponding rates for the public sector, $W A G E G_{i}$ and $K A P G_{i}$, provides estimates of resource demands. These calculations are done in eqns. (9.1)-(9.6) of Table 4. 


\subsection{Overview of GEM-3}

In the GEM-3 version of the model, resource constraints are applied and must be satisfied by the solution. The constraints are written separately for labor, capital, and land and there is actually considerable flexibility in the manner of their specification. The equations in section 10 of Table 4 represent one possible set only.

Equation (10.1) of Table 4 says the excess demand for labor in each sector is equal to the actual demand, $L P_{i}$, minus the exogenously specified sectoral supply. Alternatively this could be written in terms of demands and supplies of private and government demands and supplies in total or by sectors, implying some lack of substitutability, or even in terms of particular types of labor in one or more of the sectors.

Equation (10.2) of Table 4 is an analogous constraint on capital. It would be possible to respecify this in order to account for excess capacity in the various sectors. Again, private and government demands and supplies of capital could be distinguished in the various sectors and it would be possible to add demands and supplies of capital in sectors, perhaps those in agriculture, where there is substitutability.

Equations (10.3) and (10.4) of Table 4 specify alternative versions of the land constraint. In eqn. (10.3) of Table 4 the demands and supplies for land in $n$ sectors are added, implying substitutability. In eqn. (10.4) of Table 4 the demands and supplies of each sector are treated separately. It should be noted that, in calculating land demands and supplies, account must be taken not only of the potentials for multiple-cropping but also the constraints of crop rotation.

In order to adjust to the resource constraints, GEM-3 will change the proportions in which primary factors are used in the various types of production. That is, the specification of the Cobb-Douglas production function makes it possible for substitution to occur among labor, capital, and land, with corresponding changes in wages, the rate of return to capital, and rents. In turn, that will change the proportions of value-added in the various sectors, the income generated, and the distribution of income. Similarly, prices of the outputs of the various sectors will change and the effects will run through the entire system. Thus the solution to the model in all of its aspects will adjust to the relative availabilities of the various primary resources.

It should be noted that, while relative factor prices respond to relative factor availabilities, the absolute levels of prices and incomes are set by the macroeconomic condition that savings equal investment. It is tempting but inaccurate to fall into the habit of thinking of product and factor prices and incomes as being set by market forces of supply and demand, when it is the overall equality of savings and investment that moves the system into a consistent equilibrium.

It should be emphasized that GEM-3 is still a static model, so that different solutions represent alternatives, rather than temporal changes. However, if the exogenously specified resource supply constraints and other conditions are given a temporal interpretation, then the alternative solutions generated can also be given such an interpretation. However, GEM-3 will still only indicate the characteristics of the feasibility conditions of the constraints imposed, and not whether the constraints themselves, for example the supply constraints on labor or capital, are plausible.

Nonetheless, GEM-3 is a model with considerable richness in the range of issues that it permits to be analyzed and should make a useful contribution to policy-making in Egypt. 


\subsection{Introduction}

To arrive at an estimate of income distribution in Egypt it was first necessary to distinguish the income classes among which the income is to be distributed. It was decided that it is most appropriate for Egyptian conditions to divide the society into six income classes, three rural and three urban. In both cases they represent the lowest $60 \%$, the middle $30 \%$, and the top $10 \%$. This division was preferred to two other widely used divisions: the lowest $80 \%$ and top $20 \%$; and the lowest $40 \%$, middle $40 \%$, and top $20 \%$. The first of these latter divisions combines heterogeneous socioeconomic groups into a single unit, while the second disguises to a great extent the skewed pattern of income distribution.

To arrive at the distribution of income among the six socioeconomic classes two types of information were needed. First the factor shares in value-added are required for both the public and private sectors. The income earned in the public sector was divided generally in to two types of factor shares, labor and capital, in order to obtain the share of public labor and share of public capital, $S B L$ and $S B K$, respectively. In the private sector, value-added in the first four agricultural sectors was divided into three shares, i.e., the share of labor, the share of capital, and the share of rent. Private value added in the other private sectors was divided only into two shares, those of labor and capital.

The second step is to estimate the share of each of the six income classes in the three types of factor shares of the private sector and in the share of labor in the public sector, so giving public wages. The share of each class in the different factor shares was denoted by $S S P L_{i k}, S S P K_{i k}, S S P T_{i k}, S S G L_{i k} . k$ indexes the income classes from 1 to $6 ; i$ is the productive sector concerned; $P$ refers to private activity in sector $i$, and $G$ to government activity.

Thus, the income received by each of the six classes is:

$$
\begin{aligned}
Y H_{k}= & \sum_{i=1}^{12} H M_{i}\left[S P L_{i} S S P L_{k}+S P K_{i} S S P K_{k}+S P T_{i}(I) S S P T_{k}\right] \\
& +G M_{i}\left[S G L_{i} S S G L_{k}\right]+R M\left[S R M_{k}\right]
\end{aligned}
$$

where

$Y H_{k}=$ gross income of class $k$,

$H M_{i}=$ private value-added of sector $i$,

$G M_{i}=$ government value-added of sector $i$,

$R M=$ remit tances from Egyptian workers abroad, and

$S R M_{k}=$ the share of class $k$ in worker remit tances.

\subsection{Estimation of Value-Added and Household Income by Producing Sector}

To arrive at the distribution of income among the six classes, it was necessary to estimate gross household income. This was defined in the present study as value-added 
generated in the private sector plus wages generated in both the government and the public sectors. This required: data on value-added in the twelve sectors in the SAM (Table 1), divided between the private and public sectors; division of value-added in each sector and within each category, private and public, between wages and nonwage components; and addition of the wage component of the public sector value-added to private value-added to arrive at the household income for each sector.

The data for 1976 value-added were obtained from the followup report of 1976 of the Ministry of Planning, Department of National Accounts (CAPMAS, 1976a). The data were originally for eight different sectors. But with the help of data from the Census of Industrial Production and from an estimation of agricultural income from the Ministry of Agriculture (CAPMAS, 1978), the data were disaggregated into the twelve sectors of the input-output matrix shown in Table 5.

TABLE 5 Value-added, public and private, by economic sectors, 1976 (million Egyptian pounds).

\begin{tabular}{lcrr}
\hline Sector & Public & Private & Total \\
\hline 1. Staple food & 28 & 289.0 & 317.0 \\
2. Nonstaple food & 74 & 731.9 & 805.9 \\
3. Cotton & - & 202.0 & 202.0 \\
4. Other agriculture & - & 438.0 & 438.0 \\
5. Food processing & 30.4 & 133.6 & 164.0 \\
6. Textiles & 169.3 & 160.7 & 330.0 \\
7. Other industries & 459.5 & 109.5 & 569.0 \\
8. Construction & 178.3 & 75.7 & 254.0 \\
9. Crude oil and related products & 266.1 & 57.9 & 324.0 \\
10. Transport and communication & 425.8 & 28.2 & 454.0 \\
11. Housing & 10.1 & 123.9 & 134.0 \\
12. Other services & 956.0 & 1093.0 & 2049.0 \\
\hline
\end{tabular}

The second step was to divide the value-added in each sector into the wage and nonwage components. These data on wage by sector were available from the Ministry of Planning. By adding wages generated in the government and public sector to the private value-added in each sector, the domestically earned household income was obtained for each sector as shown in Table 6.

To domestically earned household income the 310 million Egyptian pounds of remittances were added, treating these as household exports or factor income earned abroad. Thus, the total income of the household sector becomes 5233 million Egyptian pounds. This is shown in row 20, column 37 in the SAM (Table 1).

\subsection{Factor Shares in Value-Added}

The next step is to explain the estimation of the shares in each economic sector and then the share of each income class in each factor share. For the first four production sectors three factor shares, labor, land, and capital, had to be estimated. Information was 
TABLE 6 Household income by sector, 1976.

\begin{tabular}{lc}
\hline Sector & Household income \\
\hline 1. Staple food & 302 \\
2. Nonstaple food & 755 \\
3. Cotton & 202 \\
4. Other agriculture & 438 \\
5. Food processing & 150 \\
6. Textiles & 277 \\
7. Other industries & 274 \\
8. Construction & 170 \\
9. Crude oil and related products & 75 \\
10. Transport and communication & 193 \\
11. Housing & 125 \\
12. Services & 1962 \\
Total & 4923 \\
\hline
\end{tabular}

obtained on the area cultivated for each crop, the output of that crop in 1976, and prices per unit of output in 1976. These data were secured from the Ministry of Agriculture, Department of Economics and Statistics. With these data it was possible to estimate the value of gross production for each crop. The Ministry of Agriculture also publishes estimates every year of the cost of production per feddan (unit of land) for each crop. From these data the value of intermediate inputs used per unit of land per crop was estimated. Then the value of intermediate inputs for the entire crop was calculated by multiplying the area under each crop by the value of intermediate inputs per unit of land for that crop. Subtracting the value of intermediate inputs from gross production led to the valueadded generated by each crop for all the crops cultivated in 1976.

The data on the cost of production include labor cost per crop. These were estimated by the Ministry of Agriculture as the number of labor inputs per feddan per crop multiplied by the average wage. However, the estimated labor cost based on wage rates appeared from general knowledge to be below the average wage prevailing in the labor market in agriculture. There also seemed to be an underestimate in the rental data. The rent per crop demanded on the free market by those who own land but rent it out per crop to the highest bidder rather than under official contracts sometimes reaches five times the official figure. Thus the values for both rent and wages were adjusted upwards to conform with these observations. Multiplying the rent per feddan per crop by the area cultivated by that crop, the share of rent in value-added was obtained. The share of wages in value-added per crop was calculated similarly. The share of capital represented the residual. By adding up the share of rent and wages for all the crops included in each of the four sectors, the labor, capital, and land shares for each of the four agricultural sectors were obtained.

In the remaining eight productive sectors only two factor shares were estimated. The information for factor shares in both public and private sector activity was obtained from both the Ministry of Planning and the Census of Industrial Production.

The estimated factor shares in all the sectors are shown in Table 7. 
TABLE 7 Factor shares in the Egyptian economy, 1976.

\begin{tabular}{lllllll}
\hline \multirow{2}{*}{ Sector } & \multicolumn{2}{l}{ Private sector } & & \multicolumn{2}{c}{ Public sector } \\
& Labor & Capital & Rent & & Labor & Capital \\
\hline 1. Staple food & 0.443 & 0.306 & 0.251 & 0.464 & 0.536 \\
2. Nonstaple food & 0.372 & 0.402 & 0.226 & 0.312 & 0.688 \\
3. Cotton & 0.456 & 0.312 & 0.232 & - & - \\
4. Other agriculture & 0.451 & 0.182 & 0.367 & - & - \\
5. Food processing & 0.299 & 0.701 & 0.0 & 0.539 & 0.461 \\
6. Textile industry & 0.314 & 0.686 & 0.0 & 0.687 & 0.313 \\
7. Other industries & 0.383 & 0.617 & 0.0 & 0.358 & 0.642 \\
8. Construction & 0.496 & 0.504 & 0.0 & 0.529 & 0.471 \\
9. Crude oil and related products & 0.070 & 0.930 & 0.0 & 0.604 & 0.936 \\
10. Transport and communication & 0.388 & 0.612 & 0.0 & 0.387 & 0.613 \\
11. Housing & 0.400 & 0.600 & 0.0 & 0.110 & 0.880 \\
12. Other services & 0.400 & 0.600 & 0.0 & 0.909 & 0.091 \\
\hline
\end{tabular}

\subsection{Share of Income Classes in Factor Shares}

The objective of this step is to estimate the share of each income class in each of the factor shares in each sector $(1,2, \ldots, 12)$. In the first four sectors in which rents are eamed it was necessary to relate the pattern of land distribution by ownership to the three classes: lowest $60 \%$, middle $30 \%$, top $10 \%$. The class of landless agricultural laborers was included in the first class, i.e., the lowest $60 \%$ of income recipients. But this required an estimate of agricultural landless labor and hence landless population. The estimate of the landless population began with the rural population or rural families in 1976. It was assumed that agricultural population represents $80 \%$ of rural population, hence agricultural rural families represent $80 \%$ of the number of families. From the agricultural census of 1965 an estimate was made of the number of land-owning families. The difference between land-owning families and total agricultural families represents landless families, and from the average size of the family a value for the agricultural landless population was calculated. The results were compared with information from the May 1974 round of the Labor Force Sample Survey concerning wage labor in agriculture. The estimate used, based on these two sources, of landless population comes to $35 \%$ of labor force and population.

The distribution of land-ownership was obtained from the agricultural censuses of 1961 and 1965. A curve was fitted to the pattern of distribution from which the share of the lowest $60 \%$, middle $30 \%$, and top $10 \%$ was estimated. Bearing in mind that the lowest income class includes landless labor as well, the pattern of distribution of land calculated was that given in Table 8, and the distribution of the share of rent among the three income classes was estimated according to this land distribution pattern.

The distribution of wage share among the three income classes was based on the distribution of the permanent labor force according to the size of the farm in the 1961 agricultural census. The temporary (casual) labor force was also added to the first income class.

The distribution of profits, the residual, was made with regard to two factors: the distribution of land ownership and holdings, and the pattern of crops cultivated in 
TABLE 8 Distribution of land ownership.

\begin{tabular}{lc}
\hline Income class & Percent of land \\
\hline $0-60$ & 7.0 \\
$60-90$ & 28.5 \\
$90-100$ & 64.5 \\
\hline
\end{tabular}

different farms of different size. The second factor is very important because of the great range of differences among the profitability rates of different crops, say, between wheat and vegetables or citrus production, or between cotton and rice. The shares of the three classes in the three factor shares are shown in Table 9.

TABLE 9 Share of the three land-ownership classes in factor shares.

\begin{tabular}{llll}
\hline & $S S P L$ & $S S P K$ & $S S P R$ \\
\hline SectorI & & & \\
$0-60 \%$ & 0.763 & 0.285 & 0.070 \\
$60-90 \%$ & 0.175 & 0.413 & 0.330 \\
$90-100 \%$ & 0.062 & 0.302 & 0.600 \\
Sector II & & & \\
$0-60 \%$ & 0.753 & 0.217 & 0.050 \\
$60-90 \%$ & 0.175 & 0.413 & 0.350 \\
$90-100 \%$ & 0.072 & 0.352 & 0.600 \\
Sector III & & & \\
$0-60 \%$ & 0.821 & 0.181 & 0.070 \\
$60-90 \%$ & 0.154 & 0.417 & 0.385 \\
$90-100 \%$ & 0.025 & 0.402 & 0.545 \\
Sector IV & & & \\
$0-60 \%$ & 0.771 & 0.210 & 0.070 \\
$60-90 \%$ & 0.182 & 0.382 & 0.385 \\
$90-100 \%$ & 0.047 & 0.408 & 0.545 \\
\hline
\end{tabular}

For the remaining sectors, as mentioned before, only two factor shares (labor and capital) were calculated for both private and public sectors. For the share of wages among different income classes, complete reliance was placed on the CAPMAS annual report on employment, wages, and hours of work (CAPMAS, 1976b). This source provides information for another 20 sectors (public and private) on the distribution of labor (employment) according to different levels (ranges) of wage rates per week. This includes laborers and white collar employees. From this the wage bill in each sector according to employment in different categories of wage rates was calculated. Then a curve was fitted for each sector, private and public, relating the percentage distribution of employment and the percentage distribution of the wage bill in that sector. From this curve it was possible to estimate the share of each class of income recipient in the total wage bill in every sector, whether private or public. For the distribution of the shares of different income classes in 
the wage bill of the government service sector, data were obtained from the 1976 state budget on the distribution of conventional government employees according to categories of wages and salaries and the total wage bill in every category. From this information it was possible to calculate the share of the lowest $60 \%$, middle $30 \%$, and top $10 \%$ of income recipients in the government wage bill.

As for the distribution of the share of profit in the different sectors and among the three income classes, the distribution of ind ustrial establishments in every industrial activity according to its contribution to total value-added in that industrial activity was used. This information was provided by the industrial census of establishment, 1968.

The distribution of the factor shares in the remaining eight sectors is shown in Table 10.

TABLE 10 Share of income classes in factor shares.

\begin{tabular}{llll}
\hline Sector & Private & & Public \\
\cline { 2 - 3 } & SSPL & SSPK & SSGL \\
\hline 5. Food processing & 0.494 & 0.150 & 0.414 \\
& 0.193 & 0.350 & 0.286 \\
& 0.313 & 0.500 & 0.300 \\
6. Textile industry & 0.598 & 0.150 & 0.414 \\
& 0.265 & 0.350 & 0.326 \\
7. Other ind ustries & 0.137 & 0.500 & 0.260 \\
& 0.451 & 0.150 & 0.351 \\
8. Construction & 0.239 & 0.350 & 0.337 \\
& 0.310 & 0.500 & 0.312 \\
9. Crude oil and related products & 0.394 & 0.150 & 0.167 \\
& 0.381 & 0.350 & 0.083 \\
10. Transport and communication & 0.225 & 0.500 & 0.750 \\
& 0.044 & 0.00 & 0.044 \\
& 0.581 & 0.300 & 0.581 \\
11. Housing & 0.375 & 0.700 & 0.375 \\
& 0.226 & 0.150 & 0.286 \\
12. Services & 0.137 & 0.350 & 0.326 \\
& 0.637 & 0.500 & 0.387 \\
& 0.379 & 0.200 & 0.385 \\
& 0.352 & 0.300 & 0.341 \\
& 0.269 & 0.500 & 0.274 \\
& 0.379 & 0.200 & 0.385 \\
& 0.352 & 0.300 & 0.341 \\
& 0.269 & 0.500 & 0.274 \\
\hline
\end{tabular}

In the government and public sectors the share of the middle 30\% is larger than the share of this class in the private sector in general. Moreover, in sectors where public activity dominates, the share of the first two classes is higher compared to the private sector. 
The share of wages in the government agricultural sector was distributed according to the distribution of labor.

\subsection{Distribution of Emigrant Remittances}

There remains only one element to distribute among income classes: workers' remittances from abroad (Table 11). Firstly, workers' remittances we re added to the wage side. Secondly, they were distributed according to the occupational distribution of emigrants (CAPMAS, 1974) and their average wage before leaving. The sum of all urban and rural shares is unity.

TABLE 11 Shares of remittances among income classes: rural-urban.

\begin{tabular}{ccc}
\hline & Urban & Rural \\
\hline $0-60$ & 0.210 & 0.082 \\
$60-90$ & 0.290 & 0.066 \\
$90-100$ & 0.300 & 0.052 \\
\hline
\end{tabular}

From the above information on shares of factors and the share of each income class in every factor share, the distribution of gross household income in every sector $(1,2, \ldots, 12)$ and among the six income classes, three rural and three urban, has been calculated. From this the share of each income class in total income was estimated. The results of the estimation are contained in the SAM (Table 1), rows 14-19, and the share of each income class in gross household income appears in the SAM under column 37 corresponding to rows 14-19. The distribution of income is given in Table 12.

TABLE 12 Distribution of income, 1976.

\begin{tabular}{lcccc}
\hline Income class & Rural & $\%$ & Urban & $\%$ \\
\hline $0-60$ & 721 & 41 & 1042 & 30 \\
$60-90$ & 535 & 30.4 & 1126 & 32.4 \\
$90-100$ & 503 & 28.6 & 1305 & 37.6 \\
Total & 1759 & 100 & 3473 & 100 \\
Share in total & $33.6 \%$ & & $66.4 \%$ & \\
\hline
\end{tabular}

It should be noted again, however, that "rural" in the context of distribution of income in this work means agricultural and not rural proper. That is why "rural" here includes only agricultural value-added. Thus nonagricultural activities in rural areas like industry and services are treated as urban. 


\subsection{Distribution of Expenditure}

The last task in this undertaking was estimating the distribution of consumption expenditures by income class. All items included in column 20 of the SAM (Table 1), total household expenditures, had to be distributed among the six income classes. The distribution of final consumption demand for the output of the twelve sectors, i.e., the first twelve items in column 20 of the SAM, was considered first. Added to this is the distribution of the item in row 24 , column 20 , direct imports by the household sector which are mainly consumer goods like refrigerators, automobiles, and other consumer goods. In addition, the 60 million Egyptian pounds, which represents tariffs on these imports, must be distributed. This represents the item in row 25, column 20.

The family budget survey of $1974 / 75$ carried out by CAPMAS (1974/75) was the starting place for these estimates. The total size of the sample is 12,000 households. The data were collected from these family groups every three months, to cover the whole year in four rounds. The data that were used represent the first and second rounds.

The urban rounds include sixteen size classes of total expenditure divided according to the average expenditure per family per year. They also contain information about the number of households interviewed in every expenditure class and the size of population in that expenditure class. The rural rounds also include sixteen expenditure classes.

From the data available in the survey it was possible to divide the expenditure classes in to six socioeconomic groups corresponding to the six socioeconomic groups for which the distribution was calculated.

The lowest $60 \%$ of the urban population includes the first eleven expenditure groups with less than 50 to less than 600 Egyptian pounds expenditure per year. The middle $30 \%$ in urban areas includes the next three expenditure classes with 600 to less than 1000 Egyptian pounds expenditure per year. The top $10 \%$ of urban classes includes the next two classes with 1000 to more than 2000 Egyptian pounds expenditure per year.

In the rural areas the lowest $60 \%$ of income recipients includes the first nine expenditure groups, with zero to less than 350 Egyptian pounds expenditure per year. The middle $30 \%$ includes the next three groups, with 350 to less than 800 Egyptian pounds expenditure per year. The top $10 \%$ of rural areas includes the next four groups, with 800 to over 2000 Egyptian pounds expenditure per year.

The family budget survey of $1974 / 75$ contains information for the 16 household expenditure classes in both urban and rural areas, on 38 expenditure categories. These are, in order, as follows:

1 Cereals and starches,

2 Pulses,

3 Fresh and canned vegetables,

4 Fresh and canned fruits,

5 Meat and poultry,

6 Fish and fish products,

7 Eggs,

8 Milk and dairy products,

9 Fats and oil,

10 Sugar and sugar products,
11 Other food products,

12 Tea and coffee,

13 Other beverages,

14 Total expenditure on food and beverages,

15 Total expenditure on cloth and wear,

16 Textile and final wear,

17 Footwear (shoes),

18 Expenditure on accommodation and related needs (total), 
19 Expenditure on accommodation,

20 Power, electricity, and energy,

21 Total expenditure on furniture, household tools, and equipment for household services,

22 Furniture and fixtures,

23 Household cleaning materials,

24 Payments for household services,

25 Medical care expenditure,

26 Total expenditure on transport,

27 Private means of transport,

28 Costs of transport and communication,

29 Education,

30 Total expenditure on culture and recreation,
31 Special tools and equipment for culture and recreation,

32 Expenditure on culture and recreation,

33 Total of other types of expenditure,

34 Private tools,

35 Tools and materials for cleaning and cosmetics,

36 Tobacco products,

37 Services and other expenditure,

38 Total consumption expenditure,

39 Transfer payments,

40 Installments paid in advance,

41 Total expenditure per year.

The last three items (39-41) were excluded from the subtotals of expenditure. The rest of the items were aggregated and distributed according to 13 sectors in the SAM (Table 1). These 13 sectors include the 12 major sectors in the input-output table in the SAM, plus the household imports sector, which is included in the SAM at row 24, column 20. This includes the 125 million Egyptian pounds of household imports and the 60 million Egyptian pounds of tariffs. The rules followed in allocating the items in the family budget among the thirteen sectors are given in Table 13. In Table 13, the $A_{i}$ term represents the row of every expenditure item. Thus $A_{1}$ represents the expenditure on cereals and starches, and $A_{3}$ represents the expenditure on fresh and canned vegetables. Also $0.5 A_{1}$ means half the expenditure on cereals and starches.

TABLE 13 Distribution of expenditure items among the sectors in the SAM.

\begin{tabular}{ll}
\hline Sector & Distribution of expenditure items \\
\hline 1 & $0.5 A_{1}+0.5 A_{2}$ \\
2 & $0.5 A_{3}+0.5 A_{1}+0.5 A_{5}+A_{6}+A_{7}$ \\
3 & 0 \\
4 & $0.2 A_{22}+0.2 A_{23}$ \\
5 & $0.5 A_{1}+0.5 A_{2}+0.5 A_{3}+0.5 A_{4}+0.5 A_{8}+A_{9}+A_{10}+A_{11}+A_{12}+A_{13}+0.5 A_{36}$ \\
6 & $0.5 A_{16}+0.5 A_{17}$ \\
7 & $0.5 A_{20}+0.8 A_{22}+0.8 A_{23}+A_{35}$ \\
8 & 0 \\
9 & $0.5 A_{20}$ \\
10 & $A_{28}$ \\
11 & $A_{24}+0.5 A_{37}$ \\
12 & $0.5 A_{16}+A_{19}+A_{25}+A_{29}+A_{32}+A_{34}+0.5 A_{37}$ \\
13 & $0.5 A_{8}+A_{27}+A_{31}+0.5 A_{35}+0.5 A_{36}$ \\
14 & $A_{38}$ \\
15 & $A_{42}$ \\
\hline
\end{tabular}


This procedure of distributing expenditure was carried out for each of the six income classes, three rural and three urban, to obtain the consumption expenditures according to the sectors in the SAM.

The expenditure of each income class on the products of each of the 13 sectors was divided by the total consumption expenditure of that class in the 1974/75 family budget survey. This generated the ratios or shares of consumption expenditure on the products of each sector by each income class in relation to the total expenditure of that income class.

The next step was the multiplication of the per capita expenditure of each income class as calculated from the 1974/75 family budget survey by the total population of that class as calculated from the 1976 population census. This was done to arrive at total expenditure by each income class in 1976 . However, the figures arrived at did not add up to total consumption expenditure in 1976 , but were underestimates. To adjust this, the data were scaled to fit the total expenditure of 1976 as shown in the SAM, column 20. The scaling factor was $4111 / 3535$.

The figures obtained for total expenditure by each income class were multiplied by the shares (ratio) of expenditure of that class in the 13 sectors. This led to values for the expenditure of each income class for the products of the 12 sectors plus imports. These are shown in the SAM in columns 14-19 corresponding to rows 1-12, and in columns 14-19 corresponding to row 24. The distribution of other items of expenditure in the SAM, like indirect taxes, direct taxes, and transfers, is discussed in Eckaus et al. (1979).

\section{RESULTS}

The results for a typical policy run are given in Tables 14-17. For this policy it is assumed that all consumer subsidies are set at zero. The test is made on GEM-2 where there are no restraints on factor demands and their prices remain at one.

TABLE 14 Sectoral gross output with consumer subsidies removed.

\begin{tabular}{|c|c|c|c|c|c|}
\hline & \multicolumn{2}{|l|}{ Output } & \multicolumn{3}{|c|}{ Factor prices } \\
\hline & Final & $\%$ Change & Rent & $K A P L$ & Wage \\
\hline Staple food & 443.76 & -2.470 & 1.0000 & 1.0000 & 1.0000 \\
\hline Nonstaple food & 1201.81 & -5.220 & 1.0000 & 1.0000 & 1.0000 \\
\hline Cotton & 230.53 & -1.903 & 1.0000 & 1.0000 & 1.0000 \\
\hline Other agriculture & 440.10 & -5.150 & 1.0000 & 1.0000 & 1.0000 \\
\hline Food processing industry & 1454.74 & -4.419 & 1.0000 & 1.0000 & 1.0000 \\
\hline Textile industry & 832.27 & -5.958 & 1.0000 & 1.0000 & 1.0000 \\
\hline Other industries & 1358.82 & -2.383 & 1.0000 & 1.0000 & 1.0000 \\
\hline Construction & 633.93 & -0.326 & 1.0000 & 1.0000 & 1.0000 \\
\hline Crude oil and related products & 594.23 & -2.426 & 1.0000 & 1.0000 & 1.0000 \\
\hline Transport and communication & 533.13 & -7.603 & 1.0000 & 1.0000 & 1.0000 \\
\hline Housing & 124.31 & -12.460 & 1.0000 & 1.0000 & 1.0000 \\
\hline Other services & 3033.48 & -2.711 & 1.0000 & 1.0000 & 1.0000 \\
\hline
\end{tabular}


TABLE 15 Selected important variables with consumer subsidies removed.

\begin{tabular}{lrrr}
\hline & \multicolumn{1}{c}{ Final } & Initial & Change \\
\hline Exports & 1286.009 & 1286.000 & 0.001 \\
Imports & 1878.533 & 1940.000 & -3.168 \\
Imports - exports & 592.524 & 654.000 & -9.400 \\
Investment & 1566.985 & 1567.000 & -0.001 \\
Stocks & 113.000 & 113.000 & 0.000 \\
Total investment & 1679.985 & 1680.000 & -0.001 \\
Private savings & 377.726 & 394.000 & -4.130 \\
Price difference & 176.009 & 176.000 & 0.005 \\
Government savings & 712.706 & 632.000 & 12.770 \\
Domestic savings & 1090.432 & 1026.000 & 6.280 \\
GNP $(C+I+G+E-M)$ & 6725.571 & 6972.836 & -3.546 \\
\hline
\end{tabular}

It is seen in Table 14 that the policy has a contractionary effect on all sectors, the greatest impact occurring in housing followed by transport and communications. The demand for these sectors is characterized by high elasticities.

In Table 15 it is seen that import demand falls, and since exports are assumed fixed, the export-import balance improves. Private savings falls owing to lower income levels, while the government deficit is reduced by $12.77 \%$. Overall GNP falls by $3.5 \%$.

Some of the predicted impact on specific income classes is given in Table 16. Note the relatively stronger impact on disposable income and hence expenditure for the low income urban group. Because of the differences in elasticities across income classes, one observes that at the sectoral level the changes in demand vary. Thus the relatively inelastic demand for staple food shows little change while housing demand falls substantially - an estimated $28.5 \%$ for the low income urban class.

Factor demands are given in Table 17. In this variant of the model the factor prices are assumed unchanged. Because of the contractionary effect of the policy, factor demands are reduced in all sectors. Again the biggest fall is noted for housing followed by transport and communications.

An alternate variant of the model allows one to assume full use of factors. This would result in a fall in prices. Similarly one can generate a range of scenarios to provide guid ance on policy. Application of the model to manpower planning is described in McCarthy (1981) where estimates are obtained for employment generation under the current five-year plan. 


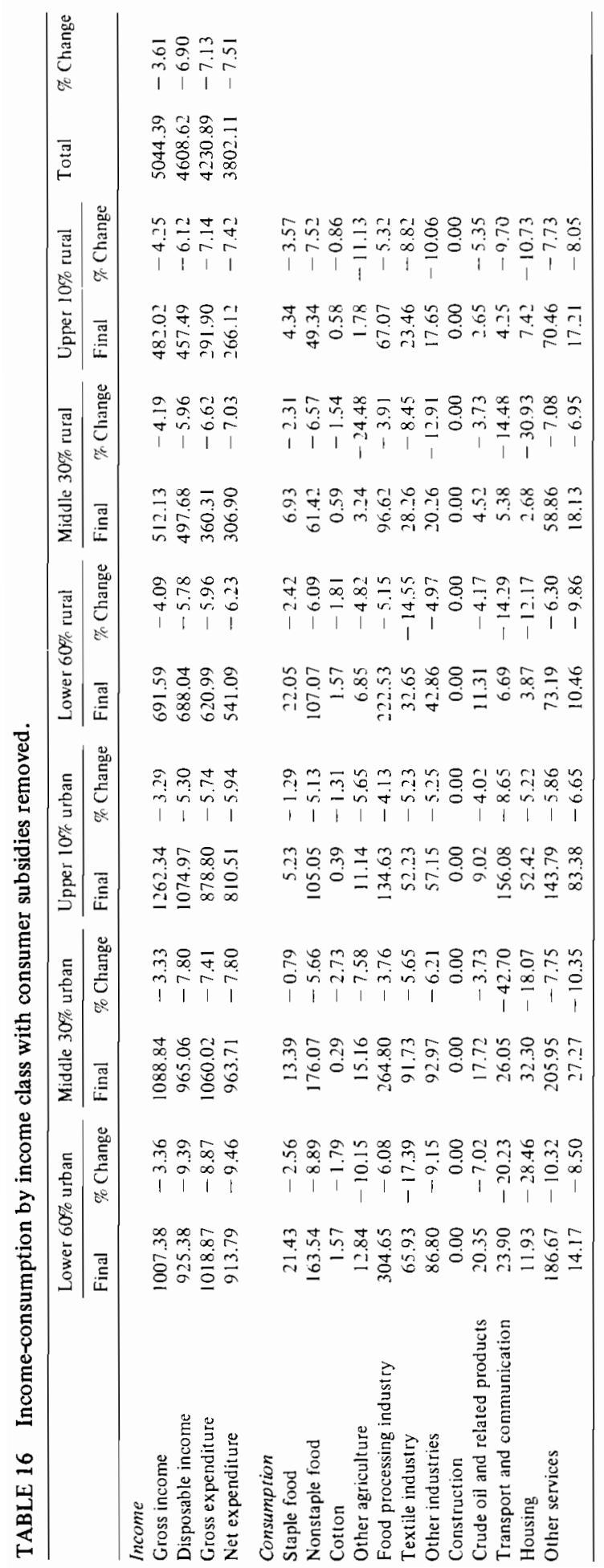




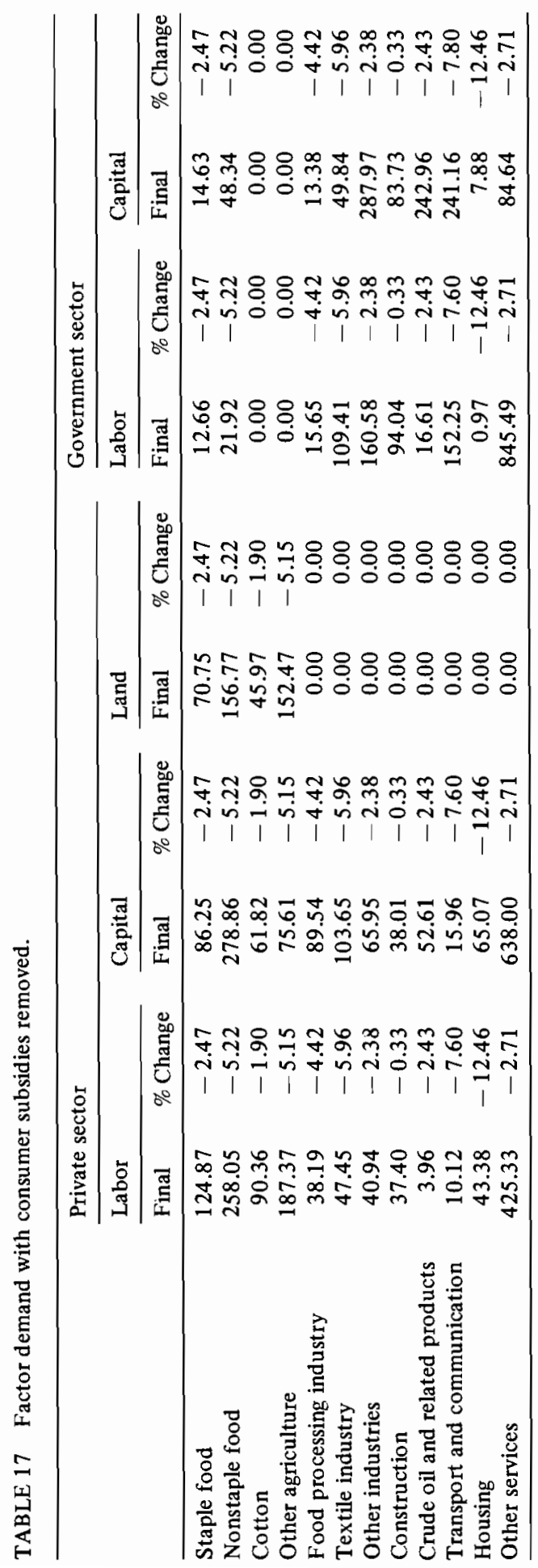




\section{REFERENCES}

Adelman, I. and Robinson, S. (1977). Income Distribution Policies in Developing Countries. Stanford University Press, Stanford, California.

Blaug, M. (1978). Economic Theory in Retrospect. 3rd edn. Cambridge University Press, Cambridge.

CAPMAS (Central Agency for Population, Mobilization, and Statistics) (1974). The Migration of Population across the Frontiers of the Arab Republic of Egypt, 1973. CAPMAS, Cairo.

CAPMAS (1974/75). Family Budget Survey. CAPMAS, Cairo.

CAPMAS (1976a). Follow-up Report of 1976. Ministry of Planning. CAPMAS, Cairo.

CAPMAS (1976b). Employment, Wages, and Hours of Work (Annual Report). CAPMAS, Cairo.

CAPMAS (1978). National Income from Agriculture (Annual Report). Budget Department, Import Tariffs. Mimeograph, based on Custom Books. CAPMAS, Cairo.

Eckaus, R.S., MoCarthy, F.D., and Mohie-Eldin, A. (1981). A social accounting matrix for Egypt, 1976. Journal of Development Economics, forthcoming.

Eckaus, R.S., McCarthy, F.D., and Mohie-Eldin, A. (1979). Multisector General Equilibrium Models for Egypt. Working Paper 233. Department of Economics, Massachusetts Institute of Technology, Cambridge, Massachusetts.

Leontief, W.W. (1936). Quantitative input and output relation in the economic system of the United States. Review of Economics and Statistics, August.

Leontief, W.W. (1941). The Structure of American Economy, 1919-1939. Harvard University Press, Cambridge, Massachusetts.

Lluch, C., Powell, A.A., and Williams, R.A. (1977). Patterns in Household Demand and Saving. Oxford University Press, Oxford.

Lysey, F.J. and Taylor, L. (1980). Income distribution simulations, 1959-1971. In L. Taylor, E.L. Bacha, E.A. Cardoso, and F.J. Lysey (Editors), Models of Growth and Distribution for Brazil. Published for the World Bank by Oxford University Press, New York.

McCarthy, F.D. (1981). Methodology for Manpower Planning in Egypt. CP-81-1. International Institute for Applied Systems Analysis, Laxenburg, Austria.

McCarthy, F.D. and Taylor, L. (1980). Macro food policy planning: a general equilibrium model for Pakistan. Review of Economics and Statistics, February.

Stone, R. (1954). Linear expenditure systems and demand analysis: an application to the pattern of British demand. Economic Journal, 64:511-527. 


\title{
MODELING DUALISM IN JAPAN
}

\author{
Hisanobu Shishido \\ International Institute for Applied Systems Analysis, Laxenburg (Austria)
}

\section{INTRODUCTION}

This paper describes an applied general equilibrium model that is used for analyzing the economic growth and urbanization of Japan during this century. One of the most salient features of Japan's experience during this period has been the dualistic nature of the economy, even within urban sectors. It is hoped that, through an extensive use of the model described, more insight can be gained into the causes and consequences of the particular form of dualism evident in the economic history of Japan.

Much research has been carried out on Japan's economic history. Kelley and Williamson (1974), in particular, used a similar approach to that described here, namely, general equilibrium modeling and dynamic counterfactuals. Their success in utilizing these tools of "new economic history" to reinterpret the Japanese economic experience has encouraged others to extend approaches based on their efforts; one such extension has been the building of the model described here.

The main ways in which the present model has extended and improved on the work of Kelley and Williamson can be summarized as follows. First, the periods covered by the present study are 1905--1930 and 1953-1963, whereas Kelley and Williamson studied the period 1887-1915 which has been termed the balanced-growth phase (Nakamura, 1971). This latter period excludes the years of urban dualistic development after World War I. Studying the pattern of this dualistic growth, a well-known feature of Japan's experience, and possibly a relevant feature for contemporary developing countries, may very well shed more light on the mechanism of economic and demographic development, as Ohkawa (1972, p. 61) notes:

"The phenomenon of such continuous differentials (between modern and traditional elements) in my view, is much more important than it appears at first glance. The problem of capital-labor allocation, availability of different technologies, the income formation pattern and distribution, etc. - these are all characterized by the differential structure."

Second, instead of assuming completely neoclassical instantaneous adjustment mechanisms, as in the Kelley-Williamson model, various lagged and/or myopic adjustments are 
assumed to take place. For example, it is assumed in the present model, and its modifications, that investment is carried out by expectations formulated myopically by investors. Although the total investment is constrained by the amount of savings in this exposition of the model, the Robinsonian "animal spirits" can also be taken into account by predetermining the investment by equalizing the actual and desired investments. Migration is another mechanism of lagged adjustment in factor allocation. Potential migrants are assumed to observe and be influenced by rural-urban income differentials and the rates with which new jobs become available to them.

Third, in order to study the dualistic wage structure, we employ the assumption that "skill" is technology-specific and an asset that competes for investment funds with physical capital investment.

Other features of the present model include "vintage" (specifying the year of installation of each item of capital stock) and open-economy characteristics, but a complete smallcountry specification is not used.

The intended form of analysis is in three steps: first, the parameter value estimation; second, the comparative statics, which examine the static responses of the model to various exogenous changes in selected parameter values or closure of the model; and third, the dynamic counterfactuals, which examine the dynamic implications of employing assumptions different from the historical reality, e.g., different rates of technological progress or population growth.

In Section 2 the phenomenon of "dualistic development" is reviewed briefly.* Section 3 describes the model in detail and concluding observations are given in Section 4.

\section{BRIEF HISTORY OF JAPAN'S DUALISTIC DEVELOPMENT}

\subsection{General Overview}

The recent economic history of Japan has received considerable attention because of the country's rapid rate of growth from the second half of the 19th century. Not only was growth continuous, but also there was a noteworthy trend of accelerated growth during this period, ${ }^{* *}$ starting with a moderate rate of growth and gradually increasing. At the same time, long swings, or fluctuations, in the economic growth occurred. Japan experienced 3.5 long swings between the end of the Matsukata Deflation in 1887 and the beginning of the 1970s. Each cycle was about 20 years long. The "trend acceleration" can be easily observed in Table 1 where the successive swings are listed. For example, the average annual growth rates of gross national expenditure (GNE) recorded during upswing periods are $3.21 \%$ (1887-1897), 3.30\% (1904-1919), 4.88\% (1930-1938), and 9.56\% (19531969). The growth acceleration has also been accompanied by structural change in the economy, starting from a genuine agrarian economy (Ohkawa and Shinohara, 1979, p. 51):

\footnotetext{
*Section 2 is not intended as a comprehensive survey of the topic. For more detailed discussion see Nakamura (1971), Minami (1973), Ohkawa (1972), Ohkawa and Rosovsky (1973), and the International Development Center of Japan Comparative Analysis Project Reports $(1976,1977,1978)$.

**Ohkawa and Rosovsky (1973) call this "trend acceleration" of the Japanese economy.
} 
TABLE 1 Long-term pattern of aggregate growth rates in $\operatorname{Japan}^{a}$ : average annual rates of growth of gross national expenditure versus population; $(U)=$ upswing, $(D)=$ downswing.

\begin{tabular}{llll}
\hline Period (length in years) & \multicolumn{2}{c}{ Annual percentage increase in } & \\
\cline { 2 - 4 } & GNE & Total population & Per-capita GNE \\
\hline (U) $1887-1897(10)$ & 3.21 & 0.96 & 2.25 \\
(D) $1897-1904$ (7) & 1.83 & 1.16 & 0.67 \\
(U) $1904-1919(15)$ & 3.30 & 1.19 & 2.11 \\
(D) $1919-1930(11)$ & 2.40 & 1.51 & 0.89 \\
(U) $1930-1938(8)$ & 4.88 & 1.28 & 3.60 \\
(D) $1938-1953(15)$ & 0.58 & 1.36 & 0.78 \\
(U) $1953-1969$ (16) & 9.56 & 1.03 & 8.53 \\
\hline
\end{tabular}

Ohkawa and Shinohara $(1979$, p. 10).

"Using sectoral shares of gainfully occupied population as an indicator shows Japan was economically backward compared to western nations. In Japan the share of labor in agriculture in $1870-80$ was $65-70$ percent, close to the developing countries' share today. It is impossible to find western nations with such a high rate in the initial years of their modern economic growth."

The structural changes can be observed in sectoral shifts of production. The industrial share in net domestic product, for example, increased from $20 \%$ in $1887^{*}$ to $52 \%$ in 1938, , while the agricultural share decreased from $42.5 \%$ to $18.5 \%$ during the same period. Within the industrial sector there were also continuous shifts from light to heavy and from traditional to modern industries.

These shifts were a result of the introduction of advanced technologies from abroad into a largely agrarian and traditional society -- the inevitable course followed by a late starter in industrialization. It was, therefore, only natural that there was a period in the history of Japan when traditional, indigenous elements and modern, imported elements coexisted. The period during which the traditional elements played an important, albeit changing role was fairly long. These traditional elements were not eliminated through competition immediately after modern elements were introduced into the economy. The years of Japanese economic development, therefore, can be said to fall into a number of distinct phases in accordance with the different roles the traditional and modern elements played. Ohkawa (1980)** divides them into four phases: Phase 01868 to 1885; Phase I 1885 to World War I (1915-1919); Phase II World War I to 1958-1962; and Phase III 1958-1962 to the present.

Phase 0 was an initial period where institutional changes that were required for modern economic growth took place. The year of the Meiji Restoration, 1868, when modern economic growth became the national objective, is considered the first year of Phase 0 , although some modern elements already existed before that time.***

\footnotetext{
*These are the middle years of five-year moving averages. Figures are from Ohkawa and Shinohara (1979).

**The rest of this section is based on Ohkawa's argument in general.

***See Yasuba (1978) for details of the socioinstitutional and demographic conditions prevailing in Japan before 1868. See Ohkawa (1978) for other economic conditions.
} 
Phase I was the period when modernization largely depended on traditional elements both in agriculture and in the nonagricultural sectors. The dependence took the form of financial sources of growth (taxes and savings), foreign exchange (exports), and supplies of labor and food.

Phase II was the period when the modern sectors started to become more independent of the traditional sectors. The strong dependence of the modern sectors on the traditional sectors as sources of labor supply, however, continued. This period started with the first investment spurt in the modern sectors and saw a fluctuating but continuous growth of modern elements, while the growth potential of the traditional sectors faced some constraints. The so-called "dualistic development pattern" was, therefore, firmly established toward the beginning of this phase and continued until well after the end of World War II.

Phase III started around 1958-1962 and has continued to the present date. During this phase modern elements have come to dominate all sectors of the economy.

A quick glance at exports also endorses the changing but important role played by the traditional sectors. In the initial phase of economic development after 1868 , raw silk, silkworm cocoons, and green tea made up $85 \%$ of total exports. By the turn of the century more industrial goods, produced by traditional manufacturing, became the dominant exports: raw silk, other silk goods, cotton products, and other miscellaneous goods. Textiles were the most important exports until the 1930s, making up 60-70\% of all manufactured exports. Within the textile exports, however, there was a remarkable shift from silk to cotton products.

An increase in heavy industry's share of exports started around the 1920s and it eventually became dominant, although only replacing textiles after World War II. A wellknown dynamic feature of the Japanese economy is that exports of manufactured goods were preceded by periods of imports and import-substitution production (see Akamatsu, 1966).

The role of the traditional sectors in financing Japan's high rate of growth is thus obvious. The three primary export commodities in the early phase were all products of the agricultural sector. The major exports from the turn of the century were manufactured textiles and miscellaneous goods produced by the traditional manufacturing sector without imported technology or by sectors with imported but largely modified technologies (e.g., cotton, matches).

Among the different phases of recent Japanese development, we will focus our attention on Phase II because this is the period when "dualism" occurred and persisted. The mechanism of urbanization and growth in the dualistic economy will also be studied using the model presented in Section 3.

\subsection{Dualistic Development: A Closer Look}

Phase II of Japanese economic development started from the time of the private investment spurt, with an almost unlimited increase in export demand because of World War I. This spurt increased the size of firms in general and that of heavy industrial firms in particular. The average annual growth rate of the manufacturing sector during World War I was an extraordinary $9.3 \%$. But the growth rates were quite uneven within the sector: machinery grew at $28.1 \%$, metals at $10.7 \%$, textiles at $4.1 \%$, and miscellaneous goods at $2.2 \%$ (Yasuba, 1966). 
The distribution of income was also strikingly uneven. The real wages of urban workers and real agricultural income both decreased in real terms until 1918, while investors were profiting greatly from the boom. The increasingly inequitable income distribution during the economic boom increased dissatisfaction among the poor, and paved the way for the rice riots of 1918 .

The stagnant condition of Japanese agriculture after World War I* is also noteworthy. It was partially caused by worldwide agricultural crises when supply increased at the same time as demand decreased because of deflationary pressures; these latter were due to the efforts of all industrialized nations to restore the gold standard to prewar rates. Another reason for the stagnation of Japanese agriculture was a shift of government policy after the rice riots of 1918. The new policy no longer protected the farmers but rather appeased the urban workers. Imports of cheaper rice from the Japanese colonies were promoted at the cost of accelerating the decline of domestic agriculture. To make matters worse, increasing urbanization decelerated the growth of consumer demand for traditional food. As a result, there was a drastic relative decline in agricultural income. The rural area, therefore, no longer had the capacity to support its population, causing an increase in labor surplus.

The "push" pressure of the rural areas thus increased, but the "pull" factors of the urban areas were limited for two reasons. First, even during the boom, investment was largely concentrated on more capital-intensive modern industries, and the gross employment effects were limited. Second, the rate of staff turnover in modem industry started to decline drastically, partly because of the increasing capital intensity which caused technology-specific skills to become important. Formal schooling gave only general background training, so almost all training in skills took place on the job. Once skills were acquired it was in the interests of both employers and employees for the latter to stay with the same firm. The wage policy of employers in modern industry, therefore, can be regarded as minimizing the sum of wages and loss of training costs caused by staff turnover.** The prevailing wage levels in the traditional sectors were much less relevant to the wages in the modern sectors than economic textbooks might suggest.

A detailed study on the behavior of the modern-sector firms (International Development Center of Japan Comparative Analysis Project Report, 1977,pp. 136, 137) clearly indicates this trend:

"World War I created an unprecedented boom in the economy. As the investment spurt proceeded, the tightness of the labor market became acute .... The boom was followed by a period of reorganization and adjustment. By this time the ground work for implanting modern technology had been laid out and the distinction between "indigenous" and "modern" skills had become more and more apparent. The former no longer could be counted on as a handy substitute for the increasing demand for industrial skilled labor. The absolute shortage of trained workers and the increasing degree of occupational specialization and division of tasks induced many large corporations to

\footnotetext{
*Napjer (1979) offers an interesting opposing view that weather was responsible for low agricultural growth during this period and that the real stagnation came much later than is conventionally believed.

**In addition, modern-sector employers had an incentive to pay higher wages in order to isolate their workers from the increasing restlessness of other urban laborers and to keep the "cream of the labor force".
} 
initiate a program of training-within-the-firm. At the Nagasaki Iron Foundry, for example, the shokko gakko [Workman's Engineering School] was set up in $1918 \ldots$. Concurrent with this new trend, there was a tendency among the large firms to put a tighter limit on the age of new entrants; it seems that the idea of kogai [workers reared from youth] became increasingly popular. The sharp distinction between regular and temporary workers was sometimes introduced in order to retain flexibility in output demand. In any event, labor turnover rates in large factories declined sharply after the close of the war, reflecting the new trend toward stability in the labor market for the "modern" sector. By contrast, it should be noted that the overall magnitude of labor mobility continued to be high throughout the 1920s."

The limited demand for labor in the modern industrial sector, coupled with the decline of the population-supporting capacity of the rural areas, limited the alternatives available to job seekers. The surplus labor flowed into various urban traditional sectors. The numbers of those gainfully employed in small-scale manufacturing, retail services, and other traditional services increased drastically. For example, the number increased by $101 \%$ for retail and wholesale services, and by $42 \%$ for other services (Nakamura, 1971). The increase of labor employed in these sectors pushed the wage levels down, giving rise to wage differentials between different sectors and between different sizes of firms.*

The interaction between urban and rural labor markets was, therefore, quite important. Wage levels went down with the decline of agricultural income not only for traditionalsector employees but also for female workers in general (employed mainly in the textile sectors). These female workers had been recruited directly from the rural areas and had a high turnover rate.

The question posed from a neoclassical point of view, then, is: why did this dualistic disequilibrium phenomenon persist for so long? It is hoped that, with the help of the model presented in the next section, more insight will be gained in to the answer to this question.

One plausible hypothesis is that this dualism occurs during a period of rapid technical or technological progress, accompanied by an increased demand for technologyspecific skills. Both the firms that own the new technology and the skilled labor that use the technology earn quasirents. This situation can last a long time if the investment embodied in new technologies stays at a high level, so restricting the diffusion of the latest technologies.

Both workers and employers have a vested interest in each other, since the skills workers now have are technology-specific. It is disadvantageous for the worker to quit so long as other opportunities are no more attractive than the present job, and it is costly to the employer if the worker does quit. Therefore, the employers pay higher wages to reduce the number of resignations, and workers stay in the same firm, possibly increasing their efficiency through learning-by-doing. This is a type of bilateral monopoly (Tan, 1980).

This hypothesis also assumes the continuing existence of surplus labor in the traditional sector. Without this surplus the wage level of traditional sectors would be pushed

\footnotetext{
*Before World War I, wage differentials were of a spatial nature, i.e., the segmented labor markets with limited spatial labor mobility and flow of information were mainly responsible for the differentials, while the dualism born after World War I was formed against a background of relatively high factor mobility and flow of information.
} 
up to a level where workers in the modern sectors would not feel such a strong incentive to stay in the same firm. This is what actually occurred in Japan during the 1960s, when the surplus labor in the traditional sector was exhausted and economic dualism largely disappeared (along with diffusion of technologies and a productivity increase in agriculture).

From the observations and hypotheses presented, it appears likely that investments in new technologies and an elastic labor supply were important factors in the formation of the dualism observed in post-World War I Japanese economic history. The model described below emphasizes these aspects.

\section{THE MODEL}

\subsection{General Features}

The model was built to incorporate aspects of Japanese economic development in this century as described in the last section. Its specific features are as follows:

- It is a "vintage" model in which each item of capital stock in a given sector is specified by the year of installation.

- It distinguishes ex ante and ex post production possibility sets, and assumes "putty-semiputty" technologies for various urban sectors with varying elasticities of substitution.

- It assumes that productive physical investment is made by investors with differing expectations, albeit myopic, on future factor and commodity prices and on demand.

- It defines rural-urban labor migration as depending largely on urban job opportunities as well as on the difference in (expected) income differentials deflated by cost-of-living indices.

- "Trade" is specified in three ways: all exports are given Armington specifications; all imports of raw materials and machinery are considered noncompetitive; and all industrial finished goods are considered competitive and given Armington specifications.

\subsection{Sector Division}

Table 2 outlines the system of sectoral division used in the model.

The manufacturing sector is divided into three subsectors in order to capture differences in technologies employed within the sector. It is assumed that the size of firms reflects the degree of indigenousness of the technology employed. One of the criteria considered for determining whether an industry belongs to the modern or the traditional subsector is, therefore, the proportion of employment in small-scale firms to total employment in the industry.* *Pre-World War II period firms with five or less employees and post-World War II period firms with 49
or less employees are considered as small-scale firms. 
TABLE 2 Sectoral divisions in the model of Japan.

\begin{tabular}{|c|c|c|}
\hline Sector & $1905-1930$ & $1950 \cdot 1963^{a}$ \\
\hline \multicolumn{3}{|l|}{ Urban sectors } \\
\hline Industry I & $\begin{array}{l}\text { Modern industry (MM) } \\
\text { Clemicals } \\
\text { Machinery } \\
\text { Metals } \\
\text { Mining } \\
\text { (Printing) } b \\
\text { (Stone, clay, and glass) } b\end{array}$ & $\begin{array}{l}\text { High capital-intensity industry }(\mathrm{HK}) \\
\text { Petroleum } \\
\text { Steel } \\
\text { Nonferrous } \\
\text { Chemicals } \\
\text { (Ceramics) }^{b} \\
\text { (Pulp and paper) }^{b}\end{array}$ \\
\hline Industry II & Textile industry (TE) & $\begin{array}{l}\text { Moderate capital-intensity industry (MK) } \\
\text { Machinery } \\
\text { Textiles } \\
\text { Printing } \\
\text { Rubber } b \\
\text { (Mining) }\end{array}$ \\
\hline Industry III & $\begin{array}{l}\text { Traditional industry (TM) } \\
\text { Food } \\
\text { Lumber and wood } \\
\text { Miscellaneous }\end{array}$ & $\begin{array}{l}\text { Low capital-intensity industry (LK) } \\
\text { Clothes } \\
\text { Leather } \\
\text { Furniture } \\
\text { Metals } \\
\text { Wood } \\
\text { Food } \\
\text { Miscellancous }\end{array}$ \\
\hline Construction & Construction & Construction \\
\hline Urban service & $\begin{array}{l}\text { Modern service (MS) } \\
\text { Modern transport } \\
\text { Electricity } \\
\text { Other public services } \\
\text { Traditional service (US) } \\
\text { The rest of service activities } \\
\text { Urban housing construction }\end{array}$ & $\begin{array}{l}\text { Modern service (MS) } \\
\text { Modern transport } \\
\text { Electricity and other utilitics } \\
\text { Public services } \\
\text { Banking and modern finances } \\
\text { Traditional service (US) } \\
\text { Retail and wholesale services } \\
\text { Urban housing construction }\end{array}$ \\
\hline \multicolumn{3}{|l|}{ Rural sectors } \\
\hline Rural service & $\begin{array}{l}\text { Rural service (RS) } \\
\text { Rural housing construction }\end{array}$ & $\begin{array}{l}\text { Rural service (RS) } \\
\text { Rural housing construction } \\
\text { (Retail services in rural areas) }\end{array}$ \\
\hline Agriculture & & $\begin{array}{l}1 \text { ture } \\
\text { ery } \\
\text { try } \\
\text { Iture }\end{array}$ \\
\hline For rental flows & & $\begin{array}{l}\text { ousing } \\
\text { ousing }\end{array}$ \\
\hline
\end{tabular}

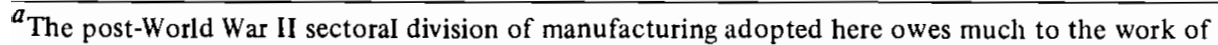
Motai and Ohkawa (1978).

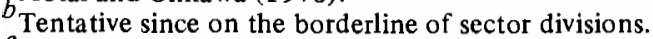

${ }^{c}$ Tentative since data not available. 
In addition, several other criteria are employed, such as capital-labor ratios, and labor and capital productivities. For the pre-World War II period, the conventional modern-traditional division is applied to these criteria, but a third subsector, the textile industry, is singled out for separate treatment because of its important role in the development of the Japanese economy in this period.

The service sector in the urban area is divided into two subsectors: capital-intensive modern services, which include transportation, communication, electricity, and other modern services; and traditional services, which include retail and wholesale businesses, personal services, financial services, and carpentry for residential buildings. Banking and other financial services are considered as traditional, mainly because of the way statistical data were recorded in the pre-World War II period. Construction is considered as a separate sector because of its specific characteristics, namely, nontradability and high laborcapital ratio.

For the rural region, economic activities consist of the primary (agriculture) and rural service sectors. "Agriculture" also includes sericulture (the production of raw silk by raising silkworms), fishery, and forestry. The rural service sector should include rural retail businesses, traditional transportation, personal services, carpentry, etc., but owing to data limitations, only rural carpentry is considered to belong to this sector in the pre-World War II period.

Finally, two additional sectors are included to account for rental flows in urban and rural housing.

The difference between the pre-and post-World War II divisions is more apparent than real. What is considered modern in the prewar period can be considered to belong to the medium range of capital intensity in the postwar period, e.g., machinery and printing. The singling out of the textile industry for the prewar period is only natural given the role it played as a major export sector, with modern or modified modern technology utilizing the unskilled (female) labor force from rural areas. This distinct and predominant role was not taken up either by the textile industry or by any other "single" sector in the postWorld War II period.

\subsection{Production Relations}

Persistent wage differentials between modern and traditional sectors in Japan have puzzled many economists and have been a source of heated arguments. It was not only the wage differentials that were persistent but also the very existence of the traditional sectors. In the stereotyped concept of modernization, traditional sectors are resiclual and are supposed to be phased out and replaced by more modern sectors as the country develops. This did not occur in Japan for a long time. Many authors have tried to explain this persistent (if not happy) coexistence, which resulted in the lasting wage differentials discussed earlier.

There have been various attempts at explaining Japan's economic development. In this paper an attempt is made to explain it from the economic and technological points of view, not only because these aspects are easier to quantify, but also because I believe they should be elaborated first. These aspects are less culture-specific and are therefore useful for finding any relevance to, or comparability with, the experiences of other countries. 
The main hypotheses proposed are as follows:

- The ex post elasticity of substitution of modern-sector technology is much smaller than that of the traditional sector.

- The physical lifetime of equipment in the modern sector is much longer than in the traditional sector.

- The equipment of the modern sector is, by definition, "borrowed" technology, while the technology used in the traditional sector is mainly indigenous.

- Investment in each sector is carried out at the most efficient point with a given expected factor-price ratio.

- Technical progress is more rapid and labor-saving in the modern sector.

Most of these hypotheses are seen clearly in the diagram of isoquants depicted in Figure 1

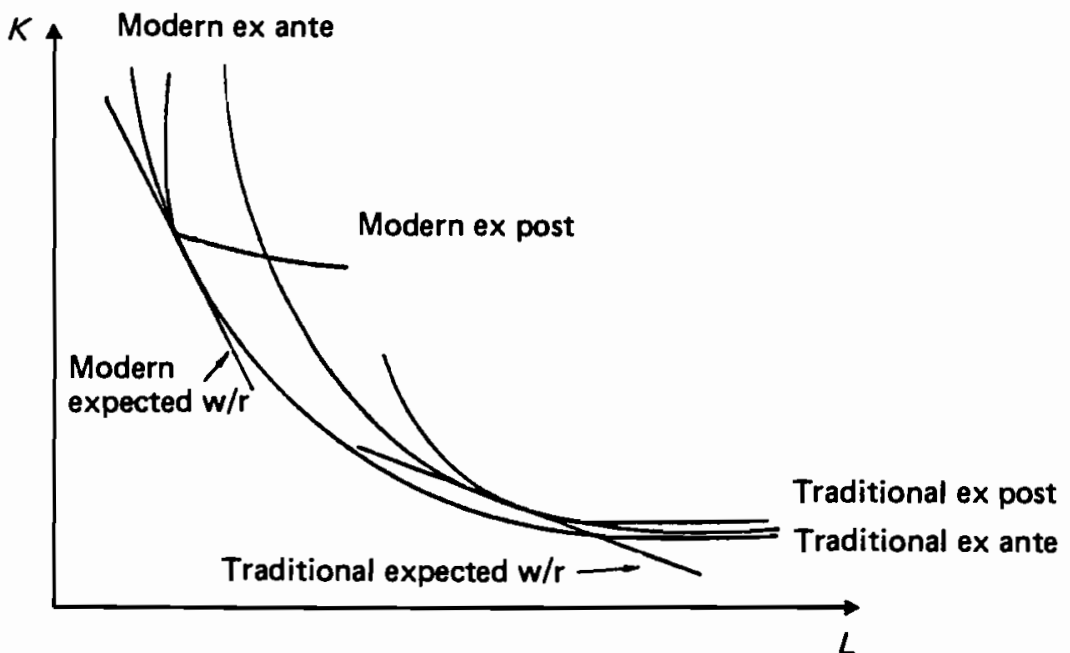

FIGURE 1 Various ex ante functions and wage-rental $(\mathrm{w} / \mathrm{r})$ expectations.

The implicit scenario is that, because of the limited substitutability in the modern sectors, a vailable capital stock and new investment alone almost completely determine the employment of labor in these sectors. The rest of the urban labor force will then have to seek employment in the nonmodern urban sectors: i.e., traditional sectors, where, because of high elasticity of substitution, employees can be hired, but at lower wages.

Finally, where capital stock is concerned, a distinction is made between structure and equipment. Capital structure $(K C)$ is supplied by the construction sector and has a longer lifetime than capital equipment $(K E)$, which is supplied by the modern manufacturing sector.

Production relations are formally expressed in the following production functions. The indices are as follows: 
$1=$ Industry I (MM for 1905-1930; HK for 1950-1963);

2 = Industry II (TE for 1905-1930; MK for 1950-1963);

3 = Industry III (TM for 1905-1930; LK for 1950-1963);

$4=$ Construction;

$5=$ Modern service;

$6=$ Traditional urban service;

$7=$ Rural service;

$8=$ Agriculture and primary activities (including sericulture);

$9=$ Urban housing;

$10=$ Rural housing.

\subsubsection{Production Technology Equations}

For $i=1,2,3,5$

Ex ante

$$
\begin{aligned}
Q_{i}= & A_{i}\left\{\hat{\phi}_{i} \mid \hat{\xi}_{i}\left(\hat{\epsilon}_{i} \underline{S}_{i}^{\hat{\delta}_{i}}+\left(1-\hat{\epsilon}_{i}\right) \underline{K E_{i}} \hat{\hat{\delta}}_{i}\right)^{\hat{\eta}_{i} / \hat{\delta}_{i}}+\left(1-\hat{\epsilon}_{i}\right) \underline{K C} \underline{C}_{i}^{\hat{\eta}_{i}}\right]^{\hat{\xi}_{i} / \hat{\eta}_{i}} \\
& +\left(1-\hat{\phi}_{i}\right) \underline{L}_{i} \hat{\zeta}_{i}^{1 / \xi_{i}}
\end{aligned}
$$

where ^ means ex ante and a bar under a variable means it is measured in efficiency units.

Ex post

$$
\begin{aligned}
Q_{i v}= & A_{i} \cdot A_{i v}\left\{\phi_{i v} \mid \xi_{i v}\left(\epsilon_{i v} \underline{S}_{i}^{\delta_{i v}}+\left(1-\epsilon_{i v}\right) \underline{K E}_{i v} \cdot \exp \left\{\sigma_{\mathrm{E}}(t-v)\right\}\right)^{\eta_{i v} / \delta_{i v}}\right. \\
& \left.\left.+\left(1-\xi_{i v}\right) \underline{K C_{i v}} \exp \left\{-\sigma_{\mathrm{c}}(t-v)\right\}\right]^{\xi_{i v} / \eta_{i v}}+\left(1+\phi_{i v}\right) \underline{L}_{i}^{\zeta_{i v}}\right\}^{1 / \xi_{i v}}
\end{aligned}
$$

where $v=$ vintage (year of installation of a given item).

$$
\begin{aligned}
& \phi_{i v}=\hat{\phi}_{i} /\left[\hat{\phi}_{i}+\left(1-\hat{\phi}_{i}\right)\left(k^{*}\right)^{\xi_{i v}-\hat{\xi}_{i}}\right] \\
& \xi_{i v}=\hat{\xi}_{i} /\left[\hat{\xi}_{i}+\left(1-\hat{\xi}_{i}\right)\left(h^{*}\right)^{\eta_{i v}-\hat{\eta}_{i}}\right] \\
& \epsilon_{i v}=\hat{\epsilon}_{i} /\left[\hat{\epsilon}_{i}+\left(1-\hat{\epsilon}_{i}\right)\left(s^{*}\right)^{\delta_{i v}} \hat{\delta}_{i}\right]
\end{aligned}
$$

where

$k^{*}=$ the efficient composite-capital $(S, K E, K C)$ to labor ratio at given factorprice ratios and a given ex ante production function;

$h^{*}=$ the efficient skill-and-equipment composite $(S, K E)$ to capital structure $(K C)$ ratio at given factor-price ratios and a given ex ante production function; 
$s^{*}=$ the efficient skill-and-equipment composite $(S, K E)$ to capital ratio at given factor-price ratios and a given ex ante production function; and

$A_{i v}=$ a sector-and vintage-specific parameter.

(Note that there is a one-to-one correspondence between production sectors and commodities.)

$$
\begin{aligned}
& \text { For } i=4 \\
& Q_{4}=A_{4}\left[\epsilon_{4} \underline{K E}_{4}^{\rho_{4}}+\left(1-\epsilon_{4}\right) \underline{L}_{4}^{\rho_{4}}\right]^{1 / \rho_{4}} \\
& \text { For } i=6,7 \\
& Q_{i}=A_{i}\left(\underline{K E_{i}}\right)^{\beta_{i}^{i}}(\underline{K C})^{\beta_{2}^{i}}\left(\underline{L}_{i}\right)^{1-\beta_{1}^{i}-\beta_{2}^{i}} \\
& \text { For } i=8 \\
& Q_{8}=A_{8}\left[\theta_{8} \underline{K E}_{8}^{\rho_{8}}+\left(1-\theta_{8}\right) \underline{K C} \underline{8}_{8}^{\rho_{8}}\right]^{\beta_{1}^{8} / \rho_{8}}\left(\underline{L}_{8}\right)^{\beta_{2}^{8}}\left(\chi_{8}\right)^{1-\beta_{2}^{8}-\beta_{1}^{8}} \\
& \text { For } i=9 \\
& Q_{9}=A_{9} K C_{9}^{\beta^{9}}\left(\chi_{9}\right)^{1-\beta^{9}} \\
& \text { For } i=10 \\
& Q_{10}=A_{10} K C_{10}
\end{aligned}
$$

where

$Q_{i}=$ total output of sector $i$

$A_{i}=$ sector-specific shift parameter;

$\phi_{i}, \xi_{i}, \epsilon_{i}, \theta_{i}=$ distribution parameters where constant-elasticity-of-substitution (CES) forms are used;

$\delta_{i}, \eta_{i}, \zeta_{i}, \rho_{i}=$ substitution parameters where CES forms are used;

$\beta^{i}=$ production parameters in Cobb-Douglas forms;

$S_{i v}=$ skilled labor of sector $i$ associated with capital stock of vintage $v$;

$L_{i v}=$ unskilled labor of sector $i$ associated with capital stock of vintage $v$;

$K E_{i v}=$ capital equipment of sector $i$ and of vintage $v$;

$K C_{i v}=$ capital structure of sector $i$ and of vintage $\nu$; and

$\chi_{i}=$ land area of sector $i$.

Equations (1) and (2) are for $i=1,2,3$, and 5 and a "putty-semiputty" assumption is used. The ex post elasticities of substitution are assumed to be smallest for modern 
manufacturing, $i=1$, and increase as the sectors become more traditional. The parameter values for ex ante and ex post production functions of the modern service sector will be derived from more empirical data. These three-stage nested CES functions are specified to incorporate the following three assumptions: equipment and skill are most complementary to one another; the composite of equipment and skills is complementary, although to a lesser degree, to structures; and unskilled labor is considered more as a substitute for any of these capital goods.

The construction sector $(i=4)$ is assumed to use only equipment and unskilled labor for building roads, harbors, and factory structures, etc. This simplification seems to be permissible, given the technology used and the pattern of employment in this sector. Cobb-Douglas specifications are used for traditional service sectors and the primary sector. Capital stock in traditional service sectors includes building structures (usually shared with structures for residential purposes) and some tools.

The Cobb-Douglas specification in agriculture (except for specifying a capital composite where CES is used) is based on past research. Most studies indicate that the elasticity of substitution between factors in this sector is equal to or close to unity. It is also assumed that disaggregation of this sector is not necessary in this case study, because Japan has enjoyed relatively unimodal agricultural development.

Some explanation of the specification with regard to embodied technical changes is in order here. This specification increases not only the number of production functions but also their complexity, in the following sense: (1) each vintage should have different input-output relations; (2) each vintage should have different quality outputs, i.e., newer machines produce better goods; and (3) each vintage can have quite different rates of return on factor inputs.

Considering point (1), where input-output data are not available for the pre-World War II period, production functions are specified in order to include intermediates in the functions in a Cobb-Douglas manner.* That is

$$
Q_{i}=\left(Y_{i}\right)^{\alpha^{\mathrm{VA}}} \cdot \mathrm{II}_{j}\left(A_{j i}\right)^{\alpha_{j}}
$$

and

$$
\alpha^{\mathrm{VA}}+\sum_{j} \alpha_{j}=1
$$

where

$$
\begin{aligned}
Q_{i} & =\text { total output of sector } i \\
Y_{i} & =\text { total value added of sector } i \\
A_{j i} & =\text { input of sector }-j \text { goods in the production of sector } i \\
\alpha^{\mathrm{VA}} & =\text { distribution parameter for value added; and } \\
\alpha_{j} & =\text { distribution parameter for input } j .
\end{aligned}
$$

\footnotetext{
*I am grateful to Warren Sanderson for pointing out that this is possibly easier than estimating the input-output tables.
} 
There are problems, however. One is the method of estimation of $\alpha$, and the other is that only intermediate input substitution through relative price change is accounted for whereas input-saving technical progress is not. The estimation of $\alpha$, for the time being, will only be carried out by simulation -- choosing a value for $\alpha$ that replicates history with a certain degree of precision. The second problem could be the topic of future research. For the post-World War II period, where the input - output data are more readily available, both value-added and total-output specifications could be tried; the former would use variable rather than fixed input--output relations.

With regard to point (2) (the quality differences among vintages), it is assumed that products of the same category are completely homogeneous in the eyes of the consumers. They pay the same price and get the same satisfaction from products produced by equipment of different vintages.

Turning to point (3), rates of return on capital are allowed to vary by vintage,* but the wage rate will be identical within each sector for the same kind of labor, regardless of the difference in vintage of the equipment used.

There are two elements determining the lifetime of capital stock: physical and economic. Both are taken into account. The first is specified by the maximum number of years a certain kind of capital stock could stay in production. This is determined by exogenously given fixed rates of depreciation, or lifetimes under the one-hoss-shay assumption.**

Economic obsolescence is taken into account by the following criterion: if any capital stock has a negative net rate of return for two consecutive years, the whole vintage of that sector will be disposed of without any cost, regardless of how old that stock is.

\subsection{Pricing and Factor Returns}

The cost of production and the value-added price will first be defined. The cost of production is the minimum required to produce the commodity, and the cost per unit of the commodity is the producer's price. This is the total cost of all inputs:

$$
P_{i}=l_{i} \frac{L_{i v}}{Q_{i v}}+q_{i} \frac{S_{i v}}{Q_{i v}}+r_{\mathrm{E} i v} \frac{K E_{i v}}{Q_{i v}}+r_{\mathrm{C} i v} \frac{K C_{i v}}{Q_{i v}}+\sum_{j=0}^{n} P_{j}^{\mathrm{c}} \frac{A_{j i}}{Q_{i v}}
$$

where

$$
\begin{aligned}
P_{i} & =\text { producer's price of commodity } i \\
l_{i} & =\text { user cost of unskilled labor in sector } i \\
q_{i} & =\text { user cost of skilled labor in sector } i \\
r_{\mathrm{E} i v} & =\text { user cost of capital equipment (quasirent) of vintage } v \text { in sector } i \\
r_{\mathrm{C} i v} & =\text { user cost of capital structure (quasirent) of vintage } v \text { in sector } i
\end{aligned}
$$

*Aggregation of capital of different vintages is impossible unless technical progress is purely capitalaugmenting, which has been ruled out.

**The production functions in eqn. (2) only use the fixed-rate-depreciation assumption but the onehoss-shay assumptions (where capital stock is assumed not to depreciate during its lifetime but is assumed to disappear completely at the end of its lifetime) will be tried in some future simulations. 
$P_{j}^{\mathrm{c}}=$ purchase price of commodity $j$; and

$A_{j i}=$ inputs of commodity $j$ to product commodity $i$ (in the case where $j=0, A_{j i}$ are imports).*

The value-added price is defined as

$$
P_{i}^{\mathrm{VA}}=P_{i}-\sum_{j} P_{j}^{\mathrm{c}} \frac{A_{j i}}{Q_{i}}=l_{i} \frac{L_{i v}}{Q_{i v}}+q_{i} \frac{S_{i v}}{Q_{i v}}+r_{\mathrm{E} i v} \frac{K E_{i v}}{Q_{i v}}+r_{\mathrm{C} i v} \frac{K C_{i v}}{Q_{i v}}
$$

The ex post user costs of primary factors and the noncompetitively imported commodity are in turn defined as:

$$
\begin{aligned}
l_{i} & =\left(1+t_{\mathrm{L}}\right) W_{i}^{\mathrm{L}}+b_{i} T_{i} \text { and } \partial l_{i} / \partial W_{i}^{\mathrm{L}}=0 \quad \text { for } i=1,2,5 \\
q_{i} & =\left(1+t_{\mathrm{S}}\right) W_{i}^{\mathrm{S}} \\
r_{\mathrm{E} i v} & =\left(\frac{1}{1-t_{r}} R_{i v}^{\mathrm{E}}+\sigma_{i}^{\mathrm{E}}\right) P_{1} \\
r_{\mathrm{C} i v} & =\left(\frac{1}{1-t_{r}} R_{i v}^{\mathrm{C}}+\sigma_{i}^{\mathrm{C}}\right) P_{4} \\
P_{0}^{\mathrm{C}} & =\left[1+t_{(i)}^{\mathrm{FNC}}\right] P_{0}^{\mathrm{W}} \cdot \tau
\end{aligned}
$$

where

$$
\begin{aligned}
t_{\mathrm{L}} & =\text { tax rate on unskilled labor wage (employer's contribution); } \\
t_{\mathrm{S}} & =\text { tax rate on skilled labor wage (employer's contribution); } \\
t_{r} & =\text { tax rate on capital profit income; } \\
t_{(i)}^{\mathrm{FNC}} & =\text { tariff rate on noncompetitive imports;** } \\
W_{i}^{\mathrm{L}} & =\text { wage rate for unskilled labor; } \\
W_{i}^{\mathrm{S}} & =\text { wage rate for skilled labor; } \\
R_{i}^{\mathrm{E}} & =\text { after-tax rate of return on capital equipment; } \\
R_{i}^{\mathrm{C}} & =\text { after-tax rate of return on capital structure; } \\
\sigma_{i}^{\mathrm{E}} & =\text { depreciation rate of capital equipment; } \\
\sigma_{i}^{\mathrm{C}} & =\text { depreciation rate of capital structure; } \\
P_{1} & =\text { price of capital equipment (三 price of modern manufacturing-sector goods); }
\end{aligned}
$$

*This particular specification assumes imported inputs of only one kind. But it is relatively easy to disaggregate them, and this is done if required.

**Average tariff rates will be used for most simulations. However, when more detailed aspects of tariff policies need to be studied, sector-specific rates $t_{(i)}^{\mathrm{FNC}}$ or $t_{(i)}^{\mathrm{FC}}$ will be employed, for noncompetitive and competitive imports, respectively. 
$P_{4}=$ price of capital structure ( $\equiv$ price of construction-sector services);

$P_{0}=$ user price of imported goods;

$P_{0}^{\mathrm{W}}=$ world price of imported goods;

$\tau=$ exchange rate;

$b_{i}=$ rate of unskilled labor turnover where $b_{i}=b_{i}\left(W_{1}, \ldots, W_{\mathrm{g}}\right)$; and

$T_{i}=$ sector-specific hiring and training cost of unskilled labor, but $T_{i}=0$ for $i=3,6,7,8$.

The above equations are quite conventional and need no further explanation except for the user cost of unskilled labor. For sectors 1,2, and 5 (modern manufacturing, textiles, and modern services) this cost is assumed to depend on the hiring and training cost and the rate of turnover as well as on wages and taxes.* This specification means that even the unskilled require a certain amount of training in these sectors. The training is firm-specific and is not considered as a "cost" unless those who received the training subsequently leave. The cost of recruitment - incurred when looking for appropriate employees - is included in the specification. This cost was historically most explicit in the textile sector where employers in the sector had to send staff to rural areas to recruit girls for the workforce.

Consumer prices for domestically produced goods are specified as

$$
P_{i}^{\mathrm{c}}=\left(l+t_{i}^{\mathrm{id}}\right) P_{i}\left(l+\psi_{i}\right)
$$

where

$$
\begin{aligned}
t_{i}^{\mathrm{id}}= & \text { indirect tax rate; and } \\
\psi_{i}= & \text { markup for transport cost, being } 0 \text { when the goods are consumed in the area } \\
& \text { of production. }
\end{aligned}
$$

Consumer prices for competitive imports are written as

$$
P_{0}^{\mathrm{c}}=\left(l+t^{\mathrm{FC}}\right) P_{0}^{\mathrm{W}} \cdot \tau
$$

Finally, the neoclassical marginal principles apply with respect to factor returns, ${ }^{* *}$ that is

\footnotetext{
*A similar specification is used for studying migration by Stiglitz (1973). For convenience the lost training cost is treated in the same way as depreciation.

**For traditional sectors, of course, these are just imputed shares. For the agricultural sector, it is explicitly assumed that the population perceives average income as a measure of welfare, especially in making decisions to migrate. See Section 3.5.3 on this subject. As to the urban traditional sectors, it is assumed that the marginal principle still holds even in rural - urban migration decisions, assuming that most migrants would not become self-employed proprietors right away. In other words, they would first be employed by a small factory or retail shops. Of course, when selfemployed proprietors using family labor decide to become employed laborers, the average family income (not wage income) should then be measured against the wage rate of the possible employment. This intraurban, intersectoral movement is left for a later sensitivity analysis.
} 


$$
\begin{array}{rlr}
l_{i} & =P_{i}^{\mathrm{VA}}\left(\partial Q_{i v} / \partial L_{i v}\right) \quad(\text { for all } v) \\
q_{i} & =P_{i}^{\mathrm{VA}}\left(\partial Q_{i v} / \partial S_{i v}\right) \quad(\text { for all } v) \\
r_{\mathrm{E} i v} & =P_{i}^{\mathrm{VA}}\left(\partial Q_{i v} / \partial K E_{i v}\right) & \\
r_{\mathrm{C} i v} & =P_{i}^{\mathrm{VA}}\left(\partial Q_{i v} / \partial K C_{i v}\right) &
\end{array}
$$

\subsection{Factor Allocation}

The three kinds of capital goods (skill, equipment, and structures) and labor are allocated over various sectors for the production of goods and services. The way the factors are allocated is crucial for an economy; how new factors are allocated and how the existing labor force shifts among the various sectors are the major determinants of the future paths the economic--demographic development of the country will take. The following description shows how this allocation is determined in the present model.

\subsubsection{Physical Productive Private Investment}

Physical productive private investment applies to both capital equipment and capital structures. Investors are supposed to be fully informed of ex ante technical possibilities, and they also have the sector-specific expectations on future factor prices and demand for their output. The most efficient factor employment per unit of output (or value added) is obtained using Shephard's Lemma (Shephard, 1953) by taking the first-order derivative of the unit cost function with respect to the user cost of that factor. Thus

$$
\partial \mu / \partial r_{\mathrm{E}}=(K E / Q)^{*}
$$

where

$$
\begin{aligned}
\mu & =B / Q \\
B & =\text { the cost function implied by the production technology; and } \\
(K E / Q)^{*}= & \text { the optimum capital-equipment-output ratio given the technology and } \\
& \text { the user cost of capital. }
\end{aligned}
$$

It is assumed that investors have expectations on future demand in addition to factor prices. Suppose then that $D_{i}^{\mathrm{e}}$ is the expected demand per year for the sector $i$ commodity, and $S_{i}^{\hat{A}}$ is the actual capacity for supplying this commodity, less depreciation. Then the new capacity for this product needed for the next period is: $\dagger$

$$
D D_{i} \underset{\text { def }}{=} D_{i}^{\mathrm{e}}-S_{i}^{\mathrm{A}}
$$

†If $D D_{i}$ turns out to be negative, an atypical case for a growing economy, it is assumed that the gross investment in the sector concerned is 0 . 
The new capital stocks required are the expected investments, and these can be specified as

$$
I_{\mathrm{E} \cdot i}^{\mathrm{e}}=P_{1}\left(\partial \mu_{i} / \partial \nu_{\mathrm{E} \cdot i}^{\mathrm{e}}\right) \cdot D D_{i}
$$

for equipment in sector $i$, and

$$
I_{\mathrm{C} \cdot i}^{\mathrm{e}}=P_{4}\left(\partial \mu_{i} / \partial \nu_{\mathrm{C} \cdot i}^{\mathrm{e}}\right) \cdot D D_{i}
$$

for structures in sector $i$, where $I_{\mathrm{E} \cdot i}^{\mathrm{e}}$ and $I_{\mathrm{C} \cdot i}^{\mathrm{e}}$ are expected investments in sector $i$ for equipment and structures, respectively, and $\nu_{\mathrm{E} \cdot i}^{\mathrm{e}}$ and $\nu_{\mathrm{C} \cdot i}^{\mathrm{e}}$ are expected costs of the use of capital equipment and structures, respectively.

The total investment, however, is constrained by total available savings although the current period's excess demand for investment has some effect on the next period's saving patterns for capital-income earners. Thus the actual investment in sector $i$ in capital goods $k(k=\mathrm{E}, \mathrm{C})$ is

$$
I_{k \cdot i}^{\mathrm{A}}=\left(I_{k \cdot i}^{\mathrm{e}} / \sum_{k} \sum_{j} I_{k j}^{\mathrm{e}}\right) S A V_{\mathrm{p}}
$$

where

$$
j=\text { the capital-using sectors }(1,2,3,4,5,6,7,8) \text {; }
$$

$k=\mathrm{E}$ and $\mathrm{C}$; and

$S A V_{\mathrm{p}}=$ saving a vailable for physical productive investment.

Finally, the specification of how expectations are formulated is as follows.* It is assumed that investors act in a "myopic" fashion. Thus

$$
\begin{aligned}
& D_{i}^{\mathrm{e} \cdot t+1}(t)=\gamma_{D}\left[D_{i}^{\mathrm{A}}(t)-D_{i}^{\mathrm{e} \cdot t}(t-1)\right]+D_{i}^{\mathrm{A}}(t) \\
& W_{i}^{\mathrm{e} \cdot t+1}(t)=\gamma_{W}\left[W_{i}^{\mathrm{A}}(t)-W_{i}^{\mathrm{e} \cdot t}(t-1)\right]+W_{i}^{\mathrm{A}}(t) \\
& r_{k \cdot i}^{\mathrm{e} \cdot t+1}(t)=\gamma_{r_{k}}\left[r_{k \cdot i}^{\mathrm{A}}(t)-r_{k \cdot i}^{\mathrm{e} \cdot t}(t-1)\right]+r_{k \cdot i}^{\mathrm{A}}(t) \quad(k=\mathrm{E}, \mathrm{C}) \\
& \nu_{k \cdot i}^{\mathrm{e} \cdot t+1}(t)=\gamma_{\nu_{k}}\left[\nu_{k \cdot i}^{\mathrm{A}}(t)-\nu_{k \cdot i}^{\mathrm{e} \cdot t}(t-1)\right]+\nu_{k \cdot i}^{\mathrm{A}}(t) \quad(k=\mathrm{E}, \mathrm{C}) \\
& q_{i}^{\mathrm{e} \cdot t+1}(t)=\gamma_{q}\left[q_{i}^{\mathrm{A}}(t)-q_{i}^{\mathrm{e} \cdot t}(t-1)\right]+q_{i}^{\mathrm{A}}(t)
\end{aligned}
$$

where

$$
\begin{aligned}
X_{i}^{\mathrm{e} \cdot t}(t-1)= & \text { the expected value of } X \text { for time } t \text { in sector } i, \text { for an expectation } \\
& \text { formed at } t-1
\end{aligned}
$$

\footnotetext{
"Expectations on factor costs are based on the technology used by the "best practice" firms of the sector concerned.
} 


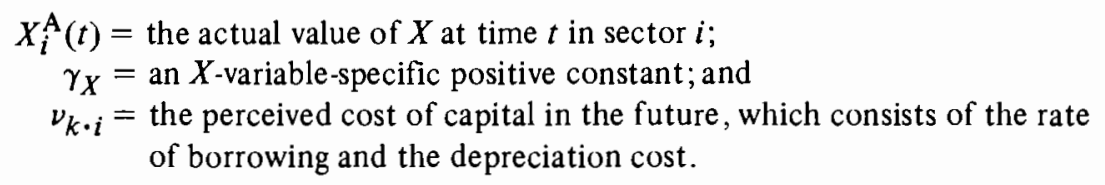

\subsubsection{Public Investment}

Public investment will in general be taken as exogenous in the model, because of its very nature: in real life it is greatly influenced by exogenous factors, such as typhoons, earthquakes, and wars.* However, a word of clarification should be added here. It is assumed that some particular government organizations, government-run factories, the national railway system, electricity generators, and so forth, are already dealt with in the appropriate sectors. That is, railways and power are placed in the modern service sector, public factories in the modern service or the appropriate industrial sectors, etc. Therefore, the remaining parts that are considered as exogenous in public investment are public infrastructure construction (both agricultural and general), natural disaster reconstruction, construction for military, religious, and cultural facilities, furniture and fixture, and nonmilitary building construction. Only public infrastructure construction is really significant, and more efforts will be made in future to endogenize this variable. Nonmilitary building construction is important in the sense that the greater part of it in Japan is for school buildings. This will be discussed in Section 3.10.

\subsubsection{Migration}

Here only intranational migration in a narrow sense is considered. For Japan, this means that population movement to Korea, Taiwan, and Manchuria would be exogenous. "Migration" is also understood here as intersectoral flows of population. More emphasis is, therefore, given to the shift of population from agricultural to nonagricultural sectors. From our assumptions on sectoral division, this movement is synonymous in the model with rural-urban migration. But one should remain aware of the differences between the nonagricultural and urban sectors. It is accepted that the present model takes a very simplistic approach with regard to migration, despite the myriad works discussing this issue.** From the economic point of view, especially concerning developing countries, the literature does not seem to have progressed much beyond the Harris-Todaro specifications (Harris and Todaro, 1970).

The Harris-Todaro concept will also be invoked here to specify migration as a function of the ratio of expected urban income to average income in the rural sector. The expected urban income is a weighted average of various urban wages. These weights, however, are different from those used in the conventional Harris-- Todaro framework. Here, because labor migration in Japan was historically highly demand-oriented, the number of available jobs for migrants in each sector will be used as a weight. This weight consists, therefore, of the number of new jobs created by new investment and the amount of employee turnover.

\footnotetext{
*During the period 1900-1940, the proportion of public investment in construction that went into work repairing the damage caused by typhoons and earthquakes varied from $10 \%$ to $15 \%$; during the same period the proportion of military investment in total government equipment investment varied from less than $10 \%$ to close to $90 \%$.

**For a summary of a more or less economic view, see Todaro (1975), and for a demographic aspect see Rogers $(1977,1980)$.
} 
Thus the rural--urban migration $\left(M_{\mathrm{ru}}\right)$ is specified as follows:

$\frac{M_{\mathrm{ru}}}{L_{\mathrm{r}}}=m \ln \left(\widetilde{W}_{\mathrm{u}} / \widetilde{W}_{\mathrm{r}}\right)$

where

$L_{\mathrm{r}}=$ rural labor force; and

$m=$ a parameter.

Also

$$
\begin{aligned}
& \widetilde{w}_{\mathrm{u}}=\frac{1}{C O L_{\mathrm{u}}} \cdot \frac{\Sigma_{i} \Sigma_{j} d^{j} \theta_{i}^{j} W_{i}^{j}}{\Sigma_{i} \Sigma_{j} d^{j} \theta_{i}^{j}} \quad \begin{array}{l}
(j=\text { skilled }(\mathrm{S}) \text { or unskilled }(\mathrm{L}) \text { labor } ; i=\text { urban } \\
\text { sectors })
\end{array} \\
& d^{j}=d \quad 0<d<1 \quad \text { (if } j=\text { skilled) } \\
& d^{j}=1 \quad \text { (if } j=\text { unskilled) } \\
& \theta_{i}^{\mathrm{S}}=\left[I_{K E \cdot i}^{\mathrm{A}}(-1)+I_{K C \cdot i}^{\mathrm{A}}(-1)\right] \cdot\left[\frac{S_{i}(-1)}{P_{1}(-1) K E_{i}(-1)+P_{4}(-1) K C_{i}(-1)}\right]+b_{i}^{\mathrm{S}}(-1) \cdot S_{i}(-1) \\
& \theta_{i}^{\mathrm{L}}=\left[I_{K E \cdot i}^{\mathrm{A}}(-1)+I_{K C \cdot i}^{\mathrm{A}}(-1)\right] \cdot\left[\frac{L_{i}(-1)}{P_{1}(-1) K E_{i}(-1)+P_{4}(-1) K C_{i}(-1)}\right]+b_{i}^{\mathrm{L}}(-1) \cdot L_{i}(-1) \\
& \widetilde{w}_{\mathrm{I}}=\frac{1}{C O L_{\mathrm{r}}} \cdot\left[\rho_{1} y_{\mathrm{o}}+\rho_{2} y_{\mathrm{p}}+\left(1-\rho_{1}-\rho_{2}\right) y_{\mathrm{N}}\right]
\end{aligned}
$$

Here

$y_{\mathrm{o}}=$ average income of owner-cultivators;

$y_{\mathrm{p}}=$ average income of peasants;

$y_{\mathrm{N}}=$ average income of nonagricultural rural workers;

$\rho_{1}=$ proportion of owner-cultivators in the rural population;

$\rho_{2}=$ proportion of peasants in the rural population;

$C O L_{j}=$ cost of living index in area $j=\Sigma_{i} \omega_{i}^{j} P_{i}^{j}(j=$ urban, rural $)$;

$\omega_{i}^{\mathrm{r}}=\omega_{i}\left(E^{\mathrm{r}}\right)$, where $E^{\mathrm{r}}=$ expenditure of rural agricultural labor;

$\omega_{i}^{\mathrm{u}}=\Sigma_{h} V^{h} \omega_{i}\left(E^{h}\right)$, where $V^{h}=$ population in income class $h /$ total urban population, $E^{h}=$ expenditure of income class $h$, and $\omega_{i}=$ budget share for commodity $i$; and

$d=$ discount factor for skilled employment. 


\subsection{Consumer Demand}

\subsubsection{Static Consumption}

For more than two decades economists have explored specifications of a complete system of demand equations that are able to extract various price and income responses froin (usually) limited data, at the same time satisfying various restrictions derived from consumer theory.

For the analysis of developing countries, the two systems used most of ten and therefore the most tested over time are the linear expenditure system (LES) and the addilog demand system. More flexible specifications include, but are not limited to, the Rotterdam (e.g., Theil, 1976), the translog (Christensen et al., 1975), and the almost ideal demand system (AIDS) (Deaton and Muellbauer, 1980) specifications. These latter specifications often use duality theory, i.e., the first-order partial derivative of the expenditure function with respect to the price of a given commodity is the (Hicksian) demand for that commodity of a utility-maximizing consumer, or the Roy identity. The former specifications (LES and the addilog demand system) have the advantages of enabling clearer and more straightforward interpretations of various concepts such as elasticities or minimum basic needs to be made, in addition to the relative easc of estimation of parameters; but at the same time the constraints imposed on the system a priori are more rigid than those demanded by specifications in the other group.

In this paper, the more flexible demand systems are preferred over LES, ELES, ${ }^{*}$ and addilog, owing mainly to a desire to avoid rigid assumptions, and also so that it will eventually be possible to examine the implications of discarding homogeneity or Slutskysymmetry assumptions. Furthermore, out of the various flexible specifications mentioned, it is proposed that AIDS be used, at least initially, for this case study. This system has advantages in that all of the following requirements are simultaneously satisfied: it gives an arbitrary first-order approximation to any demand system; it satisfies axioms of choice exactly; it aggregates perfectly over consumers without invoking parallel linear Engel curves; it has a functional form consistent with known houschold-budget data; and it is simple to estimate, avoiding nonlinearity in the parameters.

The simplified equations to be estimated and used have the form

$$
\omega_{i}=\alpha_{i}+\sum_{j} \gamma_{i j} \ln P_{j}+\beta_{i} \ln E / P_{\text {ind }}
$$

where

$$
\begin{aligned}
\omega_{i} & =\text { budget share for commodity } i \\
\alpha_{i}, \beta_{i}, \gamma_{i j} & =\text { constants }(i, j=1,2, \ldots, n) ; \\
P_{j} & =\text { price of commodity } i \\
E & =\text { total consumption expenditure; and } \\
P_{\text {ind }} & =\text { an aggregate price index.** }
\end{aligned}
$$

*Extended linear expenditure system.

**Deaton and Muellbauer (1980) derived this index as

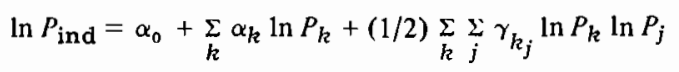

but they propose simplification to $\ln P_{\text {ind }}=\Sigma \omega_{k} \ln P_{k}$. This will be subject to further examination using Japanese data before being employed in the model. 
Constraints on parameter values are as follows:

$$
\Sigma \alpha_{i}=1, \quad \sum_{i=1}^{n} \gamma_{i j}=0, \quad \sum_{i=1}^{n} \beta_{i}=0
$$

for adding up,

$$
\sum_{j} \gamma_{i j}=0
$$

for homogeneity, and

$$
\gamma_{i j}=\gamma_{j i}
$$

for symmetry.

The following consumption-commodity groups will be used: consumer durables (produced by the modern manufacturing sector); cloths and clothing (produced by the textile industry); processed food and miscellaneous goods (produced by traditional industry); transportation, communication, electricity, and fuels (produced by the modern service sector); other services (produced by traditional service sectors); agricultural products (rice, vegetables, etc.) (produced by agriculture); and housing.

The following forms of income class will be used in the analyses: urban unskilled labor; urban skilled labor; rural labor; and rural landlords and urban capital-income earners. Landlords and capitalists are considered in the same way because many landlords in Japan were absentee landlords living in urban areas, and many did indeed become capitalists by investing in the nonagricultural sectors.

Saving ratios are taken from the historical data year by year because of the difficulty of endogenizing them through intertemporal optimization. The only system that uses endogenous saving ratios is the ELES: the saving ratio in this system is determined by the supernumerary income ratio and the marginal propensity to consume (assumed to be fixed at the ratio of the personal discount rate to the market interest rate). This is a very useful feature for short-term or cross-section analyses. For long-term simulation, however, the assumptions that the marginal propensity to consume and the amount of basic minimum bundles are fixed must be subjected to careful examination. If these assumptions do not seem to hold, the endogenous saving feature could do more harm than good. This is why the ELES has not been chosen as a system for the base simulation, although use of its modified version has not been excluded for future work, especially for the dynamic study of demand.

\subsubsection{Demographic Variables}

It is important that the links between demographic and economic features be included in the present model. One of the more important such links exists in household consumption demand: the different demographic characteristics of households are very likely to affect their patterns of demand. The demographic features concerned include number of family members, number of children, and age and sex of family heads, etc. There have been some promising attempts to incorporate demographic variables into both complete demand systems such as LES or QES (quadratic expenditure system) (see, for example, Pollak and Wales, 1978) and flexible systems. 
With AIDS, however, some demographic variables can be incorporated directly into the demand cquations in the following manner:

$$
\omega_{i}^{\mathrm{h}}=\alpha_{i}+\sum_{j} \gamma_{i j} \ln P_{j}+\beta_{i} \ln \left(E^{\mathrm{h}} / k^{\mathrm{h}} P_{\text {ind }}\right)
$$

where $\mathrm{h}$ is the household index and the new variable $k^{\mathrm{h}}$ is interpreted as some measure of family size; thus $E^{\mathrm{h}} / k^{\mathrm{h}}$ would be, according to Deaton and Muellbauer (1980), the "needscorrected-per-capita-expenditure" level.

\subsubsection{Dynamic Features}

There is no denying that the static consumption specification described above has a very serious deficiency in that, by definition, it ignores all dynamic aspects. For example, it would be misleading to consider the purchase and the consumption of consumer durables to be one and the same. One must also consider habit formation effects, or "inventory" adjustment behavior, as well as changes in taste over a long period. Part of the reason many econometric studies reject homogeneity or other assumptions derived from consumer theory may be because these assumptions ignore such dynamic features.

In the first stage of this case study, however, only changes in taste over the long run will be taken into account. The trend change of parameters is specified in the following way:

$$
X_{i \cdot t}=X_{i \cdot 0}+X_{i}(t)
$$

In other words, $X$ (which can be any parameter) is decomposed into the base-year value $X_{i \cdot 0}$ and the time-related trend value $X_{i}(t) . X_{i}$ can be positive or negative.

\subsection{Relations with the Rest of the World*}

\subsubsection{Exports}

There is no doubt that exports have played an important and active role in Japanese economic growth.** As a resource-poor country, Japan has to import raw materials and export manufactured goods. As described in detail in Section 2, however, the actual composition of trade kept on changing during the period studied; exports started with raw silk in the early Meiji period, then later other textile exports increased, and finally from the 1920 s on, the export of machinery and other heavier industrial products began to slow a clistinct rate of increase. It is also noteworthy that all these upturns in exports were preceded by import-substitution phases.

This brief review clearly shows that a mere "vent-for-surplus" specification is not enough for a model of Japan, much less for the exogenous export component. I propose

\footnotetext{
*Taiwan and Korea came under Japanese rule in 1896 and 1910, respectively. Even for the period under Japanese rule they are considered as part of the rest of the world, thereby making trade with them a part of total foreign trade (see Section 3.7.4).

**There has been a long argument as to whether Japanese economic growth was actually export-led. The argument is inconclusive, but Dohner (1979) suggests that in pre-World War II Japan growth was export-led, and that in post-World War II Japan export was export-price-led in the sense of Cave's definition (Cave, 1971).
} 
therefore to use the Armington specification (Armington, 1969):*

$$
E X_{i}=C_{i}^{x} \cdot(W T)_{i}\left(P_{i}^{\mathrm{Jex}} / \tau \cdot P_{i}^{\mathrm{W}}\right)^{\eta_{i}^{\mathrm{W}}}
$$

where

$$
\begin{aligned}
E X_{i} & =\text { exports of sector } i \\
C_{i}^{x} & =\text { constant for this sector; } \\
(W T)_{i} & =\text { total amount of world trade of goods from this sector } \\
P_{i}^{\mathrm{Jex}} & =\text { Japanese export price for sector }-i \text { goods; } \\
P_{i}^{\mathrm{W}} & =\text { world price for sector }-i \text { goods; } \\
\eta_{i}^{\mathrm{W}} & =\text { the elasticity of substitution in the world market } * * \text { for sector }-i \text { goods; and } \\
\tau & =\text { exchange rate. }
\end{aligned}
$$

This is a logical specification to use because of the divergences, shown in Figure 2, between domestic prices, export prices, and world prices that are apparent in the pre-World

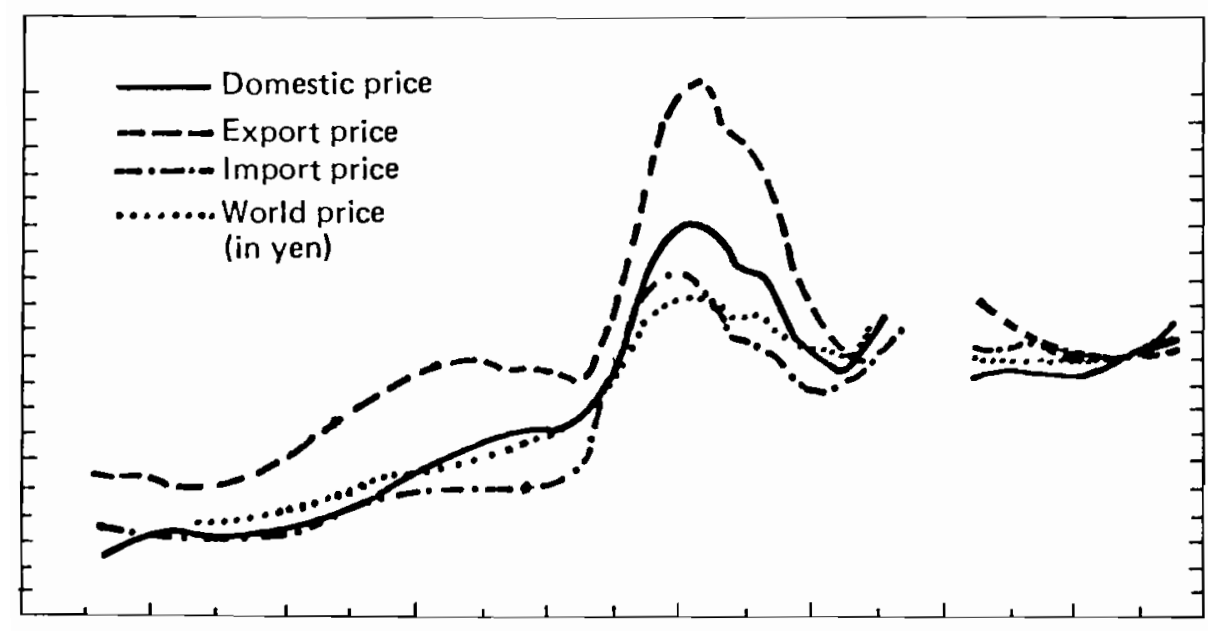

FIGURE 2 Domestic, export, import, and world trade price indexes for manufactured goods (sevenyear moving average). Source: LTES (1979).

*Accounting consistency is maintained by assuming government trade arbitrages. Other specifications, such as the use of hypothetical composite goods made up of imported and domestically produced goods, will be used in future work.

**This elasticity of substitution comes from the Armington CES specification for utilities that can be achieved by consuming products of the same kind but of differcnt origins, e.g., clothes from the UK and clothes from Singapore. 
War II period. Also, by studying the movement of prices of each product, it can be seen that, during the period 1900-1930, domestic prices increased (on average) for food products and decreased for ceramics, chemicals, metals, and textiles. These changes were passed on to export prices. On the other hand, import prices increased for ceramics and machinery, and decreased for chemicals, food, and metals (see Table 3) during the same period.

TABLE 3 Percentage change in prices of various goods in Japan between the 1900 s and the $1930 \mathrm{~s}^{a}$.

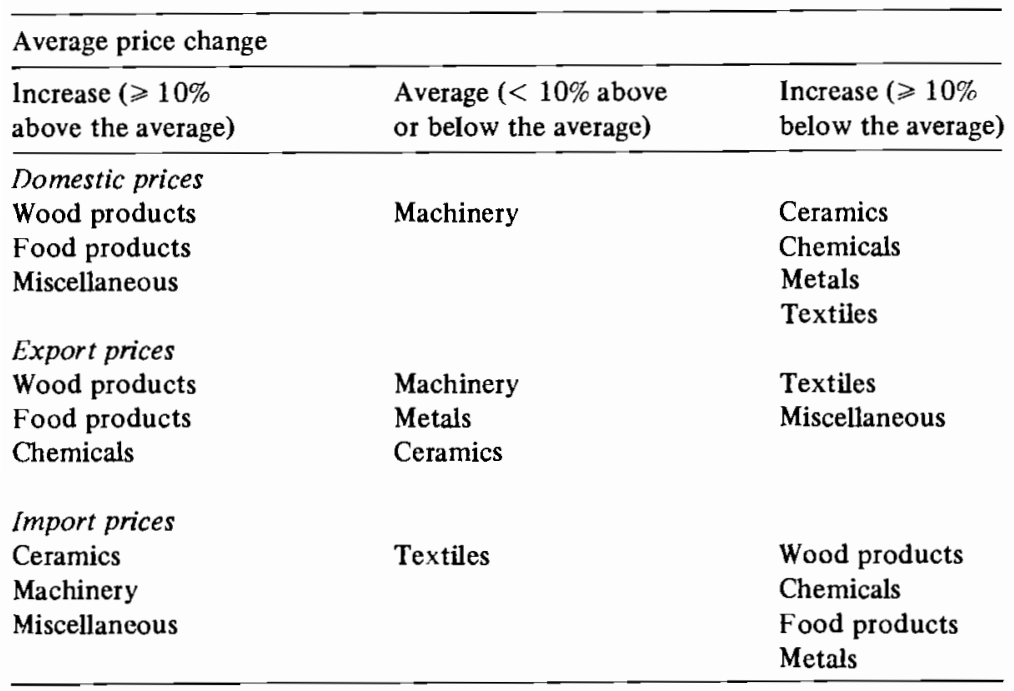

${ }^{a}$ Source: LTES (1979).

From this table, it is apparent that ceramics, textiles, and machinery experienced price changes favoring exports, while food and wood imports were bound to increase. Taken in conjunction with this, calculations of the world price and total world trade (an approximation for world demand) would determine the export of Japanese goods. It is easy to introduce complexity by considering the formation of the yen-block with different elasticities for each of the yen-block countries. But for the present purpose, it should be enough to consider these purely economic factors only.

\subsubsection{Imports}

Imports can be viewed as a mirror-image of exports in the sense that they are goods demanded by Japan from the rest of the world. In developing countries, there are many goods that cannot be produced domestically but that are needed to maintain and expand the economy. These are called noncompetitive imports. In the present work they will be treated as a function of total output and the Armington specification will not be used. For competitive imports, i.e., those goods that can be supplied from within the country but are nevertheless imported, the Armington specification is employed. 
For noncompetitive imports

$$
M^{\mathrm{NC}}=\sum_{j} a_{0 j} Q_{j} P_{0}^{\mathrm{W}} \tau\left(1+t^{\mathrm{FNC}}\right)
$$

Here $a_{0 j}$ (the input-output coefficient) can vary over time, and should do so for a longterm analysis. Also, it is possible to divide $a_{0 j}$ into the sectors of origin, e.g., using $a_{0 i j}$ for the noncompetitive imports of good $i$ to sector $j$, for the post-World War II period. $t^{\mathrm{I} N C}$ is the tariff rate on noncompetitive imports.

In general it is assumed, for the periods concerned, that raw materials and intermediate goods are noncompetitive. Competitive imports are therefore finished products (consumer goods). The specification of competitive imports is

$$
M_{i}^{\mathrm{C}}=C_{i}^{M} \cdot D_{i} \cdot\left(\tau \cdot P_{i}^{\mathrm{W}}\left[1+t_{(i)}^{\mathrm{FC}}\right] / P_{i}\right)^{\xi_{i}^{\mathrm{w}}}
$$

where

$$
\begin{aligned}
D_{i} & =\text { total domestic demand } \\
P_{i}^{\mathrm{W}} & =\text { world import price; } \\
P_{i} & =\text { domestic price; } \\
t_{(i)}^{\mathrm{FC}} & =\text { tariff rate on competitive imports (see the second footnote, p. 117); } \\
& \quad \text { and } \\
\xi_{i}^{\mathrm{W}} & =\text { elasticity (see the second footnote, p. 126). }
\end{aligned}
$$

Then the trade deficit is

$$
T D=\sum_{i} P_{i}^{\mathrm{W}} \tau M_{i}^{\mathrm{C}}+M^{\mathrm{NC}}-\Sigma P_{j}^{\mathrm{Jex}} \cdot E X_{j}
$$

which is defined as foreign saving

$$
T D \underset{\text { def }}{=} F S
$$

This assumes that the trade deficit is covered by some means of foreign capital inflow, which was, in general, the case during the period studied. This aspect is briefly mentioned below.

\subsubsection{Capital Movements}

Capital movements are treated residually or exogenously. It is not that they were unimportant. On the contrary, despite the general belief that they were unimportant for Japan, Yamazawa and Yamamoto (1979) found that growth is accompanied by significant increases of capital inflow to finance the excess demand (see also Key, 1970). But for present purposes it will be taken as residually determined from the current deficit, because the sum of long-term and short-term capital inflows more or less offsets the current deficit every year. Other capital flows are taken as exogenous because of their one-shot nature, for example, war reparations. 


\subsubsection{Taiwan and Korea}

Even though Taiwan and Korea are treated as among the "rest of the world" in the present model, it is probably worthwhile to review the roles they played in forming Japanese trade patterns, in anticipation of future studies. Trade with these two countries increased rapidly after they came under Japanese rule, but they were given very different roles from the Japanese point of view. Taiwan was regarded as a supplier of food and raw materials to Japan and therefore always had a positive surplus in trade with Japan. Korea, in contrast, was given the role of a market for Japanese products, with the exception of rice exports to Japan during the period 1918-1930.* Trade with Taiwan and Korea also differed in that only yen were used as payment; there was no incremental demand or supply of foreign exchange.

\subsection{Government}

Many government activities have already been studied in the sectors for production and investment, e.g., the railways, power generation, government factories, etc. The remainder of the government activities, which are considered as exogenous, are as follows: nonmilitary government consumption; nonmilitary government investment (general infrastructure, agricultural investment, buildings, furniture, natural disaster reconstruction); transfers to households; subsidies to various private sectors; ${ }^{* *}$ transfers to the rest of the world; and military expenditure."

Therefore, government expenditure is represented by

$$
G_{\mathrm{T}}^{\mathrm{E}}=\sum_{i} P_{i}^{\mathrm{c}} G_{i}+w_{\mathrm{G}}+\sum_{h} T H_{h}+\sum_{i} O_{i}+\overline{M I L}+G_{\mathrm{PRIV}}^{\mathrm{E}}+\overline{F I}
$$

where

$$
\begin{aligned}
G_{\mathrm{T}}^{\mathrm{E}}= & \text { total government expenditure; } \\
P_{i}^{\mathrm{c}}= & \text { purchaser's price of sector }-i \text { goods } \\
G_{i}= & \text { purchase by government from sector } i \text { for consumption or investment } \\
& \text { (not included in } \left.G_{\mathrm{PRIV}}^{\mathrm{E}}\right) ; \\
W_{\mathrm{G}}= & \text { wage bill of the government; } \\
T H_{h}= & \text { government transfer to household of labor type } h ; \\
O_{i}= & \text { subsidies to sector } i \\
\overline{M I L}= & \text { military expenditure; } \\
G_{\mathrm{PRIV}}^{\mathrm{E}}= & \text { all current and capital expenditure made by the government for railways, } \\
& \text { ships, government factories, power stations, etc. (endogenous); and } \\
\overline{F I}= & \text { foreign investment. }
\end{aligned}
$$

*This was a typical forced famine export. As described before, this had various socioeconomic implications for Japan itself. It stabilized the urban unrest caused by higher food prices, but at the same time it accelerated the decline of Japan's agriculture through competition by offering food at lower prices.

**This includes trade arbitrages by the government.

***There are various interpretations of the economic contributions of military expenditure. It is simply assumed here that it is nonproductive spending, synonymous with consumption. 
Infrastructure and agricultural investment are assumed to accelerate the underlying Hicksian neutral technical progress.* Government revenue $\left(G^{\mathrm{R}}\right)$ has a more complicated form, but a more straightforward interpretation:

$$
\begin{aligned}
G^{\mathrm{R}}= & \sum_{v} \sum_{i}\left[t_{\mathrm{L}} w_{i}^{\mathrm{L}} L_{i \cdot v}+t_{\mathrm{S}} w_{i}^{\mathrm{S}} S_{i \cdot v}+t_{r} \frac{r_{\mathrm{E} i v}}{1-t_{r i}} K E_{i \cdot v}+t_{r} \frac{r_{\mathrm{C} i v}}{1-t_{r i}} K C_{i \cdot v}\right] \\
& +t_{\mathrm{w}} W_{\mathrm{G}}+\sum_{i} P_{i} t_{i}^{\mathrm{id}} Q_{i}+\Sigma t_{y}^{\mathrm{L}} w_{i}^{\mathrm{L}} L_{i}+\Sigma t_{y}^{\mathrm{S}} w_{i}^{\mathrm{S}} S_{i}+t_{\chi}^{\mathrm{I}} \chi_{8}+t_{\chi}^{\mathrm{u}} \chi_{9} \\
& +\sum_{i} \sum_{j} P_{i}^{\mathrm{W}} t_{(i)}^{\mathrm{FNC}} a_{0 i j} Q_{j} \cdot \tau+\sum_{i} P_{i}^{\mathrm{W}} t_{(i)}^{\mathrm{FC}} M_{i}^{\mathrm{C}} \tau+\bar{F}
\end{aligned}
$$

The terms inside the square brackets and $t_{\mathrm{w}} w_{\mathrm{G}}$ are what employers have to pay: social security contributions and profit tax. The next term, $\Sigma_{i} P_{i} t_{i}^{\text {id }} Q_{i}$. is indirect tax, where applicable. The following two terms are income tax for unskilled and skilled workers (agricultural labor is considered unskilled and paying very little, if any income tax). The next two terms, $t_{\chi}^{\mathrm{T}} \chi_{8}$ and $t_{\chi}^{\mathrm{u}} \chi_{9}$, are agricultural and urban land tax, respectively. The next two are tariff income for noncompetitive and competitive imports, and $\bar{F}$ is the exogenously given foreign capital inflow.**

Finally, government saving (GS) is given by:

$$
G S=G^{\mathrm{R}}-G_{\mathrm{T}}^{\mathrm{E}}
$$

\subsection{Housing and Urban Land}

A simple framework for studying housing demand and housing investment is presented here. The land-availability constraint is imposed only for urban areas. A flat urban rent will be assumed as in Kelley and Williamson (1980). The incorporation of nonzero sloped urban rent gradients is possible, but only with the help of highly unrealistic assumptions. This, therefore, will not be attempted in the present work.

In the case of flat rent gradients, the size of urban areas (supply of urban land) has to be either given from the equilibrium of demand for urban-use and agricultural-use land or given exogenously.

*From the point of view of the general equilibrium framework, however, these are very difficult items to assign to any specific sectors, even for agricultural infrastructure, because infrastructure investment would influence all sectors, albeit unevenly;e.g., to say that "harbors" are capital stock for manufacturing or that rural roads are capital stock of only agriculture is likely to introduce an unwanted bias into the whole picture. It has been assumed therefore that these infrastructure investments affect the product augmenting technological change. Therefore, for example, assuming $G I_{j}$ to be government investment in area $j$

$$
\begin{array}{ll}
A_{i}=A_{i}\left(G I_{\mathrm{u}}, G I_{\mathrm{r}}, t\right) & \\
A_{i \cdot 1}>A_{i \cdot 2} \geqslant 0 & \text { for } i=\text { urban sectors } \\
A_{i \cdot 2}>A_{i \cdot 1} \geqslant 0 & \text { for } i=\text { agriculture }
\end{array}
$$

where $A_{i \cdot k}=$ partial derivative of $A_{i}$ with respect to the $k$ th argument.

**The possibility of part of $\bar{F}$ being new debt caused by consumption is disregarded. 
From the rental flow accounting equation for urban housing:*

$$
Q_{9}=A_{9} K C_{9}^{\beta^{9}} \cdot \chi_{9}^{\left(1-\beta^{9}\right)}
$$

the housing price is derived as

$$
\min \left(r_{C_{9}} K C_{9}+r_{\chi_{9}} \chi_{9}\right)
$$

Then

$$
T P_{9}=A_{9}^{-1} \cdot\left(\beta_{9}\right)^{-\beta^{9}}\left(1-\beta^{9}\right)^{-\left(1-\beta^{9}\right)}\left(r_{C_{9}}\right)^{\beta^{9}}\left(r_{X_{9}}\right)^{\left(1-\beta^{9}\right)} \cdot Q_{9}
$$

where $T P_{9}$ is the price of the total housing, setting

$$
T P_{9} / Q_{9}=P_{9}
$$

and

$$
A_{9}^{-1} \cdot \beta^{-\beta_{9}}\left(1-\beta^{9}\right)^{-\left(1-\beta^{9}\right)}=\overline{\bar{A}}_{9}
$$

giving

$$
P_{9}=\overline{\overline{A_{9}}} r_{C 9}^{\beta^{9}} \cdot r_{X_{9}^{1-\beta}}^{9}
$$

From the AIDS demand function

$$
\omega_{9}=P_{9} Q_{9} / E=\alpha_{9}+\sum_{j} \gamma_{9 \cdot j} \ln P_{j}+\beta_{9} \ln \left(E / P_{\text {ind }}\right)
$$

Demands for structure and land ( $\mathrm{D}$ denotes demand) are

$$
\begin{aligned}
& \frac{\beta^{9} P_{9}}{r_{C 9}} \cdot Q_{9}=K C_{9}^{\mathrm{D}} \\
& \frac{\left(1-\beta^{9}\right) P_{9}}{r_{x_{9}}} Q_{9}=\chi_{9}^{\mathrm{D}}
\end{aligned}
$$

Assume $r_{\chi_{9}}(-1)$ and $r_{C_{9}}(-1)$ are equilibrium rates of return in the previous period, which give the housing cost as $P_{9}(-1)$. Then, migrants and the natural increase of the urban population during the previous period increase the demand for housing. The depreciation of the housing stock decreases the supply, in the absence of new investment, which in turn raises the housing price.

The supply side of housing, which remains the critical unknown among urban economists, will now be considered. However, this will be done in a very straightforward

*This could be a misspecification because most empirical studies seem to indicate elasticities of factor substitution in the neighborhood of 0.5 (Muth, 1968; DeLeeuw and Lkanem, 1971). This function may have to be altered to a CES should further examination of the data demand such a change. 
manner. It will be assumed that housing structures are completely malleable; urban land is given exogenously to housing investors' decisions; urban landlords invest in housing structures that everybody rents; and landlords are more risk-averse in their investment behavior than the rest of the investing population.

Landlords invest in housing structures if the rental stream will give them higher expected rates of return than the expected rate of return on other investment opportunities. This expected rate of $\operatorname{return}(\tilde{i})$ is assumed to be lower than the average of all capital returns owing to the risk-averse nature of landlords. The expectations of rents formed by landlords are also simple and myopic

$$
\tilde{r}=r(-1)+\gamma[r(-1)-r(-2)]
$$

where the subscripts and superscripts are omitted. Then the condition

$$
\left(\tilde{r}_{\mathrm{C} 9} K_{9}+\tilde{r}_{\chi_{9}} \chi_{9}-\Upsilon K C_{9}\right) / \tilde{i} \geqslant B_{\mathrm{C} 9}\left(P_{6}, K C_{9}\right)+P_{\chi} \chi_{9}
$$

must be fulfilled if landlords are to invest in housing, assuming that their expectation of structure lifetime is fairly long. Here

$$
\begin{aligned}
\Upsilon & =\text { maintenance cost } ; \\
B_{\mathrm{C} 9} & =\text { cost of building urban housing structure; and } \\
P_{X} & =\text { price of land. }
\end{aligned}
$$

However, because $\tilde{r}_{\chi_{9}} / \tilde{i} \approx P_{\chi}$, this can be reduced to

$$
\left(\tilde{r}_{\mathrm{C} 9}-\Upsilon\right) / \tilde{i} \geqslant B_{\mathrm{C} 9}\left(P_{6}\right)
$$

where

$$
B_{C_{9}}\left(P_{6}\right)=B\left(P_{6}, K C_{9}\right) / K C_{9}
$$

Therefore, the construction of new housing will continue until

$$
\left(\tilde{r}_{\mathrm{C} 9}-\Upsilon\right) / \tilde{i}=B_{\mathrm{C} 9}\left(P_{6}\right)
$$

in other words, until all demand is met by the existing supply. Thus, at the end of every period, migrants move with the expectation that land and structure rents will be the same in the future as during the last period, and landlords invest in housing structure in accordance with their expectations concerning rents and other profit opportunities. The resulting supply and demand determines the rents for this period.

This investment in housing is assumed, for the pre-World War II period, to be financed by the landlord's own saving or borrowing from family members, thus avoiding the problem created by the assumption that $\tilde{i}$ is less than the market rate of interest. For the postWorld War II period, however, the specification changes so that housing investment competes for funds with other investment opportunities. 
The supply of new urban land, on the other hand, is determined by ex post comparisons between the agricultural rent and the urban land rent during the previous period. Thus the land rent is determined by two derived demand functions.- one for agricultural land and the other for urban land; alternatively, the three equations

$$
\begin{aligned}
& \chi_{8}^{\mathrm{D}}=P_{8}\left(1-\beta_{1}^{8}-\beta_{2}^{8}\right) Q_{8} \cdot r_{\chi_{8}}^{-1} \\
& \chi_{9}^{\mathrm{D}}=P_{9}\left(1-\beta^{9}\right) Q_{9} \cdot r_{x_{9}}^{-1} \\
& r_{x_{8}}=r_{x_{9}}
\end{aligned}
$$

could be used to calculate the allocation of land between urban and agricultural users.

\subsection{Human Capital Investment}

There are three ways for an economy to invest in human capital. One is through formal schooling, which enhances the general level of human capital for the whole economy. Another is on-the-job training where workers pay - known as "general training" because they could subseciuently use the training in other firms. Still a third way is onthe-job training where the cost is covered by employers because of the firm-specific nature of the training.

ln the present model it is assumed that all formal schooling is paid for by the government and that all on-the-job training is firm-specific.

In the modern sectors, both unskilled labor and skilled labor receive specific training. First the firm has to pay $T_{i}$ (hiring and training costs) for every unskilled laborer, which the firm gains back as increased productivity, unless the laborer quits. Hence the specification of the user cost of labor in Section 3.4 is

$$
l_{i}=\left(1+t_{\mathrm{L}}\right) w_{i}^{\mathrm{L}}+b_{i} T_{i}
$$

Skilled laborers are trained from the unskilled, depending on the rate of return on "skill". For new investment, the required skill can be written as

$$
\left(\partial \mu / \partial q^{\mathrm{e}}\right)_{i} \cdot\left(D D_{i}\right)
$$

where

$$
D D_{i}=\text { expected excess demand in sector } i \text {, and }
$$

$\left(\partial \mu / \partial q^{\mathrm{e}}\right)_{i}=$ efficient skill--output ratio in sector $i$ (from the ex ante production function).

Next, it is assumed that "skill" is movable within a sector among various vintages. Each vintage would require amounts of skilled and unskilled labor that would equate their costs to their marginal productivity, given the capital stocks: 


$$
P_{i}^{\mathrm{e}}\left(\partial Q_{v i} / \partial S_{v i}\right)=q_{i}^{\mathrm{e}}, \quad p_{i}^{\mathrm{e}}\left(\partial Q_{v i} / \partial L_{v i}\right)=l_{i}^{\mathrm{e}}
$$

The required "amount of skill" in each vintage can be obtained by solving these two equations for $S_{\nu i}$ and $L_{v i}$. Then the total new skill requirement for sector $i$ during a given period is

$$
D_{S i}^{\mathrm{e}}=\left(\partial \mu_{i} / \partial q_{i}^{\mathrm{e}}\right) D D_{i}+\sum_{\nu=1}^{N} S_{\nu i}^{*}-\left(1-\delta^{\mathrm{S}}\right) \sum_{\nu=2}^{N(-1)} S_{v i}^{\mathbf{A}}(-1)
$$

where

$S_{v i}^{*}=$ the value of $S$ from the solution of the two equations above;

$S_{v i}^{\mathrm{A}}(-1)=$ the total amount of skill employed for vintage $v$ in this sector during the previous period;

$N=$ the vintage of the oldest machine in use during this period;

$N(-1)=$ the vintage of the oldest machine in use during the last period; and

$\delta^{S}=$ the rate of retirement of skilled laborers.

The cost of skill training is assumed to be the price of the capital-intensive service sector. Thus, the intended investment in skill is

$$
I_{\mathrm{S}}^{\mathrm{e}}=P_{5}\left[D_{\mathrm{S} \cdot 1}^{\mathrm{e}}+D_{\mathrm{S} \cdot 2}^{\mathrm{e}}+D_{\mathrm{S} \cdot 5}^{\mathrm{e}}\right]
$$

However, skill training must compete for available funds with productive investment. Therefore the final actual investment in skill $\left(I_{\mathrm{S}}^{\mathbf{A}}\right)$ is

$$
I_{\mathrm{S}}^{\mathrm{A}}=S A V \cdot I_{\mathrm{S}}^{\mathrm{e}} /\left(I_{\mathrm{S}}^{\mathrm{e}}+\sum_{i} \sum_{j} I_{i j}^{\mathrm{e}}\right)
$$

where

$$
i=\mathrm{K}, \mathrm{E} \text {; }
$$

$j=$ sectors; and

$S A V=$ savings a vailable for skill and productive physical investment (三SAV total $I_{\text {housing }}$ ).

\subsection{Savings}

Some authors have recommended that propensities to save from various types of income should be exogenously given, rather than determined by intertemporal utility maximization. Even this simple specification of exogenous propensities would have an adjustment effect on total saving if the propensity to save from capital income became higher than that from wage income because of any change in functional income distribution. It might make more sense, in any case, to assume a more explicit mechanism. It will be assumed therefore that the propensity to save from capital income varies with the rate of return on capital in the previous period. Thus, the ratio of saving out of capital income from sector $i$ is given by 


$$
s_{k \cdot i}=s_{k \cdot i}\left[r_{\mathrm{E} \cdot i}(-1), \quad r_{\mathrm{C} \cdot i}(-1)\right]
$$

and

$$
\partial s_{k \cdot i} / \partial r_{\mathrm{E} \cdot i}(-1), \quad \partial s_{k \cdot i} / \partial r_{\mathrm{C} \cdot i}(-1)>0
$$

\section{CONCLUDING REMARKS AND PROPOSED FUTURE MODIFICATIONS}

The purpose of this paper was to describe an applied general equilibrium model for analyzing Japanese historical experience of urbanization and economic growth in a dualistic framework. Most of the characteristics of Japan's dualistic growth stated in Section 2 are captured in the model described. A dualistic, or rather, a differential wage structure is incorporated in the wage determination through the minimization of labor cost which consists of wages and training costs lost through staff turnover. The fact that the average agricultural income is assumed to influence the rate of turnover in the model is not unreasonable: it can directly explain wage movements in those sectors which depend greatly on the agricultural sector as their source of labor, and consequently the whole urban wage structure.

The existence of investment spurts and long swings in growth patterns is captured by the determination of investment through myopic-expectation formation on the part of investors. The sector-specific investment determinations reproduce the unbalanced growth path of the post-World War I period when the boom was largely confined to heavy industries. After modifying the closure of the model to exogenous investment, the real wage decrease during the boom can also be captured - this is a forced saving scenario (see below).

Demand-oriented rural-urban migration is partly captured by using the number of new jobs available in each urban sector as the weight in forming the expected urban income. This expected urban income is used, in the manner of Harris and Todaro, to determine the flow of migrants in each year.

The model as it stands is rather large and complex in that it has a vintage structure for production, five production factors (capital equipment, capital structure, unskilled labor, skilled labor, and land), expectation-determined investment, and sector (technology)-specific training costs determining wage structure. The complete estimation and simulation of the model would be a great challenge to any model builder. However, there are certain aspects important in studies of developing economies that are insufficiently developed or missing from the version of the model presented here.

Among modification and extension possibilities, the more urgently needed changes are: the incorporation of more demographic aspects, especially more elaboration on the specification of rural - urban migration; the use of the concept of forced saving; and the endogenizing of training costs.

In order to incorporate selective migration arguments, some discrete choice specifications could replace the migration function used here. One way, but certainly not the only way, to do this would be to estimate earning functions in urban areas with such human attributes as age and education as independent variables in the logit framework.*

\footnotetext{
*The use of an ordinary conditional logit is enough here for the assumed simplicity of decisions: to migrate or to stay. There are no alternative destinations once an individual decides to migrate; he/she just goes to an "urban area". If there is more than one homogeneous urban area assumed as a possible destination for migrants, nested logit or probit methods should be employed to avoid the "independence of irrelevant alternatives" problem.
} 
The utility a person gets is simply a monotonic function of this earning, and then the probability that an individual migrates $\left(P_{\mathrm{ru}}\right)$ is given by

$P_{\mathrm{ru}}=\exp U\left[E^{\mathrm{u}}\left(A G E, A G E^{2}, E D, S E X\right)\right] /\left\{\exp U\left[E^{\mathrm{u}}\left(A G E, A G E^{2}, E D, S E X\right)\right]+\exp U\left(E^{\mathrm{r}}\right)\right\}$ where

$$
\begin{aligned}
U(\cdot) & =\text { assumed utility function; } \\
E^{i}(\cdot) & =\text { earnings in area } i(i=\text { urban, rural }) \\
A G E & =\text { age of potential migrants; } \\
E D & =\text { education of potential migrants; and } \\
S E X & =\text { sex of potential migrants. }
\end{aligned}
$$

There is no reason to believe the ex ante saving desire is equal to the ex ante investment desire, since these decisions are made by different individuals. Ex post saving and investment, however, are equal by Walras' Law. How, then, is this equality realized in practice? Most neoclassical models, starting with the Solow -Swan-Meade model, assume that saving is the constraint on investment or that saving behavior determines investment. But another possibility is just as plausible: the desire to invest forces savings to equal the desired investment. This forced saving is most typically implemented by lowering the real wages of workers, for example, through inflation during a period with a nominally fixed wage rate. This presupposes a higher propensity to save from capital income. Similarly, the increase in the consumption demand of capital-income earners can shift the income share more favorably to capitalists. * In Japan, real wage increases have always lagged behind productivity increases during economic upswings, making the scenario of forced saving highly likely.

The allocation of unskilled labor in this model is strongly influenced by exogenous sector-specific training and hiring costs; these determine almost the entire wage structure of urban sectors. This might be more rigid than necessary. In addition, the underlying assumption that these training and hiring costs are actually teclinology-specific makes it imperative that these costs are endogenized. That is, it may be assumed that the higher the capital-labor ratio, the higher the amount of training needed. This is a plausible assumption, and it is intended to carry out a closer study of post-World War II data to find numerical evidence for an explicit specification of this training-cost function.

Efforts are being made to solve the full model ${ }^{* *}$ and make it operational, and to incorporate the extensions mentioned above. At the time of writing, a simplified version of the model described here had been solved using 1960 data. Some sensitivity analyses and comparative statics have also been carried out. The vintage structure seems to make the model solution relatively insensitive to minor disturbances in parameter values in a static framework, although this requires further testing. The change in macro adjustment mechanisms, however, has a strong impact on the solution obtained; shifting the method of closure from neoclassical endogenous investment to the Cambridge exogenous investment has had the largest impact so far, especially on the distribution of income. The calibration of the full model will be attempted after more data have been collected.

\footnotetext{
*See Keynes (1930) or Kaldor (1956). It is referred to as a "widow's cruse" type of distribution of income because capitalists' income never gets depleted however much is consumed.

**Making the full model operational would not be impossible for the post-World War I period, but for the pre-World War II period certain simplifications would be needed.
} 


\section{REFERENCES}

Akamatsu, K. (1966). Shintei Keizai Seisakuron (Economic Policies). Seirinshoin-shin-sha, Tokyo. Armington, P.S. (1969). A Theory of Demand for Products Distinguished by Place of Production. International Monetary Fund Staff Papers XVI. International Monetary Fund, Washington, D.C., pp. 159-176.

Cave, R. (1971). In J. Bhagwati et al. (Editors), Export Led Growth and the New Economic History, in Trade, Balance of Payments, and Growth. North-Holland Publishing Co., Amsterdam.

Christensen, L., Jorgenson, D.W., and Lau, L. (1975). Transcendental logarithmic utility function. American Economic Review, 65:367--383.

Deaton, A. and Muellbauer, J. (1980). An almost ideal demand system. American Economic Review, $70(3): 312-326$.

DeLeeuw, F. and Ekanem, N.F. (1971). The supply of rental housing. American Economic Review, 61:806-817.

Dohner, R.S. (1979). Japanese Economic Growth: Export-Led or Export-Price-Led? Mimeograph. Tufts University, Fletcher School, Medford, Massachusetts.

Harris, J.R. and Todaro, M.P. (1970). Migration, unemployment, and development: a two sector analysis. American Economic Review, 60:126-142.

International Development Center of Japan Comparative Analysis Project Report (1976). Submitted to the Economic Planning Agency and the Japanese Government for the project Japan's Historical Development Experience and the Contemporary Developing Countries: Issues for Comparative Analysis.

International Development Center of Japan Comparative Analysis Project Report (1977). Submitted to the Economic Planning Agency and the Japanese Government for the project Japan's Historical Development Experience and the Contemporary Developing Countries: Issues for Comparative Analysis.

International Development Center of Japan Comparative Analysis Project Report (1978). Submitted to the Economic Planning Agency and the Japanese Government for the project Japan's Historical Development Experience and the Contemporary Developing Countries: Issues for Comparative Analysis.

Kaldor, N. (1956). Alternative theories of distribution. Review of Economic Studies, 23(2):83-100.

Kelley, A.C. and Williamson, J.G. (1974). Lessons from Japanese Development: An Analy tical Economic History. The University of Chicago Press, Chicago, Illinois.

Kelley, A.C. and Williamson, J.G. (1980). Modeling Urbanization and Economic Growth. RR-80-22. International Institute for Applied Systems Analysis, Laxenburg, Austria.

Key, B. (1970). Role of Foreign Contributions in Prewar Japanese Capital Formation. Ph.D. Dissertation. University of California, Berkeley, California.

Keynes, J.M. (1930). A Treatise on Money, Vol. 1. Macmillan, London.

LTES (Estimates of Long-Term Economic Statistics of Japan) (1979). Series edited by K. Ohkawa, M. Shinohara, and M. Umemura. Volume 14: Foreign Trade and Balance of Payments. Keizai Shimposha, Tokyo.

Minami, R. (1973). The Turning Point in Economic Development: Japan's Experience. Kinokuniyashoten, Tokyo.

Motai, S. and Ohkawa, K. (1978). Small-Scale Industries: A Study of Japan's 1966 Manufacturing Census. Working Paper 11. International Development Center of Japan, Tokyo.

Muth, R. (1968). Urban Residential Land and Housing Markets. In H.S. Perloff and L. Wingo (Editors), Issues in Urban Economics. Johns Hopkins Press, Baltimore, Maryland.

Nakamura, T. (1971). Senzenki Nihonkeizai Seicho no Bunseki (An Analysis of Prewar Japan's Economic Growth). Iwanami-shoten, Tokyo.

Napier, R.W. (1979). Prometheus Absorbed: Industrialization of the Japanese Economy 1905-1937. Ph.D. Dissertation. Harvard University, Cambridge, Massachusetts.

Ohkawa, K. (1972). Differential Structure and Agriculture - Essays on Dualistic Growth. Kinokuniyashoten, Tokyo. 
Ohkawa, K. (1978). Initial Conditions: Economic Level and Structure. In Papers and Proceedings of the Conference on Japan's Historical Development Experience and the Contemporary Developing Countries: Issues for Comparative Analysis, February 13-16, 1978. International Development Center of Japan, Tokyo.

Ohkawa, K. (1980). Dualistic Development and Phases. CP-80-29. International lnstitute for Applied Systems Analysis, Laxenburg, Austria.

Ohkawa, K. and Rosovsky, H. (1973). Japanese Economic Growth: Trend Acceleration in the Twentieth Century. Stanford University Press, Stanford, California.

Olkawa, K. and Shinohara, M. with Meissner, L. (Editors) (1979). Patterns of Japanese Economic Growth: A Quantitative Appraisal. Yale University Press, New Haven, Connecticut.

Pollak, R.A. and Wales, T.J. (1978). Estimation of complete demand systems from household budget data: the linear and quadratic expenditure systems. American Economic Review, 88:348-359.

Rogers, A. (1977). Migration, Urbanization, Resources, and Development. RR-77-14. International Institute for Applied Systems Analysis, Laxenburg, Austria.

Rogers, A. (1980). Migration Patterns and Population Redistribution. RR-80-07. International Institute for Applied Systems Analysis, Laxenburg, Austria. Also published in Regional Science and Urban Economics, 9:275-310 (1979).

Shephard, R.W. (1953). Cost and Production Functions. Princeton University Press, Princeton, New Jersey.

Stiglitz, J.E. (1973). Alternative Theories of Wage Determination and Unemployment in L.D.C.'s. Part I. Cowles Foundation Discussion Paper 357. Yale University, New Haven, Connecticut.

Tan, H.W. (1980). Human Capital and Technical Change: A Study of Wage Differentials in Japanese Manufacturing. Ph.D. Dissertation. Yale University, New Haven, Connecticut.

Theil, H. (1976). Theory and Measurement of Consumer Demand. Volumes I and II. North-Holland Publishing Co., Amsterdam.

Todaro, M. (1975). Internal Migration in Developing Countries. International Labour Office, Geneva.

Yamazawa, I. and Yamamoto, Y. (1979). Trade and balance of payments. In K. Ohkawa and M. Shinohara (Editors) Patterns of Japanese Economic Growth: A Quantitative Appraisal. Yale University Press, New Haven, Connecticut.

Yasuba, Y. (1966). Nihon no Kogyoseisan Shisu 1905-1935 (Industrial Production Indices of Japan 1905 - 1935). In K. Inada and T. Uchida (Editors), Keizai seicho no Riron to Keisoku (Theories and Measurements of Economic Growth). Iwanami-shoten, Tokyo.

Yasuba, Y. (1978). Another Look at the Tokugawa Heritage with Special Reference to Social Conditions. In Papers and Proceedings of the Conference on Japan's Historical Development Experience and the Contemporary Developing Countries: Issues for Comparative Analysis, February 13-16, 1978. International Development Center of Japan, Tokyo. 


\section{Part Two}

The Usefulness of General Equilibrium and Disequilibrium Modeling to the Goals of Centrally Planned Economies 



\title{
MODELING ALTERNATIVE SOCIOECONOMIC MECHANISMS
}

\author{
Boris Mihailov \\ International Institute for Applied Systems Analysis, Laxenburg (Austria)
}

\section{INTRODUCTION}

The analysis of changes in real-life systems requires the simulation of various alternatives in the behavior of the systems analyzed. Estimating these alternatives with regard to some preliminary goals or stipulated conditions can lead to improvements in the analytical technique and in the specification of the goals or conditions.

Using this approach, the economic mechanism in some centrally planned economies was analyzed (Mihailov, 1973, 1974). Despite the theoretical nature of the models used in this analysis, the conclusions drawn about the underlying economic mechanism were later explicitly confirmed in practice.

This paper describes the analysis of changes in an economic mechanism based on a set of working, computerized models, the main elements of which, appropriately adjusted, were solved at the International Institute for Applied Systems Analysis (IIASA). These were an optimization in put-output model, based on the nonoptimization version developed by Nyhus (1980) and an equilibrium model designed by Mihailov et al. (1980) (the generalized version of this model was developed for the Swedish economy by Bergman and solved by Pór (see Bergman and Pór, 1980)).

Initial difficulties in solving the models made it necessary to work with a very aggregated form with only eight sectors, two of which admitted competition and international trade; in these two sectors only local optimization was analyzed in the equilibrium model. However, this proved sufficient to describe the influence of each sector on all the others, making it possible to use the solution procedure in the general case of competition and local optimization. These difficulties were also encountered with the models to be solved in a static form for a given year. Nevertheless, by analyzing the development of the economy in comparison with a base year, it was possible to treat the behavior of the economy and the economic mechanism dynamically.

Despite the restrictions imposed in solving the models, the conclusions are the same as those drawn from theoretical models, which shows the efficiency of the proposed approach for the analysis of changes in economic mechanisms.

Section 2 of this paper outlines the structure of the model system for a centrallyplanned economy in the period prior to the 1960s. Section 3 describes the different 
strategies followed in the same economy after economic reforms in the mid-60s and discusses the implications of these changes for the model system. The simulation of future changes in the economy is examined in Section 4, while Section 5 presents the main conclusions.

\section{THE ECONOMIC MECHANISM BEFORE THE INTRODUCTION OF REFORMS}

\subsection{Adequacy of the Models}

The most appropriate device to analyze the economic mechanism before the reforms were introduced is an optimization of economic development based on an inputoutput model*

$$
X=\mathbf{A} X+Y
$$

where

$$
\begin{aligned}
& X=\text { total production volume, } \\
& \mathbf{A}=\text { coefficient matrix }, \text { and } \\
& Y=\text { final consumption. }
\end{aligned}
$$

The final consumption is made up as follows

$$
Y=G+C+K+Z-M+\Delta K
$$

where

$$
\begin{aligned}
G & =\text { governmental consumption } \\
C & =\text { household consumption } \\
K & =\text { capital investments } \\
Z & =\text { exports } \\
M & =\text { imports, and } \\
\Delta K & =\text { capital stocks. }
\end{aligned}
$$

Some components of the final consumption can be forecast in terms of demand functions, for example, in terms of household consumption

$$
C_{i}=\mathrm{f}\left(W, P_{1}^{\mathbf{D}}, P_{2}^{\mathbf{D}}, \ldots, P_{n}^{\mathbf{D}}, \Delta W, t\right)
$$

where

$$
\begin{aligned}
W & =\text { household income (wages) } \\
P_{i}^{\mathbf{D}} & =\text { domestic prices for goods } i, \text { and } \\
t & =\text { time. }
\end{aligned}
$$

\footnotetext{
* See Nyhus (1980) for the use of an input-output model for forecasting.
} 
Turning to exports

$$
E_{i}=\mathrm{f}\left(F D, P_{i}^{\mathrm{WE}}, P_{i}^{\mathrm{D}}\right)
$$

where

$F D=$ foreign demand, and

$P_{i}^{\mathrm{WE}}=$ international market prices.

The demand for capital can be defined by

$$
K=r \bar{X}, \quad \bar{X}=\sum_{i} k_{i} X_{t-1}
$$

where

$$
\begin{aligned}
r & =\text { coefficient } \\
\bar{X} & =\text { output }, \text { and } \\
k_{i} & =\text { distribution lag. }
\end{aligned}
$$

The separate sectors can be described in terms of price equations summing the input-output table by columns

$$
P_{j}=\sum_{i=1}^{n} a_{i j} P_{i}^{\mathrm{D}} X_{j}+W_{j}+\Pi_{j} \quad(j=1,2, \ldots, n)
$$

where

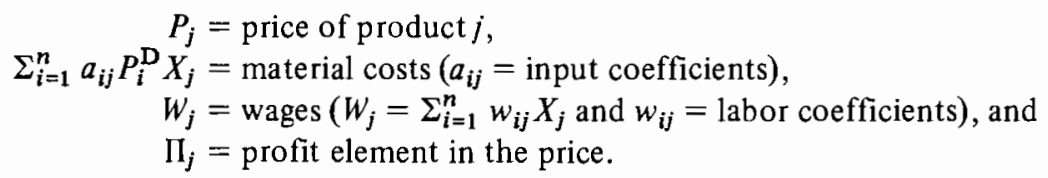

The relationship between eqns. (1) and (6) can be expressed in terms of intermediate product and the material costs

$$
\sum_{i=1}^{n} a_{i j} P_{i}^{\mathrm{D}} X_{j}=\sum_{j=1}^{n} a_{i j} X_{j}
$$

and also in terms of the final consumption and the new value

$$
\sum_{i=1}^{n} Y_{i}=\sum_{j=1}^{n}\left(W_{j}+\Pi_{j}\right)
$$




\subsection{The Optimization Phenomena}

This problem has essentially never been solved in practice for the development of a national economy. The scheme suggested in Figure 1 is closest to the specific features of the input-output model used but also contains features suggested by planning experience.

It is obvious that for the balanced overall development of the national economy, as described in eqns. (1) and (6), some restrictions on individual sectors must be imposed. In this way local optimization of each sector can be performed and the influence of the local optima on the relationships at a central level can be analyzed.

The most suitable model for the optimization of individual sectoral development is one of the mixed-integer type, which minimizes the production and social costs

$$
\sum_{i=1}^{m}\left[c_{i} x_{i}+\sum_{k=1}^{T_{i}}\left(p_{i k}+s_{i k}\right) z_{i k}\right] \rightarrow \min
$$

where

$c_{i} x_{i}=$ present production costs of product $i(i=1,2, \ldots, m)$,

$T_{i}=$ possible technological alternatives for product $i$,

$p_{i k}=$ production costs of alternative $k$ and product $i$,

$s_{i k}=$ social and other costs of alternative $k$ and product $i$,

$z_{i k}=$ a zero-one constraint, and $\Sigma_{k=1}^{T_{i}} z_{i k} \leqslant 1$.

Solution of the model is subject to the following constraints:

(i) Mixed-integer constraint on production volume

$$
X^{\min } \leqslant \sum_{i=1}^{m}\left(x_{i}+\sum_{k=1}^{T_{i}} z_{i k} A_{i k}\right) \leqslant X^{\max }
$$

where $A_{i k}=$ capacity of alternative $k$ and product $i$.

(ii) Capital investment constraint

$$
K^{\min } \leqslant \sum_{i=1}^{m} \sum_{k=1}^{T_{i}} z_{i k} f_{i k} \leqslant K^{\max }
$$

where $f_{i k}=$ capital investments for alternative $k$ and product $i$.

(iii) Constraint on labor resources (wages)

$$
W^{\min } \leqslant \sum_{i=1}^{m} \sum_{k=1}^{T_{i}} z_{i k} w_{i k} \leqslant W^{\max }
$$

where $w_{i k}=$ wages for alternative $k$ and product $i$. 


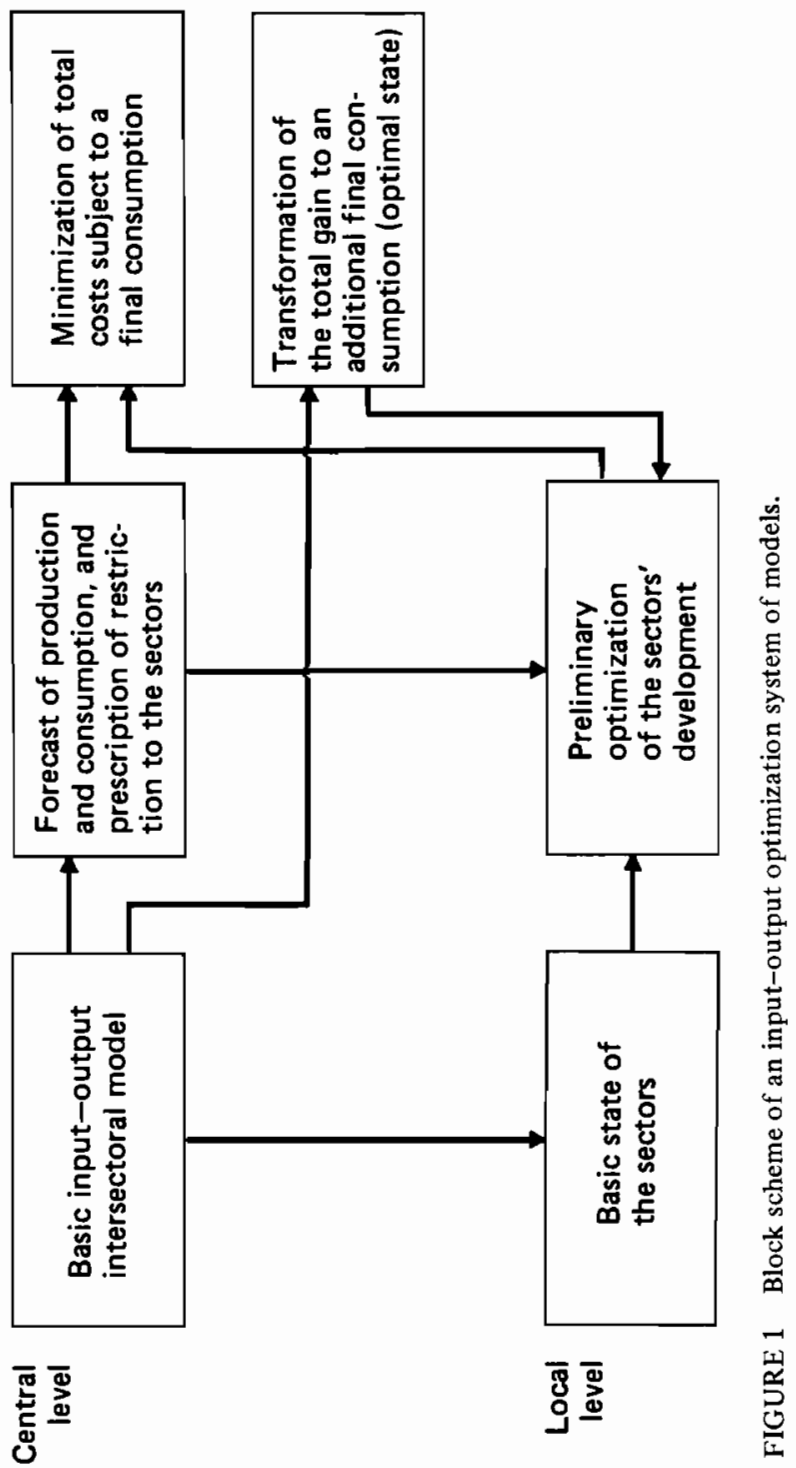


(iv) Constraints on other primary resources

$$
U^{\min } \leqslant \sum_{i=1}^{m} \sum_{k=1}^{T_{i}} z_{i k} u_{i k} \leqslant U^{\max }
$$

where $u_{i k}=$ use of other resources for alternative $k$ and product $i$.

The local optimization model was used for the analysis of two sectors only, for the following cases: substitution between input resources and substitution between input factors (labor and capital); substitution between domestic and imported goods and alternatives where environmental-pollution problems were involved.

The analysis of the influence of local optimization on interdependences at a central level showed the following:

1. When one balances the production volumes (using changed technological coefficients that result from local optimization), one must change not only the direct, but also the indirect costs and efficiencies according to some exogenous final consumption. This shows that performing local optimization does not eliminate the need for global optimization.

2. The need for global optimization requires that not only the chosen (best) alternative at the local level but also all other possible alternatives have to be estimated at the central level.

3. Global optimization must be performed simultaneously with the derivation of the new level of prices for the planning year (as a function of the changed production costs).

It is apparent that the global objective function must be connected with the maximization of the final consumption for some given period $t$

$$
\sum_{t=1}^{n} Y_{i}^{t}=\sum_{t=1}^{n} \sum_{i=1}^{n} a_{i} b_{i} x_{j}^{t} \rightarrow \max
$$

where

$a_{i}=$ assortment coefficient for goods $i(i=1,2, \ldots, n)$, and

$b_{i}=$ consumption per capita of goods $i$.

The model cannot be solved directly because the volume and structure of the final consumption must be forecast and their values are connected with a unique level of wages and volume of intermediate products. Therefore the objective function is transformed into minimum direct and indirect production costs by the exogenous volume and structure of final consumption and employment (see Figure 1)

$$
\sum_{i=1}^{n} \sum_{k=1}^{T_{i}} S_{i k} X_{i k} \rightarrow \min
$$

where $S_{i k}=$ direct and indirect production costs for product $i$ and alternative $k$. 
The solution of this model is subject to the following constraints:

(i) Constraints on the volume and structure of final consumption

$$
Y_{i}^{t}=\sum_{i=1}^{n} \sum_{k=1}^{T_{i}} a_{i} F_{i k}^{t}
$$

where $F_{i k}=$ total volume of final consumption of good $i$ and alternative $k$.

(ii) Constraints connected with the substitution of final products

$$
Y_{i}^{t}=\sum_{i=1}^{n} \sum_{k=1}^{T_{i}}\left(\gamma_{i, i} Y_{\bar{i}}+\bar{\gamma}_{i, \bar{i}}\right)
$$

where $\gamma_{i}=$ substitution coefficient between $i$ and $\bar{i}$ products.

(iii) Constraints on employment (and therefore on wages)

$$
\sum_{i=1}^{n} \sum_{k=1}^{T_{i}} X_{i k}^{t}=\sum_{i=1}^{n} \sum_{k=1}^{T_{i}} w_{i} N_{i k}^{t}=\sum_{i=1}^{n} \sum_{k=1}^{T_{i}} W_{i k}^{t}
$$

It is obvious that the problem of commensurability between different technological alternatives (according to production costs) is also a problem of the type of prices (the production costs are a result of the price levels of the resources used). This problem has been solved theoretically by Mateev (1963) who proved that only those prices which contain an element of profit that is proportional to wages are commensurable. This is because current material costs can be measured in terms of the working time needed for production in the past, i.e. in terms of wage expenditures.

Thus, if in the price equations

$$
P_{j}^{\mathbf{D}}=\sum_{i=1}^{n} a_{i j} X_{j}+w_{j}+\Pi_{j}
$$

the direct and indirect production costs are given by

$$
\sum_{i=1}^{n} a_{i j} X_{j}+W_{j}=S
$$

and if profit, as a percentage of wages, is given by

$$
\Pi_{j}=\lambda W_{j}=\Omega S_{j}
$$

then the following type of price is derived

$$
P_{j}^{\mathrm{D}}=S_{j}+\Omega S_{j}=(1+\lambda) S_{j}^{\prime}
$$


that is, the prices are proportional to production costs and can be derived as a function of production costs

$$
P_{j}^{\mathbf{D}}(t)=\mathrm{f}\left[S_{j}^{\prime}(t)\right]
$$

and will not make the production costs and efficiency lopsided when the different technological alternatives are compared.

This approach requires that the gain realized from the minimized cost, in comparison with the basic state of the economy, be transformed into an additional volume of final consumption, which is subject to forecasting

$$
\left(\sum_{i=1}^{n} a_{i j} P_{i}^{\mathrm{D}} X_{j}^{t_{0}}+w_{j}^{t_{0}}\right)-\left(\sum_{i=1}^{n} a_{i j} P_{i}^{\mathrm{D}} X_{j}^{* t}+w_{j}^{* t}\right)=\Delta \sum_{i=1}^{n} Y_{i}
$$

where

$t_{0}=$ base year,

$t=$ given year studied, and

* = optimal state of the economy.

This indirect way of maximizing the final consumption is adequate for planning practice and describes economic development dynamically, even though the model itself is static (it was not possible to use the purely static model to optimize the "consumptionaccumulation" ratio for a long period).

Hence the optimal state of the economy can be expressed in terms of production volume, level of prices, volume of resources, level of wages, volume of consumption, employment, and capital investment

$$
X_{j}^{*}, P_{i}^{* \mathrm{D}}, X_{i}^{*}, W_{j}^{*}, Y_{i}^{*}, N^{*}, \text { and } K^{*}
$$

\subsection{Stimuli and Incentives}

In this analysis, economic stimuli are always connected with the contribution of a given sector to increasing overall efficiency (reducing expenditure) in comparison with the base year

$$
\left(\sum_{i=1}^{m} a_{i j} P_{i}^{\mathrm{D}} X_{j}^{t_{0}}+W_{j}^{t_{0}}\right)-\left(\sum_{i=1}^{m} a_{i j} P_{i}^{\mathrm{D}} X_{j}^{t}+W_{j}^{t}\right)=\Delta C_{j}
$$

where $\Delta C_{j}=$ total gain, and the increase in wages is dependent on the increase in total gain

$$
w=\Delta C_{j} / \Delta W_{j}
$$

where $w=$ a coefficient. 
The problems of stimuli and incentives have to be analyzed separately at the plan's development and fulfillment stages. At the development stage (based on a given coefficient $w$ ), the increase of wages $W_{j}$ can be calculated in terms of the local optimization represented by eqns. (9) and (10)-(13). But according to the scheme in Figure 1, after each iteration all the indicators listed in (23) will be changed by the center* which shows that the level of those indicators which are subject to local optimization does not depend on the sector. ${ }^{* *}$ As regards labor resources, these must also be changed by the center, thus making it necessary to change coefficient $w$ as well. Hence, no objective basis exists for the estimation of the sector's contribution. That is why the final level of $w$ has to be derived from the prescribed planning targets.

At the fulfillment stage of the plan, there exist various possibilities for different sectors to fulfill the planned target, giving, respectively, $\Delta C_{j}^{\prime}<100 \%, \Delta C_{j}=100 \%$, or $\Delta C_{j}^{\prime \prime}>100 \%$.

Under these conditions, nonfulfillment of the plan by one sector causes nonfulfillment of the plan by the sector-users, which creates conditions for justifying the nonfulfillment in terms of objective circumstances. This forces the center either to reduce the coefficients of the sectors which have not fulfilled the plan to $100 \%$

i.e. from $w^{\prime}=\Delta C_{j}^{\prime} / \Delta C$ to $w=\Delta C_{j} / \Delta C_{j}$

or to reduce the coefficients of the sectors which have overfulfilled the plan $(w \gg 100 \%)$ to $100 \%$ plus some minimum amount (in order to compensate the losses from eqn. (26))

i.e. from $w^{\prime \prime}=\left(\Delta C_{j}^{\prime \prime} / \Delta C_{j}\right)$ to $w=\left(\Delta C_{j} / \Delta C_{j}\right)+\min \Delta C_{j}$

In both cases, the real level of fulfillment of the plan serves as a basis for the development of the plan for the next period.

This mechanism for estimating a given sector's contribution creates incentives for the sector to conceal its true production potential at the development stage in order to be able to fulfill the set target more easily. Thus the information passed from local to central levels can be inaccurate, which in turn forces the center to prescribe very high (often unrealistic) planning targets (see Figure 2).

\subsection{Basic Conclusions}

Conclusions can be drawn both from the models used and from the mechanism of contribution estimation, and can be formulated as follows:

- Local optimization is useless from both the planning and the stimulation points of view; in this respect, the convergence reached in some theoretical works between central and local levels is merely a formal convergence.

\footnotetext{
* "Center", here and elsewhere, implies a single coordinating planning body or set of bodies at the central level.

** "Sector", here and elsewhere, also implies an enterprise.
} 


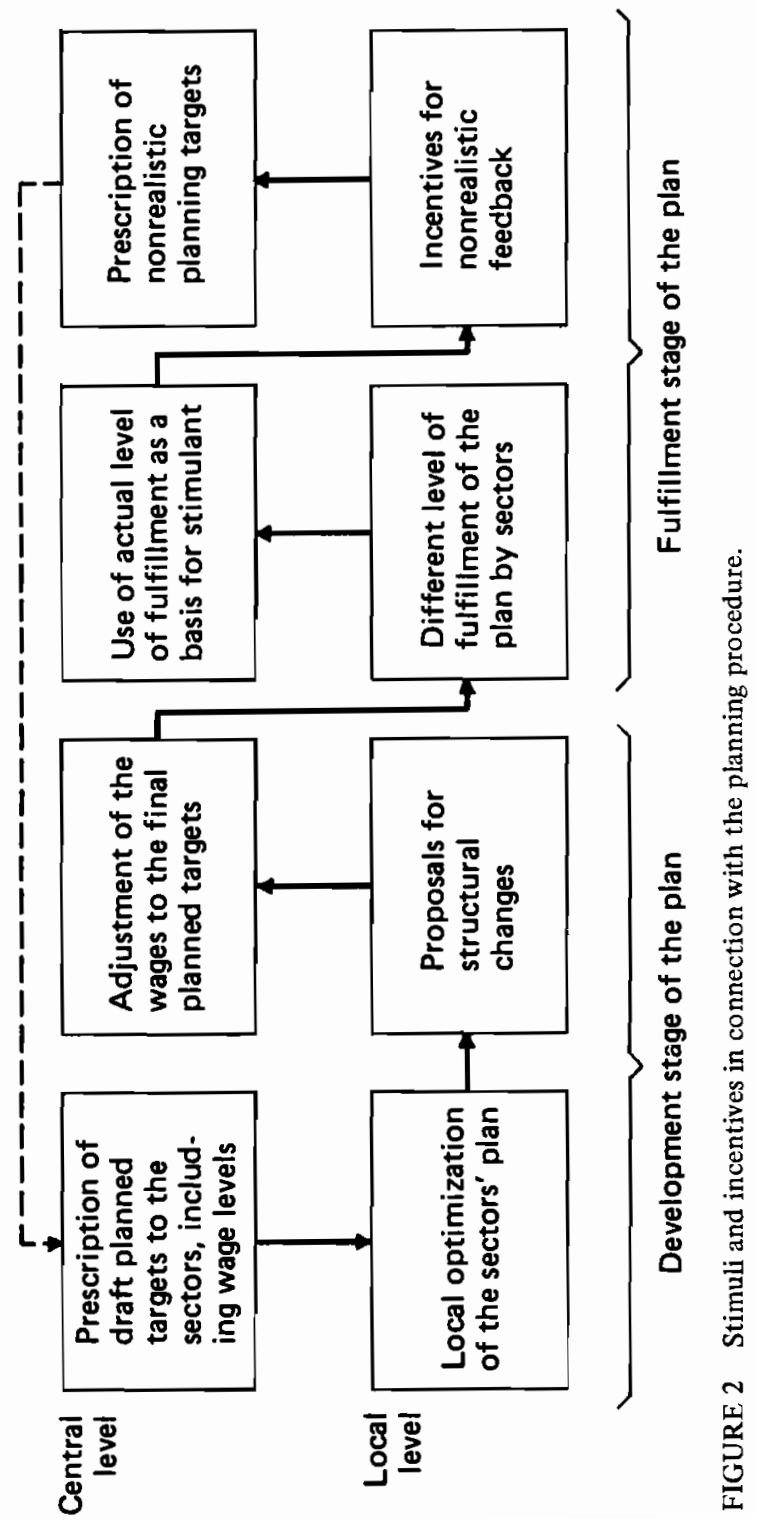


- The sectors have built-in incentives to conceal their true potentials at both the development and fulfillment stages of the plan.

- The responsibility for negative results always rests with the center because of unrealistic feedback and the practical impossibility of developing a balanced plan for all products and product mixes, which in practice may number as many as 10 million.

- The economic mechanism should ideally be absolutely centralized; each decentralization leads to negative results in the economy as a whole because of the monopoly position of the producers.

\section{THE PRESENT ECONOMIC MECHANISM}

\subsection{The New Alternative}

This alternative strategy appeared in the mid-60s as a series of economic reforms involving a combination of both centralized and decentralized management. Its main principles may be expressed as follows:

- Independence in decision-making at a local level according to the available production volume and structure, within some constraints;

- Flexible prices within some limits;

- Increase of production to be financed by the income and credits of the given sector, to be realized by increasing profit margins in prices (exceptionally, some subsidies can exist);

- Sectoral income to be regulated by taxes in order to ensure equal potentials for all sectors and to serve as long-term stimulants; and

- Wages to be regulated by uniform and long-term standards connected with the sectoral incomes.

\subsection{Effects of the Reforms on the Model System}

Before analyzing the behavior of the economy at the two levels it is necessary to say that the models represented by eqns. (1)-(8) are still used in practice but that now the prices contain different profit margins based on the value of the installed capacity in each sector. The sectors' behavior can be described by a model for profit maximization that includes the economic tools mentioned above

$$
\sum_{i=1}^{m}\left\{P_{j}+S_{j}-\left[a_{i j} P_{i}^{\mathrm{D}} X_{j}+W_{j}+T_{j}+c_{j}+\sum_{k=1}^{T_{i}}\left(p_{i k}+s_{i k}\right) z_{i k}\right]\right\}=\Pi_{j} \rightarrow \max
$$

where

$P_{j}=$ price of product $j$, bounded in such a way that $\vec{P}_{j}>P_{j}>\underline{P}_{j}$ 
$S_{j}=$ subsidy connected with the production volume: $S_{j}=\Psi X_{j}$ (where $\Psi=$ a coefficient),

$W_{j}=$ wages depending on the profit: $W_{j}=w \Pi_{j}$,

$T_{j}=$ taxes on the profit (or on the income): $T_{j}=\beta \Pi_{j}$,

$c_{j}=$ payment of interest for credits: $c_{j}=h K_{j}$.

(For definitions of the other symbols see eqn. (9).) The solution of the model is subject to eqns. (10) and (11).

An analysis of the above economic mechanism will now be made for the central and local levels and at development and fulfillment stages of the plan.

\subsection{Analysis at the Development Stage of the Plan}

If, on the basis of a forecast, the center prescribes the above economic tools in a common way to the sectors

$$
\bar{P}_{j}, \underline{P}_{j}, \bar{X}_{j}, \underline{X}_{j}, \Psi, w, \beta \text {, and } h
$$

it is obvious that it is possible to reach an equilibrium in the economy in terms of local optimizations (eqn. (28)) when the variables have marginal values

$$
\overline{\bar{P}}_{j}+S_{j}=\sum_{i=1}^{n} a_{i j} P_{i}^{\mathrm{D}} \overline{\bar{X}}_{j}+\overline{\bar{W}}_{j}+T_{j}+c_{j}+\Pi_{j}
$$

where the double bar denotes a marginal value.

On the other hand, only eqns. (1)-(8) and (14)-(18) can be used by the center for a global optimization (incidentally, including in these equations real prices that contain a profit margin proportional to the installed capacity leads to a lop-sided global optimum; see eqns. (19)-(21)). Nevertheless, we can call this solution conditionally optimal

$$
P_{j}^{*}=\sum_{i=1}^{n} a_{i j} P_{i}^{\mathrm{D}} X_{j}^{*}+W_{j}^{*}+\Pi_{j}^{*}
$$

Analysis shows that an essential difference always exists between the results from the local (eqn. (30)) and central (eqn. (31)) levels. The main reason for the difference is that indirect economic and social expenditures are not taken into account and the level of the economic tools in the base year takes no account of the prospective changes. The above differences can often express negative, undesirable consequences: a high percentage of unemployment, nonobjective differentiation in wages, etc. Hence a problem appears when the sum of local optima does not satisfy the global optimum. There are then two possibilities for the center: to change directly the planned targets for the local level or to change the prescribed level of the economic tools. The first possibility contradicts the requirements of the new reform. The second possibility requires techniques to be available to the center in order to predict the effect on the economy of changing the levels of 
the economic tools. Otherwise, differences will always appear, for example, concerning wages

$$
w \Pi_{j} \lessgtr \sum_{i=1}^{m} w_{i j} X_{j}^{*}
$$

or concerning capital investment

$$
h K_{j} \lessgtr P_{j}^{*}-\left(\sum_{i=1}^{m} a_{i j} P_{i}^{\mathrm{D}} X_{j}^{*}+W_{j}^{*}\right)
$$

and so on. Because of the lack of techniques for predicting the effects of the economic tools on overall economic development, the center must change the level of the economic tools used on the basis of the planned target levels of the optimal state (eqn. (31)). However, the lack of uniformity in natural and production conditions requires that economic tools be differentiated by sectors. For example, the changed coefficient for wages will be

$$
w=\sum_{i=1}^{m} w_{i j} X_{j}^{*} / \sum_{i=1}^{m} \Pi_{j}^{*}
$$

and similarly for the remaining tools. Hence the sectors do not have equal possibilities for development and therefore no objective basis exists for the estimation of their potential contributions. Local autonomy at the elaboration stage of the plan is excluded, because each change in planned targets by one sector leads to an imbalance in all other sectors. This was, however, the main reason why some real economic independence was admitted in practice at the very beginning of the economic reform, although it was removed immediately thereafter.

\subsection{Analysis at the Fulfillment Stage of the Plan}

The prescribed planning targets, together with the differentiated economic tools, create the same unequal possibilities for fulfillment of the plan as those created by the economic mechanism in use before the reform. In addition, the center still has to change the economic tools, and hence the coefficients for estimating each sector's contribution. All this destroys the role of the economic tools as a long-term stimulator.

The main conclusions drawn from the analysis can be divided into three areas. First, use of the above models does not allow economic autonomy to the sectors. Second, economic tools cannot be used to develop and fulfil the plan, because they are merely a passive reflection of the centrally developed and prescribed plan. Third, incentives at the local level to conceal true potentials are exactly the same as those in the economic mechanism used before the reform, even though economic tools are used. The main features of the economic mechanism at present are shown in Figure 3. 


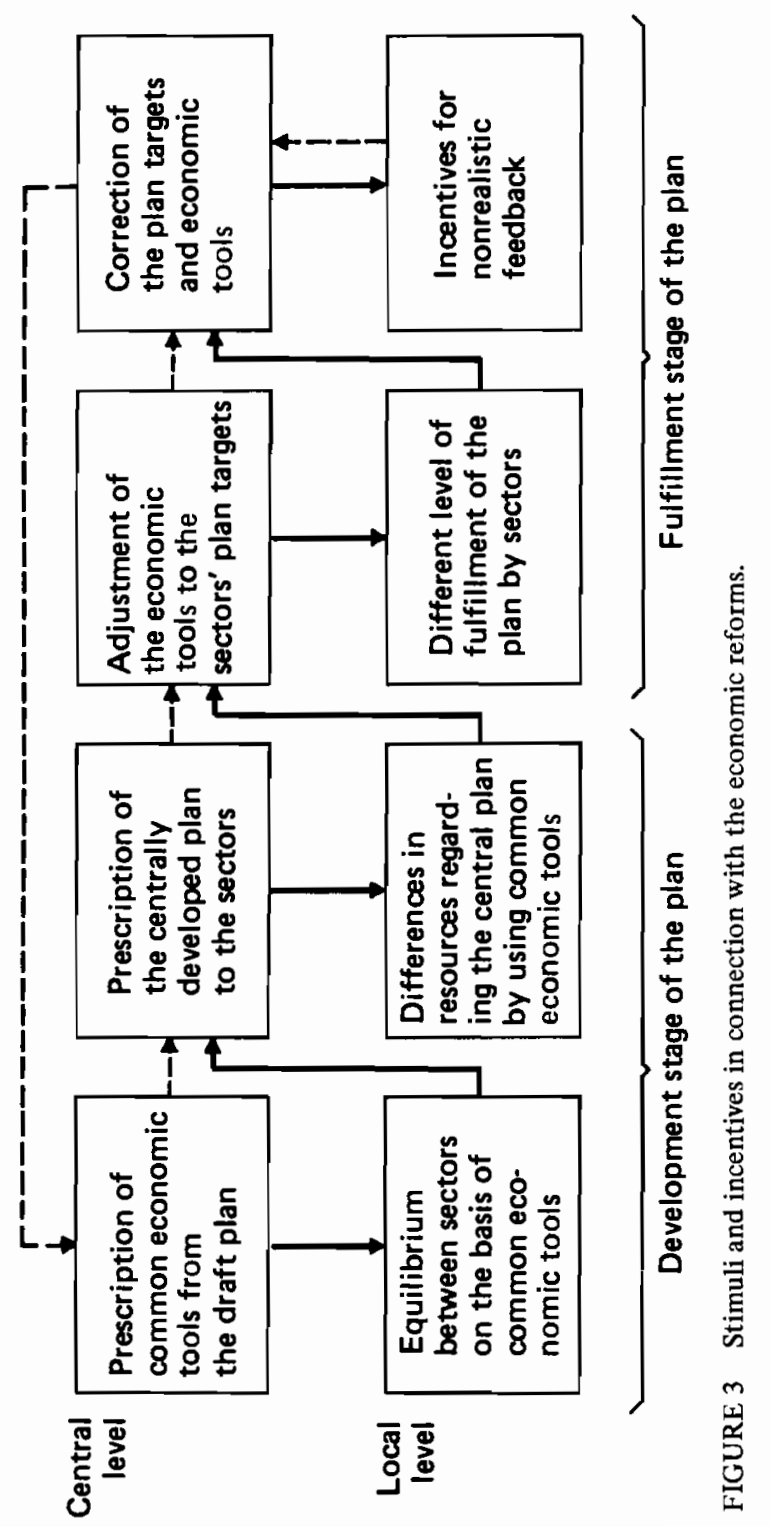




\section{NECESSARY CHANGES}

\subsection{Main Directions of the Changes}

The alternative to central planning is real independence for the sectors (production units) with regard to production volume, prices, structure, and production factors (resources, labor, and capital). The center influences sectoral incentives only indirectly.

The state of the economy when economic independence prevails in the sectors can be described in terms of an equilibrium model (see the lower half of Figu re 4, denoted II). From the analysis of the previous sections, it is known that this state is not optimal from the point of view of some global criteria. The procedure of global optimization is shown in Figure 1 (see eqns. (1)-(8) and (14)-(18); see also the upper half of Figure 4, denoted $I$, in which the local level is not based on real participation of the sectors in the planning procedure, but expresses sectoral perception of the national economy).

The main purpose of the analysis is to model procedures which allow indirect regulation of the economy without destroying local autonomy. Models elaborated at IIASA, and the Modified Equilibrium Model for Bulgaria, which are now in the process of solution, were used in the above analysis (Mihailov et al., 1980).

\subsection{Basic Equilibrium}

In order to express the dynamic development of an economy using static models, a base state of the economy must first be described. In the base year, all components of the economy are known. However, market equilibrium prices do not yet exist in practice and therefore competition between sectors is not included in the basic equilibrium and the market prices only express the requirements for expanding production (competition is included in the analysis for any given later year).

The basic equilibrium conditions, although they express one and the same state of the economy, are described in different ways in block I (the "optimization block") and in block II (the "behavioral block"). As far as block I is concerned, the procedures for which were described in eqns. (1)-(8) and (14)-(18), it is necessary to mention that the prices in the base year are derived from the market prices in block II by taking out the profit share in the prices. This profit is transformed into capital stocks of the sectors (and hence in nondistributed capital investment).

Although the prices of the products for personal consumption in block I are based on the equality between supply and demand, the excess level of prices over production costs is extracted in the form of taxes to the national budget and serves as nondistributed capital investment. This also allows the sectors producing products for personal consumption to be optimized according to their respective production costs.

An analysis of blocks I and II in parallel has been made using similar methodology and based on an equal number of sectors; similar sectors under concrete analysis (the energy sector and agriculture); and similar types of tasks solved for the two analyzed sectors. 


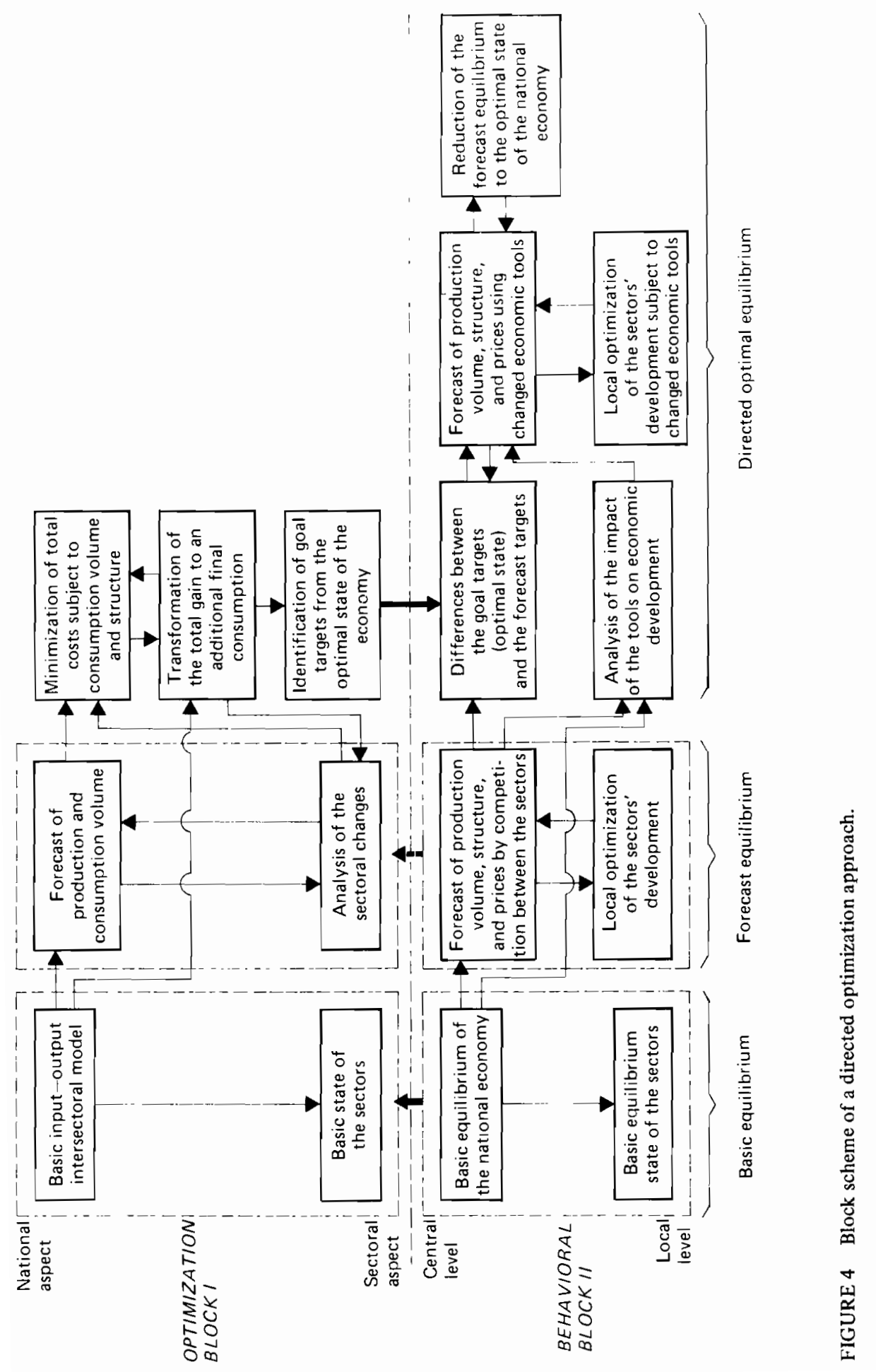


The following notation will be used in describing all further procedures (the notation from Bergman and Pór (1980) is retained).

\section{Sectors}

$$
\begin{aligned}
0 & =\text { electricity (from the energy sector) } \\
1 & =\text { fuel (from the energy sector) } \\
2 & =\text { fuel (from agriculture }- \text { biogas) } \\
3 & =\text { agriculture } \\
\cdot & \\
\cdot & \\
& \\
n & \\
n+1 & =\text { housing sector } \\
n+2 & =\text { public sector }, \text { and } \\
n+3 & =\text { capital goods sector. }
\end{aligned}
$$

\section{Exogenous Variables}

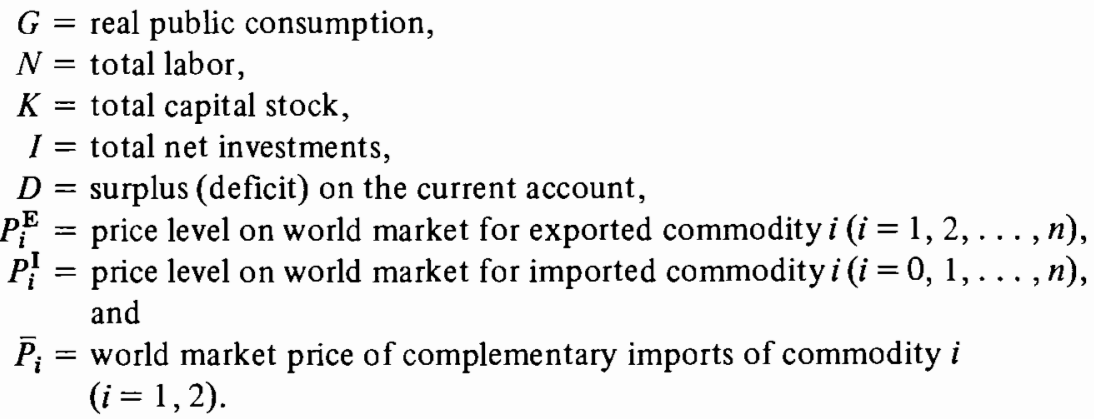

\section{Endogenous Variables}

$X_{j}=$ gross output in sector $j(j=0,1, \ldots, n+3)$,

$K_{j}=$ capital stock in sector $j(j=0,1, \ldots, n+2)$,

$N_{j}=$ employment in sector $j(j=0,1, \ldots, n+2)$,

$\bar{M}_{j}=$ input of complementary imports in sector $j(j=1,2)$,

$C_{i}=$ household consumption of commodity $i(i=0,1, \ldots, n+1)$,

$Z_{i}, M_{i}=$ exports and imports, respectively, of commodity $i(i=0,1, \ldots, n)$,

$P_{i}, P_{i}^{\mathbf{D}}=$ domestic production costs and domestic price, respectively, of commodity $i(i=0,1, \ldots, n+3)$,

$W, w_{j}=$ total wages in the economy and wage rate in sector $j$ $(j=0,1, \ldots, n+2)$, respectively,

$R, R_{j}=$ rate of return on capital in the economy and in sector $j$ $(j=0,1, \ldots, n+2)$, respectively,

$Q_{j}=$ "user cost" of capital in sector $j(j=0,1, \ldots, n+2)$,

$V=$ exchange rate (domestic currency per unit of foreign currency), 
$O=$ household consumption expenditures,

$Y=$ real gross national product,

$C=$ total real household consumption,

$Z, M=$ total real exports and imports, respectively, and

$\Pi_{j}=$ total profit in sector $j(j=0,1, \ldots, n+2)$.

\section{Parameters}

$a_{i j}=$ input of commodity $i(i=2,3, \ldots, n)$ per unit of output in sector $j$ $(j=2,3, \ldots, n+2)$,

$\bar{b}_{i j}=$ input of complementary imports $i(i=1,2)$ per unit of output in sector $j(j=1,2)$,

$\rho_{j}, \gamma_{j}=$ substitution coefficients in the production function of sector $j$ $(j=0,1, \ldots, n+2)$,

$\delta_{j}=$ annual rate of depreciation in sector $j(j=0,1, \ldots, n+2)$,

$\sigma_{j}=$ annual rate of change of world market trade in commodity $i$ $(i=1,2, \ldots, n)$,

$\omega_{j}=$ index of the wage rate in sector $j(j=0,1, \ldots, n+2)$,

$\beta_{j}=$ index of the rate of return on capital in sector $j(j=0,1, \ldots, n+2)$,

$\eta_{i}, \eta_{i j}=$ expenditure and price-elasticity parameters, respectively, in the household demand for commodity $i(i=0,1, \ldots, n+1)$,

$\epsilon_{i}, \mu_{i}=$ price-elasticity parameters in the export and import demand, respectively, for commodity $i(i=0,1, \ldots, n)$,

$A_{j}, B_{i}, Z_{i}^{0}, M_{i}^{0}=$ constants in the production, household demand, export, and import functions,

$\lambda=$ annual rate of technological change in $\operatorname{sector} j(j=0,1, \ldots, n+2)$,

$\alpha_{j}, a_{j}, b_{j}, c_{j}, d_{j}=$ distribution parameters in the production of sector $j$ $(j=0,1, \ldots, n+2)$.

\section{Decision Variables}

$$
\begin{aligned}
S_{j} & =\text { subsidy for sector } j(j=0,1, \ldots, n+2), \\
T_{j} & =\text { fuel tax parameter for sector } j(j=0,1, \ldots, n+2), \\
\theta_{i} & =\text { indirect tax on commodity } i(i=0,1, \ldots, n+2), \\
\phi_{i} & =\text { custom duty on commodity } i(i=0,1, \ldots, n), \\
E_{j} & =\text { export premium for commodity } j(j=0,1, \ldots, n), \\
F_{j} & =\text { tax on profit for sector } j(j=0,1, \ldots, n+2), \text { and } \\
\Omega_{j} & =\text { payment of interest in sector } j(j=0,1, \ldots, n+2) .
\end{aligned}
$$

The basic equilibrium state of the economy in block II is described as follows. The basic level of profit of sector $j$, including payments that derive from the economic tools (decision variables) is given by

$$
\begin{gathered}
\Pi_{j}=P_{j} X_{j}+S_{j}+E_{j}-\phi_{j}-F_{j}-\theta_{j}-T_{1 j} P_{1}^{\mathrm{D}} X_{1 j}-T_{2 j} P_{2}^{\mathrm{D}} X_{2 j}-W_{j} N_{j}-Q_{j} K_{j} \\
(j=0,1, \ldots, n+2)
\end{gathered}
$$


The equilibrium on the commodity markets is represented by

$$
\begin{aligned}
X_{1} & =\sum_{j=0}^{n+2} X_{1 j}+C_{1}+Z_{1}-M_{1} \\
X_{2} & =\sum_{j=0}^{n+2} X_{2 j}+C_{2}-M_{2} \\
X_{i} & =\sum_{j=0}^{n+3} a_{i j} X_{j}+C_{i}+Z_{i}-M_{i} \quad(i=3,4, \ldots, n) \\
X_{n+1} & =C_{n+1} \\
X_{n+2} & =G \\
X_{n+3} & =I+\sum_{j=0}^{n+2} \delta_{j} K_{j}
\end{aligned}
$$

The equilibrium for the market factors is given by

$$
\begin{aligned}
& \sum_{j=0}^{n+2} K_{j}=K \\
& \sum_{j=0}^{n+2} N_{j}=N
\end{aligned}
$$

The current account balance is given by

$$
\sum_{i=3}^{n}\left(P_{i} / V\right) Z_{i}-\sum_{i=0}^{n} P_{i}^{\mathrm{I}} M_{i}+E_{i}-\phi_{i}-\bar{P}_{1} \bar{M}_{1}-\bar{P}_{2} \bar{M}_{2}=D
$$

\subsection{Forecast of Economic Development}

The main features of the forecast economic development* in block II can be formulated as follows:

- The conditions of the world market are exogenously assigned;

- The economic tools prescribed for the sectors have the same level as in the base year;

\footnotetext{
* For a general description of the problem see Johansen (1974).
} 
- The sectors make decisions independently of the center; and

- A local optimization is analyzed in two sectors only (see below).

Local optimizations within the energy sector and agriculture and their influence on the economy as a whole are analyzed for the following cases:

- Competition between the two sectors and between them and the international market (fuel is produced by the energy sector and by agriculture via biogas);

- Different technological alternatives on the basis of substitution between capital and labor and other resources, including imports; and

- Alternatives analyzed when environmental pollution exists and its consequences for the economy must be considered.

The main features of the procedure for forecasting the behavior of the economy under the above considerations can be described as follows:

First, using different functions for forecasting (for $k$ possible alternatives ( $k=$ $1,2, \ldots, n))$.

Import function:

$$
m_{i k} \equiv \frac{M_{i k}}{X_{i k}-Z_{i k}}=\frac{M_{i k}^{0}}{X_{i k}^{0}-Z_{i k}^{0}}\left(\frac{P_{i k}}{\left(1+\phi_{i}\right) V P_{i k}^{\mathrm{I}}}\right)^{\mu_{i k}} \quad(i=0,1, \ldots, n)
$$

Capital-labor input function:

$$
F_{j k}=K_{j k}^{\alpha_{j k}} N_{j k}^{1-\alpha_{j k}} \exp \left(\lambda_{j k} t\right) \quad(j=0,1, \ldots, n+2)
$$

Composite input function:

$$
H_{j k}=\left\{c_{j k} X_{1 j k}^{\gamma_{j k}}+d_{j k} X_{2 j k}^{\gamma_{j k}}\right\}^{1 / \gamma_{j k}} \quad(j=0,1, \ldots, n+2)
$$

Gross output function:

$$
X_{j k}=A_{j k}\left\{a_{j k} F_{j k}^{\rho_{j k}}+b_{j k} H_{j k}^{\rho_{j k}}\right\}^{1 / \rho_{j k}} \quad(j=0,1, \ldots, n+2)
$$

Export function:

$$
Z_{i k}=Z_{i k}^{0}\left(P_{i k} / V P_{i k}^{\mathbf{E}}\right)^{\epsilon_{i k}} \exp \left(\sigma_{i k} t\right) \quad(i=3,4, \ldots, n)
$$

Household consumption function:

$$
C_{i k}=B_{i k} O^{\eta_{i k}}\left(T_{1 c k} P_{1 k}^{\mathrm{D}}\right)^{\eta_{1 i}}\left(T_{2 \mathrm{ck}} P_{2 k}^{\mathrm{D}}\right)^{\eta_{2 i}} P_{3 k}^{\mathrm{D}^{\eta_{3 i} i}}, \ldots, P_{n+1, k}^{\mathrm{D}^{\eta_{n+1, i}}} \quad(i=0,1, \ldots, n+1)
$$

Second, the above functions allow a more realistic prospective equilibrium to be derived with the same form as eqns. (35)-(44), denoted here $\left(35^{\prime}\right)-\left(44^{\prime}\right)$, each for $k=1,2, \ldots, n$. 
Third, the market factor equations ( $\left.42^{\prime}\right)$ and ( $\left.43^{\prime}\right)$ can be solved as a function of the factor market prices $W_{j}$ and $Q_{j}$, after which the system of prices has to be normalized

$$
\begin{gathered}
\sum_{j=0}^{n+2} P_{j k} X_{j k}+S_{j k}+\sum_{j=0}^{n} V P_{j k}^{\mathrm{I}} M_{j k}-\theta_{i k}+V \bar{P}_{1 k} \bar{M}_{1 k}+V \bar{P}_{2 k} \bar{M}_{2 k}-V P_{i k}^{\mathrm{E}} Z_{i k}+\dot{E}_{j k} \\
=\sum_{j=0}^{n+2} X_{j k}+\sum_{j=0}^{n} M_{j k}-\sum_{j=0}^{n} Z_{j k}+\bar{M}_{1 k}+\bar{M}_{2 k}
\end{gathered}
$$

Fourth, given some initial values of $W, R$, and $V$, one can derive $P^{*}, P$, and $P^{\mathrm{D}}$, where

$$
P_{j}^{*}=(1-\theta) P_{j}-\sum_{i=2}^{n} P_{i}^{\mathrm{D}} a_{i j}-V \bar{P}_{j} \bar{b}_{i j} \quad(j=0,1, \ldots, n+2)
$$

and $P_{j}^{*}$ can be inserted in the profit function $\left(35^{\prime}\right)$ which is to be maximized with respect to the sectors under analysis only (energy sector, $j=0,1$, and agriculture sector $j=2,3$ ).

Maximization of profit $\Pi_{j}^{*}$ is subject to the following constraints:

(i) Economic tools coefficients constraints $(s, \epsilon, \phi, f, p, t$, and $q=$ constant)

$$
S_{j}=s X_{j} ; E_{j}=\epsilon Z_{i} ; \Phi_{j}=\phi X_{j} ; F_{j}=f \Pi_{j} ; \theta_{j}=p X_{j} ; T_{j}=t X_{j} ; Q_{j}=P_{n+3}\left(\delta_{j}+R_{j}+q_{j}\right)
$$

(ii) Production and demand functions constraints (45)-(50), where different alternatives are included.

(iii) Conditions for factor combinations, where the left-hand sides include different technological and market alternatives and the right-hand sides include the influence of economic tools

$$
\begin{array}{ll}
a_{j k}\left(1-\alpha_{j k}\right)\left(\frac{A_{j} F_{j k}}{X_{j k}}\right)^{\rho_{j k}}=\frac{W_{j} N_{j}}{P_{j}^{*} X_{j}+s X_{j}+\epsilon Z_{j}} & (j=0,1 ; 2,3) \\
A_{j k} \alpha_{j k}\left(\frac{A_{j} F_{j k}}{X_{j k}}\right)^{\rho_{j k}}=\frac{Q_{j} K_{j}}{P_{j}^{*} X_{j}}=\frac{P_{n+3}\left(\delta_{j}+R_{j}+q_{j}\right)}{P_{j}^{*} X_{j}+s X_{j}+\epsilon Z_{j}} & (j=0,1 ; 2,3) \\
b_{j k} c_{j k}\left(\frac{A_{j} H_{j k}}{X_{j k}}\right)^{\rho_{j k}}\left(\frac{X_{1 j k}}{X_{j k}}\right)^{\gamma_{j k}}=\frac{T_{1 j} P_{1}^{\mathrm{D}} X_{1 j}}{P_{j}^{*} X_{j}+s X_{j}+\epsilon Z_{j}} & (j=0,1 ; 2,3) \\
b_{j k} d_{j k}\left(\frac{A_{j} H_{j k}}{X_{j k}}\right)^{\rho_{j k}}\left(\frac{X_{2 j k}}{X_{j k}}\right)^{\gamma_{j k}}=\frac{T_{2 j} P_{2}^{\mathrm{D}} X_{2 j}}{P_{j}^{*} X_{j}+s X_{j}+\epsilon Z_{j}} & (j=0,1 ; 2,3)
\end{array}
$$

Maximization of profit subject to the above conditions yields an optimal choice of an alternative, which at the same time influences the respective distribution and substitution coefficients, i.e. the state of all sectors. Putting the profit function equal to zero allows 
the commodity prices to be derived as a function of the factor prices, and by substituting $P_{j}^{*}$ into eqn. (52) the unknowns $P_{j}$ and $P_{i}^{\mathrm{D}}$ can be derived.

Fifth, the production volume $X_{j}$, production costs $P_{i}$, and prices $P_{j}^{\mathbf{D}}$ are a basis for deriving $N_{j}$ and $K_{j}$ and their respective differences $\Delta N$ and $\Delta K$ which allows $W$ and $R$ to be adjusted.

Finally, the equilibrium between production volume, prices, production costs, wages, and level of interest makes it possible to calculate the total production volume of fuel. This is produced in both sector 1 and sector 2 and is redistributed between the two sectors on the basis of an optimal division between fuel and electricity produced in the energy sector and between fuel and agricultural production in the agricultural sector, subject to a minimum price level for fuel (which makes these two sectors competitors)

$$
\Pi_{j 1}=\left(P_{j 0} X_{j 0}+P_{j 1} X_{j 1}\right)-\left(P_{i 0}+P_{i 1}\right) \rightarrow \max
$$

subject to $P_{j 1} X_{j 1} \rightarrow \min$, and

$$
\Pi_{j 2}=\left(P_{j 1} X_{j 1}+P_{j 2} X_{j 2}\right)-\left(P_{i 1}+P_{i 2}\right) \rightarrow \max
$$

subject to $P_{j 1} X_{j 1} \rightarrow$ min. Redistribution of the product subject to competition will influence the other sectors in terms of a lower price for this product.

Thus the final forecast state of the economy can be expressed by comparable (with regard to the optimal state (23)) indicators

$$
\hat{X}_{j} ; \hat{P}_{i}^{\mathrm{D}} ; \hat{X}_{i} ; \hat{W}_{j} ; \hat{Y}_{i} ; \hat{N}_{j} ; \text { and } \hat{K}_{j}
$$

The models were solved using the solution algorithm of Bergman and Porr (1980) as shown in Figure 5.

Some of the results from the above forecast can serve as information for block I, at the stage of forecasting the national economy.

\subsection{Directed Optimization Equilibrium}

The analysis shows that some differences always exist between comparable indicators of the forecast equilibrium (eqn. (60)) and the desirable (optimal) state of the economy which results from block I (eqn. (23))

$$
X_{j}^{*}-\hat{X}_{j}=\Delta X_{j} ; P_{i}^{* \mathrm{D}}-\hat{P}_{i}^{\mathrm{D}}=\Delta P_{i}^{\mathrm{D}} ; \text { etc. }
$$

The differences between blocks I and II regarding the basic equilibrium were analyzed as follows.

First, the differences were carefully examined in order to clarify the reasons for them. Analysis of expenditure, for example the expenditure for environmental protection appearing in block $\mathrm{I}$, shows that environmental pollution was ignored in block II when performing local optimization at the sectoral level. This conclusion determines which economic tool is to be changed (according to the basic equilibrium in block II) in order to 


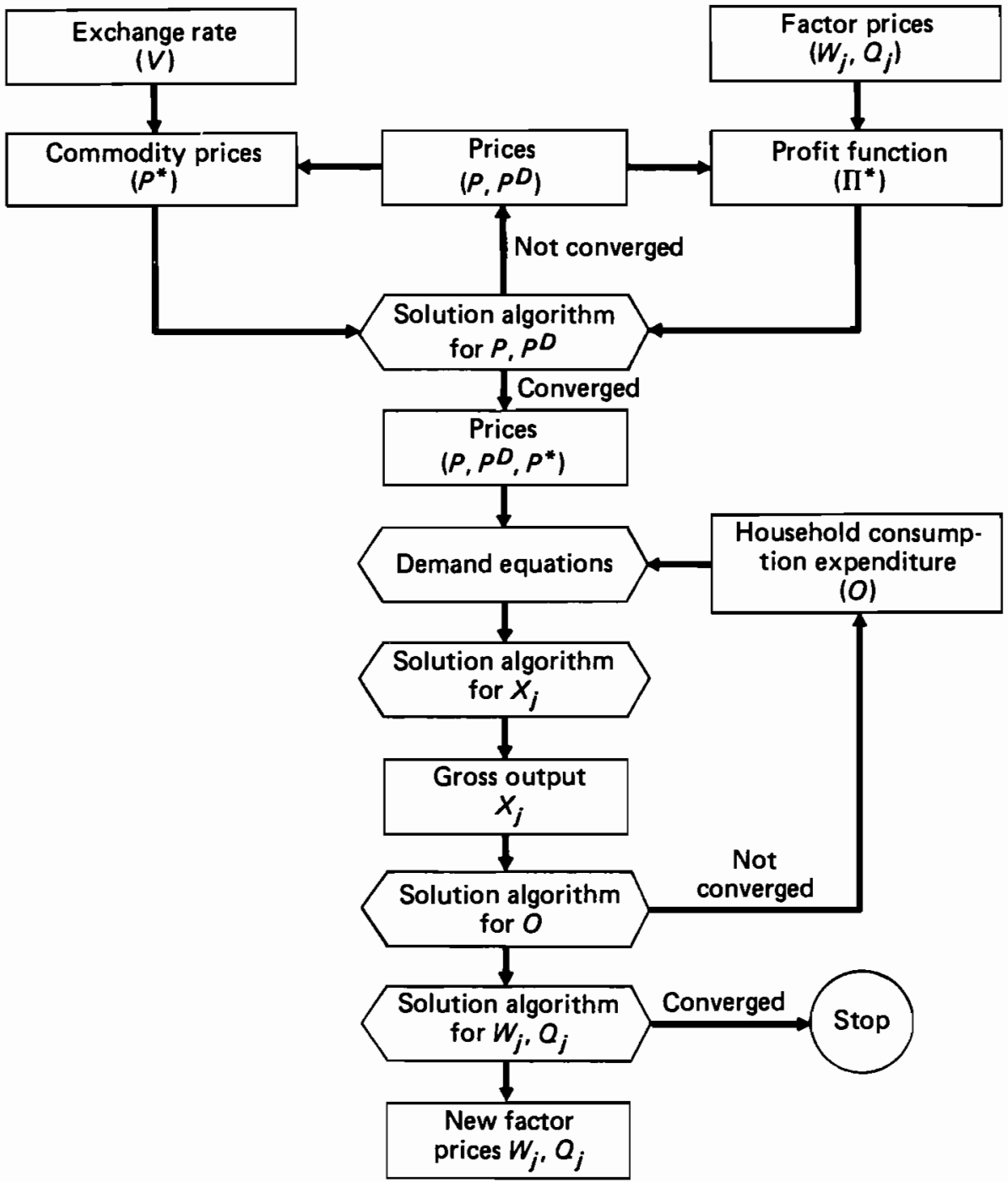

FIGURE 5 Solution algorithm for an equilibrium model.

eliminate the above difference (negative consequence). It is apparent that the level of standards or the appropriate penalties for environmental pollution have to be changed.

Second, the economic tools were directly identified. This analysis is especially necessary in the present case since no basis for changing the type and level of the economic tools exists. Some calculations are necessary for this purpose on the basis of consecutive changes in the level of each economic tool used (without changing the others), following the solution procedure described above. Comparing the level and direction of the changes in the comparable indicators according to their basic level, it is possible to define the 
direction and intensity of each economic tool. In this way, knowing the intensity coefficients and the level of the indicators which have to be changed (from the differences between blocks I and II), the required level of changes in the economic tools can be derived. For example, if

$$
l=\Delta X_{j} / \Delta s
$$

where $l=$ an intensity coefficient, then

$$
\Delta s=\Delta X_{j} / l
$$

Thus the change in the type and level of the economic tools influences the incentives of the sectors regarding their local optimization and autonomy, and, at the same time, allows the optimal (most desirable) state of the economy to be reached

$$
X_{j}^{*}-\hat{X}_{j}=0 ; P_{i}^{* \mathbf{D}}-\hat{P}_{i}^{\mathrm{D}}=0 ; \text { etc. }
$$

\section{CONCLUSIONS}

The general possibility of achieving directed optimization in the development of an economy allows some final conclusions to be drawn.

First, an economic mechanism based on directed optimization ensures a high level of incentives and responsibility for three main reasons. Equal possibilities exist for all production units and for each person; real equilibrium among the formidable number of potential products is possible only when it is a result of decision-making at a local level; real responsibility is assigned to the center on the basis of a clear distinction of its functions, which are different from those of the sectors and can only be realized at a high level of aggregation.

Second, although the conclusions drawn in respect to the economic mechanism are generally correct under limited conditions of analysis (limited optimization factors, partial competition, etc.), it is hoped that the equilibrium system of models described earlier will in future be further improved in the following directions: local optimization for all the sectors will be implemented on the basis of all possible product and factor substitutions in competition between all the sectors, taking into account the territorial (spatial) factor; the models will be solved dy namically; the global optimization in block I will be based on a multiobjective optimization approach (Wierzbicki, 1979), on a preliminary prescribed rate of growth (Andersson, 1979), and on the territorial (spatial) factor (Andersson, 1979); demographic and migration models (Kelley and Williamson, 1979) will be included in the system of models. In addition, it is hoped that after modification some of the models and some of the approaches proposed will also be used to study the market-economy countries.

Third, any improvement in the economic mechanism requires changes in the conditions for its implementation and also in modeling the national economy. This can be expressed as follows. The use of an equilibrium system of models is a necessary condition for the use of uniform economic tools; the use of uniform economic tools is a necessary 
condition for real economic autonomy at the local level. These two conditions are necessary and sufficient for the implementation of directed optimization in the development of an economy.

\section{REFERENCES}

Andersson, A. (1979). Growth and Stagnation of Economies with Public Goods - A Neoclassical Analysis. WP-79-1 2. International Institute for Applied Systems Analysis, Laxenburg, Austria.

Bergman, L. and Pór, A. (1980). A Quantitative General Equilibrium Model of the Swedish Economy. WP-80-4. International Institute for Applied Systems Analysis, Laxenburg, Austria.

Johansen, L. (1974). A Multisectoral Study of Economic Growth. Second enlarged edition. NorthHolland, Amsterdam.

Kelley, A. and Williamson, J. (1979). Modeling Urbanization and Economic Growth. WP-79-81. International Institute for Applied Systems Analysis, Laxenburg, Austria.

Mateev, E. (1963). Long-Term Planning: Intersectoral Links and Input-Output Coefficients. Partizdat, Sofia.

Mihailov, B. (1973). Modeling and Management of the Social System. Partizdat, Sofia.

Mihailov, B. (1974). Optimal Control of the Economic System. Partizdat, Sofia.

Mihailov, B., Pór, A., and Assa, I. (1980). Modified Multisectoral Equilibrium Model for Bulgaria. Paper presented at the HSS/SDS Task Force Meeting on General Equilibrium Modeling, 10-13 November 1980. International Institute for Applied Systems Analysis, Laxenburg, Austria.

Nyhus, D. (1980). The INFORUM-IIASA Trade Model: An Interim Report. WP-80-24. International Institute for Applied Systems Analysis, Laxenburg, Austria.

Wierzbicki, A. (1979). The Use of Reference Objectives in Multiobjective Optimization - Theoretical Implications and Practical Experience. WP-79-66. International Institute for Applied Systems Analysis, Laxenburg, Austria. 



\title{
ESTIMATES OF THE DISEQUILIBRIA IN POLAND'S CONSUMER MARKETS (1965-1978)
}

\author{
Leon Podkaminer \\ International Institute for Applied Systems Analysis, Laxenburg (Austria)
}

\begin{abstract}
"The question is sometimes asked: Why do we need a theory of choice; why can't we simply take the concepts of demand itself (prices, income measured in money, etc.) as the basic concepts and leave all theory of choice aside? The answer is simple. The theory of choice - and particularly the concept of a utility indicator - is assumed to be independent of the particular organizational form of the market. Even if the goods were distributed to consumers in an entirely different way, not through a market with a budget equation, etc., the utility indicator would in general exist and may, for instance, be used for estimating the behaviour of consumers under specific market forms that may be contemplated in a programming analysis." (Frisch, 1959)
\end{abstract}

\section{A PRACTICAL PROBLEM THAT REQUIRES THEORETICAL TOOLS}

One of the aspects of the economic difficulties Poland is experiencing is an acute shortage of marketable commodities. Although absolute levels of per capita consumption of particular food items (especially animal produce) and the collections of durables owned by the average household had (until 1979) approximated Western European standards, the extent of lines, waiting lists and more or less formalized rationing would suggest that the demand for virtually all commodities is far from satisfied. Although Poland is not the only country affected by the "disequilibrium malady" - since some authors already draw a firm distinction between supply-const rained and demand-constrained economies (Kornai, 1979) - the Polish case is definitely a severe and persistent one.

Some thinkers attribute this situation to purely political motives. "One could get rid of the market disequilibrium overnight" - the reasoning often goes - "just by introducing equilibrium prices. But this would" - it is stressed - "provoke popular resentment." This case seems to be well supported by historical events, with attempts at raising food prices failing as a result of widespread protests.

Before the conclusion is reached that there is nothing one can do about the present situation but increase supplies - at any cost (to be covered ultimately by external sources) - it may be worth asking whether the proposed changes in the price structure 
actually represent a move towards equilibrium or whether, on the contrary, they imply an even greater disequilibrium.

To be able to answer this question, albeit in a crude way, one would have to have a system of demand functions that could be assumed to represent at least "the average Polish consumer's" response to prices, given the average level of incomes. (Of course, having separate demand systems for households stratified according to professional, demographic, or other relevant criteria, would allow a more thorough analysis, eliciting all sorts of distributional and welfare effects caused by changing prices.)

Let us put the system of equations in question in the following manner:

$$
q_{i}=f_{i}\left(p_{1}, p_{2}, \ldots, p_{m}, y\right) \quad(i=1,2, \ldots, m)
$$

where $q_{i}$ is the quantity of good " $i$ " demanded under price system $p=\left(p_{1}, p_{2}, \ldots, p_{m}\right)$ and $y$ is total expenditure or disposable income. (Throughout this paper $y$ and $q_{i}$ are taken as per capita terms.)

Additionally, eqn. (1) has to be "at least locally consistent": for a fairly wide set of commodity bundles $q^{0}=\left(q_{1}^{0}, q_{2}^{0}, \ldots, q_{m}^{0}\right)$ there should be at least one (ideally exactly one) price vector $p^{0}$ that satisfies both eqn. (1) and the budget constraint:

$$
p^{0} q^{0}=\sum_{i=1}^{m} p_{i}^{0} q_{i}^{0}=y
$$

(Any demand system (1) derived via the utility maximization assumption and subject to this budget constraint will yield exactly one price vector ("equilibrium price") for any bundle $q$ for which the utility function is determined. Because empirical demand studies not derived via the utility assumption and not even satisfying homogeneity or symmetry conditions can be encountered, it is important to impose the condition of local consistency.)

Provided eqn. (1) satisfies both conditions, it would be possible to determine whether the proposed changes in prices really represent a move towards any equilibrium. It also follows that an adequate knowledge of eqn. (1) would permit a mathematical programming analysis for pricing and therefore the determination of optimum equilibrium price vectors.

However, unless eqn. (1) were derived via the utility maximization assumption, one would still be unable to use it for predicting the actual level of demands should the supply of one or more commodities be inadequate. Thus, if

$$
s_{1}<f_{1}\left(p_{1}, p_{2}, \ldots, p_{m}, y\right)
$$

then the value of the excess demand $\left(s_{1}-f_{1}\left(p_{1}, p_{2}, \ldots, p_{m}, y\right)\right)$ tends to be somehow distributed over other commodities. Also, it may in part increase the amount of reported savings. With utility-based demand systems, the prediction is not difficult, no matter how many commodities are in short supply. The forecast demands are the (unique) solution to the following optimization model:

$$
\max U\left(q_{1}, q_{2}, \ldots, q_{m}\right)
$$


subject to

$$
\sum p_{i} q_{i}=y
$$

and

$$
q_{i} \leqslant \bar{q}_{i} \quad(i=1,2, \ldots, m)
$$

where $\bar{q}_{i}$ are the supplies of the commodities and $U(q)$ is the utility function on which the demand system (1) is based.

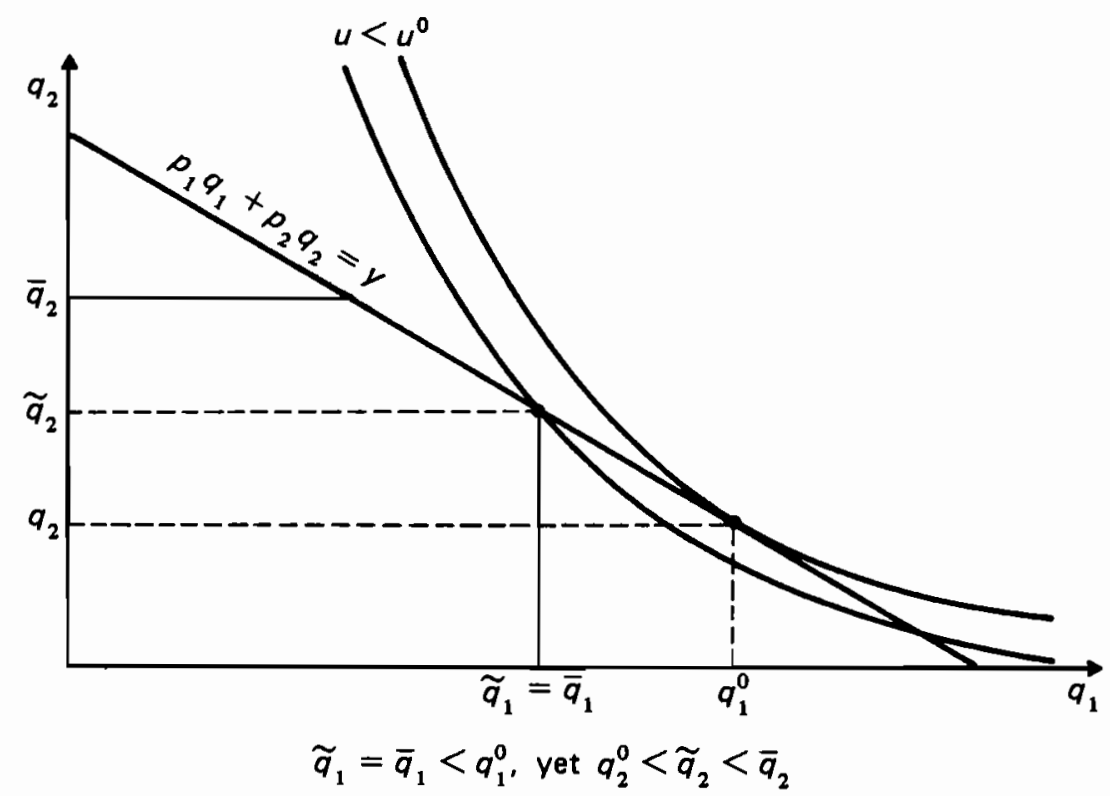

FIGURE 1 Variation in relative demand for two commodities when there is a shortage of supply.

It is obvious that the solution of the above optimization model may differ from that of a model which maximizes the utility indicator subject to budget constraints only. If the former is denoted by $q(p, y, \bar{q})$ and the latter by $q^{0}(p, y)$ then the coordinates of the vector

$$
q^{0}(p, y)-q(p, y, \bar{q})
$$

represent the extents of disequilibria for particular commodities. It is important to observe (see Figure 1) that when total supply is not smaller than total expenditure, i.e. when 


$$
\sum p_{i} \bar{q}_{i} \geqslant y
$$

then some coordinates in eqn. (2) may be negative, some positive and some zero. Hence, under conditions of disequilibrium, the observed demands for some commodities may be smaller than they should be at equilibrium, while others may be greater.

\section{SPILLOVERS CAN BE NEITHER OBSERVED NOR IGNORED}

A shortage in one commodity is enough to cause spillovers: the observed purchases of other commodities may increase to compensate for the original shortage. The situation worsens when many shortages occur simultaneously.

Although knowledge of the parameters of a demand system (based on the utility assumption) allows the final distribution of spillovers - given prices, income, and actual supplies - to be determined, it must be recognized that when these parameters are not known it is practically impossible to distinguish between past observed supplies, voluntary demands, and spillovers. This, in turn, prevents estimation of the demand system (1), whether it is based on the utility assumption or not. More specifically, a stochastic counterpart of eqn. (1), when complemented by variables for possible spillovers, can be written in the following manner.

$$
q_{i t}^{*}=f_{i}\left(a, p_{1 t}, p_{2 t}, \ldots, p_{m t}, y_{t}\right)+\varepsilon_{i t} \quad(i=1,2, \ldots, m)
$$

and

$$
p_{i t} q_{i t}=p_{i t} q_{i t}^{*}+\sum_{j} V_{i j t}+\mu_{i t} \quad(i=1,2, \ldots, m)
$$

where

$t$ numbers observations, say by years;

$q_{i t}^{*}$ represents the "pure" demand for commodity $i$ (as expressed by eqn. (1), assuming unconstrained supplies of all other commodities),

$q_{i t}$ represents the "observed" demand for commodity $i$ (or actual consumption of $i$ ),

$V_{i j t}$ represents the spillover (in monetary terms) from commodity $i$ to commodity $j$,

$a$ is the vector of parameters of eqn. (1) which is to be estimated,

$\epsilon_{i t}$ is a random factor affecting the $i$ th equation in system (1), and

$\mu_{i t}$ is a random factor affecting the $i$ th equation in system (4).

Both $q_{i t}^{*}$ and $V_{i j t}$ are unobservable. Although the number of variables $V_{i j t}$ can be reduced by the introduction of asymmetry conditions (e.g. requiring that $V_{i j t}=-V_{j i t}$ ), the system (3)-(4) still cannot be estimated econometrically.

From this it can be concluded that any nontrivial demand system $(m \geqslant 2)$, estimated solely on the basis of the observed disequilibrium prices, quantities purchased, and expenditures, cannot be adequately described as even an approximate version of the actual system (1). Additionally, it may be noticed that even the "trivial" case poses very 
considerable econometric problems (Ito, 1980) which are fairly intractable without some additional conditions.

\section{THE USE OF EXTRANEOUS INFORMATION}

It is obvious that without some extraneous information on the demand system (1) it is impossible to estimate its parameters. The information required cannot, however, be derived from the data on observed disequilibrium prices, expenditures, and quantities, as these cannot generate any more knowledge than is already present in the system (3)-(4). Certainly the knowledge of black market prices might improve the specification of the system, provided the work is set in the context of a utility-based demand system. (The Lagrange multipliers in the supply-constrained utility maximization problem would then, in principle, be analy tically related to the observed black market prices.) However, since these prices are not reported by official statistics, this approach is unlikely to be helpful.

A more promising method may be to resort to international comparisons. Existing demand studies for many countries that may be safely assumed to enjoy persistent equilibrium in consumers' markets suggest definite patterns of consumer behavior. It may then be possible to identify some of the parameters that have proved acceptable for describing the average consumer demand response for a wide range of countries with the ones that may be attributed to system (1) for Poland, i.e., to the average Polish consumer's behavior at equilibrium.

If the premises (Houthakker, 1957) that "the discovery of widely applicable generalizations is the principal aim of science" and "that there are meaning ful propositions which appear to be valid in nearly all the countries considered, without reference to their climatic or cultural conditions" are accepted, then it is possible, at least in principle, to proceed somewhat further with the analysis.

There is, however, still a need for caution. First of all, the research should be restricted to rather aggregated-level studies. It must also be recognized that the re are some differences in the reported empirical demand studies, causing the estimated parameters to vary somewhat from country to country. Also, they depend on the specific functional form of the equations adopted, the details of assumed stochastic structure, and the estimation procedure applied. Needless to say, the statistical quality of the findings is not uniform. In effect, the conclusions to be derived with respect to Poland cannot be expected to be independent of the particular foreign demand system accepted. However, if some of these conclusions demonstrate some degree of consistency, it may be possible to define some fairly definite qualifications and recommendations with respect to the Polish situation.

\section{APPLICATION OF THE EXTENDED LINEAR EXPENDITURE SYSTEMS (ELES) WITH ITALY AND IRELAND AS REFERENCE COUNTRIES}

The cross-country comparative studies of consumer demand patterns used to derive the final reference demand systems for Poland are those of Goldberger and Gamaletsos (1970), Gamaletsos (1973), and Lluch et al. (1977). Italy and Ireland, which 
resemble Poland in many historical and cultural traditions and have similar levels of overall economic development, are of particular interest. Additionally, the durables and housing per average household in all three countries are not dissimilar.

The statistical significance of the reported estimates and their theoretical plausibility strongly supported the choice of the Extended Linear Expenditure Systems (ELES) presented in Lluch et al. (1977).

To ensure comparability with average Polish data, the systems were aggregated ${ }^{*}$ to the four-commodity list containing "food" (including alcohol and tobacco), "clothing" (including footwear), "rent" (including heating and durables, but not automobiles), and "rest" (health, education, leisure, culture, etc.). This aggregation provides a general picture, al though this need not be consistent with subjective feelings about price levels and availability of particular sub-commodities. Thus, for instance, we ignore the fact that within the "food" goods category there are some items considered to be both in short supply and too highly priced (better cuts of meat), or abundant yet underpriced (cereals, milk, potatoes), or abundant and overpriced (alcohol). The same types of qualification apply to other commodity groups.

The utility function underlying ELES is given by the well known Stone-GearyRubin-Klein formula:

$$
u\left(q_{1}, q_{2}, \ldots, q_{m}\right)=\sum_{i=1}^{m} \beta_{i} \ln \left(q_{i}-c_{i}\right)
$$

where $c_{i}$ is interpreted as "committed" or "subsistence" consumption of good $i$.

There is one unfortunate feature of any demand system that presupposes the existence of subsistence levels $c_{i}$. Since an economist has to work with aggregate commodities, sometimes as nebulous as "food" or "services", the $c_{i}$ values can seldom be measured in physical quantities. Instead, one has to work with "abstract" $c_{i}$ values representing the monetary equivalent of the subsistence consumption in the prices of some given year. While this feature does not affect the usage of any demand system for the country to which it refers, it certainly creates problems in the cross-country comparisons because exchange rates have to be introduced. While this may be more or less safely done with respect to the comparable equilibrium economies, there are considerable difficulties regarding the conversion of $c_{i}$ values expressed in $1970 \mathrm{Italian}$ Lira and Irish Pounds into subsistence consumptions of the basic commodities expressed in Polish Zlotys of some given year.

Inevitably, some additional assumptions have to be adopted:

1. Besides the "average" consumer, in each of the countries under consideration there is a "marginal subsistence" consumer whose income approximates the total subsistence level.

2. The volumes of consumption $q_{i}$ (in Poland) are always bigger than the corresponding subsistence levels $c_{i}$. In effect, neither prices, nor supplies, nor budget

\footnotetext{
* The theoretical basis of the ELES for Italy is questionable, but the method of aggregation employed here ensures adequate quality.
} 
interfere with the attainment of all of the $c_{i}$ levels. In particular, no spillover between the subsistence consumptions could have occurred.*

Now, if the subsistence consumers in all three countries (retired hippies?) were identified and their average yearly allowances defined as $w^{\text {pol }}, w^{\text {irl }}, w^{\text {ita }}$, one could postulate that conversion rates for total committed expenditures follow the identities:

$$
w^{\mathrm{pol}} / \sum_{i} c_{i}^{\mathrm{pol}}=w^{\mathrm{irl}} / \sum_{i} c_{i}^{\mathrm{irl}}=w^{\mathrm{ita}} / \sum_{i} c_{i}^{\mathrm{ita}}
$$

This line of reasoning has not been rigorously followed here; instead, the average wage in the lowest-paid sector of the economy (agriculture in all three cases) has been chosen. At these levels of income the ratios given above for Ireland and Italy are not the same. This has been allowed for by calculating two sets of $c_{i}$ values for Poland:

$$
c_{i}^{1} / \sum_{i} c_{i}^{1}=c_{i}^{\mathrm{irl}} / \sum_{i} c_{i}^{\mathrm{irl}}
$$

where

$$
\sum_{i} c_{i}^{1}=\left(w^{\mathrm{pol}} / w^{\mathrm{irl}}\right) \sum_{i} c_{i}^{\mathrm{irl}}
$$

and

$$
c_{i}^{2} / \sum_{i} c_{i}^{2}=c_{i}^{\mathrm{ita}} / \sum_{i} c_{i}^{\mathrm{ita}}
$$

where

$$
\sum_{i} c_{i}^{2}=\left(w^{\mathrm{pol}} / w^{\mathrm{ita}}\right) \sum_{i} c_{i}^{\mathrm{ita}}
$$

Since there is of course a possibility of bias in the method adopted, alternative conversion rates have also been used in separate runs to test the sensitivity of the estimates. In the first runs the values $c_{i}^{1,1}=1.5 c_{i}^{1}$ and $c_{i}^{2,1}=1.5 c_{i}^{2}$ were used, while in the second runs the values $c_{i}^{1,2}=0.5 c_{i}^{1}$ and $c_{i}^{2,2}=0.5 c_{i}^{2}$ were adopted. Table 1 shows the estimates for the parameters of the two basic reference demand systems for Poland, determined as described above.

The subsistence levels $c_{i}$ are expressed in thousands of Zlotys per capita per year

\footnotetext{
* This is implicit in the ELES formulation. It is a reasonable assumption for the three countries being compared because the "average" consumer will not be so poor that he has to choose between different subsistence levels.
} 
TABLE 1 The parameters of the basic reference demand systems for Poland.

\begin{tabular}{|c|c|c|c|c|}
\hline \multirow[t]{2}{*}{ Commodity aggregate (i) } & \multicolumn{2}{|l|}{ Ireland } & \multicolumn{2}{|l|}{ Italy } \\
\hline & $\beta$ & $c$ & $\beta$ & $c$ \\
\hline Food (1) & 0.315 & 2.925 & 0.402 & 2.4 \\
\hline Clothing (2) & 0.134 & 0.436 & 0.087 & 0.52 \\
\hline Rent (3) & 0.222 & 0.907 & 0.24 & 0.56 \\
\hline Rest (4) & 0.329 & 0.931 & 0.271 & 1.12 \\
\hline Propensity to consume $m$ & \multicolumn{2}{|c|}{0.846} & \multicolumn{2}{|c|}{0.790} \\
\hline
\end{tabular}

(1971 prices) while $m$ are the estimated propensities to consume out of total disposable monetary income. Thus, it is assumed that, at equilibrium, total expenditure $y$ and total disposable monetary income $Y$ satisfy the equation

$$
y=m Y+(1-m) \sum_{j=1}^{4} p_{j} c_{j}
$$

Therefore, the estimate of voluntary savings is $(1-m)\left(Y-\sum_{j=1}^{4} p_{j} c_{j}\right)$.

\section{ARITHMETIC OF THE REFERENCE ELES SYSTEMS WHEN APPLIED TO POLAND}

Two types of equations are used. The first type comprises the equations for the determination of supplies that would have equilibrated the markets while leaving all prices and income (i.e. monetary endowment) unchanged. The second type comprises equations for the determination of prices that would have equilibrated the markets while leaving consumption and income unchanged.

The first type is given by the following general formula:

$$
q_{i, t}^{k, j}=c_{i}^{k, j}+\left(\beta_{i}^{k} / p_{i, t}\right) m^{k}\left(Y_{t}-\sum_{s=1}^{4} c_{s}^{k, j} p_{s, t}\right)
$$

where

$k=1$ (Ireland), 2 (Italy),

$j=0$ (basic), 1 (increased), and 2 (decreased) levels of total subsistence expenditure,

$i=1,2,3,4$ (commodity aggregates), and

$t=$ date (in years).

$p_{i, t}$ is therefore the actual (reported) price index of commodity aggregate $i$ in year $t$, expressed in current prices (base year $=1971$ ). $Y_{t}$ is total annual per capita income in year $t$ (this is assumed to equal total actual expenditure plus savings, as identified from bank deposits). $q_{i, i}^{k, j}$ values are therefore the vectors of supplies that would have 
equilibrated all the markets (and left the consumer with no involuntary savings or debts) estimated on the basis of the respective demand $\operatorname{system}(k, j)$.

The second type is given by the general formula:

$$
p_{i, t}^{k, j}=m^{k} Y_{t}\left[\beta_{i}^{k} /\left(q_{i, t}-c_{i}^{k j}\right)\right] /\left\{1+\sum_{s=1}^{4}\left[\beta_{s}^{k} c_{s}^{k j} /\left(q_{s, t}-c_{\delta}^{k j}\right)\right] m^{k}\right\}
$$

where all the symbols, with the exception of $q_{i, t}$ and $p_{i, t}^{k, j}$ have the same meaning as before. Now $q_{i, t}$ is the actual (observed) consumption of commodity $i$ in year $t$ (expressed in 1971 prices), and the $p_{i, t}^{k, j}$ values are the vectors of prices that would have equilib rated all the markets (and left the consumer with no involuntary savings or debts) estimated on the basis of the respective demand system $(k, j)$.

\section{ESTIMATES OF THE ACTUAL SHORT AGES (AND SURPLUSES) OF COMMODITIES FOR THE PERIOD 1965-1978}

Table 2 gives information on $p_{i, t}, q_{i, t}$, and $Y_{t}$ for the period under consideration. By applying formula (5) to the historical data, the systems of supplies that would have equilibrated all the markets, all other factors remaining unchanged, can be estimated.

TABLE 2 Historical data for Poland. ${ }^{a}$

\begin{tabular}{|c|c|c|c|c|c|c|c|c|c|c|c|}
\hline \multirow[t]{2}{*}{ Year } & \multicolumn{2}{|l|}{ Food } & \multicolumn{2}{|c|}{ Clothing } & \multicolumn{2}{|l|}{ Rent } & \multicolumn{2}{|l|}{ Rest } & \multirow{2}{*}{$\begin{array}{l}\text { Total } \\
\text { expenditure }\end{array}$} & \multirow{2}{*}{$\begin{array}{l}\text { Observed } \\
\text { savings }\end{array}$} & \multirow{2}{*}{$\begin{array}{l}\text { Monetary } \\
\text { endowment }\end{array}$} \\
\hline & $q$ & $p$ & $q$ & $p$ & $q$ & $p$ & $q$ & $p$ & & & \\
\hline 1965 & 7.33 & 0.92 & 1.59 & 1.00 & 1.28 & 0.98 & 1.94 & 0.84 & 11.22 & 1.33 & 12.55 \\
\hline 1966 & 7.80 & 0.92 & 1.85 & 1.00 & 1.22 & 1.01 & 3.08 & 0.93 & 13.12 & 1.64 & 14.76 \\
\hline 1967 & 8.06 & 0.93 & 1.93 & 1.00 & 1.34 & 0.99 & 3.29 & 0.95 & 13.89 & 1.97 & 15.86 \\
\hline 1968 & 8.26 & 0.97 & 2.08 & 1.00 & 1.54 & 0.98 & 3.47 & 0.96 & 14.90 & 2.27 & 17.17 \\
\hline 1969 & 8.52 & 0.97 & 2.20 & 1.00 & 1.60 & 0.96 & 3.68 & 0.97 & 15.57 & 2.67 & 18.24 \\
\hline 1970 & 8.91 & 0.97 & 2.32 & 1.00 & 1.69 & 0.99 & 3.85 & 1.00 & 16.49 & 2.99 & 19.47 \\
\hline 1971 & 9.05 & 1.00 & 2.33 & 1.00 & 1.95 & 1.00 & 2.62 & 1.00 & 15.45 & 3.42 & 19.37 \\
\hline 1972 & 9.43 & 1.01 & 2.54 & 1.00 & 2.21 & 1.00 & 2.98 & 0.98 & 17.19 & 4.20 & 21.39 \\
\hline 1973 & 10.18 & 1.01 & 2.90 & 1.00 & 2.45 & 1.00 & 3.38 & 1.00 & 19.01 & 5.20 & 24.21 \\
\hline 1974 & 10.48 & 1.01 & 3.21 & 1.01 & 2.85 & 1.01 & 3.65 & 1.04 & 20.50 & 6.39 & 26.89 \\
\hline 1975 & 11.28 & 1.12 & 3.17 & 1.20 & 2.85 & 1.25 & 3.17 & 1.31 & 24.15 & 7.39 & 31.54 \\
\hline 1976 & 12.18 & 1.20 & 3.27 & 1.26 & 3.02 & 1.29 & 3.56 & 1.35 & 27.44 & 8.03 & 35.47 \\
\hline 1977 & 12.64 & 1.26 & 3.22 & 1.34 & 3.67 & 1.36 & 3.38 & 1.70 & 30.98 & 8.74 & 39.72 \\
\hline 1978 & 12.63 & 1.43 & 3.01 & 1.46 & 3.42 & 1.43 & 3.48 & 1.77 & 33.51 & 9.52 & 43.03 \\
\hline
\end{tabular}

${ }^{a}$ Taken from Polish Statistical Yearbooks $(1972,1976,1979)$.

To facilitate assimilation and understanding of the data, the estimates of the disequilibria actually occurring in particular years (measured as differences between estimated equilibrium supplies and volumes actually consumed) are reported. Table 3 shows the estimates of shortages (positive) and surpluses (negative) for the basic demand system described in Table 1. 
TABLE 3 Extents of disequilibria, in quantity terms at 1971 prices.

\begin{tabular}{|c|c|c|c|c|c|c|c|c|c|c|c|}
\hline \multirow[t]{2}{*}{ Year } & \multicolumn{2}{|l|}{ Food } & \multicolumn{2}{|c|}{ Clothing } & \multicolumn{2}{|l|}{ Rent } & \multicolumn{2}{|l|}{ Rest } & \multicolumn{2}{|c|}{ Voluntary savings } & \multirow{2}{*}{$\begin{array}{l}\text { Observed } \\
\text { savings }\end{array}$} \\
\hline & Ireland & Italy & Ireland & Italy & Ireland & Italy & Ireland & Italy & Ireland & Italy & \\
\hline 1965 & -2.16 & -2.05 & -0.27 & -0.50 & 1.11 & 0.89 & 1.56 & 1.30 & 0.74 & 1.17 & 1.33 \\
\hline 1966 & -2.02 & -1.80 & -0.30 & -0.61 & 1.52 & 1.30 & 0.80 & 0.44 & 1.08 & 1.63 & 1.64 \\
\hline 1967 & -2.00 & -1.74 & -0.27 & -0.62 & 1.63 & 1.41 & 0.84 & 0.42 & 1.24 & 1.87 & 1.97 \\
\hline 1968 & -2.00 & -1.70 & -0.27 & -0.70 & 1.74 & 1.53 & 0.90 & 0.49 & 1.45 & 2.14 & 2.27 \\
\hline 1969 & -1.97 & -1.61 & -0.27 & -0.73 & 1.89 & 1.68 & 1.04 & 0.48 & 1.61 & 2.36 & 2.67 \\
\hline 1970 & -2.04 & -1.61 & -0.26 & -0.77 & 1.94 & 1.73 & 1.08 & 0.47 & 1.80 & 2.62 & 2.99 \\
\hline 1971 & -2.35 & -1.96 & -0.29 & -0.79 & 1.62 & 1.41 & 2.25 & 1.66 & 1.78 & 2.60 & 3.42 \\
\hline 1972 & -2.23 & -1.75 & -0.27 & -0.87 & 1.74 & 1.53 & 2.55 & 1.81 & 2.10 & 3.03 & 4.20 \\
\hline 1973 & -2.25 & -1.62 & -0.31 & -1.03 & 2.02 & 1.82 & 2.83 & 1.93 & 2.53 & 3.62 & 5.20 \\
\hline 1974 & -1.85 & -1.10 & -0.35 & -1.18 & 2.08 & 1.88 & 3.07 & 2.04 & 2.95 & 4.18 & 6.39 \\
\hline 1975 & -2.31 & -1.49 & -0.33 & -1.16 & 1.87 & 1.66 & 3.15 & 2.21 & 3.66 & 5.20 & 7.39 \\
\hline 1976 & -2.82 & -1.92 & -0.23 & -1.13 & 2.10 & 1.90 & 3.35 & 2.27 & 4.27 & 5.98 & 8.03 \\
\hline 1977 & -2.81 & -1.84 & -0.02 & -0.99 & 1.74 & 1.54 & 2.89 & 1.94 & 4.92 & 6.88 & 8.74 \\
\hline 1978 & -3.15 & -2.22 & -0.16 & -0.79 & 2.19 & 1.92 & 3.00 & 2.00 & 5.43 & 7.57 & 9.52 \\
\hline
\end{tabular}

By applying the formula (6) to the historical data, estimates of the system of prices that would have equilibrated all the markets, all other factors unchanged, can be obtained. Table 4 reports these estimates (together with the actual prices) for the basic demand systems described in Table 1. Additionally, the "true" price indexes (Laspayers, base year $=1971)$ corresponding to the estimated prices are given, and also the corresponding index implied by the official data.

Before the findings presented in Tables 3 and 4 are discussed a brief account of the results of the sensitivity runs will be given.

\section{SENSITIVITY RUNS}

The results of the additional sensitivity runs justify the proposition that the estimates of the extents of past market disequilibria in Poland do not actually depend on the conversion rates for total subsistence expenditure. This is exemplified by the contents of Table 5.

The "critical" commodity "food" appears - in view of the results contained in Tables 3,4 , and 5 - to be overpriced (or oversupplied) as compared with the two equilib rium situations considered. Since this may contradict some peoples' beliefs, it is worth performing yet another sensitivity analysis. This time the focus is on the possibility of the pure demand for "food" (free from possible spillovers) being greater than recorded supplies. The analysis assumes utterly implausible parameters for the supposed Polish ELES, by which the "pure" demand for food (not allowing for possible spillovers from other commodities) would be the greatest. Since this is given by the expression

$$
q_{1}=c_{1}+\left(\beta_{1} / p_{1}\right) m\left(Y-\sum_{j=1}^{4} p_{j} c_{j}\right)
$$

it is obvious that the lower $c_{2}, c_{3}$, and $c_{4}$, the greater $q_{1}$. 


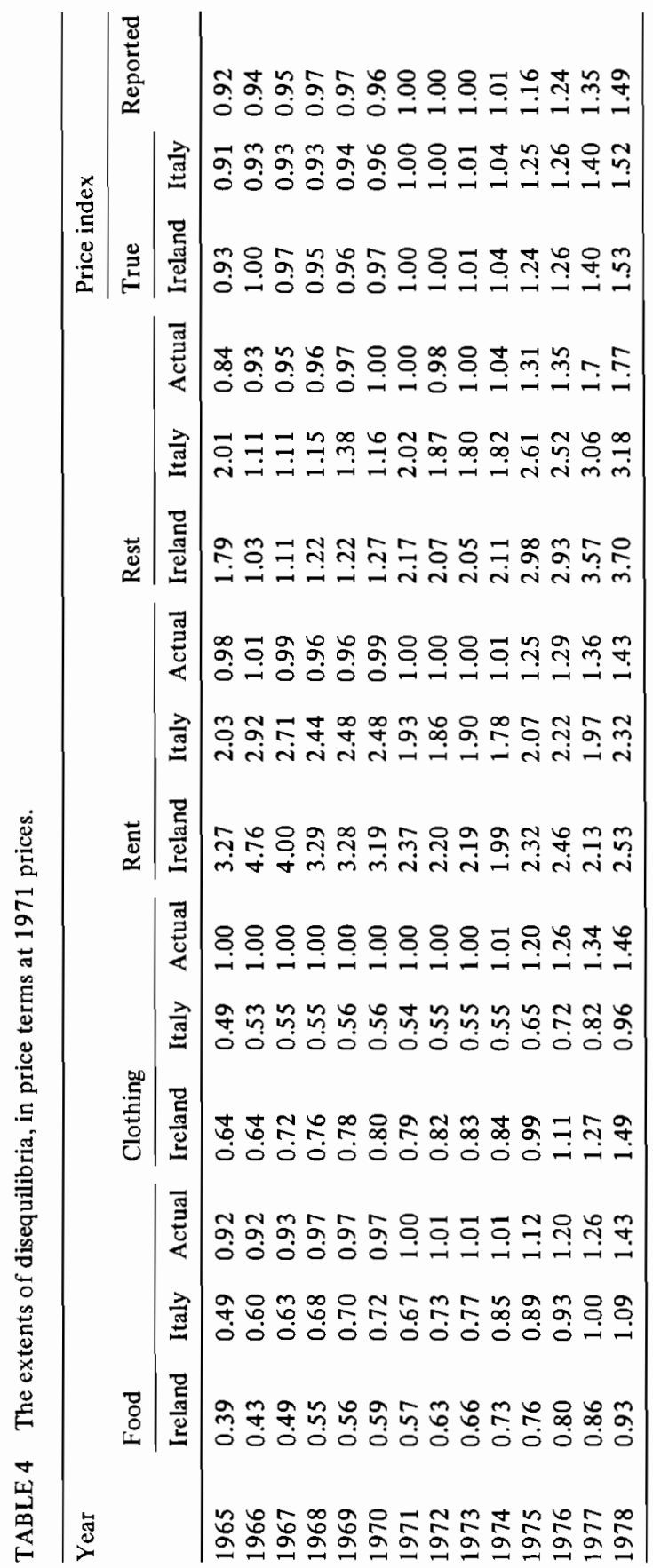


TABLE 5 Equilibrium and actual prices for food depending on run (assumption about conversion rate for total subsistence leve]) and the reference system.

\begin{tabular}{|c|c|c|c|c|c|c|c|}
\hline \multirow[t]{3}{*}{ Year } & \multirow[b]{3}{*}{ Actual } & \multicolumn{6}{|c|}{ Equilibrium } \\
\hline & & \multicolumn{3}{|c|}{ "Irish" system } & \multicolumn{3}{|c|}{ "Italian" system } \\
\hline & & Run 0 & Run 1 & Run 2 & Run 0 & Run 1 & Run 2 \\
\hline 1965 & 0.92 & 0.39 & $-1.16^{a}$ & 0.45 & 0.49 & 0.34 & 0.53 \\
\hline 1966 & 0.92 & 0.43 & $-6.29^{a}$ & 0.50 & 0.60 & 0.56 & 0.61 \\
\hline 1967 & 0.93 & 0.49 & $-0.051^{a}$ & 0.53 & 0.63 & 0.61 & 0.63 \\
\hline 1968 & 0.97 & 0.55 & 0.80 & 0.56 & 0.68 & 0.68 & 0.67 \\
\hline 1969 & 0.97 & 0.58 & 0.46 & 0.58 & 0.70 & 0.71 & 0.69 \\
\hline 1970 & 0.97 & 0.59 & 0.51 & 0.60 & 0.72 & 0.73 & 0.71 \\
\hline 1971 & 1.00 & 0.57 & 0.54 & 0.47 & 0.67 & 0.64 & 0.68 \\
\hline 1972 & 1.01 & 0.63 & 0.62 & 0.62 & 0.73 & 0.72 & 0.73 \\
\hline 1973 & 1.01 & 0.66 & 0.67 & 0.65 & 0.77 & 0.77 & 0.77 \\
\hline 1974 & 1.01 & 0.73 & 0.75 & 0.70 & 0.85 & 0.86 & 0.83 \\
\hline 1975 & 1.12 & 0.76 & 0.77 & 0.76 & 0.89 & 0.87 & 0.89 \\
\hline 1976 & 1.20 & 0.80 & 0.80 & 0.79 & 0.93 & 0.92 & 0.93 \\
\hline 1977 & 1.26 & 0.86 & 0.87 & 0.85 & 1.00 & 0.98 & 1.00 \\
\hline 1978 & 1.43 & 0.93 & 0.94 & 0.92 & 1.09 & 1.07 & 1.09 \\
\hline
\end{tabular}

a It is invalid to execute Run 1 for 1965,1966 , and 1967 for the "Irish" system: its subsistence expenditure for "rent" ( $c_{4}$ ) equals 1.35 , while the actual expenditures $q_{3,1965}, q_{3,1966}$, and $q_{3,1967}$ are, respectively, $1.28,1.22$, and 1.34 .

By setting $c_{2}=c_{3}=c_{4}=0$, it is assumed that the average Polish consumer has no positive minimum levels for consumption of any nonfood commodity. Then, since the greater $m$ and $\beta_{1}$, the greater $q_{1}$, let us suppose that of the two pairs of reported $\beta_{1}$ and $m$ values, the larger ones are taken. Thus, $m=0.846$ (the Irish propensity for total expenditure out of disposable income) and $\beta_{1}=0.4$ (the Italian marginal budget share of food) are assumed. ${ }^{*}$ Now, within the range of data for the period under study, the maximum "pure" demand for food would, in any given year $t$, be given by

$$
q_{1 t}=c_{1}+\left(0.4 / p_{1 t}\right) 0.846\left(Y_{t}-P_{1 t} c_{1}\right)
$$

Let $c_{1}$ be as high as 3.6. This is measured in thousands of Zlotys spent on food per capita (child ren included) per year in 1971 prices. (In physical terms this is equivalent to a diet consisting of $40 \mathrm{~kg}$ of meat, $25 \mathrm{~kg}$ of sugar, and practically unlimited amounts of milk, cereals, vegetables and, in addition, 2 litres of vodka.)

Now, having assumed the parameters of the equation for the "pure" demand for food that transform the average Polish consumer into an insatiable food devourer, it is possible to run eqn. (7) for any year studied.

Having done this, it is learned that the "pure" demand for food, possible spillovers disregarded, has always been lower than the consumption reported. (It is quite possible

\footnotetext{
* The Irish $m$ value is the second highest and the Italian $\beta_{1}$ value the highest among the nondeveloping countries reported by Lluch et al. (1977). This results in a product $m \beta_{1}$ higher than for any country other than Korea. Note that $q_{1}$ increases as the product $m \beta_{1}$ increases.
} 
that actual prices for food have been higher than those reported. This would mean an even greater surplus of food under the respective equilibria. Thus, even if at the same time the actual consumption has been smaller than reported, the overall impact of the biased statistical data can probably be neglected.)

\section{FIRST CONCLUSIONS}

Has there been a real shortage of food in Poland? Were the attempts at raising prices of food economically necessary?

The contents of Tables 3 and 4 may be summarized in just three statements:

1. Despite the fact that the parameters of both demand systems are rather dissimilar, the results they yield, although certainly not identical, are remarkably consistent. All the cultural differences between the "average" Italian and Irishman, as well as the difference in the price structures observed in the two countries (and hence specific structures of purchases) do not lead to any substantial disagreement in diagnosing what is "wrong" with the "average" Pole.

2. At given prices the pure demand for food has always been lower than supplies by, at least, the equivalent of some 1.5-2.5 thousand (1971) Zlotys per capita per year. The actual consumption of food has, therefore, to some extent, been the result of spillovers from the undersupplied commodities "rent" and "rest"; in other words, what have been really lacking are housing and various services. Thus, it was possible to enjoy market equilibria at lower consumption of food and at the reported prices. This, however, would have required definite increases in the supplies of the "rent" and "rest" commodities (at the reported prices).

3. Given the available supplies, the price for food has been too high by at least $15 \%$. Thus, it was possible to enjoy market equilibria with the actual supplies of food being sold at much lower prices. This, however, would have required definite increases in the prices of the "rent" and "rest" commodities (without reducing their supply).

\section{POLICY AND RESEARCH RECOMMENDATIONS}

The price reforms that were (unsuccessfully) introduced in 1970, 1976, and 1980 provided for substantial increases in the prices of food (with some compensatory decreases in the prices of nonfood products and/or some compensatory increases in incomes). In view of the analysis presented, it seems very likely that these reforms - if aimed at restoring market equilibria - would have been counterproductive. ${ }^{*}$ Therefore the policy of gradually increasing the price of food that has been followed since 1973 must be questioned.

\footnotetext{
* The increase in food prices should not be seen as an attempt to encourage greater agricultural production, since with the State as monopolist buyer and seller there is little or no relation between consumer and producer prices.
} 
A fair appraisal of the reasons that have led to the application of a market policy that could not succeed should allow for the fact that, since Lange's (1961) frivolous and unjust "critique" of the concept of utility, economic research, especially when concerned with practical matters, has had virtually nothing to do with any such "futility". "Econometric" estimates of what should have suited the average Polish consumer were derived from studies that ignore the natural theoretical background contained in the theory of choice, and instead adhere to all sorts of ideas about the predominance of the "institutional" factors in shaping the consumer needs. This may have played a role in producing a system which has not suited the consumer at all well.

The reluctance, which has been repeatedly signalled, of the "average Polish consumer" to accept the proposed price changes might suggest that he is really a more "rational man" than some tend to believe: the changes, if accepted, would have resulted in an even greater degree of disequilibrium.

The counterproposals formulated spontaneously by the population do not require increased supplies of food. (What is being requested here is the restoration of the market equilibrium for food - and this could not have been done by raising its price, while compensating with rising incomes.) ${ }^{*}$ Instead, they are concerned with increasing the supplies of housing, education, health services, leisure, and cultural goods! This spontaneous expression of social preferences does, therefore, corroborate the analytical results presented.

To reach specific policy recommendations concerning the immediate future would require data on actual supplies of particular goods that the government intends to sell to the population. (Also, the analysis should allow for the possibly beneficial effects of some changes in the structure and size of foreign trade in specific consumer goods.) Additionally, research concerned with the cross-country comparisons of the household expenditure patterns, which distinguish between various consumer groups, is still needed. This would enable the determination of the best price and - if need be - rationing policy, while taking into account possible distributional effects.

Certainly, the specification of the recommended policies concerning the aggregate commodities ("food", etc.) should be complemented by the specification of corresponding guid elines for more specific consumer goods. This, once again, necessitates additional studies. A study with respect to specific foodstuffs is presently underway (Podkaminer, forthcoming).

\section{A HYPOTHESIS CONCERNING THE DYNAMICS OF DISEQUILIBRIA IN CENTRALLY PLANNED ECONOMIES}

The cyclical nature of the socioeconomic performance of the centrally planned economies has been acknowledged by many authors, from Kalecki (1961) up to a more recent contribution by Kornai (1980). There is general agreement on many features of the cyclical pattern of behavior in these economies. Most of the governments of the centrally planned economies tend to push for maximum investment in the industrial

\footnotetext{
* Currently, the serious decline in agticultural production, caused mainly by adverse weather conditions, may be causing a genuine shortage of food.
} 
sector, with special emphasis put on heavy and mining industries, which have been identified with economic development. In practice, the "great leaps forward" do not bring about the desired growth in industrial strength. The neglect of indust rial infrastructure including the creation of the overall economic atmosphere conducive to really innovative and economic behavio r by the management of the state-owned firms - necessarily results in adverse economic and production effects.

However, it is the population's growing dissatisfaction with the fact that its standard of living is not rising fast enough (or even stagnating) which tends to curb excessive industrial investments before the failure of the over-extended industrial investment programs can be fully acknowledged.

The ensuing period of reduction in such investment is then followed by a period during which both standards of living and overall efficiency of the economy rise substantially. This period tends to end rather quickly. Despite regular 4-5\% annual growth in GDP, full employment, and full production-capacity utilization, the government tries to accelerate industrial investment as soon as the previous round of popular discontent has been forgotten.

The finding of this paper allows a further elucidation of the nature of the investment-consumption cycles in centrally planned economies. The consumption of and demand for food are shown to be of crucial importance. Although it may be assumed that the reader is familiar with the institutional framework within which the socioeconomic performance of the planned economies takes place, two points may need additional comment.

First, there is an absence of any automatic market mechanism capable of transmitting signals about the consumers' needs. The consumers' incomes, rates of interest on bank deposits (savings), prices, and actual supplies of consumer goods are determined by the government. Since consumer goods tend to be in short supply, some black marketeering ensues, but this tends to be both limited (by low marginal utility of money) and ignored by the authorities.

Second, there is some difficulty in learning what the actual demand pattern is. This is brought about by both the inadequacy of the theoretical tools used in the demand studies (disregard for the concept of utility) and the errors in the statistical observations of consumption (consumption recorded is equal to demand plus unobservable spillovers and is not simply equal to actual demand).

Both of these points mean that the government may be unaware that the observed consumption of food (and apparent demand for it) might be, to a large extent, a spillover due to the shortage of services and consumer goods. Hence, the government may be supposed to believe that the length of the lines for food could be reduced by price increases, accompanied by decreases in the price of nonfood goods and/or some income compensations.

Figure 2 illustrates the phases of a typical investment-consumption cycle. This may be viewed as similar to those Poland has experienced four times during the last thirty years. The description of the motives for particular government decisions which are also quoted could easily be substantiated by citations from official government statements 


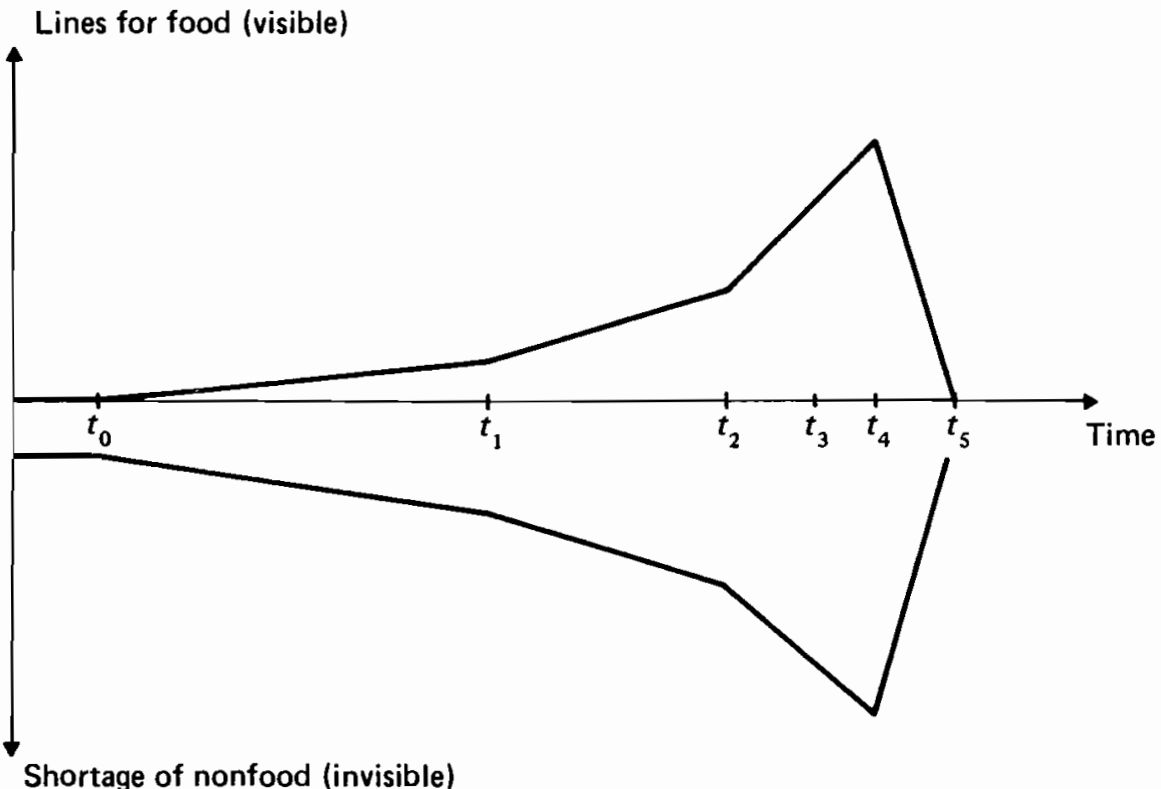

FIGURE 2 Phases of the consumption-investment cycle in a centrally-planned economy.

accompanying the application of particular measures, and also by study of the historical data. ${ }^{*}$

The description of a single cycle starts with a situation of a relatively low level of industrial investment activities. The consumers' market seems equilibrated (through adequate supplies of goods). This situation, apparently not promising any spectacular economic miracle, is, however, the source of constant concern to the ruling party, and in particular to the government.

Usually it is announcements by the governments of other centrally planned economies, boasting of substantially higher shares in industrial investment and industrial output, which precipitate a shift towards much higher rates of industrial investment (point $t_{0}$ ).

This move has two implications. The share of output represented by ind ustriallyproduced consumer goods is reduced overnight. The manufacturing and construction sectors are ordered to produce more industrial investment goods. (Since the production capacity is fully utilized, a drop in production of consumer durables must follow.) At the same time, the const ruction and utilization of the new industrial projects requires either massive rural-urban migration or an increase in the share of the professionally active segment of the population. (Even without new industrial projects there is full

\footnotetext{
* The estimates of "involuntary" consumption of food (Table 3) follow the extent of shortages of nonfood goods in Figure 1. A precise specification of the curves of Figure 2 would, however, require quarterly and not annual statistics of prices and consumption, since the cycles are usually completed in only a few months.
} 
employment.) This, in turn, can be achieved only by offering much higher wages to "newcomers". This leads to an overall increase in incomes. As a result, the demand for all goods is increased almost immediately. However, due to the Engel effects, the growth in demand for nonfood goods is by far the greatest.

Thus, the supplies of nonfood goods are reduced just when demand for them is increasing. With an unattractive rate of interest on savings and unchanged prices, the shortage of nonfood goods affects the consumption of food: the process of spilling over from nonfood to food markets sets in.

Since the shortages of nonfood goods are neither easily detected nor apparently politically damaging, the situation may continue for quite a long time. Yet, at some critical level, the spillovers clear the shelves of the food stores: the lines waiting outside the butchers' shops appear. ${ }^{*}$

These lines are, however, both too easily perceived and politically important, evoking the image of the ultimate failure: hunger! The government's first response to the lines (when they surpass in length some "acceptable" level) is a sort of surprise. According to the nutritional standards, and also in comparison with rich countries such as Sweden or Holland, the levels of per capita consumption of particular food items are quite adequate, so why should the population devour so much food? The answer to this paradox highlights not so much the shortage of nonfood goods as such items as "local traditions", "bad habits", etc. To put things right, the government introduces the policy of gradually increasing the price of food, combined with the income compensations that are thought to be adequate and/or decreases in the prices of nonfood goods. This, however, only worsens the situation: the amount of money spent on the nonfood goods becomes an even smaller fraction of the disposable incomes, and the spillovers into food are intensified. In effect, creeping price-income "sanation" transforms into a race between rising relative prices of food and lengthening lines for it. At some point $\left(t_{2}\right)$ the lines become so long that the government starts doubting its own statistics on the supplies of food. (Actually, average per capita consumption may be very high. It is only the disorderly purchasing system, with some buyers getting much more than average and others not getting enough, which creates the image of the overall malnutrition.)

To relieve the situation the government introduces additional measures. Part of the supply of industrially-produced consumer goods is diverted from the home market and sold abroad. The proceeds are then used for additional imports of food. Once again, this policy only aggravates the situation: the lower supplies of nonfood goods, sold at unchanged prices, must bring about an even greater spillover onto the food market. This market appears insatiable: neither increases in prices, nor increased supplies help a bit!

In the meantime $\left(t_{3}\right)$ the government proudly announces that substantial progress has been achieved in the completion of a number of giant industrial and mining projects. While this does not console the consumers too much, the governments of other centrally planned economies are clearly impressed.

At $t_{4}$ the market disorder becomes unbearable. The government's "economists"

\footnotetext{
* There is evidence that some consumers buy more food than they would if there were other ways of spending their money, or if they were more certain of being able to buy at a later date. This means that later would-be purchasers may not be able to buy enough: shopping for food is thus reduced to a form of hunting.
} 
declare a new doctrine: the consumers get accustomed to the gradual increases in the prices of food. Hence, to reduce the "abnormal" demand for food a price "shock" (30$50 \%$ ) is needed. Now, to the government's surprise (there is an income compensation tag attached to the price "reform"), the population's response appears hostile: the market spillover transforms into a political one. (From an economic viewpoint the protests are justified: the changes, if accepted, would aggravate the disorder beyond imagination.)

As a result of the popular resentment, the ruling party changes the government. The population's politically formulated demands for substantially higher supplies of consumer goods, housing, health and education services, cultural goods (books, journals, revival of subsidized artistic performances), travel, and leisure activities are met by the new government. This is achieved by cuts in the production of investment goods and halts in many giant projects that are underway (and which, even if completed, are likely to generate more losses than profits). Additionally, foreign aid helps to restore the equilibrium -with the unchanged prices (point $t_{5}$ ).

What is important, however, is that no lesson about the nature of the crisis seems to have been learned from the experience. The cuts in investments are deeply deplored in public by some economists and the mistaken idea of the inevitability of the revision of the price structure (whereby the food would become expensive enough to guarantee market equilibrium) is never abandoned.

These two elements, if present at $t_{5}$, will, sooner or later, give rise to the next cycle.

\section{ACKNOWLEDGMENTS}

Thanks are due to Desmond McCarthy, Janos Komai, and Kirit Parikh for helpful remarks and to Ms. Bozena Lopuch for computations. Responsibility for any remaining errors can be evenly distributed between the author and a few utility and demand theoreticians referred to in the paper explicitly or implicitly.

\section{REFERENCES}

Frisch, R.A. (1959). A complete scheme for computing all direct and cross-section demand elasticities in a model with many sectors. Econometrica.

Gamaletsos, T. (1973). Further analysis of cross-country comparison of consumer expenditure patterns. European Economic Review, 4.

Goldberger, A.S. and Gamaletsos, T. (1970). A cross-country comparison of consumer expenditure patterns. European Economic Review, 3.

Houthakker, H.S. (1957). An international comparison of household expenditure patterns, commemorating the centenary of Engel's Law. Econometrica, 4.

1to, T. (1980). Methods of estimation of multi-market disequilibrium models. Econometrica, 1.

Kalecki, M. (1961). Teoria reprodukcji rozszerzonej w gospodarce socjalistycznej. Polish Scientific Publishers.

Kornai, J. (1979). Demand-constrained vs. supply-constrained systems. Econometrica, 4.

Kornai, J. (1980). Economics of Shortage. North Holland, Amsterdam.

Lange, O. (1961). Ekonomia polity czna. Polish Scientific Publishers. (English translation available from Pergamon Press).

Lluch, C., Powell, A.A., and Williams, R.A. (1977). Patterns of Household Demand and Saving. Oxford University Press (for the World Bank).

Podkaminer, L. (forthcoming) A Linear Expenditure System Allowing for the Direct Substitutability of Various Foodstuffs. 


\title{
A NONLINEAR MULTISECTORAL MODEL FOR HUNGARY: GENERAL EQUILIBRIUM VERSUS OPTIMAL PLANNING APPROACHES
}

\author{
Ernö Zalai \\ Karl Marx University of Economics, Budapest (Hungary) and International \\ Institute for Applied Systems Analysis, Laxenburg (Austria)
}

\section{INTRODUCTION}

Recent years have witnessed a shift in macroeconomic modeling techniques. Parallel to the use of traditional linear (input-output and programming) models, which concentrate on the production sphere, has been the development of more complex, nonlinear models. These models are usually referred to as applied general equilibrium models. Such models, both static and dynamic, have been developed in increasing numbers for development planning and policy analysis purposes over the past few years. ${ }^{*}$ The purpose of this study is to investigate the possibilities and expected benefits of incorporating nonlinear and multisectoral models of the general equilibrium type into the planning methodology of socialist (centrally planned) economies.

This paper concentrates on the intratemporal rather than intertemporal equilibrium and efficiency conditions of such models. Also, the models considered here possess a lower degree of closure in their general equilibrium properties than most of the models in this field. As the basis for discussion and comparison a model developed by Bergman and Pór (1980) at the International Institute for Applied Systems Analysis (IIASA) has been chosen, for both its relatively simple structure and its close conceptual resemblance to the optimal resource allocation planning models used in some socialist countries, including Hungary.

The focus of this paper is on the techniques of applied general equilibrium models with special reference to the Hungarian planning modeling experience. After this introduction, the paper is organized into two main sections. Section 2 is a comparative modeling exercise intended partly to bridge the gap between model-builders coming

\footnotetext{
* The basic ideas of a multisectoral general equilibrium growth model were laid down by Johansen (1959). Full scale implementation of large, nonlinear models has become computationally feasible only lately. Recent applications include the IMPACT project (see, for instance, Dixon et al., 1977), Adelman and Robinson (1978), Bergman (1978), de Melo (1978), Dervis and Robinson (1978), Kelley and Williamson (1980), and McCarthy and Taylor (1980).
} 
from different socioeconomic environments and partly to pave the way for the model specified in Section 3. Although this paper is addressed mainly to planning modelers from socialist countries, who are less familiar with applied general equilibrium modeling, it is hoped that some of the conclusions of this exercise will also be of general value to experts in this field. Section 3 describes a tentative general equilibrium model framework, reflecting to a large extent - but of course in a simplified manner - existing planning theory and practice in Hungary. Different parts of the model are defined so that they can or at least could be incorporated into partial investigations concerning, for example, price formation or physical resource allocation coordination in Hungary. There are, however, a few places where the mathematical formulation differs from the "traditional" form: this is mostly because of the nonlinearity of the model. The novelty of the model outlined lies mostly in the fact that it integrates the above partial models into a consistent framework and directly takes into account the interdependence of real and value variables $-\mathrm{a}$ basic requirement not fully met by recently applied planning models in socialist countries.

It should be emphasized that this paper is only a first step toward the use of more advanced, applied general equilibrium modeling techniques in socialist economies. There are many issues not raised here which are left for further research. Planning in socialist countries is a complex social exercise. National planning itself is a highly decomposed and iterative information processing system with many informal elements. lt is a system that involves several administrative and scientific institutions. Any model that is not intended to remain a purely academic exercise must be carefully designed against that background and find its proper place within that system. This means that constraints on input and output data specifications must be recognized. It also means that one has to find the proper phase and stage of planning that are most appropriate for model use and the proper issues to which the model can be fruitfully addressed. These tasks are not easy and a great deal remains to be done.

For the reasons given above, the model developed in Section 3 sets out only a tentative and general (non issue-specific) framework of a multisectoral, static model. Throughout the study, two possible planning applications for such a model were kept in mind. One area of possible applications is the so-called coordination phase of a mediumterm plan. It is well known that, in Hungary, experiments have been made with linear programming models* during this phase of planning (where the main aim is to establish an overall consistency and optimality of detailed partial plans). The medium-term plans are concerned with the allocation of resources and various consistency requirements in the final year of a given planning period. The models are based on detailed planning calculations and use linear approximations to represent the feasible movement around the planned levels of some crucial variables. The aim of the investigation is to check the consistency of the draft plan and to indicate various possibilities for increasing the efficiency of the plan by a constrained reallocation of resources.

In this context, the proposed equilibrium model can be simply seen as a (partly) nonlinear version of the above models, in which most of the data are derived from the plan calculations or based on expert judgments. Another area of application could be the

\footnotetext{
* See Kornai (1974) for an account of the use and development of such models in Hungarian mediumterm planning calculations.
} 
early (forecasting) phase of planning, when the data of the model are, to a large extent, based on statistical sources, and the model is used for generating possible directions for detailed planning activity.

These are, however, just two possible areas. Taking into account the great flexibility of the equilibrium models (in terms of their size and structure, the choice of the endogenous and exogenous variables, the issues focused on, etc.), these models are probably worth experimenting with in other areas as well. For example, it is possible to simulate either ex post or ex ante - the likely effects of changing conditions that are exogenous to the model. It is also possible to further develop the model for multiperiod forecasting purposes. This could be done either by the use of "snapshot" techniques or by "dynamizing" the static model. In the first case the values of the exogenous variables and the parameters of the model are independently forecast for some future years and for each year a static model is solved. It seems to be promising in this context to experiment with reference path optimization techniques (see Wierzbicki, 1979) by prescribing target values for some of the endogenous variables as well. In the case of "dynamization" some exogenous variables (investment and capital stocks) are endogenized through intertemporal relationships. These loosely defined alternative uses of equilibrium models would, however, require changes in their specifications from those used in the basic models in this paper.

\section{APPLIED GENERAL EQUILIBRIUM MODELS VERSUS OPTIMAL PLANNING MODELS}

This section is a return to the old theme of the existence of fundamental equivalence between equilibrium solutions through a competitive mechanism and the optimal solutions of a centrally planned resource allocation problem. This topic has been formulated in many ways (e.g., in terms of welfare economics or a simple linear programming model). Here it will be put into a slightly different context. First, it will be used to gain better insight into the problem of how and where the analytical techniques used in multisectoral general equilibrium models could fit into the current planning modeling methodology of centrally planned economies. At the same time the exercise will help us to understand better the working of the general equilibrium model (e.g., the determination of the consumption expenditure or the possibility of incorporating various economic policy goals into a general equilibrium framework). Finally, in contrast to most of the existing literature on the subject, special emphasis will be put on the conceptual differences that lie behind the technical similarities.

The organization of Section 2 is as follows. First the basic features of a general equilibrium formulation of the resource allocation problem are summarized within the framework of a simple model economy. Second, within the same framework the problem is then reformulated in a way familiar to socialist planning modeling practice. Next, some of the fundamental technical similarities and conceptual differences are analyzed. Finally, some observations are made about the problem of using smooth production functions in macro planning models. 


\subsection{A Simple Multisectoral General Equilibrium Model}

For the purpose of the comparison, a general equilibrium model developed by Bergman and Pór (1980) at IIASA has been chosen. Its static character, relatively simple structure, and focus on allocational efficiency in the context of a small open economy make it convenient for comparison with linear programming models developed in Hungary for similar purposes. The underlying logic of multisectoral general equilibrium models and their relation to some structurally similar optimal planning models will be better understood if the resource allocation problem is reduced to its basic essentials. Therefore, some elements of the Bergman-Pór model, like foreign trade variables, government consumption, and taxes, will be disregarded and energy inputs will be treated in the same way as other intermediate in puts. (That is, energy is considered one of the intermediate commodities.) By doing this, the above general equilibrium model is reduced to the following simple form.

First the various (endogenous) variables and extraneous parameters that appear in the model will be defined. Commodities are denoted by $i(i=1,2, \ldots, n)$ and sectors by $j(j=1,2, \ldots, n) .^{\dagger}$

\section{Variables}

$X_{j}$ Gross output in sector $j$,

$X_{n+1}$ Total gross investment,

$K_{j}$ Capital stock in sector $j$,

$N_{j}$ Employment in sector $j$,

$C_{i}$ Consumption of commodity $i$,

$P_{i}$ Price of commodity $i$,

$P_{n+1}$ Price of composite capital goods,

$P_{i}^{*}$ "Net price" (value added per unit) of commodity $i$,

$W$ General index of level of wages,

$W_{j}$ Level of wages in sector $j$,

$R$ General index of return on capital,

$R_{j}$ Rate of return on capital in sector $j$,

$Q_{j}$ User cost of capital in sector $j$,

$E$ Consumption expenditures.

Data

$N$ Total labor force,

$K$ Total capital stock,

$I$ Total net investment,

$a_{i j}$ Input of commodity $i$ per unit of output in sector $j$,

$a_{i, n+1}$ Input of commodity $i$ per unit level of gross investment,

$\delta_{j}$ Annual rate of depreciation in sector $j$,

$\omega_{j}$ Index of the relative wage rate in sector $j$,

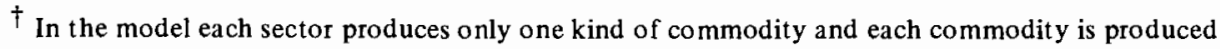
by one sector only. Thus there is a one-to-one correspondence between the sectors and the commodities produced.
} 
$\beta_{j}$ Index of the relative rate of return on capital in sector $j$, $b_{i}, c_{i}$ Parameters in the consumer's demand function for commodity $i$.

With the symbols defined above the basic features of the general equilibrium model can now be summarized. The arguments supporting specific formulations will not be reproduced here - the reader is referred to the original paper (Bergman and Pór, 1980). However, an attempt will be made to represent the model in a self-contained manner.

\subsubsection{Commodities}

There are $n$ produced commodities in the model available for both intermediate and final use, one composite capital good (which is used only for investment), and two primary commodities (capital and labor).

\subsubsection{Technology}

The production technology is given for the sectoral commodities by the combined Leontief-neoclassical formulation, used by Johansen (1959). The amounts of primary commodities needed to produce $X_{j}$ units of commodity $j$ are described by a linear, homogeneous, smooth production function, thus allowing for substitution possibilities

$$
X_{j}=F_{j}\left(N_{j}, K_{j}\right) \quad(j=1,2, \ldots, n)
$$

The use of intermediate inputs is assumed to be proportional to the output level of the produced commodity, i.e.

$$
a_{i j} X_{j} \quad(i=1,2, \ldots, n ; j=1,2, \ldots, n)
$$

The production of the composite capital good requires only intermediate commodities in amounts proportional to the level of gross investment (capital formation)

$$
a_{i, n+1} X_{n+1} \quad(i=1,2, \ldots, n)
$$

The technology defined above exhibits constant returns to scale, therefore in equilibrium the nonprofit condition must hold for each producing sector.

\subsubsection{Market Behavioral Rules for Producers}

Producers are assumed to maximize their net income (or profits), i.e., the difference between their gross income and total costs. Total costs are made up of the costs of intermediate inputs and of primary inputs. Capital is reevaluated at the current price on capital goods in accordance with the rule

$$
P_{n+1}=\sum_{i=1}^{n} P_{i} a_{i, n+1}
$$

Therefore, the cost of using capital (evaluated at base price) in sector $j$ is given by

$$
Q_{j}=\left(\delta_{j}+R_{j}\right) P_{n+1}=\left(\delta_{j}+\beta_{j} R\right) P_{n+1}
$$


The introduction of different rate-of-return requirements on capital can be interpreted, for instance, as a reflection of lasting market imperfections. It will be shown that this solution has effects similar to individual limits on sectoral capital inputs, which, in turn, can be interpreted as limited intersectoral mobility of capital.

Introducing $W_{j}=\omega_{j} W$ to represent the cost of labor, the net income earned by producing $X_{j}$ can be defined by the expression

$$
\Pi_{j}=P_{j} X_{j}-\sum_{i=1}^{n} P_{i} a_{i j} X_{j}-W_{j} N_{j}-Q_{j} K_{j}
$$

which is to be maximized subject to the constraint given by the production function

$$
X_{j}=F_{j}\left(N_{j}, K_{j}\right)
$$

Substituting $X_{j}$ by $F_{j}\left(N_{j}, K_{j}\right)$ in eqn. (3) and differentiating the net income function with respect to $N_{j}$ and $K_{j}$ yields the necessary first-order conditions for an optimal solution:

$$
\begin{aligned}
& P_{j}^{*} \partial F_{j} / \partial N_{j}=W_{j}=\omega_{j} W \\
& P_{j}^{*} \partial F_{j} / \partial K_{j}=Q_{j}
\end{aligned}
$$

where $P_{j}^{*}$ is the value added per unit of output $j^{\dagger}$

$$
P_{j}^{*}=P_{j}-\sum_{i=1}^{n} P_{i} a_{i j}
$$

It can easily be seen that if eqns. (4) and (5) are multiplied with $N_{j}$ and $K_{j}$, respectively, and then added, because of the assumed linear homogeneity of the production functions, we have

$$
P_{j}^{*}=W_{j}\left(N_{j} / X_{j}\right)+Q_{j}\left(K_{j} / X_{j}\right)=W_{j} n_{j}+Q_{j} k_{j}
$$

which in turn implies that the net income must be zero in equilibrium (the nonprofit or - more accurately - "non extra profit" condition).

If eqn. (7) is inserted into eqn. (6), after rearrangement we have

$$
P_{j}=\sum_{i=1}^{n} P_{i} a_{i j}+W_{j} n_{j}+Q_{j} k_{j}
$$

The above price-formation rule strongly resembles the form that is used to determine

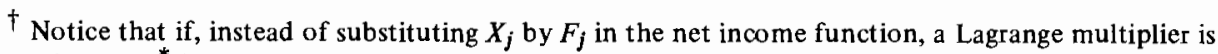
used, then $P_{j}^{*}$ is the value of that multiplier.
} 
the so-called "two channel price system" familiar in socialist price-planning theory and practice. This point will be discussed further below.

\subsubsection{Consumer Demand}

The demand for consumer goods and services is represented by a demand function

$$
C_{i}=C_{i}\left(P_{1}, P_{2}, \ldots, P_{n}, E\right) \quad(i=1,2, \ldots, n)
$$

where $E$ is the total consumption expenditure, an endogenous variable of the model. ${ }^{*}$ In most applied models a simple or extended Linear Expenditure System (LES) is used

$$
C_{i}=b_{i}+\left(c_{i} / P_{i}\right)\left(E-\sum_{j=1}^{n} P_{j} b_{j}\right) \quad(i=1,2, \ldots, n)
$$

where $b_{i}$ is sometimes interpreted as the minimum ("subsistence") consumption of commodity $i$, which must be fulfilled before the remaining income is allocated between the various commodities depending on their relative prices and on the marginal propensities to consume different commodities $\left(c_{i}\right)$. It is worth noting that such demand functions can be derived on the basis of utility maximization theory assuming a Cobb-Douglas utility function for the "surplus" consumption

$$
U=\left(C_{1}-b_{1}\right)^{c_{1}}\left(C_{2}-b_{2}\right)^{c_{2}} \cdots\left(C_{n}-b_{n}\right)^{c_{n}}
$$

and

$$
\sum_{i=1}^{n} c_{i}=1
$$

\subsubsection{The Physical (Real) Conditions of an Equilibrium}

In this simplified model the state of the economy can be fully described by the values of the endogenous variables. Among these, the variables $X_{i}, C_{i}, K_{j}, N_{j}$ (which can be called real variables) describe the production and use of different commodities. Whether it is a centrally planned or a market economy (or a mixture of the two), the above variables must fulfill certain "physical" conditions of feasibility. These conditions incorporate commodity and resource balances and technological restrictions, and will now be listed. The balance conditions will be given in the form of inequalities, and these are more general than the equalities used in the Bergman-Pór model. However, if the equilibrium price of a commodity is positive, then the corresponding balance inequality must be fulfilled as an equality. The special assumptions of the Bergman-Pór model guarantee that the prices of all commodities and resources will always be positive:

\footnotetext{
* The total expenditure in the model concerned is determined with no direct relationship to the wages. Therefore one will get, in fact, endogenously determined tax and savings rates out of the model, which could be quite absurd. The analysis of the linear programming model will shed some light on the endogenous determination of the consumption expenditure.
} 


$$
\begin{aligned}
& \sum_{j=1}^{n+1} a_{i j} X_{j}+C_{i} \stackrel{(<)}{=} X_{i} \quad(i=1,2, \ldots, n) \\
& \sum_{j=1}^{n} \delta_{j} K_{j}+I \stackrel{(<)}{=} X_{n+1} \\
& \sum_{j=1}^{n} K_{j} \stackrel{(<)}{=} K \\
& \sum_{j=1}^{n} N_{j} \stackrel{(<)}{=} N \\
& F_{j}\left(N_{j}, K_{j}\right) \stackrel{(>)}{=} X_{j} \quad(j=1,2, \ldots, n)
\end{aligned}
$$

Equations (10)-(14), together with the behavioral and pricing equations (1)-(9), define a simultaneous system of equations that must be fulfilled by all equilibrium solutions. It can easily be checked that all the equations are homogeneous in all prices (both gross and net prices), wage rates, and total consumption expenditure. Therefore, the general level of prices is indeterminate, i.e., it can be arbitrarily set. This can also be checked by counting the equations and variables $(7 n+4$ equations, $7 n+5$ variables).

\subsection{An Optimal Planning Model Version of the Problem}

A description of a typical planning model that seeks the optimal allocation of resources in the framework of the above model economy will now be given. An economywide planning model built into and upon the traditional planning methodology of a socialist country would differ from the above general equilibrium model in several respects. First, it would contain almost exclusively only "real" variables and relations reflecting physical allocation constraints. Second, because the prices used in a planning model are either constant or planned prices, forecast more or less independently of "real" processes, the interdependence of the real and value (price, taxes, rate-of-return requirements, etc.) economic variables would not be taken explicitly into consideration in the model. Third, mathematical planning models in most cases closely relate to and rely on traditional or nonmathematical planning. This means, among other things, that the values of the exogenous variables and parameters, and also certain upper and/or lower target values for some of the endogenous variables, would not be directly derived from statistical observations, but would be based on figures given by traditional planners.* (This is not to say, however, that more or less sophisticated statistical estimation techniques

\footnotetext{
* This is especially true for the nation-wide programming models used in Hungary, where the basic aim of the modelers is to check the feasibility and improve the efficiency of the plans elaborated by traditional planners (see Kornai, 1974).
} 
would not be utilized, in combination with expert "guesstimations", in traditional planning.) And, finally, planning modelers in socialist countries tend to concentrate more on the problems of how to fit their models into the actual process of planning and make them practically applicable and useful. Therefore, applied planning models tend to be simpler than those in the development planning literature both from the economictheoretical and the methodological points of view. The above list is, of course, far from complete, but nevertheless, these are some of the major characteristics common to many socialist planning models. These are also areas where the study of more sophisticated development planning models (e.g., the general equilibrium models in question) may provide useful suggestions for further development of socialist economic model building.

To illustrate this point a simplified planning model will be introduced which can be viewed as a representative example of how the above resource allocation problem would be modeled in a centrally planned economy. The variables in the present case are the production levels of the various commodities $\left(X_{j} ; j=1,2, \ldots, n+1\right)$, their consumption levels $\left(C_{i} ; i=1,2, \ldots, n\right)$, and the amounts of labor and capital allocation for their production $\left(N_{j}, K_{j} ; j=1,2, \ldots, n\right)$. All feasible resource allocation programs must satisfy the commodity (resource) balance requirements and the technological constraints given by inequalities (10)-(14). Beyond that, as mentioned earlier, the planning model should reflect certain requirements set on the basis of traditional planning calculations. Only a few representative solutions will be considered here. For example, the minimum consumption of various commodities may be set as

$$
C_{i} \geqslant C_{i}^{-} \quad(i=1,2, \ldots, n)
$$

where $C_{i}^{-}$may be taken as the planned target level, or possibly somewhat lower. Despite the striking technical similarity between the assumed LES demand function in the general equilibrium model outlined and the "demand function" implied by the objective function of the planning model, there are basic, conceptual differences between the two approaches. In the former, the $b_{i}$ terms are usually interpreted as "subsistence" or, more accurately, "committed" consumption levels and assumed to reflect the preferences of the individual consumers. Their values are, in principle, based on reliable statistical estimates. In the latter, the $C_{i}^{-}$terms are more or less arbitrarily set minimum target levels, and thus they represent directly the planners' preferences - their "commitments".

The model-builders would also take into consideration certain limitations concerning the possible intersectoral allocation of given primary resources. In the case of capital, for example, the existing sectoral capacities may be taken as lower limits, while calculations of the capital-absorptive capacities of the various sectors may indicate some upper limits for the amount of capital allocated to any given sector. In a similar way, lower and upper limits can be established for the number of workers employed in different sectors.

The first thing that the model-builder would try to do with his model would be to check the feasibility of the traditional plan and then to see if improvements could be made. For the sake of simplicity, assume that "improvement" means an increase in consumption. More precisely, the level of performance of the economy is measured by the objective (welfare) function 


$$
g(C)=\left(C_{1}-C_{1}^{-}\right)^{s_{1}}\left(C_{2}-C_{2}^{-}\right)^{s_{2}} \cdots\left(C_{n}-C_{n}^{-}\right)^{s_{n}}
$$

where $\Sigma_{i=1}^{n} s_{i}=1$ by assumption. The chosen objective function is thus formally the same as the utility function underlying the LES. Introducing $C_{i}^{+}$to represent the surplus (incremental) consumption instead of $C_{i}-C_{i}^{-}$, the above function can be rewritten in a simpler form

$$
g\left(C^{+}\right)=C_{1}^{s_{1}} C_{2}^{s_{2}} \cdots C_{n}^{s_{n}}
$$

In most of the socialist planning models several different objective functions are used to find alternative ways of improving the efficiency of the plan. The objective function corresponding to consumption increase in a linear programming model is usually the surplus consumption $(y)$ in a given structure. Thus, the consumption of commodity $i$ is given by the expression

$$
C_{i}=C_{i}^{-}+y c_{i}^{+}
$$

where $c_{i}^{+}$indicates the surplus consumption of commodity $i$ in the case of a one-unit increase in the general level of surplus consumption. This formulation may be interpreted in terms of consumer demand theory as a case where no substitutability between the different commodities exists. Thus in this case the demand function is

$$
C_{i}=C_{i}^{-}+\left(c_{i}^{+} / \sum_{j=1}^{n} P_{j} c_{j}^{+}\right)\left(E-\sum_{j=1}^{n} P_{j} C_{j}^{-}\right)
$$

Using the above specifications the optimal plan would be determined as the solution of a nonlinear programming problem in which function $g(C)$ is maximized subject to the following constraints

$$
\begin{aligned}
& \left(P_{i}\right) \quad \sum_{j=1}^{n+1} a_{i j} X_{j}+C_{i}^{-}+C_{i}^{+} \leqslant X_{i} \quad(i=1,2, \ldots, n) \\
& \left(P_{n+1}\right) \quad \sum_{j=1}^{n} \delta_{j} K_{j}+I \leqslant X_{n+1} \\
& \text { (R) } \quad \sum_{j=1}^{n} K_{J} \leqslant K \\
& \left(R_{j}^{-}, R_{j}^{+}\right) \quad K_{j}^{-} \leqslant K_{j} \leqslant K_{j}^{+} \quad(j=1,2, \ldots, n) \\
& \text { (W) } \quad \sum_{j=1}^{n} N_{j} \leqslant N
\end{aligned}
$$




$$
\begin{array}{ll}
\left(W_{j}^{-}, W_{j}^{+}\right) & N_{j}^{-} \leqslant N_{j} \leqslant N_{j}^{+} \quad(j=1,2, \ldots, n) \\
\left(P_{j}^{*}\right) \quad & X_{j}-F_{j}\left(N_{j}, K_{j}\right) \leqslant 0 \\
& X_{j}, C_{j}^{+}, K_{j}, N_{j} \geqslant 0
\end{array} \quad(j=1,2, \ldots
$$

where the meaning of the old variables and parameters is the same as before, $C_{i}^{+}$stands for the amount of surplus consumption of commodity $i$, and $K_{j}^{-}, K_{j}^{+}, N_{j}^{-}, N_{j}^{+}$represent, respectively, the lower ( $(-)$ and upper ( + ) limits of $K_{j}$ and $N_{j}$. The symbols in parentheses denote the dual variables associated with the given constraints.

\subsubsection{Shadow Valuation System and Shadow Behavioral Rules}

Under reasonable assumptions the above problem will have a solution and all the variables will have positive optimal values. In such a case the dual variables associated with the various constraints (in parentheses) will, in the optimal solution, satisfy certain conditions. These conditions may be derived by differentiating the Lagrange function with respect to the primal variables, as indicated after each equation in parentheses (it is assumed that the primal variables are positive).

$$
\begin{array}{ll}
P_{n+1}=\sum_{i=1}^{n} P_{i} a_{i, n+1} & \left(\partial L / \partial X_{n+1}\right) \\
P_{j}=\sum_{i=1}^{n} P_{i} a_{i j}+P_{j}^{*} \quad(j=1,2, \ldots, n) & \left(\partial L / \partial X_{j}\right) \\
P_{i}=\partial g / \partial C_{i}^{+} \quad(i=1,2, \ldots, n) & \left(\partial L / \partial C_{i}^{+}\right) \\
P_{j}^{*} \partial F_{j} / \partial N_{j}=W+\left(W_{j}^{+}-W_{j}^{-}\right) \quad(j=1,2, \ldots, n) & \left(\partial L / \partial N_{j}\right) \\
P_{j}^{*} \partial F_{j} / \partial K_{j}=P_{n+1} \delta_{j}+S+\left(S_{j}^{+}-S_{j}^{-}\right) \quad(j=1,2, \ldots, n) & \left(\partial L / \partial K_{j}\right)
\end{array}
$$

Now it can easily be shown that the shadow prices given by the optimal dual solution (satisfying the above equations) are, in fact, of the same nature as the equilibrium prices and rates of return in the equilibrium model that has been examined. Also, it will be shown that one can formulate behavioral equations from this model that are similar to those of the general equilibrium model. After commenting on the interpretational differences between the two models, some conclusions will be derived.

To see the formal identities of the valuation and behavioral rules in the two cases, notice first that eqns. (1) and (6) of the equilibrium model appear in identical forms in the dual version of the optimal planning model. Equations (4) and (5), which represent the necessary conditions for profit maximization, have eqns. (16) and (17) as their counterparts; at first glance they seem to be quite different, but closer examination reveals some essential similarities. Take eqns. (4) and (16) first. Although their lefthand sides are identical, the righthand sides differ. In the literature on the design of (linear) programming models for development planning (see, for example Taylor, 1975; 
Ginsburgh and Waelbroeck, 1979), the use of individual limits (like $\left.L_{j}^{-}, L_{j}^{+}\right)$is of ten criticized because they "pick up shadow prices which have no clear meaning and which, since all dual prices are independent, distort the dual solution" (Ginsburgh and Waelbroeck, 1979). In the present case, however, the shadow prices of the individual limits can be given reasonable meaning in the light of the equilibrium model. Variable $W$ can be interpreted as the general level of optimal rate of return on labor. Next, define

$$
\omega_{j}=\left(W+w_{j}^{+}-w_{j}\right) / W=1+\left(w_{j}^{+}-w_{j}^{-}\right) / W \quad(j=1,2, \ldots, n)
$$

where the derived variable, $\omega_{j}$, may be interpreted as an endogenously determined index of the relative optimal rate of return on labor in sector $j$.

Similarly, the dual variable $S$ may be interpreted as the general level of the optimal (shadow) rate of return on capital at base price. Thus one can calculate $R=S / P_{n+1}$ so as to get the same rate of return at current (shadow) prices, and

$$
\beta_{j}=\left(S+S_{j}^{+}-S_{j}^{-}\right) / S \quad(j=1,2, \ldots, n)
$$

can be interpreted as an index of relative rate of return requirement on capital in sector $j$.

It has not yet been shown that the solution of the optimal planning problem would also imply the emergence of a set of special "demand" equations. This will now be discussed. Observe that the partial derivative of the primal objective function in eqn. (15) can be substituted by the term $\left(s_{i} / C_{i}^{+}\right) g\left(C^{+}\right)$where $g\left(C^{+}\right)$is the value of the objective function. Thus

$$
P_{i}=\left(s_{i} / C_{i}^{+}\right) g\left(C^{+}\right) \quad(i=1,2, \ldots, n)
$$

Multiplying the above equations by the respective $C_{i}^{+}$values and adding them together yields

$$
\sum_{i=1}^{n} P_{i} C_{i}^{+}=g\left(C^{+}\right)
$$

On the other hand, total consumption expenditure is determined by

$$
\sum_{j=1}^{n} P_{j} C_{j}^{-}+\sum_{j=1}^{n} P_{j} C_{j}^{+}=E
$$

Incidentally, this indicates how the level of total expenditure is endogenously determined in the general equilibrium model. Since there is only one consumer, the Paretooptimal solution will be simply that which maximizes the utility function. The expenditure level will be determined by the value of this consumption bundle evaluated at the equilibrium prices.

From eqns. (19) and (20) 


$$
g\left(C^{+}\right)=\left(E-\sum_{j=1}^{n} P_{j} C_{j}^{-}\right) \quad(j=1,2, \ldots, n)
$$

Finally, substituting $g\left(C^{+}\right)$in eqn. (17) by the above value and solving the equation for $C_{i}^{+}$yields

$$
C_{i}^{+}=\left(s_{i} / P_{i}\right)\left(E-\sum_{j=1}^{n} P_{j} C_{j}^{-}\right) \quad(i=1,2, \ldots, n)
$$

Thus, the total consumption of commodity $i$ is

$$
C_{i}=C_{i}^{-}+\left(s_{i} / P_{i}\right)\left(E-\sum_{j=1}^{n} P_{j} C_{j}^{-}\right) \quad(i=1,2, \ldots, n)
$$

which is the demand function implied by the specifications of the optimal planning model. The parameters of this are, however, evaluated on the basis of information provided by traditional planning calculations.

\subsection{Technical Similarities and Conceptual Differences}

The technical similarities of the programming models and equilibrium models have been illustrated. There is only one point where the two models are not formally identical. This is the "mechanism" by which the allocation of primary resources is exogenously controlled. This is, in fact, the only deviation from the standard literature in which primary factors are assumed to be perfectly homogeneous, with no constraints on their intersectoral (re)allocation. It is even tempting to interpret these different formulations as two alternative ways of reflecting the limited intersectoral mobility of the primary factors. In an otherwise perfect market economy this immobility would be indirectly expressed by varying rates of return on the primary factors. In a centrally planned economy, on the other hand, this immobility would be directly accounted for in terms of physical constraints. The planners would separate in advance the sectorally committed (immobile) part of the primary factors from the mobile part.

Beside the word "similarity" (or "identity") the adjective "technical" also deserves attention. The formulation of a general equilibrium model is strongly influenced and directed by abstract theoretical considerations. Both the structure of the model and the numerical evaluation of its parameters depend heavily on, and should be consistent with, theoretical assumptions, e.g., individual optimization behavior and marginal productivity pricing. These are retained even though the model is usually built upon macroaggregates, to which the postulated microbehavioral rules cannot be mechanically applied. Socialist planning model-building, on the other hand, tends to be more pragmatic. Linear programming, for instance, is considered as one available technical device or framework that may help planners to generate additional information by numerical thought experiences. The term "optimal planning model" can be misleading in this context. The main 
role of programming models in planning, as indicated earlier, is in the coordination phase of planning, where it serves the purpose of checking the consistency and efficiency of the proposed resource allocation. Based on the available planning information, the model is used for generating more efficient programs by allowing a limited reallocation of resources and by formulating alternative objective functions.

Nevertheless, the main point of this exercise is that an optimal resource allocation framework can be substituted by a simultaneous equation system, i.e., by a system common to most applied general equilibrium models. At this point, however, the question arises: what are the possible benefits of such a transformation that justify the adoption of more complicated solution techniques? The answer lies in the greater flexibility of their formulation. A general equilibrium model can do almost everything that a programming model can do, but in addition it incorporates considerations that are not possible in a programming model. Of course, the usefulness of such a transformation depends, to a large extent, on the overall specification and intended use of the model. In Section 3 an attempt is made to demonstrate that in some aggregated nationwide modeling exercises a general equilibrium framework allows for, among other things, much greater flexibility in defining the relationships of the model variables and also a more realistic description of existing price-formation rules, taxes, subsidies, etc.

One of the outstanding advantages of the equilibrium framework is that it may provide ways for planners to achieve a better linkage between planning the real and the value processes. These two main planning functions are usually quite separate both in traditional planning and in modeling. Changes in relative prices, costs, tariffs, etc., are not reflected properly in physical allocation models, while the effects of production, exportimport, and consumption decisions are not always taken into consideration in priceplanning models. Planning models in the form of a simultaneous nonlinear equation system might prove to be especially useful in aggregate comparative statics analyses. These models are useful because they can accommodate substitution possibilities and prevent overspecialized solutions by means of a relatively small number of parameters, unlike the linear programming models.

Two of the above-mentioned issues will now be considered further. One of them concerns the possibility of having alternative economic policy goals to measure efficiency gains in a general equilibrium resource allocation model in a way similar to the alternative objective functions in a programming model. It should be clear from the specification of the equilibrium conditions explained above that the model is not a completely closed equilibrium system. Thus, for example, the distribution and redistribution of income do not appear in the model. At the same time the total household expenditure and consumption are endogenously determined. The programming reformulation sheds some light on the nature of such a solution. Since every other possible policy issue, such as net investment, government consumption, levels of primary input usage, and current-account balances are exogenously determined, practically all gains (resulting from increased allocational efficiency) will show up as an increase in the level of consumer utility. In the light of this consideration it becomes obvious that the same kind of general equilibrium model can be made to reflect various other possible economic policy goais, e.g., increasing government consumption or net investment, or decreasing deficit on current account, etc. (The reverse case is also interesting, i.e., when exogenous changes cause a decrease in the overall efficiency of the given economy. In such a case one could estimate losses in 
various terms.) It is also possible to build into the model some weighted sum of the improvements. The incorporation of "objective functions" other than consumption would only make necessary changes in the structure of endogenous and exogenous variables or perhaps the introduction of some new variables and equations into the model. By such simple modifications one can make the equilibrium model capable of handling alternative policy objectives in the same way as the programming models. See also Section 3 on this issue.

The second issue is related to price-formation rules. An equilibrium approach is strongly favored here. The zero or nonprofit condition has appeared in both the equilibrium model and in the programming model. The validity and usefuiness of this assumption are discussed in more detail in Section 3. However, it should be pointed out here that, with technologies showing constant returns to scale, the optimal programming model will always generate shadow prices that fulfill the zero-profit condition. On the other hand, the equilibrium framework - with slight reinterpretation - allows positive profits to be taken into account, even with constant returns to scale. The prices generated in this way can reflect more accurately the real price-formation rules.

Finally, a few words to indicate our understanding of the term "techniques of applied general equilibrium models". General equilibrium theory, especially its theoretical models possessing a high degree of closure and a rather narrow, mathematically oriented scope of investigation, has been criticized from several points of view by many Marxist and non-Marxist authors. ${ }^{*}$ It is not always clear what the boundaries of general equilibrium theory are, since it is capable of incorporating many partial models and techniques that have been originally developed independently. Different economists understand and relate to these problems differently; therefore it is useful to indicate our interpretation of general equilibrium theory and models as well as their place among the analytical tools available to economists. Two distinctions should be made, namely, between general equilibrium theory and general equilibrium techniques on the one hand and between pure and applied general equilibrium models on the other. These distinctions are rather tentative.

General equilibrium theory, in our understanding, is an abstract representation of the law of supply and demand placed within the framework of a simplified model of a much more complex economic system. ${ }^{* *}$ Here, general equilibrium modeling techniques imply the more or less standard analy tical tools that can be used either in defining the elements of a general equilibrium model (supply and demand functions, production functions, programming models, etc.) or in the definition of, or the search for, an equilibrium (e.g., complementary slackness criteria, fixed-point algorithms). A model using general equilibrium modeling techniques can be completely outside the theory. For example, consider the earlier discussion, where an attempt was made to demonstrate that there is only a formal, technical identity between an optimal planning model and a neoclassical general equilibrium theoretical model.

As is often the case, abstract general economic equilibrium theory differs in many

\footnotetext{
* See, for instance, Kornai (1971) for a systematic exposition of the most common criticisms.

** It would probably be useful to distinguish between competitive (Walrasian) and other types of general equilibrium models, however difficult it might be to identify the latter. Throughout this paper general equilibrium models are taken to imply competitive models.
} 
ways from applied models based on that theory. One important point of departure must be emphasized. The abstract theory of general equilibrium postulates a priori knowledge of the external environment (production and consumption sets, preference orderings, relative profit shares of various households, etc.), which is assumed to be independent of the endogenous variables (prices, production, and consumption decisions). The equilibrium solution - if there is one - is then determined by the parameters of the external environment and by the behavioral rules which are also postulated a priori. This approach could be characterized as "global" or "absolute". Applied general equilibrium models follow a more or less reverse order and take a "local" or "relative" point of view. What one can observe in reality is mostly the values of the endogenous variables. Whether they represent an equilibrium or not, and more importantly, whether there is any such mechanism behind the determination of these values, is not really known. As a matter of fact, one determines many of the assumed but directly nonobservable external parameters by assuming that the observed data were generated at equilibrium. (It seems to be almost impossible to test this assumption or to estimate the errors caused by this assumption in the present analysis.) The aim is to estimate the likely consequences of alternative external environmental changes in terms of relative changes, i.e., by comparing the "base equilibrium solution" with the calculated one. The equilibrium framework is, therefore, used only as one of those tools that current economic theory can offer for the complex analysis of such issues. One could also say that general equilibrium theory has empirical values, in fact, only in the "relative sense" discussed above.

The general ideas expressed by the abstract theory of general equilibrium (basically the dependence of economic decisions on relative prices and costs and on resource constraints) have certainly more empirical relevance when one tries to explain relative changes rather than absolute magnitudes. The main advantage of these models is that they provide a framework in which the partial changes envisaged can be evaluated in a consistent and coordinated way, taking into account the interdependence of some crucial variables.

\subsection{Use of Smooth Production Functions in Planning Models}

The simplified planning model that has been examined in Section 2.2 differs from the typical applied models in one particular - it is nonlinear. This nonlinearity arises only from the use of smooth production functions, because the other nonlinear relationship, the objective function, could be easily linearized. It should be clear that the production function* serves only one purpose in the model. If one had fixed labor and capital input coefficients - as in the case of the intermediate inputs - then there would be no choice between more or less labor- (or capital)-intensive techniques, in fact, there would be no technological alternatives for the different sectors at all. Linear planning models usually do allow for alternative technologies but, of course, in a different way. In rather aggregated macro planning models one would usually consider two or three alternative technologies, but, in addition, upper and/or lower limits would restrict the output levels. The

\footnotetext{
* The term "production function" is not quite appropriate here since it defines only a composite primary factor.
} 


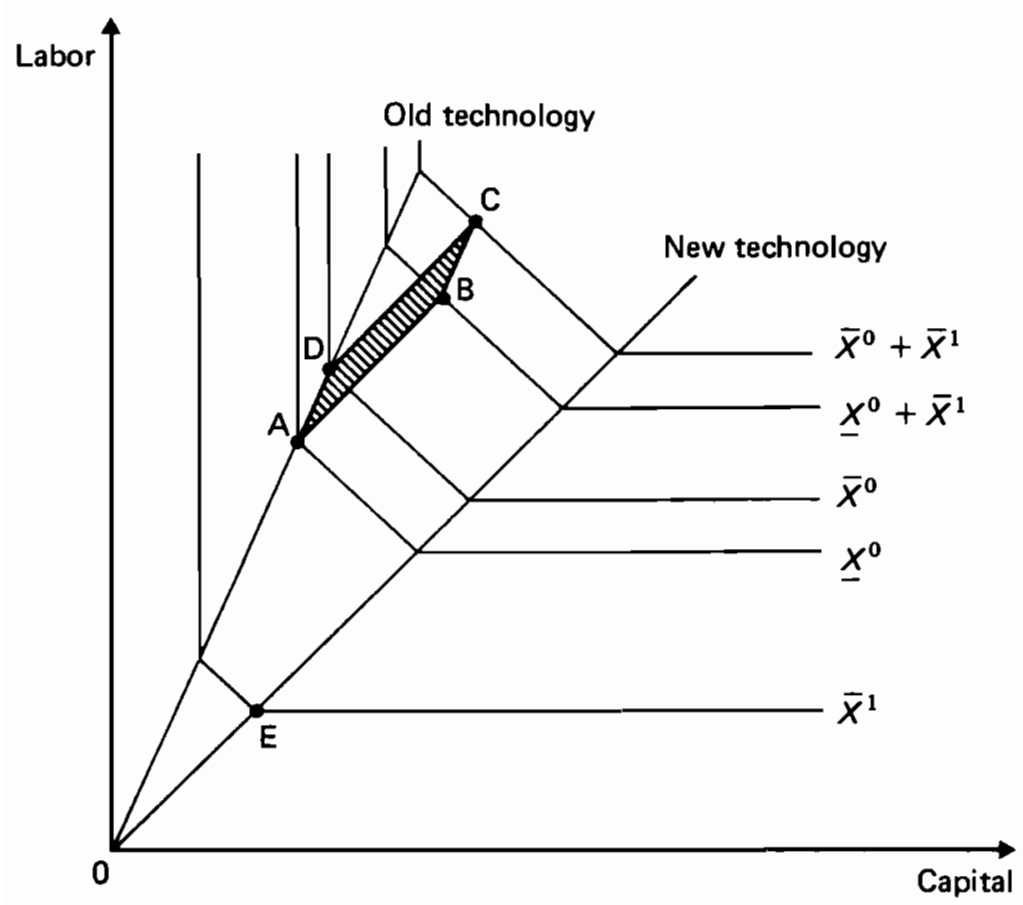

FIGURE 1 The theoretical isoquant map and the real substitution possibilities in a linear programming model.

range of choice between more or less labor- (or capital)-intensive technologies will, therefore, be very limited.

To illustrate this point, take a typical example. Suppose the model-builder has information on two technologies available in the future for a specific sector: production using old or new equipment. For the sake of simplicity, it will be assumed that these technologies differ only with respect to their labor and capital intensities. Let $k^{0}, n^{0}$, and $k^{1}, n^{1}$ represent the capital and labor coefficients in the "old" and "new" technologies, respectively. Also take into account the limits imposed on the production levels

$$
\underline{X}^{0} \leqslant X^{0} \leqslant \bar{X}^{0}
$$

and

$$
X^{1} \leqslant \bar{X}^{1}
$$

where it is assumed that the production with old equipment is limited both from above $\left(\bar{X}^{0}\right)$ and below $\left(\underline{X}^{0}\right)$, while the production with new equipment is limited only from above $\left(\bar{X}^{1}\right)$. (The upper limits can be taken as the planned capacities.)

The results of these restrictions are illustrated in Figure 1. It can easily be checked that only the points in the parallelogram ABCD will give feasible combinations of capital and labor. It is also apparent that the substitution possibilities vary with the level of 
production. At levels $\underline{X}^{0}$ and $\bar{X}^{0}+\bar{X}^{1}$ there is no possibility for substitution between the production factors, but between these levels the substitution possibility first increases, then decreases with the level of output. The feasible capital and labor coefficients will also be limited by $k^{0}, \hat{k}$ and $n^{0}, \hat{n}$, where $\hat{n}$ and $\hat{k}$ are determined by point B. (From the above observations it also becomes apparent how misleading it would be to identify the feasible technological set with the isoquant map derived from the two basic linear activities in a "textbook" fashion - see Figure 1.)

For a more realistic description of the sectoral production possibilities in a linear model one has to give up the macro character of the model. Each sector has to be broken down into subsectors and individual limits should be introduced into subsectoral activities. If, however, one wants to keep the size of the model small (to have, say, 15-20 sectors only), and still represent a reasonable technological choice for each sector, use of smooth production functions seems reasonable. Here again, the real considerations behind this choice are pragmatic rather than theoretical. What one makes use of is the information-condensing power of the production functions, as simple statistical devices (regressional schemes).

Of course, in a planning model that is based on detailed (traditional) planning calculations, the estimates of parameters of the macro production functions should also be based on these calculations. This is unlike the case of the cited applied general equilibrium models. In these models the parameters of the sectoral (macro) production functions are either econometrically estimated or simply "guesstimated" on the basis of similar econometric estimates. Beyond the well-known statistical estimation problems (see, for instance, Berndt, 1976; Caddy, 1976) these empirical estimates are more severely biased by the neoclassical marginal productivity pricing assumption widely used in the (indirect) estimation procedures. One would be rather reluctant to use such estimation techniques in socialist planning.

The estimation of the parameters of a short-term macro production function could be based on the following or a similar procedure. ${ }^{*}$ One defines first a set of activities in terms of the total level of their output, and labor and capital inputs $(\bar{X}, \bar{N}, \bar{K})$. These activities could in an ex post analysis be identified by actual enterprise (or subsectoral) data. In an ex ante (planning) model such data could be generated on the basis of calculations by enterprises concerning their future development plans. Next, upper and lower limits have to be assigned to the individual output levels within which they are allowed to vary $\left(\underline{\alpha}_{k} \bar{X}^{k}, \bar{\alpha}_{k} \bar{X}^{k}\right)$. Finally, fixing the sectoral total output at some level, say $\bar{X}$, one could generate a reasonable number of alternative intrasectoral production structures yielding the same amount of total sectoral output. The different production structures will imply different labor/capital combinations. These combinations, in turn, can be treated as points lying on or around the same isoquant. Thus, they make it possible to estimate the parameters of a linear homogeneous LES production function.

The formal procedure that generates the above alternative labor/capital combinations can be based on the solution of the following linear inequality system

\footnotetext{
* This method bears an obvious resemblance to Johansen's (1972) treatment of the sectoral production functions and also to the way in which Rimmler et al. (1972) estimated macro functions on the basis of programming models.
} 


$$
\begin{aligned}
& \sum_{k=1}^{N} X^{k}=\bar{X} \\
& \underline{\alpha}_{k} \bar{X}^{k} \leqslant X^{k} \leqslant \bar{\alpha}_{k} \bar{X}^{k} \quad(k=1,2, \ldots, N) \\
& N=\sum_{k=1}^{N} n_{k} X^{k} \\
& K=\sum_{k=1}^{N} k_{k} X^{k}
\end{aligned}
$$

The above system could be solved by parametric solution techniques, i.e., by fixing the amount of, say, labor at different levels and calculating the corresponding values for capital. It is important to note here that one does not necessarily want to look for efficient capital/labor combinations only. (Such solutions could be achieved if, instead of simply solving the inequality system, the amount of capital is minimized at each level of labor.)

It should also be clear that the substitution of basic linear technologies by smooth production functions in a planning model is, in fact, a way to decompose the problem. For each sector, first one solves separately a constrained linear activity model. Then, by production functions, one condenses this production information into a few (three or less) parameters. By doing so one can reduce the size of the core model by a considerable degree, which may be quite useful in the case of many repeated runs. This also makes the model more transparent. One suspects that the dual solutions of such aggregated models would become more stable and easier to interpret than the shadow prices of large linear systems, which have many individual limits.

Finally, the linear homogeneity assumptions are viewed simply as convenient assumptions. By using smooth functions instead of fixed capital and labor coefficients, one merely incorporates substitution possibilities into an otherwise linear model.

\section{A TENTATIVE MODEL FRAMEWORK FOR HUNGARY}

The model developed here reflects to a large extent - but of course in a simplified manner - existing planning theory and modeling practice in Hungary. It should not be viewed as a descriptive model either of the actual working of the Hungarian economy or of the planning decision-making. Instead the model should be compared with linear resource allocation (programming) models and price-formation models currently used in Hungarian planning practice. The present model, in fact, is a natural extension and combination of such models, making use of the general equilibrium framework. The model in the form outlined could serve the same kind of economic policy or planning-analysis purposes as those used currently. The novelty of the present model lies mostly in the following features. The shadow prices are reinterpreted and formed differently than in programming models. There are explicit interactions between the shadow prices and the 
real variables. Use is made of nonlinear smooth functions to describe the possible variations of production, consumption, and foreign-trade decisions. And finally, several exogenous variables have been introduced, such as world market prices, tax rates, etc., which gives room for additional simulation possibilities.

The model differs in many aspects from other applied general equilibrium models, including the Bergman-Pór (1980) model which had the strongest influence on its specifications. For example, several modifications in the treatment of foreign trade can be found. First of all, the two main trading areas (the rouble and dollar regions) are represented separately in the present model. A distinction is also made with respect to the competitive and noncompetitive nature of imported commodities. A third difference in the treatment of foreign trade is that use is made of export supply functions rather than export demand functions, which is more in line with the basic assumptions that small economies are price-takers on the world market. It is also considered that, even if a small country cannot influence world market prices on the whole, it may face decreasing returns on exports. Another important difference can be found in the way wage determination is taken into account. Instead of using the marginal productivity assumption, wages are treated as exogenously determined variables and the concept of the user cost of labor, which is made up of the wage rate and a general net return requirement, is introduced. The zero-profit assumption is also eliminated without foregoing the linear homogeneity assumptions. A further deviation from the Bergman-Pór model is that instead of treating net investment exogenously, a fixed consumption-investment ratio is introduced. Some demoeconomic elements have also been incorporated to take into account the difference in the demand structures of urban and rural households.

In Sections 3.1-3.5 the structural equations of the model are presented and discussed. Section 3.6 contains a list of variables and parameters as well as a condensed mathematical statement of the model.

\subsection{Commodities and Commodity Balances}

\subsubsection{Primary Resources and Factors of Production}

Two primary factors of production will be taken into consideration in the model presented: labor and capital. Their available quantities are assumed to be exogenously given, while their intersectoral allocations will be determined within the model. It is required that the total use of these production factors be equal to the amounts of each available. This requirement can be expressed by the resource balance equations*

$$
\begin{aligned}
& \sum_{j=1}^{n} K_{j}+K_{\mathrm{g}}=K \\
& \sum_{j=1} N_{j}+N_{\mathrm{g}}=N
\end{aligned}
$$

\footnotetext{
* The equation numbers correspond with those used in the mathematical statement of the model in
} Section 3.6. 
where $K$ stands for total capital stock, $N$ for total labor available, $K_{\mathrm{g}}$ and $N_{\mathrm{g}}$ denote capital stock and labor used in public (governmental) services (all of them exogenously determined), while $K_{j}$ and $N_{j}$ represent the amounts of capital and labor used in the different sectors $(j=1,2, \ldots, n)$.

I am aware that these are very simplistic treatments of labor and especially capital, but this simplicity makes it easier to understand the general structure of the model. If one wants to use a static model such as this, a distinction must be made at least between sectorally committed and uncommitted primary factors in order to constrain their intersectoral mobility. In a planning context some combination of ex post and ex ante production functions might provide a more realistic description of the resource allocation possibilities.

Apart from labor and capital there are $n$ noncompetitive import commodities that are treated as primary resources in the model. These will be discussed later.

\subsubsection{Intermediate Commodities and their Balances}

Production in the economy is classified into $n$ producing sectors, each producing a sector-specific commodity (or, rather, commodity group). The usual input-output modeling framework will be adopted and it will be assumed that the sectoral outputs are homogeneous commodities. Also, when competitive imports are taken into consideration, they are assumed to consist of the same homogeneous commodities as the sectoral outputs. These are rather binding but nonetheless necessary concomitant assumptions of the convenient input-output modeling framework.

The number of sectors and the character of the sectoral classification depend to a large extent on the specifics of the model as a whole, but in order to control the size of the model, it is intended to have no more than $20-30$ sectors.

For each sector there is a commodity-balance equation. More precisely, there are two commodities belonging to each sector: one composed of domestic production and the other of the noncompetitive imports of the same sectoral classification. These terms are used here in a slightly unusual way. By noncompetitive imports is meant not only those imported commodities that are not and cannot be produced within the country, but also those imports that are deemed by planning experts to be totally unsubstitutable by domestic production in the given period.

The balance equation for noncompetitive imports takes into account their use in different areas, i.e., in production $\left(\bar{M}_{i j}, j=1,2, \ldots, n\right)$, in investment $\left(\bar{M}_{i, n+1}\right)$, and in private $\left(\bar{C}_{i}\right)$ and public $\left(\bar{G}_{i}\right)$ consumption. The sum of these different uses must be equal to the total available amount $\left(\bar{M}_{i}\right)$

$$
\bar{M}_{i}=\sum_{j=1}^{n+1} \bar{M}_{i j}+\bar{C}_{i}+\bar{G}_{i} \quad(i=1,2, \ldots, n)
$$

The balance equations for the commodities that are regarded as homogeneous with (and perfect substitutes for) the domestic production will have the form

$$
X_{i}+M_{i \mathrm{r}}+M_{i \mathrm{~d}}=\sum_{j=1}^{n+1} X_{i j}+C_{i}+G_{i}+Z_{i \mathrm{r}}+Z_{i \mathrm{~d}} \quad(i=1,2, \ldots, n)
$$


The total source is, thus, made up of domestic production $\left(X_{i}\right)$, and competitive imports from the rouble $\left(M_{i \mathrm{r}}\right)$ and dollar $\left(M_{i \mathrm{~d}}\right)$ trading regions, whereas total use is the sum of intermediate usage $\left(X_{i j}, j=1,2, \ldots, n\right)$, capital accumulation $\left(X_{i, n+1}\right)$, private consumption $\left(C_{i}\right)$, consumption in public services ( $G_{i}$, exogenously given), and exports to the rouble $\left(Z_{i \mathrm{r}}\right)$ and $\operatorname{dollar}\left(Z_{i \mathrm{~d}}\right)$ trading regions.

The $(n+1)$ th sector represents gross investment. ${ }^{*}$ It is a so-called bookkeeping sector that creates homogeneous capital goods for the sectoral commodities, which are, in turn, used for replacing old capital and for net investment. The balance equation for this $(n+1)$ th sector will thus have the form

$$
X_{n+1}=\sum_{j=1}^{n} \delta_{j} K_{j}+\delta_{\mathrm{g}} K_{\mathrm{g}}+I
$$

where $X_{n+1}$ is real gross investment, $I$ is real net investment, and $\delta_{j}(j=1,2, \ldots, n)$ is the depreciation rate of capital in sector $j .^{* *}$

\subsection{Import and Export Functions, and Trade Balances}

Imports are generally classified (although not in all cases) according to four criteria: sectoral character of the imported commodity; trading area (rouble or dollar region); competitive or noncompetitive (complementary) character of the imported commodity; and area of use of the imported commodity.

Noncompetitive imports, used in production and investment, are determined as fixed proportions of the output levels:

$$
\bar{M}_{i j}=\bar{m}_{i j} X_{j} \quad(i=1,2, \ldots, n ; j=1,2, \ldots, n+1)
$$

Government (public) consumptions of noncompetitive imports are treated as exogenous parameters in the model, while the use of noncompetitive imports in private consumption is determined by demand functions.

The total noncompetitive imports of a given commodity are split into two parts: imports from the rouble (subscript $r$ ) and dollar (subscript d) trading regions, assuming a finite but rather small elasticity of substitution between imports from the two trading areas:

$$
\begin{array}{ll}
\bar{M}_{i \mathrm{x}}=\alpha_{i} \bar{M}_{i} & (i=1,2, \ldots, n) \\
\bar{M}_{i \mathrm{~d}}=\left(1-\alpha_{i}\right) \bar{M}_{i} & (i=1,2, \ldots, n)
\end{array}
$$

\footnotetext{
* Stock formation will, in general, be treated as part of the gross investment. In some calculations, however, it might be more appropriate to treat it exogenously.

** No distinction is made here between depreciation and replacement rate, which may be quite different. In some cases, especially in short-run calculations, such a distinction may be desirable.
} 


$$
\alpha_{i}=\alpha_{i}^{0}\left(\bar{\theta}_{i \mathrm{~d}} V_{\mathrm{d}} \bar{P}_{i \mathrm{~d}}^{\mathrm{WI}} / \bar{\theta}_{i \mathrm{r}} V_{\mathrm{r}} \bar{P}_{i \mathrm{r}}^{\mathrm{WI}}\right)^{\rho_{i}} \quad(i=1,2, \ldots, n)
$$

Competitive imports are treated as perfect substitutes for the sectoral output, and therefore there is no need to specify their area of use. The competitive imports of a given commodity from the rouble and dollar regions are treated separately. In both cases imports are determined by the total domestic use of the sectoral output $\left(X_{i}-Z_{i}\right)$ and variable proportions of the imports* according to the following rules:

$$
\begin{array}{ll}
M_{i \mathrm{r}}=m_{i \mathrm{r}}\left(X_{i}-Z_{i}\right) & (i=1,2, \ldots, n) \\
M_{i \mathrm{~d}}=m_{i \mathrm{~d}}\left(X_{i}-Z_{i}\right) & (i=1,2, \ldots, n)
\end{array}
$$

where

$$
Z_{i}=Z_{i \mathrm{r}}+Z_{i \mathrm{~d}} \quad(i=1,2, \ldots, n)
$$

The proportions of the imports are determined in accordance with the import functions

$$
\begin{aligned}
& m_{i \mathrm{r}}=m_{i \mathrm{r}}^{0}\left(P_{i} / \theta_{i \mathrm{r}} V_{\mathrm{r}} P_{i \mathrm{r}}^{\mathrm{WI}}\right)^{\mu_{i \mathrm{r}}} \quad(i=1,2, \ldots, n) \\
& m_{i \mathrm{~d}}=m_{i \mathrm{~d}}^{0}\left(P_{i} / \theta_{i \mathrm{~d}} V_{\mathrm{d}} P_{i \mathrm{~d}}^{\mathrm{WI}}\right)^{\mu_{i \mathrm{~d}}} \quad(i=1,2, \ldots, n)
\end{aligned}
$$

The interpretation of these import functions in a planning context could be based on the following observations. If, say, $\mu_{i d}$ in eqn. (37) were set equal to zero, then the dollar imports would be determined as fixed proportions of the total domestic use of the sectoral output (i.e., as fixed proportions of total output less exports). This kind of import determination is quite commonly used in applied input-output models, where $m_{i \mathrm{~d}}^{0}$ can be taken as the planned proportion of the imports. The modifying term in the import function is intended to reflect substitution effects in the following sense. If, other things being equal, the domestic price $\left(P_{i}\right)$ of the given commodity increases relative to its import price $\left(\theta_{i \mathrm{~d}} V_{\mathrm{d}} P_{i \mathrm{~d}}^{\mathrm{W} 1}\right)$, then the relative share of imports increases. The elasticity parameter $\mu_{i \mathrm{~d}}$ is intended to reflect whether one assumes a larger or a smaller shift in the import share (more or less "friction" in the adjustment process). It should be emphasized that, although import functions of this form are commonly used in general equilibrium models, the interpretation at tached to them is often quite different from that

\footnotetext{
* In some cases one might want to take into consideration the fact that imports from the rouble trading region are, as a rule, determined by long-term trade agreements from which it is rather difficult to deviate. In such a case, therefore, it seems more appropriate to determine the amount of imports from the rouble trading area independently of the domestic output, in accordance with import functions of the following type

$$
M_{i \mathrm{r}}=M_{i \mathrm{r}}^{\mathrm{\varphi}}\left(P_{i} / \theta_{i \mathrm{r}} V_{\mathrm{r}} P_{i \mathrm{r}}^{\mathrm{WI}}\right)^{\mu_{i \mathrm{r}}} \quad(i=1,2, \ldots, n)
$$
}


used here. ${ }^{*}$ This difference in interpretation provides an illustration for our earlier discussion on the distinction between theory and techniques.

Exports are determined in the model by export functions. There are essentially two ways to define export functions, either as export supply or as export demand functions. From a technical point of view the export function has identical forms in both cases (for the sake of simplicity in this general discussion taxes and trade-region specifications are disregarded):

$$
Z_{i}=Z_{i}^{0}\left(P_{i} / V P_{i}^{\mathrm{WE}}\right)^{\epsilon_{i}} \quad(i=1,2, \ldots, n)
$$

The interpretation of this form, however, is quite different in the two cases; also, the choice of interpretation will affect the treatment of exports in the trade (current account) balance equation.

In the case of export supply interpretation, the basic assumption is that the world market (export) price $\left(P_{i}^{\mathrm{WE}}\right)$ and the rate of exchange $(V)$ determine the price that the seller obtains for his commodity if he sells it abroad. Thus the export supply is determined on the basis of the domestic selling price $\left(P_{i}\right)$ and the export selling price $\left(V P_{i}^{\mathrm{WE}}\right)$. In this case the exports in the trade balance must be evaluated at world market (export) prices. Note also that in this case it is assumed that the given country is a perfect pricetaker in the world market.

In the second case there is an implicit assumption that the given country cannot influence the general world market price level $\left(P_{i}^{\mathrm{WE}}\right)$, but that it can set the export price for its commodity. This latter price is determined by the domestic price $\left(P_{i}\right)$ and the exchange rate $(V)$. It is assumed that foreign purchasers will increase or decrease their demand in accordance with the relative change in general world market price $\left(P_{i}^{\mathrm{WE}}\right)$ and the price level offered $\left(P_{i} / V\right)$. In this case the exports in the trade balance must be evaluated at prices $P_{i} / V$.

In the case of small, open economies it is reasonable to assume that they are, in general, price-takers rather than price-makers on the world market. This, however, does not mean that they cannot influence export prices at all. It is generally assumed that the volume of a country's exports does have an effect on the export price that it can achieve, because of the limited absorptive capacities of the markets supplied. A combination of these two assumptions gives rise to the following export specification. The export price basically follows the general world market export price $\left(P_{i}^{\mathrm{WE}}\right)$, but it is modified by a term that reflects the effect of the market share of the export on the actual export price $\left(P_{i}^{\mathrm{AE}}\right)$ :

\footnotetext{
* The theoretical justification of such functions is based on the assumption of the same type of constant elasticity of substitution (CES) preference function for each user and the optimizing behavior (see, for instance, Bergman, 1980). It has been pointed out to me by Lars Bergman that if one wants to be consistent with these assumptions, then the domestic output and the competitive imports should not be treated as perfect substitutes (they cannot be added together). It should be clear that our understanding of "limited substitution possibility" is different from that implied by the above assumptions. We do assume the perfect substitutability of competitive imports and domestic production, with an imperfect substitution mechanism. In contrast, a neoclassical interpretation would assume imperfect substitutability in practice but a perfect substitution mechanism in theory.
} 


$$
P_{i}^{\mathrm{AE}}=P_{i}^{\mathrm{WE}}\left(Z_{i}^{0} / Z_{i}\right)^{\lambda_{i}}
$$

In a planning modeling context, $Z_{i}^{0}$ can be the planned amount of exports and $P_{i}^{\mathrm{WE}}$ the forecast unit export price. ${ }^{*}$ Therefore, in this case, the export supply function will have the form

$$
Z_{i}=Z_{i}^{0}\left[P_{i} /\left\{V P_{i}^{\mathrm{WE}}\left(Z_{i}^{0} / Z_{i}\right)^{\lambda_{i}}\right\}\right]^{\epsilon_{i}}
$$

The solution of this equation for $Z_{i}$ yields

$$
\begin{aligned}
Z_{i} & =Z_{i}^{0}\left(P_{i} / V P_{i}^{\mathrm{WE}}\right)^{\epsilon_{i} /\left(1-\lambda_{i} \epsilon_{i}\right)} \\
& =Z_{i}^{0}\left(P_{i} / V P_{i}^{\mathrm{WE}}\right)^{\epsilon_{i}^{i}}
\end{aligned}
$$

where

$$
\epsilon_{i}^{\prime}=\epsilon_{i} /\left(1-\lambda_{i} \epsilon_{i}\right)
$$

The export function is, therefore, formally the same in this case as above. There is only a change in the absolute value of the elasticity parameter; it will be somewhat lower than in the case of a "pure" export supply function. Note, however, that in the trade balance the exports must be evaluated in this case at prices $P_{i}^{\mathrm{AE}}$.

In determining dollar exports the above modified export supply function will be used, with one additional change. In order to increase the export supply the government can subsidize the exporter or impose taxes on the income from exports as a means of curtailing exports. This factor has a direct effect only on the export supply function and not on the trade balance. For this reason, the following export supply functions are used

$$
Z_{i \mathrm{~d}}=Z_{i \mathrm{~d}}^{0}\left(P_{i} / \phi_{i \mathrm{~d}} V_{\mathrm{d}} P_{i \mathrm{~d}}^{\mathrm{WE}}\right)^{\epsilon_{i \mathrm{~d}}} \quad(i=1,2, \ldots, n)
$$

In determining rouble exports similar export supply functions are used, without taking into account the price-modifying effect of the export size**

$$
Z_{i \mathrm{r}}=Z_{i \mathrm{r}}^{0}\left(P_{i} / \phi_{i \mathrm{r}} V_{\mathrm{r}} P_{i \mathrm{r}}^{\mathrm{WE}}\right)^{\epsilon_{i \mathrm{r}}} \quad(i=1,2, \ldots, n)
$$

Since roubles and dollars are not exchangeable in general, it is more appropriate to have two trade balances in the model, rather than one aggregated current account. In

\footnotetext{
* In a static model like this, a change in the export volume of one country can be interpreted as if the country's share in the total world export had changed. In the light of this observation one can generalize the above price form by substituting the export volume $\left(Z_{i}\right)$ by the country's share in the total world export $\left(s_{i}\right)$. Such an export price function could then be used in a dynamic model as well. (I owe my thanks to Urban Karlström for calling my attention to this interpretational possibility.) ** Alternatively, $Z_{\text {ir }}$ could be treated as a free variable, assuming infinitely absorptive export market capacities in the rouble relation. Such a solution could be supplemented with export capacity restrictions. For each sector one could define exports as fixed proportions of the output. Thus the rouble export could be determined as the difference between total exports and dollar exports.
} 
accordance with the export-import specification, the trade balances (current accounts) have the forms

$$
\begin{aligned}
& \sum_{i=1}^{n}\left(Z_{i \mathrm{~d}}^{0} / Z_{i \mathrm{~d}}\right)^{\lambda_{i}} P_{i \mathrm{~d}}^{\mathrm{WE}} Z_{i \mathrm{~d}}-\sum_{i=1}^{n} P_{i \mathrm{~d}}^{\mathrm{WI}} M_{i \mathrm{~d}}-\sum_{i=1}^{n} \bar{P}_{i \mathrm{~d}}^{\mathrm{WI}} \bar{M}_{i \mathrm{~d}}=D_{\mathrm{d}} \\
& \sum_{i=1}^{n} P_{i \mathrm{r}}^{\mathrm{WE}} Z_{i \mathrm{r}}-\sum_{i=1}^{n} P_{i \mathrm{r}}^{\mathrm{WI}} M_{i \mathrm{r}}-\sum_{i=1}^{n} \bar{P}_{i \mathrm{r}}^{\mathrm{WI}} \bar{M}_{i \mathrm{r}}=D_{\mathrm{r}}
\end{aligned}
$$

where $D_{\mathrm{d}}$ and $D_{\mathrm{r}}$ are the target surplus or deficit levels on the dollar and rouble foreign trade balances, respectively.

\subsection{Final Demand and Regional Aspects}

Public (government) consumption is exogenously determined as well as foreign trade balances. If total net investments were also exogenously given as in the BergmanPor model, then, in a model that examines allocational efficiency, all gains that result from the reallocation of resources would show up as an increase in private consumption.* In the present model it is planned to investigate several alternatives. Here only one possible way of endogenizing net investments will be discussed. Suppose a given (real) consumption-investment ratio $(\sigma)$ is maintained. ${ }^{* *}$ This gives rise to the equation

$$
G+C-\sigma \cdot I=0
$$

The efficiency gains in this case show up as increases in both private consumption and net investment.

In another alternative solution the real value of consumption $(C)$ and that of net investment $(I)$ could be fixed exogenously and one of the foreign trade balance targets, for example, could be freed and made endogenous. In this way the efficiency gains would appear as improvements in the trade balance.

Household (private) consumption is endogenously treated. Depending on its intended use, this part of the model may become more or less crucial, particularly the interpretation and estimation of the assumed consumers' response (demand) function parameters. For simplicity the linear expenditure system (LES) will be used. For a static model applied to the final coordination phase of national economic planning, the use of such a specification can be justified on pragmatic grounds. It is assumed that one can rely on the detailed planning calculations and use the planned consumption, expenditure, and price level as a more or less consistent forecast of future consumer preferences. The model, however, would generate price levels and a total expenditure level that would vary

\footnotetext{
* On this point see the discussion in Section 2.3.

** The ratio can be determined, for example, by the planned values of the variables, $\sigma=\left(G^{0}+C^{0}\right) / I^{0}$, if the model is used for analyzing a draft plan.
} 
from this. Therefore, one would like to incorporate into the model the likely effects of such changes on the level and structure of consumer demand. One could set the constant terms in the LES demand functions equal to the planned consumption levels and determine the elasticity parameters, relying on expert estimates of the desired structure of excess consumption. This solution would be basically equivalent to that commonly used in linear programming models applied to planning (see the corresponding discussion in Section 2.2).

If one wants a more reliable forecast of structural adjustment, especially over a longer time horizon, then some crucial demographic and spatial aspects cannot be neglected in the model. In traditional national economic planning models such aspects are reflected only implicitly. (The data depict a given spatial, demographic structure and the changes are thought to be consistent with this assumed structure.) The need for formal demoeconomic models, integrating economic, demographic, and spatial variables into a consistent model framework, has been articulated mostly in the context of developing countries (see, for instance, Rogers, 1977). A few economic-demographic simulation models have recently appeared as a result of such efforts (for a critical review of these models see Sanderson, 1980). Although none of these models offers a satisfactory way of integrating the above-mentioned aspects into a planning model, they may suggest useful points of departure for future research.

For illustration, a simple device will be described that captures the interaction of economic and demographic factors within the framework of the present static model. The urban-rural distribution of economic activities and households and their interaction through final demand will be incorporated into the model. The basic idea, then, is to roughly assimilate shifts in the production structure, which imply changes in the urbanrural distribution of the economic activities and, consequently, in the household distribution and consumption demand as well. In each sector, therefore, the proportions of urban (subscript $\mathrm{U}$ ) and rural (subscript R) employment ( $s_{\mathrm{U} j}$ and $s_{\mathrm{R} j}=1-s_{\mathrm{U} j}$ ) are estimated, and these proportions assumed to be exogenous parameters. In the general equilibrium models of dualistic development (see, for instance, Karlström, 1980; Kelley and Williamson, 1980) these proportions are either 1 or 0 , so the present solution may be seen as a generalization of this concept. Thus in each solution one can calculate the total urban and rural employment

$$
\begin{aligned}
& N_{\mathrm{U}}=\sum_{j=1}^{n} s_{\mathrm{U} j} N_{j}+s_{\mathrm{Ug}} N_{\mathrm{g}} \\
& N_{\mathrm{R}}=N-N_{\mathrm{U}}=\sum_{j=1}^{n}\left(1-s_{\mathrm{U} j}\right) N_{j}+\left(1-s_{\mathrm{Ug}}\right) N_{\mathrm{g}}
\end{aligned}
$$

Next we assume that there are two different demand functions, one each for urban and rural households, and that the distribution of urban and rural households changes in accordance with urban and rural employment distribution. The aggregate household demand for commodity $i$ will thus be given by the sum

$$
C_{i}=\left\{\left(N_{\mathrm{U}} / N_{\mathrm{U}}^{0}\right) C_{i \mathrm{U}}\right\}+\left\{\left(N_{\mathrm{R}} / N_{\mathrm{R}}^{0}\right) C_{i \mathrm{R}}\right\} \quad(i=1,2, \ldots, n)
$$


Rural and urban household expenditures are assumed to increase (or decrease) in the same proportions as if there were no change in the distribution of rural and urban households. Thus if $E$ is the general level of household expenditure, then the rural and urban household expenditures will be determined by

$$
E_{\mathrm{U}}=\left(E_{\mathrm{U}}^{0} / E^{0}\right) E
$$

and

$$
E_{\mathrm{R}}=\left(E_{\mathrm{R}}^{0} / E^{0}\right) E
$$

where $E^{0}, E_{\mathrm{U}}^{0}$, and $E_{\mathrm{R}}^{0}$ are the planned (base) total, urban, and rural expenditure levels, which fulfill the identity

$$
E^{\mathbf{0}}=E_{\mathrm{U}}^{\mathbf{0}}+E_{\mathrm{R}}^{\mathbf{0}}
$$

The final demand for intermediate commodities and noncompetitive imports by the individual household sectors is determined by relative prices and total expenditure in accordance with LES demand functions

$$
\begin{aligned}
& C_{i k}=b_{i k}+\left\{\left(c_{i k} / P_{i}^{\mathbf{D}}\right) E E_{k}\right\} \\
& \bar{C}_{i k}=\bar{b}_{i k}+\left\{\left(\bar{c}_{i k} / \bar{P}_{i}^{\mathrm{DI}}\right) E E_{k}\right\}
\end{aligned}
$$

where

$$
E E_{k}=E_{k}-\sum_{j=1}^{n}\left(P_{j}^{\mathrm{D}} b_{j k}+\bar{P}_{j}^{\mathrm{DI}} \bar{b}_{j k}\right) \quad(k=\mathrm{U}, \mathrm{R})
$$

\subsection{Prices and Costs}

The price of commodity $i$ is determined in accordance with the homogeneity assumption. There are three different sources of the same commodity: domestic production, rouble-area imports, and dollar-area imports. Except for exports, the user's price, i.e., the change of its level, ${ }^{*}$ can be determined as the weighted average of the three different price levels. ${ }^{* *}$ The domestic price level of the imported commodities

\footnotetext{
* It should be noted that we are dealing with price indices (or levels) and not with actual prices, which do not even exist for the commodity aggregates. The same is true for most of the other values or financial variables, such as exchange rates and import tariffs. Their values are taken to be 1.00 at the base year (or base solution), which also means that the corresponding "real" variables are measured in these constant base-year prices.

** Recent pricing policy in Hungary (competitive pricing) connects the change of domestic prices more closely to foreign trade (either export or import) price changes. This part of the model needs revision in the light of the new price-formation principles. The model could also be used for the assessment of the likely overall impact of this change in price policy.
} 
changes if, other things being equal, there is a change in the import tariff-subsidy multiplier $(\theta)$, in the exchange rate $(V)$, or in the commodity's world market (import) price level $\left(P^{\mathrm{WI}}\right)$. Thus the average change of the domestic user's price level of commodity $i$ $\left(P_{i}^{\mathbf{D}}\right)$ can be calculated from the relationship

$$
\begin{aligned}
P_{i}^{\mathrm{D}}\left(X_{i}-Z_{i}+M_{i \mathrm{~d}}+M_{i \mathrm{r}}\right)= & P_{i}\left(X_{i}-Z_{i}\right)+\theta_{i \mathrm{~d}} V_{\mathrm{d}} P_{i \mathrm{~d}}^{\mathrm{WI}} M_{i \mathrm{~d}} \\
& +\theta_{i \mathrm{r}} V_{\mathrm{r}} P_{i \mathrm{r}}^{\mathrm{WI}} M_{i \mathrm{r}} \quad(i=1,2, \ldots, n)
\end{aligned}
$$

Dividing by $\left(X_{i}-Z_{i}\right)$ and solving the above equation for $P_{i}^{\mathrm{D}}$ yields

$$
\begin{gathered}
P_{i}^{\mathrm{D}}=\frac{1}{1+m_{i \mathrm{~d}}+m_{i \mathrm{r}}} P_{i}+\frac{m_{i \mathrm{~d}}}{1+m_{i \mathrm{~d}}+m_{i \mathrm{r}}} \theta_{i \mathrm{~d}} V_{\mathrm{d}} P_{i \mathrm{~d}}^{\mathrm{WI}}+\frac{m_{i \mathrm{r}}}{1+m_{i \mathrm{~d}}+m_{i \mathrm{r}}} \theta_{i \mathrm{r}} V_{\mathrm{r}} P_{i \mathrm{r}}^{\mathrm{WI}} \\
(i=1,2, \ldots, n)
\end{gathered}
$$

In socialist countries, the price of the domestic output is most of ten measured by the so-called producer's (factor cost) price, which does not contain turnover taxes and other ad valorem taxes or subsidies. The consumer's (market) price of the same commodity can be different, depending on the purchasing area. It would make the model overly complicated if all these variations were taken into consideration. Therefore, a rather simple correspondence is assumed between the producer's and the consumer's price of the sectoral output, namely

$$
P_{j}^{\mathrm{C}}=\left(1+\tau_{j}\right) P_{j}^{\mathrm{P}} \quad(j=1,2, \ldots, n)
$$

where $\tau_{j}$ is the net turnover tax rate on commodity $j$ and $P_{j}^{\mathbf{C}}$ and $P_{j}^{\mathbf{P}}$ are the consumer's and producer's prices, respectively. Also, since competitive import is built into the present model, the data concerning the production and use of domestic commodities are assumed to be given at consumer prices. The price of the domestic output is measured by the consumer price index, thus it reflects the changes of both the producer's price and the net turnover tax rate. The following basic price calculation scheme is used to determine the (consumer's) price of domestic output (omit ting the superscript $\mathrm{C}$, since only the consumer's price is used in the formal model)

$P_{j}=\left(\sum_{i=1}^{n} P_{i}^{\mathrm{D}} a_{i j}+\sum_{i=1}^{n} \bar{P}_{i}^{\mathrm{DI}} \bar{m}_{i j}+W_{j} n_{j}+Q_{j} k_{j}\right)\left(1+\pi_{j}\right)\left(1+\tau_{j}\right) \quad(j=1,2, \ldots, n)$

where the first expression in parentheses indicates the producer's cost of producing one unit of output $j$ (measured at base-year prices!), and $\pi_{j}$ and $\tau_{j}$ are exogenously given profit and turnover tax rates, respectively.

The above price-formation rule is inconsistent with some concepts of the neoclassical general equilibrium theory. It is well known from this theory that if technology exhibits constant returns to scale then, in equilibrium, no producer can make positive profits, i.e., the production activities that are used in the equilibrium solution must break 
even at equilibrium prices. The use of constant-return technology in an applied model is, in our view, only a convenient assumption, and one should not take it too seriously. When one speaks about nonprofit in the real world, one hides profit in "normal" (or "abnormal") rates of return on different factors of production. This treatment of profit cannot be regarded only as a matter of taste or ideology. The real problem with it is that these returns are treated as micro-level factor costs. Wages in a market economy can be treated as costs for the producers, but it seems to be highly inappropriate to interpret the rest of the value added as the users' cost of capital. It is also hard to believe that these returns are equal to the marginal products of labor and capital, unless one is a faithful advocate of the neoclassical income distribution theory. Mark-up pricing behavior, wide variations in the rates of return on capital, and other alternative theoretical considerations clearly do not support such hypotheses.

One way to bridge the gap between theory and reality in empirical general equilibrium models (see, for instance, Johansen, 1959; Bergman and Pór, 1980; see also the related discussion in Section 2 of this paper) is to incorporate (sector-specific) relative rate-of-return requirements in to the model. For example, if $\beta_{j}$ is the relative level of net return on capital in sector $j$ and $R$ is the endogenous general net rate of return on capital, then the net rate of return in sector $j$, in effect, will be $R_{j}=\beta_{j} R$.

Looking at the problem in a different way, it is obvious that the theoretical (computational) simplicity of using linear homogeneous production functions is due to a useful characteristic property; namely, that the conditions for profit maximization can be reconciled with a demand-determined output specification. Given the relative factor prices, one can determine the cost-minimizing factor proportions independently of the level of the output. If one assumes constant returns to scale, then the theoretical requirement for a meaningful profit maximization is that the unit (net) price is equal to the unit cost. In such a case, however, the producers themselves are indifferent as regards the output level; therefore it can be determined only by taking into account the demand requirement.

In general, one might assume that demand and other constraints (such as institutional constraints that require the full utilization of capacities) have in the short run a more decisive impact on the output level than mere profit-maximizing rules. Thus, for example, one might assume that producers do minimize cost, but the level of their output is determined by supply and demand relations, i.e., given the demand for the products of a sector, the output level of that sector would simply be adjusted to meet the demand. If one starts with these assumptions then the existence of (excess) profits, even in the case of linear homogeneous production functions, could also be taken into consideration. In terms of the general equilibrium theory such a solution would imply that there is pressure on the side of the producers to increase the output level in each sector, which may be constrained either by effective demand in a market economy, or by factor availability in a centrally planned one. In fact, this does not contradict experience. In the planned economies, for instance, there has been constant excess demand for both labor and capital, but, of course, for more complex reasons than that implied above.

Thus the nonprofit conditions should and could be relaxed. This would cause the model to lose some of its general equilibrium character, but at the same time it would gain some empirical relevance. Cost-minimizing and mark-up pricing behavior are therefore assumed, combined with demand-determined supply, rather than simple profit 
maximization. Further, the model in its present form treats the profit rate as an exogenous parameter. If, however, one changed the price-formation rules (for instance, allowed some prices to be determined directly by world market prices), then the corresponding profit rates would become endogenous variables.

Returning to the price equations and their remaining variables, the price index for noncompetitive imports is

$$
\bar{P}_{i}^{\mathrm{DI}}=\alpha_{i} \bar{\theta}_{i \mathrm{r}} V_{\mathrm{r}} \bar{P}_{i \mathrm{r}}^{\mathrm{WI}}+\left(1-\alpha_{i}\right) \bar{\theta}_{i \mathrm{~d}} V_{\mathrm{d}} \bar{P}_{i \mathrm{~d}}^{\mathrm{WI}} \quad(i=1,2, \ldots, n)
$$

The other cost elements that enter into price determination are user cost of labor $\left(W_{j}\right)$ and capital $\left(Q_{j}\right)$.

The user cost of labor is made up of two elements: the sectoral wage rate and a general tax rate on wages

$$
W_{j}=(1+W) w_{j} \quad(j=1,2, \ldots, n)
$$

This expression for the user cost of labor is in accordance with actual Hungarian practice. The only difference here is in the determination of the wage tax rate (a tax on employers), which in practice is given exogenously and is intended to correct wages in such a way that the resulting cost expresses the actual social cost of labor. Here $W$ is an endogenous variable and its role will be discussed later.

The user cost of capital is determined in the following way. First, the existing capital stock is reevaluated using the price index of the capital goods, which is given by

$$
P_{n+1}=\sum_{i=1}^{n} P_{i}^{\mathrm{D}} a_{i, n+1}+\sum_{i=1}^{n} \bar{P}_{i}^{\mathrm{DI}} \bar{m}_{i, n+1}
$$

Then, the user cost of the reevaluated capital will be made up of two parts, depreciation and a general tax on capital use. This solution is again not alien to actual Hungarian practice, where such tax rates have been applied and can be interpreted as minimum rate-ofreturn requirements. The taxes on labor and capital are assumed to fulfill the role of regulating the enterprises' demand for these factors of production in accordance with their availability and social costs. Thus, in the present case, the user cost of capital (evaluated at base-price level) is determined by

$$
Q_{j}=\left(\delta_{j}+R\right) P_{n+1} \quad(j=1,2, \ldots, n)
$$

Finally, $W$ and $R$ are set at such levels by the model that the demands for labor and capital of the cost-minimizing sectors match the amounts of each available. They will therefore serve the same goals as their empirical counterparts. The determination of the labor and capital input coefficients $\left(n_{j}\right.$ and $k_{j}$ ) and the factors' cost will be discussed in the following section. 


\subsection{Production Technology and Decision-Making Rules}

Production technology is described by the Johansen specification discussed earlier. Intermediate inputs and noncompetitive-import inputs are assumed to change in proportion to the level of output

$$
\begin{array}{ll}
X_{i j}=a_{i j} X_{j} & (i=1,2, \ldots, n ; j=1,2, \ldots, n+1) \\
\bar{M}_{i j}=\bar{m}_{i j} X_{j} & (i=1,2, \ldots, n ; j=1,2, \ldots, n+1)
\end{array}
$$

The uses of the two primary factors of production are determined by the assumption that producers minimize their cost at any given output level. The feasible choice of factor combination is described by linear homogeneous production functions

$$
X_{j}=F_{j}\left(N_{j}, K_{j}\right) \quad(j=1,2, \ldots, n)
$$

Minimization of the total cost of the primary factors, $W_{j} N_{j}+Q_{j} K_{j}$, subject to the production function condition, yields the necessary first-order conditions

$$
\begin{array}{ll}
W_{j}=S_{j} \partial F_{j} / \partial N_{j} & (j=1,2, \ldots, n) \\
Q_{j}=S_{j} \partial F_{j} / \partial K_{j} & (j=1,2, \ldots, n)
\end{array}
$$

where $S_{j}$ refers to the Lagrange multiplier. Further investigation reveals that $S_{j}$ is the minimum user cost of the primary factors per unit of output in section $j$

$$
S_{j}=\left\{W_{j}\left(N_{j} / X_{j}\right)\right\}+\left\{Q_{j}\left(K_{j} / X_{j}\right)\right\}=W_{j} n_{j}+Q_{j} k_{j} \quad(j=1,2, \ldots, n)
$$

This can easily be checked by multiplying the necessary first-order conditions by $N_{j}$ and $K_{j}$, respectively, and adding them together. On the right-hand side, as a result of the Euler theorem, one obtains $S_{j} X_{j}$. Division of the resulting equation by $X_{j}$ yields the desired form. Therefore, the determination of prices can be rewritten as

$$
P_{j}=\left(\sum_{i=1}^{n} P_{i}^{\mathbf{D}} a_{i j}+\sum_{i=1}^{n} \bar{P}_{i}^{\mathbf{D I}} \bar{m}_{i j}+S_{j}\right)\left(1+\pi_{j}\right)\left(1+\tau_{j}\right) \quad(j=1,2, \ldots, n)
$$

and consequently, the labor and capital coefficients $\left(n_{j}\right.$ and $\left.k_{j}\right)$ can be omitted from the model. This completes the description of the model.

\subsection{Formal Statement of the Model}

\subsubsection{Endogenous Variables}

$$
X_{j} \text { Gross output in sector } j(j=1,2, \ldots, n) \text { (real), }{ }^{*}
$$

\footnotetext{
* The word "real" in parentheses indicates that the given (real) variable is measured at base-year (constant) prices. Also note that the meanings of some symbols in Section 3 differ from those in Section 2.
} 
$M_{i \mathrm{r}}, M_{i \mathrm{~d}}$ Competitive rouble and dollar imports of commodity* $i(i=1,2, \ldots, n)$ (real),

$X_{i j}$ Use of domestic-import composite commodity $i(i=1,2, \ldots, n)$ in sector $j(j=1,2, \ldots, n+1)$ (real),

$C_{i}, C_{i \mathrm{U}}, C_{i \mathrm{R}}$ Total, urban, and rural household consumption of composite commodity $i$ $(i=1,2, \ldots, n)$ (real),

$Z_{i}, Z_{i \mathrm{r}}, Z_{i \mathrm{~d}}$ Total, rouble, and dollar export of commodity $i$ (real),

$X_{n+1}$ Total gross investments (real),

$I$ Total net investments (real),

$\bar{M}_{i}, \bar{M}_{i \mathrm{r}}, \bar{M}_{i \mathrm{~d}}$ Total, rouble, and dollar noncompetitive import of commodity $i$ $(i=1,2, \ldots, n)$ (real),

$\bar{M}_{i j}$ Use of noncompe titive import commodity $i(i=1,2, \ldots, n)$ in sector $j$ $(j=1,2, \ldots, n+1)$ (real),

$\bar{C}_{i}, \bar{C}_{i \mathrm{U}}, \bar{C}_{i \mathrm{R}}$ Total, urban, and rural household consumption of noncompetitive import commodity $i(i=1,2, \ldots, n)$ (real),

$K_{j}$ Capital used in sector $j(j=1,2, \ldots, n)$ (real),

$N_{j}$ Labor employed in sector $j(j=1,2, \ldots, n)$,

$S_{j}$ (Optimal) user cost of labor and capital per unit of output in sector $j$ $(j=1,2, \ldots, n)$,

$W_{j}$ User cost of labor in sector $j(j=1,2, \ldots, n)$,

$W$ Net rate-of-return requirement $(\operatorname{tax})$ on labor,

$Q_{j}$ User cost of capital in sector $j(j=1,2, \ldots, n)$,

$R$ Net rate-of-return requirement (tax) on capital,

$\alpha_{i}$ Share of rouble import in total noncompetitive import of commodity $i$,

$m_{i \mathrm{r}}, m_{i \mathrm{~d}}$ Proportions of competitive rouble and dollar imports of commodity $i$ $(i=1,2, \ldots, n)$,

$P_{j}$ Seller price of commodity $j(j=1,2, \ldots, n)$ produced domestically (index), ${ }^{* *}$

$V_{\mathbf{r}}, V_{\mathrm{d}}$ Exchange rates of roubles and dollars (index),

$\bar{P}_{i}^{\mathrm{DI}}$ Average domestic price of noncompetitive import of commodity $i$ $(i=1,2, \ldots, n)$ (index),

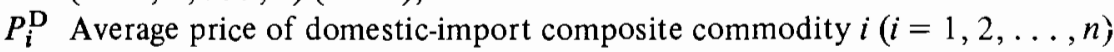
(index),

$E, E_{\mathrm{U}}, E_{\mathrm{R}}$ Total, urban, and rural household expenditure levels,

$E E_{\mathrm{U}}, E E_{\mathrm{R}}$ Urban and rural excessexpenditure levels,

$N_{\mathrm{U}}, N_{\mathrm{R}}$ Urban and rural employment,

$C$ Total household consumption (real).

\subsubsection{Exogenous Parameters (Variables or Data)}

$G, G_{i}$ Total government (public) expenditure, governmental consumption of domestic-import composite commodity $i(i=1,2, \ldots, n)$ (real),

$K_{\mathrm{g}}$ Capital used in public services (real),

\footnotetext{
* See the footnote on page 188.

** The word "index" in parentheses indicates that the corresponding variable in the base case has a value of 1.00 .
} 
$\delta_{j}$ Depreciation rate in sector $j(j=1,2, \ldots, n, \mathrm{~g})$,

$\bar{G}_{i}$ Public consumption of noncompetitive import commodity $i$ $(i=1,2, \ldots, n)$ (real),

$K$ Total capital stock (real),

$N$ Total labor,

$N_{\mathrm{g}}$ Labor usage in public services, $\left.\begin{array}{r}Z_{i \mathrm{~d}}^{0}, Z_{i \mathrm{r}}^{0} \\ \lambda_{i}, \epsilon_{i \mathrm{r}}, \epsilon_{i \mathrm{~d}}\end{array}\right\}$

Parameters in the export functions,

$P_{i \mathrm{~d}}^{\mathrm{WI}}, P_{i \mathrm{VI}}^{\mathrm{WI}}$ World market import prices of commodity $i$ (rouble-dollar, competitive$\left.\bar{P}_{i \mathrm{~d}}^{\mathrm{WI}}, \bar{P}_{i \mathrm{r}}^{\mathrm{WI}}\right\}$ noncompetitive) (index),

$D_{\mathrm{d}}, D_{\mathrm{r}}$ Target surplus or deficit on dollar and rouble foreign trade balances,

$a_{i j}$ Input coefficient of domestic-import composite commodity $i$ $(i=1,2, \ldots, n)$ in $\operatorname{sector} j(j=1,2, \ldots, n+1)$,

$\bar{m}_{i j}$ Input coefficient of noncompetitive import commodity $i(i=1,2, \ldots, n)$ in sector $j(j=1,2, \ldots, n+1)$,

$\alpha_{i}^{0}, \rho_{i}$ Parameters in the determination of the area composition of the noncompetitive import of commodity $i(i=1,2, \ldots, n)$,

$\left.\begin{array}{c}m_{i \mathrm{r}}^{0}, m_{i \mathrm{~d}}^{0} \\ \mu_{i \mathrm{r}}, \mu_{i \mathrm{~d}}\end{array}\right\}$ Parameters in the import functions $(i=1,2, \ldots, n)$,

$b_{i \mathrm{u}}, \bar{b}_{i \mathrm{u}}$

$c_{i \mathrm{u}}, \bar{c}_{i \mathrm{u}}$

$b_{i \mathrm{r}}, \bar{b}_{i \mathrm{r}}$ $\left.c_{i \mathrm{r}}, \bar{c}_{i \mathrm{r}}\right)$

$E^{0}, E_{\mathrm{U}}^{0}, E_{\mathrm{R}}^{0}$ Base total, urban, and rural consumption expenditure,

$N_{\mathrm{U}}^{\mathbf{0}}, N_{\mathbf{R}}^{\mathbf{0}}$ Base urban and rural employment distribution,

$s_{\mathrm{U} j}$ Relative share of urban employment in sector $j(j=1,2, \ldots, n)$

$\sigma$ Real consumption-net investment ratio,

$w_{j}$ Wage coefficient in sector $j(j=1,2, \ldots, n)$,

$\left.\theta_{i \mathrm{r}}, \theta_{i \mathrm{~d}}\right)$ Net import subsidy-tax factor on commodity $i(i=1,2, \ldots, n)$

$\bar{\theta}_{i \mathrm{r}}, \bar{\theta}_{i \mathrm{~d}}$ (competitive-noncompetitive, rouble-dollar) (index),

$\phi_{i \mathrm{r}}, \phi_{i \mathrm{~d}}$ Net export subsidy-tax factor on commodity $i(i=1,2, \ldots, n)$ (roubledollar) (index),

$\pi_{j}$ Profit rate in $\operatorname{sector} j(j=1,2, \ldots, n)$,

$\tau_{j}$ Net turnover tax-subsidy on commodity $j(j=1,2, \ldots, n)$.

\subsubsection{Balancing Equations}

Intermediate commodities

$$
\begin{aligned}
& X_{i}+M_{i \mathrm{r}}+M_{i \mathrm{~d}}=\sum_{j=1}^{n+1} X_{i j}+C_{i}+G_{i}+Z_{i \mathrm{r}}+Z_{i \mathrm{~d}} \quad(i=1,2, \ldots, n) \\
& X_{n+1}=\sum_{i=1}^{n} \delta_{j} K_{j}+\delta_{\mathrm{g}} K_{\mathrm{g}}+I
\end{aligned}
$$


Noncompetitive imports

$$
\bar{M}_{i}=\sum_{j=1}^{n+1} \bar{M}_{i j}+\bar{C}_{i}+\bar{G}_{i} \quad(i=1,2, \ldots, n)
$$

Primary factors

$$
\begin{aligned}
& K=\sum_{j=1}^{n} K_{j}+K_{\mathrm{g}} \\
& N=\sum_{j=1}^{n} N_{j}+N_{\mathrm{g}}
\end{aligned}
$$

Trade balances

$$
\begin{aligned}
& \sum_{i=1}^{n}\left(Z_{i \mathrm{~d}}^{0} / Z_{i \mathrm{~d}}\right)^{\lambda_{i}} P_{i \mathrm{~d}}^{\mathrm{WE}} Z_{i \mathrm{~d}}-\sum_{i=1}^{n} P_{i \mathrm{~d}}^{\mathrm{WI}} M_{i \mathrm{~d}}-\sum_{i=1}^{n} \bar{P}_{i \mathrm{~d}}^{\mathrm{WI}} \bar{M}_{i \mathrm{~d}}=D_{\mathrm{d}} \\
& \sum_{i=1}^{n} P_{i \mathrm{r}}^{\mathrm{WE}} Z_{i \mathrm{r}}-\sum_{i=1}^{n} P_{i \mathrm{r}}^{\mathrm{WI}} M_{i \mathrm{r}}-\sum_{i=1}^{n} \bar{P}_{i \mathrm{r}}^{\mathrm{WI}} \bar{M}_{i \mathrm{r}}=D_{\mathrm{r}}
\end{aligned}
$$

3.6.4 Technological Choice

$$
\begin{array}{rlrl}
X_{j} & =F_{j}\left(N_{j}, K_{j}\right) & (j=1,2, \ldots, n) \\
X_{i j}=a_{i j} X_{j} & (i=1,2, \ldots, n ; j=1,2, \ldots, n+1) \\
\bar{M}_{i j}=\bar{m}_{i j} X_{j} & (i=1,2, \ldots, n ; j=1,2, \ldots, n+1) \\
W_{j}=S_{j} \partial F_{j} / \partial N_{j} & (j=1,2, \ldots, n) \\
Q_{j}=S_{j} \partial F_{j} / \partial K_{j} & (j=1,2, \ldots, n)
\end{array}
$$

\subsubsection{Import and Export Functions}

Noncompetitive imports

$$
\begin{aligned}
\alpha_{i} & =\alpha_{i}^{0}\left(\bar{\theta}_{i \mathrm{~d}} V_{\mathrm{d}} \bar{P}_{i \mathrm{~d}}^{\mathrm{WI}} / \bar{\theta}_{i \mathrm{r}} V_{\mathrm{r}} \bar{P}_{i \mathrm{r}}^{\mathrm{WI}}\right)^{\rho_{i}} & & (i=1,2, \ldots, n) \\
\bar{M}_{i \mathrm{r}} & =\alpha_{i} \bar{M}_{i} & & (i=1,2, \ldots, n) \\
\bar{M}_{i \mathrm{~d}} & =\left(1-\alpha_{i}\right) \bar{M}_{i} & & (i=1,2, \ldots, n)
\end{aligned}
$$


Competitive imports

$$
\begin{array}{ll}
m_{i \mathrm{r}}=m_{i \mathrm{r}}^{0}\left(P_{i} / \theta_{i \mathrm{r}} V_{\mathrm{r}} P_{i \mathrm{r}}^{\mathrm{WI}}\right)^{\mu_{i \mathrm{r}}} & (i=1,2, \ldots, n) \\
m_{i \mathrm{~d}}=m_{i \mathrm{~d}}^{0}\left(P_{i} / \theta_{i \mathrm{~d}} V_{\mathrm{d}} P_{i \mathrm{~d}}^{\mathrm{WI}}\right)^{\mu_{i \mathrm{~d}}} & (i=1,2, \ldots, n) \\
M_{i \mathrm{r}}=m_{i \mathrm{r}}\left(X_{i}-Z_{i}\right) & (i=1,2, \ldots, n) \\
M_{i \mathrm{~d}}=m_{i \mathrm{~d}}\left(X_{i}-Z_{i}\right) & (i=1,2, \ldots, n)
\end{array}
$$

Exports

$$
\begin{array}{ll}
Z_{i}=Z_{i \mathrm{r}}+Z_{i \mathrm{~d}} & (i=1,2, \ldots, n) \\
Z_{i \mathrm{r}}=Z_{i \mathrm{r}}^{0}\left(P_{i} / \phi_{i \mathrm{r}} V_{\mathrm{r}} P_{i \mathrm{r}}^{\mathrm{WE}}\right)^{\epsilon_{i \mathrm{r}}} & (i=1,2, \ldots, n) \\
Z_{i \mathrm{~d}}=Z_{i \mathrm{~d}}^{0}\left(P_{i} / \phi_{i \mathrm{~d}} V_{\mathrm{d}} P_{i \mathrm{~d}}^{\mathrm{WE}}\right)^{\epsilon_{i \mathrm{~d}}} & (i=1,2, \ldots, n)
\end{array}
$$

\subsubsection{Final Demand Equations}

$$
\begin{aligned}
& C_{i \mathrm{U}}=b_{i \mathrm{U}}+\left\{\left(c_{i \mathrm{U}} / P_{i}^{\mathrm{D}}\right) E E_{\mathrm{U}}\right\} \quad(i=1,2, \ldots, n) \\
& \bar{C}_{i \mathrm{U}}=\bar{b}_{i \mathrm{U}}+\left\{\left(\bar{c}_{i \mathrm{U}} / \bar{P}_{i}^{\mathrm{DI}}\right) E E_{\mathrm{U}}\right\} \quad(i=1,2, \ldots, n) \\
& E E_{\mathrm{U}}=E_{\mathrm{U}}-\sum_{j=1}^{n}\left(P_{j}^{\mathrm{D}} b_{j \mathrm{U}}+\bar{P}_{j}^{\mathrm{DI}} \bar{b}_{j \mathrm{U}}\right) \\
& E_{\mathrm{U}}=\left(E_{\mathrm{U}}^{0} / E^{0}\right) E \\
& C_{i \mathrm{R}}=b_{i \mathrm{R}}+\left\{\left(c_{i \mathrm{R}} / P_{i}^{\mathrm{D}}\right) E E_{\mathrm{R}}\right\} \quad(i=1,2, \ldots, n) \\
& \bar{C}_{i \mathrm{R}}=\bar{b}_{i \mathrm{R}}+\left\{\left(\bar{c}_{i \mathrm{R}} / \bar{P}_{i}^{\mathrm{DI}}\right) E E_{\mathrm{R}}\right\} \quad(i=1,2, \ldots, n) \\
& E E_{\mathrm{R}}=E_{\mathrm{R}}-\sum_{j=1}^{n}\left(P_{j}^{\mathrm{D}} b_{j \mathrm{R}}+\bar{P}_{j}^{\mathrm{DI}} \bar{b}_{j \mathrm{R}}\right) \\
& E_{\mathrm{R}}=\left(E_{\mathrm{R}}^{0} / E^{0}\right) E \\
& C_{i}=\left\{\left(N_{\mathrm{U}} / N_{\mathrm{U}}^{0}\right) C_{i \mathrm{U}}\right\}+\left\{\left(N_{\mathrm{R}} / N_{\mathrm{R}}^{0}\right) C_{i \mathrm{R}}\right\} \quad(i=1,2, \ldots, n) \\
& \bar{C}_{i}=\left\{\left(N_{\mathrm{U}} / N_{\mathrm{U}}^{0}\right) \bar{C}_{i \mathrm{U}}\right\}+\left\{\left(N_{\mathrm{R}} / N_{\mathrm{R}}^{0}\right) \bar{C}_{i \mathrm{R}}\right\} \quad(i=1,2, \ldots, n) \\
& N_{\mathrm{U}}=\sum_{j=1}^{n} s_{\mathrm{U} j} N_{j}+s_{\mathrm{Ug}} N_{\mathrm{g}}
\end{aligned}
$$




$$
\begin{aligned}
& N_{\mathrm{R}}=N-N_{\mathrm{U}}=\sum_{j=1}^{n}\left(1-s_{\mathrm{Uj}}\right) N_{j}+\left(1-s_{\mathrm{Ug}}\right) N_{\mathrm{g}} \\
& C=\sum_{i=1}^{n} C_{i \mathrm{R}}+\sum_{i=1}^{n} \bar{C}_{i \mathrm{R}}+\sum_{i=1}^{n} C_{i \mathrm{U}}+\sum_{i=1}^{n} \bar{C}_{i \mathrm{U}} \\
& G+C-\sigma \cdot I=0
\end{aligned}
$$

3.6.7 Prices and Costs

$$
\begin{aligned}
& W_{j}=(1+W) w_{j} \quad(j=1,2, \ldots, n) \\
& Q_{j}=\left(\delta_{j}+R\right) P_{n+1} \quad(j=1,2, \ldots, n) \\
& P_{n+1}=\sum_{i=1}^{n} P_{i}^{\mathrm{D}} a_{i, n+1}+\sum_{i=1}^{n} \bar{P}_{i}^{\mathrm{DI}} \bar{m}_{i, n+1} \\
& \bar{P}_{i}^{\mathrm{DI}}=\alpha_{i} \bar{\theta}_{i \mathrm{r}} V_{\mathrm{r}} \bar{P}_{i \mathrm{r}}^{\mathrm{WI}}+\left(1-\alpha_{i}\right) \bar{\theta}_{i \mathrm{~d}} V_{\mathrm{d}} \bar{P}_{i \mathrm{~d}}^{\mathrm{WI}} \quad(i=1,2, \ldots, n) \\
& P_{j}=\left(\sum_{i=1}^{n} P_{i}^{\mathrm{D}} a_{i j}+\sum_{i=1}^{n} \bar{P}_{i}^{\mathrm{DI}} \bar{m}_{i j}+S_{j}\right)\left(1+\pi_{j}\right)\left(1+\tau_{j}\right) \\
& P_{i}^{\mathrm{D}}=\frac{1}{1+m_{i \mathrm{~d}}+m_{i \mathrm{r}}} P_{i}+\frac{m_{i \mathrm{~d}}}{1+m_{i \mathrm{~d}}+m_{i \mathrm{r}}} \theta_{i \mathrm{~d}} V_{\mathrm{d}} P_{i \mathrm{~d}}^{\mathrm{WI}}+\frac{m_{i \mathrm{r}}}{1+m_{i \mathrm{~d}}+m_{i \mathrm{r}}} \theta_{i \mathrm{r}} V_{\mathrm{r}} P_{i \mathrm{r}}^{\mathrm{WI}} \\
& (i=1,2, \ldots, n)
\end{aligned}
$$

\section{ACKNOWLEDGMENTS}

I wish to thank all those at IIASA and in Hungary who read the first draft and for their useful comments. I am especially grateful to Lars Bergman, Urban Karlström, and András Pór for many discussions and their valuable suggestions, from which I benefited a great deal. I would also like to acknowledge with thanks the encouragement and constant interest of Andrei Rogers and Andrzej Wierzbicki.

\section{REFERENCES}

Adelman, I. and Robinson, S. (1978). Income Distribution Policy in Developing Countries: A Case Study of Korea. Stanford University Press, Stanford, California.

Bergman, L. (1978). Energy Policy in a Small Open Economy: The Case of Sweden. RR-78-16. International Institute for Applied Systems Analysis, Laxenburg, Austria. 
Bergman, L. (1980). A Model of Multisectoral Economic Growth in a Small Open Economy. Mimeograph. Stockholm School of Economics, Stockholm.

Bergman, L. and Pór, A. (1980). A Quantitative General Equilibrium Model of the Swedish Economy. WP-80-4. International Institute for Applied Systems Analysis, Laxenburg, Austria.

Berndt, E.R. (1976). Reconciling alternative estimates of the elasticity of substitution. Review of Economics and Statistics, February: 59-68.

Caddy, V. (1976). Empirical Estimation of the Elasticity of Substitution: A Review. WP-OP-09. IMPACT Project, Industries Assistance Commission, Melbourne.

de Melo, J. (1978). A Simulation of Development Strategies in an Economy-Wide Policy Model. Mimeograph. World Bank (IBRD), Washington, D.C.

Dervis, K. and Robinson, S. (1978). The Foreign Exchange Gap, Growth and Industrial Strategy in Turkey: 1973-1983. Working Paper No. 306. World Bank (IBRD), Washington, D.C.

Dixon, P.B., Parmenter, B.R., Ryland, G.J., and Sutton, J. (1977). ORANI, A General Equilibrium Model of the Australian Economy: Current Specification and lllustrations of Use for Policy Analysis. First Progress Report of the IMPACT Project, Vol. 2. Australian Government Publishing Service, Canberra.

Ginsburgh, V. and Waelbroeck, J. (1979). On the Design of Linear Programming Models for Open Economies. Mimeograph. University of Brussels, Brussels.

Johansen, L. (1959). A Multisectoral Study of Economic Growth. North-Holland Publishing Company, Amsterdam.

Johansen, L. (1972). Production Functions; An Integration of Micro and Macro, Short Run and Long Run Aspects. North-Holland Publishing Company, Amsterdam.

Karlström, U. (1980). Urbanization and Industrialization: Modeling Swedish Demoeconomic Development from 1870 to 1914. WP-80-54. International Institute for Applied Systems Analysis, Laxenburg, Austria.

Kelley, A.C. and Williamson, J.G. (1980). Modeling Urbanization and Economic Growth. RR-80-22. International Institute for Applied Systems Analysis, Laxenburg, Austria.

Kornai, J. (1971). Anti-Equilibrium. North-Holland Publishing Company, Amsterdam.

Kornai, J. (1974). Mathematical Planning of Structural Decisions. 2nd edn. North-Holland Publishing Company, Amsterdam.

McCarthy, F.D. and Taylor, L. (1980). Macro food policy planning: a general equilibrium model for Pakistan. Review of Economics and Statistics, February:107-121.

Rimmler, J., Dániel, Zs., and Kornai, J. (1972). Macrofunctions computed on the basis of plan models. Acta Oeconomica, 8:375-406.

Rogers, A. (1977). Migration, Urbanization, Resources, and Development. RR-77-14. International Institute for Applied Systems Analysis, Laxenburg, Austria.

Sanderson, W.C. (1980). Economic-Demographic Simulation Models: A Review of Their Usefulness for Policy Analysis. RR-80-14. International Institute for Applied Systems Analysis, Laxenburg, Austria.

Taylor, L. (1975). Theoretical foundations and technical implications. In C.R. Blitzer, P.C. Clark, and L. Taylor (Editors), Economy-Wide Models and Development Planning. Oxford University Press, Oxford.

Wierzbicki, A. (1979). The Use of Reference Objectives in Multiobjective Optimization: Theoretical Implications and Practical Experience. WP-79-66. International Institute for Applied Systems Analysis, Laxenburg, Austria. 


\section{Part Three}

The Application of General Equilibrium Models to the

Problems of Development of Market Economies 



\title{
A MODEL OF MULTISECTORAL ECONOMIC GROWTH IN A SMALL OPEN ECONOMY
}

\author{
Lars Bergman \\ Stockholm School of Economics, Stockholm (Sweden)
}

\section{INTRODUCTION}

In this study a computable model of medium-term, multisectoral economic growth in a small, open economy is presented. The model is specified in accordance with basic notions of general equilibrium theory; supply and demand factors interact, and product and factor prices are assumed to be flexible enough to ensure equilibrium in all markets. However, the supply side is considerably more detailed than the demand side. Thus, in each production sector different vintages of capital are distinguished, and the substitutability of capital, labor, and different kinds of energy is modeled in some detail. In particular, a distinction is made between ex ante and ex post substitutability. On the other hand, factors such as the formation of disposable incomes and the determination of savings are treated in a rather crude way.

The general modeling approach is to emphasize the structure of the model as a whole rather than individual relations. Moreover, with two exceptions* the st ructural equations of the model are derived from explicit production and preference functions together with optimization behavior assumptions rather than from econometric analyses of the past behavior of the economy. Thus, in this study, economic theory is used in a more deterministic way than is usual in econometric model building. Accordingly, the present model is primarily a tool for quantitative analysis within the conceptual framework suggested by general equilibrium theory and the theory of economic growth, and in general cannot be used for forecasting.

The origin of the modeling effort presented here is the work of Johansen in the late 1950s (Johansen, 1960). However, Johansen's original so-called MSG model was essentially a general equilibrium model of a closed economy; net exports entered as exogenously-determined final demand components and complementary imports were proportional to domestic production. This property has been retained in later Norwegian versions of the MSG model.

\footnotetext{
* These exceptions are the determination of the gross savings ratio and the sectoral allocation of investment.
} 
The first Swedish MSG model (Restad, 1976) incorporated a current account constraint. On the basis of that constraint, fixed import shares in the domestic production sectors, and a given composition of total exports, the "export requirements" were calculated. The compatibility of these "export requirements" and world market demand conditions was then analyzed outside the model. In a later Swedish MSG model, developed by the author (Bergman, 1978; Bergman and Pór, 1980), explicit price-dependent export and import functions were incorporated. Thus, both the supply side and the demand side of the "rest of the world" were taken into account.

However, although these models describe small, open economies, neither of them incorporates foreign trade in a theoretically satisfactory way. According to the conventional notion of a "small, open economy", the prices of traded goods should be determined by, and be equal to, world market prices. In the long run, factor prices and the structure of the production system prevailing in the small economy have to adjust in order to maintain equilibrium between world market prices and domestic production costs. This feature of multisectoral economic growth in open economies is, to a varying extent, lacking in the MSG models mentioned above. This study is an attempt to incorporate foreign trade in the MSG model in a way which is consistent both with the notion of a "small, open economy"," and with observations on the actual specialization pattern in the economy.

It is well known that a multisectoral growth model of an open economy with two homogeneous primary factors of production, linearly homogeneous production functions, and parametric world market prices, i.e. a model based on the standard assumptions of the Heckscher-Ohlin model, fails to generate realistic development paths. Thus, while there are, at most, two producing and exporting sectors in the trade-exposed part of the equilibrium model economy (or, in general, $m$ producing sectors if there are $m$ homogeneous factors of production (Samuelson, 1953)), real-world economies exhibit a rather incomplete specialization pattern in the production system. Moreover, in the model economy, traded goods of a given type are either domestically produced and exported, or are imported, while there is a considerable amount of intra-industry trade even within rather disaggregated real-world production sectors.

Of course there are several ways in which the basic assumptions of the HeckscherOhlin model can be changed in order to achieve equilibrium allocations with several producing sectors in the trade-exposed part of the economy, as well as with intra-industry trade. The approach adopted here is to stay within the general equilibrium framework, but to add two factors of significant importance in a medium-term perspective. These are the immobility of the existing capital stock, and the heterogeneity of products of the same type, ${ }^{* *}$ but with different countries of origin. The "small, open economy" assumptions are retained in the sense that the model economy is assumed to face a perfectly elastic supply of imports. Moreover, it is assumed that the development of productionless-export in the rest of the world can be treated as an exogenous magnitude in spite of the fact that imports to the home country are exports from the rest of the world.

Explicit recognition of the immobility of the existing capital stock affects the assumptions about supply conditions in the Heckscher-Ohlin model; a distinction has to

\footnotetext{
* For a different approach, see Norman and Wergeland (1977).

** By "type" is simply meant the number of some commodity classification system such as the SITC.
} 
be made between production functions ex ante and ex post. If the ex ante supply conditions are represented by a linearly homogeneous neoclassical production function in capital and labor, and capital becomes an immobile resource once it is invested, the ex post production function will exhibit decreasing returns to scale in the only variable factor, labor. Accordingly, unit production costs will be a function of the level of output, and a given production sector can always maintain international competitiveness by a suitable change in the scale of operation. Consequently, complete specialization is avoided.

Explicit distinction between products of the same type but with different countries of origin, together with the assumption that these products are not necessarily perfect substitutes, implies that consumers both at home and abroad will demand both imported and domestically-produced products of the same type. Consequently there can be both import and export of each type of tradable goods in equilibrium.

This approach to the treatment of the intra-industry trade phenomenon was initially proposed by Armington (1969) and has subsequently been employed in several numerical general equilibrium models. ${ }^{*}$ It should perhaps be noted that when the elasticity of substitution between imported and domestically-produced units is finite, the "Armington assumption" implies that each trading sector in each country produces a unique product. Thus, even if the production functions are linearly homogeneous in the variable inputs, the relation mentioned above (between the number of homogeneous factors of production and the number of producing sectors in equilibrium) does not hold when the Armington assumption is adopted. Moreover, the prices of domesticallyproduced commodities can differ from the world market prices of commodities of the same type.

However, it should be noted that the Armington assumption does not, as such, imply any specific substitutability between import and domestic production. If the elasticity of substitution between the two sources of supply is infinite, imports and domestically-produced commodities with the same classification are in fact perfect substitutes. This means that the "law of one price" will apply in equilibrium, and that the Armington assumption does not a priori impose a certain specialization pattern in the economy.

There are two basic differences between a model specified in accordance with the Heckscher-Ohlin theory and one incorporating the Armington assumption. The first is that in the former, the small country is assumed to produce perfect substitutes for commodities produced abroad, whereas the substitutability of imports and domesticallyproduced goods is an empirical issue in the latter. Available empirical evidence suggests that medium-term elasticities of substitution are high but far from infinite in most small countries.

The second basic difference between the two types of modeling approaches is that in the Heckscher-Ohlin model the producers in the small country can sell any quantity they wish on the world market at the prevailing world market price. The Armington assumption implies that even if the elasticities of substitution are infinite, the quantity of exports from the small country is constrained by the size of the world market.

\footnotetext{
* See for instance de Melo (1978), Whalley (1982), and Carrin et al. (1982). For some econometric evidence, see Frenger (1980).
} 


\section{THE MODEL}

A full description of the model and its solution algorithm is given in Bergman (1982). Here we only indicate the general features of the model, emphasizing the treatment of energy, investments, and expectations formation.

The model can be subdivided into three types of markets: a set of commodity markets, one labor market, and a capital market. The treatment of the labor and capital markets is very crude, while the treatment of the commodity markets is rather more detailed. Moreover, in this part of the model, the supply side is more detailed than the demand side. On most commodity markets supply consists both of imports and domestically-produced units. However, on a few markets the entire supply is imported, while the entire supply on a few other markets is domestically produced.* The supply of imports is assumed to be completely elastic at the exogenously given world market prices. There are $n$ production sectors (including the public sector) in the model economy, and each sector is assumed to consist of a large number of production units. The domestic producers are assumed to face a linearly homogeneous neoclassical ex ante production function in capital, $K_{j}$, labor, $N_{j}$, and intermediate inputs, $X_{i j}$. The ex ante production function is subject to embodied technological change. Thus, the ex ante technology can be summarized by

$$
X_{j}=F_{j}\left(K_{j}, N_{j}, X_{0 j}, X_{1 j}, \ldots, X_{n j} ; \nu\right) \quad(\forall j)
$$

where $X_{j}$ is gross output in sector $j$, and $\nu$ is a vintage index. There is no joint production, and each product is produced in one sector only.

The requirements of nonenergy intermediate inputs are proportional to gross output and equal for all vintages. Accordingly eqn. (1) can be written

$$
\begin{aligned}
& X_{j}=f_{j}\left(K_{j}, N_{j}, X_{0 j}, X_{1 j} ; \nu\right) \quad(\forall j) \\
& X_{i j}=a_{i j} X_{j} \quad(i=2,3, \ldots, n ; \forall j)
\end{aligned}
$$

where $X_{0 j}$ and $X_{1 j}$ are the inputs of fuels and electricity, respectively, while $a_{i j}$ are constant input-output coefficients for other intermediate inputs, and products are denoted by the index $i$.

The ex post production functions corresponding to eqns. (2) and (3) can be written

$$
X_{j}=f_{j}\left(I_{j}(\nu, t), N_{j}, h_{0 \nu j} X_{j}, h_{1 \nu j} X_{j} ; \nu, t\right) \equiv g_{\nu j}\left(N_{j} ; t\right)
$$

where $I_{j}(\nu, t)$ is the gross investment in sector $j$ in time period $\nu$, not yet depreciated in period $t$, while $h_{0 v j}$ and $h_{1 v j}$ are constant energy input coefficients. Thus, on the ex ante side, capital, as well as fuels and electricity, is a variable factor of production, while all

\footnotetext{
* Thus we can distinguish three sets of commodities in the model economy:

$C^{1}=$ commodities which are both imported and domestically produced;

$C^{2}=$ commodities which are imported only;

$C^{3}=$ commodities which are domestically produced only.
} 
energy input coefficients are fixed ex post. Capital becomes a sector-and vintage-specific resource, subject to depreciation at a constant rate, once it is invested. Moreover, in terms of the use of intermediate inputs, different vintages in a given sector differ only with respect to the energy input coefficients. It should also be noted that the ex ante production functions vary with time due to technical change, while the ex post production functions change due to depreciation of the capital invested in period $\nu$.

On the basis of eqn. (4) and an assumption about profit maximization behavior, total output is allocated over vintages so that the marginal cost of production becomes equal to the market price in all sectors. Thus it is possible to derive a set of product supply functions, $X_{i}^{\mathrm{S}}(t)$, as well as a labor demand function, $N^{\mathrm{D}}(t)$, for each time period, $t$. That is

$$
\begin{aligned}
& X_{i}^{\mathbf{S}}(t)=X_{i}^{\mathbf{S}}(P(t), W(t) ; t) \quad\left(i \in C^{1} \cup C^{3}\right) \\
& N^{\mathbf{D}}(t)=N^{\mathbf{D}}(P(t), W(t) ; t)
\end{aligned}
$$

where $P(t)$ is the vector of prices of domestically-produced products and $W(t)$ is the wage rate. It should be noted that there is only one type of labor in the model economy. The real-world heterogeneity of the labor force is roughly taken into account by means of an exogenous sectoral wage structure.

The supply of labor is assumed to be completely inelastic. Thus it only remains to specify the product demand functions. In accordance with the discussion in the introductory section, a distinction is made between domestically-produced and imported units of product $i$. This approach, which is due to Armington (1969), implies that there is a preference function defining the substitutability of imported and domestically-produced units of product $i$. This preference function is assumed to be linearly homogeneous and can be written

$$
\phi_{i}=\phi_{i}\left(X_{i}, M_{i}\right) \quad\left(i \in C^{1}\right)
$$

where $X_{i}$ represent the domestically-produced units and $M_{i}$ the imported units. The assumption about linear homogeneity implies that the proportions of imports and domestic production for a product $i$ are independent of the total demand. Thus the costminimizing composition of $\phi_{i}$ is a function of the ratio between the domestic and the world market prices only.

The basic demand assumption is that the function $\phi_{i}$ applies to all domestic users of the product (imported or domestic), $i$. Thus, in the production sectors the costminimizing composition for $i$ is determined as a part of the profit-maximization process. In the same way the cost-minimizing composition is determined as a part of the utilitymaximization process in the household sector. ${ }^{*}$ Since all users face the same prices on domestically-produced goods and imported goods, respectively, all users will end up with the same composition of each one of the composite goods.

As the world market prices are assumed to be given, and are independent of the

\footnotetext{
* This requires that the utility function of the household sector, as well as the ex post production functions, is separable in $\phi_{i}$.
} 
quantity of imports, the domestic demand for domestically-produced goods, $X_{i}^{\mathbf{D}}(t)$, is a function of domestic product prices and the domestic wage level only. Moreover, the domestic demand for imports, $M_{i}^{\mathrm{D}}(t)$, is a function of the same set of variables. Thus we can write

$$
\begin{array}{ll}
X_{i}^{\mathrm{D}}(t)=X_{i}^{\mathrm{D}}(P(t), W(t) ; t) & \left(i \in C^{1} \cup C^{3}\right) \\
M_{i}^{\mathrm{D}}(t)=M_{i}^{\mathrm{D}}\left(P_{i}(t), W(t) ; t\right) & \left(i \in C^{1} \cup C^{2}\right)
\end{array}
$$

By assuming that the Armington assumption can be applied to the rest of the world as well, and that the prices and production levels in the rest of the world are essentially unaffected by the home country's exports, the export demand can be expressed as a function of domestic product prices only, i.e.

$$
Z_{i}(t)=Z_{i}\left(P_{i}(t) ; t\right)
$$

It is assumed that there is a single aggregated capital good in the model economy, which implies that the demand for composite product $i$ for investment purposes, $I_{i \mathrm{I}}(t)$, can be written

$$
I_{i \mathrm{I}}(t)=a_{i \mathrm{I}} I(t)
$$

and treated as a part of the intermediate demand for composite product $i$.

Total investment expenditures, $P_{\mathrm{I}}(t) I(t)$, where $P_{\mathrm{I}}(t)$ is a convex combination of the components of $P(t)$, are assumed to be equal to the sum of gross domestic savings and the deficit on current account, $D(t)$. Moreover, it is assumed that a constant fraction, $s$, of gross national income, $Y(t)$, is saved. The gross national income can be expressed as a function of product prices and the wage level, i.e.

$$
Y(t)=Y(P(t), W(t), t)
$$

With this background the equilibrium conditions for period $t$ can be summarized in four equations, two for the product markets, one for the labor market, and one for the capital market.

$$
\begin{aligned}
& X_{i}^{\mathrm{S}}(P(t), W(t) ; t)=X_{i}^{\mathrm{D}}(P(t), W(t) ; t)+Z_{i}\left(P_{i}(t)\right) \quad\left(i \in C^{1} \cup C^{3}\right) \\
& M_{i}(t)=M_{i}^{\mathrm{D}}(P(t), W(t) ; t) \quad\left(i \in C^{1} \cup C^{2}\right) \\
& N^{\mathrm{S}}(t)=N^{\mathrm{D}}(P(t), W(t) ; t) \\
& s Y(P(t), W(t) ; t)-D(t)=P_{\mathrm{I}}(P(t) I(t))
\end{aligned}
$$

On the basis of these four equations, equilibrium values for $P_{i}(t), W(t), M_{i}(t)$, and $I(t)$ can be determined. The specification of the savings function implies that an equilibrium in the model economy implies balance of payments equilibrium. However, in order to 
define the production possibilities in period $t+1$, the total investments in period $t$ have to be allocated between the sectors, and the technological coefficients of the new plants have to be determined.

The determination of sectoral investments in the model is very straightforward. On the basis of expected product prices and the expected wage rate, as well as the ex ante production function, producers calculate the rate of return on capital in an optimallydesigned plant. If the rate of return thus determined is larger than or equal to the market rate of interest, they invest. Otherwise they do not invest. Thus, the expectations about future development of demand and total capacity in the production sectors affect investment decisions indirectly through the formation of price expectations.

In order to model this investment behavior the ex ante unit cost function corresponding to eqns. (2) and (3) is utilized. Since the ex ante technology exhibits constant retums to scale, the ex ante unit cost is independent of the scale of operation.

$$
\hat{\kappa}_{j}(t)=\hat{\kappa}_{j}^{*}\left(\hat{Q}_{j}(t), \hat{W}_{j}(t), \hat{P}_{0}(t), \hat{P}_{1}(t)\right)+\sum_{i=2}^{n} \hat{P}_{i}(t) a_{i j}
$$

where $\hat{\kappa}_{j}$ is the expected unit cost and $\hat{\kappa}_{j}^{*}$ is the net unit cost, i.e. the expected cost of capital, labor, fuels, and electricity per unit of output, while the last term represents the cost of nonenergy intermediate inputs. The net unit cost $\hat{\kappa}_{j}^{*}$ is a function of the expected prices of capital, labor, fuels, and electricity, which can be derived from eqn. (2) by assuming cost-minimization behavior. The expected "price" of capital is defined by

$$
\hat{Q}_{j}(t)=\hat{P}_{\mathrm{I}}(t)\left(r_{t j}^{\mathrm{b}}+\delta_{j}\right) \quad(\forall j)
$$

where $r_{t j}^{\mathrm{b}}$ is the expected rate of profit in an optimally-designed plant of vintage $t$, and $\delta_{j}$ is the rate of depreciation.

It is now assumed that the investors are interested in the properties of an optimallydesigned plant with a unit production cost equal to the expected product price, i.e. a plant for which the following relation holds

$$
\hat{P}_{j}(t)-\sum_{i=2}^{n} \hat{P}_{i}(t) a_{i j}=\hat{\kappa}_{j}^{*}\left(\hat{Q}_{j}(t), w_{j}(t), \hat{P}_{0}(t), \hat{P}_{1}(t)\right) \quad(\forall j)
$$

With given expectations about product prices and the wage rate, the maximum rate of profit, $r_{j}^{\mathrm{b}}$, is determined by eqn. (15). Moreover, once $r_{t j}^{\mathrm{b}}$ is determined, the technical coefficients of an optimally-designed plant are given by the net unit cost function together with Shepard's Lemma. Thus the technical properties of the plants which can be taken into operation in period $t+1$ are determined by eqn. (15). It remains to determine the amount of new capacity in the different sectors in period $t+1$. In accordance with the discussion above this part of the model can be summarized in two equations.

$$
I_{j}(t)=\left\{\begin{array}{lll}
I_{j}\left(\frac{r_{j}^{\mathrm{b}}}{r}\right) & \text { if } & r_{t j}^{\mathrm{b}} \geqslant r(t) \\
0 & \text { if } & r_{t j}^{\mathrm{b}}<r(t)
\end{array}\right.
$$




$$
I(t)=\sum_{j=0}^{n} I_{j}(t)
$$

where $r(t)$ is the market interest rate that brings about equality between the supply and demand for investable funds.

The set of expected prices and wages employed in the expressions above is not the result of a specific expectation formation mechanism in the model. Instead the model is designed in such a way that the user of the model can control price expectation formation. Thus, the vector of expected prices is determined by

$$
\hat{P}=\zeta P(t)+(1-\zeta) P^{\mathrm{F}}
$$

where $P^{\mathrm{F}}$ is an exogenously given vector of prices and $\zeta$ is an exogenously given vector of weights. The expected wage rates are determined in a parallel way. The price vector $P^{F}$ can be regarded as a weighted average of past prices, but it can also be regarded as an official price prediction. If $\zeta=1$ investors have static expectations, while the nature of the expectations depends on the interpretations of $P^{\mathrm{F}}$ when $\zeta<1$.

In order to implement the model numerically the functional forms have to be specified. Of course the choice of functional forms should be made, at least partly, on the basis of statistical goodness-of-fit criteria. However, during the development of the model and its solution algorithm, not much time was spent on econometrics. Thus, functional forms which seemed reasonable on a priori grounds, and where the parameters have an obvious economic interpretation, were chosen. The result of this process is a set of functions where the parameters can be interpreted as price, expenditure, or output elasticities or as elasticities of substitution.

The ex ante production functions, i.e. eqns. (2) and (3), are nested CES-CobbDouglas production functions. Thus, capital and labor are combined into a Cobb-Douglas aggregate of primary inputs, while fuels and electricity are combined into a CES aggregate of energy. Then these two types of composite in puts are combined in a CES production function.

The functions $\phi_{i}$ in eqn. (7) are specified as CES functions. The functional form of the sectoral investment functions, eqn. (16), is as follows:

$$
I_{j}(t)= \begin{cases}k_{t j}^{\mathrm{b}} \delta_{j} X_{j}(t)\left(\frac{r_{t j}^{\mathrm{b}}}{r(t)}\right)^{\varphi_{j}(t)} & \text { if } \quad r_{t j}^{\mathrm{b}} \geqslant r(t) \\ 0 & \text { if } \quad r_{t j}^{\mathrm{b}}<r(t)\end{cases}
$$

where $k_{t j}^{b}$ is the capital-output ratio in an optimally-designed plant of vintage $t, \delta_{j}$ is the rate of depreciation, and $X_{j}(t)$ is total production in sector $j$ in period $t$. The product $\delta_{j} X_{j}(t)$ can be taken as a measure of the amount of output capacity that is worn out between period $t$ and period $t+1$. Multiplication by $k_{t j}^{\mathrm{b}}$ then yields the capital requirement for maintaining the capacity in sector $j$. Thus, according to this specification, the producers in a sector replace their old plants only as long as the expected rate of profit is at least equal to the market rate of interest. If the expected rate of profit is higher than 
the market interest rate, new producers will be attracted to the sector. The "attractiveness" of the sector is given by the parameter $\varphi_{j}(t)$.

The model has been implemented with Swedish data. The basic data source is an input-output table for 1975, aggregated to 17 sectors. Moreover, results from several econometric studies have been used for the numerical specification of various functions. The resulting data base is reasonable and certainly reflects important properties of the Swedish economy. However, a lot of work remains to be done on that part of the model, and results currently obtained from the model should be taken as quantitative illustrations of economic principles rather than predictions of the real world.

\section{SOME PRELIMINARY RESULTS}

In order to provide a "feeling" of how the model works, some preliminary results are presented in this section. The most interesting issue is then the performance of the investment part of the model, i.e. eqn. (19). This is because the relations in this part cannot directly be derived from the solution of a constrained-optimization problem in contrast to all the other behavioral equations in the model. Thus, the sectoral investment functions are not based on economic theory in the same way as are other equations in the model.

A reasonable test of the investment functions is to check whether they allocate total investments over sectors in such a way that the economy approaches a long-run equilibrium, i.e. in such a way that all intersectoral profit differentials are gradually reduced and finally eliminated. Since there were significant imbalances in the Swedish economy in 1975, the model's data base is well suited for a test of this issue.

In the test the model was used for a simulation of the period 1976-1990, and, in order to focus on the performance of the investment mechanism, it was assumed that no changes in world market relative prices took place during the period in question, and that the rate of embodied technical change was the same in all sectors. The test variable was the variance of $r_{t j}^{\mathrm{b}}$, i.e. $\operatorname{Var}\left(r_{t j}^{\mathrm{b}}\right)$.

Since investments in the public sector were assumed to be exogenously determined, that sector was excluded from the test. The results were as follows: for 1975 the variance of the expected rates of profit, $\operatorname{Var}\left(r_{t j}^{b}\right)$, measured in percentage units, was 9.5 . The corresponding value for 1990 was 16.9 , i.e. a quite discouragingly high result. However, a substantial part of the variance was due to one particular sector, the construction industry. If that sector was excluded, the variance for 1975 remained at 9.5 , but fell to only 4.2 for 1990 . Thus, in this case there was a strong convergence in terms of ex ante profit rates.

The reason for the bad performance of the construction industry was the relatively high rate of depreciation in that sector, $6.5 \%$ compared with an average of below $3 \%$, plus the fact that the model was solved only for the middle year in five three-year periods. Thus, solutions were obtained for the years 1975, 1978, 1981, 1984, 1987, and 1990. This means that in each of these periods three years of savings were allocated over the sectors, and there were three years of depreciation between each year of investment. In the initial year, 1975, there was an overcapacity in the construction sector, and the expected profit rate was consequently lower than the market interest rate. Accordingly 
there were no investments in that sector. Three years later the capacity had been significantly reduced due to depreciation, and the expected rate of profit went up significantly. As a result large investments were made, and too much new capacity was installed. This pattern was repeated over the projection period without tendencies towards convergence.

Thus, the model's investment mechanism works nicely in general, but for certain combinations of parameter values the opposite holds. In general, cyclical investment behavior tends to emerge if the parameters $\varphi_{j}(t)$ and $\delta_{j}$ in eqn. (19) have high values and the interval between the solution years is three years or more.

Another test of the model was to study the impact of a gradual oil price increase. In this case assumptions about exogenous variables were made essentially on the basis of various official predictions. However, again the results should be taken only as illustrations of the performance of the model.

In a baseline case it was assumed that the real price of oil was stable over time, while it was assumed to increase by $5 \%$ per annum in the other case. The possible impact of the oil price increase on world market conditions was disregarded. Moreover, expectations were assumed to be static, i.e. the parameters $\zeta$ in eqn. (18) were all set equal to unity. Some of the results are presented in Table 1.

TABLE 1 The calculated impact ${ }^{a}$ of an oil price increase on economic development, 1975-1990.

\begin{tabular}{lll}
\hline Parameter & Oil price & \\
\cline { 2 - 3 } & Constant & Increasing at 5\% per annum \\
\hline GNP & 2.4 & 2.2 \\
Consumption & 2.4 & 1.8 \\
lnvestments & 2.3 & 1.8 \\
Exports & 2.8 & 3.4 \\
Imports & 2.8 & 1.9 \\
Oil imports & 2.8 & 1.0 \\
Terms of trade & 0.1 & -1.3 \\
Wage rate & 3.3 & 2.4 \\
\hline
\end{tabular}

${ }^{a}$ Measured as the annual rate of change $(\%)$ for each parameter.

As a result of the oil price increase, import costs increase. Part of the impact can be accommodated by reduced consumption (and thus imports) of oil. This substitution away from oil is carried out through the introduction of new, more oil-efficient techniques of production, through changes in the sectoral structure of the production system, and through changes in the commodity composition of household consumption. Behind these changes are changes in relative prices; the terms of trade deteriorate partly as a result of higher oil prices, partly as a result of lower export prices; the lower export prices, a necessary condition for a larger net export volume in an "Armington" model, are made possible by a lower rate of increase of real wages.*

\footnotetext{
* In both cases real wages increase faster than GNP. The reason for this is essentially a gradual decline of the supply of labor, measured in man-hours.
} 
It is also interesting to demonstrate how the substitution away from oil on the sectoral level takes place in this model. As energy input coefficients are fixed ex post, no substitution can take place in existing plants. By introducing new "vintages" with lower oil input coefficients, however, the average oil input coefficients for the production sectors can be reduced. Thus, the price elasticity of oil demand is a function of the rate of capital accumulation, and increases, other things being equal, with the time horizon. In Table 2 the substitution process in one of the most energy-intensive sectors is illustrated.

TABLE 2 The calculated development of oil input coefficients ${ }^{a}$ in the cement industry, 1975-1990.

\begin{tabular}{lll}
\hline Year & \multicolumn{1}{c}{ Average for } & \\
\cline { 2 - 3 } & Whole sector & Newly-designed plants \\
\hline 1975 & 1.00 & 0.98 \\
1978 & 1.00 & 0.90 \\
1981 & 0.98 & 0.83 \\
1984 & 0.94 & 0.76 \\
1987 & 0.89 & 0.69 \\
1990 & 0.83 & 0.63 \\
Average annual change (\%) & -1.1 & -3.3 \\
\hline andex values, based on an overall sector average of 1.00 in 1975.
\end{tabular}

As the price of oil increases, oil becomes a progressively more important cost item. Consequently the assumed 5\% annual increase in the price of oil leads to an increasing impact on the choice of technology in new plants.

\section{CONCLUDING COMMENTS}

The further development of the model presented here will primarily be focused on its empirical basis. Thus some of the functional forms and several parameters will be revised. The intended fields of application are studies of the impact of changes in world market conditions and domestic energy policies.

\section{REFERENCES}

Armington, P.S. (1969). A theory of demand for products distinguished by place of production. IMF Staff Papers, Vol. 16.

Bergman, L. (1978). Energy Policy in a Small Open Economy: The Case of Sweden. RR-78-16. International Institute for Applied Systems Analysis, Laxenburg, Austria.

Bergman, L. (1982). A Model of Multisectoral Economic Growth in a Small Open Economy. Research Report, Economic Research Institute of the Stockholm School of Economics, Stockholm.

Bergman, L. and Pór, A. (1980). A Quantitative General Equilibrium Model of the Swedish Economy. WP-80-4. InternationaI Institute for Applied Systems Analysis, Laxenburg, Austria. 
Carrin, G., Gunning, J.W., and Waelbroeck, J. (1982). A general equilibrium model for the world economy: some preliminary results. In B.G. Hickman (Editor), Global International Economic Models. (Forthcoming.)

de Melo, J.A.P. (1978). Protection and resource allocation in a Walrasian trade model. International Economic Review, 19.

Frenger, P. (1980). Import Share Functions in Input-Output Analysis. Statistik Sentralbyrå, Rapporter 80/14, Oslo.

Johansen, L. (1960). A Multisectoral Study of Economic Growth. North-Holland, Amsterdam.

Norman, V. and Wergeland, T. (1977). TOLMOD - A Dual, General Equilibrium Model of the Norwegian Economy. Senter för Anvendt Forskning, Norges Handelshфjskole, Bergen.

Restad, T. (1976). Modeller för Samhällsekonomisk Perspektivplanering. Liber Förlag, Stockholm.

Samuelson, P.A. (1953). Prices of factors and goods in general equilibrium. Review of Economic Studies, 21:1-20.

Whalley, J. (1982). General equilibrium modeling of trade liberalization issues among major world trade blocs. In B.G. Hickman (Editor), Global International Economic Models. (Forthcoming.) 


\title{
THE AGRICULTURAL SECTOR OF ORANI 78: THEORY, DATA, AND APPLICATION
}

\author{
Peter B. Dixon \\ School of Economics, La Trobe University, Bundoora, Victoria 3038 \\ (Australia)
}

Brian R. Parmenter

Industries Assistance Commission, IMPACT Research Centre, Barry Street, Carlton, Victoria 3053 (Australia)

Alan A. Powell

University of Melbourne, Parkville, Victoria 3052 (Australia)

D.P. Vincent

Industries Assistance Commission, IMPACT Research Centre, Barry Street, Carlton, Victoria 3053 (Australia) and Institut für Weltwirtschaft, Kiel (FRG)

\section{INTRODUCTION}

This paper describes a respecification of the agricultural sector of ORANI, a multisectoral model of the Australian economy developed as part of the IMPACT Project. IMPACT is a Commonwealth Government interagency project in cooperation with the University of Melbourne, to facilitate the analysis of the impact of economic, demographic, and social changes on the structure of the Australian economy. For a comprehensive nontechnical description of the project, see Powell (1977). The first version of ORANI, hereafter referred to as ORANI 77, has been fully described by Dixon et al. (1977). The current version of the model, the subject of this paper, is referred to as ORANI 78.

Salient features of ORANI are its high degree of disaggregation and very firm basis in microeconomic theory. In recent years, increasing in terest has been shown by economists and policy makers in models of this general type. The economic disturbances of the early $1970 \mathrm{~s}$ - for example, the changes in the international monetary system, the sudden escalation in energy prices, and the dramatic increase in real wages - left many econometric models floundering. They were unable to provide useful simulations of the effects of the shocks or to give guidance on the appropriate policy responses. It became apparent that while many models can fit the available time-series data, it is only by close attention to theory that one can hope to create models capable of giving insights into the 
implications of disturbances which carry the economy away from previously-established historical trends.

In our modeling of the agricultural sector within ORANI two aspects are emphasized. First, we attempt to capture the interaction of the agricultural sector with the rest of the economy. Input-output linkages, both backward and forward, are one element of this interaction. Usually of more importance, however, is the effect on agriculture of general conditions within the economy. For example, to anticipate the application of ORANI presented later in the paper, the effect of tariff increases on general cost conditions (in particular wage costs) is the main way in which those increases impinge on agriculture. Specific input-output linkages, the extent to which agriculture uses tariff protected inputs, for instance, are of comparatively minor importance.

The second aspect of our modeling of agriculture which is emphasized concerns the internal structure of the sector. It is in this respect that the specification for ORANI 78 represents a significant improvement over that used in ORANI 77. The multiproduct basis of farm enterprises and regional differences in production technology are fundamental characteristics of Australian agriculture. Both of these are explicitly recognized in ORANI 78. With this improvement it is believed that the model is an appropriate vehicle for analyzing the effects of policy and/or naturally-occurring changes, not only on the agricultural sector as a whole, but also on the internal structure of the sector.

The remainder of the paper is organized as follows. In Section 2 we outline the theoretical structure of the ORANI model, discuss the alternative ways in which the model may be closed, and describe our computational approach. Section 3 contains a fairly detailed presentation of the theoretical specification and data base for the agricultural sector in ORANI 78. An application of the model incorporating the respecified agricultural sector is given in Section 4. The application is an analysis of the short-run effects of a general tariff increase. Brief concluding remarks appear in Section 5.

\section{A DESCRIPTION OF ORANI 78}

\subsection{Theoretical Structure}

ORANI is a large model with equations and variables numbering several million. The theoretical structure, however, is simple and orthodox. The main elements are represented in Tables 1-3.

In Table 1 a schematic version of the ORANI 78 equations is given. The variables are defined in Table 2 . The equations can be classified into five groups: (a) demands for commodities and primary factors, (b) commodity supply equations, (c) pricing equations which impose the condition of zero pure profits in all activities, (d) market clearing equations for commodities and primary factors, and (e) miscellaneous equations. This last group can be used to introduce institutional factors such as wage indexation and to define summary variables such as the consumer price index, the balance of trade, etc.

\subsubsection{Commodity and Factor Demands}

ORANI recognizes six categories of demand for commodities: intermediate input demands, demands for inputs to capital formation, household demands, export demands, 
TABLE 1 Schematic representation of ORANI 78: equations. ${ }^{a}$

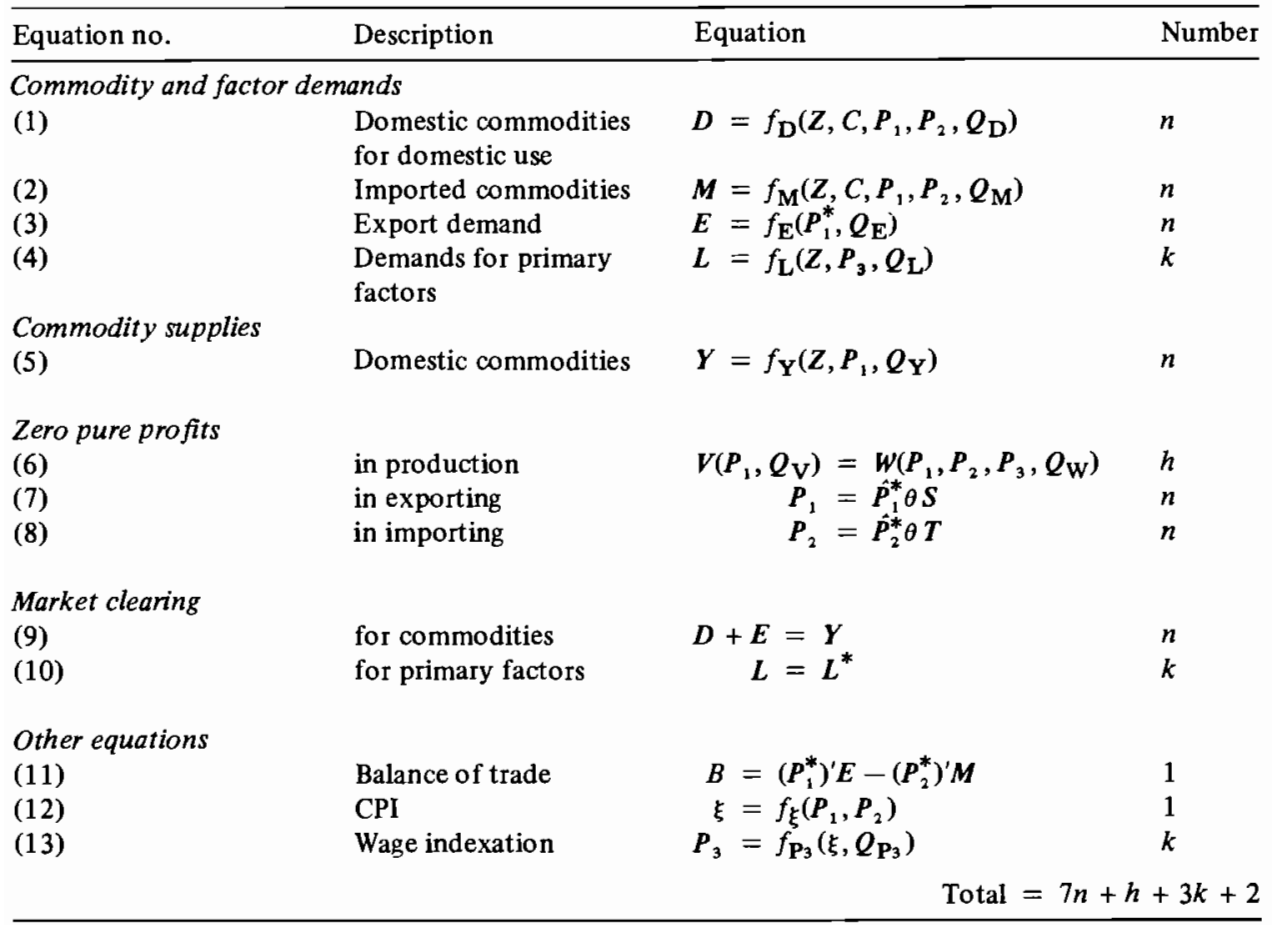

${ }^{a}$ The symbol " denotes a diagonal matrix.

demands for margins (e.g. transport, wholesale and retail services), and miscellaneous other demands (e.g. inventory and government demands). Equations (1) and ( 2 ) in Table 1 are an aggregation over the five domestic sources of demand for the $2 n$ commodities recognized in the model. Export demands are shown separately in eqn. (3).

The number of commodities is counted as $2 n$ rather than $n$ to emphasize that imports are treated as distinct from domestically-produced commodities. For example, imported footwear is treated as a different product from domestically-produced footwear, although the two are allowed to be good (but not perfect) substitutes for one another. Consequently, the vectors of prices $\left(\boldsymbol{P}_{1}\right.$ and $\left.\boldsymbol{P}_{2}\right)$ of both domestic and imported commodities appear as arguments in the demand functions for both domestic and imported commodities. An increase in the price of imported footwear will affect the demand for both types of footwear by generating substitution towards the domestic product. The treatment of import/domestic substitution follows that of Armington (1969, 1970). See also Artus and Rhomberg (1973), Dixon (1976), and Dervis (1980).

By handling imported and domestic commodities as imperfect substitutes, the unsatisfactory consequences of either of the two extremes frequently found in modeling exercises are avoided. On the one hand, the assumption of perfect substitutability, which is implied when, for example, imported footwear and domestic footwear are treated as a single product, is inconsistent with the commonplace empirical observation that prices 
TABLE 2 Schematic representation of ORANI 78: variables.

\begin{tabular}{llc}
\hline Variable & Description & Number \\
\hline$D$ & Demands for domestically-produced commodities & $n$ \\
$Z$ & Activity levels for each industry & $h$ \\
$C$ & Aggregate real absorption & 1 \\
$P_{1}$ & Local prices of domestic commodities & $n$ \\
$P_{2}$ & Local prices of imported commodities & $n$ \\
$M$ & Demands for imported commodities & $n$ \\
$E$ & Exports & $n$ \\
$P_{1}^{*}$ & Foreign currency prices for exports & $n$ \\
$P_{2}^{*}$ & Foreign currency prices for imports & $n$ \\
$L$ & Demands for primary factors & $k$ \\
$P_{3}$ & Prices for primary factors & $k$ \\
$Y$ & Commodity output levels & $n$ \\
$\theta$ & Exchange rate (\$A/\$Foreign) & 1 \\
$T$ & One plus ad valorem rates of protection & $n$ \\
$S$ & One plus ad valorem rates of export subsidy & $n$ \\
$L^{*}$ & Factor employment levels & $k$ \\
$B$ & Balance of trade (\$Foreign) & 1 \\
$\xi$ & Consumer price index & 1 \\
$Q_{\mathrm{P} 3}$ & Shift terms in factor price equations & $k$ \\
& & Total = \\
$Q_{\mathrm{D}}, Q_{\mathrm{M}}, Q_{\mathrm{E}}$, & Large number of variables designed to assist in the simulation of exogenous changes \\
$Q_{\mathrm{L}}, Q_{\mathrm{Y}}, Q_{\mathrm{V}}$, & in technology, export demands, household preferences, and indirect taxes \\
$Q_{\mathrm{W}}$ & & $h+4 k+4$ \\
\hline
\end{tabular}

TABLE 3 Schematic representation of ORANI 78: typical list of exogenous variables.

\begin{tabular}{|c|c|c|}
\hline Variable & Description & Number \\
\hline$P_{2}^{*}$ & Foreign currency prices for imports & $n$ \\
\hline$T$ & One plus ad valorem rates of protection & $n$ \\
\hline $\left.\begin{array}{l}L_{j}^{*}, j \in H_{1} \\
\left(Q_{\mathrm{P}_{3}}\right)_{j}, j \notin H_{1}\end{array}\right\}$ & A selection of factor employment levels and "real" factor prices & $k$ \\
\hline $\left.\begin{array}{l}S_{j, j \in H_{2}} \\
E_{j}, j \notin H_{2}\end{array}\right\}$ & A selection of export subsidies and export levels & $n$ \\
\hline$C$ & Aggregate real absorption & 1 \\
\hline$\theta$ & Exchange rate (\$A/\$Foreign) & 1 \\
\hline & Total & $+k+2$ \\
\hline $\left.\begin{array}{l}Q_{\mathrm{D}}, Q_{\mathrm{M}}, Q_{\mathrm{E}} \\
Q_{\mathrm{L}}, Q_{\mathrm{Y}}, Q_{\mathrm{V}} \\
Q_{\mathrm{W}}\end{array}\right\}$ & \multicolumn{2}{|c|}{$\begin{array}{l}\text { Large number of variables designed to assist in the simulation of exogenous changes } \\
\text { in technology, export demands, household preferences, and indirect taxes }\end{array}$} \\
\hline
\end{tabular}

of imported and domestic commodities can move independently of each other without causing the exclusion of either product from the market. At the other extreme, the quantity share of imports in each market is assumed to be fixed, i.e. imports are treated as non competitive. The implied assumption, that the elasticity of substitution between 
imported and domestic footwear is zero, is inconsistent with the observation that the quantity share of imported footwear in the domestic market responds to changes in the relative prices of the imported and domestic products.

Naturally, there is a cost in terms of parameter estimation involved in specifying imports and domestic commodities as imperfect substitutes. Ideally, substitution elasticities between each pair of domestic and imported products should be measured from the point of view of each of the five categories of domestic users. In practice, however, data limitations have forced us to assume that

$$
\sigma_{i}^{(l)}=\sigma_{i} \quad(\text { for all } l)
$$

where $\sigma_{i}^{(l)}$ is the elasticity of substitution between imported and domestic good $i$ from the point of view of user $l$. In defense of this assumption, it can be pointed out that most of Australia's major imports are used predominantly in only one end-use category. See Dixon et al. (1977, pp. 156-157). The $\sigma_{i}$ s have been estimated for about 30 of the more important import competing products in the input-output classification. These estimates have also been used to suggest plausible values for the remaining products where data problems have made direct estimation impossible. The data base and estimation of the $\sigma_{i}$ s are described briefly by Dixon et al. (1977, pp. 155-159). Complete details are in Alaouze (1976, 1977a, 1977b), Alaouze et al. (1977), and Marsden and Milkovits (1977).

Apart from commodity prices, the other arguments in ORANI's domestic-user commodity demand functions are activity variables and variables designed to allow simulation of the effects of technological changes and changes in tastes. In eqns. (1) and (2) these latter variables are represented by the vectors $Q_{\mathrm{D}}$ and $Q_{\mathrm{M}}$, while the activity variables are $Z$ and $C$.

The first of these activity variables, $Z$, is the vector of output levels for each of the model's $h$ industries. $Z$ appears in the ORANI equations explaining demands for intermediate inputs. Two points should be noted. First, the dimension of $Z$ is $h$ rather than $n$. ORANI 78 allows each industry to produce more than one product and each product to be produced by more than one industry. As explained in Section 3, it is particularly important in modeling Australia's agricultural sector to recognize both multiproduct industries and multi-industry supply possibilities for any one product. The second point is that the input demands by each industry are viewed as independent of the commodity composition of the industry's output. $Z_{j}$ appears in the input demand functions but not $Y_{i}(j)$, where $Y_{i}(j)$ is the output of the $i$ th commodity by the $j$ th industry. The assumption that input demands are industry- (but not product-) specific is discussed further in Section 3.

The second activity variable appearing in eqns. (1) and (2) is the level of real domestic absorption, $C$, i.e. public and private consumption and investment. Including a single scalar variable to reflect the levels of final demands by domestic users is a considerable simplification of the ORANI treatment. The ORANI equations allow commodity demands to respond to the distribution of aggregate absorption across households, the government, and capital formation by industry. For the present descriptive purposes, however, the single variable, $C$, will suffice.

By comparison with the functions describing commodity demands by domestic users, the ORANI export demand functions are very simple, taking the form 


$$
E_{i}=\left(P_{i}^{*}\right)^{-\gamma_{i}}\left(Q_{\mathrm{E}}\right)_{i} \quad(i=1,2, \ldots, n)
$$

where $E_{i}$ is the export volume for commodity $i, P_{i}^{*}$ is the foreign currency price of commodity $i, \gamma_{i}$ is the reciprocal of the foreign elasticity of demand, ${ }^{\dagger}$ and $\left(Q_{E}\right)_{i}$ is a variable allowing for shifts in the foreign-demand curves. For example, an upward movement in the foreign-demand curve for commodity $i$ would be simulated by an increase in $\left(Q_{E}\right)_{i}$. In eqn. (3) of Table 1, the export vector is shown with $n$ components. Only the $n$ domestically-produced commodities are exported, some, of course, being exported the zero level. The model allows no imported commodities to be exported without first being processed in a domestic industry.

The final set of demand equations in Table 1 is for primary factors, i.e. demands for labor, capital, and agricultural land. In ORANI 78 there are nine types of labor, 113 types of capital (one for each industry), and seven types of agricultural land. Thus $k=$ 129 , where $k$ is the dimension of the factor demand vector $L$. In eqn. (4) $L$ is explained by the industry activity levels $\boldsymbol{Z}$, the factor prices $\boldsymbol{P}_{\mathbf{3}}$, and a vector of technological change variables, $Q_{L}$. The fact that $Z$ is the only activity variable included in eqn. (4) reflects the ORANI assumption that the sole use of primary factors is in current production. The use of primary factors in capital creation, for example, is captured via primary factor inputs to the current production of the construction and machinery industries. The fact that $\boldsymbol{P}_{\mathbf{3}}$ is the only price variable included in eqn. (4) reflects the ORANI assumption that while primary factors can be substituted for each other, they cannot be substituted for intermediate inputs. For example, the steel industry can substitute capital for labor, but not capital for coal. This also explains the absence of factor prices in the commodity demand equations, (1) and (2).

\subsubsection{Commodity Supplies}

Equation (5) is an aggregation of the commodity output vectors across the $h$ industries. The vector of commodity outputs $(Y(j))$ by industry $j$ depends on $j$ 's activity level $Z_{j}$ and on commodity prices $\boldsymbol{P}_{\mathbf{1}}$. An increase in the price of wool relative to that of wheat will induce a change in the composition of $j$ 's production towards wool and away from wheat, i.e. there will be a movement around the product transformation frontier. In addition to activity levels and product prices, eqn. (5) also includes the vector $Q_{Y}$ which allows for shifts in transformation frontiers associated with technological changes.

As explained earlier, inputs are treated as being industry- rather than productspecific. This accounts for the absence of input prices in eqn. (5). Changes in input prices will affect industry $j$ 's activity level, $Z_{j}$, but will not influence the commodity composition of $j$ 's output once $Z_{j}$ is determined.

In earlier versions of ORANI (see Dixon et al., 1977) equations such as (5) were unnecessary. This is because the usual input-output convention was observed that each industry produces only one product and each product is produced by only one industry.

\footnotetext{
${ }^{\dagger}$ In the ORANI data base, foreign elasticities of demand for Australian products vary from 1.3 for wool to 20.0 for minor exports. These numbers were chosen in the light of the Australian shares in world commodity markets and fragmentary information concerning demand elasticities in importing countries and supply elasticities in competing export countries. See Freebairn (1978) and Dixon et al. (1977, pp. 172-173).
} 
In this case, industry activity levels can be identified with commodity output levels, i.e. there is no need to distinguish between the $Y$ and $Z$ vectors. The theory of ORANI 78 is written so that all industries may be treated as multiproduct industries. In practice, however, we have continued to model each nonagricultural commodity as though it is produced by a single, one-product industry. Thus, for the nonagricultural industries and commodities, eqn. (5) degenerates to

$$
Y_{j}=Z_{j}
$$

where $j$ is a nonagricultural commodity or industry.

\subsubsection{Zero Pure Profits}

The activities recognized in ORANI 78 are production (including the production of goods and services and the creation of units of capital), exporting, and importing. The zero pure profits condition for production implies that revenue per unit of activity in each industry equals costs per unit of activity. In ORANI 78, the production functions exhibit constant returns to scale. Therefore costs and revenue per unit of activity do not depend on the level of activity. Consequently, eqn. (6), which imposes the zero pure profits condition for production, can be written without reference to production levels. On the left is the $h \times 1$ vector of average revenues per unit of activity in each industry, expressed as functions of output prices and technological change variables. On the right is the $h \times 1$ vector of costs per unit of activity, expressed as functions of input prices and technological change variables.

It should be emphasized that eqn. (6) does not rule out profits; it does, however, rule out pure profits, i.e. profits not accruing to a factor of production. In models incorporating equations such as (6), variations in profits are simulated by variations in the rentals on fixed factors. Adverse events in industry $j$ will reduce the profitability of using capital in that industry, i.e. there will be reductions in the relevant input prices, namely the rentals on the fixed factors in industry $j$.

The second set of zero pure profit conditions (7) in Table 1 equates the revenue from exporting to the relevant costs. Thus on the right of (7) is the vector showing the values, in Australian dollars, of exporting units of each commodity. On the left is the cost of doing so, i.e. the domestic prices of each commodity.

The final set of zero pure profit conditions (8) equates the selling prices of imported commodities to the costs of importing. The costs of importing include the foreign currency cost converted to domestic currency and the tariff.

\subsubsection{Market Clearing}

Equation (9) equates demand and supply for domestically-produced commodities. Imports are not added to domestic production in determining total supplies, because commodities from foreign and domestic sources are treated as distinct commodities.

In eqn. (10), $L^{*}$ is the vector of factor employment levels. Thus eqn. (10) amounts to saying that employment demands $(L)$ are satisfied. Equation (10) does not necessarily impose full employment assumptions. Although $L^{*}$ could be set exogenously at full employment levels, an obvious alternative would be to set some or all factor prices exogenously and to let the model determine the corresponding elements of $L^{*}$. Under this 
latter specification, the assumption would be that some factor markets are slack, i.e. supply constraints play no role in determining employment.

\subsubsection{Miscellaneous Equations}

The ORANI model contains many appended equations which are designed to facilitate applications. Table 1 gives three examples. Equations (11) and (12) define the balance of trade and the consumer price index. Equation (13) allows the introduction of different assumptions concerning wage indexation. For example, a typical equation in (13) is of the form

$$
\left(P_{3}\right)_{i}=(\xi)^{h_{i}}\left(Q_{\mathbf{P} 3}\right)_{i}
$$

If the parameter $h_{i}$ is set at 1 and the change in the variable $\left(Q_{\mathbf{P} 3}\right)_{i}$ is set at zero, then the wage of factor $i\left(\left(P_{3}\right)_{i}\right)$ will move with the consumer price index $(\xi)$, i.e. there will be $100 \%$ indexation of this factor price. Alternatively, $\left(Q_{\mathrm{P} 3}\right)_{i}$ can be treated as an endogenous variable. If $h_{i}$ continues to be set at 1 , then movements in $\left(Q_{\mathrm{P} 3}\right)_{i}$ are the endogenously determined shifts in the real wage of factor $i$.

\subsection{Model Closure}

It is assumed that all the variables $Q_{\mathrm{D}}, Q_{\mathrm{M}}, \ldots$, etc. listed at the bottom of Table 2 are set exogenously. However, this still leaves a surplus of $3 n+k+2$ in the number of variables compared with the number of equations, i.e. a further $3 n+k+2$ variables must be set exogenously. It is a feature of ORANI that the choice of exogenous variables is left to the model user. Table 3 gives one possible choice for the schematic model set out in Tables 1 and 2. It will be useful to work through Table 3, considering some alternative choices. Much of the flexibility of ORANI in policy applications arises from the user's ability to swap variables between the exogenous and endogenous categories.

The first group of exogenous variables given in Table 3 is the foreign currency prices of imports. ORANI contains no equations describing foreign supply conditions and therefore it is difficult to imagine a plausible experiment in which $\boldsymbol{P}_{2}^{*}$ would be endogenous. By placing $\boldsymbol{P}_{2}^{*}$ in the exogenous category, the "small country" assumption is adopted on the import side, i.e. world prices are independent of Australian demands. It also allows for the computation of answers to questions of the form: what were (or will be) the effects of past (or projected) changes in foreign import supply prices?

The second group of exogenous variables is the tariffs or tariff equivalents of quantitative restrictions. The tariffs are among the exogenous variables for any computation directed at the traditional effective protection question: which industries benefit and which lose from protection? Other questions might concern the effects of protection on employment and on the rate of inflation. Each of these questions could be analyzed under exogenously given changes in the $T$ vector. On the other hand, it is possible to conduct ORANI experiments in which some, or all, of the tariffs are endogenous. For example, we might wish to compute the level of protection which would be required to maintain current employment levels in footwear, say, in the face of exogenously given movements in foreign prices, domestic wages, and the exchange rate. For such a 
computation, footwear employment would replace the footwear tariff in the exogenous list.

The third set of variables in Table 3 is a selection of factor employment levels and real factor prices. One possibility would be to set all the employment levels exogenously, i.e. $H_{1}$ would include all factors. This would accommodate the full employment case. Another possibility is to define $H_{1}$ so that it excludes labor but includes other primary factors. This would be suitable for a short-run computation (i.e. one in which changes in capital stocks can be ignored) under slack labor-market conditions. A third possibility is to endogenize the employment levels for capital but to exogenize the employment levels for labor. This would be suitable for long-run projections where it would be assumed (a) that capital stocks in each industry adjust to levels at which they can earn rates of return in line with historical experience and (b) that business cycle conditions are consistent with historically-observed average levels of unemployment.

The fourth group of typical exogenous variables is a selection of export subsidies and export levels. The model user specifies the set $\mathrm{H}_{2}$ containing the labels of those commodities for which the model is to be allowed to explain exports. For all other commodities, i.e. $j \notin H_{2}$, exports are exogenous and the model produces the export subsidy (or tax) required to achieve the given export level. Certainly, the nonexported commodities, services, construction, etc. always appear in the list given by $j \notin H_{2}$. Their exports are set exogenously at zero. The resulting endogenously determined subsidy rates are quite artificial, but also harmless. (For example, referring to Table 1 it is evident that if $(S)_{j}$ is endogenous then it can simply be deleted from the model by deleting the $j$ th component of eqn. (7).) In most ORANI computations those commodities for which exports are more than $20 \%$ of total output have been included in $\mathrm{H}_{2}$. For these commodities, it is reasonable to assume that world prices $\left(\boldsymbol{P}_{1}^{*}\right)$ strongly influence domestic prices $\left(P_{1}\right)$. Notice in eqn. (7) that if $(S)_{j}$ is exogenous, then $\left(P_{1}\right)_{j}$ will tend to move with $\left(P_{1}^{*}\right)_{j}$. In contrast, if $(S)_{j}$ is endogenous, then $\left(P_{1}\right)_{j}$ will move independently of $\left(P_{1}^{*}\right)_{j}$. Movements in $\left(P_{1}^{*}\right)_{j}$ will be absorbed by offsetting movements in $(S)_{j}$.

The next exogenous variable is $C$, the real aggregate level of domestic absorption. By placing $C$ on the exogenous list an economic environment is set in which real aggregate demand is controllable independently of other variables appearing in Table 3 . The underlying assumption is that policy makers have available macro instruments, not explained in ORANI, by which they can influence $C$. Alternatively, model users might set $B$, the balance of trade, exogenously in place of $C$. In this case, ORANI would indicate the change in real domestic absorption which would need to accompany a tariff cut, for example, in order to maintain a target level for the balance of trade.

The last variable in Table 3 is the exchange rate, $\theta$, which acts as the numeraire, i.e. it determines the absolute price level. If wages are fully indexed and the exogenous variables are as in Table 3, then a $1 \%$ increase in the exchange rate produces zero effect on all real endogenous variables and a $1 \%$ increase in all domestic price and other nominal variables. Natural alternatives to $\theta$ as the numeraire include the average wage rate and the consumer price index. Johansen (1960) and Taylor and Black (1974) chose the average wage rate.

We conclude with one final comment on the partitioning of variables into the exogenous and endogenous categories. While the discussion of Table 3 indicates a wide variety of legitimate possibilities, it is not true that ORANI can be closed by the exogenous 
setting of just any set of variables of the appropriate number. For example, at least one monetary variable should be included in the exogenous list. If all domestic currency prices, the exchange rate, all wages, and all monetary aggregates are treated as endogenous, then the computations will fail, since there is nothing to determine the absolute price level. Similarly, some care is necessary to avoid inconsistencies. For example, if an attempt were made to set all four variables $\left(P_{1}\right)_{i},\left(P_{1}^{*}\right)_{i}, \theta$, and $(S)_{i}$ exogenously, then eqn. (7) would be violated. Although no formal theory can be offered to guide model users in their choice of exogenous variables, as a working rule, if a price appears on the exogenous list, then a corresponding quantity should be on the endogenous list and vice versa. If wages are exogenous, then employment will be endogenous; if subsidies are endogenous, then exports will be exogenous, and so on.

\subsection{Computational Approach}

The first step in computing ORANI solutions is to convert each of the structural equations (i.e. the equations illustrated by Table 1) into a linear, percentage-change form. This approach was first applied to the solution of large-scale, economy-wide models by Johansen (1974). Equation (1), for example, becomes

$$
d=\eta_{\mathrm{DZ}} z+\eta_{\mathrm{DC}} c+\eta_{\mathrm{DP} 1} p_{1}+\eta_{\mathrm{DP} 2} p_{2}+\eta_{\mathrm{DQD}} q_{\mathrm{D}}
$$

where $d, z$, etc. are vectors of percentage changes in the corresponding upper-case variables $D, Z$, etc. and $\eta_{\mathbf{D Z}}, \eta_{\mathbf{D C}}$, etc. are matrices of elasticities. The $i j$ th element of $\eta_{\mathbf{D Z}}$ is the elasticity of demand for the $i$ th domestic product with respect to the activity level in the $j$ th industry. The $i$ th element of $\eta_{\mathrm{DC}}$ is the elasticity of demand for the $i$ th domestic product with respect to changes in real absorption, etc. Once all the equations have been converted into a linear form, the model can be represented as

$$
\mathbf{A x}=0
$$

where $\mathbf{A}$ is an $r \times s$ matrix of elasticities, $\boldsymbol{x}$ is the $s \times 1$ vector of percentage changes in the model's variables, $r$ is the number of equations, and $s$ is the number of variables.

The second step is to choose $(s-r)$ exogenous variables. The economicimplications of this choice were discussed in the previous subsection. Here it is noted that the choice involves a partitioning of the $\mathbf{A}$ matrix and the $\boldsymbol{x}$ vector. Equation (16) is rewritten as

$$
\mathbf{A}_{1} \boldsymbol{x}_{1}+\mathbf{A}_{2} \boldsymbol{x}_{2}=0
$$

where $x_{1}$ is the $r \times 1$ vector of endogenous variables and $x_{2}$ is the $(s-r) \times 1$ vector of exogenous variables. Finally, the model is solved by

$$
x_{1}=-\mathbf{A}_{1}^{-1} \mathbf{A}_{2} x_{2}
$$

i.e. the percentage change in each endogenous variable is expressed as a linear function of the percentage changes in each of the exogenous variables. 
The alternative to solving models such as ORANI in this linear form is to apply some nonlinear solution algorithm to the structural equations, ${ }^{*}$ i.e. the equations summarized in Table 1 . The linear method, however, has considerable practical advantages. Firstly, it allows solution of a very large model. The major step is the inversion of the $\mathbf{A}_{\mathbf{1}}$ matrix. The power of modern computers is such that data limitations, rather than computing difficulties, are the effective constraint on the size of the model, provided that the solution procedure is linear. Note that the size of the $\mathbf{A}_{1}$ matrix to be inverted can always be reduced by algebraic elimination of endogenous variables. Values for the eliminated variables can be obtained, following solution, by back solving. Computational constraints are, on the other hand, generally a problem for those who prefer nonlinear methods. Whalley $(1978$, p. 2) indicates that this has been his experience. Such constraints have certainly been responsible for limiting the theoretical specification of IMPACT's SNAPSHOT model.

To the extent that computing limitations on model specification have been avoided by those using nonlinear methods (e.g. Adelman and Robinson, 1978, p. 11), this has only been achieved by the use of algorithms which are extremely model specific. The disadvantage of model-specific as opposed to general-purpose algorithms, especially for simple matrix manipulation, is that they greatly reduce the flexibility available to the model builder in modifying the model and to the model user in employing the model in alternative configurations. We have found that the implementation of model improvements is not especially difficult with our solution method. Sections of the A matrix of eqn. (16) can easily be respecified or the dimensions of the matrix changed without requiring substantial modification of the solution programs. This has allowed the implementation of a research strategy based first on perfecting a comparatively simple version of ORANI and subsequently introducing increased degrees of sophistication as resources permit. The developments incorporated into ORANI 78, which are the subject of this paper, are a good example.

Flexibility in model use is another key advantage of our solution method. In Section 2.2 it was indicated that, by the selection of alternative sets of exogenous variables, ORANI can be used to answer a wide variety of questions. The computational changes required for each new selection just depend on a new partition of the A matrix into the submatrices $A_{1}$ and $\mathbf{A}_{2}$ (see eqns. (16) and (17)). With nonlinear methods, this type of fiexibility can only be bought at the cost of much more fundamental changes to the solution routine.

The advantages of the linear solution method do, of course, have their own price. The price is that, for any thing but a very small change in the exogenous variables, the solution obtained is only an approximation to the true solution of the nonlinear system. The approximation results from the fact that the elements of the A matrix are treated as constants, whereas in fact they are sensitive (in varying degrees) to changes in the variables. Various cost and sales shares, for example, are incorporated into the A matrix. Where the prices of commodities which are identified as variables in the model are changing, then clearly the shares of these commodities in the total costs of using industries or in the total sales of producing industries are likely to change.

\footnotetext{
* Examples of large-scale modeling exercises which use nonlinear computational procedures are Adelman and Robinson (1978), Whalley (1978), and, in the context of IMPACT, the SNAPSHOT model - see Dixon et al. (1976).
} 
The size of the linear approximation errors is a matter for empirical determination. A solution arbitrarily close to the true solution of the nonlinear system can always be obtained using the linear method, by breaking the exogenous change under consideration into a sufficiently large number of small changes and computing a series of solutions for these small changes, updating the A matrix at each step. Research along these lines within IMPACT has so far indicated that, for a small model with the same degree of nonlinearity in its structural form as ORANI 78, the errors are not very serious. Moreover, they are regular, so that the true solution can be predicted very accurately after only a small number ( 2 or 3 ) of iterations of the step procedure (Dixon, 1979, section 5.3).

\section{THE AGRICULTURAL SECTOR OF ORANI 78}

In the previous section, the ease with which modifications can be made to the theoretical specification of parts of the model was advanced as a major advantage of the Johansen approach to solving general equilibrium models. In the development of ORANI, the practical research strategy of first perfecting a fairly simple version of the model has been followed. For example, in ORAN1 77 unique one-product production functions were specified for all commodities (Dixon et al., 1977, pp. 20-25). This section demonstrates that more complex assumptions about production technology can easily be grafted on to the basic model. It describes how the agricultural sector has been respecified for ORANI 78 in order to account for joint production, product-product transformation possibilities, and region-specific technology.

\subsection{Reasons for the Respecification of the Agricultural Sector}

\subsubsection{Importance of Agriculture in ORANI Results}

The results of simulations with ORANI generally emphasize the importance of analyzing policy issues in an open economy context. For example, in a recent analysis of alternative approaches to macroeconomic recovery (Dixon et al., 1978, 1979), it was shown that the impacts of policies aimed at reducing domestic costs and of policies to stimulate domestic demand are quite different in the trading as compared to the nontrading sectors. The agricultural industries are very prominent in this type of result because of their heavy export orientation. Similarly, the results of simulations presented by Dixon et al. (1977) show that the agricultural industries are amongst the most sensitive to changes in the economy's trading conditions. They are, for example, amongst the main gainers from a successful devaluation and amongst the main losers from a tariff increase which raises the domestic price level (Dix on et al., 1977, ch. 4). For this reason, accurate modeling of the production responses of the agricultural sector is of particular importance.

\subsubsection{Problems with the Specification of Agriculture in the Australian Input-Output Tables}

Industry structure in ORANI 77 is specified according to the Australian Bureau of Statistics (ABS) 1968/69 109 industry $\times$ industry input-output tables. In this data base six product groups are identified as agricultural "industries". They are: 

1. Sheep,
2. Cereal grains,
3. Meat cattle,
4. Milk cattle and pigs,
5. Poultry, and
6. Other farming.

With the exception of poultry production, however, these groupings do not conform to any identifiable production units. The Australian agricultural sector is, to a large extent, characterized by joint production. For example, nearly all the output of the cerealslivestock complex, i.e. wool, sheep, cattle, wheat, barley, and other cereal grains, is produced on multienterprise farms. An implication of the joint production characteristics of Australian agriculture is that input bundles cannot be apportioned uniquely to the production of individual products. The columns in the input-output (I-O) tables for the agricultural product group "industries" therefore reflect arbitrary cost allocations.

A second problem with the I-O treatment of the agricultural sector is that it masks regional differences in production technology which are, because of climatic and biological factors, extremely important in the Australian context. The regional cost of production surveys of the Bureau of Agricultural Economics (BAE) provide an ideal data base for the recognition of these factors.

A final, more specific problem concerns the "commodity" produced by the industry Other Farming, as defined by the ABS. Two of the major components included in this category are tobacco, which is import competing, and sugar, which is an export commodity. In a model like ORANI which emphasizes international trade, it is unsatisfactory to have both import competing and export components aggregated in a single commodity classification.

Because of the importance of the agricultural sector, substantial modification of the I-O data base has been undertaken for ORANI 78; see Vincent and Parmenter (1978) for details of the procedure used for this modification. The agricultural sector has been respecified as a 10 -commodity $\times 8$-industry system, which includes regional variation in production technology. In addition, modifications have been made to the theoretical structure of ORANI to allow the modeling of price-induced changes in product mixes within regional industries. The revised theoretical specification is outlined in Section 3.2, and details of the data base are given in Section 3.3.

\subsection{Theoretical Specification}

Equation (19) gives a general form for a multiproduct, multi-input production function for industry $j$ :

$$
H_{j}(Y(j), X(j))=0
$$

where $Y(j)$ is the $1 \times u$ vector of $j$ 's commodity outputs and $X(j)$ is the $1 \times v$ vector of inputs. Under (19) there are, at every point in the input-output space, $u v$ free elasticities $E_{i k}$, where $E_{i k}$ is the elasticity of output of product $i$ with respect to factor $k$, i.e. $E_{i k}$ 
measures the effect on $i$ of increasing $k$ while holding all other outputs and inputs constant. The number of free elasticities can be reduced to a more manageable level by adopting the special case of (19)

$$
Z_{j}=F_{j}(X(j))
$$

and

$$
Z_{j}=G_{j}(Y(j))
$$

In eqn. (20), $Z_{j}$ is a scalar. When (20) holds, the production technology is defined to be "separable between inputs and outputs" - see Hasenkamp (1976). Under (20) there are only $u+v$ free elasticities since $E_{i k}$ can now be written as

$$
E_{i k}=A_{i} B_{k} \quad(i=1,2, \ldots, u ; k=1,2, \ldots, v)
$$

where $A_{i}$ and $B_{k}$ are, respectively, the elasticity of $Y_{i}(j)$ with respect to $Z_{j}$ and the elasticity of $Z_{j}$ with respect to $X_{k}(j) . A_{i}$ is computed from (20b) by allowing $Z_{j}$ and $Y_{i}(j)$ to vary while fixing all the other elements of $Y(j) . B_{k}$ is obtained from (20a) by computing the effect of a change in $X_{k}(j)$ on the level of $Z_{j}$, with all the other elements of $X(j)$ constant.

The simplification (21) implies that if the elasticity of (say) wool production with respect to labor inputs is twice that of wheat production with respect to labor inputs, then the elasticity of wool production with respect to capital inputs is also twice that of wheat production with respect to capital inputs. This means that factors are completely nonspecific. If relative to wheat it is easier to expand wool output by applying more of factor 1 , then it is also easier to expand wool output by applying more of factor 2 . In summary, no factor has comparative advantage in increasing the output of any particular product.

It is clear that, in applications of models based on eqn. (20), the inputs $X_{k}(j)$ should be broadly defined, e.g. labor, capital, land, and intermediate inputs. Simplification (21) would not be appropriate if the factor list included, for example, contract shearing. Obviously, this input is quite specific to the particular output, wool. Fortunately, however, fully specific inputs, such as contract shearing, often have virtually zero substitution elasticity with respect to every other factor involved in the production of their specific output. For the firm's decision making, the costs of such factors can be deducted from the product price, i.e. treated as an excise tax. Other specific factors in this category are commission and freight charges involved in getting products to market. Likewise, these factors do not possess identifiable substitutes. Thus in adopting (20) the assumption is made implicitly that any factors which are product specific do not have substitutes or at least that product-specific factors with substitutes can be ignored.

A theoretical implication of adopting (20) is that an industry's input and output decisions can be treated separately. It is assumed that outputs are selected so as to 
maximize revenue $\left(\Sigma_{i=1}^{u} P_{i} Y_{i}(j)\right)$ subject to $(20 \mathrm{~b}) .{ }^{*}$ This yields supply response equations of the form

$$
Y_{i}(j)=g_{i j}\left(P_{1}, P_{2}, \ldots, P_{u}, Z_{j}\right)
$$

Inputs are assumed to be chosen to minimize costs $\left(\Sigma_{k=1}^{v} W_{k} X_{k}(j)\right)$ subject to (20a), yielding input demand functions of the form

$$
X_{k}(j)=f_{k j}\left(W_{1}, \ldots, w_{v}, Z_{j}\right)
$$

The form in which equations such as (23) appear in ORANI 78 is unchanged from the earlier version of the model. The $f_{k j}$ continue to reflect substitution possibilities between primary factors and between alternative sources (foreign and domestic) of intermediate inputs of the same commodity class (for details, see Dixon et al., 1977, sections 2 and 3). Supply response equations were unnecessary in the earlier version of the model because it contained only single-product industries. Equations like (22) appear, however, in ORANI 78 in percentage-change form as

$$
\begin{aligned}
& y_{i}(j)=\tilde{y}_{r}(j), \quad \text { where } i \text { is included in composite commodity } r \\
& \tilde{y}_{r}(j)=z_{j}+\phi_{r}(j)\left(p_{r}(j)-\sum_{q} R_{q}^{*}(j) p_{q}(j)\right), \quad \phi_{r}(j) \geqslant 0 \\
& p_{q}(j)=\sum_{t} H_{t \boldsymbol{q}}(j) p_{t}
\end{aligned}
$$

where the notation is explained below.

Equations (22)' were derived under the assumption that the function $G_{j}$ in eqn. (20b) has a CRETH ${ }^{* *}$ form. However, the arguments of the CRETH functions are composite commodities rather than individual products. Within each composite commodity, individual products were assumed to be produced in fixed proportions. For example, as explained in Section 3.3, it has been assumed that in the Pastoral Zone sheep-meat and wool are produced in fixed proportions, i.e. sheep/wool is a composite commodity for the Pastoral Zone industry. Equation (22a)' reflects the assumption of fixed commodity proportions within composite commodities. It states that the percentage change in the production of commodity $i$ by industry $j\left(y_{i}(j)\right)$ is equal to the percentage change in the output of composite commodity $r$ by industry $j\left(\widetilde{\vartheta}_{r}(j)\right)$ for each commodity $i$ included in that composite commodity. Equation (22b) shows that,

\footnotetext{
* The $P_{i}$ s are domestic product prices net of the costs of product-specific inputs. These $P$ s are not to be confused with the vectors of prices used in Tables $1-3$. The $W_{k}$ s are the prices of the nonspecific inputs.

** CRETH (Constant Ratio Elasticity of Transformation, Homothetic) is a generalization of CET (Constant Elasticity of Transformation). CRETH generalizes CET in the same way as CRESH generalizes CES. See Hanoch (1971) for CRESH, Powell and Gruen (1968) for CET, Arrow et al. (1961) for CES and Vincent et al. (1980) for CRETH.
} 
under CRETH, the output of the $r$ th composite commodity produced in industry $j$ changes in proportion to the overall level of activity in industry $j\left(Z_{j}\right)$. It also responds to any deviation between the percentage change in price of the $r$ th composite commodity, $p_{r}(j)$, and a weighted average of the prices of all composite commodities produced in the $j$ th industry. The weight $R_{q}^{*}(j)$ is related to the share (denoted by $R_{q}(j)$ ) of composite commodity $q$ in the total revenue of industry $j .^{\dagger}$ Equation (22c) $)^{\prime}$ defines the percentage change in the price of a composite commodity as a weighted average of the percentage changes in the prices of the individual products included therein. The weights $H_{t q}(j)$ are the shares of the products $t$ in the total value of output of composite commodity $q$ for industry $j$. The nonnegative parameter $\phi_{r}(j)$ in eqn. $(22 b)^{\prime}$ reflects the ease of transformation within industry $j$ between composite commodity $r$ and other composite commodities produced in the industry.

\subsection{The Data}

\subsubsection{Industries and Commodities}

The commodity and industry categories used for ORANI 78 can be seen by glancing at Tables 12 and 13. The nonagricultural sectors of the economy are modeled, as in ORANI 77, according to the industry $x$ industry classification of the ABS 1968/69 I-O tables. Industries 9-112 are single-commodity industries and, with one exception, correspond to industries 7-109 from the ABS tables. (See Dixon et al., 1977, table 13b, p. 120, for a numbered list of the ABS categories.) ${ }^{\dagger}$ The exception is ABS industry 12 (Coal and Crude Petroleum) which has been split, in the ORANI 78 data base, into industries 14 (Coal) and 15 (Crude Petroleum). The exporting part of the original industry has thus been separated from the import-competing part. Industries $1-8$ and commodities 1-10 comprise the respecified agricultural sector. Note that ind ustries $1-4$ are explicitly regional. The first three correspond to zones designated by the BAE in its Australian sheep industry survey (Bureau of Agricultural Economics, 1973).

\subsubsection{Characteristics of the Agricultural Industries}

\subsubsection{Outputs}

The Pastoral Zone industry occupies the largest area of the three BAE cerealsgrazing zones. It includes all of the arid and most of the semi-arid parts of Australia which support a sheep population. Apart from some fringe areas, cropping is not feasible in this zone because of the inadequate and unreliable rainfall. Livestock are generally grazed extensively on natural vegetation. Hence stocking rates are low and property areas extremely large. Sheep are grazed in the Pastoral Zone almost entirely for their wool. Although a substantial amount of income is also obtained from the sale of cast for age sheep, this meat production occurs essentially in fixed proportions with that of wool.

$\dagger R_{q}^{*}(j)=\phi_{q}(j) R_{q}(j) / \Sigma_{q} \phi_{q}(j) R_{q}(j)$. Notice that if $\phi_{q}(j)=\phi(j)$ for all $q$, i.e. the CET case, then $R_{q}^{*}(j)=R_{q}(j)$ for all $q$.

$\$$ The model also includes a 113th industry, which is a dummy category included to allow for the treatment of noncompeting imports. No results for this artificial industry are included in the tables. 
Production possibilities in the Pastoral Zone have been modeled in terms of the three groups of commodities: wool/sheep, meat cattle, and other products.

The Wheat-Sheep Zone is the largest of the three zones in terms of sheep numbers and sheep properties, accounting for nearly one half the national sheep flock and well over half the number of sheep properties in Australia. Rainfall is generally sufficient for crop production, and nearly all dryland cropping of cereals is carried out in this zone. As well as forming the basis for Australian sheep and wheat production, the zone has become an increasingly important source of cattle output in recent years. Climate, topography, and soil type are such that opportunities for diversification into various cropping and livestock activities are large. The zone thus forms a classic example of a multiproduct agricultural region. We recognize six groups of competing products in the Wheat-Sheep Zone - wool, sheep, meat cattle, wheat, barley, and other products. The other products category includes small amounts of other cereal grains, milk cattle and pigs, and commodities in both the other farming export and other farming import competing categories, e.g. fruit (OFE) and tobacco (OFM).

The High Rainfall Zone consists entirely of land within 200 miles of the coast and is located predominantly in the southeast and southwest corners of Australia. Sheep concentration is highest in this zone. Sheep are often grazed in association with beef cattle. To a lesser extent, livestock are grazed in rotation with crop production. As in the Wheat-Sheep Zone, a large proportion of properties combine wool growing with prime lamb production. That is, sheep meat production is an activity in its own right. Four groups of competing commodities are recognized: wool, sheep, meat cattle, and other products. The other products category contains wheat, barley, other cereal grains, milk cattle and pigs, and the commodities in the other farming export category.

Meat cattle are produced in Australia using two quite different technologies:

(i) Beef grazing activity is conducted in each of the three BAE zones. On most properties in these zones, cattle are grazed in conjunction with sheep. The product is mainly high-quality beef for domestic consumption.

(ii) An extensive specialist beef industry is located in Northern Australia. Much of the product from these northern regions is exported as lower-quality manufacturing beef. Climatic and biological factors are such that there are virtually no alternative commodity prospects to beef cattle for the northern industry. The Northern Beef industry in ORANI is defined to include the Kimberley region in Western Australia, the Victoria River, Alice Springs, Darwin, and Gulf and Barkley Tableland regions of the Northern Territory (these regions comprise the entire Northern Territory), and the Peninsular Gulf and Coastal Central regions of Queensland.* No competing products are permitted for the Northern Beef enterprise.

The Milk Cattle and Pigs industry produces two products, meat cattle (commodity 6) and milk cattle and pigs (commodity 7). They are assumed to be produced in fixed proportions. The remaining three industries, Other Farming Export, Other Farming

\footnotetext{
*The designation of the various regions is that $\mathrm{u}$ sed by the BAE in their Beef Industry reports on the Northern Territory and Kimberley Region Beef Cattle Industry (BAE, 1974a) and the Queensland Beef Cattle Industry (BAE, 1974b).
} 
Import Competing, and Poultry, are single-product industries producing only the corresponding commodities.

Table 4 shows the base period shares of the agricultural commodities in the total value of output of each of the agricultural industries; note that the column sums of the table are ones. The composite commodity groups which were defined for some industries $^{\dagger}$ for the purpose of estimating the CRETH system of product transformation (as described in Section 3.2) are identified by the lower-case letters in the table. For example, for industry 1 (Pastoral Zone), commodities 1 (wool) and 2 (sheep) form one group, commodity 6 (meat cattle) is a single-product group, and commodities 3 (wheat), 4 (barley), 5 (other grains), and 9 (other farming import competing) form a third, other products group. Within each group, commodities are assumed to be produced in fixed proportions (see eqn. (22a)'). Unfortunately, the time-series data on which the estimation of the relevant transformation frontiers was based were not detailed enough to support an econometric analysis of the transformation behavior of components of the other products categories; see Vincent et al. (1980).

The parameters $H$ and $R^{*}$ of eqns. (22)' are based on the information contained in Table 4. For example, $H_{t q}(j)$ is the share of commodity $t$ (say sheep) in commodity group $q$ (say group (a) wool/sheep) in industry $j$ (say the Pastoral Zone). This is computed from Table 4 as $0.127 /(0.618+0.127)=0.170$. Similarly, $R_{q}^{*}(j)$ requires the computation of the share of commodity group $q$ (say (a) wool/sheep) in the total output of industry $j$ (say the Pastoral Zone). (See first footnote, p. 252.)

Table 5 shows the shares of each of the agricultural industries in the aggregate production of agricultural commodities in the base year; note that the row sums of the table are ones. The three BAE zonal industries (industries 1-3) produce all the Australian output of wool, sheep, and cereals (commodities 1-5) and about one half of the output of meat cattle (commodity 6). In addition, they make minor contributions to the production of the remaining agricultural products (commodities 7-10) which are produced predominantly by specialist producers (industries $5-8$ ).

\subsubsection{Inputs}

As well as recognizing the marked regional differences in agricultural output structures outlined above, the respecification of ORANI's agricultural sector allows the model to account for regional differences in production technology. Table 6 illustrates these latter differences. It shows the shares of various cost categories in the total costs of each of the three BAE zones. Cost share information of this type is required for the empirical implementation of input demand functions of the form of eqn. (23); see Dixon et al. (1977, sections 2 and 3).

The most important feature of Table 6 is that the High Rainfall Zone is notably more labor intensive than the other two zones. ${ }^{\ddagger}$ This is especially important for shortrun simulations in which inputs of both land and capital are held fixed.

Although not shown in Table 6, the commodity composition of total intermediate

\footnotetext{
In the present version of the model CRETH transformation possibilities have been estimated only for the first three industries, i.e. for the BAE regions. See Vincent et al. (1980).

$¥$ Note that the share of labor in total primary costs (land, labor, and fixed capital) is 0.39 in the High Rainfall Zone as opposed to 0.27 in the Pastoral and Wheat-Sheep Zones.
} 


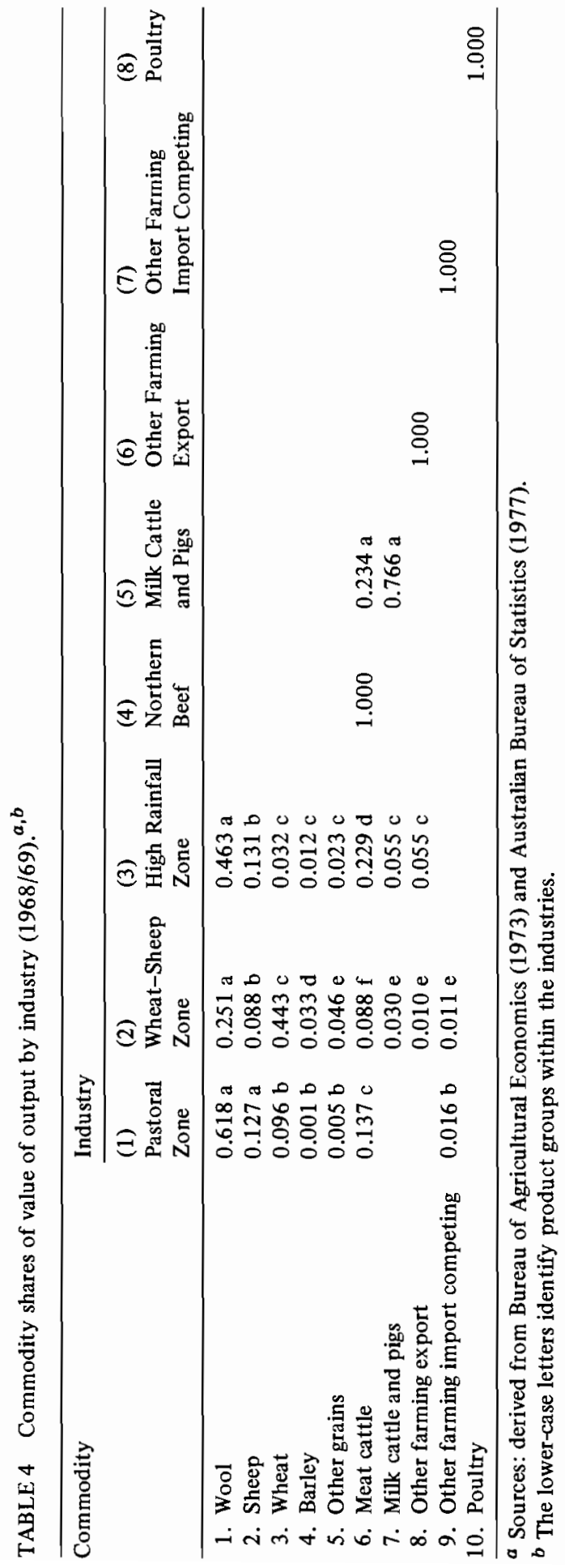




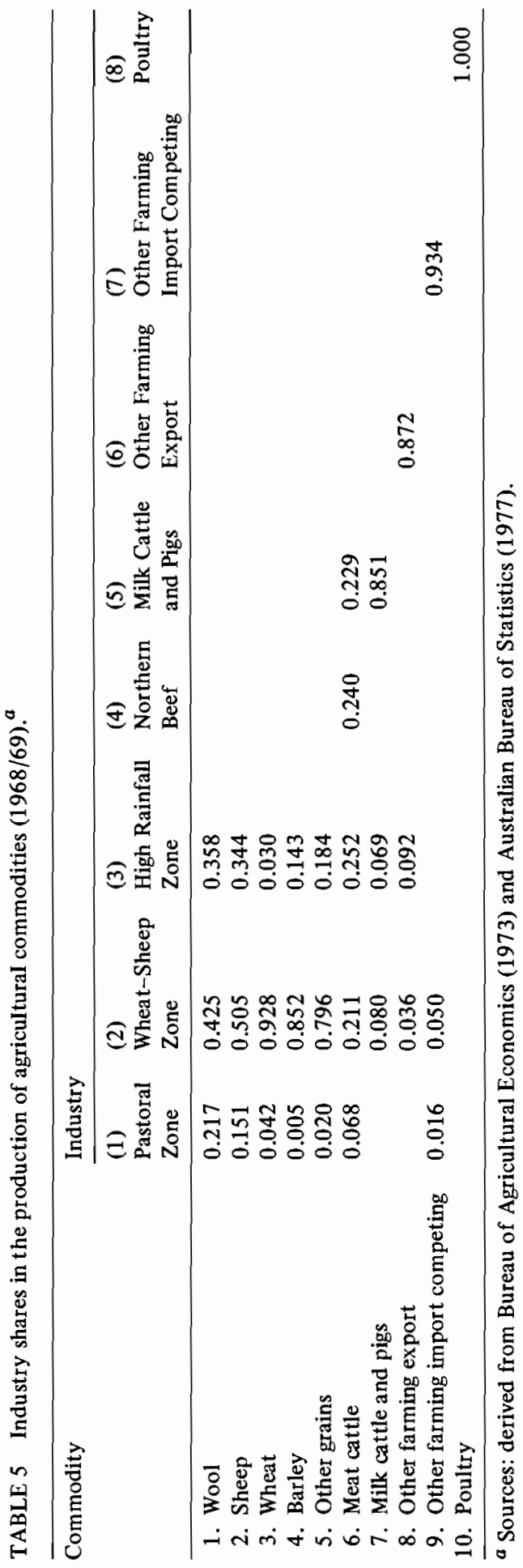


TABLE 6 Input cost shares in agricultural zones (1968/69). ${ }^{a}$

\begin{tabular}{llll}
\hline Cost category & Pastoral Zone & Wheat-Sheep Zone & High Rainfall Zone \\
\hline Domestic intermediate inputs & 0.35 & 0.28 & 0.36 \\
Imported intermediate inputs & 0.02 & 0.02 & 0.02 \\
Wages & 0.15 & 0.17 & 0.22 \\
Fixed capital & 0.20 & 0.16 & 0.09 \\
Land & 0.21 & 0.31 & 0.25 \\
Other (including taxes) & 0.07 & 0.06 & 0.06 \\
\hline
\end{tabular}

${ }^{a}$ Numbers in the table refer to shares in total costs.

inputs also differs across zones. For example, chemical fertilizers comprise $21 \%$ and $19 \%$ of total intermediate input costs in the High Rainfall and Wheat-Sheep Zones, respectively, but only one half of $1 \%$ of intermediate input costs in the Pastoral Zone; oil and coal products (fuel) inputs in the Wheat-Sheep Zone represent $8 \%$ of intermediate input costs compared with $7 \%$ in the Pastoral Zone and $5 \%$ in the High Rainfall Zone.

\subsubsection{Transformation Parameters and Supply Elasticities}

In addition to data computed from Tables 4-6, estimates of the product-product transformation parameters $\left(\phi_{r}(j)\right)$ are required for the CRETH eqns. (22) ${ }^{\prime}$. These are presented in Table 7. As explained above, to date the CRETH system has been estimated only for the first three agricultural industries, that is for the three BAE zones. Details of the econometric work and various alternative presentations of the results can be found in Vincent et al. (1980). Here we draw heavily on that source to present the results of the analysis for each zone as an asymmetric matrix of own- and cross-price elasticities of supply. For industry $j$, the elasticity of supply of composite commodity $r$ with respect to the price of composite commodity $q\left(\zeta_{r q}(j)\right)$ is given, from eqn. $(22 b)^{\prime}$, as

$$
\left[\zeta_{r q}(j)\right]_{z_{j}=\bar{Z}_{j}}=-\phi_{r}(j)\left(\delta_{r q}-R_{q}^{*}(j)\right)
$$

where

$$
\begin{array}{lll}
\delta_{r q}=1 & \text { for } & r=q \\
\delta_{r q}=0 & \text { for } & r \neq q
\end{array}
$$

\begin{tabular}{|c|c|c|c|c|c|}
\hline \multicolumn{2}{|l|}{ Pastoral Zone } & \multicolumn{2}{|l|}{ Wheat-Sheep Zone } & \multicolumn{2}{|l|}{ High Rainfall Zone } \\
\hline Commodity group & $\phi_{r}^{j}$ & Commodity group & $\phi_{r}^{j}$ & Commodity group & $\phi_{r}^{j}$ \\
\hline Wool/sheep & 0.1041 & Wool & 0.2976 & Wool & 0.0631 \\
\hline Meat cattle & 1.6129 & Sheep & 0.2342 & Sheep & 0.1153 \\
\hline \multirow[t]{4}{*}{ Other products } & 4.5455 & Cattle & 0.5181 & Cattle & 0.3745 \\
\hline & & Wheat & 1.6129 & Other products & 3.8462 \\
\hline & & Barley & 0.5208 & & \\
\hline & & Other products & 1.3158 & & \\
\hline
\end{tabular}

TABLE 7 Values for transformation parameters $\left(\phi_{r}^{j}\right)$ for eqn. $\left(22 b^{\prime}\right)$. 


\subsubsection{Pastoral Zone}

The matrix of own- and cross-product supply elasticities for the three composite commodities produced in the Pastoral Zone is shown in Table 8. As would be expected, the ease of transformation is highest when the "other products" category which includes grains is one of the product pairs. Consequently (and especially since it accounts for only a small share of total output in each zone), "other products" shows more sensitivity to price changes than does the production of wool/sheep or cattle: the "other products" row in Table 8 contains the largest elasticities. Nevertheless, for a one-year response, the elasticity of transformation between wool and cattle is quite large, implying a cross elasticity of cattle supply with respect to expected wool price of about -0.3 . Planned production of wool in the Pastoral Zone is considerably less responsive to its expected price than either cattle or "other" output to their respective prices. This result appears reasonable in view of the traditionally wool-oriented activities of the Pastoral Zone.

TABLE 8 Estimated own-and cross-price elasticities: Pastoral Zone. ${ }^{a}$

\begin{tabular}{lccc}
\hline $\begin{array}{l}\text { Percentage response one year later } \\
\text { in the planned output }{ }^{b} \text { of }\end{array}$ & \multicolumn{2}{l}{ Production whose expected price changes } \\
\cline { 2 - 4 } & Wool & Cattle & Other products \\
\hline Wool/sheep & 0.083 & -0.039 & -0.043 \\
Cattle & -0.332 & 1.008 & -0.676 \\
Other products & -0.929 & -1.724 & 2.654 \\
\hline
\end{tabular}

$a$ The elasticities refer to changes in planned product outputs in response to expected price changes under the assumption that the scale of total capacity $(Z)$ remains constant.

${ }^{b}$ Actual output may differ from planned output due to droughts, etc.

\subsubsection{Wheat-Sheep Zone}

The estimated own-and cross-price elasticities for the Wheat-Sheep Zone are shown in Table 9.* Wheat-Sheep Zone farmers have considerable possibilities for chang. ing their output mix in response to relative price changes. As might be expected from the nature of the products, the sensitivity of supply to price changes is smaller for livestock enterprises than for grains, i.e. the elasticities in the first three rows of Table 9 tend to be considerably smaller than those in the rest of the table. In the Wheat-Sheep Zone, few technical problems can be envisaged in changing the relative areas of different types of grains in response to changes in relative product prices. On the other hand, there are obvious limits on the extent to which one type of livestock may be replaced throughout a zone with another over a one-year period.

\subsubsection{High Rainfall Zone}

Own-and cross-product price elasticities for the High Rainfall Zone are shown in Table 10 . Once again, in a predominantly wool-growing region, own-supply elasticities for

\footnotetext{
* These are derived from the reduced form of the CRETH system rather than from eqn. (22b)'. They allow the scale of output to change in response to a change in the price of an individual product. The practical importance of the scale effect is small. For technical reasons, the reduced form was not used for the other two zones. For a detailed discussion see Vincent et al. (1980).
} 
TABLE 9 Estimated own- and cross-price elasticities: Wheat-Sheep Zone. ${ }^{a}$

\begin{tabular}{lrrlllr}
\hline \multirow{2}{*}{$\begin{array}{l}\text { Percent response one year later } \\
\text { in planned output }\end{array}{ }^{a}$ of } & \multicolumn{7}{l}{ Product whose expected price changes } \\
\cline { 2 - 7 } & \multicolumn{1}{l}{ Wool } & \multicolumn{1}{c}{ Sheep } & Cattle & Wheat & \multicolumn{1}{c}{ Barley } & "Other" \\
\hline Wool & 0.256 & -0.012 & -0.020 & -0.152 & -0.014 & -0.044 \\
Sheep & -0.031 & 0.225 & -0.015 & -0.118 & -0.011 & -0.034 \\
Cattle & -0.077 & -0.023 & 0.483 & -0.269 & -0.025 & -0.078 \\
Wheat & -0.254 & -0.075 & -0.114 & 0.766 & -0.080 & -0.245 \\
Barley & -0.078 & -0.023 & -0.036 & -0.270 & 0.497 & -0.078 \\
"Other" & -0.204 & -0.061 & -0.092 & -0.687 & -0.064 & 1.111 \\
\hline
\end{tabular}

${ }^{a}$ Actual output may differ from planned output due to droughts, etc.

TABLE 10 Estimated own- and cross-price responsiveness: High Rainfall Zone. ${ }^{a}$

\begin{tabular}{lcccc}
\hline Percent response one year later & \multicolumn{4}{l}{ Product whose expected price changes } \\
\cline { 2 - 5 } in the planned output ${ }^{b}$ of & Wool & \multicolumn{1}{c}{ Sheep } & \multicolumn{1}{c}{ Cattle } & Other products \\
\hline Wool & 0.060 & -0.002 & -0.005 & -0.053 \\
Sheep & -0.006 & 0.112 & -0.010 & -0.097 \\
Cattle & -0.019 & -0.010 & 0.343 & -0.314 \\
Other products & -0.196 & -0.104 & -0.320 & 0.620 \\
\hline
\end{tabular}

${ }^{a}$ These elasticities are based on a constant scale of total capacity $(Z)$.

${ }^{b}$ Actual output may differ from planned output due to droughts, etc.

wool and sheep are considerably less than those of the two other product categories distinguished. Similarly, cross-price effects are lower for wool output with respect to changes in the price of competing products than for other output and price combinations.

\subsubsection{Comparisons with Other Studies}

The estimated supply elasticities are considerably higher than those implied by Powell and Gruen (1967), who used national time-series data and a CET model (see second footnote, p. 251). Furthermore, our estimates of one-year own- and cross-price elasticities of supply are considerably higher in absolute value than those obtained from previous Australian agricultural supply studies, which generally have employed conventional singleequation techniques with the parameter space largely unconstrained.

Since the original CET work of Powell and Gruen in the mid-1960s, the only multiproduct model of Australian agriculture recognizing joint production to emerge has been the University of New England's Aggregative Programming Model of Australian Agriculture (APMAA) (Monypenny, 1975). The APMAA study has the advantage of a great deal of regional detail consisting of a set of ca. 500 regionally representative farms, for each of which a complete activity-analysis linear programming framework is developed. The APMAA model has been used to provide aggregate estimates of own and cross elasticities of supply for different product/price combinations. The methodology allows shifts in the land use between sheep, beef, and wheat in response to changes in the gross margins of these activities (APMAA, 1977). For a number of reasons, the APMAA results are not strictly comparable with those from CRETH. An obvious difference is that the 
APMAA own- and cross-price elasticities differ according to the particular combination of beef, wheat, and wool prices chosen. Assuming a "central" set of prices, viz. beef A $\$ 0.68 / \mathrm{kg}$, wheat $\$ 51.42 / \mathrm{t}$, and wool $\$ 2.32 / \mathrm{kg}$, the APMAA model yielded the following elasticities:

wool with respect to price of wheat -0.19 (vs. -0.15 , our Table 9); wool with respect to price of beef -0.21 (vs. -0.02 , our Table 9); wool with respect to price of wool +0.25 (vs. +0.26 , our Table 9).

These long-run results provide corroborating evidence of the fairly high transformation possibilities between competing products on Australian farms.

\section{THE SHORT-RUN EFFECT OF A GENERAL TARIFF INCREASE ON THE AUSTRALIAN ECONOMY WITH SPECIAL REFERENCE TO THE AGRICULTURAL SECTOR}

In this section an application of ORANI 78 is presented. The model is used to simulate the effects of a $1 \%$ across the board tariff increase on industry activity levels, employment by occupation, and various macroeconomic variables. ${ }^{*}$ Protection policy is of great significance to the agricultural sector because of the heavy involvement of that sector in exporting. Tariff increases raise domestic costs, especially when wage rates are indexed to the consumer price level. Export prices for most commodities can be regarded as more or less fixed from the point of view of a small economy such as Australia's. That is, Australian export industries cannot generally just pass on domestic cost increases to their customers, and a tariff increase can be expected to reduce the profitability of the export sector. Clearly, a general equilibrium approach is required for a quantitative analysis of these effects.

The 1977 version of ORANI has been used previously to analyze the effects of tariff increases. The results have been reported in detail by Dixon et al. (1977, chap. 4). One reason for wishing to repeat this experiment with ORANI 78 is that comparison of the results of the two simulations allows an assessment of the significance of the modifications to the model.

Apart from the respecified agricultural sector, the only other relevant modification to the theoretical structure of ORANI which has been introduced in ORANI 78 concerns the modeling of commodity taxes. ${ }^{* *}$ In ORANI 77 these we re modeled as specific. An implication is that changes in the domestic price level cause changes in the real value of tax revenue. ORANI 78 incorporates a more flexible treatment. Commodity tax rates may be set as specific, ad valorem, or indexed to the consumer price level. Exogenous changes in the rates can be imposed under any of the three specifications. In the

\footnotetext{
* The model is linear in percentage changes. Hence, subject to a caveat concerning approximation errors in the linear form (see Section 2.3), readers wishing to compute projections for, say, a $10 \%$ tariff increase or a $1 \%$ tariff decrease can simply multiply the results by 10 or -1 , respectively. ** ORANI 78 also includes a facility for handling exogenous technological and taste changes. This extension of the ORANI structure is not, however, relevant to the simulation discussed here.
} 
simulation reported here the tax rates are indexed so that for each product the real value of tax receipts per unit of sales is constant.

In addition, some improvements have been made to the data and parameter files employed in the model. There are four principal changes. Firstly, gross rather than net input-output tables are now used. This allows a more straightforward treatment of import-domestic substitution in intra-industry intermediate demand and is of particular importance for the motor vehicle industry. ${ }^{*}$ Secondly, the split of gross operating surplus between fixed capital and other claimants has been revised for some industries. Thirdly, the required household demand parameters have been re-estimated (Tulpulé and Powell, 1978). Finally, on the basis of a paper produced for IMPACT by Freebairn (1978), slightly revised values for the foreign elasticities of demand for some Australian exports have been chosen. The values of the reciprocals of these demand elasticities which are used in ORANI 78 for the major export industries are shown in Table 14. The "small country" assumption is not imposed in the export specification for ORANI, although, as can be seen from Table 14, fairly elastic foreign demand is assumed for most export commodities.

\subsection{Assumptions Underlying the Simulation}

The economic environment which is assumed for the purposes of an ORANI experiment is determined basically by the choice of the set of variables which are to be treated as exogenous. The principles governing this choice are discussed in Section 2.2. For this experiment, exactly the same environment is assumed as was used for the equivalent simulation reported by Dixon et al. (1977, pp. 192-207). The key assumptions are:

(i) fixed industry-specific capital stocks;

(ii) fixed real aggregate consumption, investment, and government spending;

(iii) a slack labor market for all occupations with $100 \%$ indexation of wage rates to the ORANI consumer price index (i.e. fixed real wages); and

(iv) a fixed exchange rate.

The first assumption implies that the results are short run. Investment takes place but is not allowed to augment capital stocks in the solution period. A suitable calendar time interpretation of this short run would be 1-2 years. Assumption (ii) indicates that the simulations abstract from any effects which tariff changes may have on real domestic absorption. The latter is regarded as determined independently of tariff levels by other arms of government policy (fiscal and monetary policy for example) which are not modeled in ORANI. Assumption (iii) would seem to be appropriate for the current state of the Australian labor market. Employment levels are thus assumed to be demand determined. The last assumption fixes the numeraire in the model. Changes in domestic prices relative to world prices in this simulation are accommodated by changes in the domestic price level rather than by changes in the exchange rate.

\footnotetext{
${ }^{*}$ For a description of the problems which arose in this regard with ORANI 77 see Dixon et al. (1977, pp. 141-143).
} 
As explained in Section 2.2, exports are determined endogenously in ORANI only for a group of major export commodities; see also Dixon et al. (1977, pp. 204-205). In the simulation reported here exports are endogenous for the following commodities: wool, wheat, barley, other cereal grains, fishing, iron, other metallic minerals, coal, meat products, food products n.e.c., prepared fibers, basic iron and steel, and other basic metal products. These commodities constitute ca. $70 \%$ of total exports in the data base. For the remaining commodities, changes in exports were specified exogenously to be zero. Note that, apart from the complications introduced by the respecification of the agricultural sector, this assignment conforms to that chosen for the experiments reported by Dixon et al. (1977).

\subsection{The Macroeconomic and Employment Results}

Table 11 gives projections of the short-run effects of the $1 \%$ tariff increase on employment by occupation and on various macroeconomic variables.

TABLE 11 Projections of the effects of a $1 \%$ across the board tariff increase on macro and employment variables.

\begin{tabular}{lcc}
\hline Variable & Projection $^{\alpha}$ & Employment weight \\
\hline Aggregate employment & -0.0078 & \\
Employment & -0.0054 & 0.0387 \\
1. Professional White Collar & -0.0023 & 0.1344 \\
2. Skilled White Collar & -0.0037 & 0.2744 \\
3. Semi and Unskilled White Collar & -0.0001 & 0.1028 \\
4. Skilled Blue Collar (metal and electrical) & 0.0042 & 0.0425 \\
5. Skilled Blue Collar (building) & 0.0006 & 0.0271 \\
6. Skilled Blue Collar (other) & -0.0049 & 0.2993 \\
7. Semi and Unskilled Blue Collar & -0.0835 & 0.0645 \\
8. Rural Workers & 0.0000 & 0.0163 \\
9. Armed Services & -0.1009 & \\
Aggregate Exports (foreign currency value) & -0.0611 & \\
Aggregate Imports (foreign currency value) & -1.3 & \\
Balance of Trade & 0.0880 & \\
Index of Consumer Prices & 0.1102 & \\
Capital Goods Price Index & & \\
\hline a All & &
\end{tabular}

${ }^{a}$ All projections are percentage changes, with the exception of the balance of trade which has the units "millions of 1968/69 Australian dollars".

These results confirm the conclusions about the effects of tariff protection which were drawn on the basis of the corresponding ORANI 77 simulation. They indicate that increased aggregate employment is not generated by tariff increases. In fact, a slight fall in aggregate employment is projected. Increased employment in import-competing industries is more than offset by falls in employment elsewhere in the economy, especially 
in the export sector. ${ }^{*}$ This pattern is indicated by the projections of changes in occupation-specific employment. The export-related occupation "Rural Workers" experiences the largest decline. The occupation classification used is insufficiently industry specific to give such a clear reflection of the increase in employment enjoyed in the import-competing sector. Only the fifth and sixth occupations "Skilled Blue Collar (building)" and "Skilled Blue Collar (other)" experience net increases in employment. The former reflects a shift in the allocation of investment from the exporting (especially the rural) sector towards import-competing manufacturing. Investment in the latter is more intensive in construction inputs. Occupation 4 is also intensively used in importcompeting industries, hence its smaller than average employment loss. ${ }^{* *}$

Just as the results cast doubt on the old conventional ideas about the relationship between tariffs and employment, they also suggest that increased protection will not improve the balance of trade. The projected fall in aggregate imports is more than offset by the adverse effects of the cost-price squeeze on the export sector. Aggregate exports are projected to fall by an amount sufficient to result in a small move to deficit on the balance of trade. Domestic absorption is assumed constant so that, consistent with the deterioration in the trade balance, a slight decline in the GNP is implied.

The final items in Table 11 are two indexes of domestic prices. Both are projected to increase by about $0.1 \%$ as a consequence of the tariff increase when $100 \%$ wage indexation is imposed. The steeper rise in the investment price index compared to the consumer price index reflects the heavier weight given in the former to highly protected imports. A detailed analysis of price-level responses in ORANI can be found in Dixon et al. (1977, pp. 214-222).

\subsection{Industry Results}

\subsubsection{The General Picture}

As in the case of the macro and employment results, the general pattern of the industry results from the current simulation strongly confirms the conclusions which were drawn on the basis of the equivalent ORANI 77 experiment. (See Dixon et al., 1977, pp. 249-253 for a detailed description of the ORANI 77 results.) Projected percentage changes in ind ustry output levels are presented in Table 12. The average output response across industries is a decline of ca. $0.005 \%$. Various groups of industries can, however, be identified as faring clearly better than or worse than average.

Not surprisingly, the highly-protected import-competing sectors of the economy provide most of the industries which are projected to gain from the tariff increase. Industries $24,28,31-39,41,43,44,46,48,50-52,54,55,57,65-68,71-75$, and

\footnotetext{
* Projections for employment by industry as well as by occupation are available. They are not presented here for reasons of space, but may be obtained directly from the authors.

** In the ORANI 77 tariff experiment, occupation 4 experienced a small employment gain (see Dixon et al. 1977, pp. 208-209). The reason for the reversal of the sign on this projection in ORANI 78 is that, because of the indexation of commodity taxes, the tariff increase is slightly more inflationary in the new version of the model. All the employment results are therefore worse, but especially those in occupations heavily concentrated in trading sectors of the economy (i.e. occupations 4 and 8 ). In the case of occupation 4 , this was sufficient to cause the sign reversal.
} 
TABLE 12 Projections of the effects of a $1 \%$ across the board tariff increase on industry activity levels (percentage changes).

\begin{tabular}{|c|c|c|c|}
\hline Industry & Projection & Industry & Projection \\
\hline 1. Pastoral Zone & -0.0286 & 57. Glass & 0.0205 \\
\hline 2. Wheat-Sheep Zone & -0.0286 & 58. Clay Products & 0.0054 \\
\hline 3. High Rainfall Zone & -0.0562 & 59. Cement & -0.0052 \\
\hline 4. Northern Beef & -0.0431 & 60. Ready-Mixed Concrete & 0.0043 \\
\hline 5. Milk Cattle and Pigs & -0.0179 & 61. Concrete Products & 0.0013 \\
\hline 6. Other Farming Export & -0.0560 & 62. Non-Metal Mineral Products & 0.0080 \\
\hline 7. Other Farming Import Competing & -0.0110 & 63. Basic Iron and Steel & -0.0859 \\
\hline 8. Poultry & -0.0153 & 64. Other Basic Metals & -0.0889 \\
\hline 9. Services to Agriculture & -0.0363 & 65. Structural Metal & 0.0192 \\
\hline 10. Forestry & -0.0164 & 66. Sheet Metal Products & 0.0197 \\
\hline 11. Fishing & -0.1002 & 67. Metal Products n.e.c. & 0.0614 \\
\hline 12. Iron & -0.0110 & 68. Motor Vehicles, Parts & 0.1048 \\
\hline 13. Other Metallic Minerals & -0.0731 & 69. Ship and Boat Building & -0.0487 \\
\hline 14. Coal & -0.1437 & 70. Locomotives & -0.0299 \\
\hline 15. Crude Oil & -0.0053 & 71. Aircraft Building & 0.0081 \\
\hline 16. Non-Metallic Minerals n.e.c. & -0.0088 & 72. Scientific Equipment & 0.0107 \\
\hline 17. Services to Mining & -0.0096 & 73. Electronic Equipment & 0.0964 \\
\hline 18. Meat Products & -0.0493 & 74. Household Appliances & 0.0371 \\
\hline 19. Milk Products & 0.0002 & 75. Electrical Machinery & 0.0332 \\
\hline 20. Fruit and Vegetable Products & 0.0073 & 76. Agricultural Machinery & -0.0726 \\
\hline 21. Margarine, Oils, and Fats & 0.0081 & 77. Construction Equipment & -0.0057 \\
\hline 22. Flour and Cereal Products & -0.0047 & 78. Other Machinery & 0.0240 \\
\hline 23. Bread, Cakes & 0.0004 & 79. Leather Products & 0.0721 \\
\hline 24. Confectionery & 0.0214 & 80. Rubber Products & 0.0277 \\
\hline 25. Food Products n.e.c. & -0.1330 & 81. Plastic Products & 0.0334 \\
\hline 26. Soft Drinks, Cordials & 0.0028 & 82. Signs, Writing Equipment & 0.0341 \\
\hline 27. Beer and Malt & 0.0011 & 83. Other Manufacturing & 0.0168 \\
\hline 28. Alcoholic Drinks n.e.c. & 0.0693 & 84. Electricity & -0.0030 \\
\hline 29. Tobacco & 0.0050 & 85. Gas & 0.0056 \\
\hline 30. Prepared Fibers & -0.0400 & 86. Water, Sewerage & -0.0027 \\
\hline 31. Man-Made Fibers, Yarn & 0.0923 & 87. Residential Building & 0.0000 \\
\hline 32. Cotton, Silk, Flax & 0.1266 & 88. Building n.e.c. & 0.0070 \\
\hline 33. Wool and Worsted Yarns & 0.0259 & 89. Wholesale Trade & -0.0097 \\
\hline 34. Textile Finishing & 0.0287 & 90. Retail Trade & -0.0029 \\
\hline 35. Textile Floor Covers & 0.0205 & 91. Motor Vehicle Repair & -0.0110 \\
\hline 36. Textile Products n.e.c. & 0.0299 & 92. Other Repairs & -0.0093 \\
\hline 37. Knitting Mills & 0.0261 & 93. Road Transport & -0.0204 \\
\hline 38. Clothing & 0.0310 & 94. Railway Transport & -0.0308 \\
\hline 39. Footwear & 0.1043 & 95. Water Transport & -0.0183 \\
\hline 40. Sawmill Products & 0.0043 & 96. Air Transport & -0.0078 \\
\hline 41. Plywood, Veneers & 0.0390 & 97. Communication & -0.0012 \\
\hline 42. Joinery and Wood Products & 0.0084 & 98. Banking & -0.0010 \\
\hline 43. Furniture, Mattresses & 0.0196 & 99. Finance and Life Insurance & -0.0004 \\
\hline 44. Pulp, Paper & 0.0124 & 100. Other Insurance & -0.0015 \\
\hline 45. Fiberboard & 0.0074 & 101. Investment, Real Estate & -0.0007 \\
\hline 46. Paper Products n.e.c. & 0.0115 & 102. Other Business Services & -0.0035 \\
\hline 47. Newspapers and Books & -0.0060 & 103. Ownership of Dwellings & 0.0000 \\
\hline 48. Commercial Printing & 0.0110 & 104. Public Administration & 0.0001 \\
\hline 49. Chemical Fertilizers & -0.0277 & 105. Defense & 0.0000 \\
\hline 50. Industrial Chemicals & 0.0402 & 106. Health & 0.0000 \\
\hline 51. Paints, Varnishes & 0.0251 & 107. Education, Libraries & 0.0002 \\
\hline 52. Pharmaceuticals & 0.0209 & 108. Welfare Services & -0.0005 \\
\hline 53. Soap and Detergents & 0.0035 & 109. Entertainment & -0.0088 \\
\hline 54. Cosmetics, Toiletry & 0.0096 & 110. Restaurants, Hotels & -0.0003 \\
\hline 55. Chemical Products n.e.c. & 0.0333 & 111. Personal Services & -0.0005 \\
\hline 56. Oil and Coal Products & -0.0053 & 112. Business Expenses & -0.0013 \\
\hline
\end{tabular}


78-83 can all be included in this category. All show relatively strong positive output responses in Table 12. Within the group, relative performance is determined by the extent of import competition faced (measured by the import shares in the relevant markets), the elasticities of substitution between imports and domestic products, and the base year ad valorem levels of protection. The values of these parameters which were used in the simulation are given by Dixon et al. (1977, tables 7 and 13(b)). Industries $31,32,39,68$, and 73 are the strongest gainers. All have base year ad valorem tariff rates of $25 \%$ or greater and in each category the elasticity of substitution between imports and domestic sources is 2.0 or greater. Of these five, only industry 39 (Footwear) faces an import share in its market smaller than $30 \%$. Its import share is only ca. $10 \%$ but, offsetting this, it faces the largest of the substitution elasticities -6.8 .

The main losers from the tariff increase are projected to be the export industries or those industries whose major customers are export industries. As suggested above, the effect of the tariff on the export-dependent sector is to induce a cost-price squeeze. Tariff increases, especially when combined with wage indexation, are inflationary in the domestic economy and exporters find it hard to pass on increased domestic costs to their overseas customers. Industries $1-3,11-14,18,25,30,63$, and 64 are all major exporters, changes in whose export levels are determined endogenously. Industries 4-6, 9, 49, 76, and 93-96, on the other hand, are not direct export industries but are heavily dependent for their sales on customers in the export sector. The industries in these two groups generally show relatively large negative output responses in Table 12.

Most of the remaining industries, including almost all of the nontraded sector, experience approximately average output effects as shown in Table 12. Various interindustry connections explain the variation in output responses within this group.

The importance of fixed factors in influencing these short-run output results should, finally, be noted. This is most evident with respect to the export-related industries. In general, the outputs of the agricultural exporters contract less strongly than those of the nonrural export industries. In this simulation, both capital and agricultural land were held constant with the result that the land-using industries (1-7) are on average more fixed-factor intensive than the rest of the economy. In the short run, fixed factors inhibit output flexibility. Only variable factor costs can be saved (or will increase) if output is cut (or increased) in the short run. The relative stability of the output of the exporting but extremely capital-intensive iron industry (12) is another good example of this phenomenon.*

\subsubsection{The Agricultural Sector}

The modifications introduced into the 1978 version of ORANI do not have a great effect on the projected responsiveness of the agricultural sector as a whole to tariff changes. The tariff increase is slightly more inflationary in ORANI 78 than it was in ORANI 77, owing to the revised treatment of commodity taxes. Consequently, agriculture as a whole is slightly more severely affected. What is added to the model by the

\footnotetext{
* Dixon et al. (1977, pp. 253-259) provide, as well as a general description, a more formal regression analysis of the output results from the ORANI 77 simulation of the effects of the tariff increase. Explanatory variables representing fixed-factor intensity, export dependence, and the usual effective protection measures together accounted for $87 \%$ of the variance in the output results across industries.
} 
CRETH respecification of agriculture is much more reliable detail about what happens within the agricultural sector.

Each of the three regional multiproduct agricultural industries in Table 12 (industries 1-3) is projected to suffer a significant decline in output as a consequence of the tariff increase. All produce mixes of mainly export-oriented, agricultural commodities (Table 4) and are subject to comparable cost-price squeezes following the inflationary increase in protection levels. The projected fall in output in both the Pastoral Zone (industry 1) and the Wheat-Sheep Zone (industry 2) is ca. 0.029\%. In the High Rainfall Zone (industry 3 ), however, the projected fall is $0.056 \%$. This difference can be seen as due to the greater labor intensity of production in the High Rainfall Zone as compared to the other two. The CES production functions employed in ORANI* imply short-run industry supply functions of the form

$$
z_{j}=\left[\sigma_{j} S_{\mathrm{L} j} /\left(1-S_{\mathrm{L} j}\right)\right]\left(p_{j}-w_{j}\right)
$$

where

$z_{j} \quad$ is the percentage change in the output of industry $j$,

$p_{j}$ is the percentage change in the unit price of value added in industry $j$,

$w_{j}$ is the percentage change in the cost per unit of labor in industry $j$,

$\sigma_{j}$ is the elasticity of substitution between primary factors in industry $j$, and

$S_{\mathrm{L} j}$ is the share of labor in primary factor cost in industry $j$.

Short-run output flexibility is therefore positively related to the share of the variable factor (labor) in primary costs. The value of $\sigma_{j} S_{\mathbf{L} j} /\left(1-S_{\mathrm{L} j}\right)$, with $\sigma_{j}=0.5$ for all industries, is 0.185 for the Pastoral and Wheat-Sheep Zones, but 0.320 for the High Rainfall Zone.

The Northern Beef industry (industry 4) produces only meat cattle (see Table 4), almost all of which is sold for intermediate usage in industry 18 (Meat Products). Since there are no competing imports, the input of domestically produced meat cattle must expand proportionately with the output of the Meat Products industry. The projected percentage decrease in the output of the Northern Beef industry $(0.043 \%)$ is, however, slightly less than the output fall projected for the Meat Products industry (0.049\%). The Northern Beef industry has slightly increased its share of the meat cattle market at the expense of the Pastoral Zone and the High Rainfall Zone which, as is shown in Section 4.3.3, substitute away from meat cattle in their product mixes.

Industry 5 (Milk Cattle and Pigs) is projected to reduce its output by $0.018 \%$. It produces, in fixed proportions, meat cattle (commodity 6 ) and milk cattle and pigs (commodity 7) (see Table 4). The former is, once again, sold almost entirely to industry

\footnotetext{
* See Dixon et al. (1977, sections 2 and 3). ORANI 78 is specified to accommodate CRESH (Hanoch, $1971)$ production functions. Attempts to estimate parameters for the CRESH system at a disaggregated level have not been successful (Vincent et al., 1980) and in the present version of the model a common value 0.5 for the elasticity of substitution between labor, land, and capital was used. Hence CRESH collapses to CES. Within the IMPACT project, different pairwise elasticities of substitution between labor, land, and capital have been estimated for the agricultural sector as a whole; see Vincent (1977) and Ryland and Vincent (1978).
} 
18. The Milk Cattle and Pigs industry has also increased its share of the meat cattle market. Commodity 7 is sold as an intermediate input to industries 18 and 19 (Milk Products). The latter, which sells primarily to household consumption, experiences almost no change in output. As noted earlier, the former decreases its output, and therefore its demand for inputs of commodity 7 , by $0.049 \%$. Ind ustry 5 is the predominant producer of this commodity (see Table 5), sales to industry 18 accounting for ca. $35 \%$ of its total sales. The decrease in intermediate demand for commodity 7 by industry 18 therefore accounts for almost all of the projected $0.018 \%$ fall in the production of the commodity by industry 5 (note that $-0.049 \times 0.35=-0.017$ ).

Industry 6 (Other Farming Export) is projected in Table 12 to experience an output contraction of $0.056 \%$ following the tariff increase. The industry produces only commodity 8 (other farming export) (see Table 4) and accounts for more than $87 \%$ of the total output of that commodity (see Table 5). A reduction of ca. $0.13 \%$ in its sales to industry 25 (Food Products n.e.c.), mainly sugar for refining, and an increase of $0.018 \%$ in the household consumption* of commodity 8 account for most of the change in the output of industry 6 . Sales to industry 25 constitute $45 \%$ of total sales and sales to consumption about $26 \%$ (note that $-0.13 \times 0.45+0.018 \times 0.26=-0.06$ ).

The projected output fall in Table 12 for industry 7 (Other Farming Import Competing) is $0.011 \%$. It produces only, and is the predominant producer of, commodity 9 (other farming import competing) (Tables 4 and 5). This commodity enjoys a high level of protection (39\%) in the base period but is not subject to effective import competition. The main import-competing product included in this commodity category is tobacco leaf. This accounts for the $11 \%$ of the sales of domestically-produced commodity 9 going to industry 29 (Tobacco). For institutional reasons the tobacco-processing industry does not vary its mix of inputs between domestic and foreign sources in response to relative prices. The elasticity of substitution between imported and domestic supplies of commodity 9 is therefore set at close to zero in the model.

The sales of commodity 9 are generally more diverse than those of the other products produced by the agricultural sector. About 53\% of total sales of commodity 9 are absorbed into intermediate usage and the remainder into household consumption. Our simulation projects a small increase in sales to consumption $(0.0045 \%)$ since the basic value price of the commodity increases by only $0.056 \%$ (see Table 13) compared to an overall increase in consumer prices of $0.088 \%$ (see Table 11). The negative result for the output of industry 7 is explained primarily by its intermediate sales to industries 2, 3, 5, 25 , and 30 , which collectively account for almost $20 \%$ of total sales. Each of these purchasing industries experiences a marked decline in its output level (see Table 12).

The final industry in ORANI's agricultural sector is industry 8 (Poultry). The projected fall in its output $(0.015 \%)$ is accounted for by the reduction in the demand for inputs to industry 18 . Sales to industry 18 account for $32 \%$ of the total sales of poultry and the output of that industry falls by ca. $0.05 \%$ as noted above (note that $0.05 \times 0.32=0.016)$. Sales to final consumption account for most of the remaining sales of poultry $(62 \%)$. Consumption of poultry is projected to remain almost static.

\footnotetext{
* Results for household consumption by commodity are available directly from the authors.
} 
TABLE 13 Agricultural commodity outputs and prices.

\begin{tabular}{|c|c|c|c|c|c|}
\hline \multirow[t]{2}{*}{ Commodity } & \multicolumn{3}{|l|}{ Industry } & \multirow{2}{*}{$\begin{array}{l}\text { Aggregate } \\
\text { output }\end{array}$} & \multirow{2}{*}{$\begin{array}{l}\text { Commodity prices } \\
\text { (basic values) }\end{array}$} \\
\hline & $\begin{array}{l}\text { Pastoral } \\
\text { Zone }\end{array}$ & $\begin{array}{l}\text { Wheat-Sheep } \\
\text { Zone }\end{array}$ & $\begin{array}{l}\text { High Rainfall } \\
\text { Zone }\end{array}$ & & \\
\hline 1. Wool & -0.0260 & -0.0179 & -0.0551 & -0.0330 & 0.0152 \\
\hline 2. Sheep & -0.0260 & -0.0380 & -0.0629 & -0.0448 & -0.0607 \\
\hline 3. Wheat & 0.0088 & -0.0365 & -0.0325 & -0.0345 & -0.0255 \\
\hline 4. Barley & 0.0088 & -0.0314 & -0.0305 & -0.0311 & -0.0260 \\
\hline 5. Other cereal grains & 0.0088 & 0.0044 & -0.0305 & 0.0020 & -0.0362 \\
\hline 6. Meat cattle & -0.0753 & -0.0448 & -0.0746 & -0.0478 & -0.0518 \\
\hline 7. Milk cattle and pigs & & 0.0044 & -0.0305 & -0.0170 & 0.0515 \\
\hline 8. Other farming export & & 0.0044 & -0.0305 & -0.0515 & -0.0037 \\
\hline $\begin{array}{l}\text { 9. Other farming import } \\
\text { competing }\end{array}$ & 0.0088 & 0.0044 & & -0.0100 & 0.0557 \\
\hline Industry output $^{\boldsymbol{a}}\left(z_{j}\right)$ & -0.0286 & -0.0286 & -0.0562 & & \\
\hline $\begin{array}{l}\text { CRETH weighted } \\
\text { industry prices }\end{array}$ & -0.0229 & -0.0206 & -0.0029 & & \\
\hline
\end{tabular}

${ }^{a}$ Note that the share-weighted sum of the changes in commodity outputs in each zone (where the shares are shares in base year zone outputs) equals the change in the output of the zone.

${ }^{b}$ These are defined by the term $\Sigma_{q} p_{q}^{(j)} R_{q}^{*(j)}$. See eqn. $(22 \mathrm{~b})^{\prime}$.

\subsubsection{Agricultural Commodities by Industry: the CRETH Results}

Recall from Section 3.2 that, under the CRETH specification of production possibilities within the three agricultural zones, commodity outputs by industry are determined according to eqns. (22)'. Table 13 gives projected percentage changes in agricultural commodity outputs in aggregate and by industry (the $y_{i}(j)$ ). Also included in the table are projected percentage changes in the basic-value prices of the commodities (the $p_{t}$ ) and projected percentage changes in the industry outputs (the $z_{j}$ ) which are taken from Table 12.

The basic-value commodity prices are equivalent to farm-gate prices. That is, they represent prices received by the producer and exclude the margins (trade, transport, and commodity taxes) which are included in the prices paid for the commodities by users. (For the case of exports, user or purchaser prices are defined as prices at port of exit.) These margins are explicitly modeled in ORANI (Dixon et al., 1977, pp. 55-72). The importance of an explicit treatment of them in the model's price accounting system can be illustrated using the results presented in Table 12 .

Consider first commodity 1 (wool), which is almost all exported either directly or indirectly via sales to export industry 30 (Prepared Fibers). Since the level of exports for commodity 1 is determined endogenously in these results, its domestic price is controlled by the world price via eqns. (25) and (26)

$$
\begin{aligned}
& p_{i}^{\mathrm{e}}=-\gamma_{i} x_{i}^{(4)} \\
& p_{i}^{\mathrm{e}}=S_{\mathrm{BV} i} p_{i 1}+S_{\mathrm{m} i} p_{\mathrm{m}}
\end{aligned}
$$


where

$p_{i}^{\mathrm{e}}$ is the percentage change in the at-port export price of commodity $i$,

$x_{i}^{(4)}$ is the percentage change in the level of exports of commodity $i$,

$p_{i 1}$ is the percentage change in the basic-value price of commodity $i$,

$p_{\mathrm{m}}$ is the percentage change in the price of margins services,

$\gamma_{i}$ is the reciprocal of the foreign elasticity of demand for commodity $i$, and $S_{\mathrm{BV} i}$ and $S_{\mathrm{m} i}$ are, respectively, the shares of basic value and margins in the at-port export value of a unit of commodity $i$.

TABLE 14 Reciprocals of export demand elasticities $\left(\gamma_{j}\right)$ and projected effects of a $1 \%$ across the board tariff increase on export levels.

\begin{tabular}{llr}
\hline Commodity & $\gamma_{j}$ & Projection \\
\hline 1. Wool & 0.77 & -0.0338 \\
3. Wheat & 0.08 & -0.0343 \\
4. Barley & 0.05 & -0.0482 \\
5. Other cereal grains & 0.05 & 0.1035 \\
13. Fishing & 0.05 & -0.1875 \\
14. Iron & 0.05 & 0.0319 \\
15. Other metallic minerals & 0.05 & -0.0378 \\
16. Coal & 0.05 & -0.3663 \\
20. Meat products & 0.06 & -0.1942 \\
27. Food products n.e.c. & 0.05 & -0.4530 \\
32. Prepared fibers & 0.38 & -0.1092 \\
65. Basic iron and steel & 0.05 & -0.6683 \\
66. Other basic metals & 0.05 & -0.2722 \\
\hline
\end{tabular}

Table 14 shows the projected percentage changes in export volumes $x_{i}^{(4)}$ for the endogenous export commodities. The reduction in the volume of exports of commodity 1 $(0.034 \%)^{*}$ is associated, via eqn. (25), with a rise in its at-port export price $\left(p_{1}^{e}\right)$ of $0.026 \%$. If it is assumed that the costs of selling and delivering wool to the wharf have risen in line with the domestic consumer price index (i.e. assume $p_{m}=0.088$ ) then, from

\footnotetext{
* The other main sale of wool is to industry 30 which, in the absence of an import source for its wool inputs, will reduce its demand for domestic wool by a percentage amount equal to the reduction in its output ( 0.04 from Table 12$)$. Notice that this reduction plus the reduction in exports account for almost all of the reduction in the aggregate output of wool shown in Table 13. That is

$$
\begin{aligned}
y_{1} & \simeq S_{30}^{(1)} y_{1.30}^{(1)}+S^{(4)} x_{1}^{(4)} \\
& =0.10 \times-0.04+0.88 \times-0.034=-0.034
\end{aligned}
$$

since the share of the sales of wool absorbed by industry $30\left(S_{30}^{(1)}\right)$ is ca. 0.10 and the share absorbed by exports is ca. 0.88 .
} 
eqn. (26), it follows that the farm-gate price of wool must have risen by ca. $0.016 \%$.* This is confirmed by Table 13 .

Pursuing a similar chain of reasoning for commodity 3 (wheat), it is possible to explain the surprising prima facie result that, although the output and export volumes of wheat have fallen, the farm-gate price of wheat is projected to decline. Since the elasticity of export demand for wheat is assumed to be greater than that for wool (see Table 14), the rise in the at-port export price of wheat induced by the fall in its export volume is smaller than was the case for wool (in fact, from eqn. (25), $p_{3}^{\mathrm{e}}=-\gamma_{3} x_{3}^{(4)}=0.003$ ). In addition, the share of margins in the at-port price of wheat $\left(S_{\mathrm{m} 3}\right)$ is 0.29 , significantly higher than was the case for wool. Given this, eqn. (26) indicates that, assuming once again a rise in the price of margins of the same order as the rise in the general price level, the farm-gate price of wheat actually falls. ${ }^{* *}$ The rise in the cost of transferring wheat from the farm to the port more than absorbs the slight increase in the at-port price. The movements shown in Table 13 in the basic-value prices of the remaining agricultural commodities can be explained in analogous ways.

We turn now to the results for commodity outputs by industry, which reflect the operation of the CRETH product-product transformation triggered by the relative changes in the farm-gate prices of the commodities. Results for each zone will be considered in turn.

\subsubsection{Pastoral Zone}

Recall from Section 3.3.2 that, for the Pastoral Zone (industry 1), CRETH was estimated for three product groups: wool/sheep, meat cattle, and other products. Within each group, individual commodities are assumed to be produced in fixed proportions so that in Table 13 the projected percentage change in output is the same for each component of a commodity group. For example, the outputs of wool and sheep in the Pastoral Zone are both projected to decline by $0.026 \%$. Using eqn. (22c)' basic-value price changes for the commodity groups in the Pastoral Zone are as follows: wool/sheep $0.0023 \%$, meat cattle $-0.0518 \%$, other products $-0.0146 \%$. That is, the price at the farm gate of wool/sheep has risen relative to the prices of both the other groups. The extent of price-induced product transformation, however, will depend on the ease of transformation between products, as well as the relative price change. For example, consider the wool/sheep result. In eqn. (22b)', the difference between the price of wool/ sheep and the CRETH share weighted prices of the three product groups $\left(p_{r}(1)-\right.$ $\left.\Sigma_{q} p_{q}(1) R_{q}^{*}(1)\right)$ is +0.0252 , i.e. moderately favorable to wool/sheep. However, the estimated transformation parameter, $\phi$, for wool/sheep is 0.1041 (see Table 7). That is,

${ }^{*}$ The value for $S_{\mathrm{BV}_{1}}$ is 0.86 and that for $S_{\mathrm{m}_{1}}$ is 0.14 , so that

$$
\begin{aligned}
p_{11} & =\left(p_{1}^{\mathrm{e}}-S_{\mathrm{m} 1} p_{\mathrm{m} 1}\right) / S_{\mathrm{BV} 1} \\
& =(0.026-0.14 \times 0.088) / 0.86=0.016
\end{aligned}
$$

** That is, from eqn. (26):

$$
\begin{aligned}
P_{13} & =\left(p_{3}^{\mathrm{e}}-S_{\mathrm{m}_{3} p_{\mathrm{m}}}\right) / S_{\mathrm{BV}} \\
& =(0.003-0.29 \times 0.088) / 0.71=-0.03
\end{aligned}
$$


transformation elasticities between wool/sheep and the other two product groups are low. Hence the positive contribution to wool/sheep output from the relative price change in favor of wool/sheep is negligible, and the net effect is a contraction in wool and sheep output only a little less than the contraction in the output of the zone. In the case of cattle, however, the term $\left(p_{r}(1)-\Sigma_{q} p_{q}(1) R_{q}^{*}(1)\right)$ is -0.0289 and the transformation parameter, $\phi$, is 1.6129 , hence the larger contraction in output from the unfavorable relative price change and the overall output contraction considerably in excess of the contraction in the output of the zone. For the "other" category of commodities, the price of which has fallen relative to wool/sheep and increased relative to cattle, the CRETH relative price term $\left(p_{r}(1)-\Sigma_{q} p_{q}(1) R_{q}^{*}(1)\right)$ is +0.0083 , i.e. slightly favorable to "other products" and the transformation term is large $(\phi=4.5455)$. (It will be recalled from Section 3.3.3 that transformation possibilities are comparatively high between the "other products" category and competing products.) Hence the favorable output response from the relative price-induced transformation towards other products is large and the net effect is an expansion in the "other products" commodities.

\subsubsection{Wheat-Sheep Zone}

Only one composite commodity group (other products) was necessary for the estimation of CRETH parameters for the Wheat-Sheep Zone. The weighted average price increase for this other products group is, via eqn. $(22 \mathrm{c})^{\prime}, 0.0045 \%$. The remaining product classifications for this zone consist of single commodities so that the relevant basic-value price changes can be read directly from Table 13.

As remarked earlier, the Wheat-Sheep Zone is the classic example in the Australian context of a multiproduct, agricultural ind ustry. Table 7 reveals that transformation possibilities are much more uniform here than in the other two zones. Nevertheless, the influence of the comparatively high values of the transformation parameters $(\phi)$ for "other products" and wheat are evident in the results. In the case of "other products" the combination of a positive price term and a fairly high transformation parameter in eqn. (22b)' is sufficient to outweigh the industry activity variable $\left(z_{j}\right)$. Although the output of the Wheat-Sheep Zone as a whole falls, its output of "other products" increases.

\subsubsection{High Rainfall Zone}

The estimation of CRETH for the High Rainfall Zone once again involved only one composite commodity group. For this zone the weighted average price increase for the composite "other products" group is $0.0039 \%$. Again the transformation parameter $(\phi)$ for "other products" is significantly higher than others for this zone (Table 7). For the High Rainfall Zone, however, the decline in overall activity is much stronger than for the other two zones (see Section 4.3.2 and Table 13). The consequence is that its output of all products declines although a change in product mix in favor of "other products" is clearly evident in the results.

Before concluding this section, it is interesting to speculate on the plausibility of the results in Table 13. To a large extent, the results depend on the estimates of transformation and hence cross-price elasticities between product groups in each zone. These parameter estimates proved reasonably robust; see Vincent et al. (1980) for details. The weakest part of the story is obviously the assumption (forced upon us by the limitations 
of the data base for estimation) that commodities are produced in fixed proportions in the "other products" group. However, in all zones, the commodities in the "other products" group constitute only a small proportion of total commodity outputs. Thus, although the output of wheat in the Pastoral Zone is projected to increase, only $4 \%$ of wheat output is produced in this zone. The performance of the wheat commodity as a whole is tied closely to its performance in the Wheat-Sheep Zone, in which 93\% of the crop is produced.

In summary then, these differences in commodity performance across zones reflect the influences of the two most important features of the modeling of the agricultural sector, namely the recognition of regional variations in production technology and regionspecific transformation possibilities for commodities.

\subsubsection{Commodity Exports}

Projected percentage changes in export volumes for the 13 commodities for which exports are determined endogenously in this simulation are presented in Table 14. As explained in Section 4.3.2, the tariff increase generates domestic-cost increases, especially via wage indexation, and imposes a cost price squeeze on exporting industries. Export volumes are projected to contract for 11 of the 13 export commodities. Agricultural commodity exports generally decline less than nonagricultural exports, owing to the greater fixed-factor intensity of the land-using agricultural ind ustries.

Commodity 5 (other cereal grains) is the only agricultural commodity for which exports expand. The explanation for this expansion is given in the CRETH product transformation discussed in the previous section. In all zones, this commodity is part of the "other products" category. In each zone the product transformation term in eqn. (22b)' is positive and in two of the zones is sufficient to outweigh the effect of the contraction in zone activity. However, it will be noted that the expansion in commodity 5's exports exceeds the expansion in its output. That is, diversion from domestic sales to exports has taken place. The reason lies in commodity 5's comparatively large sales (58\% of total sales) to industry 22 (Flour and Cereal Products), the output of which contracts slightly.

Commodity 14 (iron) is the other commodity for which exports increase. As noted in Section 4.3.2, the producing industry (industry 12, Iron) is highly capital intensive so that its short-run output flexibility is very limited. Nevertheless, the projected output change for the industry is a decline of $0.011 \%$, as shown in Table 12 . Hence some diversion of iron output towards exports has occurred. In the base year, $36 \%$ of iron sales were to industry 63 (Basic Iron and Steel), itself the producer of an export commodity, and $63 \%$ were to exports. Industry 63 is particularly hard hit by increased domestic costs following the tariff increase. Both its output and exports contract sharply (Tables 12 and 14). The consequent fall in the domestic demand for iron induces a fall in the basic-value price of iron, via a squeeze on rentals on fixed factors in the Iron industry, sufficient to allow an expansion in iron exports.

\section{CONCLUDING REMARKS}

This paper has demonstrated that quite major modifications can be made, in a piecemeal fashion, to the specification of ORANI. The flexibility which this allows is important from the point of view of adapting the model to the requirements of alternative users. As explained in Section 2.3, the linear computational procedure is crucial in allowing this flexibility. 
The revisions to the specification of the agricultural sector which have been documented here have significantly increased the realism with which that sector is modeled in ORANI. The input-output treatment of agriculture, which was incorporated into ORANI 77, represents the sector as consisting of single-product, single-technology industries. The CRETH system adopted in ORANI 78, on the other hand, recognizes multiproduct enterprises and regional differences in technology and allows enterprises to alter their product mixes in response to changes in relative product prices. It is important to note, however, that the performance of the agricultural sector as a whole is not particularly sensitive to the respecification. The results discussed in Section 4 illustrate this. The response of agriculture to the general tariff increase simulated in that section depends primarily on how the sector is linked to the rest of the model, rather than on its internal structure. The modifications are nevertheless important from the point of view of capturing changes within the sector. Thus ORANI 78 expands the scope for ORANI applications in a way which should be of special interest to agricultural economists.

\section{ACKNOWLEDGMENT}

The authors are indebted to Tony Lawson for detailed comments on an earlier $\mathrm{draft}$.

\section{REFERENCES}

Adelman, I. and Robinson, S. (1978). Income Distribution Policy in Developing Countries: A Case Study of Korea. Oxford University Press, Oxford.

Alaouze, C.M. (1976). Estimation of the Elasticity of Substitution Between Imported and Domestically Produced Intermediate Inputs, IMPACT Preliminary Working Paper No. OP-07. Industries Assistance Commission, Melbourne, 32 pp.

Alaouze, C.M. (1977a). Estimates of the Elasticity of Substitution Between Imported and Domestically Produced Goods Classified at the Input-Output Level of Aggregation, IMPACT Working Paper No. O-13. Industries Assistance Commission, Melbourne, 33 pp.

Alaouze, C.M. (1977b). A Disaggregated Measure of Pressure of Demand: its Use in Import Demand Estimation, IMPACT Preliminary Working Paper No. OP-16. Industries Assistance Commission, Melbourne, $40 \mathrm{pp}$.

Alaouze, C.M., Marsden, J.S., and Zeitsch, J. (1977). Estimates of the Elasticity of Substitution Between Imported and Domestically Produced Commodities at the Four Digit ASIC Level, IMPACT Working Paper No. O-11. Industries Assistance Commission, Melbourne, 66 pp.

APMAA Research Team, University of New England (1977). Long Run Supply Response of Australian Wool Production Relative to the Price of Wool, Beef and Wheat. Report to AWC Wool Economics Research Committee.

Armington, P.S. (1969). The geographic pattern of trade and the effects of price changes. IMF Staff Papers, XVI.

Armington, P.S. (1970). Adjustment of trade balances: some experiments with a model of trade among many countries. IMF Staff Papers, XVII.

Arrow, K.J., Chenery, H.B., Minhas, B.S., and Solow, R.M. (1961). Capital-labour substitution and economic efficiency. Review of Economics and Statistics, 43(3):225-250.

Artus, J.R. and Rhomberg, R.R. (1973). A multilateral exchange rate model. IMF Staff Papers, XX. Australian Bureau of Statistics (1977). Australian National Accounts Input-Output Tables 1968/69, Canberra.

Bureau of Agricultural Economics (1973). The Australian Sheep Industry Survey: 1967/68 to 1970/ 71, Australian Government Publishing Service, Canberra.

Bureau of Agricultural Economics (1974a). The Northern Territory and Kimberley Region Beef Cattle Industry: $1968 / 69$ to $1970 / 71$, Beef Research Report No. 13. Australian Government Publishing Service, Canberra. 
Bureau of Agricultural Economics (1974b). The Queensland Beef Cattle Industry: 1968/69 to 1970/ 71, Beef Research Report No. 14. Australjan Government Publishing Service, Canberra.

Dervis, K. (1980). Analy sing the Resource Pull Effect of a Devaluation Under Exchange Control. Journal of Development Economics, $7: 23-47$.

Dixon, P.B. (1976). Effective exchange rates and the International Monetary Fund's multilateral exchange rate model: a review. Australian Economic Papers, 15:59-75.

Dixon, P.B. (1979). A Skeletal Version of ORANI 78: Theory, Data, Computations and Results, IMPACT Preliminary Working Paper No. OP-24. Industries Assistance Commission, Melbourne.

Dixon, P.B., Harrower, J.D., and Powell, A.A. (1976). SNAPSHOT, A Long Term Economy-Wide Model of Australia: Preliminary Outline, IMPACT Preliminary Working Paper No. SP-01. Industries Assistance Commission, Melbourne, 26 pp.

Dixon, P.B., Parmenter, B.R., and Powell, A.A. (1978). Structural adjustment and the macroeconomy. Paper presented at the Conference on the Economics of Structural Change and Adjustment, University of Newcastle, November $1978.48 \mathrm{pp}$.

Dixon, P.B., Parmenter, B.R., Ryland, G.J., and Sutton, J.M. (1977). ORANI, A General Equilibrium Model of the Australian Economy: Current Specification and Illustrations of Use for Policy Analysis, First Progress Report of the IMPACT Project, Vol. 2. Australian Government Publishing Service, Canberra, xi +297 pp.

Dixon, P.B. and Powell, A.A. (with a contribution by B.R. Parmenter) (1979). Structural Adaptation in an Ailing Macroeconomy. Melbourne University Press, Melbourne.

Freebairn, J.W. (1978). Projections of Australia's World Trade Opportunities: Mid and Late 1980s, IMPACT Working Paper No. I-07. Industries Assistance Commission, Melbourne, 88 pp.

Hanoch, G. (1971). CRESH production functions. Econometrica, 39:695-712.

Hasenkamp, G. (1976). Specification and Estimation of Multiple-Output Production Functions. Springer-Verlag, Berlin.

Johansen, L. (1974). A Multisectoral Study of Economic Growth, 2nd Edition. North-Holland, Amsterdam.

Marsden, J.S. and Milkovits, L.F. (1977). The Construction of Price and Quantity Indexes for Australian Trade Flows, IMPACT Preliminary Working Paper No. IP-03. Industries Assistance Commission, Melbourne, 76 pp.

Monypenny, J.R. (1975). APMAA 74: Model, Algorithm, Testing and Application, APMAA Report No. 7. Department of Agricultural Economics and Business Management, University of New England.

Powell, A.A. (1977). The IMPACT Project: An Overview - First Progress Report of the Impact Project, Vol. 1. Australian Government Publishing Service, Canberra. xix $+182 \mathrm{pp}$.

Powell, A.A. and Gruen, F.H. (1967). The estimation of production frontiers: the Australian livestock/cereals complex. Australian Journal of Agricultural Economics, 11(1):63-81.

Powell, A.A. and Gruen, F.H. (1968). The constant elasticity of transformation production frontier and linear supply system. International Economic Review, 9(3):315-328.

Ryland, G.J. and Vincent, D. (1978). Empirical Estimation of CRESH Production Function, IMPACT Working Paper No. O-12. Industries Assistance Commission, Melbourne, I5 pp.

Taylor, L. and Black, S.L. (1974). Practical general equilibrium estimation of resource pulls under trade liberalization. Journal of International Economics, 4(1): 35-58.

Tulpulé, A. and Powell, A.A. (1978). Estimates of Household Demand Elasticities for the ORANI Model, IMPACT Preliminary Working Paper No. OP-22. Industries Assistance Commission, Melbourne, 46 pp.

Vincent, D.P. (1977). Factor substitution in Australian agriculture. Australian Journal of Agricultural Economics, 21(2):119-129.

Vincent, D.P., Dixon, P.B., and Powell, A.A. (1980). The Estimation of Supply Response in Australian Agriculture: The CRESH/CRETH Production System. International Economic Review, 21: 221-242.

Vincent, D.P. and Parmenter, B.R. (1978). The Agricultural Sector of ORANI 78: Preparation of the Data Base, IMPACT Research Memorandum, ORANI Module.

Whalley, J. (1978). General Equilibrium Analysis of US-EEC-Japanese Trade and Trade Distorting Policies: A Model and Some Initial Findings. University of Western Ontario. Mimeograph. 


\section{Part Four}

Demographic Aspects of General Equilibrium Modeling 



\title{
ASPECTS OF THE DESIGN OF BACHUROO, AN ECONOMIC-DEMOGRAPHIC MODEL OF LABOR SUPPLY
}

\author{
Alan A. Powell \\ IMPACT Project Research Centre, University of Melbourne, Parkville, \\ Victoria 3052 (Australia)
}

\section{INTRODUCTION: THE IMPACT FRAMEWORK}

BACHUROO is one of four models under development by members of the IMPACT Project team. The Project itself, now some five years old, is an interagency initiative of the Australian federal government in cooperation with the University of Melbourne. Its aim is to facilitate the analysis of the impact of economic, demographic, and social changes on the structure of the Australian economy. Here "structure" refers particularly to the industrial composition of GDP, the occupational composition of employment, and patterns of international trade. The Project has concentrated on data mobilization, model building, human capital formation in the areas of model building, manipulative, and interpretative skills, and on associated computer systems. Further institutional and historical details may be found in Dixon et al. (1979, pp. ix-xi), Powell (1977, pp. 4-14), Powell and Parmenter (1979), and Rattigan (1976).

Besides BACHUROO, the other models of the IMPACT Project are ORANI (a large computable general equilibrium model in the Johansen (1960) family), MACRO (a small continuous-time disequilibrium model in the Bergstrom-Wymer (1976)-Jonson (1976) family), and SNAPSHOT (a non-linear programming model in the Sandee (1960)-Bruno (1966)-Manne (1963)-Evans (1972) family). The last of these is designed to be used almost exclusively in stand-alone mode and need not be considered further. It is necessary, however, to understand BACHUROO's relationship to MACRO and ORANI in order to obtain a clear idea of the role of BACHUROO. These three models, when linked, will constitute IMPACT's medium-term model.

ORANI is a very large model which can be used to disaggregate an exogenously given set of macro aggregates into activity levels for ca. 100 input-output industries. In so doing, it endogenizes demands for labor disaggregated by the nine occupational groups shown in Table 1. Relative prices, profitability, imports, exports, and a large number of other variables are also endogenized by ORANI. MACRO's role is to provide 
TABLE 1 Major occupation groups used in IMPACT.

1. Professional White Collar

2. Skilled White Collar

3. Semi- and Unskilled White Collar

4. Skilled Blue Collar (metal and electrical)

5. Skilled Blue Collar (building)

6. Skilled Blue Collar (other)

7. Semi- and Unskilled Blue Collar

8. Rural Workers

9. Armed Services ${ }^{a}$

a Armed Services are included for completeness of coverage. They are usually excluded from labor-force statistical collections and are modeled largely exogenously in IMPACT, although they impinge indirectly by employing persons who would otherwise be available for the civilian labor force. A separate group "Lecturers and Teachers" is sometimes extracted from groups 1 and 2, as in Williams (1980) and Tulpulé (1980a).

macroeconomic closure for ORANI in short- and medium-term applications, ${ }^{*}$ while BACHUROO's role is to provide closure with respect to the labor market. ORANI endogenizes, at a given set of wage rates, the demand for labor in different occupations; it is BACHUROO's task to endogenize the corresponding supplies. Figure 1 is a schematic diagram of the planned linkages between the three models for short- and medium-term applications.

The current (November 1980) state of development of the IMPACT models is as follows. SNAPSHOT is fully developed and has been validated (Dixon et al., 1982) and used to investigate structural aspects of currently foreseen technical changes in production techniques (Dixon and Vincent, 1980). ORANI has gone through two complete development cycles (Dixon et al., 1977; Dixon et al., forthcoming); only a comparatively minor set of additional enhancements in model design is currently contemplated. Some 18 applications papers using the ORANI model have been written by members of the IMPACT team, and several others by other researchers. ${ }^{* *}$ MACRO has been developed by a separate, independent team at the Reserve Bank of Australia; it has been through two cycles of development (Jonson et al., 1978; Jonson and Trevor, 1979; Jonson et al., 1980) and adapted for use by IMPACT (Cooper and McLaren, 1980). The methodology

\footnotetext{
* Short- and medium-term applications are those whose focus does not extend beyond (say) three years. ORANI may also be used for long-term projections - see Vincent (1980). BACHUROO will also be suitable for long-term projections.

** A catalogue of publicly available documentation is available from the IMPACT Information Officer, Mr. M. Kenderes, Industries Assistance Commission, P.O. Box 80, Belconnen, 2616, ACT, Australia. In terms of the catalogue nomenclature, the following papers report ORANI applications: R-01, R-02, R-03, OP-1 9, OP-25, OP-26, IP-04, G-03, G-04, G-06, G-1 7, G-18, G-22, G-23, G-25, $\mathrm{G}-26, \mathrm{G}-27, \mathrm{G}-28$.
} 


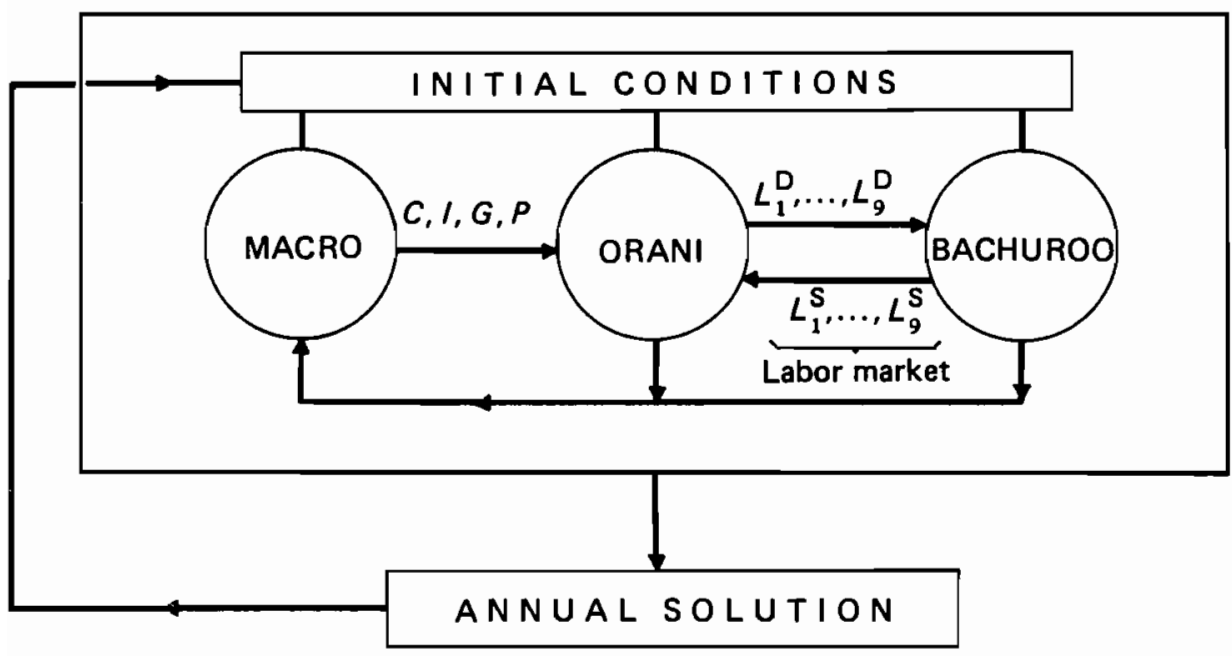

FIGURE 1 Simplified diagram of the medium-term model. The levels of consumption $C$, real investment $I$, real government spending $G$, and the general price level $P$ may be thought of as originating in MACRO. ORANI disaggregates these into 113 input-output industries and determines relative prices of commodities, imports, and exports by input-output industry, and (if wage rates are given) labor demands by nine occupations. BACHUROO determines the supplies of labor by occupation. Excess demand for or supply of labor can feed back into the macroeconomic environment. Interactively the three models will, given a set of initial conditions, produce an annual solution which then determines a new set of initial conditions for a second annual solution, and so on. (After Powell and Parmenter, 1979.)

for interfacing a Johansen model (like ORANI) with a Bergstrom-Wymer model (like MACRO) has been developed, and experimental interfacing of these two models is well under way (Cooper and McLaren, 1980). BACHUROO, the topic of this paper, is only partially developed. A major limitation has been the failure of the Project's sponsor to commit sufficient high-level professional resources to this model. ${ }^{*}$ Other factors accounting for the delay include the prevalent slack labor market, which has made supplyside constraints less urgent in the perception of policy makers, and the abysmal state of the available Australian labor market data base (Mumme et al., 1978).

With this much as background, the aim of the present paper is to review the design of IMPACT's demographic and labor supply model, BACHUROO, and to report on progress in its construction. Aspects emphasized in this account are those which are believed to be of potential methodological interest to other modelers.

\section{THE STRUCTURE OF BACHUROO}

The approach followed can be discussed conveniently in terms of attempts to answer the following hypothetical questions for a given projection date, given a

* The urgent need to do so has been pointed out publicly by the Project's director, as early as 1977 . See Powell (1977, p. 173). 
particular scenario on a host of relevant economic variables (the values of many of which are endogenized by ORANI-MACRO):

(i) How many people of potential working age would there be in the population?

(ii) How many of these people would, given the postulated conditions, choose to work?

(iii) What would the occupational composition of this hypothetical workforce be?

(iv) For those who would choose to work, what number of hours of work per week would they offer under the postulated conditions?

Because of the strong links between fertility and labor-force participation by females, (i) and (ii) are best handled simultaneously. The modules of BACHUROO dealing with demographic accounting and with family formation, female workforce participation, and fertility, are referred to jointly as the demographic core of the model (Sams, 1979). Closely allied is the question of household formation, which is treated below under the same heading. For question (iii) a new approach has been adopted based on the concept of an occupational-transformation frontier (Parham and Ryland, 1978; Craigie et al., 1979; Williams, 1980). This allows, within the limits set by the existing composition of the skills of the workforce, a flexible response in its occupational composition to changing occupational wage relativities and relative risks of unemployment. In coming to terms with question (iv) the standard neoclassical model of labor-leisure choice has been extended to include demographic linkages and an endogenous marginal wage rate (Powell et al., 1977; Powell, 1979). Our approaches to (iii) and (iv) are dealt with below under the headings occupational disaggregation and leisure and hours worked, respectively.

\subsection{The Demographic Core*}

The major roles of the demographic core are to provide projections of the population by sex, marital status, and single years of age; of the size of the labor force by sex, marital status, and three age groups; and of the number of households by sex, marital status, and quinquennial age group of the head. Conventional demographic accounting techniques have been employed for the purpose of projecting the population but have been extended to allow their integration with an econometric model which endogenizes changes in the behavioral characteristics of the population in response to changes in the social and economic environment.

The linkage between the econometric model and the demographic accounting equations is through such variables as propensities to marry, divorce, and remarry; the means and variances across ages at given points of time of the age-specific rates of marriage, divorce, and remarriage; the mean and variance at given points of time of desired family size; and the number of first nuptial confinements. These time-dependent parameters are used to summarize various age distributions which appear in the demographic accounts. They appear, in the econometric model, as endogenous behavioral variables. The econometric model relates them to each other, to other endogenous variables (such as child

\footnotetext{
* This section draws heavily on Sams (1979) and on Sams and Williams (1980).
} 
quality and female labor-force participation rates), and to a set of exogenous economic and social variables (such as the female/male wage relativity and infant mortality) (Filmer and Silberberg, 1977).

The econometric model is based on the "new home economics"," thus providing a consistent framework of family decision-making within which family formation, fertility, and labor-force participation by women are interrelated. Within this framework, fertility is treated as a sequential decision-making process in which we attempt to capture the succession of marriage, first confinement, and the progression to further children. The central construct in this decision process is the implicit desired ultimate family size which is related to the "child quality" concept of the "new home economics" and to the social and economic environment (Filmer and Silberberg, 1977; Sams, 1979; Sams and Williams, 1980). The relationship of this econometric model to the rest of the demographic core is shown in Figure 2.

Within the demographic accounting framework we explicitly deal with 101 single years of age for four marital states: never married, married, divorced, and widowed; and with five types of marital status change for each age: marriages of persons never previously married, marriages of divorced and widowed persons, plus divorces and widowings. No attempt is made to build 101 separate age-specific equations for each of these changes. In general, a three-parameter gamma distribution ${ }^{* *}$ is fitted across ages in each year of the sample period (1921-1976) (Williams, 1979). This generates a time-series of parameters with the following interpretation:

(a) an index of propensity (to first marry, to remarry, or to divorce); that is, the area under the frequency distribution of age-specific rates (of first marriage, remarriage, or divorce);

(b) the mean of the age distribution of age-specific rates (of first marriage, etc.);

(c) the variance of the age distribution of the age-specific rates.

Three typical approximations are illustrated in Figure 3, and the time-series for the parameters are illustrated in Figure 4. The condensation of the age distributions of the behavioral characteristics in this way provides a manageable number of endogenous variables for the econometric model. Working in the reverse direction, the values of the parameters supplied as projected endogenous variables by the econometric model can be used to construct the age distributions of the relevant variables. Thus the entire age distribution of the behavioral variables of interest can be projected in response to changes in exogenous variables. Given the highly disaggregated level at which we seek to track the population

\footnotetext{
* For a collection of papers defining the scope of the "new home economics", see Schultz (1973).

** For example, the divorce rate $d(x)$ at age $x\left(x>x_{0}\right)$ is approximated as

$$
d(x)=\left(P / \alpha^{\beta} \Gamma(\alpha)\right)\left(x-x_{0}\right)^{\alpha-1} \exp \left[-\left(x-x_{0}\right) / \beta\right]
$$

where $P$ is the index of the propensity to divorce, $M \equiv \alpha \beta+x_{0}$ is the mean of the age distribution of the age-specific divorce rate, and $V \equiv \alpha \beta^{2}$ is the variance of the age distribution of the age-specific divorce rate. On occasion, it has been necessary to go as far as five parameters (of which three are time dependent and two are stationary) in order to capture distributions accurately. See Williams (1979, appendix 1).
} 


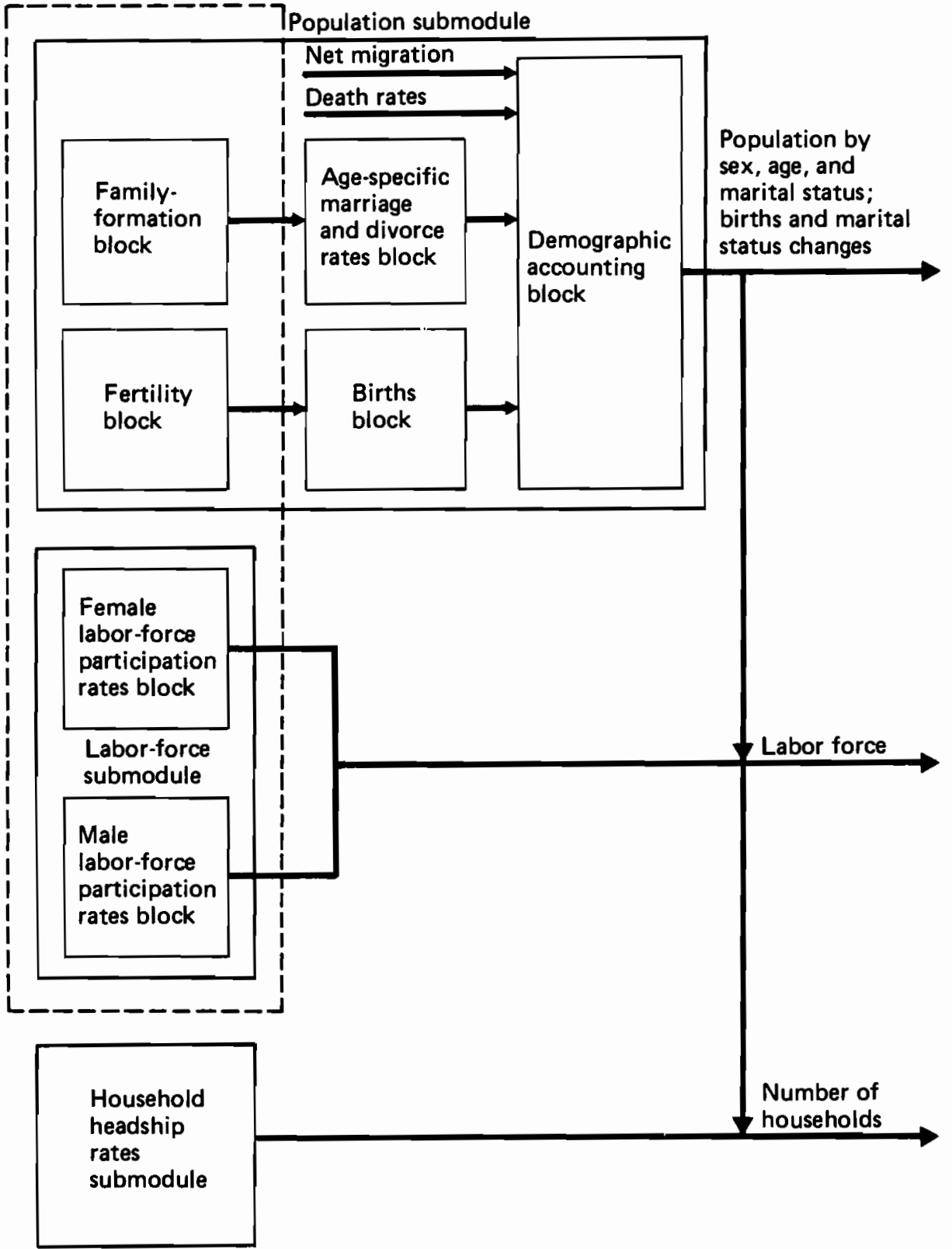

FIGURE 2 Schematic diagram of the demographic core of BACHUROO. The econometric model of family formation, fertility, and labor-force participation is contained within the dashed lines. (After Sams, 1979.) 


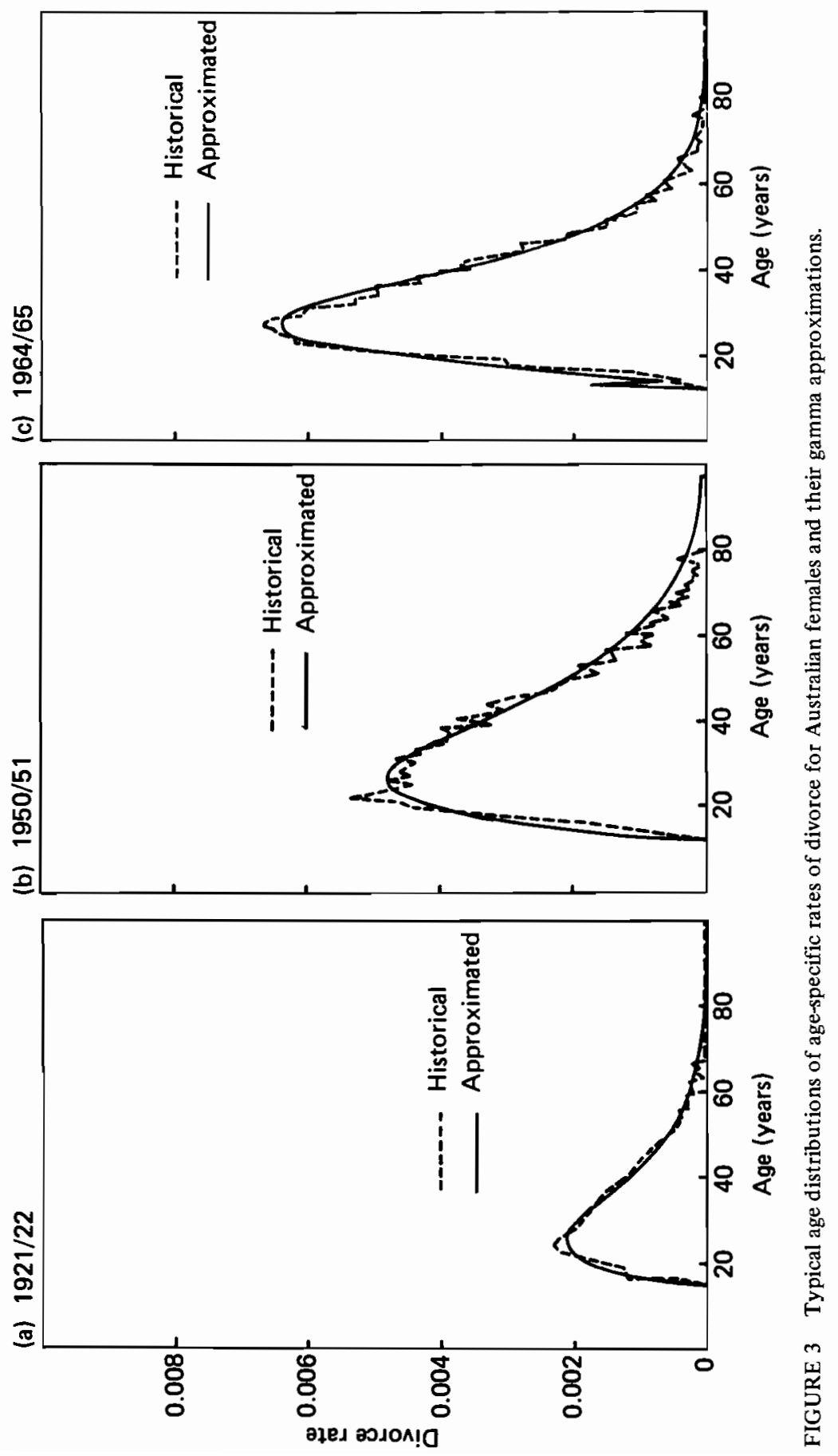




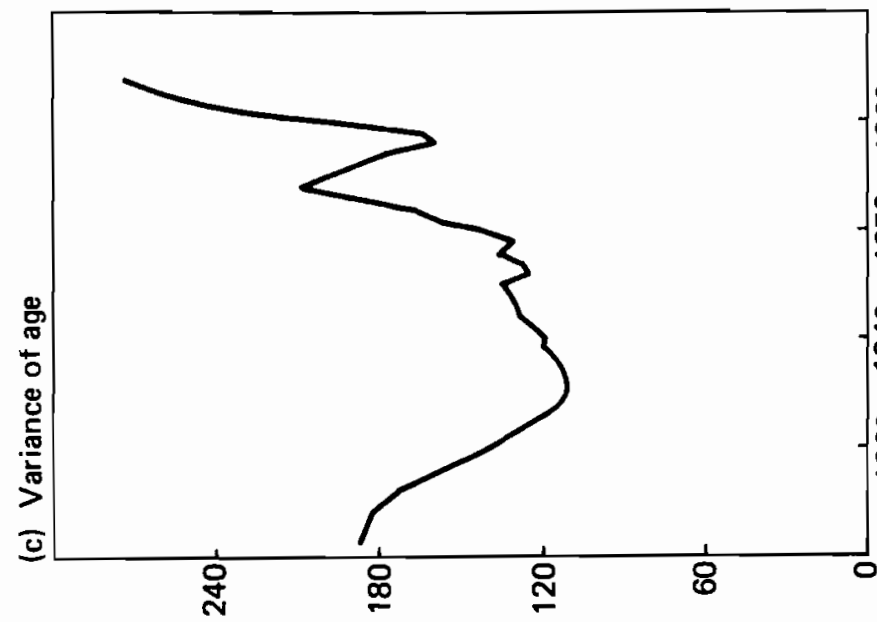

용
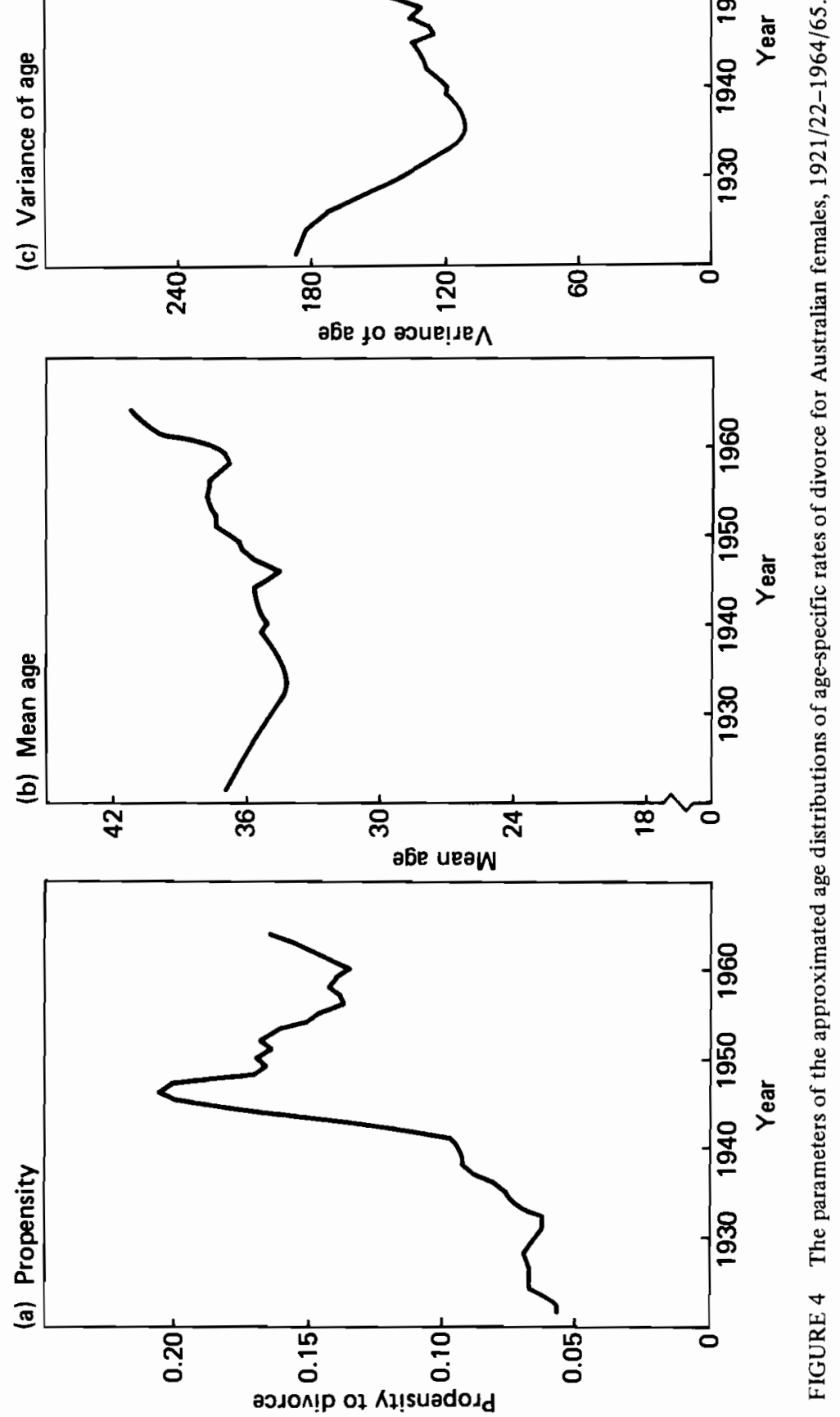
over time, this is an essential step in interfacing the demographic accounting framework with the econometric model.

The econometric model introduces certain relationships between the demographic variables, but further strong relationships are also imposed by careful attention to the preservation of necessary stock-flow identities within the accounting framework. For example, widowings are endogenized by the deaths of married men. As in conventional demographic modeling, the previous history of the population (as reflected in its age structure) exerts a strong influence on the evolution of the demographic variables through simulated time. Thus, to quote Sams (1979, p. 37):

"[Our approach to] the modelling of age-specific rates of marriage and divorce enables the [demographic core] to separate the effects of changes in behaviour from changes in the demographic structure of the population due to the mere effluxion of time (i.e., ageing). This simplifies the task of the econometric model by limiting its role to capturing the behavioural changes and not those arising from mechanical changes in the population structure. Estimates of the labour force participation rates are among the behavioural variables modelled in [the econometric model], and when these are combined with the population estimates, the demographic core provides estimates of the total Australian labour force."

At the time of writing, operational prototypes of each component of the demographic core shown in Figure 2 exist and are documented. The econometric models of family formation, fertility, and labor-force participation (Filmer and Silberberg, 1977), and of household headship (Williams and Brooks, 1978) are at the respecification and re-estimation stage. Illustrative projections with the demographic core in stand-alone mode are the next priority.

\subsection{Occupational Disaggregation}

Given the size of the workforce, what could its occupational composition be expected to be at any given set of wage relativities, if people were able to locate themselves in the most preferred occupations for which they are formally qualified? The answer to this depends on the length of run envisaged. In the annual framework used in BACHUROO, the educational endowments are taken as given. In the longer run, individuals and the (largely public-sector) education system can vary the skill mix. The lack of a suitable data base makes modeling the education system in Australia extremely difficult. (To obtain even an 11-year series of Australian student statistics on a compatible basis required a major in put by the Project team itself in primary data compilation and editing; see Craigie (1980).) At least for the foreseeable future, the throughputs of the educational sector will be treated exogenously.

The flavor of our approach to occupational disaggregation can be illustrated by Williams' (1980) treatment of within-year interoccupational mobility. Net transfers into the $j$ th occupation desired by appropriately qualified people currently in the workforce are denoted $S M_{. j}$, where $j=1,2, \ldots, 9$ refers to the occupational split shown in 
Table 1. ${ }^{*}$ The net desired flow of these transferees, at the given conditions of employment, from occupation $i$ to occupation $j$ is $S M_{i j}$. Thus, by construction

$$
-S M_{i j} \equiv S M_{j i}
$$

and

$$
S M_{. j} \equiv \sum_{i} S M_{i j}
$$

Given the skill endowments of the workforce at the beginning of the year, there exists a transformation frontier defining attainable occupational mixes. The paradigm adopted by Williams assumed that year-to-year movements in the desired occupational mix maintain equilibrium in the sense that the certainty-equivalent wage bill is maximized in the light of the prevailing expected certainty-equivalent occupational wage relativities $\left\{R_{j}\right\}$ (which are taken as predetermined). ${ }^{* *}$

This basic mechanism is illustrated in Figure 5. $Q_{1}$ and $Q_{2}$, respectively, are the supplies of workers in occupations 1 and 2 . The movement from $A$ to $B$ is seen as a response to a change in the ratio of certainty-equivalent occupational wage rates, $R_{1} / R_{2}$, from $\tan \theta_{\mathbf{A}}$ to $\tan \theta_{\mathbf{B}}$. Changes in certainty-equivalent wage rates, therefore, are identified with shifts around the transformation frontier. It is supposed that apart from certainty-equivalent wage rates $\left\{R_{1}, R_{2}, \ldots, R_{9}\right\}$, there are $K$ other explanatory variables $\left\{N_{1}, N_{2}, \ldots, N_{K}\right\}$ which generate changes in occupational labor supplies $\left\{Q_{1}, Q_{2}, \ldots\right.$, $\left.Q_{9}\right\}$. These other explanatory variables are to be identified with shifts of the occupational supply frontier shown in Figure 5, rather than with shifts around it. In the absence of suitable data, the $\left\{N_{k}\right\}$ in the empirical work are proxied by log-linear trends. In pragmatic spirit, it is assumed that a double-log functional form

$$
d \log Q_{j}=\sum_{i=1}^{9} \eta_{j i} d \log R_{i}+\sum_{k=1}^{K} \epsilon_{j k} d \log N_{k}
$$

will yield an adequate approximation to the supply functions. Parametric restraints induced by assumptions concerning the functional form of the transformation frontier reduce the 81 wage coefficients $\left\{\eta_{j i}\right\}$ to a more manageable number. In the case of the CRETH (Dixon, 1976) transformation frontier, these 81 coefficients are reduced to just nine transformation parameters (Craigie et al., 1979). In the case of the extremely meager data base available for fitting (4), however, nine parameters were too many; consequently Williams (1980) fitted a CET (Constant Elasticity of Transformation) transform of (4).

\footnotetext{
* Here "desired" means desired by those who would transfer if the opportunity became available, and who are formally qualified to make the transfer. In the case of a potential transferee to two or more occupations other than the one currently occupied, only the most preferred transfer is counted in $S M_{. j}$.

${ }^{* *}$ Here "certainty equivalent" wage rate for occupation $j$ means the actual after-tax hourly wage rate in $j$ multiplied by one minus the occupation-specific unemployment rate. "Expected" operationally implies that actual lagged data are used.
} 


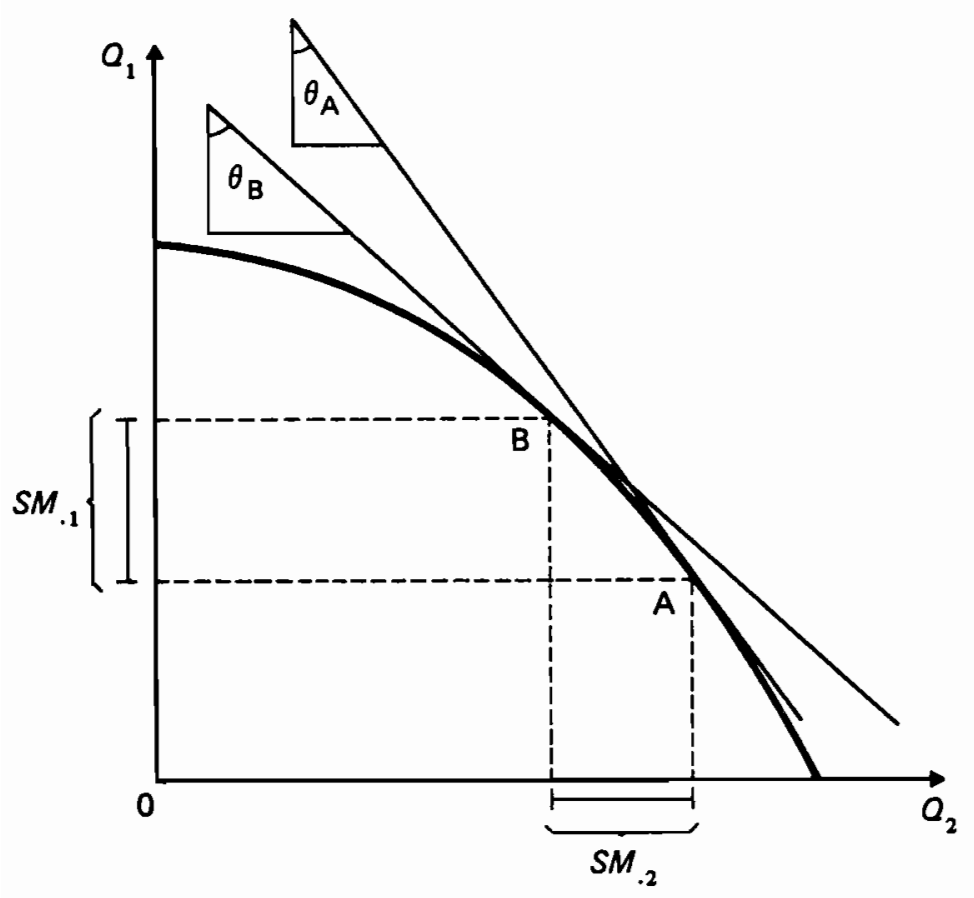

FIGURE 5 Occupational transformation frontier in the two-occupation case. Initially the certaintyequivalent occupational wage ratio $\left(R_{1} / R_{2}\right)$ is $\tan \theta_{\mathrm{A}}$. This ratio then changes to $\tan \theta_{\mathrm{B}}$, resulting in a new equilibrium occupation mix at $\mathrm{B}$.

Under this specification, the 81 coefficients $\eta_{j i}$ can all be expressed as functions of just one unknown transformation elasticity, $\tau$. Using the approximation

$$
d \log Q_{j} \doteq S M_{. j} / Q_{j}
$$

and using the CET postulate to constrain the $\eta_{i j}$ coefficients to be

$$
\eta_{i j}=\tau S_{j} \quad(\text { for all } i, \text { where } j \neq i)
$$

and

$$
\eta_{j j}=-\tau\left(1-S_{j}\right)
$$

(where $S_{j}$ is the share of occupation $j$ in the certainty-equivalent wage bill), the best estimate obtainable from the data is $\hat{\tau}=-1.3(t=3.6)$. Via eqns. (6) and (7) this estimate enables the $\left\{\eta_{i j}\right\}$ to be estimated.*

\footnotetext{
* This abbreviated account, it should be noted, has not dealt with the extremely difficult problem of generating data on the supply of transferees, $\left\{S M_{. j}\right\}$ as distinct from the actual number of transfers. Given the undoubted existence of a non-market clearing wage structure in one of the two years for which data were available, the natural starting point was Fair and Jaffee (1972). Strong priors on labor demand plus data on unemployment were essential ingredients in development of the $\left\{S M_{. j}\right\}$. Further details are given by Williams (1980).
} 
The remaining element of flexibility in the occupational mix not captured in Williams' work is that due to the flexibility of new workforce entrants. Although when an individual commits himself to a particular stream of higher education and/or vocational training he may have in mind a preferred occupation which he would like to enter upon graduation, he may nevertheless settle for another occupation if jobs are easier to find in it and/or if this other occupation commands higher relative wages at graduation than were expected when the educational decision was taken. His flexibility will be limited only by the formal requirements for entry into the various occupations. Thus the work planned by Craigie et al. (1979), but not yet implemented, uses an approach similar to that described above. Since the proposed work attempts to identify the shift variables $\left\{N_{1}, N_{2}, \ldots, N_{k}\right\}$ with the current levels of stocks of various kinds of human capital, the approach is somewhat more ambitious. For reasons mentioned in the introduction to this section, the $\left\{N_{k}\right\}$ themselves, being de termined by the initial stocks of people of given educational levels as updated by the throughputs of the educational system, are to be treated as exogenous.

At the time of writing, empirical work on occupational mobility within the workforce is complete in the sense that the information content of the currently available stock of data has been exhausted; the quality of the estimates could doubtless be improved if and when better and/or more data were to become available. A data base and a theory to extend this work to cover all elements of occupational flexibility within the work force are available: currently professionals to do the work are not. It is hoped that this situation can be rectified within the next six months.

\subsection{Leisure and Hours Worked}

In Sections 2.1 and 2.2, descriptions were given of our approaches to the determination of the size and age structures of the population and workforce, and to the occupational composition of the latter. What remains to be discussed is the endogenization of the number of hours supplied by members of the workforce having a given occupational affiliation.

The framework adopted is the standard neoclassical labor-leisure choice paradigm in which the shadow price of "leisure" is the wage rate foregone for an additional hour of work voluntarily declined. ${ }^{*}$ Because of the increasing importance of part-time work and of progressive income-tax scales and penalty rates for overtime, the paradigm required cannot, as in the early literature, take the after-tax marginal wage rate as an exogenous constant which is independent of the number of hours worked. Powell et al. (1977) extended the standard framework to allow the after-tax marginal wage to be an arbitrary, twice-differentiable function of the number of hours worked. This was in the context of a Klein-Rubin utility function. Burtless and Hausman (1978) worked with an arbitrary, not necessarily convex, budget constraint, and with a particular utility function (namely, that implied by a constant-elasticity labor-supply function). Woodland and Wales (1979) also considered an arbitrary budget constraint allowing for endogenous

\footnotetext{
* Early references include the work of Robbins (1930), Paish (1941), and Gilbert and Pfouts (1958). For more recent contributions see Betancourt (1973), Abbott and Ashenfelter (1976), Phlips (1978), and Barnett (1979).
} 
variations in the shadow price of leisure. Their utility specification was CES. Finally, Powell (1979) gave a general treatment of the problem in which both the hours/earnings offer curve (relating after-tax labor income per week to the number of hours worked) and the utility function are arbitrary. This latter paper by Powell covers all cases of movements in the supply of hours of an individual which are induced by changes in the parameters of the hours/earnings curve and/or of the utility function, except those changes involving discrete jumps and comer solutions. The extension of the conceptual framework to handle the latter is trivial; its empirical implementation, however, involves formidable difficulties.

The basic ideas involved are illustrated in Figures 6 and 7. Figure $6 \mathrm{~b}$ is the after-tax marginal hourly wage-rate schedule derived from a hypothetical hours/earnings offer curve which rewards overtime at steadily increasing penalty rates. This induces the nonconvex budget constraint shown in Figure 7. Non-corner solutions are generated by points of tangency between indifference curves and the budget constraint. With $y_{0}$ denoting broadly-defined "leisure" (i.e. time not spent in paid employment), the fundamental equation from which elasticities of hours supplied can be inferred (Powell, 1979) is

$$
y_{0 \theta}=y_{0 \alpha}\left[G_{\theta}-\frac{\lambda}{\lambda_{\alpha}} y_{0 \alpha} \psi_{\theta}\right]+\frac{\lambda \psi_{\theta}}{u_{00}+\lambda \psi^{\prime}-u_{0}^{\mathrm{T}} \mathrm{U}^{-1} u_{0}}
$$

in which $y_{0 \theta}$ is the vector of the slopes of the demand for "leisure" (equal to the negative of the slopes of the supply of hours) with respect to the parameters $\theta$ of the hours/ eamings offer curve; $\boldsymbol{G}_{\theta}$ is the vector of derivatives of after-tax earnings with respect to the parameters $\theta ; \lambda$ is the marginal utility of (optimally spent) income; $\lambda_{\alpha}$ is the derivative of the marginal utility of income with respect to non-labor income, $\alpha ; y_{0 \alpha}$ is the derivative of the demand for "leisure" with respect to non-labor income; $\psi_{\theta}$ is the vector of derivatives of the after-tax marginal wage rate with respect to the parameters $\theta ; u_{00}$ is the second derivative of the utility function with respect to the amount of "leisure" consumed; $\psi^{\prime}$ is the derivative of the marginal wage rate with respect to hours worked; $\boldsymbol{u}_{0}$ is the vector of derivatives with respect to the quantities of commodities consumed of the marginal utility of "leisure"; and $U$ is the principal sub-matrix of the Hessian of the utility function corresponding to arguments other than "leisure".

To apply eqn. (8) empirically, the following steps are necessary:

(i) the adoption of a particular functional form for the utility function;

(ii) the identification of groups of workers whose utility parameters could reasonably be supposed to be homogenous;

(iii) the adoption of a particular functional form for the hours/earnings offer curves;

(iv) the identification of groups of workers who could reasonably be assumed to face the same hours/earnings offer curves;

(v) the estimation of the relevant utility parameters for the groups isolated under (ii); and finally,

(vi) the estimation of the offer curves isolated under (iv).

In the work by Tulpule $(1980 \mathrm{a}, \mathrm{b})$ which is now described, the functional form of the utility function adopted is Klein-Rubin, i.e. 
(a)

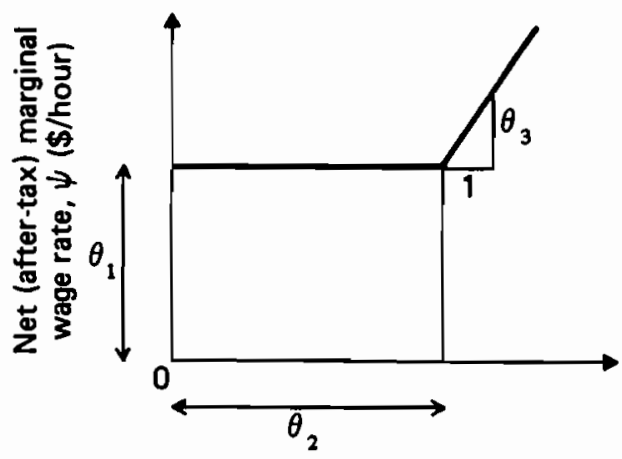

Hours worked per week, $H$ (b)

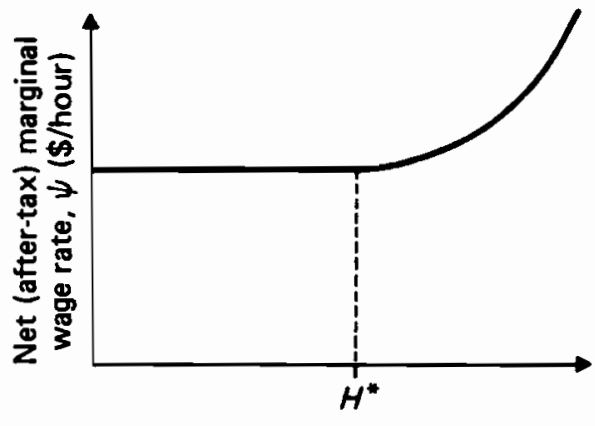

Hours worked per week, $H$

FIGURE 6 (a) A simple earnings/hours schedule with parameters $\theta,(\$ / h$, basic hourly wage rate), $\theta_{2}$ (h, defining the standard working week), and $\theta_{3}(\$ / h / h$, steepness of the overtime progression). $G(H)$ is the area under the curve. (After Powell, 1979.) (b) Hypothetical earnings/hours schedule in which the after-tax marginal hourly wage rate is constant up to $H^{*}$ hours per week, and thereafter steadily increases.

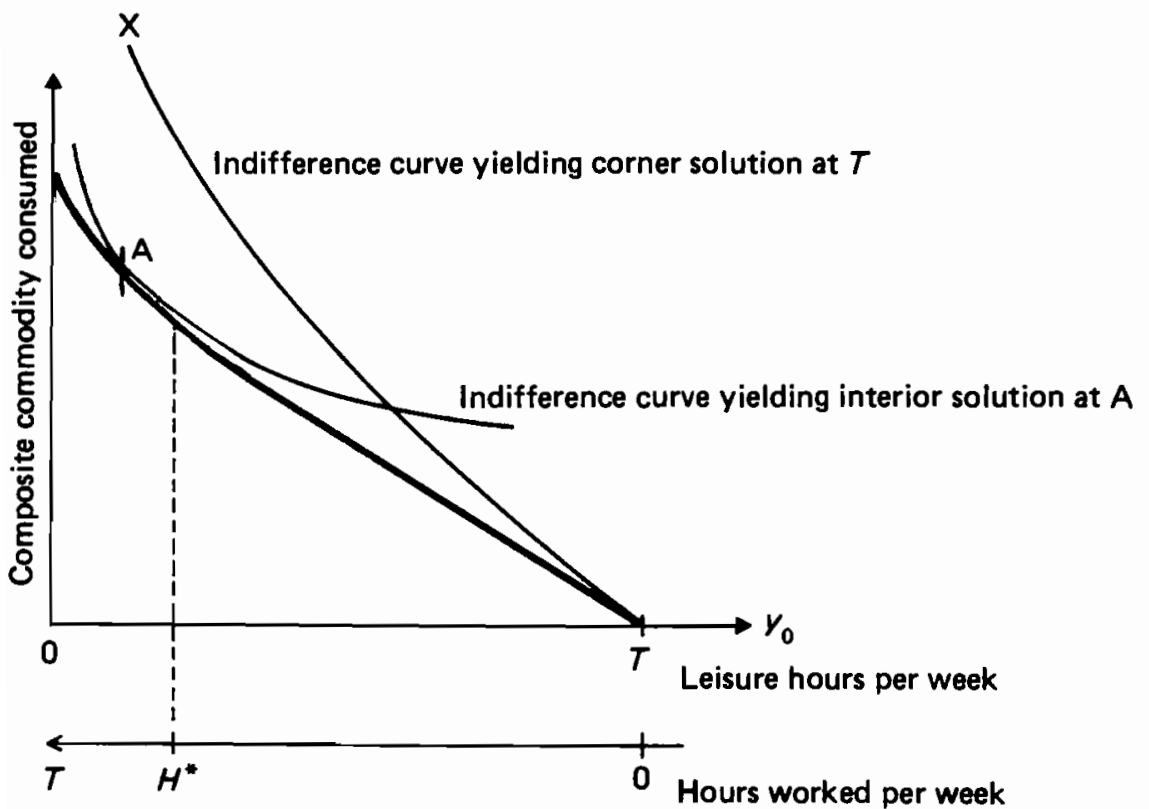

FIGURE 7 The heavy line is the budget constraint of a consumer/worker who faces a $\psi$ schedule which is flat from 0 to $H^{*}$ hours, but which then rises. The relative convexity of this line and of the indifference map determines whether the solution point is in the interior of $[0, T]$ or at a corner. (After Powell, 1979.) 


$$
u=\sum_{i=1}^{n} \beta_{i} \ln \left(x_{i}-\gamma_{i}\right)+\beta_{\mathbf{L}} \ln \left(L-\gamma_{\mathbf{L}}\right)
$$

in which the betas and gammas are parameters. The arguments of this function are ( $n-1)$ commodities, savings (whose associated gamma is zero), and "leisure", $L$, consumed. ${ }^{*}$ The groups of workers distinguished are:

(a) married males with working wives;

(b) married working females;

(c) married males with non-working wives;

(d) single males;

(e) single females.

The gamma parameters are chosen in such a way as to be compatible with international evidence on the Frisch parameter (Lluch et al., 1977). Time-series evidence is then used to estimate the marginal leisure preference parameters, $\beta_{\mathbf{L}}$. The estimates obtained for the different groups of workers are shown in Table 2.** These values are to be interpreted as the fraction of an additional dollar of "full income" (i.e. of labor plus non-labor income, plus the imputed value of leisure) which would be "spent" in the implicit purchase of one's own time by declining to work additional hours.

TABLE 2 Estimates of marginal leisure preference parameters, $\beta_{\mathbf{L}}$, for different types of workers.

\begin{tabular}{lc}
\hline Worker type & $\begin{array}{c}\text { Estimated } \\
\beta_{\mathbf{L}}{ }^{a}\end{array}$ \\
\hline 1 Married male with working wife ${ }^{b}$ & 0 \\
2 Working wife & 0.2743 \\
3 Married male with non-working wife & $(49.98)$ \\
4 Single male & 0 \\
5 Single female & 0.2760 \\
& $(27.56)$ \\
& 0.2879 \\
Total workforce & $(28.96)$ \\
\hline
\end{tabular}

$a$ Ratio of parameter estimate to estimated asymptotic standard error shown in parentheses.

${ }^{b, c}$ Constrained estimate. In absence of constraint, estimated values would have been -0.0443 and -0.1041 , respectively. Source: Tulpulé (1980a, p. 37).

\footnotetext{
* Howe (1975) has shown that introducing savings directly into the utility function with unit price and zero gamma provides a heuristic device for the derivation of Lluch's (1973) extended linear expenditure system, thus giving the maximization of (9) an intertemporal interpretation.

** In the case of married males, unconstrained estimates of $\beta_{L}$ turn out to be negative (see footnotes to Table 2). In the raw data this is reflected by a very small response in hours worked by married males, despite a substantial increase in income. The matter is discussed below (p. 293).
} 
The functional form adopted by Tulpule (1980b) for the hours/earnings offer curves is

$$
G(H)=\theta_{0} H \quad\left(\text { when } \quad H \leqslant \theta_{2}\right)
$$

and

$$
G(H)=\theta_{0} H+\theta_{1}\left(H-\theta_{2}\right)^{3} \quad\left(\text { when } \quad H>\theta_{2}\right)
$$

in which $G(H)$ is the after-tax weekly wage packet when $H$ hours per week are worked, $\theta_{0}$ is the after-tax hourly wage rate up to standard hours $\theta_{2}$ per week, and $\theta_{1}$ is the overtime progression parameter. In qualitative terms, the schedule defined by eqns. (10a) and (10b) would resemble Figure $6 \mathrm{~b}$. To obtain groups of workers displaying a reasonable degree of homogeneity with respect to the offer curves confronting them, the nine occupational groups in Table 1 are further cross-classified by age (junior, adult) and by sex. The parameters $\theta_{0}, \theta_{1}$, and $\theta_{2}$ are then estimated from cross-sectional evidence. An example of these estimates is shown in Table 3.

TABLE 3 Estimated parameters of hours/earnings offer curves for junior males by occupation,

\begin{tabular}{|c|c|c|c|}
\hline Occupation & $\begin{array}{l}\theta_{0} \\
\text { Basic hourly } \\
\text { wage rate } \\
(\mathrm{A} \$ / \mathrm{h})\end{array}$ & $\begin{array}{l}\theta_{1} \\
\text { Overtime } \\
\text { progression }\end{array}$ & $\begin{array}{l}\theta_{2} \\
\text { Standard } \\
\text { hours } \\
\text { (h/week) }\end{array}$ \\
\hline 1. Professional White Collar ${ }^{a}$ & - & - & 34.97 \\
\hline 2. Teachers and Lecturers ${ }^{a}$ & - & - & 31.41 \\
\hline 3. Skilled White Collar & 2.4542 & 0.026410 & 36.04 \\
\hline 4. Semi- and Unskilled White Collar & 2.2867 & 0.005690 & 38.82 \\
\hline 5. Skilled Blue Collar (metal and electrical) & 2.1739 & 0.010976 & 39.43 \\
\hline 6. Skilled Blue Collar (building) & 2.3252 & 0.008642 & 39.42 \\
\hline 7. Skilled Blue Collar (other) & 2.3428 & 0.003279 & 38.93 \\
\hline 8. Semi-and Unskilled Blue Collar & 2.2565 & 0.017835 & 38.70 \\
\hline All occupations & 2.2538 & 0.013728 & 38.91 \\
\hline
\end{tabular}
1975-76.

${ }^{a}$ Estimation not possible due to small sample size. Source: Tulpulé (1980b).

To obtain estimates of the response of the supply of hours worked in different occupations via eqn. (8), data of the type given in Tables 2 and 3 suffice. It is, of course, necessary to know the age, sex, marital status, and occupational distribution of the workforce. These are to be supplied by the demographic core and by the occupational disaggregation modules discussed above. There is scope for forging further links between these three segments of BACHUROO via the role of family timing and size in the workforce participation of married females. In terms of the labor-leisure choice paradigm, increased labor-force participation of married women would show up in the form of an "as if" decline in the utility parameter $\gamma_{L}$ applicable to this group. 
At the time of writing, the estimation of the labor-leisure choice module is complete. The finding that $\beta_{\mathrm{L}}=0$ for married men, however, is worrying. While the idea that this parameter would be lower for married men than for married women and for single people is plausible, in some long-run sense $\beta_{\mathbf{L}}$ must exceed zero. That is, we would expect married men to take out at least some small part of rising living standards in increased leisure. Over the sample period 1964/65-1975/76 it is estimated by Tulpule (1980a) that married men with a non-working wife decreased their average hours of work by $2 \%$; and that those with working wives actually increased their average hours by $1.5 \%$. While a host of technical problems might account for the anomaly, it is unlikely that respecification and re-estimation will improve matters unless the quantity and quality of the available data can be increased. (In the sample data, average hours worked by married males with working wives are about $6 \%$ below those worked by married males whose wives are not in the workforce. Insofar as rising male wage rates are correlated with increased female labor-force participation, therefore, there is some negative association between hours worked by males and their rates of pay.)

\section{THE INTERFACE WITH ORANI AND MACRO}

In discussing the interfaces it is convenient to start with the largest of the models, ORANI. Being in the Johansen (1960) family, ORANI's final form in simulation mode is linear in logarithmic differentials, and may be written

$$
y_{0}=A_{0} z_{0}
$$

where $y_{0}$ and $z_{0}$ may be thought of as the proportional changes in the endogenous and exogenous variables, respectively. Although the structural form of ORANI recognizes many thousands of endogenous variables, the solution method involves "substitution out" of all but about 300 of these. Other endogenous variables whose solution values are required are subsequently recovered by the process of back solution. The exogenous variables, which include world prices of those traded goods with respect to which Australia is a small country, number approximately one thousand.

There are technical problems associated with interpreting the timing of events in a comparative static model such as ORANI, and in reconciling this timing with that of a macro model fitted to quarterly data. These problems are dealt with at a technical level by Cooper and McLaren (1980), and more heuristically by Powell (1980): they will not be discussed here. For our purposes, it will suffice to note that a transform of our MACRO model can be derived to correspond to the same time-frame as ORANI; its final form in simulation mode can be written in a format similar to eqn. (11); that is

$$
y_{\mathbf{M}}=A_{\mathbf{M}} z_{\mathbf{M}}
$$

where $y_{M}$ and $z_{M}$, respectively, are the endogenous and exogenous MACRO variables.

Prior to the final forms (11) and (12), the structural forms of the model appear as

$$
B_{0} y_{0}+C_{0} z_{0}=0
$$


and

$$
B_{\mathbf{M}} y_{\mathbf{M}}+C_{\mathbf{M}} z_{\mathbf{M}}=0
$$

so that the essence of the solution procedures for the models in stand-alone mode is the computation of

$$
A_{0}=-B_{0}^{-1} C_{0}
$$

and

$$
A_{\mathrm{M}}=-B_{\mathrm{M}}^{-1} C_{\mathrm{M}}
$$

respectively. What makes (13a) and (13b) a system (as distinct from two independent systems) is the fact that some of the ORANI exogenous variables are endogenized in MACRO, so that certain elements of $y_{M}$ and $z_{0}$ overlap (for instance, the change in aggregate consumption expenditure). The second connection, less important for viewing ORANI-MACRO as a system, is that they share some common exogenous variables $\left(z_{0}\right.$ and $z_{M}$ overlap). Note, however, that $y_{0}$ and $y_{M}$ must be disjunct. ${ }^{*}$ After appropriate algebraic substitutions which take into account the overlapping variables, the combined system can be written as

$$
B_{\mathbf{S}} y_{\mathbf{S}}+C_{\mathbf{S}^{z}} \mathbf{S}=0
$$

whose solution is

$$
y_{\mathrm{S}}=-B_{\mathrm{S}}^{-1} C_{\mathrm{S}} z_{\mathrm{S}}
$$

The computational approach to the solution of ORANI is amenable to the addition of extra variables and equations. Thus the macroeconomic closure of ORANI can be thought of as the addition to ORANI of extra variables and extra equations prior to solution. Elsewhere (Powell, 1980) it has been argued that in view of new developments (Dixon et al., 1982, ch. 5) which allow the elimination of linearization errors from Johansen models at low cost, the flexibility, ease of computation, and transparency of the latter class are likely, in time, to lead to its acceptance as the dominant method for the formulation and solution of nonlinear economy-wide models.

The demand for labor by occupational group is endogenized in ORANI. At present the relevant variable is the vector $\boldsymbol{m}^{\mathrm{d}}$ of (percentage changes in) man-hours of labor demand for the various occupations. Following the notation of Section 2.3, let the vectors of occupation-specific basic hourly wage rates, of standard hours, and of overtime progression parameters be $\theta_{0}, \theta_{2}$, and $\theta_{1}$, respectively. Currently, only a vector $r$

\footnotetext{
* At the time of writing there remain less than half a dozen scalar variables which are doubly endogenized. The double endogeneities provide an indirect check on the simulation properties of ORANI via MACRO - see Powell (1980). At the final interface these double endogeneities will be eliminated.
} 
of overall average wage rates for each occupation is recognized in ORANI. Thus the existing ORANI-MACRO structural form equation for $\boldsymbol{m}^{\mathrm{d}}$ is of the form

$$
\phi\left(\boldsymbol{m}^{\mathrm{d}}, r, x\right)=0
$$

where $x$ is a subset of the other variables in the combined system. It is intended to respecify this equation so that $\theta_{0}, \theta_{1}$, and $\theta_{2}$ appear explicitly

$$
\phi^{*}\left(\boldsymbol{m}^{\mathrm{d}}, \theta_{0}, \theta_{1}, \theta_{2}, x\right)=0
$$

As a matter of identity, the proportional changes $\boldsymbol{h}^{\mathrm{d}}$ in the number of hours per week on average demanded per man and $l^{\mathbf{d}}$ in the number of men demanded are related to $\boldsymbol{m}^{\mathbf{d}}$ by the vector equation

$$
m^{\mathrm{d}} \equiv h^{\mathrm{d}}+l^{\mathrm{d}}
$$

Missing in ORANI-MACRO at this stage, but to be added before interfacing with BACHUROO, is an equation to endogenize the proportions in which $\boldsymbol{m}^{\mathrm{d}}$ splits in eqn. (19); let this missing structural form equation be

$$
\nu\left(l^{\mathrm{d}}, \theta_{0}, \theta_{1}, \theta_{2}, x\right)=0
$$

Then, given the existing flexible facility for choosing which variables shall be endogenous and which shall be exogenous that characterizes the ORANI computing system, the ORANI-MACRO system in any simulation could be used either:

(a) to endogenize the occupational demands for men $\left(l^{\mathrm{d}}\right)$, for hours per man $\left(\boldsymbol{h}^{\mathrm{d}}\right)$ and for man-hours $\left(\boldsymbol{m}^{\mathrm{d}}\right)$ at a given set of employment conditions $\left(\theta_{0}, \theta_{1}, \theta_{2}\right)$; or

(b) to endogenize the employment conditions $\left(\theta_{0}, \theta_{1}, \theta_{2}\right)$ which would be compatible with a given set of occupational demands $\left(l^{\mathrm{d}}, \boldsymbol{m}^{\mathrm{d}}, \boldsymbol{h}^{\mathrm{d}}\right)$.

Where does BACHUROO fit into all this? First, it should be noted that (like ORANI) its initial building blocks are not equations which are linear in log differentials. Its functions are, however, analytic and so a local representation of the model which is locally linear in proportional changes can be presumed to exist. At this stage, it is not clear whether the optimal approach to obtaining such a linearization of BACHUROO would involve numerical or algebraic differentiation. If the latter, a computer-implementable analytic differentiator will be needed, since BACHUROO's structure is not nearly so amenable to algebraic manipulation as ORANI's or MACRO's. In any event, let the linear-in-proportional-changes representation of BACHUROO's structural form be

$$
B_{\mathbf{B}} y_{\mathbf{B}}+C_{\mathbf{B}} z_{\mathbf{B}}=0
$$

This set of equations will be derived from the modules of BACHUROO described above. 
Among them will be equations for the supplies, by occupations, of men, and of manhours per man. Let these equations be

$$
\mu\left(l^{\mathbf{S}}, \theta_{0}, \theta_{1}, \theta_{2}, X\right)=0
$$

and

$$
\xi\left(h^{\mathbf{S}}, \theta_{0}, \theta_{1}, \theta_{2}, X\right)=0
$$

respectively, where $X$ is a subset of $\left\{y_{\mathrm{B}}, z_{\mathrm{B}}\right\}$. Parallel to (19) is the identity

$$
m^{\mathrm{s}} \equiv l^{\mathrm{S}}+h^{\mathrm{S}}
$$

where $\boldsymbol{m}^{\mathbf{S}}$ is the vector of man-hours supplied by different occupations. Then, in standalone mode, BACHUROO will endogenize labor supplies $\left(l^{\mathbf{S}}, m^{\mathbf{S}}, h^{\mathbf{S}}\right)$ for given employment conditions $\left(\theta_{0}, \theta_{1}, \theta_{2}\right)$; or alternatively, will endogenize the employment conditions which would be consistent with a given scenario on labor supplies.

To discuss the interface of ORANI-MACRO with BACHUROO, further notation is needed:

$$
\begin{aligned}
& \Delta L^{\mathrm{u}} \equiv \hat{l}^{\mathrm{s}} L^{\mathrm{s}}-\hat{l}^{\mathrm{d}} L^{\mathrm{d}} \\
& \Delta M^{\mathrm{u}} \equiv \hat{m}^{\mathrm{s}} M^{\mathrm{s}}-\hat{m}^{\mathrm{d}} M^{\mathrm{d}} \\
& \Delta H^{\mathrm{u}} \equiv \hat{h}^{\mathrm{s}} H^{\mathrm{s}}-\hat{h}^{\mathrm{d}} H^{\mathrm{d}}
\end{aligned}
$$

These variables are to be interpreted as follows. Upper-case letters represent the levels of the corresponding lower-case variables. Thus $\boldsymbol{M}^{\mathrm{S}}$ is the number of man-hours supplied, while $m^{\mathbf{S}}$ is the proportional change in this variable. The operator " placed over a vector converts it to the corresponding diagonal matrix. If positive, $\Delta L^{\mathbf{u}}$ is the increase in the number of unemployed people; if negative, it represents the increase in unfilled vacancies. If positive, $\Delta \boldsymbol{H}^{\mathrm{u}}$ is to be interpreted as an increase in under-utilization of those people who are in employment; if negative, as an increase in unfilled demand by employers for additional overtime hours. Finally, $\Delta \boldsymbol{M}^{\mathbf{u}}$, if positive, indicates an increase in overall slackness in the labor market; if negative, an increase in overall excess demand.

The complete IMPACT medium-term model, in proportional-change form, will be obtained by adding BACHUROO's structural form equations, plus the equation set (25a)-(25c) to ORANI-MACRO. The same type of condensation of the notation as discussed above for the ORANI-MACRO interface would again be carried out, and the solution procedure would follow the ORANI strategy.

What will the total system ORANI-MACRO-BACHUROO endogenize? At given conditions of employment $\left(\theta_{0}, \theta_{1}, \theta_{2}\right)$, the vectors of changes in excess labor supplies $\left(\Delta \boldsymbol{L}^{\mathrm{u}}, \Delta \boldsymbol{M}^{\mathrm{u}}, \Delta \boldsymbol{H}^{\mathrm{u}}\right.$ ) will be obtainable from its solution. Alternatively, if the latter are set exogenously, the corresponding conditions of employment (if they exist) will be endogenized. If the vector $\left(\Delta \boldsymbol{L}^{\mathrm{u}}, \Delta \boldsymbol{M}^{\mathrm{u}}, \Delta \boldsymbol{H}^{\mathrm{u}}\right)$ is set exogenously to the particular value 
$(0,0,0)$, the medium-term model will yield the shadow wage rates and other conditions of employment which would, in a certain sense, clear the labor market.*

The alternative methods of closure described above are adequate for policy analysis, which is the principal focus of the IMPACT Project. Clearly, for forecasting, they are not adequate. My own view is that the present state of the art does not allow forecasters of the Australian economy to predict, with any confidence, which particular bargains in terms of real wages and unemployment will be struck. To forecast with the medium-term model, therefore, scenario-writing with a substantial element of political and industrialrelations know-how will be needed.

\section{CONCLUDING REMARKS}

Those who are familiar with the early documents on the design of BACHUROO (Tulpulé and McIntosh, 1976; Tulpulé, 1976; Powell, 1977, section 3.3) will have noted that the scope and design of the endeavor have undergone substantial evolution. Some areas in which it was initially hoped that the behavior of the relevant agents could be endogenized proved, for various reasons, too hard. The main examples are (a) the education sector, (b) immigration flows, and (c) mapping from the functional to the personal distribution of income. In the case of (a) and (c), the limited Australian data bases will preclude serious work for the foreseeable future. In the case of immigration, it was possible to endogenize government policy during the postwar period at one level of sophistication (Kelley and Schmidt, 1978) but not at another (Caddy et al., 1978). The internal politics of immigration and the external supply conditions for immigrants have changed very radically since the late 1960 s, making it very unlikely that an econometric approach would successfully endogenize the interaction of government policy and overseas conditions. Accordingly, immigration is to be handled as a set of exogenous variables for which, like education, specific-purpose scenarios must be written by the model user.

While its scope has narrowed to this extent, in other ways the model has become much more ambitious. Given its intended policy-analytic role, it is most important that linkages between economic and demographic variables be captured in such a way as to allow counterfactual simulation. The micro-underpinnings of the model have been accordingly considerably strengthened.

My final perspective concerns the conservative strategy which has been adopted towards interfacing the various components of BACHUROO. This is a microcosm of the strategy adopted towards the interfacing of ORANI with MACRO. If one is to have any idea, in the context of such large models, about the features of the model which are responsible for producing particular simulation results, it is first necessary to understand very well each of its components, and to have developed an appropriate methodology for interfacing them. IMPACT will not, for instance, attempt to make illustrative projections

\footnotetext{
* If the initial conditions from which the solution is computed involve labor market equilibrium in the sense that $\left(L^{\mathrm{S}}, M^{\mathrm{S}}, H^{\mathrm{S}}\right)=\left(L^{\mathrm{d}}, M^{\mathrm{d}}, H^{\mathrm{d}}\right)$, then setting $\left(\Delta L^{\mathrm{u}}, \Delta M^{\mathrm{u}}, \Delta H^{\mathrm{u}}\right)$ to zero results in the labor market clearing absolutely. If some other initial set of conditions is used, setting the lastmentioned vectors to zero results in a projection involving no change in the degree of disequilibrium in the labor market.
} 
with BACHUROO as a whole in stand-alone mode until satisfactory, well understood projections have been made with each of its components. This may seem to slow down the rate of progress, but that is an illusion. Unsatisfactory simulations produced with a whole whose parts are individually of doubtful status would leave the user forever in a quandary as to what went wrong.

\section{ACKNOWLEDGMENTS}

I am grateful for helpful comments and suggestions from my colleagues Dennis Sams, Ashok Tulpulé, and Lynne Williams. All remaining errors are of course my own.

\section{REFERENCES}

Abbott, M. and Ashenfelter, O. (1976). Labour supply, commodity demand and the allocation of time. Review of Economic Studies, XLIII (3, No. 135):389-411.

Barnett, W.A. (1979). The joint allocation of leisure and goods expenditure. Econometrica, 47(3): 539-563.

Bergstrom, A.R. and Wymer, C.R. (1976). A model of disequilibrium neoclassical growth and its application to the United Kingdom. In A.R. Bergstrom (Editor), Statistical Inference in Continuous Time Econometric Models. North-Holland, Amsterdam.

Betancourt, R. (1973). Household Behavior in a Less Developed Country: An Econometric Analysis of Cross-Sectional Data. Department of Economics, University of Maryland, College Park (August) (mimeo).

Bruno, M. (1966). A programming model for Israel. In I. Adelman and E. Thorbecke (Editors), The Theory and Design of Economic Development, Ch. 12. Johns Hopkins, Baltimore, pp. 327352.

Burtless, G. and Hausman, J.A. (1978). The effect of taxation on labour supply: evaluating the Gary negative income tax experiment. Journal of Political Economy, 86(6):1103-1130.

Caddy, V., Jackson, B., and Powell, A.A. (1978). Determinants of Australian Migration, IMPACT Working Paper No. B-07, Melbourne.

Cooper, R.J. and McLaren, K.R. (1980). The ORANI-MACRO Interface, IMPACT Preliminary Working Paper No. IP-10, Melbourne.

Craigie, R. (1980). Australian Student Statistics 1966 to 1976, IMPACT Preliminary Working Paper No. BP-21, Melbourne.

Craigie, R., Parham, D.J., and Ryland, G.J. (1979). Educational Attainment and Occupational Supply: A Theoretical Outline, IMPACT Preliminary Working Paper No. BP-16, Melbourne.

Dixon, P.B. (1976). The Costs of Protection: The Old and the New Arguments, IMPACT Preliminary Working Paper No. IP-02, Melbourne.

Dixon, P.B., Harrower, J.D., and Vincent, D.P. (1978). Validation of the SNAPSHOT Model, IMPACT Preliminary Working Paper No. SP-12, Melbourne.

Dixon, P.B., Parmenter, B.R., Ryland, G.J., and Sutton, J. (1977). ORANI, A General Equilibrium Model of the Australian Economy: Current Specification and Illustrations of Use of Policy Analysis. Australian Government Publishing Service, Canberra.

Dixon, P.B., Parmenter, B.R., Sutton, J., and Vincent, D.P. (1982). ORANI, A Multisectoral Model of the Australian Economy. North-Holland, Amsterdam.

Dixon, P.B., Powell, A.A., and Parmenter, B.R. (1979). Structural Adaptation in an Ailing Macroeconomy. Melbourne University Press, Melbourne.

Dixon, P.B. and Vincent, D.P. (1980). Some economic implications of technical change in Australia to 1990/91: an illustrative application of the SNAPSHOT model. Economic Record, 56(155): 347-361.

Evans, H.D. (1972). A General Equilibrium Analysis of Protection. North-Holland, Amsterdam. 
Fair, R.C. and Jaffee, D.M. (1972). Methods of estimation for markets in disequilibrium. Econometrica, 40(3):497-514.

Filmer, R. and Silberberg, R. (1977). Fertility, Family Formation and Female Workforce Participation in Australia, IMPACT Preliminary Working Paper No. BP-08, Melbourne.

Gilbert, F. and Pfouts, R.W. (1958). A theory of the responsiveness of hours of work to changes in wage rates. Review of Economics and Statistics, 40:116-121.

Howe, H. (1975). Development of the extended linear expenditure system from simple savings assumptions. European Economic Review, 6:305-310.

Johansen, L. (1960). A Multi-sectoral Study of Economic Growth. North-Holland, Amsterdam.

Jonson, P.D., McKibbin, W.J., and Trevor, R.G. (1980). Models and Multipliers. Reserve Bank of Australia, Research Discussion Paper No. 8006, Sydney.

Jonson, P.D. (1976). Money and economic activity in the open economy. Journal of Political Economy, 84(5): 979-1012.

Jonson, P.D., Moses, E.R., and Wymer, C.R. (1978). The RBA Model of the Australian Economy, in Conference on Applied Economic Research, December 1977. Reserve Bank of Australia, Sydney, pp. 9-36.

Jonson, P.D. and Trevor, R.G. (1979). Monetary Rules: A Preliminary Analysis. Reserve Bank of Australia, Research Discussion Paper No. 7903, Sydney.

Kelley, A.C. and Schmidt, R.M. (1978). Modelling the role of government policy in post-war Australian immigration. Economic Record, 55(149):127-135.

Lluch, C. (1973). The extended linear expenditure system. European Economic Review, 4:21-32.

Lluch, C., Powell, A., and Williams, R. (1977). Patterns in Demand and Saving. Oxford University Press for the World Bank, New York.

Manne, A.S. (1963). Key sectors of the Mexican economy 1960-70. In A.S. Manne and H.M. Markowitz (Editors), Studies in Process Analysis, Ch. 16. John Wiley, New York, pp. 379-400.

Mumme, A. (Chairman), Abrahart, A., Jolly, R., Neville, G.I., and Tucker, K.A. (1978). The Adequacy of Information Systems Supporting Industry and Employ ment Policies in Australia, Report of Working Group No. 2 to Sir John Crawford's Study Group on Structural Adjustment, Canberra.

Paish, F.W. (1941). Economic incentive in wartime. Economica, 8(31): 239-248.

Parham, D.J. and Ryland, G.J. (1978). Models of Skill Substitution and Transformation in an Occupationally Disaggregated Labour Market: Economic and Econometric Specification, IMPACT Preliminary Working Paper No. OP-18, Melbourne.

Phlips, L. (1978). The demand for leisure and money. Econometrica, 46(5):1025-1044.

Powell, A.A. (1977). The IMPACT Project: An Overview, March 1977, First Progress Report of the IMPACT Project, Vol. 1. Australian Government Publishing Service, Canberra.

Powell, A.A. (1979). The theory of labor supply and commodity demand with an exogenous marginal wage rate. Recherches Economiques de Louvain, 45:215-239.

Powell, A.A. (1980). The Major Streams of Economy-wide Modelling: Is Rapprochement Possible? IMPACT Working Paper No. I-09, Melbourne; also available in J. Kmenta and J.B. Ramsey (Editors), Large Scale Econometric Models: Theory and Practice. North-Holland, Amsterdam (1981), pp. 219-264.

Powell, A.A. and Parmenter, B.R. (1979). The IMPACT Project as a tool for policy analysis: brief overview. Australian Quarterly, 51(1):62-74.

Powell, A.A., Tulpulé, A., and Filmer, R.J. (1977). Commodity Specific Subsidies, Demand Patterns and the Incentive to Work, IMPACT Preliminary Working Paper No. BP-10, Melbourne; also in Housing Economics: Papers Prepared for National Housing Economics Conference 1978. Australian Government Publishing Service, Canberra (1980).

Rattigan, G.A. (1976). Notes on IMPACT. Industries Assistance Commission, Canberra.

Robbins, L. (1930). On the elasticity of demand for income in terms of effort. Economica, 10:123129.

Sams, D. (1979). The Demographic Core of the IMPACT Project: An Overview, IMPACT Preliminary Working Paper No. BP-18, Melbourne.

Sams, D. and Williams, P. (1980). The IMPACT Project's Facility for Disaggregated Population Projections: A Brief Exposition and Progress Report, IMPACT Preliminary Working Paper No. BP-22, Melbourne. 
Sandee, J. (1960). A Long Term Planning Model for India. Asia Publishing House, New York; and Statistical Publishing Company, Calcutta.

Schultz, T.W. (Editor) (1973). Economics of the Family, A Conference Report of the National Bureau of Economic Research. University of Chicago Press, Chicago.

Tulpulé, A.H. (1976). Estimation and Mapping of the Distribution of Income of Australia for the IMPACT Model, IMPACT Preliminary Working Paper No. BP-05, Melbourne.

Tulpulé, A.H. (1980a). Estimation of Elasticities of Supply of Latour Hours for Australian Workers Classified by Sex and Marital Status, IMPACT Preliminary Working Paper No. BP-23, Melbourne.

Tulpulé, A.H. (1980b). Effects on the Supply of Labour Hours by Employees of Changes in their Conditions of Employment, IMPACT Preliminary Working Paper No. BP-25, Melbourne.

Tulpulé, A.H. and McIntosh, M. (1976). BACHUROO - An Economic-Demographic Module for Australia, IMPACT Working Paper No. B-02, Melbourne.

Vincent, D.P. (1980). Some Implications for the Australian Economy of Trade Growth with Newly Industrializing Asia: The Use and Limitations of the ORANI Framework, IMPACT Preliminary Working Paper No. OP-26, Melbourne.

Williams, L.S. (1980). Occupational Mobility in Australia: a Quantitative Approach, IMPACT Working Paper No. B-13, Melbourne; also to be published in European Economic Review.

Williams, P. (1979). Marital Status Change for Australian Females: A Time Series of Fitted Distributions, IMPACT Preliminary Working Paper No. BP-20, Melbourne.

Williams, P.J. and Brooks, R.C. (1978). An Econometric Model of Household Headship, IMPACT Preliminary Working Paper No. BP-14, Melbourne.

Woodland, A.D. and Wales, T.J. (1979). Labour Supply and Progressive Taxes. Review of Economic Studies, XLVI (3, No. 142): 83-96. 


\title{
A TWO-SEX GENERAL EQUILIBRIUM MARRIAGE MODEL
}

\author{
Warren C. Sanderson \\ International Institute for Applied Systems Analysis, Laxenburg (Austria)
}

\section{BACKGROUND}

This paper presents and analyzes a two-sex general equilibrium marriage model. Demographers will recognize the model as a solution to the two-sex marriage problem in the sense that, given the age structures of the nonmarried male and female populations and a set of parameters, it produces a matrix of the numbers of marriages by the ages of the partners. Economists will recognize the framework as being of the general equilibrium variety in the sense that the mathematical formulation is based on explicitly-portrayed interrelated marriage markets.

The work in this paper is preliminary in nature. It includes a formal presentation of a new two-sex marriage model and some analysis of the sensitivity of predicted marriage patterns to changes in parameters. It is, however, only one piece within a much larger research agenda. The first stage of the research has been focused on obtaining a framework which would yield some insight into the problem of determining the distribution of marriages given the distributions of eligible males and females. This paper suggests a reasonable framework, although its practical value will depend on the results of the tests of its empirical plausibility now being conducted. If the new approach proves to be fruitful, then the second stage of the research will begin, in which the model is made dynamic through the addition of considerations of mortality, divorce, and remarriage. The ultimate goal of this work is the formulation of a complete analytic model of family demography.

Although the work on an analytic family demography is only in its infancy, it is useful to report on the current results because they relate to other ongoing research in economics and demography. Within the last two decades, analytic specifications for mortality (e.g. Coale and Demeny, 1966; Brass, 1977), fertility (Coale, 1971), marriage (Coale, 1971; Coale and McNeil, 1972), and migration processes (Rogers et al., 1978) on the macrodemographic level, as well as a host of specifications of microdemographic processes (e.g. Lesthaeghe and Page, 1980) have been developed.

The macrodemographic specifications have a number of uses. They provide a framework within which we can gain a deeper understanding of past demographic 
developments* as well as a vehicle for making systematic and consistent projections into the future. They also provide a tool for graduating imperfect data and for deducing information from incomplete data. Yet, to date, the parameterized macrodemographic formulations have virtually all been one-sex models, referring separately to males and to females without consideration of any interaction between the two groups although the work of Schoen (1977), which is discussed below, is close to a parameterized two-sex model. This paper, then, may be seen as continuing the trend of recent work in analytic macrodemography by providing a parameterized two-sex model.

In economics there are two lines of research which are related to the work presented here. In microeconomics, the economic theory of marriage ${ }^{* *}$ predicts that the relative scarcity of potential mates, among other things, should influence the proportion of eligible individuals who marry at a given age. The current model provides a functional representation in which these demographic factors can be separated from economic influences which affect the magnitudes of the parameters. In macroeconomics, a substantial literature has developed dealing with economic-demographic simulation models. By and large, the demographic segments of these models have been quite weak; several models have been reviewed in detail by Sanderson (1980). The parameterized two-sex marriage specification presented here is one step towards a complete analytic model of family demography comparable in quality with extant economic models.

\section{RELATED RESEARCH}

The first step toward an analytic formulation of a nuptiality function came in Coale (1971), when it was shown that first marriage frequencies for females could quite consistently be related in a relatively simple way to a standard set of first marriage rates derived from data for Swedish women during 1865-1869. To be more precise, Coale demonstrated that, in general,

$$
\mu_{j}=\frac{c}{k} \cdot \mu_{\mathrm{s}}\left(\frac{j-a}{k}\right)
$$

where

$\mu_{j}$ is the first marriage rate for all females of age $j$ (regardless of whether they are married or not);

$c$ is the proportion of the group of women in question who ultimately eventually marry;

$k$ is a parameter which (once $a$ is fixed) controls the mean age at marriage; $\mu_{\mathrm{s}}(j-a) / k$ is a function whose argument, $(j-a) / k$, is a "standard age" and whose value is the "standard" first marriage rate for females of that "standard age"; and

$a$ is the age at which a consequential number of females first marry.

\footnotetext{
* An example of how the Coale marital fertility function and the Coale and McNeil nuptiality function have been used to investigate the historical diffusion of family limitation in the US can be found in Sanderson (1979).

** See the basic work of Becker (1974).
} 
Equation (1) is quite powerful in the sense that plausible first marriage rates for females could be generated from the "standard" rates once the three parameters $a, k$, and $c$ were specified. Still, the necessity of always having to refer to a table of "standard" rates was somewhat cumbersome and inelegant. Coale and McNeil (1972) suggested a formulation which eliminated the need for standard rates. They found that, quite generally, first marriage rates for females could be represented by the following equation

$\mu_{j}=\left(0.1946 \cdot \frac{c}{k}\right) \cdot \exp \left(-0.174 \cdot\left(\frac{j-a}{k}-6.06\right)-\exp \left[-0.28881 \cdot\left(\frac{j-a}{k}-6.06\right)\right]\right)$

where the symbols are defined as above. Equation (2) is, in a sense, a conceptual breakthrough in analytic demography somewhat akin to the development of the CobbDouglas production function in economics. With eqn. (2), plausible patterns of first marriage rates for females are produced once the three parameters $a, k$, and $c$ are given, without reference to any "standard" schedule. The parameter $k$ may be expressed as

$$
k=(\bar{a}-a) / 10.0664
$$

where $\bar{a}$ is the median age at marriage, and 10.0664 is the median age at marriage in "standard years" derived from the work of Coale (see table 3 of Coale, 1971) by linear interpolation.

Substituting the expression for $k$ in eqn. (3) into eqn. (2) yields

$\mu_{j}=\frac{1.9589 \cdot c}{\bar{a}-a} \cdot \exp \left\{-1.752 \cdot\left(\frac{j-a}{\bar{a}-a}-0.602\right)-\exp \left[-2.9073 \cdot\left(\frac{j-a}{\bar{a}-a}-0.602\right)\right]\right\}$

One important feature of this version of the Coale-McNeil specifications is that the three parameters, $a$ (the earliest age at which a consequential number of women marry), $\bar{a}$ (the median age at first marriage), and $c$ (the proportion of women eventually marrying), all have clear and useful interpretations. Indeed, unlike quantities such as the elasticity of substitution between two factors of production (used in economics), the parameters in the Coale-McNeil nuptiality function can all be estimated independently of the specification in which they appear.

Given some data on first marriage frequencies for females, eqn. (4) can be used to estimate the three parameters and, given those three parameters, eqn. (4) can be used to produce the single years of age marriage rates. What eqn. (4) is not designed to do is to answer questions about how female marriage rates could be expected to change when the population of potential mates changes. Questions about the impact of changes in the male population distribution on the marriage rates of females are behavioral in nature and require some additional structural formalization.

An example from economics might be useful here. Once the parameters of a production function are given, the level of output can be computed from a knowledge of the quantities of the inputs, just as in eqn. (4) the level of the first marriage rate can be 
computed from the knowledge of the women's ages. Without additional assumptions, however, the production function in general cannot reveal how the input mix would change in response to a change in input prices. In order to accomplish this, economists typically make assumptions about the nature of firm behavior (e.g., optimizing or satisficing behavior) and about the market environments in which the firm operates. The problem of whether an analogous framework can be devised for use with eqn. (4) to give it more behavioral content is discussed in Section 3. Before we get there, however, it is useful to ascertain how demographers have treated the two-sex marriage problem in the past.

A good example of recent demographic work on two-sex marriage models can be found in Schoen (1977). To understand Schoen's contribution, however, requires a little preparation. Let $\pi_{i j}$ be the number of marriages of females of age $j$ to males of age $i$ in a given year, ${ }^{*} F_{j}$ be the number of unmarried females of age $j$ in the year in question, and $M_{i}$ be the number of unmarried males of age $i$ in the year in question. One approach to the problem of specifying a function which yields the age-specific numbers of marriages is to start with the hypothetical age-specific numbers of marriages which would occur if the population in question had some "standard" age-sex-marital status composition and to adjust those figures according to the observed age-sex-marital status composition of the population. The number of marriages of females of age $j$ to males of age $i$ could then be expressed as

$$
\pi_{i j}=\pi_{i j}^{\mathbf{s}} \cdot \eta_{i j}
$$

where

$\pi_{i j}^{\mathrm{s}} \quad$ is the hypothetical number of marriages of females of age $j$ to males of age $i$ which would be obtained if the population had some "standard" age-sex-marital status composition, and

$\eta_{i j} \quad$ is an adjustment factor for marriages of females of age $j$ to males of age $i$ which depends on the observed age-sex-marital status composition of the population.

If an appropriate expression for $\eta_{i j}$ could be found, then perhaps eqn. (5) could be used to determine age-specific numbers of marriages. Pollard (1975, pp. 70-71) suggested the following specification of $\eta_{i j}$

$$
\eta_{i j}=M_{i} \cdot F_{j} /\left(\sum_{l} M_{l} \cdot \alpha_{i j}^{\mathrm{m}}+\sum_{l} F_{l} \cdot \alpha_{l i}^{\mathrm{f}}\right)
$$

where

$\alpha_{l i}^{\mathrm{f}} \quad$ is an index of the relative attractiveness of females of age $l$ to males of age $i$, and $\alpha_{l j}^{m} \quad$ is an index of the relative attractiveness of males of age $l$ to females of age $j$.

\footnotetext{
* The age designations can be interpreted generally to mean between exact ages $i$ and $i+\Delta$ and between $j$ and $j+\Delta$. The duration of the period with which we are concerned can just as easily be other than one year. In practical work such distinctions are often quite important. At this level of discussion, however, it is useful to pick some set of conventions and retain them throughout.
} 
Since $\alpha_{j i}^{\mathrm{f}}$ is not necessarily equal to $\alpha_{i j}^{\mathrm{m}}$ in Pollard's formulation, the whole set of adjustment factors, the $\eta_{i j}$, is determined once the $2 \times I \times J$ parameters, ${ }^{*}$ the $\alpha_{i j}^{m}$ and the $\alpha_{i j}^{f}$ are known. This latter observation, however, can be somewhat disturbing. To understand this recall that in each year there are only $I \times J$ observations on the joint male-female age structure of marriages. Therefore, data for at least two years are required to estimate the parameters of the Pollard adjustment factor. If one were interested in estimating the parameters for a given year, then the Pollard specification would not be suitable.

Now let us return to Schoen (1977). In order to construct a two-sex nuptialitymortality life table for a particular year, Schoen needed a two-sex marriage model whose parameters could be estimated from the data for the year in question. To do this, Schoen suggested a modification of Pollard's formulation:

$$
\pi_{i j}=\rho_{i j} \cdot M_{i} \cdot F_{j} /\left(\sum_{l} \omega_{l j} \cdot M_{l}+\sum_{l} \omega_{i l} \cdot F_{l}\right)
$$

where

$$
\omega_{i j}=\rho_{i j} /\left(\sum_{l} \rho_{i l}+\sum_{l} \rho_{l j}\right)
$$

and where the $\rho_{i j}$ are the hypothetical marriage rates of females of age $j$ to males of age $i$ which would occur if the number of unmarried males and females at each age were constant.

By introducing the concept of a rectangular population of eligibles, Schoen essentially compresses Pollard's $\alpha_{i j}^{m}$ and $\alpha_{j i}^{f}$ schedules into a single function $\rho_{i j}$. The $\rho$ values are then used in two places; firstly to create weights which appear in the denominator of eqn. (7), and secondly as the "standard" rates to be modified according to the age structures of the unmarried male and female populations. This illuminating simplification allows the $I \times J$ number of marriages in any given year to be expressed as a function of $I \times J$ parameters, the $\rho_{i j}$.

The Schoen formulation is very useful because it allows the estimation of the parameters of a two-sex nuptiality function from the observed numbers of marriages in a particular year. In comparison with the Coale-McNeil specification, however, it is still very cumbersome. For example, the Coale-McNeil function requires only three parameters to produce all the single years of age marriage rates for females, say from age 15 through age 44 . The Schoen formulation would require 900 parameters to perform the same task for both males and females. Even with an aggregation into five-year age groups the Schoen formulation would still require 36 parameters to produce the necessary 36 numbers of marriages.

The number of parameters, however, is no problem if the purpose is to create a two-sex nuptiality-mortality life table for a given year. The nature and number of parameters becomes a consideration, however, when one has an alternative objective in mind - the production of an easily interpretable specification. For this purpose the

\footnotetext{
${ }^{*} I$ is the number of age groups of males and $J$ the number of age groups of females considered.
} 
Schoen formulation does not suffice. The parameters are the hypothetical "standard" marriage rates themselves, not characteristics of patterns of marriage rates.

The state of the demographic literature on nuptiality specifications then, is mixed. There exists an elegant one-sex nuptiality function due to Coale and McNeil but no analogous two-sex formulation. Schoen has provided a theoretically acceptable two-sex model whose parameters could be estimated from the data for a single year, but his framework is not suitable for analytic modeling.

Although there is now an interesting and growing literature in economics on marriage (see, for example, Becker, 1974; Frieden, 1974; Keeley, 1974; Santos, 1975; or Becker et al., 1977), there has as yet been little use made of the available demographic tools. One exception is the economic-demographic simulation model known as BachuePhilippines (Rodgers et al., 1976). The "standard" nuptiality rate table for females in Coale (1971) is used to place rural and urban females of various ages into marital status categories. The distributions of women by age and marital status then influence both the regional fertility and the regional female labor force participation levels. The impact of economic conditions on nuptiality rates is postulated to affect mainly the parameter $k$ in eqn. (1). This parameter, treated separately for urban and rural areas, is assumed to depend on the education of the relevant women and their labor force participation rates.

This portion of the specification of Bachue-Philippines is very advanced in its conception. It would be made even better, though, if the numbers of unmarried males in the urban and rural areas were allowed to influence the respective female marriage rates.

\section{THE FORMAL MODEL}

In the preceding section, the question was raised concerning whether an appropriate two-sex marriage model could be constructed by placing the Coale-McNeil nuptiality specification into a more behaviorally oriented framework. In this section, that question is answered in the affirmative. The central notion here is that, in the aggregate, the interactions of males and females in searching for potential mates may be formally represented as a special kind of a market. This is hardly a new idea - the concept of a "marriage market" is firmly entrenched in economics, demography, and sociology. What is new here is the application of formal economic methods designed for the study of market phenomena to this demographic question.

A "marriage market" is most closely related to what economists call a pure exchange economy, but even in this case there are some important differences. $\mathbf{A}$ "marriage market" can be thought of as a hypothetical place in which participants gather in order to search for potential mates. Each person comes endowed with a single "vow" and the exchange of "vows" - one for one - constitutes a marriage." What makes this phenomenon of the exchange of vows an interesting one is that the participants in the market have discernible characteristics which make them more or less attractive as possible spouses. Therefore, some types of individuals will be in relatively great demand, while others will

\footnotetext{
* I am grateful to Sherman Robinson for suggesting the relationship between a marriage market and an exchange economy and for suggesting the word "vow" for that which is exchanged.
} 
be in relatively great supply. At any moment, we would expect individuals of the first type to have comparatively high marriage rates and to marry more selectively according to the characteristics they desire in their mates. Individuals of the second type would be expected to have comparatively low marriage rates and not to be as selective.

The foregoing suggests that the best way to consider the "marriage market" is not as a single exchange economy, but rather as a set of interrelated markets - in this simple case - for mates of different sexes and ages. A natural formulation of the problem of allocation in a set of interrelated markets is what economists call a "system of demand equations". A well-known system which has a number of desirable features for the present purpose is the extended linear expenditure system (ELES) described in Lluch et al. (1977). The demands of females of age $j$ for males of various ages can be expressed in the ELES framework as:

$$
D_{j i}^{\mathrm{f}}=F_{j} \cdot\left[g_{j i} s_{i j}+b_{j i} \cdot\left(1-\sum_{i} g_{j i} s_{i j}\right)\right] \quad\left(\text { for } i^{\prime} \leqslant i \leqslant i^{*} ; j^{\prime} \leqslant j \leqslant j^{*}\right)
$$

where

$D f_{i}$ is the demand of females of age $j$ for males of age $i$;

$F_{j}$ is the number of eligible females of age $j$;

$g_{j i}, b_{j i}$ are parameters of the demand system;

$s_{i j}$ is the relative scarcity indicator (males as compared to females) for marriages between males of age $i$ and females of age $j$;

$i^{\prime}, j^{\prime}$ are the initial ages, respectively, of males and females considered in the model; and

$i^{*}, j^{*}$ are the terminal ages, respectively, of males and females considered in the model.

The demands of males of age $i$ for females of age $j$ can be similarly expressed as

$$
D_{i j}^{\mathrm{m}}=M_{i} \cdot\left[\gamma_{i j} s_{i j}+\beta_{i j} \cdot\left(1-\sum_{j} \gamma_{i j} s_{i j}\right)\right] \quad\left(\text { for } i^{\prime} \leqslant i \leqslant i^{*} ; j^{\prime} \leqslant j \leqslant j^{*}\right)
$$

where

$D_{i j}^{\mathrm{m}}$ is the demand of males of age $i$ for females of age $j$, and $\gamma_{i j}, \beta_{i j}$ are parameters.

The model is closed by imposing the restrictions that the number of females of age $j$ who marry males of age $i$ must always equal the number of males of age $i$ who marry females of age $j$. Stating this mathematically, we must always observe the condition that

$$
D_{j i}^{\mathrm{f}}=D_{i j}^{\mathrm{m}} \quad\left(i^{\prime} \leqslant i \leqslant i^{*} ; j^{\prime} \leqslant j \leqslant j^{*}\right)
$$

The equations above form an $I \times J$ (where $I=i^{*}-i^{\prime}+1$ and $J=j^{*}-j^{\prime}+1$ ) set of linear equations in $I \times J$ unknowns, the $s_{i j}$. Once the $s_{i j}$ are known, the age structure of 
marriages can be easily computed from either eqn. (9) or eqn. (10) above. $t$ There are, however, $4 \times I \times J$ parameters in those equations so it appears that the marriage model above is even more cumbersome than the Pollard formulation.

There are, however, ways of simplifying the parameter structure in the current model. None of the array of alternatives is without some disadvantages, but there is one particular approach which appears to be quite promising. When all the relative scarcity indices have value zero, the males' marriage hazard rate at age $i$ is given by

$$
\left(\sum_{j} \pi_{i j}\right) / M_{i}=\sum_{j} \beta_{i j} \quad\left(i^{\prime} \leqslant i \leqslant i^{*}\right)
$$

where $\pi_{i j}$ is, as above, the number of marriages between males of age $i$ and females of age $j$.

When all the relative scarcity indices have value zero, the females' marriage hazard rate at age $j$ is given by

$$
\left(\sum_{i} \pi_{i j}\right) / F_{i}=\sum_{i} b_{j i} \quad\left(j^{\prime} \leqslant j \leqslant j^{*}\right)
$$

In order to relate the current two-sex nuptiality model to the Coale-McNeil onesex model it is assumed that the marriage hazard rates above (i.e., when all $s_{i j}=0$ ) are consistent with marriage hazard rates generated by Coale-McNeil nuptiality functions. To be more precise, let $a^{\mathbf{m}}, \bar{a}^{\mathbf{m}}$, and $c^{\mathbf{m}}$ be the three parameters of the Coale-McNeil nuptiality function in eqn. (4) above, and let $\mu_{i}^{\mathrm{m}}$ be the marriage rate implied by those three parameters for males of age $i$. Equation (12) may now be expressed as

$$
\sum_{j} \beta_{i j}=\mu_{i}^{\mathrm{m}} /\left(1-\sum_{l=\boldsymbol{a}^{\mathrm{m}}}^{i-1} \mu_{l}^{\mathrm{m}}\right) \quad\left(i^{\prime} \leqslant i \leqslant i^{*}\right)
$$

Analogously, let $a^{\mathbf{f}}, \bar{a}^{\mathrm{f}}$, and $c^{\mathrm{f}}$ be the three parameters of the Coale-McNeil nuptiality function for females, and let $\mu_{j}^{\mathbf{f}}$ be the marriage rate implied by those three parameters for females of age $j$. Equation (13) may now be expressed as

$$
\sum_{i} b_{j i}=\mu_{j}^{\mathrm{f}} /\left(1-\sum_{l=\mathbf{a}^{\mathbf{f}}}^{j-1} \mu_{l}^{\mathrm{f}}\right) \quad\left(j^{\prime} \leqslant j \leqslant j^{*}\right)
$$

The next question then, is how to distribute the parameter sum across the individual components of the sums. The simplest of the plausible methods of allocating the sums is to assume that for each $i$ the $\beta_{i j}$, and for each $j$ the $b_{j i}$, are distributed like an

† The structure of the demand system allows the $I \times J$ set of linear equations to be solved by inverting a matrix of order MIN $(I, J)$. A demonstration of this property is presented in the Appendix. This property allows the model to be used to generate marriage rates by single years of age without generating, in the process, large computer bills. 
inverted $\mathrm{V}$. The peak of the inverted $\mathrm{V}$ is simply the most preferred age of spouse in the situation where the relative scarcity indicators are all zero.

The determination of the $\beta$ and the $b$ values, except for the computational details, is completed when the peaks of the inverted $\mathrm{V}$ distributions are known. These are specified in eqns. (16) and (17).

$$
p_{i}^{\mathrm{m}}=\delta^{\mathrm{m}}+\phi^{\mathrm{m}} \cdot\left(i-a^{\mathrm{m}}\right) \quad\left(i^{\prime} \leqslant i \leqslant i^{*}\right)
$$

and

$$
p_{j}^{\mathbf{f}}=\delta^{\mathbf{f}}+\phi^{\mathbf{f}} \cdot\left(j-a^{\mathbf{f}}\right) \quad\left(j^{\prime} \leqslant j \leqslant j^{*}\right)
$$

where $p_{i}^{\mathrm{m}}$ is the peak spousal age among the set of allocation weights for males of age $i$, $p_{j}^{\mathrm{f}}$ is the corresponding age for females of age $j$, and $\delta^{\mathrm{m}}, \phi^{\mathrm{m}}, \delta^{\mathrm{f}}$, and $\phi^{\mathrm{f}}$ are parameters. The linearity of eqns. (16) and (17) is merely a computational convenience. Its appropriateness will be tested in future work.

This ends the discussion of the determination of the $2 \times I \times J$ parameters, $\beta_{i j}$ and $b_{j i}$. Next, let us turn to the question of the determination of the $2 \times I \times J$ parameters $\gamma_{i j}$ and $g_{j i}$. We have assumed that when the relative scarcity indicators are all zero, the model should produce marriage hazard rates consistent with two Coale-McNeil nuptiality functions. It is useful to continue with this approach and consider what kind of behavior we would like the model to produce when the relative scarcity indicators are at other levels. Let us take an example. As the relative scarcity of males increases across all ages, we would expect that female marriage hazard rates would fall. But how would the marriage hazard rates of women of a given age react? It is plausible that as relative scarcity of all males increases, the tastes for males of particular ages would become progressively less marked. In other words, when males were relatively more plentiful, their age would be a more important consideration for females than when males were relatively scarce. Of course, the symmetry of the model implies the same for male tastes.

The foregoing discussion suggests, then, when all relative scarcity indicators reach some "high enough" level, the demands of females for potential spouses of all ages go to zero and similarly that, when the relative scarcity indicators reach some "low enough" level, the demands of males for potential spouses of all ages go to zero. For simplicity, it is assumed that, when all the relative scarcity indicators take on a value of 1.0 , the female demand for males of all ages is zero and that, when all relative scarcity indicators take on a value of -1.0 , the male demand for females of all ages is zero. Formally, we write

$$
0=g_{j i}+b_{j i}\left(1-\sum_{i} g_{j i}\right) \quad\left(i^{\prime} \leqslant i \leqslant j^{*} ; j^{\prime} \leqslant j \leqslant j^{*}\right)
$$

Equations of this form can be easily solved to determine the values of $g_{j i}$ in terms of $b_{j i}$. The solutions are

$$
g_{j i}=-b_{j i} /\left(1-\sum_{i} b_{j i}\right) \quad\left(i^{\prime} \leqslant i \leqslant i^{*} ; j^{\prime} \leqslant j \leqslant j^{*}\right)
$$


Similarly

$$
\gamma_{i j}=\beta_{i j} /\left(1-\sum_{j} \beta_{i j}\right) \quad\left(i^{\prime} \leqslant i \leqslant i^{*} ; j^{\prime} \leqslant j \leqslant j^{*}\right)
$$

In this manner, the $\gamma_{i j}$ and $g_{j i}$ can be computed from the $\beta_{i j}$ and the $b_{j i}$, without additional parameters.

To summarize, we have used an economic tool, the extended linear expenditure system of Lluch et al. (1977), and a demographic tool, the nuptiality function specification of Coale and McNeil (1972), to produce a new two-sex marriage model. The parameters are easily interpreted and the specification may be easily used for the purpose of analy tic modeling.

\section{THE EFFECTS OF CHANGES IN PARAMETERS}

In the previous section, a relatively simple procedure was suggested for computing an $I \times J$ matrix of the number of marriages by the ages of the partners, given the initial age distributions of the eligible populations. The proof of the usefulness of that framework is in its application. The parameters should be estimated and the goodness of fit measured. Further, the stability of the parameters over time and space both require careful study. This phase of the research has not yet been carried out. For the present a discussion of the sensitivity of the results to parameter changes and changes in the distributions of the eligible populations will have to suffice.

Table 1 contains data on the effects of five different parameter changes on aggregate measures derived from the single years of age marriage matrix. The base populations of eligible persons and the baseline parameters were chosen so as to approximate the situation in Austria in 1975. For females, the model used single year of age data for 30 years (ages 15-44 inclusive) and for males the model used age data for 38 years (ages 17-54 inclusive). Comparing Run 1 with the baseline computation one can see the effect of increasing $\bar{a}^{\mathrm{m}}$, all other parameters being held constant. In the Coale-McNeil nuptiality specification, increasing the parameter $\bar{a}$ increases the mean age at marriage. It can be seen from the columns referring to Run 1 that the increase in $\bar{a}^{\mathrm{m}}$ increases both the male and female probabilities of eventually marrying as well as increasing both their mean ages at marriage. The hazard rates by age show that the increases in mean ages at marriage are due to decreases in the marriage hazard rates at the early ages, and to increases in those rates in later marriage ages.

A comparison of the results of Run 2 and the baseline calculation shows the effects of increasing $\bar{a}^{\mathrm{f}}$. The mean ages of marriage of both females and males rise, but unlike the results of Run 1, the proportions eventually marrying fall. This reversal is fundamental to the model. The proportion eventually married depends on the extent to which male and female demands for partners match. Increasing $\bar{a}^{\mathrm{m}}$ increases the degree of consistency in the demands and hence increases the proportions eventually marrying. Increasing $\bar{a}^{\mathrm{f}}$, on the other hand, decreases the degree of consistency in the demands and therefore decreases the proportions eventually marrying. 


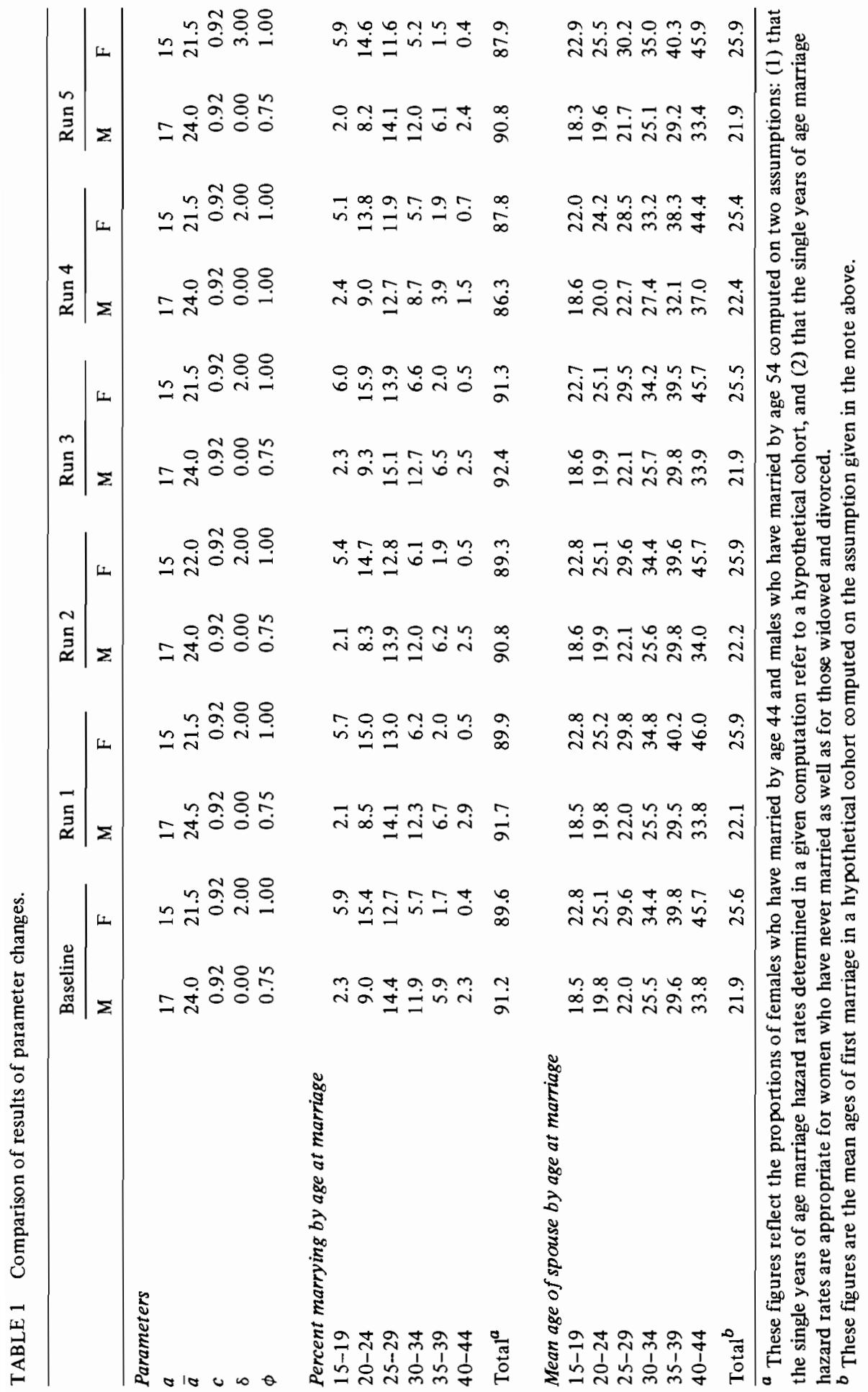


A comparison of the results of Run 3 and the baseline calculation shows the effect of a small increase in $c^{\mathbf{f}}$, the proportion of women eventually marrying in the CoaleMcNeil nuptiality function. An increase in $c^{f}$ causes the proportions of both males and females who eventually marry to rise. The mean ages at marriage remain more or less constant.

A comparison of the results of Run 4 and the baseline computation shows the effects of a difference in male spousal age preferences. In the baseline computation the largest of the $\beta_{i j}$ for 40 -year-old males would be at $j=32.25$; in Run 4 the largest of the $\beta_{i j}$ for 40 -year-old males would be at $j=38.00$. Roughly speaking, in the baseline run the difference between the male's age and the most desirable spousal age is itself an increasing function of the male's age. In Run 4, this difference is assumed to be independent of the male's age. The effects of this change are quite marked. The male proportion eventually married falls by 4.9 percentage points, and the mean age at marriage decreases by half a year. The proportion eventually married for females also falls, but only by 1.8 percentage points, and, in contrast, their mean age at marriage increases by half a year. These results are basically what one would expect a priori, but it is interesting to note that a difference in spousal age preferences can, indeed, have a substantial impact on the pattern and the extent of marriages.

A comparison of the results of Run 5 and the baseline computation shows the effects of a different sort of change in female spousal age preferences. In the baseline run it is assumed that females' most preferred mates were those four years older than themselves. In Run 5, this age gap is changed to five years. This change in taste reduces both the male and female proportions married. It has no effect on males' average age at marriage, but does cause women, on average, to marry later in life.

Table 2 contains data comparing the effects of changes in the age structures on the eligible populations. In Run 6, there are $20 \%$ fewer eligible females at each age than in the baseline computation. The effects of this change are to raise the proportion of females eventually marrying from $89.6 \%$ to $92.1 \%$ and to lower the proportion of males eventually marrying from $91.2 \%$ to $88.6 \%$. The mean age at marriage for females decreases by 0.3 of a year, while it increases by half a year for males. The effects of decreasing the female population by $20 \%$ at each age are shared by both sexes. For example, the marriage hazard rate for 20 - to 24 -year-old females increases by $11 \%$, while the marriage hazard rate for 20- to 24-year-old males decreases by $13 \%$.

In Run 7, the male eligible population is made younger by reducing the male eligible population in the baseline computation by one percent for each year of age over 16. To be precise, if $M_{i}$ were the number of eligible males at age $i$ in the baseline calculation, then the number of eligible males at age $i$ in Run 7 would be $(0.99)^{i-16} \cdot M_{i}$. Among the younger male eligible population the proportion eventually married rises to 92.3\% from $91.2 \%$, but their mean age at marriage is the same as in the baseline population. A younger population of eligible males reduces slightly the proportion of females who eventually marry, but induces those who do marry to do so at a slightly earlier age.

By and large, the effects of population structures on the mean age at marriage and the proportion eventually marrying seem relatively small. It should be kept in mind, however, that these are computed on the assumption that the rates generated by the calculations apply to a hypothetical cohort of women. The effects of changes on the actual numbers of person-years lived in a married state may be greater when actual histories of 


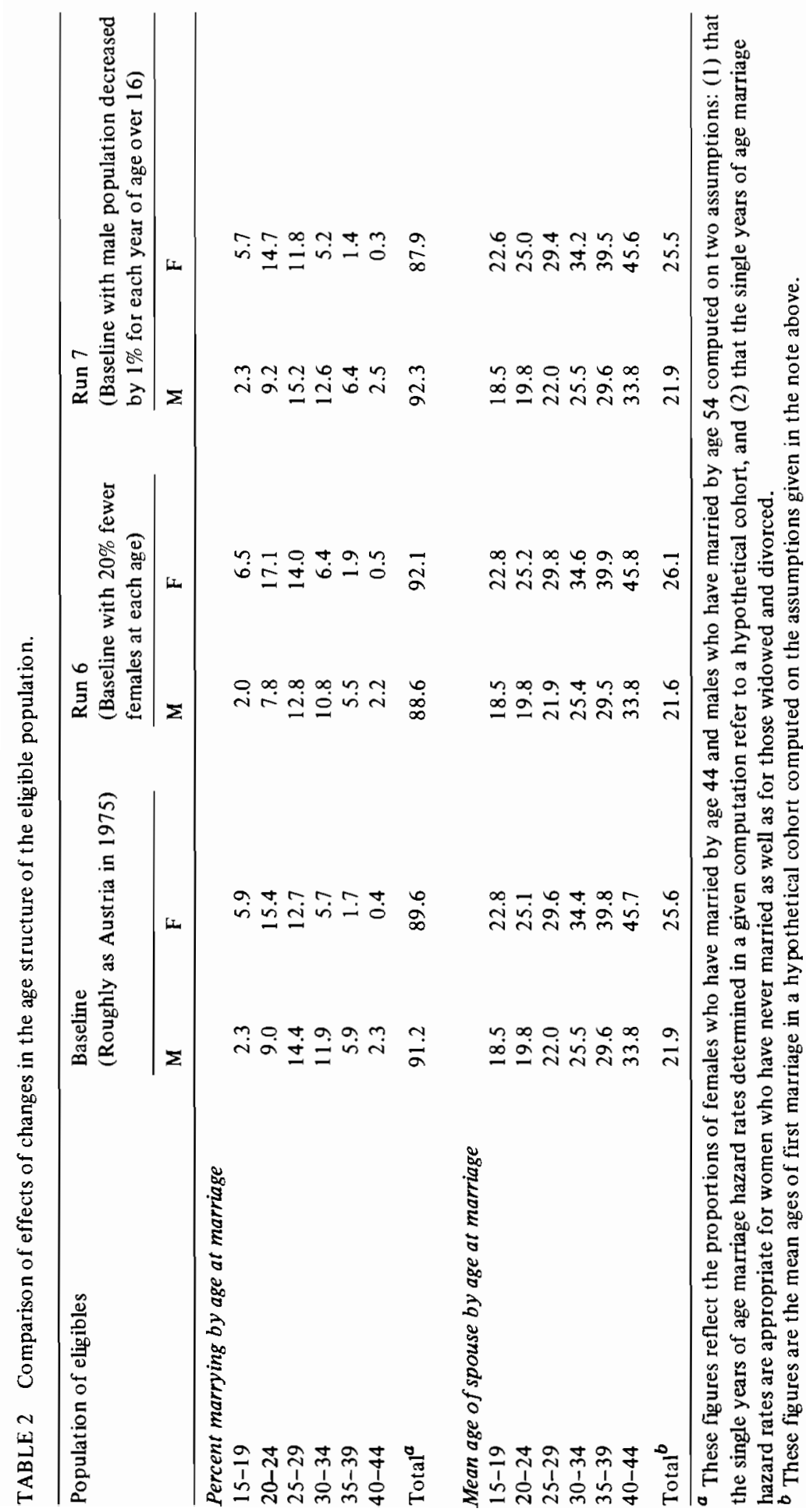


cohorts are generated through simulations of the demographic development of a given country or region.

\section{CONCLUSION}

This paper presents a parameterized two-sex marriage model and shows that it yields plausible results when parameters of the age structures of the eligible populations are changed. This is, of course, only a first step. The next step is to analyze how well the model fits observed data. If it works well, analytic demography will have one more tool with which to work.

\section{ACKNOWLEDGMENT}

I would like to thank Sherman Robinson for a set of very helpful comments on an earlier draft.

\section{REFERENCES}

Becker, G.S. (1974). A theory of marriage. In T.W. Schultz (Editor), Econo mics of the Family. University of Chicago Press, Chicago.

Becker, G.S., Landes, E.M., and Michael, R.T. (1977). An economic analysis of marital instability. Journal of Political Economy, 85(6):1141-1188.

Brass, W. (1971). On the scale of mortality. In W. Brass (Editor), Biological Aspects of Demography. Taylor and Francis, London.

Coale, A.J. (1971). Age patterns of marriage. Population Studies, 25(2): 193-214.

Coale, A.J. and Demeny, P. (1966). Regional Model Life Tables and Stable Populations. Princeton University Press, Princeton, New Jersey.

Coale, A.J. and McNeil, D.R. (1972). The distribution by age of the frequency of first marriage in a female cohort. Journal of the American Statistical Association, 67:743-649.

Frieden, A. (1974). The United States marriage market. In T.W. Schultz (Editor), Economics of the Family. University of Chicago Press, Chicago.

Lesthaeghe, R.J. and Page, H.J. (1980). The post-partum non-susceptible period: development and application of model schedules. Population Studies, 34(1):143-169.

Lluch, C., Powell, A.A. and Williams, R.A. (1977). Patterns in Household Demand and Savings. Oxford University Press, New York.

Pollard, J.H. (1975). Modeling human populations for projection purposes - some problems and challenges. Australian Journal of Statistics, 17:63-76.

Rodgers, G.B., Hopkins, M.J.D., and Wery, R. (1976). Economic-demographic modelling for development planning: Bachue--Philippines. Population and Employment Working Paper 45. International Labour Organization, Geneva.

Rogers, A., Raquillet, R., and Castro, L.J. (1978). Model migration schedules and their applications. Environment and Planning A, 10(5):475-502.

Sanderson, W.C. (1979). Quantitative aspects of marriage fertility and family limitation in nineteenth century America: another application of the Coale specifications. Demography, 16(3); 339358.

Sanderson, W.C. (1980). Economic-demographic simulation models: a review of their usefulness for policy analysis. IIASA Reports, 1(2):433-542. 
Santos, F.P. (1975). The econo mics of marital status. In C.B. Lloyd (Editor), Discrimination and the Division of Labor. Columbia University Press, New York.

Schoen, R. (1977). A two-sex nuptiality-mortality life table. Demography, 14(3):333-350.

\section{APPENDIX}

The results of the two-sex marriage model presented in Section 4 required, in essence, the solution of a set of 1140 linear equations in 1140 unknowns $(I=38, J=30)$. To make such an exercise computationally feasible requires that use is made of the particular characteristics of the extended linear expenditure system. To begin, it is useful to note that all the $I \times J$ values of $s_{i j}$ (see eqns. 9 and 10) can be expressed as weighted sums of $I+J$ intermediate variables. This can easily be seen by defining:

$$
T_{i}^{\mathrm{m}} \equiv \sum_{j} \gamma_{i j} s_{i j} \quad\left(i^{\prime} \leqslant i \leqslant i^{*} ; j^{\prime} \leqslant j \leqslant j^{*}\right)
$$

and

$$
T_{j}^{f} \equiv \sum_{i} g_{j i} s_{i j} \quad\left(i^{\prime} \leqslant i \leqslant i^{*} ; j^{\prime} \leqslant j \leqslant j^{*}\right)
$$

Equation (11) now implies

$$
s_{i j}=\frac{\left(F_{j} b_{j i}-M_{i} \beta_{i j}\right)-F_{j} b_{j i} T_{j}^{\mathbf{f}}+M_{i} \beta_{i j} T_{i}^{\mathrm{m}}}{M_{i} \gamma_{i j}-F_{j} g_{j i}} \quad\left(\text { for } i^{\prime} \leqslant i \leqslant i^{*} ; j^{\prime} \leqslant j \leqslant j^{*}\right)
$$

where

$$
\gamma_{i j} \text { and } g_{j i} \neq 0
$$

Equation (A3) shows that the $I+J$ values of $T_{i}^{\mathrm{m}}$ and $T_{j}^{\mathrm{f}}$ determine the $I \times J$ values of the $s_{i j}$, given the age structures of the eligible populations and the parameters of the demand systems. Equation (A3) may also be used to form a system of $I+J$ linear equations in $T_{j}^{f}$ and $T_{i}^{\mathrm{m}}$. To see this, multiply $s_{i j}$ in eqn. (A3) by $\gamma_{i j}$, and for each value of $i$ sum the products over the index $j$. The resulting expression is

$$
T_{i}^{\mathrm{m}}=\sum_{j} \frac{B_{i j} \gamma_{i j}}{G_{i j}}-\sum_{j} \frac{T_{j}^{\mathrm{f}} F_{j} b_{j i} \gamma_{i j}}{G_{i j}}+T_{i}^{\mathrm{m}} M_{i} \sum_{j} \frac{\beta_{i j} \gamma_{i j}}{G_{i j}}
$$

where

$$
\begin{aligned}
& \gamma_{i j} \text { and } g_{i j} \neq 0 \\
& B_{i j} \equiv F_{j} b_{j i}-M_{i} \beta_{i j}
\end{aligned}
$$


and

$$
G_{i j} \equiv M_{i} \gamma_{i j}-F_{j} g_{j i}
$$

Rearranging terms we obtain

$$
-\sum_{j} \frac{B_{i j} \gamma_{i j}}{G_{i j}}=-\sum_{j} \frac{T_{j}^{\mathrm{f}} F_{j} b_{j i} \gamma_{i j}}{G_{i j}}+T_{i}^{\mathrm{m}} \cdot\left(-1+M_{i} \sum_{j}-\frac{\beta_{i j} \gamma_{i j}}{G_{i j}}\right) \quad\left(i^{\prime} \leqslant i \leqslant i^{*}\right)
$$

where

$\gamma_{i j}$ and $g_{i i} \neq 0$

Analogously, multiplying $s_{i j}$ in eqn. (A3) by $g_{j i}$ and summing over $i$ yields

$$
-\sum_{i} \frac{B_{i j} g_{j i}}{G_{i j}}=-T_{j}^{\mathrm{f}} \cdot\left(1+F_{j} \sum_{i} \frac{b_{j i} g_{j i}}{G_{i j}}\right)+\sum_{i} \frac{T_{i}^{\mathrm{m}} M_{i} \beta_{i j} g_{j i}}{G_{i j}} \quad\left(j^{\prime} \leqslant j \leqslant j^{*}\right)
$$

where

$\gamma_{i j}$ and $g_{j i} \neq 0$

There are $I$ equations of the type in (A5) above and $J$ equations of the type in (A6) above. The resulting $I+J$ equations in the $T_{i}^{\mathrm{m}}$ and $T_{i}^{\mathrm{f}}$ are easily solved. In matrix terminology we may write

$$
[B]=[C][T]
$$

where $[B]$ is an $(I+J) \times 1$ vector, listing first the $I$ left-hand-side variables in eqn. (A5) then the $J$ left-hand-side variables from eqn. (A6). [C] is an $(I+J) \times(I+J)$ matrix of coefficients of the $T_{i}^{\mathrm{m}}$ and $T_{j}^{\mathrm{f}}$, and $[T]$ is an $(I+J) \times 1$ vector listing first the $I$ values of $T_{i}^{\mathrm{m}}$, then the $J$ values of $T_{j}^{\mathrm{f}}$.

The $(I+J) \times 1$ vector $T$ can immediately be computed as

$$
[T]=[C]^{-1}[B]
$$

The structure of the [C] matrix allows for a natural partitioning and only requires the inversion of a matrix of the order $\operatorname{MIN}(I, J)$.

Given the elements of $T$, the scarcity indicators are computable from eqn. (A3) and given these scarcity indicators the numbers of marriages by age may be calculated from either eqn. (9) or eqn. (10) in the text. In this manner an $I \times J$ matrix of marriages can be calculated while only inverting a matrix of the order of $\operatorname{MIN}(I, J)$. 


\title{
INCORPORATING DEMOGRAPHY INTO GENERAL EQUILIBRIUM MODELING
}

\author{
Robert M. Schmidt \\ University of Richmond, Richmond, Virginia (USA)
}

\section{INTRODUCTION}

Much has been written about the economic significance of rapid population growth in the developing countries. Indeed, an increasing number of Computable General Equilibrium (CGE) models have examined demographic change explicitly.* This paper adds to that literature by presenting, estimating, and applying a demographic framework for use with a CGE model of economic development. The basic approach of the demographic framework is to apply annual, disaggregated (here, age-sex-regional) rate schedules to a similarly disaggregated population in order to forecast future population change.

A distinguishing feature of our demographic projection is its extensive reliance on "model" rate schedules; i.e. continuous representations of various life-cycle patterns. Model schedules are attractive for several reasons: they are convenient in computer use; they provide graduation of discontinuous or noisy rate schedules; and they allow interpolation to single-year rates. Moreover, model schedules are parsimonious in data requirements because of the theoretical and empirical content embedded in their specification. This attribute is significant given the dearth of reliable, detailed demographic data for developing countries. Finally, model schedules provide flexibility in the analysis of changing rate schedules over time. Time paths for the parameters can be expressed either exogenously or endogenously. Since this particular paper is concerned with such issues as the sensitivity of demographic projections to various model parameters, all parameters will be specified exogenously. On the other hand, it is quite feasible to permit the demographic parameters to be endogenous to an integrated economic-demographic model. For example, levels and age patterns of fertility, mortality, labor-force participation and

\footnotetext{
* Coale and Hoover (1958) initiated the effort in their pioneering study of the influence of alternative population growth paths on Indian economic development. Economic-demographic development models since that time have included those by GE-TEMPO (Enke, 1966; McFarland et al., 1973), ILO's Bachue series (Rodgers et al., 1978; Moreland, 1979; Anker and Knowles, 1980), and Casetti (1977).
} 
rural-urban migration can be determined by such variables as per capita income, income distribution, and literacy levels.

After this short introduction, the paper is organized into three main sections. Section 2 describes each of the model schedules (nuptiality, fertility, mortality, and net rural-urban migration), estimates their parameters, and then validates the integrated demographic framework. Section 3 applies the demographic model in two dimensions. Section 3.1 presents the results of three alternative demographic projections in addressing the question of whether the economic impact of appending a demographic framework to a typical CGE model is worth the effort. Section 3.2 then examines the sensitivity of economically-oriented measures to several demographic parameters. Which parameters have the largest quantitative impact on selected economic variables? Are the impacts lagged? If so, which are the likely impacts to be felt within the time frame of an economic model? Given these results, Section 4 points toward the future by discussing further research plans.

\section{THE MODEL SCHEDULES}

The demographic framework utilizes model schedules to represent age patterns by sex and region for nuptiality, marital fertility, mortality, and rural-urban net migration.* This section describes these model schedules as well as their parameter estimates for a "Representative" Developing Country (hereafter, RDC) over the decade of the 1960s."* The individual model schedules are then integrated through standard demographic accounting into a complete demographic framework. Validation of this framework and the parameter estimates is performed by projecting the RDC's 1960 population for ten years, and comparing it with the RDC population distribution observed in 1970.

\subsection{The Nuptiality and Marital Fertility Models}

The Coale fertility model formulates explicitly the role of marriage (including quasilegal, long-term unions) in determining age-specific fertility rates. As a result, two model schedules are required in Coale's analysis: a nuptiality schedule and a marital fertility schedule. Coale (1971) and Coale and McNeil (1972) argue that the age pattern of female first marriages can be distinguished from a "standard" age pattern through three parameters, namely, $C$, the proportion of females who ultimately marry, $a_{0}$, the age at which females begin marrying, and $k$, the "pace" of first marriages relative to the standard. Specifically, the rate $\left(g_{i}\right)$ of first marriage at age $i$ is represented as

\footnotetext{
* These represent the basic components of our demographic framework. We also utilize age-sexregional labor-force participation rates, but not in model-schedule form. An early future extension of the model will be to further disaggregate the population by education level.

** The initial application of the demographic framework will be to the Kelley-Williamson CGE model of development and urbanization (Kelley and Williamson, 1980). As such, the sample upon which we base our parameter estimates includes the 40 "representative" developing countries listed in Kelley and Williamson (1982).
} 


$$
\begin{aligned}
g_{i}= & C(0.19465 / k) \exp \left\{(-0.174 / k)\left(i-a_{0}-6.06 k\right)\right. \\
& \left.-\exp \left[(-0.2881 / k)\left(i-a_{0}-6.06 k\right)\right]\right\}
\end{aligned}
$$

A $C$ value of unity implies that every female eventually marries. A value of unity for $k$ reproduces the standard age pattern. Earlier marriage (i.e., a faster "pace" of marriage) than the standard is implied by a $k$ value of less than unity, and older marriage by $k$ greater than unity. Assuming no marriage dissolution occurs except for that caused by death, the proportion married at age $i$ is calculated by summing $g_{i}$ from age $a_{0}$ through age $i$.

Coale and Trussell (1974) developed a marital fertility model in which the marital fertility rate $\left(r_{i}\right)$ at age $i$ is measured in terms of deviations from natural fertility $\left(n_{i}\right)$ via a standard age pattern of voluntary fertility control $\left(v_{i}\right)$ which increases with age. Thus

$$
r_{i}=M n_{i} \exp \left(v_{i} m\right)
$$

A value of zero for the $m$ parameter reproduces the natural fertility age pattern, while a value of unity replicates the standard contraceptive age pattern. $M$ changes the level of fertility without altering relative rates. The fertility rate at age $i$ can be calculated by multiplying the proportion of females who are married by the marital fertility rate, $r_{\boldsymbol{i}}$.

We have estimated region-specific parameters for the Coale fertility model using cross-sectional data from United Nations Demographic Yearbooks (various years) and the World Tables of the International Bank for Reconstruction and Development (IBRD) $(1976,1980)$. The estimation has been simplified by assuming the same nuptiality age patterns in both regions* and further assuming that marriage begins at age 15 (i.e., $a_{0}=$ 15). We employ the technique of Hajnal (1953) to estimate the "Singulate" Mean Age at Marriage $(S M A M)$ for individual countries from census data on percentages of single females by five-year age groupings. The $k$ nuptiality parameter follows readily since the relationship between $k$ and $S M A M$ in the Coale-McNeil nuptiality model has been shown by Hill and Trussell $(1977$, p. 314) to be

$$
k=\left(S M A M-a_{0}\right) / 11.37=(S M A M-15) / 11.37 .
$$

We have collapsed the level parameters ( $C$ from nuptiality and $M$ from marital fertility) into a single parameter, $c$, because the data available preclude their separate estimation. Thus, two region-specific parameters, the $c$ level parameter and the $m$ contraceptive parameter, remain to be estimated.

Although data on regional, age-specific fertility rates are scarce, country-wide rates, which are readily available, can be rewritten as weighted sums of the regional rates. Thus, the country-wide fertility rate $\left(f_{i}\right)$ at age $i$ can be seen to be

\footnotetext{
* While this assumption appears to be innocuous, it precludes "marriage squeezes" resulting, for example, from high levels of sex-biased rural-urban migration. Sanderson (1982) presents an interesting extension to the Coale-McNeil model. Within this two-sex marriage framework, female agespecific marriage rates are affected by the age structure of available males, and vice versa. Given the emphasis on rural urban migration in many economic models, Sanderson's work will nicely augment the demographics of CGE modeling.
} 


$$
f_{i}=\sum_{h=\mathbf{R}, \mathrm{U}}\left(F_{i, h} / F_{i}\right) f_{i, h}
$$

where $\left(F_{i, h} / F_{i}\right)$ represents the proportion of women aged $i$ living in region $h$. This decomposition can be rewritten in terms of the fertility model

$$
f_{i}=G_{i} \sum_{h=\mathbf{R}, \mathrm{U}}\left(F_{i, h} / F_{i}\right) C_{h} n_{i} \exp \left(m_{h} v_{i}\right)
$$

where $G_{i}$ is the known proportion married at age $i$ of those ultimately marrying (from the nuptiality estimation), $n_{i}$ and $v_{i}$ are obtained from the standard schedules, and $c_{h}$ and $m_{h}$ are the parameters to be estimated. We have pooled five age-specific rates from a number of developing countries* for use in nonlinear least-squares estimation at two points in time -1960 and 1970. Standard hypothesis tests indicate that (a) the $c$-level parameter does not vary regionally in either decade, and (b) the parameter estimates do not vary between decades. Pooling the data across decades results in the following parameter estimates. (Asymptotic $t$-values are given in parentheses.)

$\begin{array}{ccc}c & m_{\mathbf{R}} & m_{\mathrm{U}} \\ 0.757 & 0.072 & 0.720 \\ (39.742) & (0.943) & (3.740)\end{array}$

The rural contraceptive parameter, $m_{\mathbf{R}}$, does not differ significantly from zero, indicating "natural" fertility in that region. In contrast, substantial fertility control occurs in the urban area.

One point remains. We impose Crude Birth Rates (CBRs) on the validation exercise of Section 2.4 to ensure the $2.7 \%$ annual growth rate observed for the RDC during the 1960s. The CBRs represent the RDC averages of 45 per 1000 in 1960 and 41 per 1000 in 1970. The level parameter, $c$, has been derived residually to ensure these results. Additionally, the RDC averages of 19.9 years for 1960 and 20.8 years for 1970 are used for the mean age at marriage (SMAM).** The following represents the full set of parameters.

\footnotetext{
* The countries used in this particular statistical inquiry must have nuptiality data, country-wide fertility rates, and an age-sex-regional population census. RDCs for which these data are available include Chile $(1960,-1970)$, Colombia (1964), Costa Rica $(1963,1973)$, the Dominican Republic $(-1960,1970)$, Ecuador $(1962,1972)$, El Salvador $(1961,1971)$, Guatemala (1973), Honduras (1961, 1974), Korea (1960), Mexico (-1960, 1970), Nicaragua (1963), Pakistan (1968), Panama (1960, 1970), Peru (1961 , 1969), Philippines (1970), Sri Lanka (-1962), Thailand (1970), Togo (1961), Turkey $(1967)$, and Yugoslavia $(-1961,1971)$. Countries or years denoted by a "-" were excluded from our sample since preliminary estimation of their country-wide parameters resulted in a meansquare error falling below the minimally acceptable level suggested by Coale and Trussell (1978). ** IBRD (1980, pp. 442-447) lists crude birth and death rates for nearly all of the 40 RDCs in 1960 and 1970. The average CBRs (45 and 41 for 1960 and 1970, respectively) and CDRs (18 and 14) imply identical population growth rates of $2.7 \%$ for the two years. As discussed above for the nuptiality estimation, individual country estimates for $S M A M$ were derived from age-specific census data on percentage single.
} 


$\begin{array}{lllll}\text { Year } & k & c & m_{\mathrm{R}} & m_{\mathrm{U}} \\ 1960 & 0.43 & 0.766 & 0.072 & 0.720 \\ 1970 & 0.51 & 0.808 & 0.072 & 0.720\end{array}$

These parameters imply approximately constant Total Fertility Rates (TFRs, or the sum of the age-specific rates) between 1960 and 1970 (6.7 in the rural area, 4.9 in the urban area, and 6.1 overall). However, due to changes in the age and/or regional distribution of the female population, CBRs fall between 1960 (47.4 rural, 39.8 urban, 45.0 overall) and 1970 (42.5 rural, 38.4 urban, 41.0 overall).

Figure 1 illustrates the 1960 curves in three panels. Panel a contrasts the much earlier marriage pattern of our RDC with the standard pattern of Coale and McNeil. Panels $b$ and $\mathrm{c}$ depict, respectively, the marital and composite fertility rates for the rural and urban areas.

\subsection{The Model Mortality Schedule}

The Brass (1971) mortality model is utilized to determine regional age-sex patterns of mortality. While other model schedules, most notably the Coale-Demeny (1966) model life tables, could be used for this purpose, the Brass model possesses four useful characteristics. First, it provides single-year age groupings. Second, Brass' standard mortality age pattern reflects the moderate-to-high mortality case existing in many developing countries. Third, it is extremely flexible in computer use. Fourth, its parameters are easily manipulated for counterfactual experimentation.

The Brass model uses two parameters to relate observed mortality age patterns to a standard pattern $-\alpha$, which pertains primarily to the level of mortality and $\beta$, which primarily affects the age pattern. Brass argues that a linear relationship can be observed between the logits of life-table survivorship rates $\left(l_{i}\right)^{*}$ and a set of standard survivorship rates $\left(l_{i, \mathrm{~s}}\right)$

$$
\operatorname{logit}\left(l_{i}\right)=\alpha+\beta \operatorname{logit}\left(l_{i, \mathrm{~s}}\right)
$$

The standard survivorship pattern is critical to the reliability of this relationship. Accordingly, Brass has developed a general standard for the moderate-to-high mortality case which emphasizes relatively high infant and childhood mortality. With $\alpha=0$ and $\beta=1$, the standard pattern and level (expectation of life at birth of 43.4 years) is reproduced.

* The logit transformation is defined as follows:

$$
\operatorname{logit}\left(l_{i}\right)=0.5 \ln \left(l_{i} /\left[1.0-l_{i}\right]\right)
$$

An excellent presentation of the biological and statistical theory underlying the use of the logit function for human mortality is provided in Hill and Trussell (1977, pp. 315-317). The survivorship rate $\left(l_{i}\right)$ is related to the mortality rate actually used in the population projections $\left(q_{i}\right)$ as follows

$$
q_{i}=1.0-\left(l_{i+1} / l_{i}\right)
$$



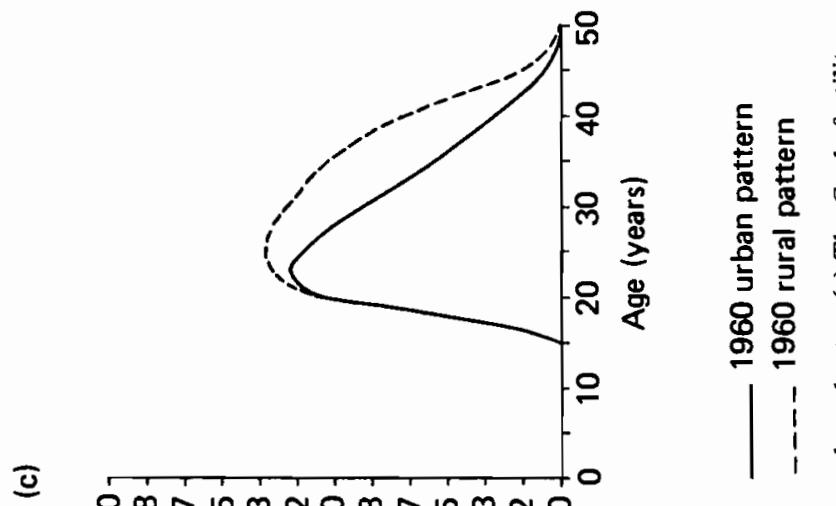

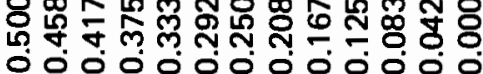

ałed Ał!!นa」

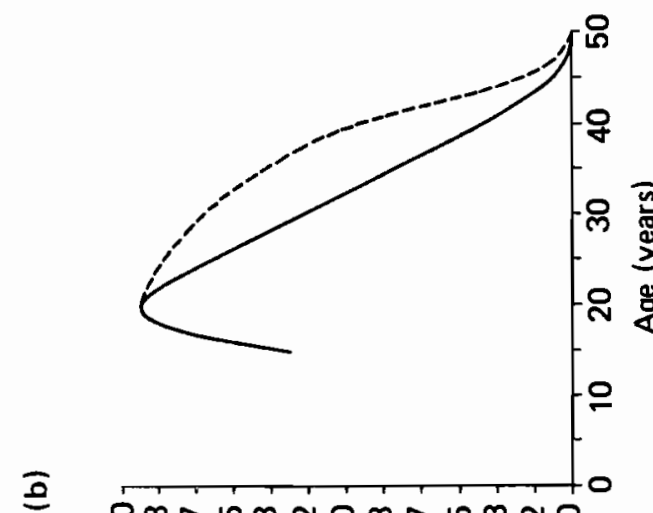

尺

움ํํำ

ó ó ó ó ó ó 0 ó

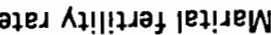

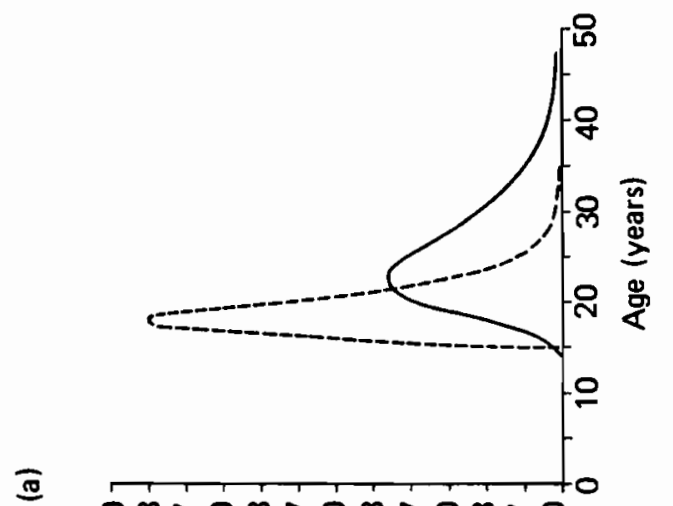

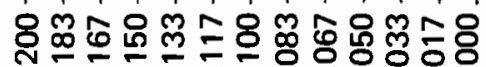

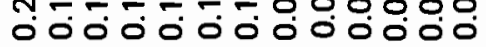
әles $A$ !!je!̣dnN 
Increasing $\alpha$ for a constant $\beta$ raises the mortality level. Raising $\beta$ for a constant $\alpha$ results in mortality rates which rise more rapidly with age.

Neither the pattern nor the level of published age-specific mortality rates is deemed to be reliable for many developing countries. Indeed, even published life tables can be less trustworthy than the rates obtained by imposing a single dependable measure of the mortality level on a model life table. The most convenient summary measure of this type is the expectation of life at birth. Male and female life expectancies are available for many countries from United Nations Demographic Yearbooks. Additionally, case studies provide estimates of urban and rural life expectancies for 17 RDCs. However, data which are disaggregated by both sex and region are only available for five countries in our sample. Accordingly, we have assumed that the ratio of male-to-female life expectancies (average over the 1960s of 0.950 ) is the same in both regions, and that the ratio of rural-to-urban life expectancies (average of 0.914 ) is the same for both sexes.*

Given these ratios and a further assumption that the Brass standard mortality pattern is applicable for both sexes and regions (i.e., that $\beta=1$ ), the four sex- and regionspecific $\alpha$ values have been computed as part of the validation exercise of Section 2.4. Specifically, we impose the average RDC crude death rate (CDR) of 18 per 1000 for 1960 and 14 per 1000 for 1970 on the validation. The $\alpha$ values are then derived to be consistent with these CDRs and the relative life expectancies.

The parameter estimates, together with the implied life expectancies and CDRs, are presented in Table 1. While the aggregate CDRs have been imposed on the estimation, the aggregate life expectancies have not. They compare well with the RDC averages of 49 years in 1960 and 54 years in 1970. As an experiment, we have applied 1960's parameter estimates to 1970's population distribution and have found that changes in the population distribution account for approximately one-half of the decline in the CDR over the decade.

TABLE 1 Summary statistics implied by the estimated mortality parameters.

\begin{tabular}{llccccc}
\hline & \multirow{2}{*}{ Aggregate } & \multicolumn{2}{c}{ Urban } & & Rural & \\
& & Males & Females & & Males & Females \\
\hline 1960 & & -0.21 & -0.29 & & -0.07 & -0.15 \\
$\alpha$ & & 50.3 & 52.8 & & 45.8 & 48.4 \\
$e^{0}$ & 48.4 & 15.6 & 14.9 & & 20.2 & 18.3 \\
$C D R$ & 18 & & & & \\
1970 & & -0.32 & -0.42 & & -0.28 & -0.26 \\
$\alpha$ & & 53.8 & 56.7 & 49.0 & 51.9 \\
$e^{0}$ & 52.1 & 12.3 & 11.1 & 16.4 & 14.4 \\
$C D R$ & 14 & & & & \\
\hline
\end{tabular}

\footnotetext{
* Some support for this assumption is provided by the five countries with disaggregated data. On average, the male-to-female ratio does not differ substantially between the urban $(0.966)$ and rural $(0.953)$ areas. Nor does the rural-to-urban ratio differ substantially for males $(0.922)$ and females (0.932).
} 


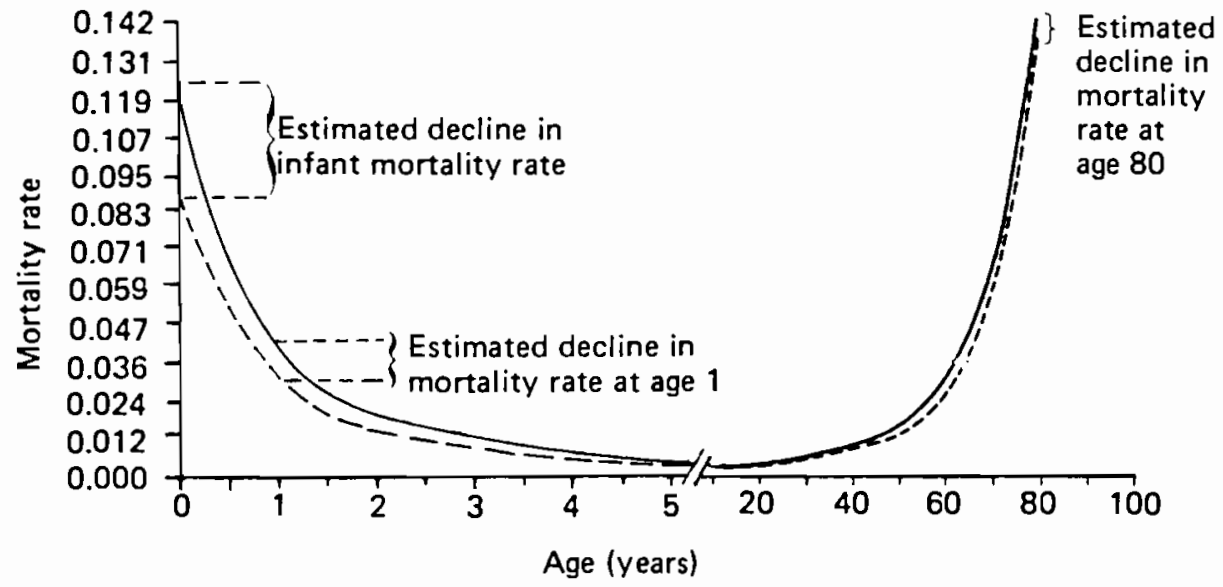

1960 pattern 1970 pattern

FIGURE 2 Estimated country-wide mortality rates, 1960 and 1970. (Note that the age scale is discontinuous and expanded over the age range $0-5$ to illustrate changes in child mortality more clearly.)

Country-wide, age-specific mortality rates are presented in Figure 2 for 1960 and 1970. Mortality rates are lower at every age in 1970 . Given the nonlinear nature of the Brass model, however, the age pattern of mortality differs slightly between the two periods even though the same "pattern" parameter $(\beta=1)$ is employed for both. As expected, the decline in mortality is greatest for the younger age groups.

\subsection{The Model Net Migration Schedule}

An important element of many development models is the transfer of labor from the countryside to the cities. For example, in the Kelley-Williamson (1980) CGE model, a potential migrant responds to such factors as relative wage differentials, expectations for obtaining favored urban employment or skills training, and regional cost-of-living differences. The Kelley-Williamson model determines the net number of laborers who migrate annually between the rural and urban areas. The demographic task in such a model is to represent the age and sex patterns of these net migrants. Unlike fertility and mortality, however, no existing model migration schedule is ideally suited to this purpose. We have consequently developed such a model.*

The net migration model includes three parameters - the Crude Migration Rate ( $C M R$, or net migrants as a percentage of the rural population) and two sex-specific shift

\footnotetext{
* A detailed description of the model's development and estimation is provided in Schmidt (1981, ch. VD. We have benefitted in this regard from Pittenger's $(1974,1978)$ analytical classification scheme for various net migration age patterns. The gross migration model of Rogers et al. (1978) has also been instrumental to our effort.
} 
parameters, $C_{\mathrm{M}}$ and $C_{\mathrm{F}}$. Imposition of a $C M R$ determines both the age and sex composition of the net migrant pool. Estimation of the various constants of the model has been performed through nonlinear least-squares regression on a sample of eleven developing countries with age-sex rates over the 1960 s. ${ }^{*}$ The model has three components. The first two components determine the age pattern of the rates for each sex, and are similar in functional form to the Coale-McNeil nuptiality model. ${ }^{* *}$ The net migration rate $\left(m_{i, \mathrm{M}}\right)$ for males at age $i$ is given by

$m_{i, \mathbf{M}}=C_{\mathbf{M}}(0.168 / \kappa) \exp \{(-0.026 / \kappa)(i-4.803 \kappa)-\exp [(-0.218 / \kappa)(i-4.803 \kappa)]\}$

where

$$
\kappa=0.770+0.153 C M R
$$

For females

$m_{i, \mathrm{~F}}=C_{\mathrm{F}}(0.127 / \kappa) \exp \{(-0.017 / \kappa)(i-3.677 \kappa)-\exp [(-0.395 / \kappa)(i-3.677 \kappa)]\}$

where

$$
\kappa=0.939+0.036 C M R
$$

Within both of these functions, the higher the $C M R$, the larger is $\kappa$, the older is the age at the peak rate, and the flatter is the profile of the age-specific rates. The relatively large male $C M R$ coefficient implies that, across a broader age spectrum, rural males are more responsive to rapidly expanding urban opportunities than are rural females. This could be the result of relatively limited urban opportunities for females, opportunities (e.g., as domestics) which are largely independent of the migration level. Additionally, female mobility could be strongly influenced by cultural factors inhibiting independent female migration.

The third component of the migration model determines the male share of the migrant pool. We postulate a simple linear relationship between the $M A L E \%$ and the CMR. Cultural differences result in low male shares (e.g., 45-50\%) in Latin American

\footnotetext{
* These eleven countries are Brazil, Chile, Colombia, the Dominican Republic, Ecuador, El Salvador, Mexico, Panama, Peru, Sri Lanka, and Syria. Migration rates are provided in 14 five-year age groupings, implying 154 age-specific observations in a pooled sample. The net rural-urban migration rates have been estimated through a "survival" technique from age-sex-regional census data compiled by Preston (1979) while at the Population Division of the United Nations. The strengths and weaknesses of the data and of the survival technique are discussed in Schmidt (1981, Appendix B).

** This net migration model is not fully general. While the model is capable of capturing the general age pattern illustrated in Figure 3, Pittenger (1974) has depicted a number of alternative net migration patterns. Further, the present formulation is incapable of generating negative rates at any age. Finally, regardless of the level of net migration, the model postulates a constant ratio of the rate of ascent ( 0.026 for males) to the rate of descent ( 0.218 for males). A more general model would provide for a varying ratio. Nevertheless, we believe this model to be adequate for representing age patterns of a relatively high level (say $1 \%$ or more annually) of net rural-urban migration in a developing country.
} 
countries and high male shares (e.g., 50-55\%) in Asian countries. In our formulation, such differences are calculated by including an Asian binary variable $(A S I A N)$ in the regression. ( $t$-values are given in parentheses.)

$$
\begin{aligned}
M A L E \%= & 43.596+1.787 C M R+8.394 A S I A N \\
& (154.05)(10.51) \quad(26.40)
\end{aligned}
$$

The $r^{2}$ value is 0.775 . Predicted male shares range from $46 \%$ for the lowest observed $C M R$ to $50 \%$ for the highest $C M R$. $^{*}$

Although the key parameter of the net migration model, the $C M R$, is stated in terms of people, economic models typically determine the net number of migrating laborers. Some iteration within the demographic block of an integrated economicdemographic model would therefore be necessary to determine a $C M R$ consistent with the required number of laborers, the rural population distribution, and rural age-sex labor-force participation rates. As part of this process, $C_{\mathrm{M}}$ and $C_{\mathrm{F}}$ values would be derived to ensure the desired $M A L E \%$ and $C M R$.

(a)

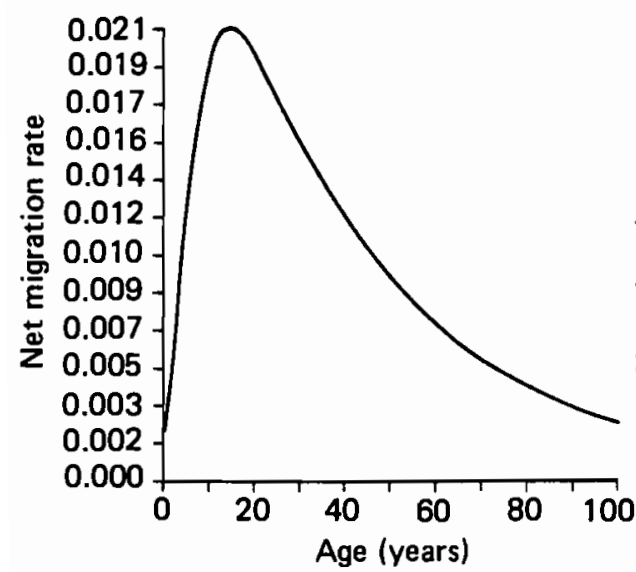

(b)

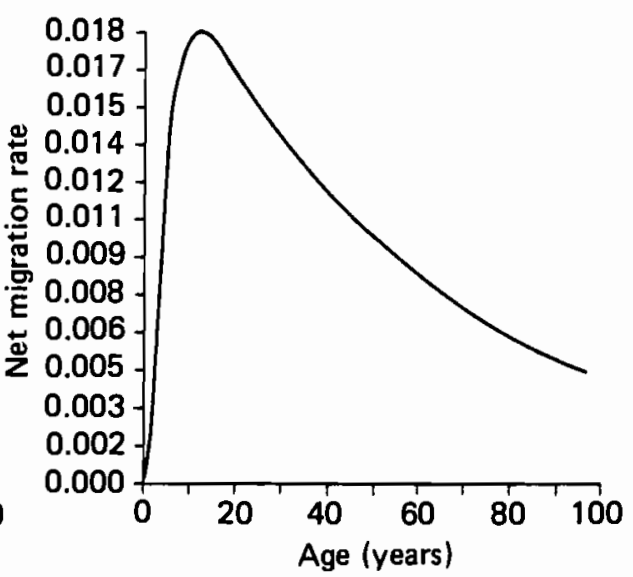

FIGURE 3 "Standard" net rural-urban migration rates: (a) male, (b) female.

Figure 3 illustrates male and female net migration rates at the estimation sample's mean $C M R(1.46 \%) .{ }^{* *}$ The curves reveal the youthfulness of the migration - peak rates in the mid-teens for males and early teens for females. A detailed analysis of the reliability of these results is provided in Schmidt (1981, ch. VI). Briefly, rural-urban migration in

\footnotetext{
* These predictions and our demographic projections employ an intercept (45.485) which is the sum of 43.596 plus the proportion of Asian countries in the RDC sample (9/40) times 8.394.

** Were these graphs to follow standard demographic practice, they would depict negative rates since they illustrate net out-migration from the rural area. For convenience of exposition and estimation, however, we have deviated from this convention.
} 
developing countries is quite youthful. Overall, the model is least successful in replicating the percentage of the migrant population who are less than five years of age (underestimating that figure), and more successful in reproducing the remainder of the age distribution. The model is quite successful in predicting broader aggregates such as average migrant and labor-force ages, as well as the dependency ratio of the migrant pool.

\subsection{Validation}

Up to this point, we have described and estimated all of the basic components of a demographic framework. The fertility and mortality results have illustrated the utility of the model-schedules approach in estimating age-sex-regional rates in the face of scarce and/or unreliable data. The net migration results have depicted the usefulness of model schedules when levels of demographic events are determined within the economic rather than the demographic module. A final question remains in assessing the viability of our demographic framework: will the integrated components provide a reliable demographic projection? This section addresses that question by projecting a 1960 age-sex-regional population for ten years and comparing the result with the actual 1970 population. ${ }^{*}$

For the purposes of the projection, we assume linear change for those nuptiality, fertility, and mortality parameters which vary over the decade. Further, since the demography is not yet linked to an economic paradigm, we impose a net migration level exogenously. Our estimate of an annual 1.13\% CMR was calculated as follows. The estimated fertility and mortality parameters, in conjunction with the 1960 and 1970 population distributions, imply rural CBRs and CDRs for the period. The average annual $C M R$ was therefore calculated by comparing the actual 1970 rural population with the population implied by natural increase alone.

The results of the ten-year projection are presented in Table 2. The projection appears to replicate 1970 quite well. The imposition of the CBRs and CDRs observed for the RDC in 1960 and 1970 is responsible for the close correspondence between the observed and estimated population size. The most encouraging result in Table 2 is the replication of the sex and regional population distributions. This success lends credence to the fertility and mortality model schedules themselves as well as their sex-and regionspecific parameter estimation. It also substantiates the theoretical and empirical content of the net migration model. The slight ( $1 \%$ ) overestimate of the urban percentage most probably results from error in the estimate of a $1.13 \%$ annual CMR. While this rate is constant and exogenous in the present projection, its endogenous determination is a focus of most economic development models. With regard to the age distribution, the fit is very good until the 45-49 age cohort is reached. The larger percentage errors beyond age 45 are not serious since they are computed on relatively small bases. Hence, the absolute errors are small.

\footnotetext{
* Tables A1 and A2 in the Appendix list the 1960 and 1970 age-sex-regional population distributions. These distributions represent unweighted averages of RDC censuses published in United Nations Demographic Yearbooks. Evidence of substantial age misreporting was discerned for the first four five-year age groups. Consequently, the figures for these cohorts have been adjusted in accordance with standard demographic techniques. A more detailed description of the countries with censuses and of the adjustment procedure is provided in Schmidt (1981, ch. VII and appendix A).
} 
TABLE 2 Correspondence between observed and projected 1970 population measures.

\begin{tabular}{lccr}
\hline & Observed & Projected & \% Error \\
\hline Population size & 130.53 & 129.39 & -0.87 \\
Population distribution (\% in each category) & & \\
Urban & 38.59 & 38.97 & 0.98 \\
Male & 50.06 & 50.09 & 0.06 \\
Urban-male & 18.86 & 19.14 & 1.48 \\
Urban-female & 19.73 & 19.83 & 0.51 \\
Rural-male & 31.20 & 30.95 & -0.80 \\
Rural-female & 30.22 & 30.07 & -0.50 \\
Age distribution $(\%$ in each age group) & & \\
$0-4$ & 16.79 & 17.06 & 1.59 \\
$5-9$ & 14.60 & 14.72 & 0.80 \\
$10-14$ & 12.50 & 12.41 & -0.69 \\
$15-19$ & 10.66 & 10.70 & 0.34 \\
$20-24$ & 8.09 & 8.12 & 0.41 \\
$25-29$ & 6.73 & 6.74 & 0.21 \\
$30-34$ & 5.93 & 5.94 & 0.11 \\
$35-39$ & 5.40 & 5.35 & -0.91 \\
$40-44$ & 4.55 & 4.58 & 0.64 \\
$45-49$ & 3.59 & 3.89 & 8.33 \\
$50-54$ & 3.02 & 2.99 & -0.94 \\
$55-59$ & 2.27 & 2.45 & 7.74 \\
$60-64$ & 2.15 & 2.02 & -5.97 \\
$65-69$ & 1.38 & 1.24 & -39.34 \\
$70-74$ & 1.10 & 1.06 & 0.29 \\
$75+$ & 1.22 & 0.74 & \\
\hline
\end{tabular}

\section{THE DEMOGRAPHIC MODEL: PROJECTIONS AND SENSITIVITY ANALYSIS}

While the primary purpose of the demographic model is to include a detailed population specification within an integrated economic-demographic framework, much can and should be learned about the demography before the linkage is made. Two issues are relevant here. The first pertains to the potential economic impact of demographic change. That is, are the additional economic insights provided by the demographic specification worth the research effort of estimating such a detailed population structure? Section 3.1 addresses this question by analyzing three alternative population projections. The second issue focuses on the particulars of the demographic module. Which are the most important parameters of the module; which parts of the economy might they be expected to affect, and by how much? Section 3.2 approaches these questions through sensitivity analysis, i.e. by calculating the elasticities of various economically-oriented measures to several of the model schedule parameters.

\subsection{Population Projections: $1970-1990$}

This section summarizes the results of three alternative population projections. Since the purpose of the projections is analy tic rather than predictive, an element of 
arbitrariness exists in the time paths chosen for the dynamic parameters. The projections are the same in three respects. First, they all replicate the 1960-1970 growth experience validated in Section 2.4. Second, they all extrapolate the observed 1960-1970 increase in life expectancy linearly through 1990 (rising from 48.4 years in 1960 to 52.1 in 1970 and 59.9 in 1990). Third, a constant net proportion of the rural population (1.13\%) migrates to the cities every year.

The manner in which the projections differ is in the trend of their population growth rates. In the intermediate projection, the annual growth rate is held approximately constant at $2.7 \%$ by allowing the singulate mean age at marriage (SMAM) to increase at the pace observed for the period 1960-1970 (thereby rising from 19.9 years in 1960 to 20.8 in 1970 and 22.6 in 1990). The " $c$ " fertility parameter is then allowed to decline just fast enough (0.775 in 1990) to offset the decline in mortality. In the lowgrowth projection, the growth rate falls from $2.70 \%$ in 1970 to $2.36 \%$ by 1990 . Doubling the SMAM's rate of increase after 1970 (rising to 24.4 years in 1990) while again allowing the " $c$ " parameter to fall to 0.775 ensures this result. For the high-growth projection, the fertility parameters are held constant at their 1970 level, resulting in a population growth rate of $3.20 \%$ by 1990 .

The results of these three projections are presented in Table 3. As can be seen, differences in population growth rates become evident by 1980 , with the disparities increasing by 1990 . The pace of urbanization declines over time in all cases, even in the face of a constant Crude Migration Rate (CMR). The NR1 (Natural Rate of Increase) and TFR (Total Fertility Rate) rows provide a description of the urbanization process. In 1960, the urban NRI is lower than the rural NRI. In 1970 and 1980, they are approximately the same even with a constant rural-to-urban life expectancy and a rising (low and intermediate cases) or constant rural-to-urban TFR. By 1990, the 1960 pattern resurfaces. These findings appear to result from a net migration flow which is disproportionately young and, to a lesser extent, female. The shifting age-sex distributions between the regions effectively negates the higher rural age-specific rates for 1970 and 1980 . With a larger urban population by 1990 , however, the youthful migration no longer provides an age shock large enough to outweigh the lower age-specific urban rates. With a lower urban NRI and a constant CMR, urbanization falls.

While these results are interesting, they provide little insight into the value of appending a demographic framework to an economic model of development. If the demography is to have a noticeable impact, that impact will most likely be evidenced through changes in the age-sex-regional population distribution and the labor-force participation rate. Consider first the demographic impact on the regional population distribution. While the urban percentage rises dramatically over the 30-year projection from $32 \%$ in 1960 to $51 \%$ in 1990 , it does not appear to be substantially affected by widely different fertility regimes. Apparently, it is the level of rural-urban migration that is critical to this regional distribution, and the age-sex profile of the migrants plays only a subsidiary role.

In contrast to the regional population distribution, the demographic module plays a much larger role in determining the population's age structure. In the declining fertility cases, the share of the first two cohorts falls substantially between 1970 and 1980, and again between 1980 and 1990. The reduced importance of these cohorts in 1980 implies a reduction in the population share of the 10-14 and 15-19 cohorts in 1990 . The economic implications of these differing age distributions depend to a certain extent upon 
TABLE $3^{a}$ Population projections for alternative growth paths.

\begin{tabular}{|c|c|c|c|c|c|c|c|c|}
\hline & \multirow[t]{2}{*}{1960} & \multirow[t]{2}{*}{1970} & \multicolumn{3}{|l|}{1980} & \multicolumn{3}{|l|}{1990} \\
\hline & & & Low & Medium & High & Low & Medium & High \\
\hline Population size & 100.0 & 130.3 & 167.9 & 170.0 & 172.8 & 213.4 & 222.4 & 235.4 \\
\hline \multicolumn{9}{|l|}{ Compound growth rate $(\%)$} \\
\hline Total & & 2.7 & 2.6 & 2.7 & 2.9 & 2.4 & 2.7 & 3.1 \\
\hline Urban & & 4.7 & 4.2 & 4.3 & 4.5 & 3.6 & 3.9 & 4.3 \\
\hline Rural & & 1.6 & 1.4 & 1.5 & 1.7 & 1.4 & 1.6 & 2.0 \\
\hline \multicolumn{9}{|l|}{$N R I(\%)$} \\
\hline Total & 2.7 & 2.7 & 2.5 & 2.7 & 3.0 & 2.4 & 2.7 & 3.2 \\
\hline Urban & 2.5 & 2.7 & 2.5 & 2.7 & 3.0 & 2.2 & 2.6 & 3.1 \\
\hline Rural & 2.8 & 2.7 & 2.5 & 2.7 & 3.0 & 2.5 & 2.9 & 3.3 \\
\hline \multicolumn{9}{|l|}{$T F R$} \\
\hline Total & 6.1 & 6.0 & 5.1 & 5.4 & 5.8 & 4.3 & 4.9 & 5.7 \\
\hline Urban & 4.9 & 4.9 & 4.2 & 4.5 & 4.9 & 3.6 & 4.1 & 4.9 \\
\hline Rural & 6.7 & 6.8 & 6.0 & 6.3 & 6.8 & 5.3 & 5.9 & 6.8 \\
\hline \multicolumn{9}{|l|}{$e^{0}$} \\
\hline Total & 48.4 & 52.1 & 56.1 & 56.1 & 56.1 & 59.9 & 59.9 & 59.9 \\
\hline Urban & 51.6 & 55.2 & 59.2 & 59.2 & 59.2 & 62.8 & 62.8 & 62.8 \\
\hline Rural & 47.0 & 50.4 & 53.9 & 53.9 & 53.9 & 57.2 & 57.2 & 57.2 \\
\hline$\%$ Urban & 31.9 & 38.9 & 45.5 & 45.5 & 45.5 & 50.9 & 51.0 & 51.0 \\
\hline \multicolumn{9}{|c|}{ Age distribution (\% in each age group) } \\
\hline $0-4$ & 17.7 & 17.2 & 15.7 & 16.5 & 17.5 & 14.6 & 16.0 & 17.8 \\
\hline $5-9$ & 14.3 & 14.6 & 13.8 & 13.9 & 14.0 & 12.9 & 13.6 & 14.5 \\
\hline $10-14$ & 11.0 & 12.3 & 12.4 & 12.3 & 12.1 & 11.7 & 11.9 & 12.1 \\
\hline $15-19$ & 9.3 & 10.6 & 11.1 & 10.9 & 10.8 & 10.6 & 10.4 & 10.1 \\
\hline $20-24$ & 8.2 & 8.1 & 9.2 & 9.1 & 9.0 & 9.5 & 9.1 & 8.6 \\
\hline $25-29$ & 7.5 & 6.7 & 7.9 & 7.8 & 7.6 & 8.4 & 8.0 & 7.6 \\
\hline $30-39$ & 12.1 & 11.2 & 10.9 & 10.8 & 10.6 & 12.9 & 12.4 & 11.7 \\
\hline $40-49$ & 8.2 & 8.5 & 8.1 & 8.1 & 7.9 & 8.0 & 7.8 & 7.3 \\
\hline $50-59$ & 5.7 & 5.5 & 5.8 & 5.8 & 5.6 & 5.8 & 5.6 & 5.2 \\
\hline $60+$ & 6.0 & 5.3 & 5.1 & 4.8 & 4.9 & 5.6 & 5.2 & 5.1 \\
\hline LFPR $(\%)$ & 33.5 & 33.0 & 34.2 & 33.7 & 33.2 & 35.4 & 34.1 & 32.5 \\
\hline$\%$ Change from 1970 value & & & 3.6 & 2.1 & 0.6 & 7.3 & 3.3 & -1.5 \\
\hline
\end{tabular}

a The data presented in this table are based upon the population at the beginning of the year. There are slight discrepancies, therefore, between these figures and the mid-year figures presented in Table 2.

the way in which the economic model formulates demand and saving for households and the government. The appropriate way to model these aspects of economic behavior remains an open issue in the literature. On the one hand, rapid population growth and a younger population have been represented in some models to reduce government saving (Barlow, 1967), reduce household saving (Coale and Hoover, 1958; Enke, 1966, 1971, 1974; McFarland et al., 1973; and Rodgers et al., 1978), and alter patterns of household commodity demand (Rodgers et a1., 1978). On the other hand, empirical studies have shown that ignoring the stimulatory effect of household size on household income may bias the effect of size on saving in a negative direction (Kelley, 1980). Further, the role 
of household size and age structure may take the form of substitution between quantity and quality within the broad commodity aggregates of many economic models (e.g. the substitution of cereals for meats within an agricultural classification). Demographic variables may therefore be insignificant as shown in empirical household expenditure studies of broad aggregates (Pollack and Wales, 1978; Kelley, 1981). We do not wish to join this debate. Rather, we merely wish to point out that if household size and age structure are modeled to influence savings and demand, then the results of Table 3 indicate a potentially important demographic influence.

A more immediate and obvious impact of demographic change is on labor-force participation. In this regard, we have applied a constant age-sex-regional Labor-Force Participation Rate (LFPR) schedule* to the population and report the country-wide rates in the LFPR row. The results are striking. Within the time frame of many development models ( 20 years), this rate rises by $7.3 \%$ in the low-growth case and falls by $1.5 \%$ in the high-growth case. The quantitative effect of these alternative patterns on per capita income cannot be easily estimated, however. Changes in labor force growth may affect saving, which would in turn influence capital formation and average labor productivity. Average labor productivity may also change as a result of labor being redistributed between technologically growing and technologically stagnant sectors. In short, the potential for a substantial demographic impact through varying LFPRs on per capita income exists. The magnitude of this impact will be determined by the economic model.

\subsection{Sensitivity Analysis: 1970-1990}

The population projections of the previous section have indicated a potentially important role for demographic change in an economic development model. This section continues the analysis by examining the relative importance of two of the model schedule parameters with the use of sensitivity analysis. Specifically, the elasticities of various economically-oriented measures resulting from a $10 \%$ increase in the relevant parameters are presented for three points in time $-1970,1980$, and 1990.**

The first parameter in the analysis, the singulate mean age at marriage $(S M A M)$, is a nuptiality measure affecting the proportion of females married at each age. This measure influences exposure to the risk of pregnancy, with a higher $S M A M$ implying lower fertility. The $S M A M$ can be increased in a population either by delaying the minimum age of marriage ( 15 years here) or by reducing the rate at which marriages occur (the $k$ parameter). The latter approach is employed for this analysis. The second parameter, the

\footnotetext{
* This schedule, listed in Table A3 of the Appendix, has been estimated as the unweighted average of the RDC schedules listed in Durand (1975).

** Schmidt (1981, ch. VII) presents a detailed discussion of the elasticities of a number of demographically-oriented measures (e.g. aggregate, urban, and rural measures of population size, growth rate, natural rate of increase, crude birth rate, crude death rate, total fertility rate, life expectancy, and age distribution) with respect to all 15 of the model schedule parameters. Briefly, the results are as follows. Two fertility measures (the $S M A M$ and the $c$-level parameter) display elasticities with absolute values exceeding unity for population growth rate, crude birth rate, total fertility rate, and early cohorts in the age distribution. No other parameters displayed elasticities exceeding 0.6 in absolute value.
} 
crude migration rate $(C M R)$, relates to the net migration schedule, and is a focus of many economic development models. The $C M R$ is held constant over time in these experiments, but it would vary endogenously in an integrated economic-demographic simulation.

With respect to output measures, many of the economic effects of changes in population distribution and growth derive from a person's life-cycle behavior toward schooling, consumption, saving, and employment. Even if a parameter change had little impact on population growth, it could still have an impact on the economy if the size and/or regional distribution of the population were altered at certain key points in the life cycle. For this reason, we present elasticities for seven output measures. The first two relate to population size and growth rate. The remaining five are life-cycle measures - the laborforce participation rate, the potential number of students (ages 5-14), the number of potential labor-force entrants (ages 15-19), the number in the prime family and home building ages (ages 20-24), and the number of retirement age (ages 65+).

The baseline values and two sets of elasticities are presented in Table 4 for 1970, 1980 , and $1990 .^{*}$ The most striking feature of the table is the relative size of the two sets of elasticities. In general, the absolute values of the nuptiality elasticities are larger than are those for migration. Further, the disparity increases over time even though both sets rise in absolute value. In evaluating the full impact of the parameter changes, however, one must consider the anticipated size of the change as well as its elasticity. For the RDCs, the $S M A M$ was observed to rise at an annual rate of $0.4 \%$ between 1960 and 1970. Although comparable information for the CMR is not available, Ledent (1980) has devised a model for projecting $C M R \mathrm{~s}$. He has applied the model to four RDCs (Egypt, India, Mexico, and Nicaragua) for the period 1950-2000. His model predicts average rates of change in the CMR for the four countries of $4.1 \%$ between 1950 and 1975 , and $1.5 \%$ between 1975 and 2000. If these are indicative of the magnitudes that can be expected to result from the economic model, then the impact of changes in the $C M R$ will be higher than those of changes in the $S M A M$.

The results in Table 4 further reveal that the influences of reduced fertility are more skewed than are those resulting from changes in the migration level. As can be seen in the table, the primary economic impacts of fertility changes are lagged. The effects are comparatively small at the end of the first decade and are localized to the school-age cohorts. The increase in the labor-force participation rate results from the decline in the size of the first two cohorts. The smaller cohorts progress through the age distribution in the succeeding decades, increasing the absolute magnitudes of the elasticities. By 1980 , the reduced cohorts are moving into the labor force, starting their own families, and building homes. Relative to the earlier, larger cohorts, housing demands decline in both regions. By 1990 , the reduced cohorts have advanced sufficiently far into the working ages that the positive stimulus on the LFPR is declining. At the same time, however, these cohorts are in their prime reproductive ages. The resulting "echo" effects serve further to reduce the number of school-aged children.

By comparison with the fertility effects, an increase in the CMR has a less pronounced, although still noticeable effect on the age distribution. The 1970 impact is

\footnotetext{
"These values use the "intermediate" projection. Experiments employing the "low" and "high" yielded very similar results.
} 
TABLE 4 Economically-relevant elasticities.

\begin{tabular}{|c|c|c|c|c|c|c|c|c|c|}
\hline & \multicolumn{3}{|l|}{1970} & \multicolumn{3}{|l|}{1980} & \multicolumn{3}{|l|}{1990} \\
\hline & Base value & $S M A M$ & $C M R$ & Base value & $S M A M$ & $C M R$ & Base value & $S M A M$ & $C M R$ \\
\hline \multicolumn{10}{|c|}{ Population } \\
\hline Total & 130.29 & -0.43 & -0.00 & 167.87 & -0.79 & -0.01 & 213.40 & -1.16 & -0.02 \\
\hline Urban & 50.73 & -0.47 & 0.18 & 76.31 & -0.84 & 0.28 & 108.59 & -1.21 & 0.33 \\
\hline Rural & 79.56 & -0.40 & -0.12 & 91.56 & -0.74 & -0.25 & 104.81 & -1.10 & -0.38 \\
\hline \multicolumn{10}{|c|}{ Growth rate (\%) } \\
\hline Total & 2.65 & -1.65 & -0.01 & 2.66 & -1.44 & -0.02 & 2.69 & -1.55 & -0.03 \\
\hline Urban & 4.64 & -1.03 & 0.39 & 4.21 & -0.96 & 0.23 & 3.82 & -1.11 & 0.13 \\
\hline Rural & 1.56 & -2.64 & -0.78 & 1.52 & -2.36 & -0.86 & 1.63 & -2.43 & -0.81 \\
\hline \multicolumn{10}{|c|}{ School ages } \\
\hline Total & 35.15 & -0.70 & -0.00 & 44.41 & -1.46 & -0.02 & 56.65 & -1.72 & -0.03 \\
\hline Urban & 12.97 & -0.79 & 0.17 & 19.20 & -1.62 & 0.26 & 27.66 & -1.85 & 0.32 \\
\hline Rural & 22.18 & -0.65 & -0.10 & 25.22 & -1.33 & -0.23 & 28.98 & -1.60 & -0.37 \\
\hline \multicolumn{10}{|c|}{ Labor-force entry ages } \\
\hline Total & 13.87 & -0.00 & 0.00 & 18.59 & -1.30 & -0.00 & 23.11 & -1.52 & -0.02 \\
\hline Urban & 5.62 & -0.03 & 0.24 & 8.38 & -1.45 & 0.28 & 11.89 & -1.64 & 0.33 \\
\hline Rural & 8.25 & 0.02 & -0.16 & 10.22 & -1.18 & -0.24 & 11.23 & -1.40 & -0.39 \\
\hline \multicolumn{10}{|c|}{ Prime home-buying ages } \\
\hline Total & 13.87 & -0.00 & 0.00 & 18.59 & -1.30 & -0.00 & 23.11 & -1.52 & -0.02 \\
\hline Urban & 5.62 & -0.03 & 0.24 & 8.38 & -1.45 & 0.28 & 11.89 & -1.64 & 0.33 \\
\hline Rural & 8.25 & 0.02 & -0.16 & 10.22 & -1.18 & -0.24 & 11.23 & -1.40 & -0.39 \\
\hline \multicolumn{10}{|c|}{ Retirement ages } \\
\hline Total & 4.10 & 0.00 & 0.00 & 5.40 & -0.00 & 0.01 & 7.46 & -0.00 & 0.01 \\
\hline Urban & 1.51 & -0.01 & 0.12 & 2.32 & -0.02 & 0.21 & 3.67 & -0.02 & 0.27 \\
\hline Rural & 2.59 & 0.01 & -0.07 & 3.08 & 0.01 & -0.14 & 3.80 & 0.01 & -0.24 \\
\hline \multicolumn{10}{|c|}{$L F P R(\%)$} \\
\hline Total & 30.89 & 0.45 & -0.00 & 31.68 & 0.64 & -0.00 & 32.25 & 0.59 & 0.00 \\
\hline Urban & 30.24 & 0.47 & 0.02 & 31.04 & 0.69 & 0.02 & 31.82 & 0.62 & 0.01 \\
\hline Rural & 31.31 & 0.43 & -0.01 & 32.22 & 0.59 & -0.01 & 32.70 & 0.57 & -0.00 \\
\hline
\end{tabular}

highest for labor-force entry and home-buying ages, less for school ages, and least for retirement ages. By 1980 this disparity is reduced and by 1990 it has virtually disappeared. Migration has no noticeable effect on the total size of any cohort; it merely affects their regional distribution. ${ }^{*}$ While this is true, the redistribution in these cohorts will have disproportionately large impacts on demands for new schools, new housing, and old-age services in the city. On the supply side, it is interesting to note that neither regional nor country-wide LFPRs are sensitive to the $C M R$.

\footnotetext{
* For this reason, the regional discrepancies in elasticities are somewhat misleading. Each region has a numerator which is essentially the negative of the other. The elasticity differences result from differences in the regional size. As the relative regional sizes change so do the relative magnitudes of the corresponding elasticities.
} 


\section{FUTURE DIRECTIONS}

This paper has presented a demographic framework for use with an economic model. A key feature of this framework is its extensive use of model rate schedules. The model-schedules approach approximates the elegance of general equilibrium modeling in its continuous representation of life-cycle behavior, its parsimonious data requirements, and its flexibility for policy analysis. After estimating the demographic parameters and validating the framework for the 1960s, we analyzed selected elements in the economic impact of demographic change. Population projections under alternative growth assumptions demonstrate potentially important demographic impacts. Beyond the anticipated differences in population size, substantial discrepancies in the aggregate labor-force participation rate become evident within ten years. Further, if relative prices play a role in an economic model, household demand and saving play roles in determining relative prices, and household size and age structure play roles in household demand, then the demonstrated disparities in age distributions between the projections indicates another important demographic impact.

Nevertheless, various time paths could be specified exogenously for population growth and labor-force participation. What is gained by detailing the demography? Sensitivity analysis of two parameters illustrates markedly different results depending upon the manner in which the demographic change is specified. Raising the average age at first marriage appears to be a potent tool for simultaneously reducing population growth and reducing dependency (hence, increasing the labor-force participation rate). In contrast, increasing rural-urban migration plays little role in changing the size of any age group within the 20-year experiment. However, it does change the regional population distribution at certain key ages in the economic life cycle. Further, these economic impacts are more immediately pervasive than are the nuptiality effects.

In short, demographic detail can play an interesting and important role in a general equilibrium model of development. The next step in the present research effort is to link the demographic framework with the Kelley-Williamson (1980) model of urbanization and development. At that stage, the level of net rural-urban migration will be endogenously determined, but the other demographic components (nuptiality, marital fertility, mortality, and labor-force participation) will continue to be exogenous. Questions similar to those of this paper will be asked of the integrated framework. Is the economic potential of the demographic framework realized? Which demographic parameters are quantitatively most important? Additionally, we would like to explore a householddemand framework in which household size and age structure play a role as compared to one in which they do not. Such analysis will establish priorities for estimating demographic parameters which are endogenous to the economic structure.

\section{ACKNOWLEDGMENTS}

I would like to thank Allen Kelley for his constructive comments on this paper. I am also grateful to Bryan Boulier, Luis Castro, Jacques Ledent, and Andrei Rogers for illuminating discussions at various points in this project. 


\section{REFERENCES}

Anker, R. and Knowles, J.C. (1980). BACHUE-Kenya: A Brief Overview. Research Triangle Institute, Research Triangle Park, North Carolina. (Mimeograph.)

Barlow, R. (1967). The economic effects of malaria eradication. American Economic Review, 57 : 130-157.

Brass, W. (1971). On the scale of mortality. In W. Brass (Editor), Biological Aspects of Demography. Taylor and Francis, London.

Casetti, E. (1977). Economic growth and population explosion: simulation experiments using a growth model with population endogenous. Journal of Development Studies, 13:238-261.

Coale, A.J. (1971). Age patterns of marriage. Population Studies, 25:193-214.

Coale, A.J. and Demeny, P. (1966). Regional Model Life Tables and Stable Populations. Princeton University Press, Princeton, New Jersey.

Coale, A.J. and Hoover, E.M. (1958). Population Growth and Economic Development in Low-Income Countries. Princeton University Press, Princeton, New Jersey.

Coale, A.J. and McNeil, D.R. (1972). The distribution by age of the frequency of first marriage in a female cohort. Journal of the American Statistical Association, 67:743-749.

Coale, A.J. and Trussell, T.J. (1974). Model fertility schedules: variations in the age structure of childbearing in human populations. Population Index, 40:185-258.

Durand, J.D. (1975). The Labor Force in Economic Development: A Comparison of International Census Data, 1946-1966. Princeton University Press, Princeton, New Jersey.

Enke, S. (1966). Economic aspects of slowing population growth. Economic Journal, 76:44-56.

Enke, S. (1971). Description of the Economic-Demographic Model. Tempo Center for Advanced Studies, General Electric Company, Santa Barbara, California.

Enke, S. (1974). Reducing fertility to accelerate development. Economic Journal, 84:349-366.

Hajnal, J. (1953). Age at marriage and proportions marrying. Population Studies, 7:111-132.

Hill, K. and Trussell, T.J. (1977). Further developments in indirect mortality estimation. Population Studies, 31:313-334.

International Bank for Reconstruction and Development (1976). World Tables 1976. The Johns Hopkins Press, Baltimore, Maryland.

International Bank for Reconstruction and Development (1980). World Tables: The Second Edition (1980). The Johns Hopkins Press, Baltimore, Maryland.

Kelley, A.C. (1980). Interactions of economic and demographic household behavior. In R.A. Easterlin (Editor), Population and Economic Change in Developing Countries. University of Chicago Press, Chicago, Illinois.

Kelley, A.C. (1981). Demographic impacts on demand patterns in the low-income setting. Economic Development and Cultural Change, 30(1):1-16.

Kelley, A.C. and Williamson, J.G. (1980). Modeling Urbanization and Economic Growth. RR-80-22. International Institute for Applied Systems Analysis, Laxenburg, Austria.

Kelley, A.C. and Williamson, J.G. (1982). A computable general equilibrium model of third world urbanization and city growth: preliminary comparative statics. In A.C. Kelley, W.C. Sanderson, and J.G. Williamson (Editors), Modeling Growing Economies in Equilibrium and Disequilibrium. This volume, pp. 3-41.

Ledent, J. (1980). Rural-Urban Migration, Urbanization, and Economic Development. WP-80-19. International Institute for Applied Systems Analysis, Laxenburg, Austria.

McFarland, W.E., Bennett, J.P., and Brown, R.A. (1973). Description of the TEMPO II Budget Allocation and Human Resources Model. GE73TMP-13. Tempo Center for Advanced Studies, General Electric Company, Santa Barbara, California.

Moreland, R.S. (1979). Population, Internal Migration, and Economic Growth: An Empirical Analysis. Department of Economics, University of Warwick, Coventry. (Mimeograph.)

Pittenger, D.B. (1974). A typology of age-specific net migration rate distributions. American Institute of Planners Journal, $40: 278-283$.

Pittenger, D.B. (1978). On making flexible projections of age-specific net migration. Environment and Planning A, 10:1253-1272.

Pollack, R.A. and Wales, T.J. (1978). Demographic Variables in Demand Analysis. Discussion Paper 7848. Department of Economics, University of British Columbia, Vancouver.

Preston, S.H. (1979). Patterns of Urban and Rural Population Growth. United Nations, Population Division, New York. 
Rodgers, G., Hopkins, M., and Wery, R. (1978). Population, Employment and Inequality: Bachue Philippines. ILO, Saxon House.

Rogers, A., Raquillet, R., and Castro, L.J. (1978). Model migration schedules and their applications. Environment and Planning A, 10:475-502. Reprinted in A. Rogers (Editor), Migration and Settlement: Selected Essays. RR-78-6. International Institute for Applied Systems Analysis, Laxenburg, Austria.

Sanderson, W.C. (1982). A two-sex general equilibrium marriage model. In A.C. Kelley, W.C. Sanderson, and J.G. Williamson (Editors), Modeling Growing Economies in Equilibrium and Disequilibrium. This volume, pp. $301-316$.

Schmidt, R.M. (1981). The Demographic Dimensions of Economic-Population Modeling. Unpublished PhD Dissertation, Duke University, Durham, North Carolina.

United Nations (various years). Demographic Yearbook. United Nations, New York.

\section{APPENDIX}

TABLE A1 1960 Percentage population distribution by age, sex, and region.

\begin{tabular}{lrrrrr}
\hline Age group & Total & \multicolumn{2}{c}{ Urban } & & Rural \\
\cline { 5 - 6 } & & Male & Female & Male & Female \\
\hline $0-4$ & 17.45 & 2.66 & 2.57 & 6.21 & 6.01 \\
$5-9$ & 14.41 & 2.14 & 2.12 & 5.20 & 4.95 \\
$10-14$ & 11.09 & 1.75 & 1.79 & 3.94 & 3.61 \\
$15-19$ & 9.35 & 1.59 & 1.65 & 3.16 & 2.95 \\
$20-24$ & 8.27 & 1.34 & 1.46 & 2.64 & 2.84 \\
$25-29$ & 7.50 & 1.16 & 1.29 & 2.40 & 2.64 \\
$30-34$ & 6.48 & 1.06 & 1.12 & 2.12 & 2.17 \\
$35-39$ & 5.60 & 0.90 & 0.96 & 1.88 & 1.86 \\
$40-44$ & 4.43 & 0.71 & 0.73 & 1.52 & 1.47 \\
$45-49$ & 3.78 & 0.61 & 0.64 & 1.31 & 1.22 \\
$50-54$ & 3.36 & 0.52 & 0.56 & 1.16 & 1.12 \\
$55-59$ & 2.30 & 0.36 & 0.40 & 0.81 & 0.73 \\
$60-64$ & 2.36 & 0.32 & 0.40 & 0.82 & 0.81 \\
$65-69$ & 1.30 & 0.19 & 0.23 & 0.45 & 0.42 \\
$70-74$ & 1.06 & 0.14 & 0.19 & 0.36 & 0.37 \\
$75-79$ & 0.55 & 0.07 & 0.10 & 0.19 & 0.18 \\
$80-84$ & 0.39 & 0.04 & 0.07 & 0.13 & 0.14 \\
$85+$ & 0.31 & 0.03 & 0.06 & 0.11 & 0.12 \\
Total & 100.00 & 15.60 & 16.34 & 34.45 & 33.62 \\
\hline
\end{tabular}


TABLE A2 1970 Percentage population distribution by age, sex, and region.

\begin{tabular}{lrrrrr}
\hline Age group & Total & Urban & & Rural & \\
\cline { 2 - 5 } & & Male & Fermale & Male & Female \\
\hline $0-4$ & 16.79 & 2.94 & 2.84 & 5.59 & 5.43 \\
$5-9$ & 14.60 & 2.61 & 2.56 & 4.82 & 4.61 \\
$10-14$ & 12.50 & 2.37 & 2.37 & 4.06 & 3.70 \\
$15-19$ & 10.66 & 2.14 & 2.33 & 3.16 & 3.03 \\
$20-24$ & 8.09 & 1.65 & 1.84 & 2.32 & 2.29 \\
$25-29$ & 6.73 & 1.33 & 1.45 & 1.93 & 2.02 \\
$30-34$ & 5.93 & 1.18 & 1.24 & 1.74 & 1.77 \\
$35-39$ & 5.40 & 1.06 & 1.12 & 1.62 & 1.61 \\
$40-44$ & 4.55 & 0.91 & 0.94 & 1.37 & 1.33 \\
$45-49$ & 3.59 & 0.71 & 0.74 & 1.09 & 1.05 \\
$50-54$ & 3.02 & 0.56 & 0.60 & 0.95 & 0.91 \\
$55-59$ & 2.27 & 0.43 & 0.47 & 0.71 & 0.65 \\
$60-64$ & 2.15 & 0.37 & 0.43 & 0.68 & 0.66 \\
$65-69$ & 1.38 & 0.25 & 0.30 & 0.43 & 0.41 \\
$70-74$ & 1.10 & 0.18 & 0.23 & 0.35 & 0.34 \\
$75-79$ & 0.53 & 0.09 & 0.12 & 0.16 & 0.16 \\
$80-84$ & 0.39 & 0.06 & 0.09 & 0.12 & 0.13 \\
$85+$ & 0.30 & 0.04 & 0.07 & 0.09 & 0.10 \\
Total & 100.00 & 18.86 & 19.73 & 31.20 & 30.22 \\
\hline
\end{tabular}

TABLE A3 Age-sex-regional labor-force participation rates.

\begin{tabular}{lllll}
\hline Age group & \multicolumn{2}{l}{ Urban } & \multicolumn{2}{c}{ Rural } \\
\cline { 2 - 3 } & Male & Female & Male & Female \\
\hline $10-14$ & 0.102 & 0.057 & 0.321 & 0.138 \\
$15-19$ & 0.512 & 0.240 & 0.791 & 0.247 \\
$20-24$ & 0.846 & 0.293 & 0.944 & 0.248 \\
$25-29$ & 0.943 & 0.250 & 0.972 & 0.236 \\
$30-34$ & 0.962 & 0.235 & 0.978 & 0.236 \\
$35-39$ & 0.966 & 0.235 & 0.980 & 0.232 \\
$40-44$ & 0.962 & 0.236 & 0.979 & 0.250 \\
$45-49$ & 0.952 & 0.229 & 0.977 & 0.253 \\
$50-54$ & 0.926 & 0.208 & 0.966 & 0.249 \\
$55-59$ & 0.876 & 0.179 & 0.955 & 0.237 \\
$60-64$ & 0.778 & 0.147 & 0.914 & 0.215 \\
$65-69$ & 0.654 & 0.114 & 0.853 & 0.171 \\
$70-74$ & 0.548 & 0.090 & 0.764 & 0.144 \\
$75+$ & 0.387 & 0.055 & 0.603 & 0.111 \\
\hline
\end{tabular}





\section{Part Five}

Panel Discussion 



\section{PANEL DISCUSSION}

Kemal Dervis, Andrzej Wierzbicki, János Kornai, François Bourguignon, and Lance Taylor

\section{KEMAL DERVIS*}

This morning we thought it might be interesting to allow a bit more discussion on some of the key issues underlining the general equilibrium modeling approach and focus on some key criticisms, particularly those pertaining to a purist approach of having fully flexible prices and market clearing. The comments below relate to this issue of price flexibility in general equilibrium modeling.

I think there may be a consensus developing: in the long run one can be neoclassical and prices can be market clearing. However, this approach is being seriously questioned for shorter-run analyses. I have been working on Egypt for the last year and, in contrast to my previous work with flexible-price Walrasian-type models, the Egyptian work has taken an almost opposite approach with purely fixed prices. In Egypt, the Government attempts to set a large number of prices. There is of course a part of the economy that is free and a substantive part of the controlled economy in fact "escapes" the controls. From a modeler's point of view, the central question is to determine how flexible prices are, and what happens when they are fixed. It may be worth discussing various aspects of this question and in the process trying to link together important areas whose interrelations have not always been made explicit.

First it is important to distinguish the microeconomic and macroeconomic aspects of the issue of flexible prices. If the price of a particular commodity is fixed, the market is likely to exhibit disequilibrium at the micro level for that particular commodity. Podkaminer's paper on Poland emphasizes such disequilibrium at the micro level, while stressing the spill-over effects that are created because there is a certain amount of income that cannot be spent on a particular commodity. But immediately the question arises: can you have disequilibrium in all markets simultaneously, and if so, how does that relate to macroeconomic disequilibrium?

Overall excess demand in the economy is clearly different from the problem of simply having the "wrong" relative prices. In a Walrasian system, the wrong set of relative prices may still be consistent with zero overall excess demand, if excess demand in some markets is compensated by excess supply in other markets. By having the wrong prices, it

\footnotetext{
* The World Bank, 1818 H Street NW, Washington, D.C. 20433, USA.
} 
is not clear what kind of disequilibrium is created in the aggregate. On the other hand, there can be inflation and macroeconomic disequilibrium without major microeconomic disequilibrium.

There are, therefore, two sets of related but distinct issues which I think need to be linked. One is the question of how you treat fixed prices and disequilibrium at the micro level for specific commodities. The other is the issue of macroeconomic disequilibrium and, if you like, imperfect price level adjustment as opposed to adjustment of relative prices. Both problems can exist in a closed economy. When the economy is opened to trade, it is necessary to identify to what extent excess demand can be met simply by imports, and what consequences this will have for specifying the equilibrating mechanism.

A number of the models that have been developed exhibit a complete dichotomy in the way price flexibility is treated. In most CGE models relative prices are completely flexible in the core version of these models, whereas the price level is completely fixed by a normalization rule. This abstracts from the macro problems and focuses entirely on the micro problem.

On the contrary, another approach, which is perhaps best typified in the work of Lance Taylor, is the one in which the macro story rules the micro story. The macro closure mechanism in a sense dominates the system. One set of models focuses on the macro side, the other on the micro side.

Consider now the trade issue which is intimately linked to the question of price determination and price flexibility. In an open economy model in which foreign goods and domestic goods are perfect substitutes - the typical kind of model in the neoclassical trade literature - prices are fixed on the world market by the small-country assumption and the issue of price adjustment does not even arise except for nontradables. If there is excess demand for a particular tradable good, then that excess demand will be met by imports, and similarly, excess supply will be eliminated by exports; there will be an equilibrium solution where in some markets you export and in some markets you import. If all commodities are tradable, then Walras' Law implies that there cannot be a trade disequilibrium. Walras' Law says that total income must equal total expenditure, and therefore the value of exports must equal the value of imports.

To build a realistic model, it is usually assumed that there is some distinction between competitive imports and noncompetitive imports. Increasingly the literature has used a CES formulation in which imports and domestic goods are imperfect substitutes. In this two-level function, you get a domestic-use ratio - the desired ratio between domestic goods and imported goods - as a function of the relative price of domestic goods and import prices. This specification, contained in Bergman's paper on Sweden and in my own paper, is the Armington assumption, which is increasingly used both in the econometric literature and in the general equilibrium modeling literature. What the Armington specification does is to recast the commodity-balance equation in terms of domestic goods only. At a given set of prices in this type of model it is not possible to satisfy excess demand by importing because the excess demand functions are in terms of the domestic good alone. In this kind of model the re are commodity balances for domestic goods and an aggregate commodity balance for imports and exports. Here the price that goes with each of the domestic commodity balance equations is the domestic price of a good, and the price that goes with the trade equation is an exchange rate. 
With the Armington specification, trade can no longer, in itself, act as a market clearing mechanism and domestic prices again become endogenous variables in the system.

When one wants to build a fixed price model it is necessary to focus on the spillover effects and the exact rationing rules. If consumers cannot spend their money on what they really want, they will spend it on something else. To model all the rationing rules and spill-over effects is infeasible. So what one usually does is to concentrate on those areas of price rigidity that seem to be most crucial. One area where price rigidity has been explored in some detail is that of foreign trade and exchange.*

Although domestic prices may be free to vary, a fixed exchange rate may imply that none of the excess demand functions is satisfied because consumers are not allowed to "mix" foreign and domestic goods in the desired, utility-maximizing or cost-minimizing, proportions. When the exchange rate is fixed and a country has exhausted its capacity to borrow, excess demand is handled by some form of foreign-exchange rationing.

We started our work with Sherman Robinson on the Turkish model by taking the exchange rate as fixed and introducing a pure rationing mechanism in the sense that people who get allocations can actually buy foreign goods at the fixed exchange rate. This means that there are spill-over effects, and these spill-over effects must be modeled. For example, an enterprise may have a certain demand for foreign exchange. If it cannot get as much as it wishes, it switches its expenditures to the domestic market. Here we made a strong assumption. If, for instance, the demand for foreign synthetic textiles cannot be wholly accommodated, then the residual demand is assumed to be diverted to domestic cotton textiles. Yet this is wrong from a purely utility-maximizing point of view because the spill-over would not only go into the domestic substitute but would also go elsewhere. Nevertheless, we made the strong separability assumption for simplicity, and the spill-over was therefore limited or localized in the aggregate commodity group. In general, our approach is not strictly correct but is a simple way to get a model working. True, when imports are rationed the domestic producers who supply substitutes for the rationed import make very large profits. Yet, the profits would not be as large if the spill-over were allowed to be more evenly distributed throughout the economy.

Another way of dealing with fixed exchange rates is to assume a black market where bidding develops for foreign exchange, or where goods that are directly allocated can be resold. In that market, the real price for foreign exchange rises. If full adjustment is allowed on the import side, then there is no spill-over problem because it is as if you had a model with fixed exports and a flexible exchange rate on the import side. Although there is a formal fixed exchange rate, the black market rate is allowed to clear the market. Exports are a function of the official exchange rate only, so that it is the demand for imports that must adjust to the given supply of foreign exchange. It is much easier to attack the problem this way, but in a sense it avoids the fixed-price problem by going back to a flexible price model on the import side. In modeling a black market there are also the issues of rent seeking and of the real costs that might be expended on getting quantity allocations which do not arise in a Walrasian model.

This methodology, and distinctions between pure and premium rationing, were

\footnotetext{
* See K. Dervis, J. de Melo, and S. Robinson, “General Equilibrium Models for Development Policy”, Cambridge University Press, 1982.
} 
applied to an analysis of Turkey. ${ }^{*}$ During the foreign exchange crisis of $1977-1980$, the Government tried to enforce fixed-price rationing, failed, and gave up. For a year or so there were stiff penalties on the resale of imported goods, and the black market was suppressed. The Government tried to get the goods to the people who had the rations, with little success. The black market developed very fast and finally the Government legalized it by permitting people to bid for the limited amount of foreign exchange. There was, therefore, a movement from a fixed-price rationing scheme to a premiumrationing regime where the import exchange rate was allowed to clear the market. After a while it went further than that: the flexible price even started to apply to exports. The exporter was allowed to keep a certain percentage of his dollars and was able to resell these dollars at whatever price he got in the market. Thus Turkish experience represents an example of how a system of rationing and fixed prices eventually produces a market adjustment of a kind that almost returns the system to a flexible price situation. Prices can be rigid in the short run, and a "rationed" equilibrium is then a relevant concept. But in the longer run, it is very likely that "Walrasian" forces will reassert themselves. I discussed this in terms of the foreign-exchange market, but the situation is likely to be similar in other markets. For models that focus on the longer-term future, market-clearing price flexibility may still capture the essence of the structural adjustment problem at the micro level. This leaves open, however, the question of macroeconomic adjustment and inflation.

\section{ANDRZEJ WIERZBICKI**}

Some notions common to the general equilibrium community are being used here that are for me, a mathematician, rather disturbing. The first is the phrase "equilibrating mechanism" and the second is the word "disequilibrium".

For me, an equilibrating mechanism does not mean an equation that expresses some market-clearing conditions. This constitutes a static approach. Instead, an equilibrating mechanism should specify what happens dynamically if, say, demand and supply are not equal. The adjustment process would describe a true disequilibrium while all that we have discussed so far are comparative static solutions under various assumptions of rigid markets, supply restrictions, and so forth. I would describe such static studies as highly restricted equilibrium studies. I would prefer to reserve the word disequilibrium for describing dynamic phenomena.

\section{JÁNOS KORNAI***}

My point of departure will be Leon Podkaminer's paper, which I find an excellent contribution. It contains some very good analyses of problems in one Eastern European

\footnotetext{
* See K. Dervis and S. Robinson, "The Foreign Exchange Gap, Growth and Industrial Strategy in Turkey: 1973-1983', World Bank Staff Working Paper No. 306, Washington, D.C., 1978.

** International Institute for Applied Systems Analysis, Laxenburg, Austria.

*** Institute of Economics, The Hungarian Academy of Sciences, Budaörsi ut 47, 1112-Budapest XII, Hungary.
} 
economy's consumer market. 1 fully agree with the main point that under supply constraints you cannot observe demand functions directly in the traditional sense, since they are distorted by the quantity constraints. 1 also like Podkaminer's approach of looking at data on Italian and Irish demand functions to make hypothetical estimates of Polish consumer demand. That is a very interesting approach to the consumer demand problem; I find it a brave attack on this important issue.

I agree with the main conclusion that food price increases would not solve the food shortage in Poland. This conclusion is supported not only by Podkaminer's analytical study, but by empirical experience as well. My comments start where his paper stops. He stops at the gates of the consumer market, which he has a right to do, but I think the key problem of the Eastern European economy is not the consumer market. In searching for the ultimate cause of chronic shortages, I would never stop at the consumer market because of what Podkaminer calls spill-overs - spill-overs from the production and investment side. I think a more general approach is required where we look at all the interdependencies between the different branches of the system. In this respect Poland and Hungary are similar. While Hungary seems to be a more stable system, Poland is nevertheless a member of the same family of systems.

The household sector behaves more or less like a regular monetarized sector in that demands depend on income and prices. Concerning the rest of the economy, consider now the sector of state-owned enterprises which produces the majority of the output. This sector behaves very differently and in this respect the Eastern European socialist countries are different not only from the highly developed capitalist countries, but also from most LDCs. One cannot jump from the institutional pattern of one system to another. One has to capture the institutional realities of each system.

Kemal Dervis was talking about price rigidities and explaining disequilibria partly by referring to price rigidities. Discussing the Eastern European situation, the point of departure is not the problem of price rigidities, but rather the lack of price responsiveness in the behavior of the firm. Whether the price is rigid or flexible does not matter much. What does matter is that the firm does not respond to prices at all, or only slightly or weakly. It responds a little bit as a seller; it does not respond much as a buyer. Firms buy as much as possible, as much as they can get. There is an almost unlimited demand. The firm budget constraint is "soft". It is only an ex post accounting identity. Since the state subsidizes firms when they get into financial trouble, their purchases are not really constrained by a consideration of costs. The budget constraint is not an effective ex ante constraint on the firm's choices. This is the reason for their insatiable hunger for factors in general and their insatiable demand for investment in particular. As long as resources are available, firms will invest and invest and invest.

If I look at the Polish experience - but the same also applies to a lesser extent to Hungary - there have been incredible investment booms. Recall that there were oil shocks over the whole world and capitalist entrepreneurs became less optimistic and very cautious in investment expansion. At the same time, in ' 74 , ' 75 , and ' 76 , there were fantastic investment booms in Eastern European countries. This illustrates the main source of the excess demand problem. While there is a constrained demand in the household sector, there is a practically unlimited demand by firms.

One can give different names to this phenomenon. Kemal Dervis calls it a macro phenomenon. Another approach is to refer to the institutional background, to the special 
position of the public firm in a socialist country. I would not put the final emphasis on the macro forces because the macro situation is a consequence of the institutional framework. If one accepts the second approach, then the Podkaminer paper fits very well into this general system.

Let us talk about housing. The Podkaminer paper is right: if people cannot spend their money on housing, they go to the butcher and try to get more meat. But what is the cause of chronic housing shortage? On the demand side: the low rent of state-owned apartments leads to a demand "explosion". It would be, however, an oversimplified suggestion to expect the elimination of chronic housing shortages by a drastic increase of rents ceteris paribus. Still remaining on the demand side: the apartments vacated by households which cannot pay the higher rent will be immediately occupied by firms and public agencies which are much less price-responsive, and which will be happy that their office-space troubles can be finally solved. And what is even more important: there is no automatic response to higher rents on the supply side. Supply is not necessarily an increasing function of the rent. On the contrary, the easing of the troubles in the residential housing sector can serve as a signal that resources can be reallocated to other sectors where shortages are more intense. As a final outcome, there is no guarantee that the housing market will come closer to a Walrasian equilibrium. It is more probable that the normal accustomed intensity of chronic shortage will be restored sooner or later.

I have a few additional words on research strategy. I would like to concentrate now only on Eastern Europe and not make a recommendation on research strategy in general. My personal feeling is that we need an explanatory theory. The world is as it is, and we cannot start with normative theories; rather, we have to start by explaining reality. Starting with normative theories usually leads to naive and superficial proposals. For instance, if one takes Walrasian theory in a simplistic way, then one comes up with the recommendation that "freeing up" relative prices will solve everything. But in Eastern Europe nothing will be solved since some economic agents, firms in particular, are simply not responding to prices. What we need first then is an explanatory theory, something comparable to a Keynesian macro theory of modern capitalism. I am strongly for model building, but one cannot rush ahead without theory. The lack of an explanatory theory about Eastern systems is a most important deficiency.

Consider the nature of formalizing explanatory theories. If one consults the history of economic thought, descriptive theories emerge early: first Keynesian theory, followed by Tinbergen's and Klein's econometric models. One initially needs explanations about what is happening. Then one can come forward with quantitative predictions and recommendations.

\section{FRANÇOIS BOURGUIGNON*}

I simply wish to say a few words about the typology of the models we have been discussing. There seems to be a great deal of ambiguity about the words one uses to describe these models, especially about "equilibrium" and "disequilibrium".

\footnotetext{
* Ecole Normale Superieure, Laboratoire D'Economie Politique, 45 rue d'Ulm, 75230 Paris, France.
} 
What do we mean by equilibrium? First, all of these models have an accounting identity which implies that supply equals demand. But what we mean by equilibrium is much more than that. In any economic system there is some decentralization where units are making decisions about their economic plans. Not all these decisions are compatible with short-run equilibrium. The problem in those models is to represent decentralized behavior or plans by economic agents and to make some assumptions about the mechanisms that will make individual plans consistent.

Models treat these two points in different ways. Most scholars who talk about "general equilibrium" typically refer to the Walrasian competitive equilibrium model. Here all agents are price takers, they maximize profits or utility, and prices are free to adjust to clear markets. It should be noted however that, when a temporal dimension is introduced in this simple Walrasian equilibrium framework, some kind of disequilibrium becomes possible. These might be called "temporary equilibrium" models where period after period we have a truly Walrasian equilibrium, but each equilibrium is in some sense constrained by parameters that are given for that period and by the expectations of individual agents about the future. It is in those constraints that some disequilibrium situations may be found. For example, consider Sherman Robinson's model, which has been shocked through international trade and went from a Walrasian equilibrium to another. Capital stocks being fixed, their sectoral structure is now in disequilibrium and some dynamic adjustments will take place. As capital keeps being accumulated, it is very probable that, after some time, the new structure of the economy will depend not only on the exogenous choice of the next external price structure, but also on the speed and characteristics of the adjustment process to the initial disequilibrium situation.

So, conventional equilibrium models may capture some important disequilibrium phenomena. Yet, "disequilibrium" models in the recent literature are something else. They essentially deny prices their instantaneous market-clearing function. Prices being rigid, decentralized behavior by economic agents leads to inconsistencies which require additional market-clearing mechanisms, like rationing or inventory operations. Those mechanisms will have spill-over effects on decisions by individual agents on other markets, where the same kind of mechanisms will take place, until all markets are cleared. We are back, then, to some type of (fixed-price) "equilibrium". From one period to the next, prices will probably change to adjust disequilibrium situations of the same type as those found in temporary Walrasian equilibrium models.

In summary, 1 am not sure that models based on non-price market-clearing mechanisms are equivalent to disequilibrium models. There is a wide variety of such mechanisms as well as possible types of disequilibrium. Therefore, I believe it would be extremely useful to try to build a typology of those market-clearing assumptions and disequilibrium situations in order to better understand their different implications for the results of modeling exercises. Also, I think we would all like to know how important these alternative microassumptions are at the macro level and in the long-run behavior of economic systems. 


\section{LANCE TAYLOR*}

I thought it would be interesting to talk in macro terms about what equilibrium means. Equilibrium implies that savings and investment are equal, or that the sum of excess demands in the economy (which is equal to investment minus savings) is zero. Consider the specific mechanisms that permit savings to become equal to investment in the short run under different institutional arrangements.

On the blackboard in the upper quadrant I relate investment demand to the rate of profit (by which I mean that which is available to firms after they have paid their prime costs - wages, materials, and intermediate-input costs). With the profit rate on the horizontal axis, and investment and growth rates on the vertical axis, you expect the rate of the overall saving in the economy to rise as a function of the profit rate, and at the same time you expect investment demand to respond to the profit rate. The overall equilibrium condition is that investment demand has to be less responsive to the profit rate than to saving.

You could then ask: what mechanisms equilibrate savings and investment demand? There are several possibilities. In the lower diagrams I have measured capacity utilization, which varies from zero to $100 \%$. You would expect that as the capacity utilization goes up, the surplus left over for firms will increase, and the profit rate will increase. Thus, if you have an increase in investment demand, savings are going to increase as a function of increasing capacity utilization. In this case you have the classical Keynesian adjustment mechanism, which I have indicated by "adjustment mechanism l".

Once you reach $100 \%$ capacity utilization, you next have to ask: how much further can profits increase? The only way that profits can increase further is by reducing the real wage. This can occur in a variety of ways. If the money wage is fixed in the short run, price increases will ensure a fall in the real wage - a sort of Kaldorian story which people may or may not believe. A reduction in the real wage generates additional surplus for firms, which they can save. Further increases in investment demand can be accommodated via real wage reductions, either explicitly via price inflation against a fixed nominal wage, or implicitly by rationing and queues. I term this "adjustment mechanism 2".

"Adjustment mechanism 3" would occur if investment demand shifted up, and savings rose to accommodate further increases in investment at some fixed rate of profit. How could savings increase? One macroeconomic mechanism is to expand imports: as you let in imports, you raise the balance-of-payments deficit, which amounts to foreign savings; as a consequence, there is an upward shift in the savings supply curve.

A fourth mechanism, which I have not sketched explicitly, is the strictly neoclassical Walrasian story: assuming full employment, productivity, and thrift determine savings, and investment responds passively.

Given this classification of macro adjustment processes, we can now make observations about how practical models might work. One immediate issue is this kinky story around here [pointing at blackboard] between regimes 1 and 2. Suppose you assume that the overall price level were given by something like prices equal to $(1+\tau)$ times the money wage, where $\tau$ is a mark-up rate. Additionally, let mark-ups gradually increase as

\footnotetext{
* Department of Nutrition and Food Sciences, Massachusetts Institute of Technology, 18 Vassar Street, Cambridge, Massachusetts 02139, USA.
} 
you approach capacity utilization. Then the kink basically disappears, and regimes 1 and 2 tend to dissolve into the same adjustment mechanism.

Regime 3 is like Chenery's model of regional development in Italy which is a pure fixed-price model, solved by a linear program. In effect, he allows imports to cover capacity shortfalls. Chenery's model omits two things: (1) you cannot let imports in for nontraded goods; (2) spill-overs in the consumer market that we were talking about this morning must be suppressed. I am not sure one could solve a pure fixed-price model with this added complexity using existing algorithms, but it is something worth considering.

A final observation. The fourth regime is not very interesting since it is obviously untrue in the short run. It becomes interesting in a medium-term context as János Kornai was discussing.

\section{JÁNOS KORNAI}

I shall try to be brief. I am going to underline only one idea which was put forward by François Bourguignon - that we need a kind of typology of adjustment mechanisms instead of simply asking whether the present situation satisfies the assumptions of the neoclassic competitive-type adjustment model. Instead, we have to look at different systems and find a description of different existing adjustment mechanisms of nonprice signals combined with price signals. I agree that in some forms of socialist system the central decision-makers, the planning agents, will make relevant choices. But in that case there are some signals to which they are responding. I like the phrase "exit and voice" introduced by Hirschman. Sometimes "voice" is a feedback mechanism. If the same agent has to decide on construction capacity for productive investment versus construction capacity for residential construction, then the two souls may be in the same body. Here the conflict is internalized in the same planning agency. If they hear managers urging more investment, this is one of the voices; if they feel protests or dissatisfaction of the population, that is another voice. Listening to these two voices is also a feedback mechanism. 



\section{AUTHOR INDEX}

Bergman, L., 225

Bourguignon, F., 346

Dervis, K., 43, 341

Dixon, P.B., 237

Kelley, A.C., v, 3

Keyzer, M.A., 57

Kornai, J., 344, 349

McCarthy, F.D., 71

Mihailov, B., 141

Parmenter, B.R., 237

Podkaminer, L., 167

Powell, A.A., 237, 277
Sanderson, W.C., v, 301

Schmidt, R.M., 317

Shishido, H., 103

Taylor, L., 348

Vincent, D.P., 237

Wierzbicki, A.P., 344

Williamson, J.G., v, 3

Zalai, E., 185 



\section{SUBJECT INDEX}

addilog demand system, 123

Adelman-Robinson model, 185

adjustment mechanisms, 348,349

typology of, 349

almost ideal demand system (AIDS), 123, 125 , 131

analytic family demography, 301

antiequilibrium, Kornai's work, vi

APMAA (Aggregative Programming Model of Australian Agriculture), 259, 260

Armington specifications, 45, 109, 126, 128 , $129,226,227,229,230,234,239,342$, 343

Bachue model series, 317

Bachue-Philippines model, 306

BACHUROO

demographic core, see below

design aspects, $277-300$

economic-demographic model of labor supply, 277-300

endogenizing employment conditions, 296 evolution of model, 297

IMPACT Project, role in, 278, 279, 285

interface with ORANI and MACRO, 293

leisure and hours worked, see below occupational disaggregation, see below structure, 279-293

BACHUROO, demographic core, 280-285

age-specific rates, 281

age structure of population, 285

"child quality" concept, 280,281

demographic accounting, 280, 281

family formation, 280, 281, 285

fertility, $280,281,285$

gamma distributions, 281

household headship, 285

labor-force participation, 280, 281, 285

labor-force size projection, 280,285

"new home economics", 281

number of households projection, 280

population size projection, 280

"propensity" indexes, 281

BACHUROO, leisure and hours worked, 288-293

budget constraints, 290

earnings-hours schedule, 290,292

extended linear expenditure system (ELES), 291

Frisch parameter, 291

Klein-Rubin utility function, 288 labor-force participation, 293

labor-leisure choice, 293

labor-leisure choice, neoclassical, 288

marginal leisure preference, 291

BACHUROO, occupational disaggregation, 285-288

CET approach, 286, 287

CRETH approach, 286, 287

occupational mix, 286

occupational mobility, 288

skill endowments, 286

Bergman-Pór model, 141, 157, 185, 210, 214, $225-236$

analysis, policy, 235

analysis, quantitative, 225

Armington approach, 226, 227, 229, 230, 234

capital, 228, 229

capital, immobility of existing stock, 226

CES-Cobb-Douglas production functions, 232

commodities, 228

cost functions, 231

data base, 233

demand functions, 229

description, 228-233

elasticity of substitution, 227,232

energy input coefficients, 228, 229, 235

equations, $225,228-233$

equilibrium conditions, 230

expenditure elasticities, 232

factor substitutability, ex ante/ex post, 225

foreign trade, 226

impact of world market changes, 235

implementation, 233

interest rates, clearing investment market, 232

investment mechanism, 233, 234

investment, sectoral, $225,231,232$

investment, total, 230,231

labor, 228

labor supply, inelastic, 229

output elasticities, 232

preference functions, 229

preliminary results, 233-235

price elasticities, 232

prices, 232

production functions, ex ante/ex post, 227 , 228

production functions, nested CES-Cobb-

Douglas, 232

rate-of-return expectations, 231

savings, 230 
Bergman-Pór model, continued simplified version, see below simulation, general (1976-1990), 233, 234 simulation, oil price rise (1975-1990), 234, 235

solution algorithm, 232

subdivision into markets, 228

supply-side detail, 225,228

vintage specification, $225,228,229,231$, 232,235

wages, 232

Bergman-Pór model, simplified, 188-192

commodities, 189

consumer demand, 191

data, 188

equilibrium conditions, 191,192

linear expenditure system (LES), 191, 193, 194

market behavior of producers, 189-191

sectors, 188

technology, 189

variables, 188

Brass mortality model

nonlinearity, 324

Schmid demographic framework, use in, 321

standard mortality pattern, 323

Bulgaria, multisectoral equilibrium model for, $141,155-164$

Casetti model, 317

centrally planned economies

consumer goods, 182,183

cyclical performance, 180

disequilibria, dynamics, $180-184$

disequilibria, in consumer markets, $167-184$

economic mechanism, analysis of, 141-165

general equilibrium and disequilibrium modeling, $139-222$

institutional factors, 345,346

investment booms, 345

investment-consumption cycles, 181,182

investment, industrial, 180,181

market mechanism, absence of, 181

model design criteria, 185

optimal planning models, 185

planning, coordination phase, 186,198

planning, forecasting phase, 187

planning, procedure, 185,186

price responsiveness of firms, absence of, 345

research strategy for, 346

see also economic mechanism under central planning

CES approach, 6, 44, 45, 114, 115, 208, 232, $251,266,342$

CET approach, 251, 259, 286, 287

Coale-Demeny life tables, 321

Coale marital fertility function, 302

Coale marital fertility model, 318-322

Coale-McNeil nuptiality function, 302, 303, $305,306,308-310,312$

analogy to Cobb--Douglas production function, 303
Coale-McNeil nuptiality model, $318,319,321$, 322,325

Coale nuptiality function, 302

Coale-Trussell marital fertility model, 319

Cobb--Douglas functions, $6,73,83,84,87$, $114,115,191,232,303$

complementarity problem formulation of policy adjustment rules, 60

constant elasticity of substitution (CES), see CES approach

constant elasticity of transformation (CET), see CET approach

constant ratio elasticity of substitution, homothetic (CRESH), see CRESH approach

constant ratio elasticity of transformation, homothetic (CRETH), see CRETH approach

CRESH approach, 251

CRETH approach, 251, 254, 257-259, 266, $270-273,286,287$

currency and trading areas

dollar, 204, 206, 207, 209, 212, 213

rouble, 204, 206, 207, 209, 212, 213

yen, 127,129

de Melo model, 185

demographic aspects of general equilibrium modeling, 275-337

demographic content of general equilibrium model for Japan, 104, 109, 121, 122, 124, 125,135

demographic core of BACHUROO model, $280-285$

demographic-economic model of labor supply (BACHUROO), 277-300

demographic-economic models, see economicdemographic models

demographic framework (Schmidt), 317-337

basis in model rate schedules, 317

Brass mortality model, 321, 323, 324

fertility rates, 321,322

fertility schedule, marital, 318-321

Kelley-Williamson model, links with, 317 , $318,324,334$

labor-force participation rates, 318, 331, 334

migration, age structure, 326

migration, male/female differences, 325,326

migration model, net, 324

migration schedule, net, 324-327

migration, work of Rogers et al., 324

migration, work of Pittenger, 324, 325

mortality schedule, 321, 323, 324

nuptiality schedule, $318-321$

population growth rates, 334

projections, $327-331$

representative developing country (RDC),

$318,320,321,323,326,331$

sensitivity analysis, $331-334$

validation, $327,328,334$ 
demography

analytic family, see analytic family demography

incorporation in general equilibrium modeling, 275-337

Dervis-de Melo-Robinson model, 44-48, 55

Armington specifications, 45

CES functions, 44,45

demand, 46, 47

equations and variables, 44

exchange rate, $45-47$

exports, 46

foreign protectionism, effects, $48-52$

imports, 45,46

imports, imperfect substitutes, 46

imports, small-country assumption, 46

input-output matrix, 44

production, 44

sectoral division, 44

solution, general equilibrium, 47

solution, numerical, 47

supply, 44-47

trade liberalization, effects, 52-55

Dervis-Robinson model, 185

developing semi-industrial economy model (Dervis-de Melo-Robinson), see Dervisde Melo-Robinson model

directed optimization approach, 156, 162-165

disequilibria in Poland's consumer markets (1965-1978), estimates, 167-184

see also market disequilibrium in Poland and market disequilibrium in Poland, estimates

disequilibrium

analysis, vii

consumer markets, in Polish, 344-346

economic concept, vii

macroeconomic, 341,342

microeconomic, 341,342

modeling, for centrally planned economies, 139-222

models, $277,280,346,347$

role in economic growth and development, vii static/dynamic interpretations, 344

dollar trading area, 204, 206, 207, 209, 212, 213

dualism in Japanese economic history

agriculture, stagnation of, 107

coexistence of "traditional indigenous" and "modern imported" elements, 105

differentials between modern and traditional sectors, 103

disappearance of, 109

heavy industry, growth of, 106

income distribution, 107

migration push/pull factors, 107

overview, 104-109

pattern established, 106

period covered, 106

persistence of dualistic disequilibrium, 108

skills and training, 107, 108

structural evolution from agrarian economy, 104,105

urbanization and growth, 106

wage differentials, 108 duality theory, 123

dual/primal formulation of planning models, $195,196,203$

economic-demographic models, 211, 277-300, 306,317

Bachue-Philippines, 306

Bachue series, 317

BACHUROO, 277-300

Casetti, 317

GE-TEMPO, 317

economic development problems

general equilibrium models, applications, $1-138$

general equilibrium models, for market economies, 223-274

economic mechanism under central planning, $141-165$

analysis of, see below

central plan, development, 149

central plan, fulfillment, 149

economic tools, $151-153,158,159,161-164$

planned targets, $149,152,153$

reforms during $1960 \mathrm{~s}, 141-154$

sectoral au tonomy, degree, $144,151,153$, 155,160

economic mechanism under central planning, analysis of, $141-165$

dynamic treatment, 141

multisectoral equilibrium model, 141 , $155-164$

optimization input-output model system, 141-154

sectoral division, 141

set of models, $141-165$

static model solution, 141

see also multisectoral equilibrium model for Bulgaria

and optimization model system

Egypt

general equilibrium models (GEMs) for, $71-102$

studies of, 341

Engel curves, 123

Engel effects, 183

Engel's Law, 7

Euler Theorem, 216

export-oriented policies, 43

extended linear expenditure system (ELES), 6 , $123,124,171-176,291,307,310,315$ see also linear expenditure system (LES)

fertility function, marital (Coale), 302

fertility model, marital (Coale), 318-322

fertility model, marital (Coale-Trussell), 319

fertility schedule, marital, in Schmidt demographic framework, 318-321

Frisch parameter, 291

GEM models for Egypt, 71-102

applicability, 72

data disaggregation and preparation, 90-98 
GEM models for Egypt, continued data sources, 90-98

emigrant remittances, 95

expenditure distribution, 96,97

factor shares in value added, 90,92

GEM-1, 73, 78, 82-87

GEM-2, 78, 87, 98

GEM-3, 78, 88

household income by sector, 89,91

income and expenditure, 89-98

income distribution, 89,95

land ownership distribution, 93

policy analysis, 72

results of typical run, 98-101

share of emigrant remittances by rural-urban income class, 95

share of factor shares by income class, 92,94

share of factor shares by land ownership class, 93

structure, see below

value added by sector, 89,90

GEM models for Egy pt, structure

Cobb-Douglas production functions, 73,83 , $84,87,88$

detailed "government" sector, 73, 87

differences from conventional input-output models, 87

emigrant remittances, 86

endogenous variables, 78

equations and identities, $73,78,80-82$

exogenous variables and parameters, 79

exports and imports, 81,86

GEM-1, 73, 78, 82-87

GEM-1 overview, 86

GEM-2, 78, 87

GEM-2 overview, 87

GEM-3, 78, 88

GEM-3 overview, 88

government expenditure and revenue, 81,84

household consumption, 80

income generation, 80,84

input-output relations, 78,80

linear ex penditure system (LES), 83

multisector macroeconomic basis, 73

price determination, 80,83

private consumption, 83

resource constraints, 82

resource demands, 82

savings and investment, 81,86

value added by sector, 80,83

GE-TEMPO model, 317

general equilibrium approach

agricultural models, vi

economic development problems, $1-138$

energy policies, consequences, vi

Johansen's work, v, 185, 214

Leijonhufvud's work, vi

macroeconomic problems, vi

market clearing conditions, 341-344

price flexibility, $341-344$

protectionism, effects of foreign, 43-56

structural evolution, vi theory and techniques, 199,200

versus optimal planning, 185-222

general equilibrium model for Japan (Shishido)

almost ideal demand system (AIDS), 123 ,

125,131

Armington specifications, 109, 126, 128, 129

capital movements, 128

capital stock and new investments, impor-

tance, 112

capital structure and equipment, distinction, 112

CES functions, 104, 136

Cobb-Douglas functions, 114, 115

comparative statics, 104,136

demand constraints, 124

demand, consumer, 123

demand equations, simplified, 123

demographic content, 104, 109, 121, 122 , $124,125,135$

demographic variables, 124,125

dynamic counter factuals, 104

dynamic features, 125

endogenizing training costs, 135,136

equations and variables, 113-126, 128-135

estimation/simulation, difficulties of, 135

expectation formulation, 120

exports, 125,126

factor allocation, 119

forced saving, 135,136

formal schooling, 133

general features, 109

government activities, 129, 130

government expenditure, 129

government revenue, 130

government saving, 130

Harris-Todaro approach to migration, 121

household consumption, 124

housing demand, 130, 131

housing supply and investment, 131, 132

imports, competitive, $109,128,129$

imports, noncompetitive, 109, 128, 129

investment, 109

investment closure, impact of changing

method, 136

investment, human capital, 133

investment, private, 119

investment, public, 121

Kelley-Williamson work, extensions, 103, 104 lagged/myopic adjustment mechanisms, 103 , 104

migration, 104, 109, 121, 122

neoclassical marginal factor returns, 118

openeconomy characteristics, 104

parameter estimation, 104

periods covered, 103

pricing and factor returns, 116

production relations, 111-116

production technology, 113

"putty-semiputty" assumption, 109, 114

rest of world, relations with, 125

rural-urban income differentials, 104

savings, 134 
general equilibrium model for Japan, continued sectoral division, 109-111

sensitivity analy sis, 136

size and complexity, 135

skills and training, 104, 133, 134

static consumption, 123

urban land availability, 130, 133

vintage specification, $104,109,113,116,117$

wage differentials, 111

general equilibrium models

Adelman-Robinson, 185

Bachue series, 317

Bergman-Pór, 141, 157, 185, 210, 214, $225-236$

Bergman-Pór, simplified, 188-192

Casetti, 317

centrally-planned economies, for, 139-222

computation, relative ease, 73

de Melo, 185

demographic aspects, $275-337$

Dervis-de Melo-Robinson, 44-48, 55

Dervis-Robinson, 185

dualism in Japan, modeling, 103

economic development problems, applications, $1-138$

Egypt, simplified multisector static (GEM), 71

flexibility, 187

GE-TEMPO, 317

IMPACT Project, 185

Japanese economic growth and urbanization (Shishido), 103

Johansen solution methods, 248

Karlström, 211

Kelley-Williamson, 3-41, 185, 211, 317, $318,324,334$

Kelley-Williamson-Cheetham, 19

Keyzer, 57-70

market economies, applications, 223-274

McCarthy, 71-102

McCarthy-Taylor, 185

Mihailov-Pór-Assa, 141, 155-164

multisectoral, for Bulgaria (Mihailov-PórAssa), 141, 155-164

multisectoral, growth in small open economy (Bergman-Pór), 141, 157, 185, 210, 214, $225-236$

multisectoral, nonlinear, for Hungary (Zalai), $185-222$

multisectoral, simplified static, for Egypt

(McCarthy), 71-102

open exchange (Keyzer), 57-70

ORANI, $237-274,277$

pure and applied, 199, 200

Sanderson, 301-316

semi-industrial developing economy (Dervisde Melo-Robinson), 44-48, 55

Shishido, 103-138

Third-World urbanization (Kelley-Williamson), 3-41, 185, 211, 317, 318, 324,334

two-sex marriage (Sanderson), 301-316

Zalai, $185-222$ general equilibrium versus optimal planning approaches, 187-222

equivalence of solutions, 187

general equilibrium formulation, 188-192

optimal planning formulation, 192-197

planning, for, 187

policy a nalysis, for, 197-199

similarities and differences, 197-200

smooth production functions, 200-203

"goal programming" formulation, 58

Hecksher-Ohlin model, 226, 227

Hungary, nonlinear multisectoral model for, $185-222$

Hungary, studies of, 345

IMPACT Project, 185, 237, 277

BACHUROO, 277-279, 285

description, 237,277

documentation available, 278

MACRO, 277-279

medium-term model, 279

occupation groups, 278

ORANI, 237, 248, 277-279

policy analysis, 297

SNAPSHOT, 247, 277, 278

income distribution

in GEM models for Egypt, 89, 95

in Kelley-Williamson model, 6

INFORUM - IIASA trade model (Almon-

Nyhus), 141

optimization variant, 141-154

input-output models

forecasting, use in, 142

INFORUM-IIASA trade model (Almon-

Nyhus), 141

optimization, 141-154

Japan

dualism in economic history of, 103

long "swings" in economic growth, 104

long-term patterns of economic growth, 105

modeling dualism in, 103-138

phases of modern economic development, 105

structural change from agrarian economy, 104 see also dualism in Japanese economic history and modern economic development of Japan

Karlström model, 211

Kelley-Williamson-Cheetham model, 19

Kelley-Williamson model, 3-41, 185, 211, $317,318,324,334$

CES production functions, 6

Cobb-Douglas production functions, 6

comparative statics, 4,10

convergence criteria, 27

demographic content, 26

dynamic solution, 24

elasticities, detailed comparative static, 27-41 extended linear expenditure system (ELES), 6 future extensions, 24 
Kelley - Williamson model, continued income distribution, 6 initial conditions, 9 neoclassical features, 6,28 nonlinearity, 28 optimal land use, 6,25 overview, 5 projections, 24,25 shocks imposed, 27 urban-rural cost of living differentials, 6 validation, $4,9,25$ variables, 41

wage differentials, 24

Keyzer model, 57-70

Klein-Rubin utility function, 288, 289

Korea and modern economic development of Japan, 121, 125, 129

Kuznets' curve, 7

Leontief-neoclassical production technology formulation, 189

life tables

Coale-Demeny model, 321

two-sex nuptiality-mortality, 305

linear expenditure system (LES), 61, 64, 83, $123,124,191,193,194,202,210-212$ see also extended linear expenditure system (ELES)

linear programming models, $185-18$ ?

linear solution methods, 247

logit method, 135,321

\section{MACRO}

continuous-time disequilibrium model, small, 277,280

IMPACT Project, role in, 278, 279

in terface with BACHUROO and ORANI, 293

ORANI-MACRO structural form equations, 295

overlap with ORANI, 294

solution procedures, 294

variables, 293

macrodemographic formulations, uses, 301,302

Manchuria and modern economic development of Japan, 121

market disequilibrium in Poland

commodity shortages, 167

estimates, see below

foreign trade, effects, 180

household expenditure patterns, 180

policy recommendations, 179,180

price reforms, effects, 179

research recommendations, 180

severity and persistence, 167

shortages and surpluses, estimates, 175-178

spillovers, $170,171,173,176,178,179$

market disequilibrium in Poland, estimates

black market prices, 171

commodity aggregation, 172

commodity supplies, 168 consumer, "average", 172, 173, 178, 179

consumer, "subsistence", 172, 173

demand parameters, estimation, 171,173

demand, "pure" and "observed", 170

demand systems, $167,168,170,171,173,175$

ELES equations, 174, 175

equilibrium economies, comparison, 172

exchange rates, 172

extended linear expenditure system (ELES), $171-176$

expenditure, total, 173,174

food, consumption, 178,179

food, price, 172, 175-180, 183, 184

food, "pure" demand, 176,178

income, total, 174

international comparisons, $171-174$

mathematical programming analysis, 168

optimization model, 168, 169

savings, voluntary, 174

sensitivity runs, $176,178,179$

spillovers, $170,171,173,176,178,179$

subsistence levels, 172, 173

utility indicator, 167

utility maximization, 168,171

market economies, general equilibrium modeling of, $223-274$

marriage

analy tic family demography and, 301

economics literature on, 306

economic theory of, 302

"market" representation, 306, 307

Sanderson two-sex model, 301-316

Schoen two-sex model, 304-306

matrix inversion to solve two-sex marriage model (Sanderson), 308, 316

McCarthy models, 71-102

McCarthy-Taylor model, 185

microdemographic processes, 301

microeconomic analysis, 44

microeconomic approach to

general equilibrium modeling, vii

macroeconomic behavior, $v$, vi

microeconomic theory of marriage, 302

migration

Harris-Todaro approach, 121

in general equilibrium model for Japan, 104, $109,121,122$

migration schedule, net

in Schmidt demographic framework, 324-327

Mihailov-Pór-Assa model, 141, 155-164

mixed-integer model, 144

modeling alternative socioeconomic mechanisms, $141-165$

modeling dualism in Japan, 103-138

model rate schedules in Schmidt demographic framework, 317-328

advantages, 317

labor-force participation, 331

marital fertility, $318-321$

mortality, 321, 323, 324

net migration, $324-327$

nuptiality, $318-321$ 
modern economic development of Japan agriculture, role, 106

dualism, disappearance, 109

dualistic disequilibrium, persistence, 108

dualistic phase, 106

exports, importance, 125

four phases, 105, 106

heavy industry, role, 106

hypotheses to explain, 112

import substitution periods, 125

Korea, relationship to, 121, 125, 129

Manchuria, relationship to, 121, 125, 129

persistence of traditional sectors, 111

Phase 0 , institutional change, 105

Phase I, dependence on traditional sectors, 106

Phase II, dualistic phase, 106

Phase III, dominance of modern elements, 106

price changes (1900s-1930s), 127

price indexes, manufactured goods, 126

Taiwan, relationship to, $121,125,129$

textile industry, role of, 106

traditional sectors, role of, 106

training, on-the-job, 108

training, firm- and technology-specific, 108

yen-block countries, relationship to, 127, 129

mortality schedule, in Schmidt demographic

framework, 321, 323, 324

multiplier effects in employment, 20

multisectoral equilibrium model for Bulgaria

(Mihailov-Pór-Assa), 141, 155-164

basic equilibrium, 155-159

Bergman-Pór model, relation to, 141, 157

Bergman-Pór solution algorithm, 162, 163

commodity equilibrium, 159

current account balance, 159

directed optimization approach, 156, 162-164

directed optimization equilibria, 162-164

equations, $158-162$

factor market equilibrium, 159

forecasting with, 159-162

notation, 157,158

parameters, 158

sectoral division, 157

variables, decision (economic tools), 158,

$162-164$

variables, endogenous, 157

variables, exogenous, 157

multisectoral growth (MSG) models, v, 225-236

Bergman-Pór, 225-236

foreign trade, incorporation in, 226

Johansen's work, 225

Norwegian, 225

Restad's work, 226

Swedish (Bergman-Pór), 226

Swedish (Restad), 226

neoclassical approach

development issues, vi

general equilibrium theory, 213

income distribution theory, 214 labor-leisure choice, 288

-Leontief production technology, 189

marginal factor returns, 118

marginal productivity pricing, 202

resource allocation, 6

nonlinear multisectoral model for Hungary

(Zalai), 185-222

balance equations, 218, 219

Bergman-Pór model and, 204, 210

CES functions, 208

commodities, 204-206

commodity balances, $204-206$

decision rules, 216

demoeconomic content, 204, 211

exports, 208, 209, 220

final demand, $210,211,220,221$

formal statement, $216-221$

general equilibrium framework, 203

imports, 206-208, 219, 220

linear expenditure system (LES), 210-212

parameters, exogenous, 217,218

prices and costs, $212-215,221$

production technology, 216

regional aspects, 211,212

technological choice, 219

trade balances, 209

trading areas, rouble/dollar, 204, 206, 207, $209,212,213$

variables, endogenous, 216, 217

nonlinear programming models, 247, 277

nonlinear solution methods, 247

nuptiality formulation

Coale, 302

Coale-McNeil, 302, 303, 305, 306, 308-310, 312

Pollard, 304, 305, 308

Schoen, 302, 304-306

nuptiality model (Coale-McNeil), 318, 319, $321,322,325$

nuptiality--mortality life table, two-sex, 305 nuptiality schedule, in Schmidt demographic framework, 318-321

open exchange model, basic (Keyzer), 60-64

balance equations, 61,62

buffer stock agency, 62

equations, 61,62

general equilibrium framework, 57, 60

government demand, 61

linear expenditure system (LES), 61

market policies, adjustment of, 63

model version with money, see below

policy adjustment rules, $62-64$

policy interactions, 63

private demand, 61

sectoral division, 60

solution algorithm, 63,64

trade deficit, endogenous, 57, 60-70

trade deficit and money, endogenous, 64-70

open exchange model, with money (Keyzer), $64-70$

balance equations, 66 
open exchange model, with money, continued buffer stock demands, 65

government demand, 65

linear expenditure system (LES), 64

linkage to international model, 70

operation, 69,70

policy adjustment rules, 66,67

policy targets, 66

private demand, 64,65

public demand, 65

reduction to basic model (see above), 68, 69

simultaneous nature, 70

optimal planning approach

in centrally planned economies, $185-222$

versus general equilibrium, $185-222$

optimal planning model for centrally planned economy, 192-197

commodity balance, 193

consumption, 193

factor allocation, 193

general equilibrium approach, differences, 192,193

primal/dual formulation, 195, 196, 203

production, 193

shadow behavioral rules, 195, 196

shadow valuation system, 195, 196, 203

solution, 194, 195

surplus consumption, 194, 195

technological constraints, 193

optimization model system for centrally planned economy, 141-154

Almon-Nyhus INFORUM model, relation to, 141

analysis at plan development stage, 152, 153

analysis at plan fulfillment stage, 153

central plan, relation to, $149-151$

conditionally optimal solution, 152

directed optimization approach, 156

dynamic description of economy, 148

factor substitution, 146

global optimization, 146,152

implications of 1960 s reforms for, 151,152

local optimization, $144,146,149,152$

mixed-integer model, 144

sectoral contribution, 149

solution, 146

solution constraints, 144,147

static nature, 148

stimuli, incentives, and efficiencies, $148-150$, 154

optimization techniques

directed, 156, 162-165

reference path, 187

ORANI

Armington specifications, 239

CES functions, 251, 266

comparative static nature, 293

computational approach, 294

CRESH functions, 251

CRETH functions, 251, 254, 257-259, 266, $270-273$

data base, 248 disaggregation, degree of, 237

general equilibrium model, large computable, 277,280

IMPACT Project, role in, 237

interface with BACHUROO and MACRO, 293

linear solution method, 246, 247, 272

macroeconomic closure, 294

microeconomic basis, 237

modified specification, 272

multisectoral model of Australian economy, 237

ORANI 77, see below

ORANI 78, see below

ORANI-MACRO structural form equations, 295

overlap with MACRO, 294

solution procedures, 246,294

ORANI 77, 237, 238, 248, 260-263, 265, 273

ORANI 78

agricult ural sector, see below

commo dity/factor demands, 238

commodity/industry categories, 252

commodity supplies, 242

computational approach, 246

data for agricultural sector, 252-260

description, 238-248

equations, 239

equations, miscellaneous, 244

exchange rate as numeraire, 245

exogenous factor employment, 245

exogenous prices, 244,245

exogenous tariffs, 244

exogenous variables, typical, 240

increased realism versus ORANI 77, 273

linear approximation errors, size, 248

market clearing, 243

model closure, 244-246

tariff increase application, see below

theoretical structure, $238-244$

variables, 240

variables, exogenous/endogenous partition, 245

zero pure profits condition, 243

ORANI 78, agricultural sector, $248-260$

commodity shares, 255

comparisons with other studies, 259

data, $252-260$

importance, 248

industry characteristics, 252

industry shares, 256

input cost shares, 257

inputs, 254

internal structure, 238

outputs, 252

respecification, reasons for, 248,249

rest of economy, interaction with, 238

simulated tariff increase, effects, 265--272

specification, problems with, 248

specification, theoretical, 249-252

supply elasticities, $257-259$

tariff increase application, see below

transformation parameters, 257 
ORANI 78, tariff increase application, 260-272 agricultural commodities, CRETH results, 268 agricultural commodities, outputs/prices, 268 agricultural sector, 265

assumptions, underlying, 261

commodity exports, 272

employment, 262,263

export demand elasticities, 269

export levels, 269

industry activity levels, 264

industry results, $263-272$

mactoeconomic results, 262,263

Poland's consumer markets (1965-1978), estimates of disequilibria in, 167-184 see also market disequilibrium in Poland policy adjustment rules

complementarity problem formulation, 60 in an open exchange model, $57-70$

policy targets and instruments, 57,58

policy variables in an open exchange model, 57-59

Pollard nuptiality formulation, 304, 305, 308

population growth

economic effects of rapid, 330

significance for developing countries, 317

population pressure

land markets, response of, 19

Third-World urbanization, effects on, 15

primal/dual formulation of planning models, $195,196,203$

probit method, 135

protectionism, foreign

compared to "free trade", 52-55

developing countries, effects on, 43,44

"new protectionism", 43

OECD, 43, 44

policy implications, domestic, 52-55

project selection in a developing economy, effects on, 53, 55

resource allocation in a developing economy, effects on, 43-56

quadratic expenditure system (QES), 124

reference path optimization technique, 187

representative developing country (RDC)

approach, 4,7

basis in "typical" development pattern, 7

labor-force participation rates, average, 337

population distributions, average, 336,337

Schmidt demographic framework and, 318 , $320,321,323,326,331$

selection of sample, see below

simulation of historical development, 10

representative developing country (RDC), selection of sample

conformity with model assumptions, 7

countries excluded, 8

countries included, 9

data availability, 7,8 resource allocation

centrally planned economies, vi

effects of foreign protectionism, 43-56

endogenous treatment, $v$

market economies, vi

Rotterdam system, 123

rouble trading area, 204, 206, 207, 209, 212 , 213

Roy Identity, 123

Rybczynski Theorem, 13, 15, 19

Sanderson two-sex marriage model, see two-sex marr iage model (Sanderson)

Schmid t demographic framework, 317-337

Schoen nuptiality formulation, 304-306

Schoen two-sex marriage model, see two-sex marriage model (Schoen)

Shephard's Lemma, 119, 231

Shishido model, 103-138

small open economy

Bergman-Pór model for, 225-236

concept, 225-227

SNAPSHOT

IMPACT Project, role in, 247, 278

nonlinear programming model, 247, 277

social accounting matrix (SAM) for Egypt, $73-77,97$

socioeconomic mechanisms, modeling alternative, $141-165$

Solow-Swan-Meade model, 136

spillover effects, $170,171,173,176,178,179$, $181,183,341,343,345,347,349$

Stone-Geary-Rubin-Klein formula, 172

Taiwan and modern economic development of Japan, 107, 121, 125, 129

tâtonnement, Walrasian, 47

Third-World problems

balance of payments, 20

foreign indebtedness, 20

trade and distribution, vi

Todaro model, 21, 24

Todaro-Corden-Findlay model, 21-24

translog system, 123

Turkey, studies of, 343,344

two-channel price system, 191

two-sex marriage model (Sanderson), 301-316, 319

and Coale-McNeil one-sex model, 308

and Schoen two-sex model, 302, 304, 305

computation, 315

demand specification, 307

description, 306-310

exchange of "vows", 306

extended linear expenditure system (ELES), $307,310,315$

general equilibrium framework, 301

marriage hazard rates, 308, 309

"marriage market" representation, 306, 307

matrix inversion to solve, 308,316

model closure, 307 
two-sex marriage model, continued parameter change, effects, $310-314$ rela tive scarcity indicators, 307-309 sensitivity analysis, 301

solution, 315,316

two-sex mariage model (Schoen), 304-306 two-sex nuptiality-mortality life table, 305 typologies

adjustment mechanisms, 349

equilibrium and disequilibrium models, 346 , 347

urbanization and growth in Japan, 106

urbanization in Third World

consequences, 3

general equilibrium model, 3

limits on, see below

quantitative assessments, lack of, 4

rate, 3

sources, see below

urbanization in Third World, impact of exogenous variables

capital stocks, formation, and accumulation, 12

demand, 11

general prices and world market conditions, 11,12

government policies, $13,16,17$

investment patterns, 13

institutional change, 13

labor, 13

land, $13,18,19$

low-rent housing, 12

population, 15,18

prices of fuel, 20,21 prices of nonfuel intermediates, 20, 21

tax on urban real estate, 13

unbalanced productivity growth, 10

wage differentials, 13,23

urbanization in Third World, limits on

building of new housing, 6

cost of living in cities, 5

fuel price and availability, 4, 5

investment requirements, 5

land availability, 5

lower fertility in cities,

skill bottlenecks, 5

slower population growth, 4

technological regression, 4

urbanization in Third World, sources

availability of public services, 3

cheap energy, 3

employment prospects, 3

population growth, 3

technology, 3

urban wage policy, Todaro-Corden-Findlay model, 21

utility function, Cobb-Douglas, 191

utility maximization theory, 191

Wagner's Law, 7

Walrasian tâtonnement, 47

Walras' Law, 47, 136, 342

welfare economics, 187

yen-block countries and modern economic development of Japan, 127, 129

Zalai model, 185-222 


\section{LIST OF PARTICIPANTS}

Task Force Meeting on General Equilibrium Modeling, International Institute for Applied Systems Analysis, Laxenburg, Austria, 10-13 November 1980

External Participants

Lars Bergman

Stockholm School of Economics

Box 6501

S-11383 Stockholm

Sweden

François Bourguignon

Ecole Normale Superieure

Laboratoire D'Economie Politique

45, rue d'Ulm,

75230 Paris

France

Krzysztof Cichoki

Systems Research Institute

ul. Newleska 6

01447 Warsaw

Poland

Kemal Dervis

The World Bank

1818 H. Street NW

Washington, D.C. 20433

USA

Peter B. Dixon

School of Economics

La Trobe University

Bundoora

Victoria 3038

Australia
Victor Ginsburgh

University of Brussels

50 Ave. Roosevelt

B-1050 Brussels

Belgium

Jurij R. Ivanilov

The Computer Center of the USSR

Academy of Sciences

Vavilov St. 40

Moscow 117333

USSR

Allen C. Kelley

Department of Economics

Duke University

Durham,

North Carolina 27706

USA

Michiel A. Keyzer

Centre for World Food Studies

Vrije Universitet Amsterdam

Postbus 7161

Amsterdam-Buitenveldert

The Netherlands

János Kornai

Institute of Economics

The Hungarian Academy of Sciences

Budaörsi ut 47

1112-Budapest XII

Hungary 
V. Makarov

Institute of Mathematics

Siberian Branch of the USSR

Academy of Sciences

Novosibirsk

USSR

Alexander Meeraus
Development Research Center
The World Bank
1818 H. Street NW
Washington, D.C. 20433
USA
Victor Norman
Norwegian School of Economics
$\quad$ and Business Administration
Helleveien 30
N-5000 Bergen
Norway

Lennart Ohlsson

EFI

Stockholm School of Economics

Box 5601

S-11383 Stockholm

Sweden

Zbigniew Pawlowski

Narbutta 52

02-541 Warsaw

Poland

D. Pospelov

The Computer Center of the USSR Academy of Sciences

Vavilov St. 40

Moscow 117333

USSR
Sherman Robinson

The World Bank

1818 H. Street NW

Washington, D.C. 20433

USA

Timon Ryabushkin

Institute for Sociological Research

USSR Academy of Sciences

Krshishanovskogo 24/35

Moscow

USSR

Robert M. Schmidt

Department of Economics

Duke University

Durham

North Carolina 27706

USA

Lance Taylor

Department of Nutrition and Food Sciences

M.I.T.

18 Vassar Street

Cambridge

Massachusetts 02139

USA

Vladislav Tokarev

Institute of Control Sciences

USSR Academy of Sciences

65 Profsoyznaya

Moscow 117342

USSR

David P. Vincent

Institut für Weltwirtschaft

D-2300 Kiel 1

FRG

Jeffrey G. Williamson

Department of Economics

University of Wisconsin

Madison

Wisconsin 53706

USA 
Ernö Zalai

Department of Economics

Karl Marx University

Dimitrov ter 8

Budapest IX

Hungary

IIASA Participants

Murat Albegov

Regional Development

Isak Assa

System and Decision Sciences

Brian Arthur

System and Decision Sciences

Luis Castro

Human Settlements and Services

Urban Karlström

Human Settlements and Services

F. Desmond McCarthy

Food and Agriculture

Boris Mihailov

Regional Development
Kirit S. Parikh

Food and Agriculture

Leon Podkaminer

Food and Agriculture

András Pór

Computer Services

Piet Rietveld

Regional Development

Tyrrell Rockafeller

System and Decision Sciences

Andrei Rogers

Human Settlements and Services

Warren C. Sanderson

Human Settlements and Services

Hisanobu Shishido

Human Settlements and Services

Folke Snickers

Regional Development

Andrzej P. Wierzbicki

System and Decision Sciences 



\section{Books of related interest}

\section{Duke Press Policy Studies}

Population and Development in Rural Egypt

Allen C. Kelley, Atef M. Khalifa, and M. Nabil El-Khorazaty

Economic Policy Making in Mexico

The Limits of Oil-Based Growth

Robert E. Looney

The World Tin Market

Political Pricing and Economic Competition

William L. Baldwin

\section{Other books}

Theory of Spatial Pricing and Market Areas

Melvin L. Greenhut and Hiroshi Ota

Introduction to Corporate Modeling

Friedrich Rosenkranz

\section{Duke University Press}





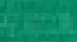

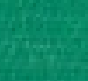

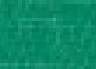
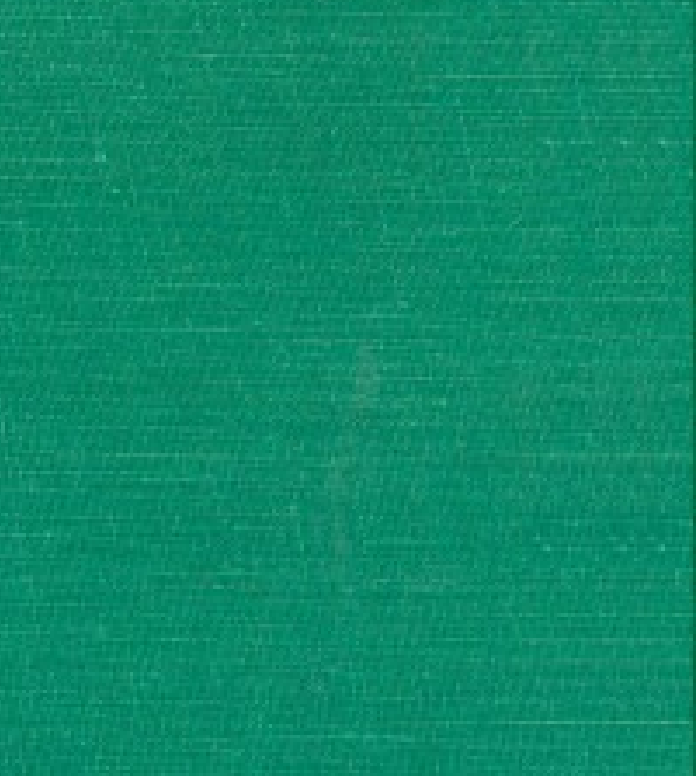

ISBN $0-8223-0567-4$

titi 